THE IMPACT OF CULTURAL VARIABLES ON THE PERFORMANCE OF U.S. OVERSEAS MANAGERS AND ON PERFORMANCE MEASUREMENT CRITERIA: AN EXPLORATORY STUDY

by

Bhagwan S. Khanna

A dissertation

submitted to the Victoria University of Wellington

in fulfilment of the

requirements for the degree of

Doctor of Philosophy in Accounting

Victoria University of Wellington

1992 


\title{
ABSTRACT
}

\section{THE IMPACT OF CULTURAL VARIABLES ON THE PERFORMANCE OF U.S. OVERSEAS MANAGERS AND ON PERFORMANCE MEASUREMENT CRITERIA: AN EXPLORATORY STUDY}

by

\author{
Bhagwan S. Khanna
}

October 1992

\author{
Supervisor: Professor Maxwell E. Aiken \\ Major Department: Accountancy
}

The study is related to the perceived impact of selected cultural variables on the performance of U.S. executives working overseas. Consideration given to these variables for the measurement of performance at the corporate headquarters was also researched in the course of the study.

For the purpose of this study, twelve foreign cultural variables were chosen. The general perception of these variables and their perceived impact on the eight specific aspects of performance among the U.S. overseas managers was examined. An attempt has also been to made to ascertain the general perception of these cultural variables among evaluators and the consideration they assign to their perceived effect on the specific aspects of managerial performance in their evaluation of overseas managers. Five regions were chosen for the study on the basis of their being representative of distinct cultural clusters: Far East (more populous than some of the other regions with strong family ties and leanings toward collectivism), Middle East 
(religion oriented), Africa (tribal), Europe (industrially advanced) and South America (developing countries).

Data were obtained from all the five regions. In all 127 responses were received from the U.S. overseas managers. A total of eighteen responses were received from the evaluators for these five regions. Statistical tests were undertaken to explore the similarities and differences in perception of the twelve selected foreign cultural factors, their perceived effect on the eight specific aspects of managerial performance within and between the five selected regions, and between U.S. overseas managers and their evaluators.

Statistically significant differences were identified in the mean responses from U.S. overseas managers regarding their general perception of the cultural factors and their perceived effect on specific aspects of performance within and between regions. However, the differences in the effects of a cultural factor on the selected eight aspects of managerial performance were not statistically significant at a global level although among regions these differences were statistically significant. From a global (aggregate) perspective, the tests failed to identify any statistically significant difference between evaluators' and managers' general perceptions of cultural factors and their perceived effects on the selected aspects of managerial performance. Within African, European and Latin American regions there are some statistically significant differences between managers and evaluators pertaining to a few of the cultural factors.

The study has attempted to identify those cultural variables which have differential perceived and considered impact on various aspects of performance. The differential impact of these variables on performance 
measurement on a regional basis was also studied. Step wise discriminant analysis was employed to identify those cultural variables whose general perception and the perceived effect on the specific aspects of managerial performance would distinctly identify the region.

This study by exploring the differences in perceptions of the twelve selected cultural factors and their perceived and considered effect on the specific aspects of managerial performance among managers and evaluators, it is submitted, has helped create a new perspective on measurement, analysis and evaluation of managerial performance on a more comprehensive basis.

After measuring the compatibility of managers' perceptions for cultural elements and the consideration accorded to these in the evaluation process at corporate headquarters, and concluding that no statistically significant differences exist at a global (aggregate) level suggestions for future can be made. It is submitted that any differences, if remaining, between managers' and evaluators' perception of performance, can only be due to other factors which merit further investigation in future research endeavours.

Multivariate discriminant analysis was employed to identify whether their exists statistically significant differences across various regions. The computed Wilks' lambda and the associated $F$ value rejected the null hypotheses of no differences amongst regions. The stepwise discriminant procedure was used to isolate a subset of twelve variables from the ninety six variables submitted for the test. The selected twelve variables produce a robust discriminant model with a hit ratio of $99 \%$ for classification. 
The study successfully confirmed the existence of significant differences in the perceptions of U.S. overseas managers about the foreign cultural factors and their effects on the specific aspects of their performance. Also, the regions can be effectively differentiated (discriminated) on the basis of U.S. overseas managers' perceptions of cultural factors and their effects on their performance. extant there. 


\section{Acknowledgements}

This doctoral research work has been successfully completed with the help, guidance, advice, and constant encouragement of many individuals and organisations. I express my thanks to them all.

I wish to record my deepest gratitude to Professor Max Aiken of La Trobe University, Melbourne (previously at Victoria University of Wellington) under whose supervision this study has been carried out. It is his perennial inspiration, encouragement and invaluable guidance, which has helped me throughout the course of this work. I am also grateful to Professor Whatarangi Winiata for his encouragement at the early stage for this project and his suggestion to tap the fabulously rich resource of Professor Aiken's erudition.

I also express my thanks to Professor Tony van $\mathrm{Zijl}$, the chairperson of the Accountancy Group who has been a great source of support and encouragement. His empathic stance is sincerely appreciated.

I wish to record my grateful thanks to a large number of executives of multinational corporations who spared their invaluable time and provided support and information: in person, on phone, and through Questionnairefilling to enable me to carry out this study.

I want to thank my friends and colleagues for their enduring inspiration, ungrudging support, and cheerful disposition during all the time of my research work. Their friendship contributed in many ways to help me maintain a sense of perspective and a sense of humour, both of which are so important to sustain a robust rigour for such studies. 
The assistance given by many others such as the personnel at the U.N.Centre for Transnational Corporations, New York, library staff, and programmers, especially Andrew Sirvid is sincerely appreciated. A special thank is extended to Miss Val Leifi, the sercretary of the Accountancy Group for her ever-willing attitude to help in this wok of mine particularly if it is related to computer and her overall cheerful disposition.

The greatest thanks is saved for my wife, Santosh and son, Vikramaditya. Their support has always helped in the accomplishments of my goals. Her ever-willing attitude to help with patience and endurance especially during the course of data collection is sincerely appreciated. I owe a heartfelt and affectionate gratitude to my son whose help and cooperation, concern and thoughtfulness, and 'you can do it dad' attitude made it all possible. Never was their love and understanding, care and patience, support and thoughtfulness more appreciated than during my efforts culminating with this doctoral work.

October 1992.

Bhagwan S. Khanna 


\section{TABLE OF CONTENTS}

$\begin{array}{lr}\text { Abstract } & \text { Page } \\ \text { Acknowledgements } & \mathrm{i} \\ \text { List } \text { of Figures } & \mathrm{v} \\ \text { List } \text { of Tables } & \mathrm{x} \\ \text { List } \text { of Appendices } & \mathrm{xii} \\ \end{array}$

\section{Chapter}

I INTRODUCTION 1

Perspective $\quad 2$

Statement of the Problem $\quad 7$

Need of and Importance for the Study 11

Purpose and Objectives of the Study 16

$\begin{array}{ll}\text { Hypotheses } & 20\end{array}$

Cultural Variables and Aspects of Performance 21

$\begin{array}{ll}\text { Performance } & 24\end{array}$

$\begin{array}{ll}\text { Scope and Limitations of the Study } & 27\end{array}$

Environmental 27

Cultural $\quad 28$

Performance $\quad 28$

Regional 30

Personnel $\quad 32$

Sample $\quad 32$

Plan of the Study 33

Preview of the Study $\quad 35$

II REVIEW OF RELEVANT LITERATURE 38

$\begin{array}{ll}\text { Introduction } & 38\end{array}$

Paradigms $\quad 39$

Role of Socio-Cultural Factors $\quad 41$

Culture Defined $\quad 44$

Cross-Cultural Studies $\quad 48$

Performance Measurement and Evaluation $\quad 54$

III HISTORICAL DEVELOPMENT OF THEORETICAL 68 FOUNDATIONS FOR THE HYPOTHESES

Introduction 
General Assumptions about the Nature of Social Sciences

Concept of Culture

Various Perspectives

Patterns and Themes of Culture 82

Management and Culture 88

Cultural Determinants of Managerial Effectiveness $\quad 100$

Cross-Cultural: A Few Elaborations 105

Culture and Communication 108

Cultural Bias

PART I:

Multinational Corporation and Cultural Differences

Comprehensive Approaches to Cultural Assessment

IV RESEARCH DESIGN, METHODOLOGY AND DATA COLLECTION

Introduction

Initial Contact

Format of Study and Selection of Participants (Sample) 141

Research Objectives of the Study

Hypotheses

146

Data Sets and Analysis

Statistical Analysis and Tests

Limitations

Questionnaires Soliciting Data

Pretest and Pilot Study

Survey and Administration of Questionnaires

Data Collection and Results of Survey 
Experience Profile

Number of Assignments

Number of Years in the Current Assignment

Profile and Other Characteristics of Evaluators

of U.S. Overseas Managers' Performance

Age Distribution

SECTION II

U.S. Overseas Managers' Perceptions of Foreign

Cultural Factors

Global (Aggregate) Perspective

Regional Perspective

Evaluators' (of Overseas Managers' Performance)

Perceptions of Foreign Cultural Factors

Global (Aggregate) Perspective

Regional Perspective

SECTION III

Hypotheses Testing and Data Analysis

Comparison Between Managers and Evaluators Inter-Regional Comparisons

VI SUMMARY, CONCLUSIONS AND RECOMMENDATIONS FOR FUTURE RESEARCH

Summary of Nature and Purpose of the Research

Summary of Methodology Employed and Limitations

Conclusions and Implications

Recommendations for Future Research

FIGURES

TABLES

APPENDICES:

A - Reasons for Sending Home Country Managers Overseas

B - Cultural Universals

C - U.S. Values and Possible Alternatives

D - Selected Cultural Factors

$\boldsymbol{E}$ - Details of Survey with Executive MBA Candidates

$\boldsymbol{F}$ - Letter to Respondents

G - Questionnaire for U.S. Overseas Managers

H - Questionnaire for Evaluators 


\section{LIST OF FIGURES}

Figure 1.1

Basic Elements of Management Control System

Figure 3.1

Closed System - Open System

Figure 3.2

External (environmental) Determinants of Organisational

Patterns and Effectiveness

Figure 3.3

(Cultural) Determinants of Managerial Effectiveness

Figure 5.1

Mean Scores (in aggregate) Representing U.S. Overseas

Managers'Responses to the Twelve Selected Cultural factors and Their Impact on the Eight Selected Performance Variables Across the Five Selected Regions

Figure 5.2

Mean Scores Representing U.S. Overseas Managers' Responses

to the Twelve Selected Cultural factors and Their Impact on the Eight Selected Performance Variables in the Far East.

Figure 5.3

Mean Scores Representing U.S. Overseas Managers' Responses to the Twelve Selected Cultural factors and Their Impact on the Eight Selected Performance Variables in the Middle East.

Figure 5.4

Mean Scores Representing U.S. Overseas Managers' Responses to the Twelve Selected Cultural factors and Their Impact on the Eight Selected Performance Variables in Africa.

Figure 5.5

Mean Scores Representing U.S. Overseas Managers' Responses to the Twelve Selected Cultural factors and Their Impact on the Eight Selected Performance Variables in Europe.

Figure 5.6

Mean Scores Representing U.S. Overseas Managers' Responses to the Twelve Selected Cultural factors and Their Impact on the Eight Selected Performance Variables in Latin America. 
Figure 5.7

Mean Scores (in aggregate) Representing Evaluators'

Responses to the Twelve Selected Cultural factors and Their Impact on the Eight Selected Performance Variables Across the Five Selected Regions.

Figure 5.8

Mean Scores Representing Evaluators' Responses to the Twelve 252 Selected Cultural factors and Their Impact on the Eight Selected Performance Variables In the Far East.

Figure 5.9

Mean Scores Representing Evaluators' Responses to the Twelve 253

Selected Cultural factors and Their Impact on the Eight Selected Performance Variables in the Middle East.

Figure 5.10

Mean Scores Representing Evaluators' Responses to the Twelve 254

Selected Cultural factors and Their Impact on the Eight Selected Performance Variables in Africa.

Figure 5.11

Mean Scores Representing Evaluators' Responses to the Twelve 255 Selected Cultural factors and Their Impact on the Eight Selected Performance Variables in Europe.

Figure 5.12

Mean Scores Representing Evaluators' Responses to the Twelve 256 Selected Cultural factors and Their Impact on the Eight Selected Performance Variables in Latin America. 


\section{LIST OF TABLES}

Table 1.1

Selected Cultural Factors

Table 1.2

Selected Aspects of Performance

Table 2.1

Financial Measures Used as Indicators of Internal Performance

Evaluation (Performance of the Companies* Financial Measures)

Table 3.1

Primary Message System

Table 3.2

Environmental Constraints

Table 4.1

(For 'A' part of each question dealing with cultural factors)

Table 4.2

(For 'B' part of each question dealing with the impact of cultural

factors on different aspects of performance)

Table 4.3

Region-wise and Country-wise Distribution of Responses

Table 4.4

Response Distribution Amongst Multinational Corporations on the Basis of Number of Employees

Table 4.5

Response Distribution Amongst Multinational Corporations on the Basis of Ranking Based on Sales

Table 4.6

Response Distribution Amongst Multinational Corporations on the Basis of Ranking Based on Assets Value

Table 4.7

Response Distribution Amongst Multinational Corporations on the Basis of Ranking Based on Market Value

Table 4.8

Response Distribution Amongst Multinational Corporations on the Basis of Ranking Based on Net Profit 
Table 5.1

Age Distribution of U.S. Overseas Managers

Table 5.2

Domestic Experience (with present organisation) Distribution of 258 U.S. Overseas Managers

Table 5.3

Overseas Experience (with present organisation) Distribution of

U.S. Overseas Managers

Table 5.4

Domestic Experience (with other organisations) Distribution of

U.S. Overseas Managers

Table 5.5

Overseas Experience (with other organisations) Distribution of

U.S. Overseas Managers

Table 5.6

Number of Assignment' Distribution of U.S. Managers

Table 5.7

Distribution Showing 'Number of Years' Spent in Current

Assignment

Table 5.8

Age Distribution of Evaluators of U.S. Overseas Managers'

Performance

Table 5.9

Domestic Experience (with present organisation) Distribution

of Evaluators of U.S. Overseas Managers' Performance

Table 5.10

Overseas Experience (with present organisation) Distribution

of Evaluators of U.S. Overseas Managers' Performance

Table 5.11

Domestic Experience (with other organisations) Distribution

of Evaluators of U.S. Overseas Managers' Performance

Table 5.12

Overseas Experience (with other organisations) Distribution

of Evaluators of U.S. Overseas Managers' Performance

Table 5.13

Mean Scores (in aggregate) Representing U.S. Overseas

Managers' Responses to the Twelve Selected Cultural factors and Their Impact on the Eight Selected Performance Variables Across the Five Selected Regions 
Table 5.14

Mean Scores Representing U.S. Overseas Managers'

Responses to theTwelve Selected Cultural factors and Their Impact on the Eight Selected Performance Variables in the Far East

Table 5.15

Mean Scores Representing U.S. Overseas Managers'

Responses to theTwelve Selected Cultural factors and Their Impact on the Eight Selected Performance Variables in the Middle East

Table 5.16

Mean Scores Representing U.S.Overseas Managers'

Responses to theTwelve Selected Cultural factors and Their Impact on the Eight Selected Performance Variables in Africa

Table 5.17

Mean Scores Representing U.S.Overseas Managers'

Responses to theTwelve Selected Cultural factors and Their Impact on the Eight Selected Performance Variables in Europe

Table 5.18

Mean Scores Representing U.S. Overseas Managers'

Responses to theTwelve Selected Cultural factors and Their Impact on the Eight Selected Performance Variables in Latin America

Table 5.19

Standard Deviations (in aggregate) of U.S. Overseas Managers'

Responses to the Twelve Selected Cultural factors and Their

Perceived Impact on the Eight Selected Performance

Variables Across the Five Selected Regions

Table 5.20

Standard Deviations of U.S. Overseas Managers' Responses to the Twelve Selected Cultural factors and Their Perceived Impact on the Eight Selected Performance Variables in the Far East

Table 5.21

Standard Deviations of U.S. Overseas Managers' Responses to the Twelve Selected Cultural factors and Their Perceived Impact on the Eight Selected Performance Variables in the Middle East

Table 5.22

Standard Deviations of U.S. Overseas Managers' Responses to the Twelve Selected Cultural factors and Their Perceived Impact on the Eight Selected Performance Variables in Africa 
Table 5.23

Standard Deviations of U.S. Overseas Managers' Responses to the Twelve Selected Cultural factors and Their Perceived Impact on the Eight Selected Performance Variables in Europe

Table 5.24

Standard Deviations of U.S. Overseas Managers' Responses to the Twelve Selected Cultural factors and Their Perceived Impact on the Eight Selected Performance Variables in Latin America

Table 5.25

Mean Scores (in aggregate) Representing Evaluators' Responses 276 to the Twelve Selected Cultural factors and Their Impact on the Eight Selected Performance Variables in Across the Five Selected Regions

Table 5.26

Mean Scores Representing Evaluators' Responses to the Twelve 277 Selected Cultural factors and Their Impact on the Eight Selected Performance Variables in the Far East

Table 5.27

Mean Scores Representing Evaluators' Responses to the Twelve 278 Selected Cultural factors and Their Impact on the Eight Selected Performance Variables in the Middle East

Table 5.28

Mean Scores Representing Evaluators' Responses to the Twelve Selected Cultural factors and Their Impact on the Eight Selected Performance Variables in Africa

Table 5.29

Mean Scores Representing Evaluators' Responses to the Twelve Selected Cultural factors and Their Impact on the Eight Selected Performance Variables in Europe

Table 5.30

Mean Scores Representing Evaluators' Responses to the Twelve Selected Cultural factors and Their Impact on the Eight Selected Performance Variables in Latin America

Table 5.31

Standard Deviations of the Evaluators' Responses to the Twelve Selected Cultural factors and Their Impact on the Eight Selected Performance Variables Across the Five Selected Regions

Table 5.32

Standard Deviations of the Evaluators' Responses to the Twelve 280 Selected Cultural factors and Their Impact on the Eight Selected Performance Variables in the Far East 
Table 5.33

Standard Deviations of the Evaluators' Responses to the Twelve

Selected Cultural factors and Their Impact on the Eight Selected

Performance Variables in the Middle East

Table 5.34

Standard Deviations of the Evaluators' Responses to the Twelve

Selected Cultural factors and Their Impact on the Eight Selected

Performance Variables in Africa

Table 5.35

Standard Deviations of the Evaluators' Responses to the Twelve

Selected Cultural factors and Their Impact on the Eight Selected Performance Variables in Europe

Table 5.36

Standard Deviations of the Evaluators' Responses to the Twelve

Selected Cultural factors and Their Impact on the Eight Selected Performance Variables in Latin America

Table 5.37

Analysis of Variance for Cultural Variables and Aspects of

Managerial Performance Based on (Aggregate) Responses

from the U.S. Overseas Managers

Table 5.38

Analysis of Variance for Aspects of Managerial Performance and Cultural Variables Based on (Aggregate) Responses from the U.S. Overseas Managers

Table 5.39

Correlation Matrices: For Perceived Effects of A Cultural Factor

on Specific Aspects of Managerial Performance

Table 5.40

Correlation Matrices: For the Perceived Effects of Cultural

Factors on a Specific Aspect of Managerial Performance

Table 5.41

Relational (Regression) Coefficients of Cultural Variables for

Aspects of Managerial Performance (Dependent Variables)

after testing for Multicollinearity on Global Data

Table 5.42

Cultural (Explanatory) Variables with their $t$ Values being less

than 1 Dropped after the Multicollinearity Test on Global Data

Table 5.43

Significant Differences Amongst Responses from Overseas

Managers on The Impact of Twelve Cultural Factors on the Specific Aspects Their Performances: An Aggregate Perspective 
Table 5.44

Significant Differences Amongst Responses from Overseas

Managers Relating to the Perceived Effect on the Specific

Aspects Their Performance of The Impact of Twelve Cultural Factors : An Aggregate Perspective

Table 5.45

Significant Differences in Responses from Overseas Managers

Relating to Their Perceptions of Twelve Cultural Factors and

Their Impact on Specific Aspects of Their Performance as a

Group Across the Selected Five Regions: An Aggregate

Perspective

Table 5.46

Significant Differences in Responses from Overseas Managers

Relating to their Perceptions of the Impact on Specific Aspects of

Their Performance of the Twelve Selected Cultural Factors As a

Group and Across the Selected Five Regions: An Aggregate

Perspective

Table 5.47

Analysis of Variance for Cultural Variables and Aspects of

Managerial Performance Based on (Aggregate) Responses

from the Evaluators

Table 5.48

Analysis of Variance for Aspects of Managerial Performance

and Cultural Variables Based on (Aggregate) Responses from

the Evaluators

Table 5.49

Significant Differences Amongst Responses from Evaluators

on the Perceived Impact of Twelve Cultural Factors on the

Specific Aspects of the Managerial Performances: An Aggregate

Perspective

Table 5.50

Significant Differences Amongst Responses from Evaluators

Relating to the Perceived Effect on the Specific Aspects of the

Managerial Performance of the Impact of Twelve Cultural

Factors Across Five Regions: An Aggregate Perspective

Table 5.51

Significant Differences in Responses from Evaluators Relating to their Perceptions of Twelve Cultural Factors and their Impact on Specific Aspects of the Managerial Performance as a Group Across the Selected Five Regions: An Aggregate Perspective 
Table 5.52

Significant Differences in Responses from Evaluators Relating

to their Perceptions of the Impact on Specific Aspects of the

Managerial Performance of the Twelve Selected Cultural Factors

As a Group Across the Selected Five Regions: An Aggregate

Perspective

Table 5.53

Hotelling's T2 for Testing the Equality of Means of (Aggregate)

Responses of Two Groups: U.S. Oversea Managers and

Their Evaluators

Table 5.54

Within Regions Statistically Signifcant Differences Between

Mean Responses of the U.S. Overseas Managers and the

Evaluators about Their Perceptions of Foreign Cultral Factors and

Their Perceived Effect on the Aspects of Managerial Performance

Table 5.55

Analysis of Variance Procedure showing Within Regions

Statistically Signifcant Differences Between Mean Responses

of the U.S. Overseas Managers and the Evaluators about Their

Perceptions of Foreign Cultral Factors and Their Perceived Effect

on the Selected Aspects of Managerial Performance

Table 5.56

Relational (Regression) Coefficients of Cultural (Explanatory)

Variables for Aspects of Managerial Performance (Dependent

Variables) after testing for Multicollinearity on Data from the

Far Eastern Region

Table 5.57

Relational (Regression) Coefficients of Cultural (Explanatory)

Variables for Aspects of Managerial Performance (Dependent

Variables) after testing for Multicollinearity on Data from the

Middle Eastern Region

Table 5.58

Relational (Regression) Coefficients of Cultural (Explanatory)

Variables for Aspects of Managerial Performance (Dependent

Variables) after testing for Multicollinearity on Data from the

European Region

Table 5.59

Relational (Regression) Coefficients of Cultural (Explanatory)

Variables for Aspects of Managerial Performance (Dependent

Variables) after testing for Multicollinearity on Data from the

Latin American Region 
Table 5.60

Cultural (Explanatory) Variables with their $t$ Values being less

than 1 Dropped after the Multicollinearity Test on Data from the Far Eastern Region

Table 5.61

Cultural (Explanatory) Variables with their $t$ Values being less

than 1 Dropped after the Multicollinearity Test on Data from the Middle Eastern Region

Table 5.62

Cultural (Explanatory) Variables with their $t$ Values being less

than 1 Dropped after the Multicollinearity Test on Data from the European Region

Table 5.63

Cultural (Explanatory) Variables with their $t$ Values being less

than 1 Dropped after the Multicollinearity Test on Data from the

Latin American Region

Table 5.64

Inter-Regional Statistically Signifcant Differences Among

Mean Responses of the U.S. Overseas Managers about Their

Perceptions of Foreign Cultral Factors and Their Perceived

Effect on the Aspectsof Managerial Performance

Table 5.65

Multivariate Statistics and F Approximations

Table 5.66

Stepwise Discriminant Analysis

(Based on Part A of every question)

Table 5.67

Pairwise Generalized Squared Distances Between Groups

(Based on Part A of every question)

Table 5.68

Classification Results

(Based on Part A of every question)

Table 5.69

Stepwise Discriminant Analysis

(Based on B1-B8 of every question)

Table 5.70

Pairwise Generalized Squared Distances Between Groups

(Based on B1-B8 of every question)

Table 5.71

Classification Results (Based on B1-B8 of every question) 


\section{LIST OF APPENDICES}

Appendix A

Reasons for Sending Home Country Managers Overseas

Appendix B

Cultural Universals

Appendix C

U.S. Values and Possible Alternatives

Appendix D

Selected Cultural Factors: with explanations

Appendix $E$

Details of the Survey with Candidates of Executive MBA and Advanced Management Programs at Georgia State University, Atlanta, Ga, USA.

Appendix $F$

Letters to Respondents ( Overseas Managers and Evaluators)

Appendix G

Questionnaires for U.S. Overseas Managers

400

Appendix $\mathrm{H}$

Questionnaires for Evaluators

409 


\section{CHAPTER I}

\section{INTRODUCTION}

One of the most dramatic and significant world trends of the last four decades has been the rapid and sustained growth of the multinational business enterprise as an important vehicle of international trade. ${ }^{1}$ Through the agency of multinational enterprise ${ }^{2}$ (MNE) personnel, capital, goods, management methods, technology, marketing techniques, and general skills cross over to other countries. ${ }^{3}$ In fact, most of the major American

1 Stefan M. Robock, Kenneth Simmonds and Jack Zwick, International Business and Multinational Enterprises (Homewood, Illinois: Richard D. Inwin, Inc., 1977), pp. vii-x. John M. Stopford and John H. Dunning, Multinational Company Performance and Global Trends (London: Macmillan Publishers Ltd., 1983), pp. 23-4.

2 The term 'multinational enterprise' is used in this study to embrace the similarly used terms such as multinational corporation, transnational corporations, etc. Also, for the purpose of this study 'multinational enterprise' is defined as a business organisation which owns or controls production or service facilities outside the country in which it is based. These businesses may operate in extractive, agricultural, manufacturing or service sectors. Accordingly, multinational enterprise would exclude companies whose international operations are mere extensions of home country operations (e.g. marketing). G.M. Cunningham, An Accounting Research Framework for Multinational Enterorise (Ann Arbor, Michigan: UMI Research Press, 1978), pp. 1-5. Academicians have also talked about the 'structural 'criterion - where multinationality is judged according to organisation of the company , a 'performance' criterion to focus on some relative or absolute measure of international spread, e.g. number of foreign subsidiaries, percentage of sales accounted for by foreign sales, and a 'behavioural' criterion based on corporation/s degree of geocentricity.Peter J. Buckley," A Critical View of Theories of the Multinational Enterprise, in The Economic Theory of The Multinational Enterprise edited by Peter J. Buckley and Mark Casson, (London: The Macmillan Press Limited, 1985), pp. 1-20

3 Mira Wilkins, The Maturing of Multinational Enterprise: American Business Abroad from 1914 to 1970 (Massachusetts: Harvard University Press, 1974), pp. 374-411; Kiyoshi Kojima, Direct Foreian Investment (London: Croom Helm Ltd., 1978), pp.134-151; Richard E. Caves, Multinational Enterprise and Economic Analysis (Cambridge, London:Cambridge University Press, 1982), pp.196-220, John M. Stopford and John H. Dunning, ep.cit., pp. 39-45, and Chris Pass and Bill Neale," The Multinational Corporation in the UK Economy," Management Accounting, (January 1990), pp. 30-32. 
corporations tend not to confine themselves to domestic operations, but participate widely in business beyond national boundaries.

It is estimated that more than 3,000 American corporations currently operate in 122 foreign countries, controlling more than 22,500 foreign business enterprises. ${ }^{4}$ The total accumulated direct private investment ${ }^{5}$ of these firms has increased from $\$ 145$ billion in 1977 to $\$ 308$ billion in 1987 , registering an annual growth rate of more than 12 percent over the period. U.S. direct investment abroad was in excess of $\$ 44$ billion in 1987 alone bringing in an income of $\$ 52.3$ billion and thus giving a rate of return of more than $17 \%$ for 1987 on that year's total investment. The value of all the foreign assets owned by U.S. firms was more than $\$ 710$ billion in 1987.6

\section{PERSPECTIVE}

In the early 1950's and 1960's the majority of business corporations became international by a process of creeping 'incrementalism', rather than by a global strategy choice. ${ }^{7}$ Although each firm has its own specific reasons

${ }^{4}$ Directory of American Firms Operating in Foreian Countries (New York: World Trade Academy Press, Inc., 1987), Vol 1. p. 1.

5 Direct investment is the equity held by U.S. investors in business enterprise abroad for the purpose of influencing or controlling the activities of that enterprise. The U.S. government defines this as an ownership interest in foreign enterprises of at least 10 percent. It is distinguished from portfolio investment, which brings an ownership interest but not managerial involvement. J. M. Ivancevich, The American Manager Overseas Representing Large U.S. Industrial Comorations: A study of Selected Staffing Steps and Job Attitudes (Ann Arbor, Michigan: University Microfilm, Inc., 1969), p.1.

6 Patricia C. Walker, "U.S. Direct Investment Abroad in 1987", Survey of Current Business, U.S. Department of Commerce, Vol. 68, No. 8, Aug. 1988, pp. 40-60.

7 John S. Schwendiman, "International Strategic Planning: Still in Its Infancy?" Worldwide P \& I Planning, Sept. - Oct. 1971, p. 52. 
for going overseas John G. McDonald, besides mentioning pure emotional factors as reasons, has enumerated six factors which have played a significant role in increasing international operations. ${ }^{8}$ First, increased overseas marketing activities of U.S. corporations created a demand for greater and continuous customer services for the dealers of their products; and, accordingly, many corporations moved overseas to meet this demand. Second, the stiff competition at home forced many of the U.S. corporations to seek new markets overseas. Third, the higher tax rates at home also motivated these corporations to set up overseas operations to take advantages of lower taxes in other countries. Fourth, overseas operations serve as a buffer to counteract the cyclical fluctuations of the U. S. economy. Fifth, the saturated home markets made the economic significance of overseas operations irresistible. Sixth, the emergence of common markets provide new potential markets to be substituted for the already saturated U.S. market. These markets have offered opportunities for the investment of idle capital and eligibility for tax advantages. ${ }^{9}$ In addition, the need to retain and develop new export markets and to reap benefits of low costs of production overseas as a part of some long range strategy have led a number of U.S. corporations to expand their business operations into other countries. ${ }^{10}$ Still in many cases multinational investment was encouraged to contribute

8 John G. McDonald, "New Organizational Concept of the World Enterprise", Management International, No. 5-6 1961. pp.7-25.

9 U. W. Kitzinger, The Challenge of the Common Market (Oxford: Basil Blackwell, 1961), p. 163.

10 Sidney M. Robbins and Robert B. Stobaugh, "The Bent Measuring Stick for Foreign Subsidiaries," Harvard Business Review, (Sept. - Oct. 73), pp. 80-88. 
towards the economic development of host less developed countries (LDCs). ${ }^{11}$

Frances S. Lee States that:

Some U.S. corporations have found that it has been necessary to develop local production facilities in the countries served in order to retain export markets. In other cases American firms are prompted to produce overseas to develop new market opportunities. In still other cases, the development of foreign operations has helped achieve balance of payments benefits for the United States. But, whatever may be the underlying reasons, international operations represent a large and growing segment of business for many U.S. corporations, especially for those in the Fortune 500 category. ${ }^{12}$

In a study, Czechowicz, Choi and Bavishi 13 noted the following reasons for attempts of MNE's to set up overseas operations:

- $\quad$ to maximise long-term and short-run profits

- $\quad$ to avoid losing a market to competitors

- $\quad$ to secure access to raw materials

- $\quad$ to satisfy the foreign government's investment regulations.

- $\quad$ to diversify risk.

- $\quad$ to secure labour cost advantages.

- $\quad$ to circumvent trade restrictions.

The reasons for setting up overseas operations are varied and often differ in importance and priority over time.

11 Seong Rae Moon," Economic Impact of Multinational Investment on the Korean Economy," (Ph. D. Dissertation, The American University, 1987), pp. 1- 5.

12 Francis A. Lee, "Reporting Transnational Business Operations", Research Report No. 780, The Conference board, 1980, pp. 5-6.

13 I. James Czechowicz, Frederick D. S. Choi and Vinod B. Bavishi, Assessing Foreian Subsidiary Performance (New York :Business International Corporation, Jan, 1982), p. 159. 
These foreign operations have increased so much over the last four decades that in the case of certain U.S. corporations more than 40 percent of overall profits is accounted for by them. ${ }^{14}$ The rapid growth of direct investments of American companies abroad has created the need for competent managerial personnel. Although there has been a general tendency on the part of U.S. corporations to employ local nationals whenever possible to manage overseas operations, it is often necessary to send a complement of U. S. managers." The use of local nationals in encouraged by at least five factors:

(1) host countries' requirements for a fixed percentage of managerial posts to be filled by the local managers; ${ }^{15}$ (2) the estimated higher cost of sending a U.S. manager and his family to foreign assignment compared to the cost of hiring a national;16 13 (3) local managers' more intimate environmental knowledge; 17 (4) the shortage of well qualified U.S. managers; and (5) increasing nationalism in some countries. ${ }^{18}$

14 Forbes, June 25, 1985, pp. 56-63.

" 'Managers and 'executives' are used interchangeably in this study.

15 Stefan H. Robock, et. al., International Business and Multinational Enterprise, op. cit., p. 534.

16 Calvin Reynolds, 1968-1973 Policy Changes Which Affect the Income of Americans Working Abroad - Preliminary Results (New York: National Foreign Trade Council, 1973); Roger M. Pritchard, "Incremental Cost Associated with the Use of United States or Foreign Personnel in Overseas Operations" (S. M. thesis, Massachusetts Institute of Technology, 1969), p. 97; Henry J. Ruff and Graham I. Jackson, "Methodological Problems in International Comparisons of the Cost of Living," Journal of International Business Studies, Fall 1974, pp. 57-67.

17 Richard D. Robinson, International Business Management, 2nd Ed., (Hinsdal, Illinois: The Dryden Press, 1978), p. 291.

18 Roy Blough, International Business: Environment and Adaptation (New York: McGraw--Hill Book Co., 1966), pp. 314-7. 
While there are convincing arguments for reducing the ratio of Americans to foreign nationals, nonetheless there will still be an increasing number of Americans employed as more and more companies set up or expand operations abroad.

According to Yoram Zeira most MNE's find expatriates a necessary and indispensable element in their operations because of their familiarity with the parent company's policies and operational procedures. ${ }^{19}$

Richard D. Robinson has provided an exhaustive list of situations in which use of parent-company nationals may be justifiable (Appendix A). Although the degree of persuasiveness for many of these situations varies in the long run, their basic validity remains intact. 20

It is estimated that the number of U.S. personnel working outside the United States is significant. According to Frank Gaston, U.S. personnel working overseas in 1982 numbered between 100,000 - 165,000.21 Hays noted that these personnel invariably occupied positions of significant authority and responsibility in regional headquarters and foreign subsidiaries

19 Yoram Zeira, "Rotation of Expatriates in MNEs", Management International Review, (Fall, 1976), pp. 37-46 and Nakiye Avdan Boyacigiller," Why Multinational Corporations Use Expatriates: An Organizational and Environmental Study," (Ph. D. Dissertation, University of California, Berkeley, 1986), pp. 1-10.

20 Richard D. Robinson, International Business Management, op. cit., pp. 293-94.

21 J. Frank Gaston, Director International Studies - Conference Board, letter dated February 17, 1982. According to the information contained in the volume 1 and 2 of the World Directory of Multinational Enterprises 1982-83 appertaining the World's Top 500 MNEs approximately 26 million people were employed by them in 1981 (quoted in John M. Stopford and John H. Dunning, op.cit., pp. 75-6). 
of U. S. multinational enterprises. ${ }^{22}$ Miller states that as a result of their position in the management hierarchy of overseas operations, the degree of success experienced by the foreign subsidiary depends heavily on them and their performance. ${ }^{23}$

\section{STATEMENT OF THE PROBLEM}

("Man is the measure of all things" Protagoras 481-411 BC)

The notable expansion in the direct investment of U. S. corporations in overseas operations and the sizeable number of U. S. personnel working abroad add up to an irresistible argument for increased attention to a variety of problems faced by U. S. personnel working abroad.

The problems arise due to environmental differences between domestic and international business operations. The most pervasive distinction between international and domestic business lies in the environmental framework. ${ }^{24}$ Aside from its relationship to the elements of risk and conflict, the multiplicity of environments in international business creates a wide range of operational problems that initiate new tools, concepts, analytical methods and types of information. MNEs and their subsidiaries are important players in the international business game. They cope with a fluid

22 R. Hays, "Expatriate Selection Insuring Success and Avoiding Failure," Journal of International Business Studies, No. 1 (1974), pp. 25-37.

23 Edwin L. Miller, "Managerial Qualification of Personnel Occupying Overseas Management Positions as Perceived by American Expatriate Managers," Journal of International Business Studies (Spring-Summer, 1977), p. 57.

24 Richard N. Farmer and B.M. Richman, International Business, 3rd edition (Bloomington, Ind: Cedarwood Press, 1980), pp.8-10. and William Persen and Van Lessig, Evaluating the Financial Performance of Overseas Operations, (New York: The Financial Executives Research Foundation, 1978). 
environment with potentials to affect various facets of their working, impinging upon the state of technology, institutional arrangements, governmental expectations, consumer demands. As a result a conflicting array of demands is made on them. 25 The wider the scope of the multinational enterprise's overseas activities, the greater would be the environmental diversities. The complex and diverse nature of overseas environments has a significant influence on the effectiveness of managerial personnel and hence of business operations. Consequently, the task of identifying, evaluating and predicting environmental variables becomes more crucial and assumes greater significance. 26

One important category of environmental variables is the existence of cultural differences that affect the business management. These differences influence the behaviour of customers, suppliers and employees, and may be responsible for a full range of communication problems arising out of different languages, customs and values. ${ }^{27}$ A considerable amount of literature has been focused on the cultural adjustment of expatriate managers and on the

25 Hamid Etemad and Louise Seguin Dulude," Managing The Multinational Subsidiary", in Managing The Multinational Subsidiary: Response to Environmental Change and to Host Nation R \& D Policies edited by Hamid Etemad and Louise Seguin Dulude," , (London: Croom Helm, 1986), pp 1-21.

26 lbid., and Stefan H. Robock et al., International Business and Multinational Enterprises, op. cit., pp 10-12.

27 Stefan H. Robock et al., International Business and Multinational Enterprises, op. cit., p. 12, Philip R. Harris and Robert T. Moran, Managing Cultural Differences, 2nd ed. (Houston, Texas: Gulf Publishing Co., 1987), pp. 25-54, Thomas G. Evans, Martin E. Taylor, and Oscar Holzmann, International Accounting and Reporting (Boston, Mass.: PWS-Kent Publishing Company, 1988), pp. 282-85, and Dhia D. AlHashim and Jeffrey S, Arpan, International Dimension of Accounting, 2nd Ed., (Boston, Mass.: PWS-Kent Publishing Company, 1988), pp. 173-195. 
differences in foreign management and work forces that might require adjustments of organisation and procedures within MNEs. ${ }^{28}$

Researchers have studied the overseas manager and his job from a variety of perspectives, and substantial publications have resulted from such efforts. It appears that most studies have focused upon job attitudes of the expatriates, the reasons for their accepting the assignments, and the behavioural determinants of the job success or failure. ${ }^{29}$ Some researchers have attempted to study the overseas manager from the firm's viewpoint by focusing on the qualifications considered to be important for selection of an individual for an overseas assignment. ${ }^{30}$

It is increasingly evident that one of the more crucial determinants of efficient and effective operations of U. S. multinational enterprises is the performance of the U. S. expatriate managers. ${ }^{31}$ Also, it is widely acknowledged that because of growing competition from non-American multinational enterprises and the dynamic underpinnings of international management, the performance of expatriates can no longer be measured

28 William K. Brandt and James M. Hulbert, "Patterns of Communications in Multinational Corporations: An Empirical Study;" Journal of International Business Studies Vol. 7. No 1,Spring, 1976, pp. 55-8.

29 N.J. Adler, "Expecting International Success: Female Managers Overseas," Columbia Journal of World Business, Vol. 19, No. 3, Fall 1984, pp. 79-86, W. Gudykunst and Y.Y. Kim (eds.) Methods for Intercultural Communication Research (Beverly Hills, CA.: Sage Publications, 1984 (annual), G. Hofstede, Cultures Consequences: International Differences in Work Related Values_(Beverly Hills,CA.: Sage Publishing, 1980), and G.F. Shea, Managing a Difficult or Hostile Audience (Englewood Cliffs, N.J.: Prentice Hall, 1984).

30 Richard F. Gonzalez and Anant R. Negandhi, "The United States Overseas Executive: His Orientations and Career Patterns" (Institute for International Business and Economic Development Studies, Division of Research, Graduate School of Business Administration, Michigan State University, East Lansing, Michigan, 1966), pp. 1-10.

31 Yoram Zeira, "Rotation of Expatriates in MNEs," ㅇp. cit., pp. 26-46. 
against the criterion of their relevant knowledge and skills alone. ${ }^{32}$ Multinational business brings with it many unique problems in the management of resources, the most fundamental of which is the necessity for managers raised and experienced in one culture to play bicultural or multicultural roles. Often, managers of foreign subsidiaries play a boundary or middleman role between two sets of cultural patterns. ${ }^{33}$

To sustain an effective internal accountability ${ }^{34}$ of overseas subsidiaries of MNE's and their managers, performance evaluation is to be undertaken on an objective, equitable and consistent basis. Performance evaluation is an integral element for effective application of the philosophy of decentralisation. Several criteria or measuring sticks have been used by enterprises in order to evaluate performance fairly and logically. Quantitative criteria include both financia| ${ }^{35}$ and non-financia| ${ }^{36}$ measures. Often, qualitative criteria involving cultural factors ${ }^{*}$ are extremely important even

32 v. Davar, "An Empirical Study of the Underlying Determinants of Culture-Shock manifestation in American Expatriates" (Ph. D. Dissertation, The University of Nebraska, 1978), pp. 1-2.

33 Stefan H. Robock, et al., International Business and Multinational Enterprise, op. cit., pp. $309-41$.

34 Wagdy M. Abdallah, Internal Accountability: An International Emphasis (Ann Arbor, Michigan: UMI Research Press, 1984), pp. 1-4.

35 John J, Mauriel," Evaluation and Control of Overseas Operations", Management Accounting, May 1969, pp, 35-9; J.M. Mclnnes, Financial Control Systems for Multinational Opertions: An Empirical Investigation," Journal of International Business Studies, Fall 1971, pp. 11-27; Edward C. Bursk, Dearden John, David F. Hawkins, and Victor M. Longstreet, Financial Control of Multinational Operations (New York: Financial Executive Research Foundation, 1971), pp. 1 - 45; Helen G. Morsicato and Lee H. Radebaugh," Internal Performance Evaluation of Multinational Enterprise Operations," The International Journal of Accounting: Education and Besearch, Fall 1979, pp. 77-94; Helen G. Morsicato, Currency Translation and Performance Evaluation in Multinationals ,( Ann Arbor, Michgan: UMI Research Press, 1980), pp.1-105.

36 Wagdy M. Abdallah, op. cit., pp. 1- 109.

" 'Cultural factors' and 'Cultural Variables ' are used interchangeably in this study 
though they are the most difficult to assess. Accordingly, the impact of cultural factors should be given adequate consideration in measuring the performance of overseas managers.

\section{NEED FOR AND IMPORTANCE OF THE STUDY}

A large number of U. S. enterprises operating overseas, whether they use nationals of the country as managers or not, tend to staff top managerial positions with U. S. managers. ${ }^{37}$ The overall success or failure of the enterprise may depend on the performance of managers working overseas. In order to keep a well satisfied cadre of managerial personnel whether for domestic operations or overseas business, and to effectively sustain the application of decentralisation, their performance needs to be measured and evaluated on an objective and equitable criteria. The problems inherent in performance evaluation have been aptly brought out by Professor Kolde who states that:

"Even in a purely domestic setting most multi-unit companies face difficult problems in measuring and evaluating the performance of their subsidiaries and managers thereof. Dissatisfaction with budgets, standards, or any other performance criteria are voiced at one time or another in all companies; and human problems resulting from performance criteria, which are often perceived as "unfair", are well known to personnel managers and top management in all businesses...."

".... In a multinational setting these problems have taken new dimensions and become more complex. There is not only the

37 Lawrance G. Granko. "Who Manages Multinational Enterprises?" Columbia Journal of World Business, Summer 1973, pp. 30-42, R. Hays, "Expatriates Selections Insuring Success and Avoiding Failure", 1974, pp. 25-37. Yoram Zeira, "Rotation of Expatriates in MNEs, 으. cit., pp. 37-46; 
question what should be the "right" performance criteria, right accounting principles, or right psychological measures, but also such issues as whether or not domestic profit standards should be extended into the international realm; and whether affiliate executives should be judged in the context of their particular countries or some regionalisation of the worldwide operations should be adopted. "38

The growing need for performance evaluation criteria for MNEs can be seen through the development of MNEs on the world stage. In the early stages of multinational organisations, operations once begun were virtually controlled and managed from the corporate headquarters. Domestic methods that had proved to be of some value were transplanted. As the foreign subsidiaries were established and became a strategic link in place of a stepchild, it was natural that concern would begin to gravitate from continued existence to performance measurement.

Contributions of individuals represent a combination of circumstances, stimuli and actions. Each is significant in its impact on an individual's performance and hence should be evaluated for its impact in the measurement of performance. But until someone invents a valid single measure to effectively accomplish the task of performance evaluation, various yardsticks (surrogates) will have to be used, depending on the objectives, roles and activities within the purview of managers. ${ }^{39}$ Budgets, standard

38 E. J. Kolde, The Multinational Company (Massachusetts: Lexington Books, 1974), pp. $173-178$.

39 J.M. McInnes, Financial Control Systems for Multinational Opertions: An Empirical Investigation, ep.cit., Fall 1971, pp. 11-27; Edward C. Bursk, et al., Financial Control of Multinational Operations. op. cit., 1971, pp. 1 - 45; Helen G. Morsicato and Lee H. Radebaugh," Internal Performance Evaluation of Multinational Enterprise Operations," op. cit., Fall 1979, pp. 77-94; Helen G. Morsicato, Currency Translation and Performance Evaluation in Multinationals ,1980, op. cit., pp.1-105; and Wagdy M. Abdallah, Internal Accountability: An International Emphasis. 1984, pp. 1- 24 
costs, and responsibility reports are financial measures that can be manipulated to fit most circumstances. Hence, non-financial measures become increasingly important as money loses its ability to serve as a common denominator, alone or in translation. 40 Kolde further aptly observed that "Comprehensive financial measures, such as profit and return on investment, are constructed upon foundations containing flawed assumptions. They should be used with caution even in the best of circumstances and should only serve as starting points for more valid criteria." 41

The 1972 Committee on International Accounting of the American Accounting Association (AAA) also provides an early indication that the traditional profit centre concept for performance evaluation is inappropriate for MNEs because there is no clear distinction between operating divisions of MNEs. With integrated, centrally coordinated operations, local management does not have responsibility for many decisions which affect profits. Also the multiple objectives of international transfer prices tend to invalidate profit measures. 42

The need to maintain duality in foreign appraisals has been considered essential; that is, knowing how efficiently the subsidiary uses its resources and what is the ability or effectiveness of its manager. The committee reported that subsidiaries were most often evaluated by the use of conventional financial measures, with mental revisions to allow for

40 E. J. Kolde, The Multinational Company, op. cit., p. 198

41 lbid., p. 198.

42 "Report of the Committee on International Accounting", George M. Scott, chairman, in Supplement to Accounting Reveiw (1973), pp. 120-167. 
circumstances. The Committee recommended the use of quantitative criteria other than financial data, such as performance audit and "point-system."43

The 1973 Committee on International Accounting of the AAA considered the problem of performance measurement. 44 The Committee agreed with the previous findings and indicated that differences between countries, particularly cultural differences, affect perceptions and motivations of an individual's performance. The committee indicated that the performance evaluations by MNEs represented a mixture of subjective appraisals, absolute measures (such as profit or return on investment) and comparative assessments (with other foreign units, prior period results and/or operating budgets). Each of the evaluation methods then in use was cited for a failure to maintain a necessary separation between the subsidiary's and the manager's performance. The committee report concludes that "there is a need for further research to introduce additional elements into accounting based evaluation systems." 45

A most provocative criticism of the methods used to evaluate foreign operations was authored by Robbins and Stobaugh. ${ }^{46}$ They stated that the evaluation practices in use were confusing, misunderstood and unsound. Almost without exception, the MNEs admitted using the same measures to evaluate overseas and domestic operations. Return on investment was the

43 lbid., p. 159 and I. James Czechowicz et al., op. cit.. pp. 25-36.

44 "Report of the Committee on International Accounting" (1974), pp. 250-269.

45 lbid., p. 253 and I.J. Czechowicz et al., on. cit, pp. 20-40.

46 Sidney M. Robbins and Robert B. Stobaugh, ㅇ․ cit., pp. 80-88. 
criterion applied in virtually all cases, even to evaluate those subsidiaries that were captive cost centres. 47

In the light of preceding comments regarding the persistent use of a few evaluation methods irrespective of the specific needs of the situation, and of the inadequate consideration being given to the factors influencing the performance of overseas personnel, 48 this researcher contends that there is a need for a study to probe and analyse the impact of foreign environmental factors such as climatic, economic and socio-cultural issues on the performance of U.S. managers working overseas.

This study, by highlighting the perceived impact of foreign cultural factors on performance measurement, may help to achieve a better and more efficient utilisation of human resources. By focusing on the impact of cultural factors the study will help to analyse and evaluate the performance of overseas managers on a more comprehensive basis than is presently being done. Also, by attempting to measure the extent of similarities and differences in overseas managers' perceptions about the impact of foreign cultural factors on their performance and the consideration accorded to it in performance measurement criteria then the area/s for further exploration may be pinpointed.

47 Ibid., p. 82; Helen G. Morsicato and Lee H. Radebaugh," Internal Performance Evaluation of Multinational Enterprise Operations," op. cit., Fall 1979, pp. 77-94; Helen G. Morsicato, "Currency Translation and Performance Evaluation in Multinationals", ㅇ․ cit., 1980, pp.35-40.

48 Wagdy M. Abdallah, Internal Accountability: An International Emphasis.1984, pp. 110. 
This would also help to identify the more influential cultural factors, on a regional basis, thus providing more effective recruitment, assignment and relocation of managerial personnel overseas. Further, in the words of Morsicato and Diamond,49 "it would contribute towards environmentalising the performance evaluation system."

Notable researchers such as Cunningham, Morsicato and Radebaugh, Jacobson, Choi and Mueller, and Wagdy Abdallah have consistently made a suggestion through their research studies over last ten years or so regarding the need for continued research to consider among other things, factors affecting performance, and relevant evaluation criteria. 50

\section{PURPOSE AND OBJECTIVES OF THE STUDY}

The purpose of this research study is to explore the impact of foreign cultural factors on the performance measurement of the U.S. managers working overseas. This research aims to produce findings that may be added to the body of existing research to be utilised in determining, modifying, and improving the management control process.

49 Helen G. Morsicato and Michael A. Diamond. "An Approach to Environmentalizing Multinational Enterprise Performance Evaluation Systems," The International Journal of Accounting: Education and Research, Vol 16, No. 1, (Fall 1980), pp. 248-66.

50 Gary M. Cunningham, "An Accounting Research Framework for Multinational Enterprises", op. cit., pp. 72-21; Helen G. Morsicato and Lee H. Radebaugh," Internal Performance Evaluation of Multinational Enterprise Operations," op. cit., Fall 1979, pp. 77-94; Helen G. Morsicato, "Currency Translation and Performance Evaluation in Multinationals", of. cit., 1980, pp.1-105; Lyle Jacobson," Multinational Accounting: Research Priorities for the Eighties-Latin America," in Multinational Accounting A Research Framework for the Eighties edited by Frederick D.S. Choi, (Ann Arbor: Michigan, UMI Research Press,1981), pp.221-39; Frederick D.S. Choi and Gerhard G. Mueller, International Accounting (New Jersey, PrenticeHall, Inc., 1984), pp. 365-420; and Wagdy M. Abdallah,op. cit.,_pp. 90-3. 
The specific objectives of this study are to:

(1) Ascertain the views of U.S. managers working overseas about specific foreign cultural factors.

(2) Determine the effect and direction of these specific cultural factors as perceived by the U.S. Managers working overseas on their performance.

Also to check if there are any variations in the perceived effects of these cultural factors on any aspect of managerial performance which are jointly accounted for by more than one cultural variable which are interrelated (that is, to test for multicollinearity).

Ascertain as to which aspect/s of performance is relatively more responsive to a cultural factor and in which direction.

(3) Ascertain the views of performance evaluators at corporate headquarters about these specific foreign cultural factors.

(4) Determine the consideration given to the impact of these specific foreign cultural factors by the evaluators in evaluating the performance of U.S. executives working overseas.

(5) Ascertain the similarities and differences among the views of overseas managers and evaluators about those specific foreign cultural factors.

(6) Measure the similarities and differences in the perceptions of overseas managers about the impact of these specific foreign cultural factors on their performance and the consideration accorded to the impact of these specific foreign cultural factors by the evaluators in evaluating the performance of U.S. executives working overseas given the following model (on the following page):

(7) Ascertain the similarities and differences among the views of the U.S. overseas managers of the selected five regions regarding the specific foreign cultural factors.

(8) Explore the differences (if any) in the perceptions of overseas managers about the impact of these specific foreign cultural factors on performance on a regional basis. Also to identify those foreign cultural factors (if any) which are perceived to have a distinct impact on the specific aspects of performance of U.S. executives working overseas on a regional basis (based on responses of overseas managers). 


\section{* Basic Elements Of Management Control System (ADAPTED)}

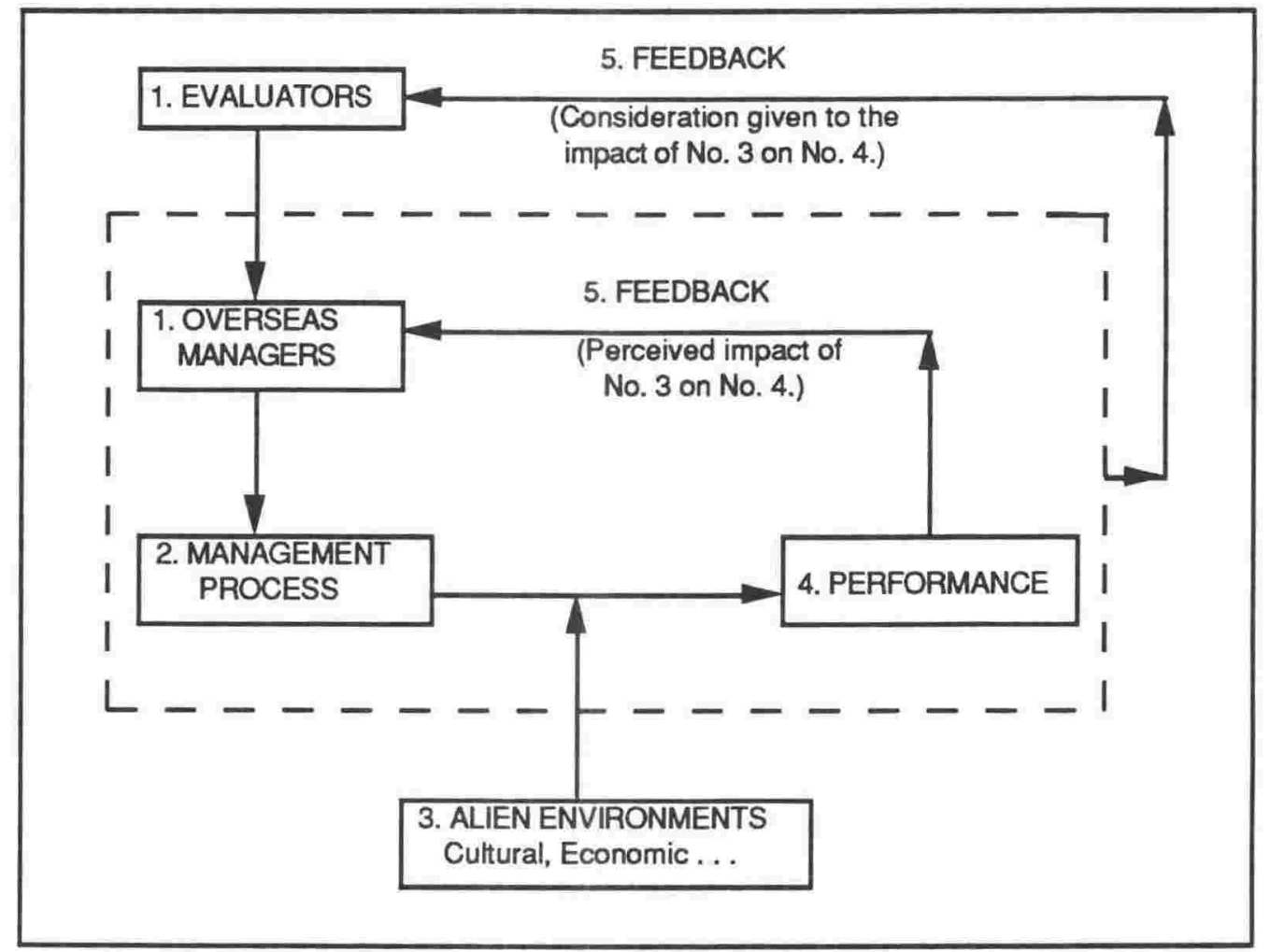

SOURCE: Adapted from H. Itami, Adaptive Behaviour: Management Control and Information Analysis (Sarasota, Fla., American Accounting Association,1977), p. 9.

Note: An attempt would be made to measure similarities and differences (step No. 5) in the perceptions of overseas managers about the impact of cultural environments on their performance and the consideration accorded to the same (impact of cultural factors) by evaluators of managerial performance.

This study is intended to help identify and measure the impact of cultural factors on the performance of U. S. executives stationed abroad. By providing a better and more comprehensive gauge of the determinants of performance, a more effective and efficient management control system can be maintained. In addition, the feedback pertaining to the perceptions of overseas executives about the impact of these cultural factors on their performance would aid corporate officers in the home country exercise their 
functions more effectively. The findings should help in management decisions such as overseas assignments, relocations, promotions and other performance measurement related considerations.

Identification and interpretation of the role of these external factors on the performance measurement of overseas executives would help strengthen the internal reporting function. ${ }^{51}$ It would also facilitate the appropriate modifications in goal setting by pointing out factors for systematic inclusion therein and, thus supporting performance evaluation on a more rational and objective basis. 52 This would eventually reinforce the commitment of executives to the overall corporate goals.

51 " Because of technological changes and advances in knowledge of human behavior the scope and methods of accounting are changing and can be expected to continue to change. .... Major areas in which changes are occurring which will influence accounting in the future are perceived as including: (a) Knowledge of decision processes, (b) Knowledge of human behavior, (c) Computer technology and systems design, and (d) Measurement theory and information theory.". . , "In the light of these developments accounting theory and practice will probably be broadened considerably in the future, ... The scope of accounting may include the measurement and communication of data revealing past, present, and prospective socioeconomic activities. Improvement of control methods and decision making at all levels become major goals of accounting." (Charles T. Zlatkovich, "A Statement of Basic Accounting Theory," Evanston, Illinois: American Accounting Association, 1966, pp. 63-71); J.G. Birenberg and Raghunath," Implications of Behavioral Science for Managerial Accounting," Accounting Beview. July 1967, pp. 468-79; William J. Bruns Jr., "Accounting Information and Decision Making: Some Behavioural Hypotheses," Accounting Review, July 1968, pp. 469-80; T. R. Hofstedt and J.C. Kinard, "A Strategy for Behavioral Accounting Research," Accounting Review, January 1970, pp. 38-54 and Ahmed Belkaoui, Inquiry and Accounting: Alternate Methods and Research Perspectives, (Westport, Connecticut: Quorum Books, 1987).

52 Hanns-Martin W. Schoenfeld, "The Present State of Performance Evaluation in Multinational Companies," in Managerial Accounting and Analysis in Multinational Enterorises eds. H.P. Holzer and H.M. Schoenfeld (New York: Walter de Gruyter 1986) pp. 218-51; Anant R. Negandhi," Cross-Cultural Management Research: Trend and Future Directions," Journal of International Business Studies, Vol. 14, No. 2 , Fall 1983, pp. 17-28 and Rabindra N. Kanungo and Richard W. Wright," A Cross-Cultural Comparative Study of Managerial Job Attitudes," Journal of International Business Studies, Vol. 14, No. 2 , Fall 1983, pp. 115-29. 


\section{HYPOTHESES}

The following null hypotheses are formulated in accordance with the previously stated objectives of the study: (Numerals in parentheses correspond with those of objectives).

No hypotheses are proposed

(2) H1: There is no difference among the mean scores representing the general perception and impact of a specific cultural factor on eight different aspects of performance as viewed by the U.S. managers working overseas. (There are twelve hypotheses, one for each of the twelve foreign cultural factors).

H2: $\quad$ There is no difference among the mean scores representing the impact of twelve selected foreign cultural factors on an individual aspect of performance as viewed by the U.S. managers working overseas. (There are eight hypotheses, one each for the eight selected aspects of performance).

(3) \& (4) No hypotheses are proposed, as few responses representing the views of performance evaluators would be forthcoming.

(5) H3 There is no difference between the mean scores representing the views of the U.S. managers working overseas and performance evaluators regarding the general perception of twelve specific foreign cultural factors.

(6) $\mathrm{H} 4$ There is no difference between the mean scores representing the views of the U.S. managers working overseas and performance evaluators regarding the impact of twelve specific foreign cultural factors on the selected eight aspects of performance.

(7) $\mathrm{H} 5 \quad$ There is no difference among the mean scores representing the views of the U.S. managers working in the five selected overseas regions regarding twelve specific foreign cultural factors.

(8) $\mathrm{H} 6$ There is no difference among the mean scores representing the views of the U.S. managers working in the five selected overseas regions regarding the impact of twelve specific foreign cultural factors on the selected eight aspects of performance. 


\section{CULTURAL VARIABLES AND ASPECTS OF PERFORMANCE}

Culture ${ }^{53}$ per se consists of numerous elements manifested in institutions, beliefs, attitudes, and customs. Culture is the unique life style of a particular group of people. Its common understandings are both acquired and inculcated. It is the set of rules and behaviour patterns that an individual learns rather than inherits at birth. Each cultural group produces its own special answers to life's challenges, such as, birth, growth, and social relations. Culture facilitates living by providing solutions to problems, by establishing patterns of relations and ways for preserving group cohesion and consensus. There are many roadmaps, or different approaches for analysing and categorising culture to make it more understandable. 54

George P. Murdock 55 proposed an elaborate list of 70 cultural universals, which he argued occur in every culture known to history or ethnography. Arranged in alphabetical order to emphasise their variety these are provided in Appendix B. While a one-dimensional checklist such as this has major limitations on account of its focus on very narrow facets of culture, it can nevertheless be of considerable value. A sensitivity to the elements of

53 This study utilised the definition provided by Edward B. Tylor, "a complex whole which consists of beliefs, laws, customs, arts and habits acquired by its societal members." Primitive Culture: Researches into the development of Mrthology. Philosophy. Religion. Lanquage Art and Custom (New York: Henry Holt \& Co., 1977) ,Vol. 1, p. 1.

54 Jeffrey Marc Wachtel, "A Cross-Cultural Comparative Management Study Measuring the Differences in Managerial Motivation and the Effects of Cultural and Other Explanatory Variables of Potential Managers from Mexico and the United States," (Ph.D. Dissertation, Georgia State University, 1986), pp. 1-12.

55 George P. Murdock "The Common Denominator of Cultures", in Ihe Science of Man in the World Crises, edited by Ralph Linton, (New York: Columbia University Press, 1945), pp. 123-26. 
culture and also the ways in which they differ, bring with it an ability to analyse the happening from a cultural perspective. ${ }^{56}$

Harris and Moran have done comprehensive work in their monumental book on cultural differences. 57 They have presented a comparison of various aspects of U.S. culture with those of other cultures as these influence the various managerial functions (Appendix C).

Farmer and Richman 58 have developed a model that relates external constraints to internal firm functions and ultimately to management and management effectiveness. This model helps analyse the relationships among environmental constraints, management performance, and budget numbers and therefore can be adopted by MNEs to develop performance standards. In discussing the model they noted, ".... that if the environment is different, firms will be operated and managed differently, with this leading to different efficiency results between similar firms in different environments ...." 59 The critical socio-cultural elements proposed by them are provided in Appendix $\mathrm{D}$ together with their individual explanations.

From the list of socio-cultural elements provided by Farmer and Richman, the twelve given in Table 1.1 were selected for the purposes of this study. The selection of these cultural factors is obtained on the basis of their

56 Rabindra N. Kanungo and Richard W. Wright, ㅇ․ cit., pp. 115-29.

57 Philip R. Harris and Robert T. Moran, op. cit., pp. 76-7.

58 R. N. Farmer and B. M. , Richman, Comparative Management and Economic Progress (Bloomington, Ind., Cedarwood Press, 1970), pp. 26-35.

59 1974), p. 83. International Business, 2nd ed. (Bloomington: Ind.,Cedarwood Press, 
distinctiveness in the context of performance evaluation. The informal discussions with local managers, evaluators and members of the academic community too have contributed in the selection of these twelve elements. The list, it is hypothesised, 60 has elements which affect the performance of U.S. personnel working overseas and, accordingly these elements were considered for their impact on performance measurement and the selection of evaluation criteria.

TABLE 1.1

\section{Selected Cultural Factors}

Attitude toward Education

View of authority and subordinates

Interorganisational cooperation

Attitude toward achievement and work

Class structure and individual mobility

Attitude towards scientific method

Attitude toward risk taking

Attitude toward change

Communication and Language

Attitude toward time and time consciousness

Sense of self and space

Relevant legal rules of the game

60 , Comparative Management and Economic Progress, op. cit., pp. 2636. 


\section{PERFORMANCE}

Appraising the performance of managers is itself an important and challenging management activity. Its importance is derived from the functions it serves. A systematic and equitable appraisal system provides information crucial for decisions about selecting managers and assigning them to appropriate jobs; for the allocation of rewards, both financial compensation and promotion; and for the development of managers (the information can indicate areas for feedback, further training, and planning a career path to include developmental assignments). Managerial performance appraisal is challenging because management is inherently complex and involves various set of activities. ${ }^{61}$

Measurement of performance is an essential prerequisite for effective and efficient management control. There are many dimensions ${ }^{*}$ of performance measurement. For a division it may include profitability, market share, product leadership, or some other key output variables. ${ }^{62}$ Similarly, for managerial personnel there may be numerous criteria because performance involves conflicting objectives, difficult choices, and a continuous trade-off

61 Nancy J. Adler," A Typology of Management Studies Involving Culture," Journal of International Business Studies, Vol. 14, No. 2, Fall 1983), pp. 29-47; Rabindra N. Kanungo and Richard W. Wright," op . cit., pp. 115-29; Anant R. NeGandhi," Cross-Cultural Management Research: Trend and Future Directions," op. cit, pp. 17-28; Andre Laurent," The Cross-Cultural Puzzle of International Human Resource Management, Human Resource Management, Vol. 25, No. 1, (Spring 1986), pp. 91-102; Michael Sokol and Robert Oresick," Managerial Performance Appraisal," in Performance Assessment: Methods and Applications edited by Ronald A. Berk, (Baltimore, Maryland: The Johns Hopkins University Press, 1986), pp. 376-93.

" 'Dimensions", 'Aspects', and 'Measures' are used interchangeably in relation to performance in this study.

62 David Solomons, Divisional Performance Measurement and Control (Homewood, Illinois: Richard D Inwin, 1968), pp. 220-60 and Wagdy M. Abdallah, Internal Accountability: An International Emphasis. 1984, pp. 8- 12 
between criteria and contributors. ${ }^{63}$ For an objective measurement framework, there should be legitimate consideration for each of the possible (feasible) dimensions. ${ }^{64}$ Traditional accounting-based techniques do not provide detailed information on executive performance. Hence, there is need for other non-financial measures 65 the consideration of which assumes greater significance in case of multinational enterprises wherein managers working overseas are exposed to unfamiliar foreign socio-cultural environments. ${ }^{66}$ For most MNEs, the operational and objective way in which to treat the effects of environmental factors on foreign operations has not been reached. ${ }^{67}$ The performance of an overseas subsidiary's manager should not reflect how well the manager has done, without regard to environmental constraints, but how well the manager has performed his/her job within those environmental constraints. Recognising the inadequacy of traditional management

63 William Travers Jerome III, Executive Control - The Catalyst (New York: John Wiley and Sons, 1967), pp. 37-68.

64 George S. Odiorne," Measuring the Unmeasurable: Setting Standards for Management Performance," Business Horizons, Vol. 30, No. 4, (July-August 1987), pp. 69-75.

65 George M. Scott, Financial Control and Reporting in Multinational Enterprises in Accounting for Multinational Enterprises, edited by Dhia D. Alhashim and James W. Robertson (Indianapolis, Ind.: Bobbs - Merrill Educational Publishing, 1978), pp. 143-170.

66 Edward C. Bursk et al. Einancial Control of Multinational Operations (New York: Financial Executives Research Association, 1971), pp. 20-28 and Lane Kelley, Arthur Wahtley, and Reginald Worthley," Assessing The Effects of Culture on Managerial Attitudes: A ThreeCulture Test," Journal of Intemational Business Studies, Vol. 18, No. 2 (Summer 1987), pp. 17 31.

67 Mark Mendenhall and Gary Oddou," Acculturation Profiles of Expatriate Managers: Implications for Cross Cultural Training Programs," The Columbia Journal of World Business, Vol. 21, No. 4, winter 1986), pp. 73-79. I. James Czechowicz et al., quote the differing views about the unit versus managerial performance in their work, "Assessing Foreign Subsidiary Performance op. cit.,1982, Controller A: "I think generally we would look upon the manager's and unit's performance as about one and the same. The operations of the foreign unit is the responsibility of the manager and how the unit does is pretty much tied in with his evaluation (p. 25 ) and Controller B, "In terms of evaluating the manager, it is very much related to how he is doing against his budget because he did present his budget which was approved by the executive office and this was his plan of action for the coming year. Now in terms of evaluating whether his unit is one that we want to continue or invest in or whether we should be looking at other alternatives, the return on investment becomes the significant factor (p. 26). 
accounting approaches to appropriately reflect these environment-specific problems Wagdy Abdallab studied the effects of the sociological, economic, political-legal, and educational constraints. 68

This study attempts to continue the similar thrust but focusing on foreign cultural factors for American overseas managers. For the purposes of this study the dimension/s (aspects) of performance listed in Table 1.2 have been selected from an adapted list of those which were employed by Fleming 69 in his 1966 study.

TABLE 1.2

\section{Selected Aspects Of Performance}

1. Ability to plan

2. Ability of organise

3. Ability for effective decision-making

4. Ability to understand and execute duties

5. Ability to motivate

6. Initiative

7. Ability of get things done

8. Overall performance

68 Wagdy M. Abdallah, Internal Accountability: An Intemational Emphasis, on. cit., 1984, pp. 90-3.

69 R. J. Fleming. "Cultural Determinants of the Effectiveness of American Executives Abroad", (Ph. D. Dissertation, Louisiana State University, 1966), pp. 1-255. 
The selection has been accomplished through a survey carried out by the author (details of the survey are provided in Appendix E ).

\section{SCOPE AND LIMITATIONS OF THE STUDY}

Keeping in view the time-frame and the available resources, it was proposed to limit the scope of the study as follows:

\section{Environmental}

At a given place there are several factors: regional climate, legal, economic, cultural, and political which exercise a significant influence on the behaviour and work of individuals. Regional climate factors are somewhat permanent and man has succeeded in overcoming some of these. Legal factors are a changing phenomenon and must conform to the present aspirations of the population, as perceived by the elected officials. Similarly, political factors are a function of the ruling party's platform, which also may be anything but stable. When administrations are changed it has been witnessed that political priorities can also be changed. Likewise the economic factors are products of various forces working for different priorities and objectives. With the change in political systems it is quite obvious that economic factors also would be modified to suit the party's economic philosophy. Cultural factors remain visible and tend not to change over short time periods. Therefore, it was proposed to limit the study to only the analysis of cultural influences. 


\section{CULTURAL}

As stated earlier culture consists of numerous elements, manifested in institutions, beliefs, attitudes, and customs. The detailed list is provided in Appendix B as given by George P. Murdock. 70 The consideration of all of the elements may be desirable to reach pervasive and meaningful conclusions. However, to consider all of these in this study may render the proposed task unmanageable. Accordingly, it was proposed to study the impact of selected cultural factors enumerated in Table 1.1.

\section{PERFORMANCE}

Performance of a manager, like that of a subsidiary, has many dimensions and its measurement may include any of these dimensions. Performance may be measured in terms of output variables depending upon the financial responsibility including such as cost incurred, profit earned or return on investment achieved. Performance is also measurable in terms of non-financial measures, such as increase in market share and changes in employee turnover. Performance can also be gauged against some abstract traits (input variables) such as ability to control, ability to plan, and ability to develop employees.

Many corporations hitherto, have shown inflexible inclination to use the established policies consisting of financial and non-financial output measures for performance evaluation on a worldwide basis. Others seem to have favoured subjective adjustments for foreign environmental factors on an

70 George P. Murdock, "The Common Denominator of Cultures" in the Science of Man in the World Crises, edited by Ralph Linton, op. cit., pp. 123-44. 
ad hoc basis. Still others believed that the overseas managers must build the foreign environments into their budgets. ${ }^{71}$ MNEs do perceive the need to incorporate environmental peculiarities into financial control systems but no feasible method of accomplishing this task has been developed. ${ }^{72}$ Financial as well as non-financial output measures are the results of multiple factors, including many over which managers have no control. These include frequently changing economic policies of the host country government regarding price control, quotas, labour laws and tariffs. Further in cases where the vital decisions are determined at headquarters and expenditures are made by the home office, any evaluation of performance to be made against output measures would be improper, unjust and could lead to frustrations among managers.

The impact of the above limitations can be minimised if the performance is measured against input variables. These input variables form the critical elements in the management process and are more responsive to the environments. For this reason it is hypothesised that these input variables have a marked impact on the managerial performance. 73

It was proposed in the design for this study to limit consideration to those input variables (aspects of performance) where the interplay of cultural factors may be more prominent. Therefore, the aspects of performance

71 Helen G. Morsicato and Michael A. Diamond, An Approach to "Environmentalizing" Multinational Enterprise Performance Evaluation Systems The International Journal of Accounting: Education and Research, Vol. 16, No. 1, Fall 1980, pp 247-268.

72 lbid, p. 255.

73 Richard N. Farmer and Barry M. Richman, International Business, op. cit., pp. 80-96. 
employed by Fleming 74 in his study were adapted and used to select the specific areas for investigation. The selection of aspects of performance for this study was accomplished through a survey the details of which are provided in Appendix E.

\section{REGIONAL}

U.S. multinational enterprises in 1987 operated in more than 122 countries. ${ }^{75} \mathrm{~A}$ study comprised of all the countries with their distinct cultures was considered to be unrealistic at the time, and hence, the contemplated plan was to limit the study to five regional clusters based on specific major commonalities. These commonalities permit the clustering of countries on the basis of similarities in their environments and economic features. ${ }^{76}$

Attempts made in the past have yielded various classes of clusters based on similarity of accounting practices ${ }^{77}$, business environments, ${ }^{78}$ and economic characteristics. ${ }^{79}$ Also, these clusters may further be refined on the

74 R.J. Fleming, op. cit.

75 Directory of Firms Operating in Foreian Countries, 11th Ed. (New York: World Trade Academy Press, Inc. 1987).

76 Philip R. Harris and Robert T, Moran, Managing Cultural Differences, op. cit., pp 320 490; Jeffrey S. Arpan and Lee Radebaugh, International Accounting and Multinational Enterprises, (New York: Warran, Gorhan and Lamont, 1981), pp 1-21.

77 Gerhard B. Mueller, An Introduction to International Accounting (Englewood Cliffs, New Jersey: Prentice Hall, 1965).

78

"Accounting Principles Generally Accepted in the United States Versus Those Generally Accepted Elsewhere", International Journal of Accounting: Education and Research, Spring 1968, pp 83-94.

79 Hani Mahmoud Abu-Jbarah, "A Subentity for Financial Reporting by Multinational Firms: A Cluster Analysis Approach", (Ph. D. Dissertation, University of Wisconsin, 1972). 
basis of other pertinent features such as disclosure practices, ${ }^{80}$ legal requirements, stage of economic development, and degree of conformity with national policies. Some clusters are better than others, depending upon their degree of specificity, the methods used to derive them, and their relevance to the subject under study. ${ }^{81}$

The five regional clusters choosen for this study are: Europe, Middle East, Far East, Africa and Latin America. These five regions are conspicuous because of fairly distinct characteristics. The Middle East region is predominantly religion-orientated, while the African region is distinctly tribal. The Far East region is more populous than some of the other regions with strong family ties and leanings toward collectivism. The European region is more industrialised than the region of Latin America, which consists of developing nations by and large under authoritarian regimes. The selection of these five regions was based on personal observation of and perceived commitments among cultural entities rather than on anter-subjective scientific rationale. It is believed that political boundaries per se may be of minor importance for this study. The study excluded direct consideration of political factors.

80 G. Watt, R. Hammer, and M. Burge, Accounting for Multinational Corporation, (New York: Financial Executives Research Institute, 1977), pp. 185-8.

81 Jeffrey S. Arpan and Lee Radebaugh, International Accounting and Multinational Enterprise, New York: Warran, Gorham and Lamont, 1981, pp. 1-21. 


\section{PERSONNEL}

U.S. Multinational enterprises do not necessarily pursue a policy of staffing their overseas managerial positions with U.S. citizens. Nationals of other countries also occupy positions of high responsibility in overseas offices of U.S. multinational enterprises. ${ }^{82}$ However, keeping in view the likely similarity in their background, it is proposed to consider only U.S. expatriates working in overseas offices of U.S. multinational enterprises.

\section{SAMPLE}

This study focused on Multinational enterprises with offices and officers in the aforementioned five overseas regions. The consideration of a larger number of MNEs having business operations in a greater number of overseas regions was not undertaken in this study because of time and resource limitations.

Cultural factors can bear an affinity with specific regions. This study did not examine all of the numerous regions where U.S. multinational enterprises conduct business. Accordingly, the study's findings may not be generalised to other regions.

Secondly, as this study focused on selected foreign cultural factors and their impact on specific input variables of performance, the generalisability of its findings would not be applicable to the effects of other cultural factors and for other measures of performance.

82 Lawrence G. Franko, "Who Manages Multinational Enterprises?" op. cit., pp. 30-42 
Third, the study, because of its exclusion of related environmental factors - political, legal, climatic, and economic, does not attempt to explain the total differential in performance measurement. Another limitation is that this study describes its findings with reference to U.S. executives and, therefore, the validity of its findings is limited to U.S. personnel working overseas.

In addition, because of characteristics peculiar to the studies involving the relatively small sample size, the validity of the findings may be restricted. Nonetheless, these features of the study should not preclude further use of the findings in the development of hypotheses and the carrying out of further studies which may replicate, expand and confirm these findings.

\section{PLAN OF STUDY}

This design consisted of four phases (detailed discussion of each phase is provided in Chapter IV). The first phase involved the contacting of executives in charge of international personnel of multinational enterprises to solicit their permission and cooperation thus assessing the feasibility of the study. The second phase comprised of the developing and testing of questionnaires for both groups of respondents, namely overseas managers and the evaluators of performance of those managers. Surveying respondents and the collection of data constituted Phase III, and the final phase involved the analysis of the data.

Because of the particular nature of the data source, it was decided to first appraise the feasibility of the study and availability of data. Accordingly, a few MNEs were selected from the Forbes top 100. Telephone contact was 
established with executives in charge of international personnel placements for these enterprises. The response was encouraging and some committed themselves to cooperate in this study, based on briefings about the proposed project. However, the specific study was conducted using only a few enterprises having a sufficient number of U.S. executives working overseas from the five regions.

Questionnaires [Appendix $\mathrm{G} \& \mathrm{H}$ ] have been prepared on a comprehensive basis, including questions on the selected socio-cultural variables and their impact on the proposed aspects of manager's performance. To avoid different interpretations and appreciation of the selected cultural factors and hence unusable responses it was decided to provide a definition of each cultural factor in the relevant question itself. These definitions were based on prior studies. In part $\mathbf{A}$ of each question the respondent was asked a general type question with a view to elicit his common perception of the particular cultural factor. Part B of each question appertains the application of that common perception to the eight specific aspects of managerial performance. A Likert scale was used for response analysis of both the parts. Where the response sought was different, the explanation of the same was provided along with the question.

As the first step in data collection, a pretest was conducted using colleagues who have spent some time in foreign countries. Pretesting the questionnaire was critically important to assess the difficulty of the task and to learn of any defects or inadequacies in the questionnaire. The participants were asked to comment on the difficulty of the response task and clarity of the instructions. A few improvements were suggested and the same were incorporated in the questionnaire. 
With the pretest favourably concluded, a pilot study was undertaken to refine and validate the questionnaire, using subjects (managers in MNCs) who have returned from foreign assignments, and their superiors in the enterprises under study. The pilot was also undertaken to test the sequence and the context of each question, to evaluate the response rate, to assess informally the managers' abilities to handle the questions and the instructions. Personalisation was considered in all aspects of the pilot. A cover letter was sent with each questionnaire to introduce the participants to the nature and relevance of the research and acted as an appeal for their cooperation and participation. This phase of the study yielded some valuable modifications in the sequencing and fine-tuning of questions and was effectively concluded.

The next phase was to survey the personnel working overseas. Their responses were solicited through questionnaires, which were sent by the corporate headquarters located in the U.S., but the responses were received by the author directly. The second set of questionnaires would be given to the executive/s responsible for evaluating the performance of foreign managers. Also, personal interviews with the corporate headquarter's personnel were used to supplement the data from the survey.

The data collected are organised in an interval scale, and appropriate analyses of the same have been undertaken to test the proposed hypotheses. Details of design and of analysis have been provided in Chapters IV and V.

\section{PREVIEW OF THE STUDY}

Chapter I provides an introduction to the study by stating the problem and emphasising the need for such an undertaking. It also outlines the 
study's scope and possible limitations. It highlights the importance of the study by emphasising its potential contributions.

Chapter II presents a thorough review of literature pertaining to the topic of the study, tracing the gradual developments on this path over several years. The studies undertaken in this general area over the last few decades have been discussed with respect to their distinct contributions and recommendations.

Chapter III presents the theoretical foundations for the development of hypotheses by providing an elaboration of the concept of culture, and its various patterns and themes, together with subcultures and traits. A thorough discussion pertaining to the cultural determinants of the managerial effectiveness has been provided. An attempt has also been made to show the impact that some of these cultural traits (variables) may have on the managerial functions and effectiveness thereof especially in the case of a MNE manager functioning in an alien culture.

Chapter IV gives the details of the research design and methodology that were adopted in carrying out this study. It also provides the details of developing questionnaires for managers and evaluators, pretest and pilot study, the survey and administration of questionnaires and the results of the survey.

Chapter $\mathrm{V}$ presents the description of profiles of overseas managers in the five regions and of the evaluators for these five regions. It also provides the general description of overseas managers' as well as evaluators' perceptions of the selected cultural factors. The hypothesis testing, analysis 
of data and findings of this study are provided in the last part of the chapter. An attempt was also undertaken to see whether the effect of any cultural variable is correlated with that of other/s. The research endeavour through its detailed analysis of collected responses from the U.S. overseas managers has successfully highlighted the relative impact of each of the cultural factors on their performance and its measurement. Also, the analysis is geared to provide the extent of similarity in perceptions of overseas managers about the impact of cultural factors on their performance and consideration assigned to the impact of cultural factors on performance in its (performance) evaluation by the evaluators. Differences in the perceived impact of cultural factors on performance of managers working overseas on a regional basis were also examined.

Chapter VI presents the summary of the nature and purpose of the research study. It also provides the discussion of the findings and conclusions, together with recommendations and suggestions for further research in the area of performance evaluation in the context of multinational corporations. 
CHAPTER II

\section{REVIEW OF RELEVANT LITERATURE}

\section{INTRODUCTION}

The emergence of the multinational enterprise (MNE) has been one of the significant economic phenomena of this century. Enormous technical and human resources employed by the MNEs in their worldwide operations have profoundly affected the contemporary international economic system and have introduced complexities for theories in economics, business administration and even in political science. ${ }^{1}$ Understandably, they have generated considerable interest in academic circles. Economists, management and financial experts, political scientists and to a lesser extent

1 K.M. Thiagarajan, A Cross-Cultural Study of the Relationships Between Personal Values and Managerial Behavior, Technical Report 23, NONR N00014-67A, (Rochester, NY: University of Rochester, Management Research Center, 1968), R. Nath," A Methodological Review of Cross-Cultural Management Research," in Comparative Management and Marketing, edited by J. Boddewyn (Glenview, II.: Scott, Foresman, 1969), pp. 195-223, John J. Dugan ," The Relationship Between Culture and Managers' Behavioral Decisions: A Two Country Study of the Preference Formation and Choice Processes, " (Ph. D. Dissertation, Temple University, 1984), pp. 275, John M. Stopford and John H. Dunning, Multinationals: Company Performance and Global Trends, (London: Macmillan Publishers, 1983), pp. 17-55, Nancy J. Adler," Typology of Management Studies Involving Culture," Journal of International Business Studies. Fall 1983, pp. 29-47, Anant R. Negandhi," Cross-Cultural Management Research: Trend and Future Directions," Journal of International Business Studies, Fall 1983, pp. 17-28, John Child, "Culture, Contingency and Capitalism in the Cross-National Study of Organisations," in Research in Organisational Behavior. Vol. III,edited by L.L. Cummings and B.M. Shaw (Greenwich, Ct.: JAI Press, 1981), Etemad Hamid and Dulude, Louise Seguin ," Managing The Multinational Subsidiary", in Manaoing The Multinational Subsidiary: Response to Enviromental Change and to Host Nation R \& D Policies.edited by Etemad Hamid and Dulude, Louise Seguin,London: Croom Helm, 1986, pp. 1-21, and Philip R. Harris and Robert T. Moran, Managing Cultural Differences. 2nd ed. (Houston, Texas: Gulf Publishing Co., 1987). 
anthropologists and sociologists have started to display a keen interest for MNE impacts. As a result, literature on MNEs has been proliferating. ${ }^{2}$

\section{PARADIGMS}

Scholars have followed two distinct but interrelated routes, which can be designated as "micro" and "macro" approaches. The ones following the former path confine themselves to the structures and functioning of MNEs, while those interested in the alternative route seek to examine their impact on economic and political systems -- national and international. The "micro" scholars have investigated subjects such as the growth of MNEs, their motivations for investing abroad, their organisational structures, product strategies, management and corporate policies, personnel and labour relations, finance, taxation, marketing strategies, and relationship with government officials. In fact all the major dimensions of MNEs have been closely examined by these individuals. Most of these investigations have been designed to facilitate the functioning of MNEs, the objective being to feed the almost insatiable information needs of MNEs and/or the agencies dealing with them. ${ }^{3}$

2 The Centre on TNC of the U.N. Survey of Research on TNC (New York: United Nations, 1978), pp. 1-40. Hertner, Peter and Jones, Geoffrey, "Multinational:Theory and History," pp.118; and Wilkins, Mira, " Defining a Firm: History and Theory," pp. 80-96, both from Multinational:Theory and History edited by Hertner, Peter and Jones, Geoffrey, (Brookfield, Vermont: Gower Publishing Company, 1986).

3 K. Kumar, Social and Cultural Impact of Multinational Corporations (Hawaii: East-West Centre, 1978), p. 3 , Jangho Lee, "Strategic Choice. Foreign Involvement and Firm Performance" (Ph.D. Dissertation, University of Washington, 1986), pp. 193, K.M. Thiagarajan, A Cross-Cultural Study of the Relationships Between Personal Values and Managerial Behavior, op. cit., R. Nath," A Methodological Review of Cross-Cultural Management Research," op. cit, John J. Dugan ," The Relationship Between Culture and Managers' Behavioral Decisions: A Two Country Study of the Preference Formation and Choice Processes, " (Ph. D. Dissertation, Temple University, 1984), Nancy J. Adler," Typology of Management Studies Involving Culture," Journal of International Business Studies, op. cit., Anant R. Negandhi," Cross-Cultural 
Macro-level analysts have investigated the effects of MNEs on a wide range of subjects such as employment, manpower and productivity, labour relations and taxation systems, balance of payment situation, transfer of technology, industrialisation and economic development. ${ }^{4}$ Additionally, scholars have also attempted to explore the impact of MNEs on national sovereignty and international stratification.

This study has its focus on the "micro-level". Hence the literature dealing with the macro-level approach was not surveyed in depth.

Despite the enormous literature pertaining to "micro-level" analysis of MNEs, relatively little attention has been accorded to the impact of sociocultural factors on the managerial personnel and their performance measurement. The apparent lack of interest could be explained as follows: First, sociologists and anthropologists who often zealously guard their disciplinary territories against outside encroachments are generally not accustomed to analysing social and cultural phenomena in the context of their

\footnotetext{
Management Research: Trend and Future Directions," op. cit., John Child, "Culture, Contingency and Capitalism in the Cross-National Study of Organisations," op. cit., Etemad Hamid and Dulude, Louise Seguin ," Managing The Multinational Subsidiary", in Managing The Multinational Subsidiary: Response to Enviromental Change and to Host Nation R \& D Policies, op. cit, Frederick H. Schwarz," An Alternative Method of Evaluating the Financial Performance of Foreian Subsidiaries," (Ph.D. Dissertation, St. Louis University, 1986), pp. 1-155, Robert David Russell," The Effect of Environmental Context and Formal and Informal Organizational Influence Mechanisms on the Process of Innovation: Toward An Integrated Theory of Innovation," (Ph. D. Dissertation, University of Pittsburg, 1986),pp. 1-125, and Philip R. Harris and Robert T. Moran, Managing Cultural Differences, op . cit.

4 Kiyoshi Kojima, Direct Foreian Investment (London: Croom Helm Ltd., 1978),pp. 100150, Richard E. Caves, Multinational Enterprise and Economic Analysis (Cambridge,London: Cambridge University Press,1982), pp. 130-220, and John A. Cantwell and T.A.B. Corley," The Theory of International Production: Some Historical Antecedents in Multinational: Theory and History edited by Peter Hertner and Geoffrey Jones, on. cit., pp. 19-42, Mohammed Farid Yasin Kurashi," The Social Responsibility of the Multinational Corporations Operating in Saudj Arabia," (Ph.D. Dissertation, Claremont Graduate School, 1984), and Jean J. Boddewyn, "Political Aspects of MNE Theory," Journal of International Business Studies, Fall 1988, pp. 341-63.
} 
impact on multinational personnel. They have long regarded national social and cultural systems as more or less self-contained and self-sustained. ${ }^{5}$ Second, national and corporate planners have in the past treated MNEs as merely economic systems which could only be justified and/or evaluated with reference to economic criteria. ${ }^{6}$ However, it does appear that the lack of interest is being replaced by a growing realisation that the performance of MNEs and their personnel should be judged with due consideration given to varying socio-cultural environments. ${ }^{7}$

\section{ROLE OF SOCIO-CULTURAL FACTORS}

A prime requirement for a manager working in a multinational environment is an understanding of the cultural differences between peoples of various countries. Managers raised and experienced in one culture are often expected to play bicultural and multicultural roles. To headquarters they are local managers who belong to subsidiaries and hence should be capable of effectively interfacing with the host country's cultural nuances. To their employees and customers they represent the company which personifies a

5 K. Kumar, op. cit., p. 4.

6 Bart Alister Paff," A Conceptual Studv of Multinational Firms and the Maior Dimensions of their Environments," (Ph. D. Dissertation, The American University, 1968), pp. 274; Karl P. Sauvant, "The potential of Multinational Enterprise as Vehicles for the Transmission of Business Culture", in Controlling Multinational Enterprises: Problems. Strategies and Counter strategies, edited by Karl P. Sauvant and Farid G. Lavipour (Boulder, Colorado: Westview Press, 1976); and Glynn Cochrane, The Cultural Appraisal of Development Projects (New York: Praeger Publishers, 1979), pp. 1-10.

7 Wagdy M. Abdallah, Internal Accountability: An International Emphasis (Ann Arbor, Michigan: UMI Research Press, 1984), pp.18-25, Jeffrey Marc Wachtel," A Cross-Cultural Comparative Management Study Measuring the Differences in Managerial Motivation and the Effects of Cultural and Other Explanatory Variables of Potential Managers from Mexico and the United States." (Ph.D. Dissertation, Georgia State University, 1986), pp. 1-12, and Philip R. Harris and Robert T. Moran, op. cit., pp. 20-23. 
different (alien) cultural system unable to understand and appreciate their value system and aspirations. The greater the difference in cultures, the more likely is an overseas manager prone to suffer failures and frustrations. Managers of overseas offices get sandwiched between their own culture and that of the host country. ${ }^{8}$

It is felt that:

Knowledge about cultures, both general and specific, provides insights into the learned behaviour of groups. It helps the learner to gain awareness of what makes a people unique their customs and traditions, their values and beliefs, attitudes and concepts, hierarchies and roles, time and space relationship, and verbal and non-verbal communication processes. $^{9}$

Any business operating within a single country must adjust to the culture within which it operates, but the need for sensitivity towards culture is much greater in the context of the multinational enterprise. ${ }^{10}$ Cultural differences that can affect the international business operations arise virtually

8 Stefan H. Robock, Kenneth Simmonds and Jack Zwick, International Business and Multinational Enterprise (Homewood, Illinois: Richard D. Irwin, 1977), pp. 309-41 and Harris and Moran, of. cit., pp. 23-5.

9 Harris and Morran, Managing Cultural Differences,_op. cit., 1979, pp. 20.

10 Stefan H. Robock, et al.,International Business, op. cit., pp. 309-41; H.W. Lane," Systems, Values and Action: An Analytic Framework For Intercultural Management Research," Management International Review, Vol. 20, No. 3, 1980, pp. 61-70; S.G. Redding," Cognition As An Aspect of Culture and lts Relation to Management Processes: An Exploratory View of the Chinese Case,"Journal of Management Studies, Vol. 17, May 1980, pp. 127-48; Lane Kelley and Reginald Worthley," The Role of Culture in Comparative Management: A Cross-Cultural Perspective," Academy of Management Journal, Vol. 24, No.1, 1981, pp. 164-173; David K. Tse, Kam-hon Lee, Ilan Vertinsky, and Donald A. Wehrung," Does Culture Matter? A CrossCultural Study of Executives' Choice, Decisiveness, and Risk Adjustment in International Marketing, Journal of Marketing, Vol. 52, October 1988, pp. 81-95; J. Hayes and C.W. Allinson," Cultural Differences in the Learning Styles of Managers," (Research Note) Management International Review, Vol. 28, No. 3 1988, pp. 75-80, and Rose Knotts," Cross-Cultural Management: Transformations and Adaptations," Business Horizons, Vol. 32, No. 1, Jan.-Feb. 1989, pp. 29-33. 
in all aspects of business activity and have their impact manifested within each of the traditional functions. ${ }^{11}$

The preference of the German housewife for packaged soup and the insistence of the French housewife for homemade soup explains their respective values for convenience and their perception of motherhood. Similarly, the still-prevalent paternalism in African factories has literally no place in the US, where it would restrict a need to express individuality. ${ }^{12}$

Even in the external relations of the multinational enterprise, the role of the socio-cultural variables can hardly be ignored. ${ }^{13}$ Harris and Moran in their famous work, Managing Cultural Differences, presented a comparison of aspects of U.S. culture with those of other cultures, as these affect the various managerial functions. ${ }^{14}$ These are provided in Appendix C.

A careful study of Appendix $C$ has revealed the varied impact which these cultural aspects have on management functions. This makes the measurement of the effectiveness of the functions more difficult and complex. In addition, the potential difficulties in performance measurement suggested

11 op. cit., and Arvind V. Phatak, Managing Multinational Corporations (New York: Praeger Publishers, 1974), pp. 136-44.

12 Stefan H. Robock, et al., International Business, op. cit., pp. 313-4.

13 Hamid Etemad and Louise Seguin Dulude," Managing The Multinational Subsidiary", in Managing The Multinational Subsidiary: Response to Environmental Change and to Host Nation R \& D Policies, edited by Hamid Etemad and Louise Seguin Dulude (London: Croom Helm, 1986), pp 1-21; Stephan H. Robock et al., International Business and Multinational Enterprises, op. cit., pp. 10-12, and Batya Bertha Weinreb, "Cultural Reflections in Multinational Corporations: A Comparison Between Israeli and U.S. Subsidiaries," (Ph.D. Dissertation, Stanford University, 1987), pp. 274.

14 Philip R. Harris and R.T. Moran, op. cit., 1983, p. $76-77$. 
the need for the development of a framework of performance measurement criteria wherein an adequate consideration is provided for the impact of foreign cultural factors on the managerial performance.

\section{CULTURE DEFINED}

Culture is the unique life style of a particular group of people. Unlike good manners, it is not something possessed by some and not by others - it is possessed by all human beings and is in that sense, a unifying factor. Culture is also communicable knowledge, learned behavioural traits that are shared by participants in a social group and manifested in their institutions and artifacts. ${ }^{15}$

Despite the enormous literature (or perhaps because of it), "culture" remains an imprecise construct. ${ }^{16}$ There has been almost no agreement on the definition of the cultural factors (variables) in cross-cultural studies. Ajiferuke and Boddewyn, using culture as the main explanatory variable found only two studies out of 22 attempting more than an implied definition. ${ }^{17}$ Kroeber and Kluckhohn ${ }^{18}$ in their critical review of definitions of culture emphasised that culture represents patterns of "learned" behaviour which have historical and evaluative components. Kaplan, for example has

15 lbid. , p. 57.

16 J.L. Gross and S. Rayner, Measuring Culture: A Paradigm for the Analysis of Social Organisation, (New York: Columbia Press, 1985), pp. 146.

17 Ajiferuke and J. Boddewyn, "'Culture' and Other Explanatory Variables in Comparative Management Studies", Academy of Management Journal , June 1970, pp.153-78

18 L. Kroeber and C. Kluckhohn, Culture: A Critical Review of Concepts and Definitions (Cambridge, Massachusetts, Harvard University Press,1952), p.186. 
reviewed four theoretical sub-systems that explain cultural variation. ${ }^{19}$ They are ideology, social-structure, technoeconomics, and personality. All are anthropological in orientation, although the latter sub-system personality does encompass social and psychological dimensions.

The concept of culture is so broad that it gives little guidance to anyone wishing to study or compare culture. Cultural processes are multicausal, and no single explanation holds for all times and places. Some classification of the elements of a culture is needed as a basic framework for grasping the cultural pattern. By far, the most comprehensive list of cultural universals has been proposed by George P. Murdock. These, he has argued, occurred in every culture known to history or ethnography. ${ }^{20}$ While his list of more than 60 one-dimensional universals (Appendix B) suffers from serious limitations on account of its focus on very narrow facets of culture, it can nevertheless be of considerable value.

The works reviewed here followed the definition of culture as provided by Edward B. Tylor21, "...as a complex whole which consists of beliefs, laws, customs, arts, and habits acquired by its societal members".

19 Kaplan A., Culture Theory (Englewood Cliffs, N.J.: Prentice Hall, 1972); and Deitrich L. Schaupp, A Cross-Cultural Study of a Multinational Company (New York: Praeger Publishers, 1978), p. 9.

20 George P. Murdock, "The Common Denominator of Cultures" in The Science of Man in the World Crises, op. cit., pp. 123-26.

21 Edward B. Taylor, Primitive Culture - Researches into the Development of Mythology Philosophy. Religion. Language. Art and Custom (New York: Henry Holt \& Co., 1977), vol. 1, p.1. 
However, despite the fine semantical underpinnings, almost everybody dealing with the concept of culture recognises that culture:

- is a social product

- is learned

- is adaptive

- tends to become a consistent and integrated whole

- increases the interdependence of society's members. ${ }^{22}$

Robertson contends that world cultures can be classified within the framework of distributive, organisational, and normative dimensions. ${ }^{23}$ The distributive is the same as demographic. The organisational dimension includes cultural participation patterns, e.g., family relationships. It is the normative dimension which encompasses values, assumptions and beliefs. The major thrust between cultures that leads to behavioural and attitudinal dissimilarities can be attributed to the normative dimensions of the cultural makeup.

Harris and Moran 24 have listed 10 major characteristics of culture:

1. Communications and Language

2. Dress and Appearance

3. Food and Feeding Habits

4. Time and Time Consciousness

5. Rewards and Recognitions

6. Relationships

7. Values and Norms

8. Sense of Self and Space

9. Mental Process and Learning

10. Beliefs and Attitude p.147.

22 J.J. Honigmann, Personality in Culture (New York: Harper \& Row Publishers, 1967),

23 Thomas S. Robertson, Consumer Behavior (Glenview, Illinois.: Scott, Foresman \& Co., 1970), pp. 100-106.

24 Philip R. Harris and R.T. Moran, op. cit., 1983, pp. 190-95. 
They argued that the differences in cultures can be explained on the basis of these major features. A point was also made that cultures are different if they differ on any one of these major features. Cultures do not need to differ on all of the characteristics to be considered different.

In another study, Farmer and Richman 25 proposed a framework for analysing differences in business practices. They organised environmental characteristics into four major groups: educational, socio-cultural, legal and political, and economic. The various elements in each of the four groups explain the way business organisations operate in a particular country. They contended that their model can be used to explain the differences in the ways business is conducted in one country compared to another. They proposed a list of fifteen critical socio-cultural factors which, along with their individual explanations, is provided in Appendix D.

The preceding review highlights the lack of unanimity among authors regarding the elements of culture. Each one has viewed it from a different perspective. These differences regarding the elements of culture provide a stimulus to continue the search for its elements and their impact in the area of interest.

25 Richard N. Farmer and Barry M. Richman, Comparative Management and Economic Progress Bloomington, Ind.: Cedarwood Press, 1970), pp. 20-30. 


\section{CROSS-CULTURAL STUDIES}

Cross-cultural studies are comparative in orientation and attempt to emphasise the similarities and differences across cultures under study. 26 The focus in the studies conducted so far has been on the similarities and differences in the elements of cultures and their impact on the behaviour, attitudes, and working patterns of the societal members. ${ }^{27}$ There are three viewpoints from which to look at the cross-cultural studies - universal, economic, and cultural cluster. The universalists believe that no appreciable difference exists in managerial behaviour across cultures. Proponents of this theory include Likert, and Mouton and Black. The economic cluster school maintains that managerial behaviour is the product of a nation's economic and industrial development. 28

The basic premise of the cultural cluster school has been that culture is the independent variable in explaining managerial behaviour and attitudes. This group maintains that international behavioural and attitudinal differences are the result of divergent values within different cultural spheres. ${ }^{29}$

26 lbid., pp. 20-133; Nancy J. Adler," Typology of Management Studies Involving Culture," op. cit., pp. 29-47 and Anant R. Negandhi," Cross-Cultural Management Research: Trend and Future Directions," ㅇ․, cit., pp. 17-28.

27 Stefan H. Robock, et al., International Business, op. cit., p. 315.

28 R. Likert, "Trends Towards a World-wide Theory of Management", Proceedings of the CIOS XIII International Management Congress 2 (1963), pp. 110-4; J. Mouton and R. Black, "Issues in Transnational Organization Development", in Managing for Accomplishments, edited by B.M. Bass, et al. (Massachusetts: Lexington Books, 1970), pp. 208-24; Richard N. Farmer and Barry M. Richman, Comparative Management and Economic Progress, op. cit., pp.179-89 and David C. McClelland, The Achieving Society (Princeton, N.J.: Van Nostrand Co., 1961.

29 John Child, "Culture, Contingency and Capitalism in the Cross-Cultural Study of Organizations," in Research in Organizational Behavior, vol 3 edited by L.L. Cummings and B.M. Shaw (Greenwich,CT: JAI Press, 1981), pp.303-56; and Monir Tayeb, "Theoretical Perspective in Cross-National Organizational Research," International Studies of Management 
Nancy Adler 30 in her "Typology of Management Studies" enumerated six main approaches to cross-cultural research studies. In parochial research the emphasis is placed on a single culture and the main thrust assumes the existence of similarities. In the ethnocentric approach efforts are directed to explore the possibility of applying the domestic theories in foreign cultures. In the polycentric paradigm the efforts are geared to identify the differenes in multi-cultural situations to help highlight the culture-specific patterns in management. In the comparative research group an endeavour is undertaken to bring focus on both the differences as well as similarities by studying the comparative organisations in many cultures. In the geocentric approach the attempt is to search for similarities, to see how the multinational oragnisations function. Typically the majority of recent studies fall in this category. The last group of studies ${ }^{*}$, distinct because of its synergistic thrust, demonstrates the effort to use similarities and differences as a resource. It tends to create a semblance of universality. Fundamentally, the emphasis is placed on the inquiry as to how can organisations create structures and processes which will be effective in working with members of all cultures? Generally, it is not

and Organzation, Winter 1982-3, pp. 23-70; R.N. Farmer and B.M. Richman," A Model for Research in Comparative Management," California Management Review, Winter 1964, pp. 5568; Anant R. Negandhi," Comparative Management and Organization Theory: A Marriage Needed," Academy of Managemnt Journal, June 1975, pp. 334-43 and Geert Hofstede, Culture's Consequences: Intenational Differences in Work-Belated Values (Beverly Hills, CA: Sage Publications, 1980

30 Nancy J. Adler, op. cit., pp. 29-32.

* Alfred M. Jaegar, "The Transfer of Organization Culture Overseas: An Approach to Control in the Multinational Corporation," Journal of International Business Studies, Fall 1983, pp. 91-114. This paper describes an alternative organisational ideal type that relies on an organisational culture for control (as opposed to Weberian bureaucracy, in which rules and regulations specify desired behaviour, and rewards are based on explicit performance measures. In this type of system, behaviour is specified by the organisation culture, and performance is maintained via mechanisms of social/ cultural pressure. An example of latter type of control is found in the Type $\mathrm{Z}$ organisation, an American organisational form similar in many ways to the Japanese form. 
that easy to fit research endeavours in any one specific category for there are always cases which may overlap in coverage and emphasis.

In their studies, Farmer and Richman, as well as Negandhi and Estafen, reason that environmental factors determine the management and enterprise effectiveness. ${ }^{31}$ Farmer and Richman have provided a matrix approach using a list of critical environmental factors, against which they set another list of more than 75 critical elements in the managerial process. The general categories for the critical elements cited, are planning and innovation, control, organisation, staffing, direction, leadership and motivation, marketing policies, productions and procurement, research and development, finance, and public and external relations. The authors concluded that the managerial effectiveness is largely determined by the pattern of management. ${ }^{32}$

Haire, Ghiselli, and Porter undertook a cross-cultural study of managerial attitudes, wherein they surveyed approximately 36,000 managers in 14 countries. Although their study avoided the use of sophisticated statistical tests, they did succeed in providing general stratification, showing that the relative differences are caused by cultural differences. ${ }^{33}$ Similarly, Sadler and Hofstede carried out an extensive survey, soliciting the views of 21,000 employees of various countries, on leadership styles. They too concluded that differences in employees' preferred leadership styles are

31 R.N. Farmer and B.M. Richman, International Business. 2nd ed., (Bloomington, Ind, Cedarwood Press, 1974); and A.R. Negandhi and B.D. Estafen, "A Research Model to Determine the Applicability of American Know-how in Different Cultures and/or Environments", Academy of Management Journal , December 1965, pp. 309-18.

32 Farmer and Richman, Comparative Management, op. cit., pp. 77-89.

33 M. Haire, E.E. Ghiselli, and L.W. Porter, Managerial Thinking: An International Study , (New York: John Wiley \& Sons, 1966). 
based on their national culture entirely or partly. ${ }^{34}$ Kelly ${ }^{35}$ et al and Stephen ${ }^{36}$ also concluded that managerial attitudes and preferred leadership style are culturally determined. Graham ${ }^{37}$ researched the cultural constraints on the audit independence and Mckinnon ${ }^{38}$ explored the impact of culture on the process of business negotiation and concluded that these are culturedependent.

Fleming, ${ }^{39}$ undertook a study to isolate the cultural determinants of the effectiveness of American Executives abroad. He listed 10 cultural traits (commonly perceived as personality traits) associated with executives' background culture, and hypothesised the same as counteracting and reducing these cultural conflicts, resulting eventually in managerial success and effectiveness. The 10 cultural determinants used in his study were:

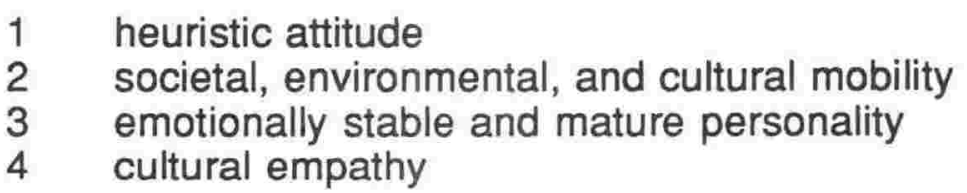

34 P.J. Sadler and G.H. Hofstede,, "Leadership Styles: Preferences and Perceptions of Employees of an International Company in Different Countries", Mens en Onderiming 26,1972, pp. 43-62.

35 Lane Kelley, Arthur Whatley, and Reginald Worthley," Assessing The Effects of Culture on Managerial Attitudes: A Three-Culture Test," Jeurnal of International Business Studies, vol. 18, No. 2, Summer 1987, pp. 17-31.

36 D.B. Stephens," Cultural Variation in Leadership Style: A Methodological Experiment in Comparing Managers in the U.S. and Peruvian Textile Industries," Management International Beview, vol. 21, No. 3 1981, pp. 47-55.

37 John L. Graham," The Influence of Culture on the Process of Business Negotiations: An Exploratory Study," Journal of International Business Studies,Spring 1985, pp. 81-96.

38 Jill McKinnon," Cultural Constraints on Audit Independence in Japan," The Intemational Journal of Accounting: Education and Research, Fall 1984, pp.17-43.

39 Richard J. Fleming, "Cultural Determinants of the Effectiveness of American Executives Abroad," (Ph.D. Dissertation, Louisiana State University, 1966), pp. 50-60. 


$\begin{aligned} 5 & \text { communicative skills } \\ 6 & \text { international philosophy } \\ 7 & \text { belief in mission } \\ 8 & \text { technical competence } \\ 9 & \text { organisational skills } \\ 10 & \text { political sensitivity. }\end{aligned}$

These traits were considered as multi-dimensional and the questionnaires were prepared accordingly. 40 He used 13 criteria for evaluating and rating each executive's performance:

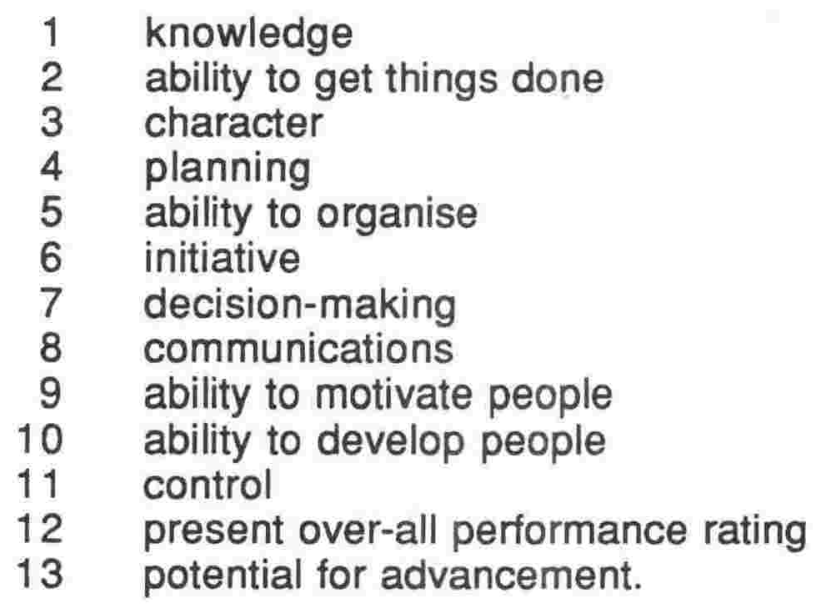

These 13 criteria were used by the company in evaluating its overseas executive's performance. ${ }^{41}$ He noted that for overseas managers some of the cross-cultural conflicts resulted from: (1) ethnocentrism (monocentric or home oriented); (2) latent and manifest culture patterns; (3) inappropriate American philosophy and management principles; (4) divergence of time perception; (5) mis-communication; (6) personality; and (7) attitude toward assignment. 42

\footnotetext{
40 Ibid., pp. 72-108.

41 lbid., p. 68.

42 lbid., p. 157.
} 
Using chi-square analysis, Fleming indicated that the "company's more successful and effective businessman, as shown by appraisals, also possessed the awareness and understanding of the cultural determinants in varying degrees. Results of the study substantiated the hypothesis that cultural differences led to cross-cultural conflict in expatriate personnel which in turn resulted in reduced effectiveness and efficiency overseas. The possession of the awareness, understanding, and appreciation of the indicated cultural determinants tended to alleviate this conflict which resulted in the executive being more productive". 43

In another study, Davar made an attempt to study the underlying determinants of culture-shock manifestations. 44 The study was geared more towards the attitudinal and behavioural formation as a result of cultural shock. The subjects chosen for this study were based in Iran. The main hypothesis of the study was that the behavioural manifestations of cultural shock are multidimensional in form. Also, the intensity of behavioural manifestation was hypothesised to be dependent on other variables, such as age, the length of pre-departure training, number of foreign assignments already served and their length, number of children living with the executive and so on. ${ }^{45}$

This study suggested three types of behavioural manifestations of cultural shock which together possess multiple directiveness. These manifestations were: frequency of becoming angry; frequency of spending

43 lbid., p.xiii.

44 Venous Davar, "An Empirical Study of the Underlying Determinants of Culture-Shock Manifestation in American Expatriates," (Ph.D. Dissertation, University of Nebraska, 1978), pp. 3-5.

45 lbid., pp. 10-17. 
time in social clubs or organisational activities; and frequency of getting physically fatigued without any apparent reason. ${ }^{46}$

By linking these manifestations with expatriates' belief systems, Davar purports to emphasise a careful screening of the potential assignee with regard to his belief system, along with the consideration of other variables, such as age, education and length of stay in the foreign post. 47

Davar's study highlights the underlying determinants of behavioural and attitudinal manifestations of cultural shock. The study did not focus on the impact of cultural shock on the manager's performance per se.

\section{PERFORMANCE MEASUREMENT AND EVALUATION}

The philosophy of decentralisation as applied in the United States has resulted in authority for decision-making being delegated to division managers. Periodically, those having the authority to make decisions have to account for the efficiency and effectiveness of their operations and decisions. Assessment by top management of the reported results (measurement) is therefore important in the process of performance evaluation. ${ }^{48}$

It is well recognised that evaluation of the economic unit should be separated from the evaluation of the entity's manager. In order to measure

46 lbid., pp. 3-4.

47 lbid., pp. 130-5.

48 Paul S. Tse," Evaluating Performance in Multinational," Management Accounting, June 1979, pp. 21-5. 
managerial performance fairly, several criteria have to be used. It can be asserted that a majority of decisions are made on some form of "cost-benefit" analysis. The policy to emphasise only cost-benefit criteria may render the performance evaluation narrowly focused and will raise problems of accountability, short period versus long period, beneficial to the subsidiary or the corporation as whole and of balance between the commercial aspirations and social commitments. However, performance measurements are still based on some financial indicator, e.g. profit, return on investment, or residual income. 49

In order to place performance measurement into a manageable context, the concept of responsibility accounting is widely applied, such that control over costs and/or revenues can be identified with specific individuals. ${ }^{50}$ Additionally, developments over the last 35 years have demonstrated the inappropriateness of using a single criterion of performance such as the traditional accounting-based profitability measures of return on investment or residual income. ${ }^{51}$

One of the first efforts to introduce multiple measurements was by the General Electric Company. At the time decentralisation was introduced by that company, they conducted a measurement project which recommended

49 D.D. AlHashim," Internal Performance Evaluation in American Multinational Enterprises, "Management International Review, vol. 20, No.3, 1980, pp. 33-9.

50 Elwood L. Miller, Accounting Problems of Multinational Enterorises (Massachusetts: Lexington Books, 1979), pp. 179-99.

51 Richard F. Vancil, "What Kind of Management Control Do You Need?" Harvard Business Review, March-April ,1973. 
an approach for evaluation of a division manager based on eight "key result" areas:
1. Profitability
2. Market position
3. Productivity
4. Product leadership
5. Personnel development
6. Employees' attitudes
7. Public responsibility
8. Harmony between short-range and long-range goals. 52

Through this approach General Electric indicated that over-emphasis on a single goal may lead to success in one area but overall failure to attain effectiveness.

Davies and Francis ${ }^{53}$ contended that there is more to performance than profits or growth. In any organisation, performance involves a trade off between conflicting objectives and criteria. A fair and equitable performance measurement for a unit should not be based on a single criterion. Instead, many indices of accomplishments should be considered.

Robert Irish in the course of his interviews, found that controllers strongly agreed with the assertion that profitability as a measurement criterion cannot be used exclusively. Such a measurement focuses on short-term results and does not gauge how well the divisional manager is fulfilling his long-term objectives. Performance of the manager should be measured with

52 David Solomons, Division Performance: Measurement and Control (Homewood, Illinois.: Richard D. Inwin, 1968), pp.277-86 and R.D. Buzzell, B.T. Gale, and R.G.M. Sultan, "Market Share - a Key to Profitability," Harvard Business Review, January-February, 1975, p. 97.

53 Celia Davies and Arthur Francis, "There is More to Performance than Profits or Growth", Organizational Dynamics ,Winter 1975, pp. 51-65. 
respect to all divisional objectives. His study concluded that objectives, controllable factors, and performance measurements relating to division should be determined jointly by the central management and by the division manager under the system of management by objectives. ${ }^{54}$

The growth of MNEs from a mere extension of operations into foreign markets to substantial overseas involvement made it necessary to search for other measures of performance. Since MNEs have multiple goals and objectives, it is reasonable to expect the performance of MNEs to be measured in terms of accomplishments of all the recognised objectives. However, as stated earlier, traditional approaches tend to evaluate performance towards a single objective. Therefore, it seems apparent that alternative approaches are needed to evaluate the performance of MNEs managers. Cunningham 55 states that (to the best of his knowledge) there has been no significant research to date related to development of comprehensive performance measurement systems for MNEs.

An earlier study of the larger MNEs indicated that primary concern was still being placed upon the safety of capital at risk in the relatively new foreign markets. ${ }^{6}$ Parent firms literally managed the overseas units. Since the soundness of the parent's division to make foreign investments was supreme,

54 Robert Reon Irish, "The Measurement of Divisional Performance in Terms of Accounting Data." (Ph.D. Dissertation, University of Texas at Austin, 1977), pp. 1-12.

55 Gary M. Cunningham, An Accounting Framework for Multinational Enterprises (Ann Arbor, Michigan: UMI Research press, 1978), pp. 127-132.

56 John J. Mauriel, "Evaluation and Control of Overseas Operations," Management Accounting, March 1969, pp. 35-39. 
performance evaluations paralleled domestic practices and focused upon profits.

In another study 57 sponsored by Financial Executives Research Foundation under the chairmanship of Bursk, it was found that 94 percent (of 34 MNEs studied) of MNEs held their subsidiary managers responsible for profit performance, which was used as a measure of performance evaluation. Profit as compared to profit budget was the principal measure and Return on Investment (ROI) was the secondary measure. In the study it was concluded that an MNE control system should measure how well the foreign subsidiary manager has managed his/her operations in the light of environmental conditions and foreign currency translations.

The 1972 Committee on International Accounting of the AAA indicated that traditional approaches to evaluating the performance of the operating subdivisions of business organisations are not well-suited for MNEs and recommended the use of alternate approaches such as performance audit and "point systems". 58

A subsequent $\mathrm{AAA}$ committee 59 brought out a report wherein it expressed that performance evaluations by MNEs represented a mixture of subjective appraisal, absolute measures (such as return on investment), and

57 Edward C. Bursk, John Dearden, David F. Hawkins, and Victor M. Longstreet, Financial Control of Multinational Operations (New York: Financial Executive Research Foundations, 1971).

58 "Report of the Committee on International Accounting", George M. Scott, Chairman, in Supplement to the Accounting Review, 1973, pp. 71-3.

59 "Report of the Committee on International Accounting", Bernard Horwitz, Chairman, in Supplement to The Accounting Review, 1974, pp. 250-69. 
comparative assessments (interfirm, inter-temporal). Each of the evaluation methods then in use was cited for its failure to maintain the necessary separation between subsidiary economics and managerial performance. A critical need was also believed to exist for the development of new, more valid approaches to performance evaluation by MNEs. ${ }^{60}$

Robbins and Stobaugh61 in an extensive survey of 189 U.S. MNEs reported that the evaluation methods in use were confusing and unsound. Almost without exception, the MNEs admitted using the same measures to evaluate overseas and domestic operations. The authors suggested that the return on investment (the "best measuring stick") be discarded so that the need to create fictitious profits by means of synthetic transfer prices would be avoided. Budgets tailored to fit the real objectives and peculiar circumstances of foreign subsidiaries were recommended. 62

Morsicato63 examined the use of U.S. dollars and local currency information by international division executives (IDE's) in evaluating the

60

lbid., p. 253.

61 Sidney M. Robbins and Robert B. Stobaugh, "The Bent Measuring Stick for Foreign Subsidiaries", Harvard Business Review ,September-October ,1973, pp. 80-82 and Harold S. Green," The Case for Managing by Numbers," Eortune, October 1, 1984.

62 lbid., p. 88.

63 Helen Gernon Morsicato, "In Investigation of the Interaction of Financial Statement Iranslation and Multinational Performance Evaluation," (Ph.D. Dissertation, The Pennsylvania State University, 1978) and also Currency Translation and Performance Evaluation in Multinationals, Research and Business Decisions, No. 20, (University Microfilms International, 1980), pp. 30-105; Istemi S. Demirag," The Treatment of Exchange Rates in Internal Performance Evaluation," Accounting and Business Research, Spring 1986, pp. 15763; Wagdy M. Abdallah, Internal Accountability: An International Emphasis, ㅇ․ cit.,1984, and Donald E. Keller," Measuring the Multinational's Performance," Management Accounting, October 1985, pp. 26-30 and 56; and Wagdy M. Abdallah," Change the Environment or Change the System," Management Accounting, October, 1986, pp. 33-36. 
internal performance of their foreign managers. 70 U.S. based MNEs with subsidiaries operating abroad participated in the study. The information on the measure used is provided in Table 2.1. (Abdallah and Keller [1985] also carried out a survey of measures used in evaluating foreign subsidiaries of MNEs and found their results to be consistent with those of Morsicato).

TABLE 2.1

Financial Measures Used as Indicators of Internal Performance Evaluation

\begin{tabular}{c}
$\frac{\text { Performance of the }}{\text { Companies }^{*}}$ \\
\hline 81.4 \\
80.0 \\
78.6
\end{tabular}

72.9

65.7

48.6

45.7

34.3

21.4

12.9
Einancial Measures

Profit

Return

Budget compared to actual profits

Budget compared to actual sales

Cash flow potential from foreign subsidiary to U.S. operations Return on Equity

Budget compared to actual return on investments

Ratios

Residual Income

Others

$\left({ }^{*}\right.$ These figures represent the percent of the total 70 corporations which report using each particular measure.)

The Morsicato results are consistent with the results of prior studies. In another study Mauriel found that fifteen MNEs surveyed employed budgeting, financial planning, comparisons, the profit centre concept emphasising return on investment, and sales and profit targets. ${ }^{64}$ Mclnnes $^{65}$ reported that the

64 John J. Mauriel, "Evaluation and Control of Overseas Operations", op. cit., pp. 32-35.

65 J.M. Mclnnes," Financial Control Systems for Multinational Operations: An Empirical Investigation," Journal of International Business Studies, Fall 1971, pp. 11-28. 
corporations studied mentioned return on investment (ROI), actual compared

to budgeted performance and historical comparisons as the most useful

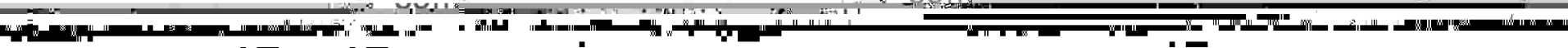
(1) - - : 19:

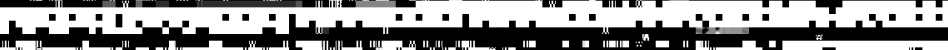

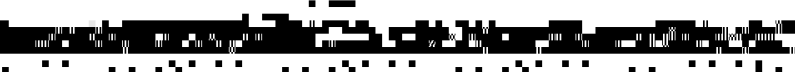
ril

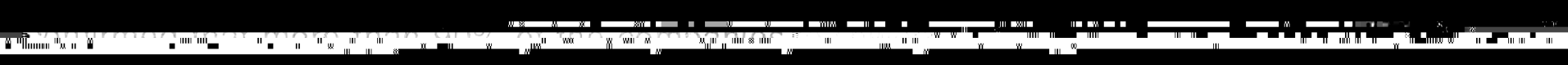

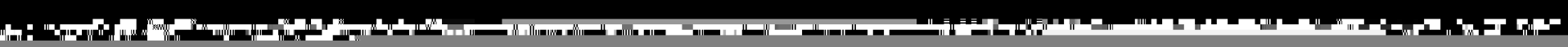


relative measurement of performance was to compare the return on equity (ROE) with residual cash generated by income after translation adjustment.

Many business organisations, including MNEs, often attempt to motivate operating managers by relating manager's compensation to performance evaluation measurements. ${ }^{69}$ On account of the centralised coordination of the operating activities of MNEs, many factors affecting entity performance are outside the control of managers. Also, because of integration, actions by operating managers in one operating division may be reflected in the performance of other operating divisions. ${ }^{70}$ The 1973 Committee on International Accounting of the AAA indicated that local cultural differences cause differing attitudes towards such things as work, loyalty, and honesty. Hence, it may be stated that cultural differences preclude meaningful comparison among performances of managers in different countries.

The 1972 Committee on International Accounting suggested a "point system" based on formulas. ${ }^{71}$ Smith et al72 suggested the management audit, so as to evaluate the performance according to several criteria.

Robbins and Stobaugh ${ }^{73}$ stated that

69 Gary M. Cunningham, Accounting Framework for Multinational Enterporises, op. cit., p.133 and W.M. Abdallah," How to Motivate and Evaluate Managers with International Transfer Pricing Systems," Management International_Review, vol. 29, No.1, 1989, pp.65-71.

70 "Report of the Committee on International Accounting", ㅇ․ cit., 1974, pp. 252-7.

71 "Report of the Committee", 1973, op. cit., p. 73.

72 Charles H. Smith, et al, "The Need for and Scope of the Audit of Management: A Survey of Attitudes", The Accounting Review , April 1972, pp. 270-81.

73 Sidney M. Robbins and Robert B. Stobaugh, "The Bent Measuring Stick for Foreign Subsidiaries", Harvard Business Review, September.-October, 1973, p. 81. 
". . . the budget should be an MNE's key tool for assessing local management. MNEs should replace company-wide ROE measures with a budget system containing a set of goals for each subsidiary. These goals should be determined on the basis of prior experience of the subsidiary in question and the economic conditions expected during the budget period."

They further advocated the use of secondary criteria, such as market share, introduction of new products, strength of brand franchise, gross margin, manufacturing costs, overhead costs, man hours per unit of production and various balance sheet items. ${ }^{74}$ The typical weaknesses of budgets are highlighted and it is suggested that appropriate consideration should be given to other relevant factors. ${ }^{75}$

Regardless of which performance evaluation measure of a MNE one uses, the financial results which a subsidiary manager reports to headquarters will be affected by the characteristics of the local operating environment. The performance evaluation systems should reflect this circumstance. ${ }^{76}$

Morsicato and Diamond 77 categorised the environmental influences in the following three categories:

1. Those items which can be quantified in monetary terms. These items should be incorporated and considered when

74 lbid., p. 83.

75 lbid., p. 82-83.

76 Wagdy M. Abdallah, Internal Accountability: An International Emphasis, op. cit.,1984, and Donald E. Keller," Measuring the Multinational's Performance," op. cit, 1985 and Wagdy M. Abdallah," Change the Environment or Change the System," op. cit., 1986.

77 Helen G. Morsicato and Michael A. Diamond, An Approach to "Environmentalizing Multinational Enterprise Performance Evaluation Systems," The International Journal of Accounting: Education and Research, Vol.16, No. 1, Fall 1980, pp. 248-66. 
the performance evaluation system for foreign operations is designed. This group includes considerations related to the use of different currencies, the devaluation of currencies, changes in the price level, and the multiplicity of tax practices found overseas.

2. Those items which are related to operating and financial risk. These items should be incorporated into the desired performance standards. This group of risk considerations includes exchange controls, the risk of expropriation, political instability, various government regulations, and import-export controls.

3 Those that influence the effectiveness of a performance evaluation system's administration. These are behavioural considerations and reflect the different personal value systems, cultural backgrounds, and educational levels of the nationals in the overseas management hierarchy. ${ }^{78}$

Their paper focused on the last two groups of environmental variables over which a foreign subsidiary manager has little or no control. They recommended that proper allowances should be made for these factors lest it should give rise to dysfunctional consequences. ${ }^{79}$

In another study, Czechowicz, Choi and Bavishi80 attempted to survey the foreign performance evaluation practices of both U.S. and nonU.S. MNEs. On the basis of enterprises (64 MNEs for U.S. and 24 for nonU.S.) surveyed they concluded that firms employed a number of performance criteria, both financial and non-financial. Financial criteria tend to dominate performance evaluation systems, the most popular being budget comparisons and return on investment, when evaluating foreign operations. Despite

78 lbid., p. 250.

79 lbid., p. 251.

80 I. James Czechowicz, Frederick D.S. Choi and Vinod B. Bavishi, Assessing Foreian Subsidiary Performance (New York: Business International Corporation, 1982), pp. 1-12. 
difficulties in measurement, they noted that a few firms have made use of nonfinancial criteria such as market share and relations with the host government.

A particularly noteworthy finding of the study was the similarity in criteria employed by both U.S. and non-U.S. multinationals in evaluating the performance of the foreign unit as well as that of its manager. The similarity extended to both financial and non-financial criteria, as well as domestic and foreign operations. They noted the awareness on the part of MNEs to evaluate managers somewhat differently than the unit (either subjectively or otherwise), though for many enterprises the distinction is apparently blurred. ${ }^{81}$

From amongst many suggestions advanced by the authors of the study, a few suggestions stand out distinctly, such as use of non-financial criteria to reinforce the financial performance statistics, an adequate consideration for country risk, greater emphasis on organisational objectives rather than external reporting standards, and a systematic consideration of environmental (social, economic and legal-political) variables in internal performance evaluation systems. ${ }^{82}$ Russell in his recent doctoral study on innovation processes and before him Wagdy too, alluded to the importance of these external environmental variables. ${ }^{83}$

81 lbid., p. 78, A. Hosseni and R. Aggarwal," Evaluating Foreign Affiliates: The Impact of Alternative Foreign Currency Translation Methods," International Journal of Accounting: Education and Research, Fall 1983, pp. 65-87; Wagdy M. Abdallah," Change the Environment or Change the System," of. cit., 1986; Istemi S. Demirag," How U.K. Companies Measure Overseas Performance," Accountancy, March and April 1987, pp. 101-3 and 87-90 and "Assessing Foreign Subsidiary Performance: The Currency Choice of UK MNCs", Journal of International Business Studies, Spring 1988, pp. 257-75.

82 lbid., pp. 81-87.

83 Robert David Russell," The Effect of Environmental Context and Formal and Informal Organizational Influence Mechanisms on the Process of Innovation: Toward An Integrated Theory of Innovation," (Ph. D. Dissertation, University of Pittsburg, 1986), pp.115-125 and Wagdy M. Abdallah, Internal Accountability: An International Emphasis, op. cit.,1984, pp. 16-30. 
Wagdy posited that on account of foreign environments being so different from the domestic environments of overseas managers, the discipline of management accounting should be extended in an effort to find effective solutions. A management accounting framework for performance evaluation is badly needed which can address: (a) systematic recognition of environmental differences, (b) achievement of goal congruence in decisionmaking by management and (c) optimise the utilisation and allocation of limited resources. ${ }^{84}$

The review of studies concluded so far has focused on the need to develop managerial performance evaluation systems that include environmental (especially cultural) factors. ${ }^{85}$ Belkaoui appropriately posits,

$" \ldots .$. that the accounting literature has well reflected the richness of the discipline by presenting a spectrum of roles, images, and foundations of accounting. Each of the roles, images, and foundations presents a specific lens to view particular aspects of the scope of the field. Some may prefer to examine all lenses as a way of covering all possible scopes of the field. other s may prefer to search for the most appropriate lens, the one most compatible with a given ideology and role perceptions of the field, and to argue for its primacy. Finally,

84 Wagdy M. Abdallah, Internal Accountability: An International Emphasis, of . cit.,1984, pp. 89-90.

85 Schoenfeld while talking about evaluation procedures alludes to evaluation measures beyond accounting which ought to form part of the evaluation system. The environmental (political, societal, regulatory, technological) analysis which forms the basic foundation for strategy, plans and programmes may necessitate the use of those measures and methods which have not been considered in accounting to date. The role of management accountant in this setting takes on a larger profile and therein comes the relevance and justification of the present research piece. The common need for measurement at various stages to give appropriate consideration to people's efforts (e.g. inputs both quantitative \& otherwise) and hence to have a well reasoned reckoning of the outputs (outcomes) thus ensuring the sustaining of motivational thrust of the management in general and accounting in particular. (Hanns-Martin W. Schoenfeld," The Present State of Performance Evaluation in Multinational Companies," in Managerial Accounting and Analysis in Multinational Enterorises ed. H.P. Holzer and H.M. Schoenfeld, New York, NY: Walter de Gruyter, 1986, pp. 218-51) . 
others may adopt both approaches, using the first approach as a scanning approach towards the final choice of the alternative image and foundations of accounting most congruent with their various beliefs. In making that final choice, it is important to the market to be ideologically correct." 86

The empirical results presented indicate that although international division's executives (IDEs) perceive the importance of these variables, these constraints are not presently being systematically incorporated into evaluation systems.

It is contended that a study to examine the impact of cultural factors on the performance and its evaluation in the context of MNEs is highly desirable. The findings of the study would go a long way to strengthen the internal controls within the organisations and perhaps improve managerial performance evaluation systems.

86 Ahmed Belkaoui, Inquiry and Accounting: Alternate Methods and research Perspectives, Westport, Conn.: Quorum Books, 1987.) 
CHAPTER III

\section{HISTORICAL DEVELOPMENT OF THEORETICAL FOUNDATIONS FOR THE HYPOTHESES}

\section{Introduction}

This chapter presents an elaboration of the term culture and many approaches to understand and appreciate its varied manifestations. The interface between culture and management and the effects of cultural factors on management's traditional functions are presented first in a generic and conceptual framework mode at the national level and subsequently in greater details with country-specific examples at the international level. Later an attempt is made to provide the theoretical rationale for the development of the hypotheses for the present study together with a discussion of partial and comprehensive methodologies for assessing cultural differences.

The chapter on account of its broad scope and resultant coverage has been divided into two parts. Part one focuses on the elaboration of the basic concepts while the second part deals with the specific issues pertaining to the culture and management of the multinational corporations.

\section{PART I}

Culture operates in a society and pertains to the general behaviour and attitudes, beliefs and habits of its members and therefore any study of 
culture must to some extent entail the study of the society it operates in. Hence, the study of culture will fall within the sphere of the social sciences.

\section{GENERAL ASSUMPTIONS ABOUT THE NATURE OF SOCIAL SCIENCES}

All social scientists approach their subject via explicit or implicit assumptions about the nature of the social world and the way in which it may be investigated. First there are assumptions of an ontological nature assumptions which pertain to the very essence of the phenomena under investigation, that is the nature of the being. Social scientists are faced with a basic ontological question: whether the reality to be investigated is external to the individual - imposing itself on individual consciousness from without - or the product of individual consciousness; whether "reality" is of an "objective" nature, or the product of individual cognition; whether "reality" is a given "out there" in the world, or the product of one's mind. ${ }^{1}$

The second set of assumptions is of an epistemological nature. These assumptions relate to the theory of methods used, that is to the grounds of knowledge - about how one might begin to understand the world and communicate this as knowledge to fellow human beings. These assumptions entail ideas, for example, about what forms of knowledge can be obtained, and how one can sort out what is regarded as "true" from what is to be regarded as "false". Indeed, this dichotomy of "true" and "false" itself presupposes a certain epistemological stance. It is based upon a view of the nature of knowledge itself: whether, for example, it is possible to identify and

1 Gibson Burrell and Gareth Morgan, Sociological Paradiams and Organisational Analysis: Elements of the Sociology of Corporate Life, (London, U.K.: Heinemann Educational Books Ltd., 1979), pp. 1-2. 
communicate the nature of knowledge as being hard, real, and capable of being transmitted in tangible form, or whether "knowledge" is a "softer", more subjective, spiritual or even transcendental kind, based on experience and insight of a unique and essentially personal nature. These assumptions pertain to the issue of whether knowledge is something that can be acquired on the one hand, or is something which has to be personally experienced on the other. ${ }^{2}$

The third set of assumptions although associated with the ontological and epistemological issues is a separate one and pertains to human nature . In particular, to the relationship between human beings and their environments. All social sciences, clearly, must be predicated upon this type of assumption, since human life, and human behaviour are essentially the subject and object of enquiry. Thus, one can identify perspectives in social science which entail a view of human beings responding in a mechanistic or even deterministic fashion to the situations in their external world, that is, human beings and their experiences are regarded as products of their environments, one in which human beings are conditioned by their external circumstances. The other extreme perspective can be contrasted with one which attributes to human beings a much more creative role, where the man is regarded as the creator of his environments, that is, controller as opposed to the controlled, the master rather than the marionette. ${ }^{3}$

The aforementioned three sets of assumptions would obviously incline social scientists towards different methodologies. It is possible, for example, to
2 lbid.
3 lbid., pp. 2-3. 
identify methodologies employed in social science research which treat the social world like the natural world: as being hard, real, and external to the individual and others which often could view this social dimension as being of a much "softer", personal, and of a more subjective quality. The adherents of the former will focus upon an analysis of relationships and regularities between the various elements of the social world. The concern is with the identification and definition of these elements and with the discovery of ways in which these relationships can be expressed. The issues of importance would be concepts, their measurements and the identification of underlying themes.

The proponents of the latter subscribe to the alternative view of social reality, which stresses the importance of the subjective experience of individuals in the creation of a social world. The emphasis is to be placed upon the explanation and understanding of what is general and universal. This approach questions whether there exists an external reality worthy of study. ${ }^{4}$

It is in these relevant contexts that this study attempts to explore the impact (if any) of different cultural characteristics on the members of another culture with reference to the multinational's management, its policies, functions and operations and the effectiveness thereof.

4 lbid. 


\section{CONCEPT OF CULTURE}

The concept of culture is the major theme of cultural anthropology, and is also "central to the behavioural sciences". 5 This concept is a very comprehensive one, and is not restricted to any one group. Anthropologists do not talk of cultural ladies sipping tea at a PTA (Parent-Teacher Association) meeting. Such people are properly styled "cultivated," i.e., persons who appreciate good music, art, and literature. Historians, when they speak of culture, think in terms of special developments in artistic and intellectual fields, such as "Greek Culture," referring specifically to some learned Greeks of the Golden age in Greece's history. ${ }^{6}$ Others confuse culture with civilisation, 7 such as referring to the Egyptian civilisation as one separate culture. We can neither say comfortably that "culture" is the heritage of learned symbolic behaviour that makes humans human nor especially, (amid the tides of change and individual diversity) that "a culture" is the heritage people in a particular society share. 8

5 Bernard Berelson and Gary A. Steiner, Human Behaviour: An Inventory of Scientific Findings, (New York, NY.: Harcourt, Brace \& World, Inc., 1964), pp. 644 and Fritz J. Roethlisberger," Contributions of the Behavioral Sciences to a General Theory of Management," in Toward a Unified Theory of Management, ed. Harold Koontz, (New York, NY.: McGraw-Hill Book Co., Inc., 1964), pp. 41-2.

6 Godfrey Lienhardt, Social Anthropology, 2nd Ed., (Oxford, U.K.: Oxford University Press, 1966), pp. 1-32.

7 Ralph L. Beals and Harry Hoijer," An Introduction to Anthropology (New York, NY.: Macmillan Co., 1959), pp. 220-7 and Maneck S. Wadia, "The Concept of Culture," Journal of Retailing, Vol. 41, No.1, Spring 1965, pp. 21-30. 73-97.

8 Roger M. Keesing," Theories of Culture," Annual Review of Anthropology, 1974, pp. 
E.B. Taylor, ${ }^{9}$ in 1871, was the first to use the word "culture" in English in the sense now accepted by anthropologists and sociologists following the lead of some German writers who used Kultur in this sense. 10 What is culture? Some anthropologists conceive of culture as that which separates humans from non-humans. Others think of culture as a communicable knowledge. There are some anthropologists who speak of culture as the sum of historical achievements (experiences) produced by man's social life. These differences in conceiving culture are differences of emphasis rather than of total content, and are not mutually exclusive. Yet these differences have led to the formulation of many definitions of culture, some of which were analysed by Kroeber and Kluckhohn. ${ }^{11}$ It was found that every definition had something in common with the others. Kluckhohn and Kelby defined culture as, "historically created designs for living, explicit and implicit, rational, irrational, and nonrational which exist at any given time as potential guides for the behaviour of man." 12 Culture is frequently taken to mean as a set of taken-for-granted assumptions, expectations, or rules for being in the world. As paradigm, map, frame of reference, interpretive schema, or shared understanding, the culture concept emphasises the shared cognitive approaches to reality that distinguish one group from another. ${ }^{13}$

9 Edward B. Taylor, Primitive Culture - Researches into the Development of Mythology. Philosophy. Religion. Lanquage. Art and Custom, (New York: Henry Holt \& Co., 1977), Vol. 1, p.1.

10 A.L. Kroeber and Clyde Kluckhohn, Culture: A Critical Review of Concepts and Definitions." (Cambridge: Massachusetts: Peabody Museum of Archeology and Ethnology, Vol. XLVII, Harvard University Press, 1952), p. 9. 1985.

11 lbid., pp. 18-33 also published in book form by Random House/Vintage Books,

12 Clyde Kluckhohn and William Kelby, "The Concept of Culture," The Science of Man in World Crises, Ed. Ralph Linton, (New York, NY.: Columbia University Press, 1945), pp. 95-101.

13 Nancy J. Adler and Mariann Jelinek," Is "Organization Culture" Culture Bound?" Human Resource Management. Vol. 25, No.1, Spring 1986, pp.73-90. 


\section{Various Perspectives}

Culture has been viewed by many in an evolutionary perspective. Studies of human social life has led many to see more clearly that the human biological design is open-ended and its completion and modification is through cultural learning that makes human life viable in particular ecological settings. A vast literature has dealt with the interweaving and relative importance of biological and cultural components of human behaviour, e.g. aggression, territoriality, sex roles, facial expression and other domains. ${ }^{14}$ The evolutionary/ecological approaches emphasise cultures as adaptive systems (of socially transmitted patterns) that serve to relate human communities to their ecological settings. These ways-of-life-of communities include technologies and modes of economic organisation, settlement patterns, modes of social groupings and political organisation, religious beliefs and practices and so on. Binford posits that "Culture is all those means whose forms are not under direct genetic control. . . which serve to adjust individuals and groups within their ecological communities." 15 Harris views culture as behaviour patterns associated with particular groups of people, that is to "customs" or to a people's "way of Life."16

Seen as adaptive systems, cultures change in the direction of equilibrium within ecosystems, but when balances are upset by environmental, demographic, technological, or other systematic changes,

14 A. Alland, The Human Imperative, (New York: NY:, Columbia University Press, 1972); , Evolution and Human Behaviour, 2nd Ed., (New York, NY: Doubleday, 1973 and R.J. Holloway Jr., Culture a Human Domain, Curr. Anthropology,_.10: pp. 395-407.

15 L.R. Binford, "Post-Pleistocene Adaptations," in New Perspectives in Archaeology, ed. L.R. Binford and S.R. Binford, (Chicago, Illinois: Aldine, 1968), pp. 311.

16 M. Harris, The Bise of Cultural Theory, (New York, NY: Crowell, 1929). 
further adjustive changes tend to ramify through the cultural system. Feedback mechanisms in cultural systems may thus operate both negatively (toward selfcorrection and equilibrium) and positively (toward disequilibrium and directional change). ${ }^{17}$

In contrast to the diverse adaptationist theorists of culture stand a number of theorists who see cultures as ideational systems. These researchers have attempted to approach culture from three perspectives: cognitive, structural, and symbolic. The cognitive anthropologists see cultures as systems of knowledge. Ward Goodenough appropriately states:

"A society's culture consists of whatever it is one has to know or believe in order to operate in a manner acceptable to its members. Culture is not a material phenomenon: it does not consist of things, people, behavior, of emotions. It is rather an organization of these things. It is the form of things that people have in mind, their models for perceiving, relating, and otherwise interpreting them." 18 (emphasis added)

"Culture ... consists of standards for deciding what is, ... for deciding what can be, ... for deciding what one feels about it, ... for deciding what to do about it, and ... for deciding how to go about doing it." 19

Goodenough contrasts this ideational sense of culture with the sense used by the adaptationists, who conceive culture to be the patterns of life within a community. Cultures are epistemologically in the same realm as language, as inferred ideational codes lying behind the realm of observable events. In this conceptualisation, language is a subsystem of culture; and

17 Roger M. Keesing," Theories of Culture," op. cit., p. 76.

18 W. H. Goodenough, "Cultural Anthropology and Linguistics," in Report of the Seventh Annual Round Table Meeting on Linguistics and Lanquage Study, ed. P Garvin, Monogr. Series No. 9, (Washington D. C.: Georgetown University, 1957), p. 167

19 , "Comment on Cultural Evolution," Daedalus, pp. 522. 
explorers in cognitive anthropology have assumed that linguistic methods and models will be appropriate to other cultural realms as well. However, the early cognitive anthropology has yielded few fragments of cultural description. 20

Levi Strauss, ${ }^{21}$ the most well known of the structuralists elaborated his view of men's symbolic worlds and the processes of mind that generate them. His writings have elicited an ever-widening stream of exegetical literature. 22 He viewed cultures as shared symbolic systems that are cumulative creations of mind; he seeks to discover in the structuring of cultural domains - myths, art, kinship, language - the principles of mind that generate these cultural elaborations. The physical world humans live in provides the raw materials which the universal processes of mind elaborate into substantively diverse but formally similar patterns. The mind imposes culturally patterned order, a logic of binary contrast, of relations and transformations, on a continually changing and often random world. The gulf between the cultural realm, where man imposes his arbitrary order, and the realm of nature becomes a major axis of symbolic polarity: "nature vs culture" is a fundamental conceptual opposition in many, perhaps all, times and places. He is more concerned with "Culture" than with "a culture."23

Another perspective treats cultures as systems of shared symbols and meanings. ${ }^{24}$ Geertz, a leading proponent of this symbolic paradigm maintains

20 Roger M. Keesing," Theories of Culture," op. cit, p. 77-8.

21 C. Levi-Strauss, Mythologiques. IV: L'Homme Nu, (Paris, France: Plon, 1971).

22 F. Bailey, Stratagems and Spoils: A Social Anthropology of Politics, (New York, NY.: Schocken, 1969).

23 Roger M. Keesing, op. cit, p. 78-9.

24 Edward Sapir," Symbolism," in Encyclopaedia of the Social Sciences, (New York, NY.: MacMillan Company, 1930), pp. 492-95. 
that meanings are not "in people's heads"; symbols and meanings are shared by social actors - between, not in them: they are public not private. 25 He sees culture as semiotic. To study culture is to study shared codes of meaning. Anthropology thus becomes a matter of interpretation, not decipherment. For Geertz interpretation becomes thick description that must be embedded in the contextual richness of social life. ${ }^{26} \mathrm{He}$ cautions against analyst mapping a culture in such a way as to maximise and neaten its integration and internal consistency, where in fact only partial integration and often disconnectedness and internal contradiction exist. He uses an apt metaphor to elucidate his point:

\begin{abstract}
$\therefore$. The problem of cultural analysis is as much a matter of determining independencies as interconnection, gulfs as well as bridges. The appropriate image, if one must have images, of cultural organisation, is neither a spider web not the pile of sand. It is rather more the octopus, whose tentacles are in large part separately integrated, neurally quite poorly connected with one another and with what in the octopus passes for a brain, and yet who nonetheless manages to get around and to preserve himself, for a while anyway, as a viable, if somewhat ungainly entity." 27
\end{abstract}

Schneider believes that analysis of cultures as systems of symbols can profitably be carried out independently of the "actual states of affairs" one can observe as events and behaviours. However, one must ask questions about

25 C. Greetz, "The Growth of Culture and the Evolution of Mind," in Theories of Mind, ed. by J. Scher, (Glencoe, Illinois: Free Press, 1962), pp. 713-40; "Ideology as a Cultural System," in Ideology and Discontent, ed. by D. Apter, (Glencoe, Illinois: Free Press, 1964), pp. 47-56; New Views on the Nature of Man, ed. by J. R. Platt, (Chicago, Illinois, 1965), pp. 93-118, and , The Interpretation of Culture, (New York, NY: Basic Books, 1973).

26 Roger M. Keesing, op. cit.

27 C. Geertz," Person, Time and Conduct in Bali: An Essay in Cultural Analysis," Yale Southeast Program, Cultural Rep. Series No. 14, 1966. 
the connections between the plane of cultural symbols and the plane of observable events so that one can discover how the cultural constructs are generated, the laws governing their change, and in just what way they are systematically related to the actual state of affairs of life." 28

One would like to see if an eclectic composite can be obtained from the various perspectives on culture, where adaptationists and those propogating other ideational themes agree. One may like to look at sociocultural systems which represent the social realisations or enactments of ideational designs-for-living in particular environments. A settlement pattern or a mode of subsistence technology is more a part of socio-cultural system but not (strictly speaking) of cultural system. Nonetheless, it is these systems that are adaptive to environments, that is in economic domain and at the same time ideational in terms of religion, ideology, law and art etc. ${ }^{29}$

The cognitive model underscores a composite of the cultural knowledge of individuals in different social niches, thus it is remarked,

" . . . People learn as individuals. Therefore, if culture is learned, its ultimate locus must be in individuals rather than in groups, ... . Cultural theory must (then) explain in what sense we can speak of culture as being shared or as the property of groups ... and what the processes are by which such sharing arises, ... . we must ... try to explain how this analytically

28 D. Schneider, American Kinship: A Cultural Account, (Englewood, New Jersey: Prentice Hall, 1968), p. 7.

29 Geertz warns for the dangers of swallowing the social into the cultural or the cultural into the social by stating, ". . . Either culture is regarded as wholly derivative from the forms of social organization .... or the forms of organization are regarded as behavioral embodiments of cultural patterns. In either case . . . the dynamic elements in social change which arise from the failure of cultural patterns to be perfectly congruent with the forms of social organizations are largely incapable of formulations" ("Ritual and Social Change, A Javanese Example," American Anthropology, No. 59, 1957, p. 992). Many others share the premise that cultural and social realms are distinct though interrelated: neither is a mere reflection of the other - each must be considered in its own right. 
useful construct relates to . . the social and psycho-logical processes that characterize men in groups." ${ }^{30}$

Culture is seen as transcending individual's cognitive worlds to the collective ideas and behaviour 31 of populations. The collective representations reflect and reveal the structures and processes of the individual minds of which they are cumulative creations. Individuals live their lives mainly in familiar phenomenological space whose particularities guide their response. They call cultural roles and rules - based on general and abstract, not concrete and individual - into play mainly on the periphery of their immediately familiar space when dealing (in culturally appropriate ways) with strangers or bureaucracies.

The structure of cultural systems is created, shaped and constrained by individual minds and brains. What forms cultures take depend on what individual humans can think, imagine, and learn, as well as what collective behaviours shape and sustain viable patterns of life in ecosystems. Cultures must be thinkable and learnable as well as livable. 32

Bascom and Herskovits in their book of essays state that, ...

". . . Culture includes not only social institutions and their derivative form of learned behaviour but also those manifestations of creativity whereby the artist produces something new and individual within the range of forms and patterns which are part of his tradition ...

30 W. H. Goodenough," Culture, Language and Society," McCalb Module in Anthropology, (Reading, Massachusetts: Addison-Wesley, 1971), p. 20.

31 "Psychology aims at providing explanations of individual behavior, sociology of group behavior, and cultural anthropology of the effect of social value and norms on individual and group behavior," William G. Scott, Organisation Theory: A Behavioral Analysis for Management, (Homewood, Illinois: Richard D. Irwin, Inc., 1967), pp.5-6.

32 Roger M. Keesing, op. cit. p. 86. 
The study of culture involves not only the institutions that frame man's reactions to fellow members of his society, but also the extra-institutional aspects of human behaviour, including language, the relation between language and behaviour, between personality and culture, and the system of values that gives meaning to the accepted forms of behaviour of a people." 33

According to Kluckhohn and Kelby the description of culture relates to organisational analysis especially in its reference to the concept of rational, irrational and non-rational forms of behaviour. This concept has been of interest to anthropological, managerial and organisational scholars for many years. 34

In the words of W.T. Tucker, "Anthropologists, based on their vast experience of cross-cultural studies, believe that a large portion of human behaviour, and this, of course, includes the behaviour of managers as well as those managed (sic), is neither totally compatible with reason nor incompatible with reason, but is brought about through cultural conditioning the non-rational dimension." 35 Thus, behaviour, such as having three meals a day, or wearing a tie, and beliefs, such as the virginity of Mary or the validity of monogamy (sic, though the rationale of monogamy can to some extent be based on medical rationale) have their roots not in reason or against reason, but in culture. 36 1958.

33 Bascom, W. R. and Herskovits, M. J. , ed., Continuity and Change in African Cultures,

34 Clyde Kluckhohn and William Kelby, op. cit.; E. Glenn, Man and Mankind: Conflict and Communication Between Cultures, (Norwood, New Jersey: Ablex Publishing, 1983) and Philip R. Harris," Management in Transition: Transiorming Managerial Practices and Organisational Strategies for a New Work Culture, (San Francisco, CA.: Jossey-Bass, 1985).

35 W.T.Tucker, Eoundations for a Theory of Consumer Behaviour, (New York, NY.: Holt Rinehart and Winston, 1967), pp.1-3 and Ross A. Webber, Culture and Management, (Homewood, Illinois: Richard D. Inwin,1969), pp. 1-100.

36 Maneck S. Wadia, Management and the Behavioural Sciences, (Boston, Massachusetts: Allyn and Bacon, Inc., 1968) 
That cultures vary in their assumptions about the world has long been accepted by the anthropological community. 37 Anthropologists with a philosophical bent of mind assert that what is rational is often based on the culture. This theory is founded on the fact that as a culture undergoes change, the notion of what is rational or irrational also changes $A$ case in point from the western culture is the changing view on the death penalty. At one point of time it was supported on the rational grounds that it deterred crime, while in the recent past this was being opposed on rational grounds. And the death penalty is again gaining strength in the United States as more violent crimes are being committed. Cross-culturally, what is rational behaviour in one culture may be considered irrational in another, as is the case of taboos against beef eating among Indian Hindus and pork eating among Jews and Moslems. 38

Culture is shared with others in an organisation, society, country, etc. Hence, when one studies culture one studies the culture of some group. The end results of this study are generalisations and their analysis, pertaining to the culture of that group. Some of these generalisations may be found in all cultures, and hence are viewed as cultural universals and lead to broader considerations of human nature. 39 "The diversity of cultures turns out in part to be different ways of accomplishing similar ends." 40

37 Nancy J. Adler and Mariann Jelinek," op. cit.,p.74., Marston Bates, Gluttons and Libertines: Human Problems of Being Natural, (New York, NY.: Random House inc., 1968) and C.W. Ceram, Graves, Gods and Scholars, (New York, NY.: Alfred A. Knopf, Inc, 1967).

38 Maneck S. Wadia, "The Concept of Culture in the Analysis of Consumers," American Marketing Association Proceedinas, 1967, pp.186-90.

39 George P. Murdock," The Common Denominator of Cultures," The Science of Man in the World Crises, ed. Ralph Linton, (New York, NY.: Columbia University Press, 1945), p.12342.

40 Beals and Hoijer, op.cit., p. 246. 


\section{Patterns and Themes of Culture 41}

Some cultural anthropologists, especially $\mathrm{Dr}$. Ruth Benedict, 42 have tried to develop the concept of a single integrative pattern to describe a culture and its influence on the behaviour of its members. Thus, for Benedict, the culture of the Pueblos is integrated under one major pattern called "Apollonian." Apollonian, as described by Nietsche in his studies of Greek tragedy, applies to those who stick to the "middle of the road," avoiding any form of excess or conflict, to arrive at the values of existence. Through this single pattern Benedict has tried to facilitate the understanding of Pueblo culture by her summation of the integrating force. She believed that,

"a culture, like an individual is a more or less consistent pattern of thought and action. Within each culture there comes into being characteristic purposes not necessarily shared by other types of society for variety of reasons. In obedience to these purposes, each people further and further consolidates its experience, and in proportion to the urgency of these drives the heterogeneous items of behaviour take more and more congruous shape." 43

The difficult task is to pin-point a dominant pattern for a culture, as once this is accomplished the benefits are obvious and meaningful. This is on account of the overlap of various themes and patterns in a culture that one faces hurdles and experiences inabilities in understanding human behaviour

41 Oswald Spengler," On the Style-Patterns of Culture," in Theories of Society: Foundations of Modern Sociological Theory, Vol. II, ed. Talcott Parsons, Edward Shils et. al., (New York, NY.: The Free Press of Glencoe, Inc., 1961), pp. 1345-55.

42 Dr. Ruth Benedict, Patterns of Culture, (Boston, Massachusetts: Houghton-Mifflin Co., 1934), pp. 44-46.

$43 \underline{l b i d}$ and Francis L.K. Hsu (ed.), Aspects of Culture and Personality, (New York, NY.: Abelard-Schuman,1954) 
under Benedict's method. How would one classify the U.S. culture under one pattern - "affluent," "easy-going," "hard-working," "materialistic," "achieving," "excitable," "status seeking,"? Obviously the majority consider this integrative principle too generalised and very difficult to arrive at. Accordingly, many anthropologists seem to prefer Opler's summative (sic) method, i.e., it would be better to organise the content of a culture around a number of summative themes. 44 A theme is then defined as " a postulate or position, declared or implied, and usually controlling behaviour, or stimulating activity, which is tacitly approved or openly promoted in a society." 45 One can note that in most Asian cultures there is a "fatalism" theme, while in American business subculture the theme is self-determination, profits or the "bottom line."46 Though the concept of a pattern of culture seems more useful to the understanding of human behaviour, in practice, the concept of themes and their interplay, provide a better theoretical tool for studying and understanding human behaviour and (sic) hence in studying a manager's behaviour. 47 Authors like Vance Packard, John Kenneth Galbraith, and David C. McClelland have successfully utilised the concept of a dominant pattern. Taking one important pattern, such as affluency in the case of Galbraith or the need for achievement as in the case of McClelland, new ideas and theories have been put forward, some of which are quite pertinent to managerial

44 Morris E. Opler," Some Recently Developed Concepts Relating to Culture," Southwestern Journal of Anthropology, Vol. 4,1948, pp.105-125.

45 llid.

46 Philip R. Harris and Robert T. Moran, Managing Cultural Differences, (Houston, Texas: Gulf Publishing Company, 1979, 1987), pp. 64-65 and Robert T. Moran and Philip R. Harris, Managing Cultural Synergy, (Houston, Texas: Gulf Publishing Company, 1982).

47 Morris E. Opler, "Themes as Dynamic Forces in Culture," American Journal of Sociology November, 1945, pp. 190-207 and Abu-Hilal Maher, "Foreian Students' Interaction. Satisfaction and Attitudes Toward Certain Aspects of the American Culture: A Case Study of Arab Students in Southern California" (Ph.D. Dissertation, University of California, Riverdale, 1986), pp. 225. 
performance (sic). Though these theories provide a uniform approach, but they suffer from the same weakness as the Benedict's concept of patterns of culture.

Culture is an abstraction from behaviour. 48 We do not see culture but observe manifestations of it just as we do not see electricity or gravity but observe manifestations of them. Nobody observes a total culture directly, but only parts of it, such as words, actions, and things. 49

What we observe about culture are certain regularities. Some of these are readily observable while others are difficult to pin-point. Each different way of life makes its own assumptions about the ends and purposes of human existence, about what human beings have a right to expect from each others, about what constitutes fulfilment or frustration. Some of these assumptions are made explicit in the folk lore, while others are to be inferred by finding

48 Social systems can only exist because human behaviour is not random, but to some extent predictable. But for each prediction of behaviour one should take both the person as well as the situation into account. We assume that each person carries a certain amount of mental programming which is stable over time and leads to the same person showing more or less the same behaviour in similar situations. One cannot observe mental programming but can observe behaviour from which the presence of stable mental programming is inferred. Mental programmes like 'forces' in physics are intangibles and are called constructs. These constructs do not 'exist' in an absolute sense these are defined into existence. (Geert Hofstede, Culture's Consequences: International Differences in Work-Related Values, (Beverly Hills, CA: Sage Publications, 1980),p. 14.

Every person's mental programming is partly unique and partly shared with others. The mental programming can be visualised at three levels: universal, collective and individual. The least unique and most basic is universal, akin to biological operating system. The collective level is shared with some but not with all other people, it is common to people belonging to certain groups/categories but different in others. The whole area of subjective human culture belongs to this level. The individual level is truly unique as no two people are programmed exactly alike. This is the level of individual personality, and it provides for a wide range of alternative behaviours within the same collective culture. It is difficult to draw sharp dividing lines between individual personality and collective culture. (lbid). 15.

49 John H. Honigmann, The Worid of Man, (New York, NY.: Harper \& Brothers, 1959), p. 
consistent trends in word and deed. 50 In the sphere of business and management (more so in international), as it would be valid in other areas of interest too, that one would do better if besides relying on explicit elements of culture one also tries to appreciate the otherwise more difficult to observe implicit elements of culture and analyse them, as these are of far greater relevance. The appreciation of implicit elements of culture will help one to understand the rationale, the justification for particular patterns and logistics of people's behaviour.

Within a larger society, group, or nation sharing a common majority culture, there may be subgroupings of people possessing characteristic traits that set them apart and distinguish them from others. These subcultures or microcultures may be described in group classification by age, class, sex, race or some other feature, that differentiates this microculture from the macroculture. However, it is true that these sub-culture groups share many traits with others of the same main culture group. These clustered traits may also be shared by societies which otherwise differ from each other. In other words a sub-culture refers to a distinguishable entity within a larger culture or to the clustered cultural traits shared by certain entities in differing cultures. ${ }^{51}$ It seems obvious that the concept of sub-culture has strong implications for business and management, particularly international, as the members of the similar sub-cultures in different parts of the world may behave similarly.

50 Clyde Kluckhohn, Mirror for Man: A Survey of Human Behaviour and Social Attitudes, (Greenwich, Connecticut: Fawcett Publications Inc., 1959), pp.30-35. and Geert Hofstede, culture's Consequences: international Differences in Work-Related Values, op. cit., ch. 1.

51 Philip R. Harris and Robert T. Moran, op. cit., pp. 64-67; Andrea L. Rich, Interracial Communications, (New York, NY.: Harper \& Row, 1974), and T. Kochman, Black and White-Styles in Conflict, (Chicago, Illinois: University of Chicago Press, 1981). 
Of the variety of terms invented to designate the central core of meanings in societies the most familiar are "unconscious systems of meanings" (Sapir)52, unconscious canons of choice" (Benedict) ${ }^{53}$, "configurations" (C. Kluckhohn) 54 , "culture themes (Opler)55, and "core culture" (Thompson). ${ }^{56}$ Basic "personality type" (Kardiner and Linton) ${ }^{57}$ is an equally familiar concept which has similarities to those just mentioned but differs from them in having a more definitely psychological focus. Still another and more recently formulated concept is that of "world view"(Redfield). 58 Bateson summarises and posits,

"The human individual is endlessly simplifying, organizing, and generalising his own view of his own environments; he constantly imposes on this environment his own constructions and meanings; these constructions and

52 Edward Sapir, Selected Writings in Lanquage, Culture and Personality, ed. by David Goodman Mandelbaum, (Berkeley, CA.: University of California Press, 1949).

53 Dr. Ruth Benedict, op. cit.

54 Clyde Kluckhuhn," Values and Value Orientations in the Theory of Action," in Toward a General Theory of Action. ed., Talcott Parson, Edward A. Shils et. al., (Cambridge, Massachusetts: Harvard University Press, 1951), pp. 409-10 and Category of Culture," in Anthropology Today, ed. Alired C. Kroeber, (Chicago, Illinois: University of Chicago Press, 1953) pp. 507-24.

55 Morris E. Opler," Some Recently Developed Concepts Relating to Culture," op. cit.

56 Laura Thompson, Ioward a Science of Mankind, (New York, NY.: McGraw Hill, 1961).

57 Abraham Kardiner, The Individual and His Society and Psychodynamics of Primitive Social Oraanizations, (New York, NY.: Columbia University Press, 1939), p. 503; Ralph Linton, The Study of Man, (New York, NY.: Appleton-Century, 1936) and Florence Rockwood Kluckhohn and Fred L. Strodtbeck, Variations in Value Orientations, (Evanston, Illinois: Row, Peterson \& Company, 1961), pp.1-48.

$58 \mathrm{He}$ distinguishes four concepts - the culture of a people, its ethos, the national character of a people, or its personality type, and world view. His distinctions seem in part to be a matter of level of generality, but even more important considerations are the difference of focus of attention upon the evaluative or the existential and the problem of whose point of view is being considered, that of the observer or the observed. (Robert Redfield, The Primitive World and Its Transformations, (Ithaka, NY.: Comell University Press, 1953), Chapter IV. 
meanings [are] characteristic of one culture, as over against another." 59

Human culture varies in space. This cultural diversity affects human behaviour. Social organisations, marriage customs, food habits, and religious ceremonies all vary endlessly. There is a close relationship between man and culture as White asserts, "In a consideration of the differences of behaviour between peoples, therefore, we may regard man as a constant, culture as a variable. This is to say that the differences in behaviour that we observe between Eskimos and Hottentots, Chinese and Russians, Canadian and Brazilians, are due to their respective cultures rather than biological anatomical, physiological, or psychological - differences between them." 60

For the field of international business and management and the resultant analysis of host countries' employees' behaviour and its repercussions on managerial personnel in their usual functioning, the impact of the diversity of culture seems endless. Take the use of colour, for instance. In Iran blue is mourning: mourners wear white in Japan, while in America white is typically associated with weddings, and black with sombre and the sad, and purple symbolises death in Latin America.61

59 Gregory Bateson," Cultural Determinants of Personality" in Personality and the Behavior Disorders, ed. J. McV. Hunt, (New York, NY: Ronald Press, 1944), p. 273.

60 Leslie A. White, The Science of Culture: A Study of Man and Civilisation, (New York, NY.: Farrar, Straus and Cudahy, 1949), pp. 120-26.

61 Maneck S. Wadia, "The Concept of Culture," op. cit, pp. 21-30. 


\section{MANAGEMENT AND CULTURE}

Organisations and their management are extremely complex topics as each possesses numerous dimensions which can be studied independently or in conjunction with other/s. Researchers have approached the study of management from a variety of perspectives thus giving rise to various "schools" of management theory, each claiming to provide new and momentous insights into the discipline. In the words of Harold Koontz:

"There are behaviorists ... who see management as a complex of interpersonal relationships and the basis of management theory, the tentative tenets of the new and undeveloped science of psychology. There are also those who see management theory as simply a manifestation of the institutional and cultural aspects of sociology. Still others, observing that the central core of management is decisionmaking, branch in all directions from this core to encompass everything in organisation life. Then, there are mathematicians who think of management primarily as an exercise in logical relationships expressed in symbols and the omnipresent and ever revered model. But the entanglement of growth reaches its ultimate when the study of management is regarded as one of a number of systems and sub-systems, with an understandable tendency for the researcher to be dissatisfied until he encompassed the entire physical and cultural universe as a management system. ${ }^{62}$ (emphasis added)

The thrust of the'management process' 63 school is the identification of universal functions of the manager. It is submitted that once correctly identified these functions may serve as a base to help develop a conceptual framework around which knowledge can be accumulated and synthesized. R.C. Davis, ${ }^{64}$

62 Harold Koontz," The Management Theory Jungle," Academy of Management Journal, IV, No. 3, (December 1961, pp. 174-5.

63 Also known as 'functional' school.

64 Ralph C. Davis, Industrial Organisation and Management, (New York, NY.: Harper \& Brothers, 1940, first published in 1928), pp. 35-36. His views, it seems, were influenced by the French theorist Henry Fayol's Administration Industrielle et Generale (1916). 
probably the most influential of this group submitted three organic functions: Planning, Organising65, and Controlling, though others following on his heels modified and added a few more 66 to the list. This approach attempts to describe the essential functions of the manager, to show their interrelationships, and then to introduce logic toward inferring how each function may be effectively performed. Another approach, known as the'empirical school'67 emphasises the study of real experiences of organisations and managers in order to arrive at principles.68 This method enjoys an advantage as this "real world" emphasis permits the use of a variety of techniques in deriving information toward a comprehensive grasp of situations. It is posited that if used alone, with no attempt to structure the findings, this approach yields only a set of individual findings derived from a specific situation/s, certainly not compatible with the construction of science. ${ }^{69}$

Lawrence Appley ${ }^{70}$ sees the essence of management to be gaining the active cooperation of others in the pursuit of common objectives. The focal point for the manager, therefore, is to understand the determinants of human behaviour ${ }^{71}$ in organisations, and then to convert these insights into a system

65 For an indepth analysis of behavioral dimensions of organisation please see Chester I. Bernard, The Functions of the Executive, (Cambridge, Massachusetts: Harvard University Press, 1938), especially chapters $6 \& 7$.

66 Such as 'leading', 'motivating', 'executing', 'directing', 'coordinating' etc... .

67 Known also as the "case study" approach.

68 Peter M. Blau, The Dynamics of Bureaucracy, (Chicago, Illinois: University of Chicago Press, 1963), pp. 3-5.

69 Paul E. Torgersen and Irwin T. Weinstock, Management: An Integrated Approach, (Englewood Cliffs, New Jersey: Prentice-Hall, Inc., 1972), pp.6-15.

70 L.A. Appley, Management in Action, (New York, NY.: American Management Association, 1956), pp. 322-24. Executive.

71 Known as 'human behaviour' school. Also refer to Bernard's, The Functions of the 
of leadership that will yield maximum efforts by subordinates or by others whose inputs are required. The approach examines the theories of motivation, perception, and learning and is basically the application of psychology to the understanding of normal individual behaviour determinants. It emphasises the behavioural dynamics of small groups, with respect to the processes of establishing group values, status structures, socially accepted behaviour and so on. Moving a step further toward the macro-level of the behaviour school is the study of relationship between groups, the question of inter-departmental cooperation, conflict, status, and communication. Focus is directed towards the goals and perceptions of interdependent departments, the effects of work flow on their relationships and efficiency and the obstacles in their communication. ${ }^{72}$ According to this school, the behavioural sciences hold the key to management theory and practice.

The 'social system' 73 school views the business organisation as being composed of a great variety of inputs, which are controlled by diverse segments of society - the greater social system. Essentially it views the organisation as a social device for creating and distributing utility. 74 Management is another of the required inputs. The role of the manager is to acquire and efficiently utilise all other inputs so as to satisfy divergent and, at times, conflicting demands. This school views management in a realistic mode

72 Paul E. Torgersen and Irwin T. Weinstock, op. cit., pp.9-10.

73 For more details, please refer to J. G. March and H. A. Simon, Organizations, (New York, NY.: John Wiley \& Sons, 1958), pp. 84-111.

74 The output (inducements) must be of greater value than the utility contributed by each person or group and be greater than the utility realizable through alternative use of the contributions. A potential employee will join and remain with an organization only if he perceives that various satisfactions to be gained by participating are of greater utility than may be obtained by his alternatives. (Paul E. Torgersen and Irwin T. Weinstock, 00. cit., pp.11-2. 
and puts the manager in the most demanding role as he is to simultaneously satisfy many publics.

The 'decision theory' 75 school views manager as a decision maker and attempts to study the rational decision procedures as well as the actual ways by which managers reach decisions. The school delves in both quantitative as well as qualitative models for problem solving. The aspect relating to the actual managerial decision behaviour, strongly resembles the human behaviour school and similarly focuses on human motivation, perception, and conditioning emphasising one's personal experiences and values. Still others who show reluctance to use the term science with a discipline unless it is highly quantified would like to see the potential for precise and measured language of mathematics in the discipline of management. It is sufficient to state that management is moving in that direction but with a slower pace. 76

The 'comparative management' school seeks to develop generalisations from the study of management in diverse cultures. Efforts are made to determine in what ways managerial systems resemble each other in heterogeneous cultures, providing insights into possible universal management characteristics. The school seems to resemble the empirical school but endeavours to free the latter from the usual criticism of 'culture bound' findings. 77

75 Known also as 'decision science', 'management science', and 'operations research'.

76 Paul E. Torgersen and Irwin T. Weinstock, op. cit., p.14.

77 lbid., p. 14-15. 
There is an apparent interrelatedness and commonality among these schools of management thought. All provide insights into management processes but none studied by itself can provide a comprehensive view of the discipline as Koontz himself conceded. ${ }^{78} \mathrm{He}$ viewed behavioural and quantitative approaches as tools to be used by managers. He favoured a 'process approach' (functional) that could encompass and synthesize the diversity of the day. The mid -1960s witnessed the emergence of the 'systems approach' which emphasises the inter-relationships and interdependencies of parts in a manner that produces a unified whole. It was the open system (Figure 3.1) approach which caught the attention of many as it recognises the dynamic interaction of the system with its environments. 79 The organisation is envisaged as made up of ' interdependent' factors, including individuals, groups, attitudes, motives, formal structure, interactions, goals, status and authority. 80 The manager's job is to ensure that all parts of the organisation are coordinated internally so that the organisations goals can be achieved. ${ }^{81}$

The most recent development is the 'contingency approach'.82 This perspective allows us to specifically identify the internal and external variables that have an impact on managerial actions and organisational performance. The contingency approach has attempted to deal with real life situations by

\footnotetext{
78 Harold Koontz," The Management Theory Jungle," op. cit.
}

79 The concept of 'open systems' was talked about as early as 1930 by Chester Bernard, oD. cit. Frederick W. Taylor's 'Scientific Management' approach was more akin to 'closed systems', i.e. oblivious to its external environments.

80 Kenyon B. DeGreene, Sociotechnical Systems: Factors in Analysis. Design and Management, (Englewood Cliffs, N.J.,: Prentice Hall, 1973), p. 13.

81 Stephen P. Robbins and Debu Mukerji, Managing Organisations: New Challenges and Perspectives, (Sydney, Australia: Prentice Hall,1990), pp.38-40.

82 Also known as 'situational approach'. Louis W. Fry and Deborah A Smith, "Congruence, Contingency, and Theory Building," Academy of Management Review, January, 1987, pp. 117-132. 
integrating management concepts into a situational framework. Recent efforts in contingency theory have tried to isolate the situational determinant/s to gauge and assess its/their effect/s on managerial functions and control designs.

\section{FIGURE 3.1}

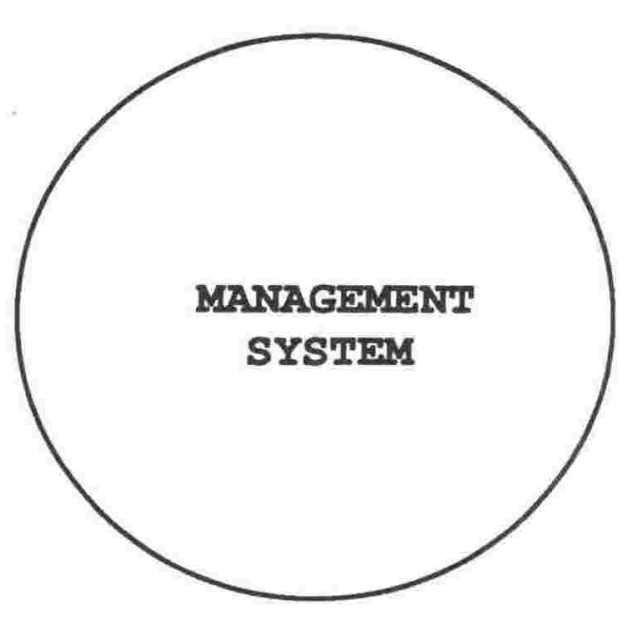

Closed System

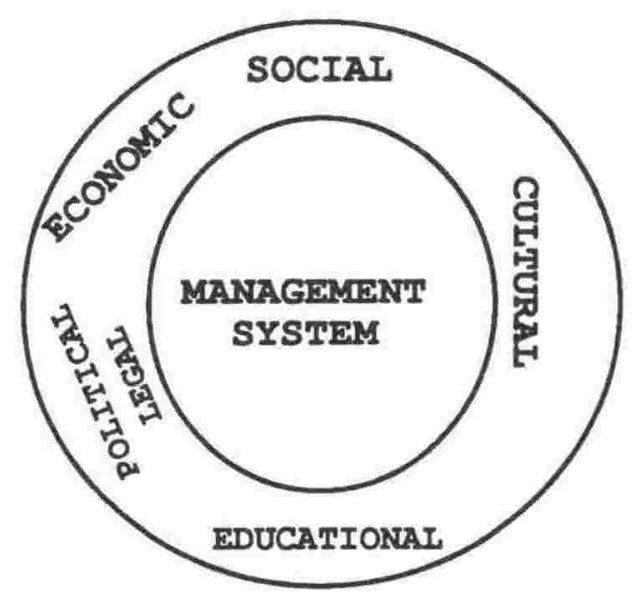

Open System

Essentially management refers to the process 83 of getting activities completed efficiently with and through other people. As Appley states, "management is personnel management." 84 Notwithstanding a particular framework, it is the people in an organisation who work to achieve objectives. These people represent different individuals.

83 The process represents the primary activities engaged in by managers such as planning, organising, leading, controlling and so on. Organisations' goals are defined, strategies established and an integrated hierarchy of plans put in place. Structure detailing what tasks are to be done, in what order, by whom, to be reported to whom and by whom, developed and put in place. Motivating people with a view to accomplish the overall goals efficiently. After the goals are set, the plans are formulated, the structural arrangements delineated and the people hired, trained and motivated, there is a need for monitoring the performance to make sure that things are on the track, and if not, a corrective action is initiated. These functions also view manager's different roles, such as inter-personal, informational and decisional (Henry Mintzberg, The Nature of Managerial Work, (New York, NY.: Harper \& Row 1973)

84 L.A. Appley, op . cit, p. 323. 
The manager is - first and foremost - a decision maker and by and large all of his decisions involve his people directly or indirectly. The success or otherwise of his endeavours on various dimensions of managerial functions depend on the skill, motivation, and cooperation of those with whom he works inside and outside the organisation. Human motivation and perception play an important role in determining human behaviour. A rational manager should understand his needs and should reflect on way/s his interpretations of the world affect his own behaviour. He must possess a similar understanding of others in the organisation if he is to constructively influence their actions. An essential corollary to a basic grasp of human psychology is a fundamental comprehension and appreciation of the processes underlying the behaviour of people individually, in small groups, in bigger groups, within an organisation and so on.

Every individual has something that psychologists term as personality 85 which is made up of a set of relatively permanent and stable traits. These traits get manifested in his beliefs, attitudes, and value systems. One of the important determinants of individual's personality is the cultural system he has has been exposed to since his inception. As alluded to in the earlier parts of this chapter it is culture of the group (tribe, society, or region) besides other environmental factors which dictates how each member will act toward fellow members and outsiders. It presents a framework of assumptions, norms,

85 The normal personality is in a state of dynamic equilibrium. It preserves its identity, yet is able to change. It is flexible, but maintains a consistent character. Personality is goal-directed behavior. In a real sense it is the choice among goals that distinguishes one personality from another. Also personality conceived as a whole actualises itself in a determinant environment. That means that an individual cannot be understood apart from his environment. In fact personenvironment forms a syndrome, two or more mutually dependent interacting parts, creating a fairly stable structure of relationships which possesses an inherent potential of predictability. Personality is also a process of becoming. (Hubert Bonner, Psychology of Personality, New York, NY.: Ronald Press Co., 1961, pp. 38-41). 
attitudes, 86 and values. The cultural traits of employees of an organisation will have a significant effect on their work, inclination, and efficiency.

The management implications with regard to the employees' attitudes are three fold. First, very little of human conduct is logical. 87 Most human conduct, says Pareto, ${ }^{88}$ is nonlogical and originates in psychic states, inclinations, preconceptions, and subconscious feelings. Management must be aware that people are not logic machines, rationally conjoining means with ends in the pursuit of some goal. Second, the most usual form of behaviour is a nonlogical one based on feelings and prejudices. The attitudes underlying nonlogical behaviour have been long established and are brought by the employees to the organisation. Additionally, other attitudes in this sense are socially produced in the work situation. Nonlogical attitudes are subtle and varied, but they are no less a reality than logical attitudes. Third, it is often a purely relative matter whether attitudes are logical or nonlogical. It is not enough to consider our attitudes as logical and the other fellow's as nonlogical - a bias which management frequently has. ${ }^{89}$

Organisations are not islands unto themselves. They interact with, and are influenced by their environments: the economic, political, technological

86 Attitudes are, ". . . an enduring organization of motivational, emotional, perpetual, and cognitive processes with respect to some aspect of the individual's world." (D. Krech and R.S. Crutchfiled, Theory and Problems of Secial Psychology, (New York, NY.: McGraw-Hill Company, Inc., 1948), pp. 152.

87 Attitudes are thought to fall into two general classifications - logical and nonlogical. Logical behaviour is prompted by logical attitudes. Nonlogical attitude is more characteristic of 'typical' behaviour. It arises from opinions, beliefs, and values held by people with respect to the events surrounding them. People give opinions to judge 'right' or 'wrong' conduct out of their frame of reference. (William G. Scott, op. cit., pp. 70-72).

88 Vilfredo Pareto, Ihe Man and Society, translated and edited by Arthur Livingston, (New York, NY.: Harcourt, Brace and Co., 1935).

89 William G. Scott, op. cit. 
and cultural (Figure 3.2) ) $^{90}$. All are vital to the effectiveness of managerial functions individually as well as jointly. These influence not only the long term planning and size and scope of organisational structure, but also the day to day task management and human resource utilisation and development. As cultural factors/traits are more stable and durable, this study's focus is on cultural factors from a managerial perspective. Accordingly, it is surmised that management will do well if in its various decisions the role of cultural factors in their varied manifestations is given due consideration. The organisational structure, the degree of subordinate participation in decision making, the reward system and so on are all influenced by the relevant culture of the organisation's personnel.

Culture is a group phenomenon, more so a group problem-solving tool for daily coping in a particular environment. The work place provides its own unique environment of shared values and goals developed over the years to successfully exploit challenges and opportunities through the interaction between management and those managed thus giving rise to another culture, 'organisation culture'. The organisation culture conveys assumptions and norms, governing values, activities and goals; and doing so, it tells employees how things should be done and what is important. It is a system of shared meaning. 91 These shared values determine, in large degree,

90 Anant R. Negandhi," Three Decades of Cross-Cultural Management Research: Alice in Wonderland," in The Enterprise and Management in East Asia, eds Stewart R. Clegg, Dexter C. Dunphy and S. Gordon Redding, (Hong Kong: Centre of Asian Studies, University of Hong Kong, 1986), pp 35-66.

91 It is a system of shared meaning. In every organisation there are systems or patterns of values, symbols, rituals, myths and practices that have evolved overtime Linda Smircich," Concepts of Culture and Organisational Analysis," Administrative Science Quarterly, Sept. $1983, \mathrm{p} 339$. 
what managers see and how they respond to their world. 92 Organisation culture is a 'perception'. This perception exists in the organisation, not in the individual. As a result individuals with different backgrounds or at different levels in the organisation tend to describe the organisation in similar terms. Second, organisation culture is descriptive rather than evaluative as it is concerned with how members perceive the organisation, not whether they like it or not. 93

While all organisations have cultures, they do not all have an equal impact on employees. The more that employees accept the organisation's key values and the greater their commitment to those values, the stronger the culture is. It has been aptly posited,

\begin{abstract}
"Culture controls the manager ... through automatic filters that bias the manager's perceptions, thoughts and feelings. As culture arises and gains strength, it becomes pervasive and influences everything the manager does, even his own thinking and feeling. The point is especially important because most of the elements that the managers views as aspects of effective management - setting objectives, measuring, following up, controlling, giving performance feedback, and so on - are themselves culturally biased to an unknown degree in any given organisation. There is no such thing as a culture-free concept of management." 94 (emphasis added)
\end{abstract}

92 Alice M. Sapienza, "Believing is Seeing: How Culture Influences the Decisions Top Managers Make," in Ralph H. Kilman et. al (eds) Gaining Control of the Corporate Culture, (San Francisco, CA.: Jossey-Bass, 1985), p. 65.

${ }^{93}$ Stephen P. Robbins and Debu Mukerji, on cit., pp.16-7.

94 Alice M. Sapienza, "Organisational Culture and Leadership, (San Francisco, CA.: Jossey-Bass, 1985), pp. 314-15. 
FIGURE 3.2

\section{External (Environmental) Determinants of Organisational Patterns and Effectiveness}

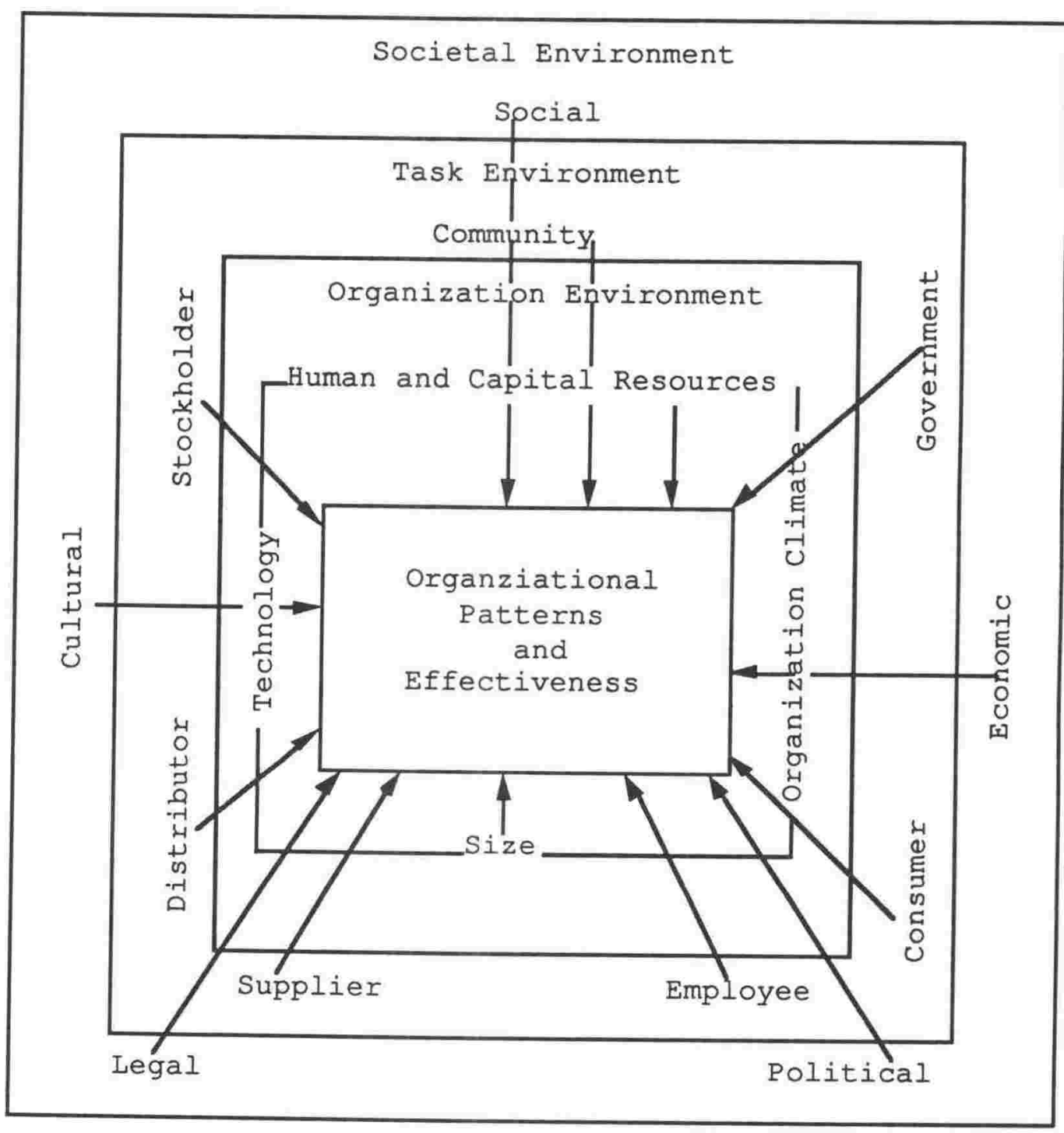

Source: Anant R. Negandhi," Three Decades of Cross-Cultural Management Research: Alice in Wonderland," in The Enterprise and Management in East Asia, eds Stewart R. Clegg, Dexter C. Dunphy and S. Gordon Redding, (Hong Kong: Centre of Asian Studies, University of Hong Kong, 1986), pp 35-66. 
An organisation's culture, 95 especially a strong one, therefore constrains (or facilitates) a manager's decision - making options concerning all manage ment functions. It must reflect the history of the organisation as it has developed over the years in response to the then extant environments. 96 However, it need not be in conflict with the group culture outside the organisation as that will retard its efficacy. It merely articulates and sharply focuses their value system in a particular (business) context. From a slightly wider perspective one may like to look at the culture of a bigger group, say a nation. National culture is something that is shared by all inhabitants of a country 97 and that shapes their behaviours and the way they see the world. 98

An obvious question may arise as to which one is more important: organisational culture or the national culture? The research indicates that national culture has a greater impact on employees that does their organisation's culture. 99

95 Group culture (analogous to organisation culture and also to national culture in the sense of ethnic group or a collection thereof) is quite durable largely because of the wariness its members have toward potentially disrupting influences originating in its history and environments. Even turnover in its membership seems not to alter greatly the content of this culture. The group preserves its culture through the process of transmitting it from the older members to the new. William G. Scott, op. cit., p. 96.

96 Stephen P. Robbins and Debu Mukerji, op. cit., pp. 19-20.

97 Some nations have different ethnic groups which show quite a few distinct traits but overall one may discern a conspicuous degree of commonality (see earlier discussion).

98 Geert Hofstede, Culture's Consequences: International Differences in Work-Related Values, (Beverly Hills, CA., Sage Publications, 1980), pp. 22-6 and Somkao Runglertkrengkrai and Suda Engkaninan," The Pattern of Managerial Behaviour in Thai Culture," Asia Pacific Journal of Management. Vol. 5, No. 1, September, 1987, pp.8-15.

99 Nancy J. Adler, International Dimensions of Organisational Behaviour, (Boston, Massachusetts: Kent Publishing 1986), pp. 46-8; Andre Laurent, "Cultural Dimensions of Managerial Ideologies: National Versus Multinational Cultures," Presented at the Eifth Annual Meeting of the European International Business Association, London Business School, December 12-14, 1979, pp.1-17; Rosalie L. Tung, "Selection and Training of Personnel for Overseas Assignments," Columbia Journal of World Business, Spring 1981, pp. 68-78 and , "Cross-Cultural Managerial Research: The Ostrich and the Trend," Academy of Management_Review, April 1983, 226-32. 


\section{Cultural Determinants of Managerial Effectiveness}

The role of cultural (factors) in its various manifestation in determining the effectiveness of managerial functions cannot be over emphasised.100 Hofstede 101 in a comprehensive survey of first 40 countries and later 63 countries, identified four major dimensions along which national cultures could be characterised. Power distance, individualism, masculinity and uncertainty avoidance.

Power Distance, from large to small. It is defined as the extent to which members of a society accept that power in institutions and organisations is distributed unequally. A high power-distance society accepts wide differences in power in organisations. Employees show a great deal of respect for those in authority. In contrast, a low power-distance society plays down inequalities as much as possible. Fundamentally, it describes a society's way of handling inequality: from institutionalising and accepting it to minimising it. It identifies some societies as more and others as less equal.

Individualism describes the relationship between the individual and the collectivity which prevails in the society. ${ }^{102}$ Individualism is made possible because of a large amount of freedom that a society allows its members. In some cultures individualism is seen as a blessing and a source of well being;

100 David J. Hickson, C.R. Hinings, C.J. McMillan and J.P. Schwitter, " The Culture-Free Context of Organization Structure: A Tri-National Comparison," Sociology, Vol. 8, 1974, pp. 5980 .

101 Geert Hofstede, Culture's Consequences: International Differences in Work-Related Values, op. cit.

102 Lynn R. Anderson, Self-Monitoring and Managerial Effectiveness, Working Paper No. 7, (Auckland, New Zealand: The Department of Management Studies, The University of Auckland, 1981), pp.1-22. 
in others it is seen as disturbing, that is, a society which is characterised by a tight social framework in which people expect others, in groups of which they are a part, to look after them and protect them when they are in trouble. It operates at the level of the group, like an extended family.

Masculinity with, as its opposite, Femininity. On the masculine side, one finds strong differentiated social sex roles: the masculine role implies achievement, assertiveness, sympathy for the strong, and material success. On the feminine side, one notices overlapping social sex roles: both imply warm relationships, modesty, care for the weak, and quality of life. It opposes tough, competitive societies to tender, solidarist societies. Where femininity dominates members put human relationships before money and are concerned with quality of life, preserving environments and helping others. ${ }^{103}$

Uncertainty Avoidance, from strong to weak. It is defined as the level of anxiety within members of a society in the face of unstructured or ambiguous situations - expressed in aggressivity and emotionality, in institutions promoting conformity, in beliefs promoting certainty. Some societies are relatively tolerant of behaviour and opinions that differ from their own because they do not feel threatened by them. While a society high in uncertainty avoidance endeavours to create mechanisms to provide security and reduce risk. Their organisations are likely to have more formal rules and a lower tolerance level for deviant ideas and behaviours. Fundamentally, it describes a society's intolerance for ambiguity: from trying to control it at all cost, to accepting to live with it. It identifies some societies as rigid and others as flexible.

103 Geert Hofstede, "The Cultural Relativity in Organizational Practices and Theories," Journal of International Business Studies, Fall 1983, pp. 75-89. 
The way decisions are made and the degree of risk a decision-maker (manager) is willing to take will depend upon the organisation's external cultural environments (Figure 3.3). Management in countries with a high score on individualism would be less inclined to make group decisions. On the other hand, places where collectivist values are stronger managers would be naturally inclined to make group decisions (e.g. in Japan). Similarly, countries with high power-distance values, subordinates as a rule do not want to participate. It is part of their expectation that managers will make decisions autocratically.

Countries low on uncertainty tolerance would witness a preference on the part of management to plan for shorter time-periods. Unstable political and economic environments in countries with a high power distance score would, too, observe an accentuated thrust for short-term planning by the management. 104 Management decision making would be more decentralised in countries with a low power-distance rating. Similarly environments of high uncertainty avoidance would result in a high formalisation level. ${ }^{105} \mathrm{For}$ instance French and Italian managers tend to create rigid bureaucracies that are high in both centralisation and formalisation (high power-distance and high uncertainty avoidance). Indian managers, on the other hand, prefer centralisation and low formalisation (high power - distance and low uncertainty avoidance) while German managers prefer formalisation with decentralisation (high uncertainty avoidance with low power-distance). ${ }^{106}$

104 Stephen P. Robbins and Debu Mukerji, op. cit., pp. 506-8.

105 Geert Hofstede, "Motivation, Leadership and Organisation: Do American Theories Apply Abroad," Organisational Dynamics, Summer 1980, pp.42-63 and Bob Garratt, "Contrasts in Chinese and Western Management Thinking," LODJ. 2, 1 1981, pp. 17-22.

106 Geert Hofstede, "The Cultural Relativity in Organizational Practices and Theories," op. cit. p. 87. 
FIGURE $\mathbf{3 . 3}$

(Cultural) Determinants of Managerial Effectiveness

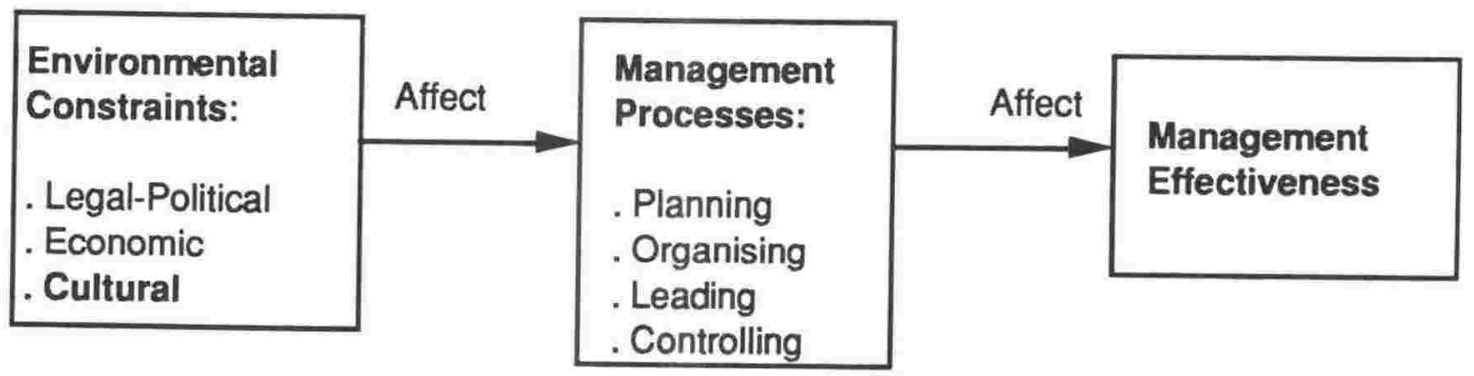

It has been observed that 'Management by Objectives' (MBO) is an effective way of integrating and operationalising the planning function. But MBO is bound by culture. It is well adapted to the United States, because its key components align reasonably well with the US culture. 107 MBO assumes that subordinates will be reasonably independent (not too high a score on power-distance), that managers and subordinates will seek challenging goals (low in uncertainty avoidance), and that performance is considered important by both (high in masculinity). ${ }^{108}$ Countries with high uncertainty avoidance would see its business management teams less receptive to the innovative structural designs and excursions into uncharted and unknown spheres.

The theories of motivation underscores the need for achievement. The view that a high need for achievement acts as an internal motivator presupposes the existence of two cultural characteristics: a willingness to accept a moderate risk and a proclivity towards better performance. The

107 J.T. Gullahorn and J.E. Gullahorn, "An Extension of the U-Curve Hypothesis," Journal of Social Sciences, January 1963, pp. 34-47.

108 Stephen P. Robbins and Debu Mukerji, ㅇ․ cit., p. 507. 
countries with high uncertainty avoidance and feminine ratings would obviously observe a lack of interest in achievement and hence would tend to constrain the manager's ability to motivate. ${ }^{109}$ Similarly the leadership styles will hinge to a great extent on the national culture of the subordinates. "What is feasible depends to a large extent on the cultural conditioning of a leader's subordinates". 110 Participatory leadership is likely to be most effective in low power-distance countries such as theNordic cluster for it favourably affects the employees' willingness to accept participation.

The cultural system is a dynamic system with homeostatic tendencies which tend to stabilise the system internally, that is, put the body of culture and and the management at equilibrium, and externally, that is, put the cultural system and environment at rest. Alfred Kuhn aptly posits,

"... Any operative culture system contains sub-systems which establish and maintain certain norms, or consensus values about many things. These sub-systems do have an equilibrium action which tends to maintain whatever particular level the system happens to have attained. The main sub-system is essentially that of deviation and conformity, in which the pressure to conform varies directly with the deviation, and the deviation varies inversely with the pressure of conformity." 111

The manager's decisions and behaviour impinge upon his environment and the cultural system. His behaviour assumes meaning when viewed in terms of his environment and culture which acts as reference points from which he determines his best course of action towards his and

109 Geert Hofstede, "Motivation, Leadership and Organisation: Do American Theories Apply Abroad," op. cit., pp.55-6..

$110 \underline{\text { bid. }}$ and Stephen P. Robbins and Debu Mukerji, op. cit., p. 509.

111 Alfred Kuhn, The Study of Society: A Unified Approach (Homewood, Illinois: Richard D. Irwin and The Dorsey Press Inc., 1963), pp 205-7. 
corporation goals. The value of such goals is culturally and environmentally determined. His assumptions about the goals, decisions, and the means to goal attainment are subject to his perception and interpretation of the relevant culture and environment. The culture and environment, in turn prescribe the manager's value system and behaviour which guides his assumptions. If the assumptions of the manager are correct and his fellow societal members subscribe to his value system, he receives a positive reaction and vice versa. ${ }^{112}$ The compatibility between the cultural system followed by the employees and the managers is vitally important for the effective and efficient accomplishment of the employees' as well as management's goals. The issue assumes increased seriousness and enhanced importance in the context of international management and multinational corporations.

\section{Cross-Cultural: A Few Elaborations}

Knowledge about cultures, both general and specific, provides insights into the learned behaviour of groups. It helps the learner to gain awareness of what makes a people unique - their customs and traditions, their values and beliefs, attitudes and concepts, hierarchies and roles, time and space relations, and verbal and non-verbal communication processes. ${ }^{113}$ Culture is fundamentally a group problem-solving tool for daily coping in a particular environment. It enables a unique group of people to grow in self-actualisation,

112 Richard John Fleming, "Cultural Determinants of the Effectiveness of American Executives Abroad," (Ph.D., Dissertation, Louisiana State University, 1966), p. 43.

113 Philip R. Harris and Robert T. Moran, Managing Cultural Differences, 2nd Ed. op cit., pp. 20-22; D.B. Stephens,"Cultural Variation in Leadership Style: A Methodological Experiment in Comparing Managers in the U.S. and Peruvian Textile Industries,"Manaoement International Beview,vol.21, No. 3, 1981, pp. 47-55, and John L. Graham,"The Influence of Culture on the Process of Business Negotiations: An Exploratory Study," Journal of International Business Studies, Spring 1985, pp. 81-96. 
to create a distinctive world around them, to control their own destinies. Since human social and technological advancement are the legacy of all mankind, various people of diverse cultures should borrow from one another so that the exchange will promote a new level of human development. The pertinent data for all this may come from a variety of behavioural sciences, such as cultural anthropology, psychology, cross-cultural communication and linguistics. Information gained from these (cross-cultural) studies will enable managers to become more cosmopolitan (literally, the one who functions effectively anywhere in the world), to cope more effectively abroad, to reduce stress and resolve conflict more readily in the international business arena. Such transcultural competency should be an integral aim of any MNE's management. 114

By culture we mean the whole set of social norms and responses that condition a population's behaviour. It is these that make one social (and general) environment different from another and gives each a shape of its own. Basic to all is the idea that culture is acquired and inculcated. It is the set of rules and behaviour patterns that an individual learns but does not inherit at birth. For every society these norms and behavioural responses develop into a different cultural pattern 115 which gets passed down through the generations with continual embellishment and adaptation; but with its own

114 A. Sorge and M. Warner," Culture, Management \& Manufacturing Organization: A Study of British and German Firms," Management International Review, Vol. 21, No. 1, 1981, pp. 35-48; Andre Laurent," The Cross-Cultural Puzzle of International Human Resource Management," Human Resource Management, Vol. 25, No. 1, Spring 1986, pp. 91-102; Mark Mendenhall and Gary Oddou," Acculturation Profiles of Expatriate Managers: Implications for Cross-Cultural Training Programs," The Columbia Journal of World Business, Vol. 21, No. 4, Winter 1986, pp. 73-9; Susan C. Schneider, "National vs Corporate Culture: Implications for Human Resource Management," Human Resource Management, Vol. 27, No. 2, Summer 1988 , pp. 231-46, and Robert C. Maddox and Douglas Short," The Cultural Integrator," Business Horizons, Vol. 31, No. 6, November-December 1988, pp. 57-9.

115 Culture is defined as 'collective programming of mind.' (G. Hofstede, Culture's Consequences: ... Values, op cit. p.13. 
focus on aspects that are most highly developed. For much of cultural conditioning, the individual is unaware of the learning. The subtle process of inculcating culture through example and perceived reward or punishment is generally more powerful than direct instruction, and the individual unwittingly adopts the cultural norms. This process is called enculturation which conditions the individual so that a large proportion of his behaviour fits the requirements of his cultural environment (sic) and yet is determined below his level of conscious thought. ${ }^{116}$ Much of the cultural conditioning of an individual is like an iceberg - he is unaware of nine-tenths of it. ${ }^{117}$ For example a person from the warrior caste of India may not realise how he developed a tendency towards war (sic) (fight) at the slightest provocation. But of course this is also a cultural factor, as some cultures may prefer being taught while others prefer the more subtle technique.

A sensitivity to the elements of culture and the ways in which they differ brings with it an ability to analyse any happening from its cultural perspective. What on the surface may simply look like a similar happening in different cultures may well be composed of many different cultural elements. The apparently simple phenomenon of a family meal, for instance, could be viewed as an extensive set of different rules concerning the time the meal is eaten, the seating arrangements (where the father or mother sits in relation to the rest of the family), the roles played by each in initiating or ending conversation and in interrupting or changing the subject, the comments regarded as humourous, the facial expressions used, the values placed on different foods, the attitudes

116 Melville J. Herskovits, Cultural Anthropology, (New York, NY.: Alfred A. Knopf, Inc.,1963), p. 326.

117 Stefan H. Robock, Kenneth Simmonds and Jack Zwick, International Business and Multinational Enterorise , (Homewood, Illinois: Richard D. Inwin Inc., 1977), pp. 309-10. 
toward age, and so on. Moreover, the shape and size of the table will differ, as will the utensils, the way they are used, and how the people eat. 118

\section{CULTURE AND COMMUNICATION}

The communication system, verbal and non-verbal distinguishes one group from another. Apart from the multitude of "foreign" languages, some nations have fifteen or more spoken languages (within one language group there are dialects, accents, slang, jargon, and other such variations). Furthermore, the meaning given to the gestures, for example, often differ by culture. 119

A language ${ }^{120}$ is inextricably linked with all aspects of culture, and each culture reflects in its language what is of value to the people. Culture is largely inculcated through language - spoken or written. For example, the author of this study once commented on an examination script, in an attempt to motivate the student to their potential that, "I know that you could have done much better and can do much better." The student from a different culture interpreted this as a means of chastisement and conveyed this feeling to the author.

118 lbid., pp. 310.

119 Robert T. Moran and Philip R. Harris on cit.,1987, pp. 43-45 and George H. Mead, "From Gesture to Symbol," in Theories of Society: Foundations of Modern Sociological Theon, Vol. II, op. cit., pp. 999-1005.

120 'Language is both the vehicle of most cross-cultural research as well as part of its object.' G. Hofstede, Culture's Consequences..... Values, $0 \mathrm{p}$. cit., p.34. 
Language then becomes the embodiment of culture. ${ }^{121}$ It may even condition what we look for and therefore see. It is more on the abstract or interpretational or motivational dimension rather than on a tangible or solid aspect. One anthropologist comparing the structure of languages pointed out that Eskimo languages have several different words for types of snow, while the English language has one, and Aztec uses the same basic word stem for snow, ice, and cold.122 A plausible reason for this occurrence may be that Eskimos are familiar with snow and identify "different" types of "snow," while Aztecs would consider "snow" (or ice or cold) a foreign substance and hence group it simply on a "touch" basis while the English lie in between the two extremes climatically and hence the language.

Studies have shown that cultures can be categorised within a framework of a high to low context, depending on the cultural reliance on verbal versus non-verbal cues for meaning and interpretation of a situation. In high context cultures, communications depend largely on the context or nonverbal cues, and low-context cultures depend depend heavily on verbally expressed and more explicit communication. This measure is only a broad and general one but at the same time quite important to facilitate an understanding of personal relationships in diffrent societies. ${ }^{123}$

When communication involves translation from one language into another, the problems of ascertaining meaning that arise within one culture

121 lbid.

122 Paul Henle, Language. Thought, and Culture (Ann Arbor, Michigan: University of Michigan, 1958).

123 Christopher T. Selvarajah and Katrin Cutbush-Sabine, eds., International Business, (Melbourne: Longman Cheshire, 1991), pp. 6-8. 
are multiplied many times. ${ }^{124}$ Translation is not merely a matching of words with identical meanings. It involves interpretation of the cultural patterns and concepts of one country in terms of patterns and concepts of another to sustain an appropriate level of appreciation. ${ }^{125}$ Awareness of difficulties of translation is particularly important for legal agreements. As a distinguished international lawyer has noted," When contracts cross national borders, they may alter in character as well as language. ${ }^{126}$ "Verite en-deca des Pyrenees, erreur au dela." i.e. "There are truths on this side of the Pyrenees which are falsehoods on the other," (Blaise Pascal, Penees). For example, in some cultures a hand shake is equivalent to a signature.

Communication does not always take the form of language.127 All behaviour communicates and, as Edward Hall so cleverly pointed out, each culture may be different in the way it experiences and uses time, space, relationships, and a variety of other aspects of culture. 128 The use of time in one culture may convey a set of meanings quite different from the meanings for a similar use of time in another culture. To be 30 minutes late for an appointment with a business associate may be the height of rudeness in one

124 Translators of English literature have noticed that French and many other modern languages have no adequate equivalent for the English 'achievement'; Japanese has no equivalent for 'decision-making'. (G. Hofstede, culture's Consequences: _... Values, op. cit..p. 34.

125 Antoine Meillet," How Words Change Their Meanings," in Theories of Society: Foundations of Modern Sociological Theory, Vol. II, op. cit., pp. 1013-18.

126 Henry P. deVries," The Language Barriers," Columbia Journal of World Business July-August, 1969, p.79.

127 George H. Mead, "From Gesture to Symbol," in Theories of Society; Foundations of Modern Sociological Theory, Vol. II, op. cit., pp. 999-1005.

128 Edward T. Hall, The Hidden Dimension: The Silent Lanquage, (Garden City, NY: Doubleday \& Company, 1966,1959). 
culture but in another culture it may be early and unexpectedly reliable. 129 The author has personal experiences of these for having served in Kenya, India, and at different places in U.S.A. Different messages may be conveyed by the amount of notice given for a meeting, the time of departure, invitations to future commitments, or the way in which a party agrees to the order of discussion at the meeting. In some cultures a delay in answering a communication is interpreted by the other party as a lack of interest. In other cultures the more important a matter the more time is taken to respond. 130 Operating difficulties can arise when workers are accustomed to a different set of values: where work is not equated with time, (sic) for example agrarian work is not regularly and precisely scheduled. Thus the setting of schedules or deadlines will evoke a positive response in certain cultures and a negative response in another. ${ }^{131}$

In a similar way, the use of space conveys different meanings. The distance one person stands away from another indicates the degree of relationship or interest and can dramatically influence what is said. Different cultures have different norms for the appropriate distance for a given type of interaction. Middle Easterners and Latin Americans, for instance, stand much closer than Americans and Western Europeans. ${ }^{132}$ The Latin speaking may also break the "bubble" without saying "excuse me." Instead of handshakes

129 Leonard Broom and Philip Selznick, Sociology: A Text with Adapted Readings, 3rd Ed., (New York, NY.: Harper \& Row Publishers, 1963), p. 64 and Philip R. Harris and Robert T.
Moran op. cit. , 1987, pp. 40-45.

130 Stefan H. Robock, Kenneth Simmonds and Jack Zwick, ,으. cit., p. 312.

131 Conrad M. Arensberg and Arthur M. Niehoff, Introducing Social Change: A Manual for Americans Overseas, (Chicago, Illinois: Aldine Publishing Co., 1964), pp.160-165 and Rose Knotts," Cross-Cultural Management: Transformations and Adaptations," Business Horizons, Vol. 3, No. 1, January-February 1989, pp. 29-33. 187-209.

132 Edward T. Hall, The Hidden Dimension: The Silent Lanquage, 1966, op. cit., pp. 
men often embrace. The size of an office in relation to other offices conveys a great deal about the status of an American executive. In the Arab world, the size and location of an office are poor indicators of the importance of the person who occupies it. 133

\section{CULTURAL BIAS}

In all cases requiring cross-cultural assessment the problem of cultural bias will be present. Everyone tends unwittingly to bias their view of other cultures by unconscious acceptance of their own cultural conditioning. It takes a great deal of discipline to force one's mind to see things that one's own culture ignores or places in low value. Cultural bias may be reduced through the development of culturally sensitive management. Attempts to eliminate 'self-reference criterion' (SRC), however can be incorporated in the system.134

Hofstede 135 , in the preface of his book notes,

" ... The survival of mankind will to a large extent depend on the ability of people who think differently to act together. International collaboration presupposes some understanding of where other's thinking differs from ours. Exploring the way in which nationality predisposes our thinking is therefore not an intellectual luxury. A better understanding of invisible cultural differences is one of the main contributions the social sciences can make to practical policy makers in governments, organizations and institutions - and to ordinary citizens."

133 Stefan H. Robock, et al, ,op. cit., p. 313 and H.W. Lane," Systems, Values and Action: An Analytic Framework for Intercultural Management Research," Management International Review, Vol. 20, No. 3, 1980, pp. 61-70.

134 James A. Lee, "Cultural Analysis in Overseas Operations," Harvard Business Review, March-April, 1966, pp.106-14.

135 G. Hofstede, Culture's Consequences: .... Values, o․ cit..Preface. 
Cross cultural management studies following an environmental approach tend to highlight the impact of external environmental factors - for example, socio-economic, political, legal, and cultural - on management practices and effectiveness. ${ }^{136}$ It is essentially a macro approach with the underlying hypothesis that managerial practices and effectiveness are the functions of external variables; accordingly, interfirm differences in both practices and effectiveness can be explained on the basis of differences in environmental conditions facing firms in different locations or countries. While those adopting a behavioural approach in comparative management studies attempt to explain behaviour patterns of individual and groups in organisational settings. Here, basically researchers have concentrated on national character profiles, ${ }^{137}$ attitudes and perceptions ${ }^{138}$ of managers concerning some key management concepts and activities and prevalent beliefs, value systems and need hierarchies ${ }^{139}$ in a given society. The basic assumption here is that attitudes, beliefs, value systems, and need hierarchies are functions of a given culture. ${ }^{140}$ By establishing relationships between these concepts and managerial practices and effectiveness, one can deduce the impact of cultural variables on management practices and effectiveness,

136 R.N. Farmer and Barry M. Richman, Comparative Management and Economic Progress, (Homewood, Illinois: Richard D. Inwin, Inc., 1965).

137 Stanley M. Davis, Comparative Management: Cultural and Organizational Perspetives, (Englewood Cliffs, NJ: Prentice-Hall, Inc., 1971) and Dhirendra Narain, "Indian National Character in the Twentieth Century," Annals, March, 1967, pp. 124-132.

138 G.V. Barrett and B.M. Bass, " Comparative Surveys of Managerial Attitudes and Behavior," in Comparative Management: Teaching. Research and Training, ed. J. Boddewyn, (New York: Comparative School of Business Administration, 1970), pp. 170-207; M. Haire, E.E. Ghiselli, and L.W. Porter, Managerial Thinking: An International Study, (New York: John Wiley and Sons, 1966) and K.M. Thiagarajan," A Cross-Cultural Study of Relationships Between Personal Values and Managerial Behavior," Iechnical Report 23, NONR N00014-67-A. (Rochester, NY: University of Rochester, Management Research Center, 1968).

139 Stanley M. Davis, ㅇ․ cit.

140 Anant R. Negandhi," Three Decades of Cross-Cultural Management Research: Alice in Wonderland," in op. cit., pp.35-66. 
hence, this an endeavour which assumes enhanced significance in the context of multinational corporations. ${ }^{141}$

\section{PART II}

This part specifically discusses the issues pertaining to the cultural characteristics of the host countries and the resultant effects on the effectiveness of the managerial personnel of the multinational corporations. Various approaches to look at the present and potential problems of this area particularly in the sphere of managerial performance and its measurement have been discussed in details.

\section{MULTINATIONAL CORPORATION AND CULTURAL DIFFERENCES}

Because the microculture is a reflection of the macroculture, it stands to reason that the location of an organisation will be affected by the culture of the community that surrounds it. Even within a country, such as the United States or India, this would be a significant factor affecting employee behaviour. There is a continuous interaction between majority and minority cultures, each influencing the other (in intriguing yet fascinating ways). Any business operating within a single country must adjust to the culture within which it operates, but the need for cultural sensitivity and adjustment is much greater for the international firm. The local firms may introduce an innovation in the form of a new product or new business practice only infrequently. For the international firm, in comparison, cross-national transfers of any one of its old

141 Lane Kelley and Reginald Worthley, "The Role of Culture in Comparative Management: A Cross-Cultural Perspective," Academy of Management Journal, Vol. 24, No. 1 1981, pp. 164-73. 
products or conventional practices may represent innovations. When a firm has an existence outside a culture, many of its actions will introduce something new. There are many ways in which a firm may be an unwitting agent for transplanting aspects of one culture into another. ${ }^{142}$

Our very way of thinking can be culturally conditioned. Eastern cultures analyse in ideograms or visualisations, where as Western cultures tend to use concepts. Because a concept is a general notion or idea that combines characteristics known about a subject, it provides a framework for thinking or analysing a particular topic or experience. Cultural differences that can affect international business operations arise in all aspects of business activity and have their impact within each of the traditional functions. ${ }^{143}$ Differences in behaviour of customers must be taken into account in product policies and marketing strategies. The German housewife values convenience and can be rather easily persuaded to buy packaged soup. The French housewife prefers homemade soup because it fulfils her image of herself as the mother.

Differences in behaviour and values of employees can have a major impact on the effectiveness of production-management policies. The African and Indian factory worker, for example, may find paternalism a desirable practice because it helps replace security feelings that are lost when the worker leaves the tribal group. The American factory worker, on the other

142 K. Kumar, Iransnational Enterprises: Their Impact on Third World Societies and Cultures, (Boulder, Colorado: Westview Press, 1980), pp. 1-30.

143 "Culture is the sum total of an individual's experience and knowledge gained as a member of society. The experience and knowledge is gained from a number of areas which include religion, moral values, customs, law, art and influences that make an individual a complex whole." The various facets of this complex whole are inter-related in such a way that they operate as a system, that is, if a single aspect is changed it will affect the other parts and cause changes in the whole system. This system perspective of culture is important and the interrelated nature of culture should be understood. (Christopher T. Selvarajah and Katrin CutbushSabine, eds., op cit., pp.6-9). 
hand, tends to feel that paternalistic management is outdated because it restricts a need to express individuality. ${ }^{144}$

That cultures vary in their assumptions about the world has long been accepted by the anthropological community. While national cultural differences have tended to be ignored by management researchers, ${ }^{145}$ recently they have begun to be accepted by a subset of the management community. 146 Most notably, the Japanese style of management has been delineated as an alternative, contrasting, and highly effective approach, ${ }^{147}$ very different from the traditional American approach. It is asserted that the full range of human attitudes and behaviours exists within any society, but that each society favours certain behaviour over others. There is no single, universal pattern. ${ }^{148}$

The external relations of the international firm can also be strongly influenced by cultural variables. In dealing with local business firms in a

144 Stefan H. Robock, et al, 'individualism - collectivism' of G. Hofstede. op.cit., p. 313 and 'masculinity - femininity' and

145 Nancy J. Adler, "'Cross-Cultural Management: The Ostrich and the Trend," Academy of Management Review, Vol. 8, No.2, April 1983, pp. 226-32.

146 Geert Hofstede, Culture's Consequences: International Differences in Work-Belated Values, op. cit. "Motivation, Leadership and Organisation: Do American Theories Apply Abroad," $\mathrm{Op}$. cit., pp. 42-63; and Andre Laurent," The Cultural Diversity of Western Management Conceptions," international Studies of Management and Organization, Vol. XIII, No. 1-2, Spring/Summer 1983, pp. 75-96.

147 Richard Tanner Pascale and Anthony G. Athos, The Art of Japanese Management, (New York: Simon and Schuster, 1981) and William Ouchi, Theory Z , (Reading, MA.: AddisonWesley, 1981) and John L. Graham," The Influence of Culture on the Process of Business Negotiations: An Exploratory Study, Journal of International Business Studies, Spring 1985, pp. 81-96.

148 Talcott Parsons,"Suggestions for a Sociological Approach to the Theory of Organizations," Administrative Science Quarterly, Vol. 1, No. 1, 1956, pp. 62-85; - Theories of Society, (New York, NY.: Free Press, 1961) and Marvin Harris," The Sleep-Crawling Question," Psychology Today, May 1983, pp. 26-7. 
specific national environment, the international enterprise may have to recognise that agreements and accommodations among potential competitors, rather than aggressive competition, are the accepted norms. In raising money from the local banks or security markets, personal reputation may be the key requirement in one environment whereas a high degree of financial disclosure may be the more important element in another and yet in others a careful balance of both. 149

For the multinational enterprise the impact of cultural variables affects management at two levels - the national and the multinational. The issues at the national level might be referred to as bicultural. At the national level, the situation is largely of a "we and they" type. The manager of a subsidiary must be aware of possible conflicts between local conditions and the cultural assumptions underlying the business practices being imported. Essentially these problems are two sided, and management personnel of subsidiaries must be the bridge between the local situation and the international enterprise.

At the multinational level, or more specifically at the global or regional headquarters of the international enterprise, the task is to effectively coordinate and integrate business activities that are operating in many different cultural environments. Managers must deal with languages and across many cultures. The problems are both horizontal--across many cultures--and vertical--between each subsidiary and the headquarters. The organisational structure and policies of the global enterprise must facilitate communications that allow all regions to incorporate the global goals and the

149 lbid., pp. 313-4 and Sushil Vachani," Strategic Product Market Choices by Multinationals and Local Firms in a Newly Industrializing Country," (D.B.A, Thesis, Harvard University, 1985). 
implementation of policies across many cultures in order to achieve global goals.

\section{THE NEED TO ASSESS CULTURAL DIFFERENCES}

Culture appears in many layers: national culture is the shared mental programming of most members of a nation; organisational or corporate culture is the additional programming shared by most members of an organisation; and occupational culture is the programming acquired by those exercising a distinct profession like accountants or accounting professors. On the top of that one can think of a generation culture, a class culture, a family culture, and so on. 150

For the multinational corporation, managers of foreign operations tend to be less closely controlled by the head office, for no other reason than that distance precludes direct controls. The managers brought up and accustomed to a particular cultural system are required to interact with those brought up and familair with the cultural system of the host country. Cultural background affects the management style of the overseas managers which need to interface with the subordinates from a different cultural environments. There are possibilities that these two cultural systems may not be exactly supportive and totally sustaining for each other in all of their aspects.

The extent of the impact of cultural differences on international business makes quite clear the need for skills in cultural assessment on the

150 Geert Hofstede, "The Cultural Context of Accounting," Accounting and Culture, ed. Barry E. Cushing, (Sarasota, FL.: American Accounting Association, 1987), pp. 1-4 and C.J.J. Vermeulen and A. de Ruijter, "Dominant Epistemological Presuppositions in the Use of the Cross-Cultural Survey Method," Current Anthropology Vol. 16, No. 1, March 1975, pp. 29-52. 
part of the MNE's manager. The manager may never become an expert anthropologist, sociologist, or social psychologist in addition to her/his prime role as a management specialist, but $s /$ he should at least develop skills in assessing the key cultural elements that will have a direct bearing on his effectiveness as a manager and that of the firm.

Vern Terpstra151 identifies five factors to be considered in international business: Cultural Variability, that is the degree to which conditions within a macroculture are at a low or high, stable or unstable rate. The more turbulent the macroculture, for instance, the more unpredictable are the business operations. The internal structure and processes in that situation requiring rapid adjustment to change, would demand open channels of communication, and decentralised decision-making. Cultural Complexity - that is the issue of high and low context cultures which would help determine the type of approach (covert or overt) the corporation needs to take toward the macroculture. Cultural Hostility - the degree to which conditions locally are threatening to organisational goals, norms, values and so on. The indigenous environments may range from munificent to malevolent in terms of acceptability of MNE and its overseas staff.

Terpstra maintains that the previous three dimensions occur within culture, but that the next two can be observed among macrocultures. Cultural Heterogeneity -the degree to which cultures are dissimilar or similar. It is relatively easier to operate within a homogeneous culture but when a culture is diverse and disparate, then it is difficult for the corporate headquarters to coordinate the behaviour of subsidiaries, its managerial personnel and other

151 v. Terpstra., The Cultural Environment of International Business, (Cincinnati, Ohio: South-Western Publishing Co., 1978). 
staff. Cultural Independence - the degree of sensitivity of the culture to respond to conditions and developments in other cultures. This may range from economic dependence on other nations for raw materials, supplies and equipment, to adaptation and adoption of new technology and processes from other interacting cultures, to being subject to scrutiny in the host culture for attitudes and actions that occurred on the part of the corporation in another culture.

There is no one method to adopt in making cultural assessment as a basis for specific business decisions. Business problems cover such a wide range that the methods used may extend from a narrow-depth study of receptivity to a new management practice through to a broad assessment of a society's attitudes to spending. Attempts have also been made to focus on organisational culture as opposed to exogenous cultural environments. 152

\section{METHODOLOGIES FOR ASSESSING CULTURAL DIFFERENCES}

For at least the last thirty years or so, the literature has yielded diverse positions on the transferability of modern management principles into different cultures. A review of research shows that most cross-cultural studies are actually cross-national studies which means comparing socio-cultural, political, and economic systems not just culture. Two of the more important models are described in terms of the role of culture-the Farmer-Richman

$152 \underline{\mathrm{lbid}}, \mathrm{p} .316$, Yosup Lee,"A Comparative Study of Manager's Perceptions in Korea and the United States on Selected Socio-Cultural Dimensions," (Ph.D. Dissertation, Claremont Graduate School, 1982), pp. 157; Farhad Fassihi Harandi," A Comparative Study of Cultural Attitudes Underlying Management Practices of Iranian and American Managers,"( Ph.D. Dissertation, United States International University, 1984), pp. 161 and Sally Wallace, "Ihe Culture of an Organisation: A Case Study," (Ph.D. Dissertation, Marquette University, 1986), pp. 235. 
model and the Negandhi-Prasad model. These models identify management as a dependent variable, and as an independent variable respectively. ${ }^{153}$ Evidence from the research studies conducted so far suggest the viability of Farmer and Richman's position on the role of culture in the formation of managerial attitudes and not the position of Negandhi-Prasad model. This does not negate the importance Negandhi places on other contextual variables such as organisation size, technology, location, and market position. 154

For the purpose of this model we shall construe culture as an independent factor. The two common methods of assessing cultural differences available to researchers are the partial and comprehensive approaches. The partial approaches are relatively less powerful than comprehensive approaches that attempt to identify and classify an entire range of cultural differences.

\section{Partial Approach}

The most common methodology of cultural assessment is a partial one confined to studying particular aspects of a culture. The immense number of elements that can vary between cultures, however, makes overall (comprehensive) approaches extremely unwieldy and costly to use. A

153 R. Farmer and B.A. Richman, "A Model for Research in Comparative Management," California Management Review, Vol. 4 No. 2, 1964, pp. 55-68; C.J.J. Vermeulen and A. de Ruijter, "Dominant Epistemological Presuppositions in the Use of the Cross-Cultural Survey Method," op. cit., and A.R. NeGandhi and B. Prasad, Comparative Management, (New York, NY.: Appleton-Century-Crofts, 1971).

154 Lane Kelley and Raginald Worthley, "The Role of Culture in Comparative Management: A Cross-Cultural Perspective," Academy of Management Journal, Vol. 24, No.1, 1981, pp. 164-173 and E. Harari and Y. Zeira,"Attitudes of Japanese and Non-Japanese Employees: A Cross-National Comparison in Uninational and Multinational Corporations," International Journal of Comparative Sociology, September-October 1977, pp. 3-5. 
compromise, often used by social anthropologists, is to compose a word picture of some constrained slice of behaviour in the culture being examined, emphasising, as would an artist, the more significant elements in the subjects. Examples of such word pictures would be a description of a day in the life of a typical consumer 155 or a typical day of a producer.

In examining cultural patterns the managers should be aware of similarities as well as differences. Cross-cultural analysis for multinational business tends to emphasise differences because they are likely to create business problems. But to err by perceiving more differences than actually exist can also cause serious problems. For instance, an American executive may see the Japanese as less risk-taking while some of the studies suggest that they are alike. 156 Often times similarities could cause problems due to previous conceptions of the new culture.

Another general caveat is that observed cultural patterns may be representative of a national group yet not applicable to everyone in the group. What is usually being discussed is a modal pattern, and considerable variation from the mode will exist within a group or a subset (sub-culture) of the group. In fact, for some cultural traits there may be a wider range within a given society than between societies. Care needs to be exercised to define the limits of the group one is interested in and still be cognisant for individual differences. 157

155 Oscar Lewis, Five Families: Mexican Case Studies in the Culture of Poverty, (New York, NY.: Basic Books, Inc., 1959).

156 Bernard M. Bass, The American Adviser Abroad, Technical Report 27, Management Research Centre of the College of Business Administration, (Rochester, New York: University of Rochester, August, 1969), p.12

157 Stefan H. Robock et al , op. cit., pp. 315-17. 
Whatever the scope of the variables included in a cultural assessment, the assessment may be either static or dynamic. A static assessment serves only to identify the differences in variables between cultures. A dynamic assessment seeks to indicate which variables will change and perhaps in what order and with what speed. For the MNE engaged in cross-cultural transfers of products, practices, and ideas, the identification of what changes will be readily accepted and what will be rejected can mean the differences between success and failure. 158 In other words the awareness of these variations and likely pace of change thereof will decidedly have a significant impact on the proposed training of personnel, efforts at motivations, encouragement for innovation and for the initiative, extent of decentralisation, and the like. 159

\section{Some Significant Aspects}

It would be impossible to list and evaluate any significant proportion of the cultural variables that could have a major impact on an MNE manager (management). Accordingly this section will be devoted to the consideration of only a few of those traits which are perceived to be fundamental in the MNE's management and tend to vary greatly among cultures.

158 lbid., p. 315 and Stephen Ayres Nunes," Toward a Theoretical Framework for CrossCultural Training Programs," (Ed.D. Thesis, The Florida State University, 1987), pp. 210.

159 Bruce W. Stening and Mitchell R. Hammer,"Cultural Baggage and the Adaption of Expatriate American and Japanese Managers," Management International Review, Vol. 32 , 1992, pp. 77-89; Mark Mendenhall and Gary Oddou," Acculturation Profiles of Expatriate Managers: Implications for Cross-Cultural Training Programs," op. cit. pp. 73-9; J. Hayes and C.W. Allinson," Cultural Differences in the Learning Styles of Managers," Management International Review, Vol. 28, No. 3, 1988, pp. 75-80 and Chris Hendry, "HRM in Internationalisation and Domestic Business Management: Is There Any Difference," Research Paper No. 63, Warwick Business Research Bureau, 1992, pp. 1-23. 


\section{Attitude Toward Work and Achievement ${ }^{160}$}

The dominant view in a society toward wealth and material gain can have a significant bearing on the types, qualities, and numbers of individuals who pursue entrepreneurial and management careers as well as on the way workers respond to material incentives. ${ }^{161}$ In most countries in the world, wealth tends to be considered desirable and the prospects of material gain operates as a significant motivation. But there are societies where workers will be on the job until they earn a certain amount of money and then be absent until these earnings are exhausted. In some affluent societies, moreover, young people are becoming more inclined for job satisfaction, per se, than in straight financial rewards. 162

Variations among cultures in the dominant views toward work and achievement, which can be a vital determinant of managerial performance and productive efficiency, have been the subject of considerable research under the title "achievement motivation" by David C. McClelland.163 That is, a willingness to commit oneself to the accomplishment of the tasks considered to be worthwhile and challenging. An achievement motivated person makes

160 Peter J. Dowling and Trevor W. Nagel, "The Influence of Culture on Work Attitudes: A Study of Australian and American Threshold Managers," Working Paper No. 1, The Graduate School of Management, The University of Melbourne, May 1985, pp. 1-26.

161 Richard Farmer and Barry M. Richman, Comparative Management and Economic Progress, (Bloomington, Ind., Cedarwood Press, 1965), pp. 177-90.

162 Stefan H. Robock et al, op. cit., p. 318 , and John J. Dugan," The Belationship Between Culture and Managers' Behavioural Decisions: A Two Country Study of the Preference Formation and Choice Processes," (Ph.D. Dissertation, Temple University, 1984).

163 David C. McClelland, The Achieving Society, (Princeton, New Jersey: D. Van Nostrand Co., 1961). 
accomplishment an end in itself. He does not reject tangible rewards, but they are not essential. 164

Cultures also differ on the basis of the their members' attitudes relating to a man's ability to influence the future. For instance, an assumption that people can substantially influence the future underlies much of U.S. management philosophy. The notion of self-determination or "master of destiny" attitude relates the necessary hard work with the accomplishment of realistic future goals, the belief which underscores the relevance and importance of long range planning that the future can be influenced. On the other hand this "master of destiny" concept may not sit well with a fatalistic viewpoint in some Moslem cultures and some religious sects in Asia. Still it differs from a mythical view that events are likely to be determined by the capricious influence of spirits that must be appeased. 165 Obviously in these types of cultures the U.S. managerial personnel would have an uphill task to install a dependable planning system and instil the basic rudiments of motivation.

Also the extent to which objective analysis is used for decision making varies among cultures. There are strong culture goals underlying U.S. management practices that decisions should be based on objective analyses of the facts and all persons who can contribute pertinent information should do so. This practice invariably results in large collections of data and somewhat impersonal decision making. On the other hand decision making on a factual and rational basis may not be a regular practice in many cultures. The

164 Stefan H. Robock et al op. cit., p. 318.

165 William H. Newman, "Is Management Exportable?" Columbia Journal of World Business, January-February, 1970, pp.7-8. 
personal judgement of a senior executive may be enough by way of a go ahead. To ask a senior personnel for the reasoning or substantiation of his decision may tantamount to lack of faith in his ability. Also the senior may be perceived as being unsure if he attempts to ask information from others and solicit their opinion-especially juniors. In such cultures, hierarchical, emotional, and mystical considerations, rather than objective analyses seem to dominate decision making. 166

\section{Attitude toward Authority and Subordinate}

The dominant view of authority in a society may range from an autocratic system at one extreme to a democratic-participative system at the other extreme.167 If authority is looked upon as an absolute natural right of management or of other types of formal leaders, the effect on managerial behaviour would typically be a high degree of centralisation and little or very little delegation of authority. At the other extreme, managerial authority would be shared with subordinates and workers, and considerable decentralisation in decision making may result. 168

It may be futile to state which forms of managerial authority along this continuum are best in terms of efficiency or in being effective. The forms vary from Japan to West Germany to Yugoslavia to the United States. Yet each of

166 Stefan H. Robock et al, ㅇp. cit., pp. 318-9.

167 T.A. Martyn-Johns," Cultural Conditioning of Views of Authority and Its Effect on the BusinessDecision-Making Process with Special Reference to Java," in Basic Problems in CrossCultural Psychology, ed. Y.H. Poortinga, (Amsterdam: Swets and Zeitlinger, 1977), pp. 344-52 and J.C. Abegglen," Subordination and Autonomy Attitudes of Javanese Workers," American Journal of Scoiology, Vol. 63, No. 1, 1957, pp. 181-9.

168 bid., p. 319-20 
these countries has had impressive records of business performance and economic growth in recent years. It may be sufficient to state that whatever authority system prevails in a given country, the multinational enterprise management will have to relate its management patterns/paradigms to the expectations and traditions of local employees to attain optimum results. 169 The knowledge of prevalent cultural patterns in this respect will also accrue benefits when negotiations are to take place with government officials and other important civic personalities.

Akin to communication and language a feature which invariably assumes significance is the expression of disagreement. In Far Eastern cultures it is traditional to value politeness over blunt truth. The Japanese businessmen find it difficult to say "no" in many situations. In many situations "will think about it" may mean "no" while in others it may mean it deserves serious consideration and may result in an affirmative answer. In many Latin American countries expressing a disagreement with the boss may be construed as a personal attack and may not be taken up easily. Persons in subordinate positions are expected to either present information or judgements that support the ideas of senior personnel or be silent.

Cultures also differ with respect to family ties. Strong and extended family ties can result in what has been termed as patrimonial management. 170 This obviously may breed nepotism and result in staffing all strategic positions with relatives and friends. The system is a mixed blessing. It fosters teamwork,

169 lbid.

170 Frederick Harbison and Charles A. Myers, Management in the Industrial World, (New York, NY.: McGraw-Hill Book Co., 1959), pp.69-75. 
loyalty and mutual interest, but may breed sluggishness and limit the supply of qualified managers.

Cultures may also show their distinctiveness on their social structurestheir main elements and pervasiveness thereof. These structures may include variables such as interclass mobility, patterns of education and the like. Despite making an assumption that all men are equal, many societies have traditional systems of ranking individuals and groups. The relative positions in the social hierarchy are based on ethnic,171 cultural, educational, and linguistic differences as well as on economic position. Some are rigid like the caste system in India while in some cases the system may not be rigid and interclass mobility may be easy. Class relations are relations of power. The concept of class and power are akin, in that the place in which they are constituted is the field bounded by social relations. Class relations are no more the foundations of power relations than power relations are the foundations of class relations. ${ }^{172}$ Nevertheless there is a discernible distinction between the elite and those who fall under 'have-nots."

Anglo cultures (e.g. Australia, Canada, New Zealand, U.K. and U.S.) were found in the survey carried out by Hofstede ${ }^{173}$ which was mentioned earlier, as representing low power distance, high individualism, high masculinity and low uncertainty avoidance. On the other hand Asian countries

171 J. M. Feldman, I.A. Sam, W. F. McDonald, and G.G. Bechtel, "Work Outcome Preference and Evaluation: A Study of Three Ethnic Groups," Journal of Cross-Cultural Psychology, 1980, pp. 444-68.

172 Nicos Poulantzas, Political Power and Social Class, Trans. by Timothy O'Hagan, (London: U.K.: NLB and Sheed and Ward, 1973), pp. 99-104.

173 G. Hofstede, Culture's Consequences: Values, op. cit. 
(e.g. Japan, Korea, and Muslim countries) exhibit large power distance with strong uncertainty avoidance.

Hofstede174 in his presentation at the Plenary Session at the American Accounting Association on Accounting and Culture, quoted one of his American Colleagues who taught at INSEAD international business school in France. The friend used their individual term papers based on one and the same case study, a conflict between two departments in an organisation. The students were asked to determine what was wrong and what should be done to resolve the problem. The French in majority referred the problem to the next higher authority level. The Germans suggested the setting of the written rules to resolve such problems in the future. The British wanted to improve communication between the two department heads, perhaps by some kind of human relations training. The friend concluded that the dominant underlying model of an organisation for the French was a pyramid, a hierarchical structure held together by unity of command (large power distance- as well as by rules (strong uncertainty avoidance). The model for the Germans was a well-oiled machine; the exercise of personal command was largely unnecessary because the rules settled everything (strong uncertainty avoidance but small power distance). The Model for the British was a village market, no decisive hierarchy, flexible rules, and a solution of the problem by negotiating (small power distance and weak uncertainty avoidance).

The understanding and appreciation of the national value systems deservedly plays an important role in MNE's overseas operations as it may become awfully difficult to accomplish managerial effectiveness if the social 
structure inhibits the interclass mobility. ${ }^{175}$ The problem may not stay confined to internal management it may make the actual work of doing business more difficult if doing a business (or a particular business) has been assigned a low priority. Hall and Amado-Fischgrund stated .... "that the British social system, although much more flexible than it was a few decades ago, still assigns great importance to family and university background when individuals are being considered for high-level positions in government and business." 176

Educational patterns generally reflect and reinforce patterns of class mobility and status. Where class mobility is high and status depends upon merit rather than family name or caste, the educational system, is likely to be open to students on the basis of their performance, and training in technical and managerial fields is available.

\section{Structure/Institution}

These two concepts must be clearly distinguished. By institution it is meant a system of norms and rules which is socially sanctioned. The concept of institutions must not therefore be reserved for juridico-political institutions alone, since the company, school, church, etc., also constitute institutions. (This " reserved" sense is current and is even often admitted by Marxism, in a notion of superstructural institutions). On the other hand, the concept of structure covers the organising matrix of institutions. Through the functioning

175 George Shouksmith, Cross-Cultural And Occupational Group Differences in Leadership Style, Occasional Papers in Psychology, No. 6, (Palmerston North, New Zealand: Massey University, 1981), pp.1-9.

176 David J. Hall and Gilles Amado-Fischgrund,"Chief Executive in Britain," European Business, January, 1969. 
of the ideological, the structure always remain hidden in and by the institutional system which it organises. It must be added that structure is present in an allusive and inverted form in the institution itself, and it is in the reiteration of these successive, hidden presences that one can discover the principle of elucidation of the institutions. 177 One must not lose note of this when venturing to assess the legal system and other related norms prevalent in other cultures.

\section{Comprehensive Approaches to Cultural Assessment}

Although there may well be a justified temptation to focus on individual elements of cultures that have a direct bearing on the managerial effectiveness, yet a familiarity with one or two ways in which an overall culture can be conceptualised would certainly accord a framework on which to draw the picture of specific culture. Hitherto, two overall (comprehensive) approaches have been attempted, both two dimensional and both widely quoted in the relevant literature.

The first overall approach has been developed by Edward T. Hall 178 while the second one is built on an attempt made by Farmer and Richman. The latter is a cultural framework ${ }^{179}$ specifically related to business decision making.

177 Nicos Poulantzas, Political Power and Social Class, , op. cit., pp. 115-6.

178 Edward T. Hall, The Hidden Dimension: The Silent Lanquage, op. cit., chap. 3.

179 Richard N. Farmer and Barry M. Richman, Intemational Business, op. cit., pp. 80-3. 
Hall presents his map of culture as a two dimensional matrix composed of 10 aspects of human activity which he calls Primary Message Systems. These are presented in the Table 3.1. Hall shows that how a grasp of the complex relationships of a culture can be obtained by commencing with any of these 10 aspects and studying its interaction with each of the others. In a matrix there will be two interactions of each pair of aspects. Both aspects will differ from culture to culturea and this may have a more direct application in International business, and management of MNEs. 


\section{PRIMARY MESSAGE SYSTEMS 180}

\section{Primary Message System}

1. Interaction

2. Association

3. Subsistence

4. Bisexuality

5. Territoriality

6. Temporality

7. Learning

8. Play

9. Defense

10. Exploitation
Depicts Attitudes and Cultural

Rules for:

The ordering of man's interaction with those around him, through language, touch, noise, gesture, and so forth

The Organisation (grouping) and structuring of society and its components

The ordering of man's activities in feeding, working, and making a living

The differentiation of roles, activities, and function along sex lines

The possession, use, and defense of space and territory

The use, allocation, and division of time

The adaptive process of learning and instruction

Relaxation, humour, recreation, and enjoyment

Protection against man's environment, including medicine, warfare and law

Turning the environment to man's use through technology, construction, and extraction of materials.

Farmer and Richman also used a matrix approach. They proposed a four-group list comprising of 29 critical environmental constraints, or cultural elements as follows:

180 Edward K. Hall, The Hidden Dimension. The SilentLanquage, (Garden City, New York: Doubleday \& Company, Inc., 1966, 1959), pp. 6-80. 
TABLE 3.2

\section{ENVIRONMENTAL CONSTRAINTS 181}

\section{Educational:}

1. Literacy level

2. Specialised vocational and technical training and

general secondary education

$3 . \quad H i g h e r$ education

4. Special management development programs

5. Attitude toward education

6. Education match with requirements

\section{Sociological Characteristics:}

1. View toward industrial managers and management

2. View toward authority and subordinates

3. Interorganisational cooperation

4. View toward achievement and work

5. Class structure and individual mobility

6. View toward wealth and material gain

7. View toward scientific method

8. View toward risk taking

9. View toward change

\section{Political and Legal Characteristics:}
1. Relevant legal rules of the game
2. Defense Policy
3. Foreign Policy
4. Political stability
5. Political organisation
6. Flexibility of law and legal changes

\section{Economic Characteristics:}
1. General economic framework
2. Central banking system and monetary policy
$3 . \quad$ Fiscal policy
4. Economic stability
5. Organisation of capital markets
6. Factor endowment
7. Market size
8. Social overhead capital

181 Richard N. Farmer and Barry M. Richman, International Business, II Ed. (Bloomington, Indiana: Cedarwood Press, 1974). pp. 80-3. 
Against these they set another list of 77 critical elements in the managerial process. The general categories for the critical elements are planning and innovation, control, organisation, staffing, direction, leadership and motivation, marketing policies, production and procurements, research and development, finance, and public and external relations and each with their own specific elements. They suggest a number of uses for their methodology that range from measuring system-wide efficiency to evaluating local constraints. In a particular sense it could be used to rate the relative environments of different countries as they contend that managerial effectiveness is largely determined by the pattern of external constraints. As the environment changes, so too must the pattern of management. What might be effective in producing results in one culture may be completely ineffectual in another. Russell182 found in his research study that associated with an increased level of organisational effectiveness are a degree of decentralisation, environmental uncertainty, and innovation-related norms. And that increased level of external uncertainty (moderated by organisational structure) apparently contributes to a higher level of innovation.

Davidson 183 posited, ". . . that a recent trend in international management research has been the develooment of continaency modes that

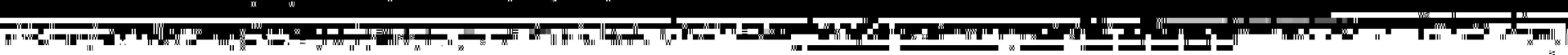


market and industry conditions, but also by internal aspects of the firm's administrative orientation", i.e. the MNE's philosophy and its constant interface with local staff. The data and results obtained pointed to the complexity of trade-offs between centralised and decentralised management. That centralised firms exhibit lower sales growth but higher profit growth than their decentralised counter parts as they show relatively less responsiveness to market and lack entrepreneurial skills.

A subsidiary manager responsible for a division in a country with a higher overall environmental rating would be expected to obtain a higher level of performance rating than managers operating in environments with lower ratings. For instance Farmer and Richman suggest that the Delphi technique could be used to develop ideal weights for each environmental constraint. The same technique could also be used to weigh the same constraints in various countries.

The differences between ideal and actual represent the degree of environmental difficulty with which the manager must cope and accordingly must be accorded some consideration at the time of performance measurement and evaluation to sustain a valid objective and acceptable consensus. It is also likely that by examining the managerial alternatives against the background of external constraints, managers will move toward a pattern of business practice most appropriate to the situation and away from absolute rules, which are conceived as a generalisation and hence cannot take into account in every particular situation.

However, there are a number of difficulties with their approach. First, the task of quantification using the Delphi technique to rate all the constraints 
is expensive and time consuming. Second this approach ignores the interrelationship between environmental constraints and firm-specific functions. Thus, it becomes impossible to quantify the effects of various environmental constraints on performance measures. A more efficient approach would be for a multinational corporation to determine which particular management functions are more critical to the operating performance of a subsidiary, 184 and which of the prevalent cultural factors might have a significant impact.

\section{THE HYPOTHESES}

It has been indicated earlier that the profit centre concept cannot stand alone as a measure of the performance of managers of a MNE, primarily because the corporate headquarters of the firm rather than the subsidiary manager makes most of the major decisions affecting the profitability of the subsidiary. 185 The similar problems may arise even in the case of the Return on Investment (ROI) concept. No clear relationship between authority and responsibility exists under these conditions. As a matter of fact, each manager is encouraged to make decisions which may benefit other subsidiaries, as long as those decisions maximise the overall profit of a MNE. Therefore, other means for evaluating managerial performance throughout the global system need to be pursued.

184 Helen G. Morsicato and Michael A. Diamond, "An Approach to "Environmentalizing" Multinational Enterprise Performance Evaluation Systems," The International Journal of Accounting:Education and Research, Vol. 16, No. 1, Fall, 1980, pp. 247-66.

185 Robert S. Kaplan, Advanced Management Accounting, (Englewood Cliffs, New Jersey: Prentice-Hall, Inc., 1982), pp. 438-342. 
Given the different environments under which a MNE conducts its operations, it is only logical that a multidimensional system be utilised to evaluate the performance of its managers or its subsidiaries. This system may be sub-divided into both financial and non-financial sub-systems. Financial sub-systems utilise the responsibility accounting concept including comprehensive budgeting in order to better evaluate the performance of managers of a MNE. Non-financial sub-systems would involve the measurement and reporting of such attributes as managers' attitudes, cooperation, and motivation. All these attributes are affected to varying degrees by the environments of the place where the MNE manager is posted. In order to have an optimum performance measurement model one must opt for the comprehensive methodology so as to embrace all the cultural variables along with the normal managerial functions. ${ }^{186}$ The comprehensive format could show the relative effects of cultural factors on various managerial functions individually and interactively across different regions/countries of the world.

However, in the light of the time and other constraints it was proposed to carry out this study using the commonly followed methodology: a partial approach. Accordingly, this study has focused on twelve cultural factors (Table 1.1) selected from the 29 given by Farmer and Richman (Table 3.2). These are held to be very pertinent for the managerial functions and the

186 Sigma Can," Non-Financial Indicators in Performance Evaluation of Multinational Enter-prises: Exploring the Use of Fuzzy Outrankina Relations," (Ph.D. Dissertation, University of Illinois at Urbana Champaign, 1988), pp. 245. In this study an effort was undertaken to develop a performance evaluation model that relates non-financial indicators such as (i) total productivity growth index; (ii) change in the number of employees index ; (iii) the market share growth index to return-on-investment and to determine the temporal relationships as well. An attempt was also undertaken to utilise multi-criteria fuzzy outranking relations to appraise the performance of MNE with a view to gain some insight as regard to the manager's perception of different activities. However these indicators are quantitative and more in the form of outputs/outcomes, while the emphasis in this research is on input variables which are qualitative in character. 
effectiveness thereof, both explicitly and implicitly. Although, Farmer and Richman provided a list of 77 critical elements in managerial process, but this study adapted eight (Table 1.2) from the already adapted list of dimensions of managerial performance used by Richard Fleming ${ }^{187}$ (and added a few others), through carrying out a survey (Appendix F).

The following chapter provides the details of the proposed hypotheses, the rationale for the research design and methodology, development of relevant questionnaires for overseas managers and their evaluators, pretest and pilot study. The chapter also provides detailed reasoning and explanations for adopting a particular set of statistical analyses and tests, together with their assumptions and limitations. The chapter also narrates the details of data collection and presents the descriptive results of the survey.

187 Richard John Fleming, op. cit., pp. 66-70. 


\section{CHAPTER IV}

\section{RESEARCH DESIGN, METHODOLOGY AND DATA COLLECTION}

\section{INTRODUCTION}

This chapter presents in detail the reasoning for the research design and methodology adopted for the collection and analysis of the data for this study. It also provides the details related to the different phases of the study: initial contact, selection of subjects to be studied, proposed questionnaire, pretest and pilot study, transmittal of questionnaires, and collection of data. The chapter also includes the list of countries from which responses were received and presentation of descriptive statistics relating to the participating MNCs from the chosen five regions.

\section{INITIAL CONTACT}

Executives involved with international operations at the headquarters of MNCs were selected for initial contact. These executives were contacted by telephone in order to assess the feasibility of this study and to obtain their commitment for co-operation.

As an initial step, a few corporations were randomly selected from the 100 largest MNCs for contact. ${ }^{1}$ Eleven executives in charge of overseas

1 Forbes, April 30, 1984, pp. 286-326. 
personnel were contacted. The main contents of the study were explained to these executives to solicit their views related to the feasibility of the study and seek their co-operation in the subsequent stages of the contemplated endeavour. From amongst those contacted five executives agreed to provide their enterprises' support for this study by assuming the responsibility of sending out the questionnaires to their overseas executives along with a cover letter stating the purpose and usefulness of the survey. The responses from overseas executives were to be addressed directly to the researcher. The same (five) executives have shown their enthusiastic support and commitment to provide information pertaining to performance evaluation on a regional basis. Overall, it was felt that the first phase, i.e., initial contact had accomplished its intended purpose, i.e. the assessment of the feasibility of the study and several firms' commitment of co-operation.

\section{FORMAT OF STUDY AND SELECTION OF PARTICIPANTS}

Keeping in mind the time and resource constraints, it was proposed to limit the study to only a few multinational enterprises and their U.S. executives working overseas. Additionally, as this research study was of an exploratory nature, it was contended that it would help us learn enough from a few specific case studies, and would also enable interested persons in the future to develop pertinent hypotheses ${ }^{2}$ for the variables and features covered under this study.

2 Edwin H. Caplan and Joseph E. Champoux, Cases in Management Accounting: Context and Behavior, (New York: National Association of Accountants, 1978), pp. 1-10. 
The study did not make use of a formal control group to identify and analyse the effects of region-specific cultural factors. The likely confounding of organisation-specific culture's effects with region-specific culture's effects was guarded against by the following reasoning.

Firstly, the effect of organisation-specific culture is likely to be minimal as there are ten multinational organisations which one may contend might have neutralised the specific effects of an individual organisation's culture by being in a group. Secondly, the endeavour of comparing the managers' responses with those from evaluators on a regional basis also underscores the fact that the evaluators group could well be taken as a control group.

Thirdly, from a slightly different angle one could also argue that by being members of the group comprising ten MNCs the managers of individual regions may be taken as acting as control groups for the others. The organisations being common in two regions, the impact of the organisationspecific culture may also be common, hence other things being equal one can successfully contend that the differences in their perceptions for the effects of cultural factors on their performance (and its aspects) are on account of distinct regional cultural factors. This, however, will highlight differences between regions but not for a region for the US overseas managers per se unless the comparison is undertaken with the evaluators.

The case study format was considered but not proposed for this study as there were doubts about the availability of matched data for the U.S. overseas managers. The case method suffers from the limitations which pertain to the fact that the information obtained is scientifically weak and often 
completely unacceptable. ${ }^{3}$ Even if objective measures are relied upon, the case study does not control for factors that might account for the same patterns of results. ${ }^{4}$ Also, as the thrust of this study was more towards hypothesesgeneration rather than hypotheses-testing, it was felt appropriate not to make use of the case method of analysis. ${ }^{5}$

This study's format of exploratory research evinces a few concerns with regard to the validity of findings when compared with a comprehensive field of study. These weaknesses may arise because of the number of subjects chosen, the perceived lack of adequate representation and the randomness of selection. However, it is contended that the amount of information, which is rich in description and details, certainly helps establish a link between the few

${ }^{3}$ A major concem about the information derived from a case study is the generalisabilty to other situations. Scientific research attempts to establish relationships between independent and dependent variables. Although such relationships may be demonstrated for an individual case, the assumed purpose of science is to develop general "laws" of behaviour that hold without respect to the identity of any case. The goal of science lies beyond uncovering idiosyncratic laws about different cases these laws would not permit development of a general science. Alan E. Kazdan, Research Desian in Clinical Psychology, (New York, NY.: Harper \& Row, Publishers, 1980), pp. 9-30. Further, it has also been remarked, "... never assume that we can argue from the truth of singular statements to the truth of theories, never assume that by force of verified conclusions, theories can be established as true or even as merely probable." Karl R. Popper, The Logic of Scientific Discovery, (Hutchinson of London, 1969), p.33.

4 Alan E. Kazdan, lbid.

5 Hypotheses are used differently in various research methods. Experimentation is primarily a hypothesis-testing method. Experimenters derive a hypothesis from a theory, design an experiment, and gather data to test the hypothesis. Participant observation is primarily a hypothesis-generating method. Participant observers record their observations and begin to create hypotheses and develop a theory to explain the data. Hypothesis testing is deductive research while hypotheses generating is inductive research. The former proceeds from hypotheses to data, the latter from data to hypotheses. In practice researchers do both. Participation observers create hypotheses from their data, but they also began their data collection with some hunches that serve as hypotheses to guide their work. Experimenters may test some of the hypotheses they began with but then develop new hypotheses when they see the data. Seldom is research purely deductive or purely inductive. (Louise H. Kidder, Besearch Methods in Social Relations, 4th Ed., (New York, NY.: Holt, Rinehart and Winston, 1981), pp. 811. 
selected subjects and more general conditions and hence, the pertinent research propositions. 6

Though the limited size of the sample raises issues about the validity of the conclusions, the format of this study does not preclude us from appreciating its contributions - both in terms of findings and in providing a model for future research. ${ }^{7}$

There is a conspicuous lack of information relating to overseas personnel of U.S. multinational enterprises. Neither statistical directories, nor statistical data banks maintained by institutions seem to possess or even have access to information pertaining to U.S. overseas executives.

Without a direct source of information it was considered necessary to rely on other sources, such as contact with selected MNC headquarters. As noted earlier, some of the MNCs do not send U.S. managers abroad but use local talent.

In addition, as this study proposed to focus on five regions: Europe, Middle East, Far East, Africa, and Latin America (for reasons cited in Chapter I) it was proposed to contact only those enterprises which have officers in these

6 Lawrance R. Jauch, Richard N. Osborn, and Thomas N. Martin, "Structured Content Analysis of Cases: A Complementary Method for Organizational Research,"Academy of Management Review, 1980, Vol. 5, No. 4, pp. 517-25.

7 Edwin H. Caplan and Joseph E. Champoux, op. cit., pp. 2-5. 
regions. (Information on these was available in the Directory of American Firms Operating in Foreign Countries. Vol.l. 1 . and III). ${ }^{8}$

As stated earlier, a few MNCs were randomly selected from the Forbes top 100. But it was decided that a more broad based sample (stratified) would better represent the population and hence MNCs not in the Forbes top 100 were also included based on their (willingness) commitment to assist in this endeavour. Contacts by telephone were established with executives in charge of international personnel placements for these enterprises. The responses were encouraging and a few committed at their own to co-operate in this study. However, keeping in mind the administrative expediency and constraints in terms of time and resources, it was decided that the specific study be conducted on a few selected MNCs only. The criterion for choosing these enterprises from amongst those who showed their enthusiasm and willingness to co-operate, was the greatest coverage of geographical regions and largest numbers of U.S. executives working overseas.

As this study proposed to explore the impact of specific foreign cultural factors on the performance of U.S. executives, the non-U.S. executives working overseas in the selected MNCs were not contacted. Also, as it was an exploratory study it seemed appropriate that all of the U.S. overseas executives of the chosen MNCs be surveyed through questionnaires to solicit their views about the impact of the selected foreign cultural factors on their performance.

8 Directory of American Firms Operating in Foreign Countries. 9th Edition. Vold. ll. and 11 , (New York: World Trade Academy Press Inc., 1984). 
On the basis of the promised support and commitment shown toward the usefulness of this study by the personnel contacted at corporate headquarters, it was believed that an adequate number of responses would be forthcoming from the overseas personnel. The executives in charge of the evaluation of performance of overseas managers were provided with five sets of questionnaires - one for each region of response. The executives contacted agreed to fill these out and also provide time for follow-up interviews.

\section{RESEARCH OBJECTIVES OF THE STUDY}

The research endeavour proposed to study the perceived and considered effect of twelve foreign cultural factors on the eight specific aspects of performance of the U.S. overseas managers of the selected five regions. The specific objectives of this study were to:

(1) Ascertain the views of U.S. managers working overseas about specific foreign cultural factors.

(2) Determine the effect and direction of these specific cultural factors as perceived by the U.S. Managers working overseas on their performance.

Also to check if there are any variations in the perceived effects of these cultural factors on any aspect of managerial performance which are jointly accounted for by more than one cultural variable which are interrelated (that is, to test for multicollinearity).

Ascertain as to which aspect/s of performance is relatively more responsive to a cultural factor and in which direction.

(3) Ascertain the views of evaluator/s at corporate headquarters about these specific foreign cultural factors.

(4) Determine the consideration given to the impact of these specific foreign cultural factors by the evaluator/s in evaluating the performance of U.S. executives working overseas. 
(5) Ascertain the similarities and differences among the views of overseas managers and evaluators about these specific foreign cultural factors.

(6) Measure the similarities and differences in the perceptions of overseas managers about the impact of these specific foreign cultural factors on their performance and the consideration accorded to the impact of these specific foreign cultural factors by the evaluators in evaluating the performance of U.S. executives working overseas.

(7) Ascertain the similarities and differences among the views of the U.S. overseas managers of the five selected regions regarding the specific foreign cultural factors.

(8) Explore the differences (if any) in the perceptions of overseas managers about the impact of these foreign cultural factors on performance on a regional basis. Also identify those foreign cultural factors (if any) which are perceived to have a distinct impact on the specific aspects of performance of U.S. executives working overseas on a regional basis (based on responses of overseas managers).

\section{HYPOTHESES}

The following null hypotheses were formulated in accordance with the previously stated objectives of the study: (Numerals in parentheses correspond with those of objectives).

(2) $\mathrm{H} 1$

No hypothesis is proposed

There is no difference among the mean scores representing the general perception and impact of a specific cultural factor on eight different aspects of performance as viewed by the U.S. managers working overseas. (There are twelve hypotheses, one for each of the twelve foreign cultural factors).

$\mathrm{H} 2$ There is no difference among the mean scores representing the impact of twelve selected foreign cultural factors on an individual aspect of performance as viewed by the U.S. managers working overseas. (There would be eight hypotheses, one for each of the eight selected aspects of the performance). 
(3) \& (4) No hypotheses are proposed as only a few responses representing the views of performance evaluators would be forthcoming.

(5) H3 There is no difference between the mean scores representing the view of the U.S. managers working overseas and performance evaluators regarding twelve selected foreign cultural factors.

(6) $\mathrm{H} 4$ There is no difference between the mean scores representing the views of the U.S. managers working overseas and performance evaluators regarding the impact of twelve specific foreign cultural factors on the selected eight aspects of performance.

(7) H5 There is no difference among the mean scores representing the views of the U.S. managers working in the five selected overseas regions regarding twelve specific foreign cultural factors.

(8) $\mathrm{H} 6$

There is no difference among the mean scores representing the views of the U.S. managers working in the five selected overseas regions regarding the impact of twelve specific foreign cultural factors on the selected eight aspects of performance.

\section{DATA SETS AND ANALYSIS}

The data sets for the U.S. overseas managers' responses pertaining to their general perception of cultural factors globally as well as regionally would appear as in Table 4.1. The averages in the column cells of the response row would facilitate an overall descriptive comparison of U.S. overseas managers' general perceptions of the twelve foreign cultural factors both at global as well as at regional levels. 


\section{FOR OVERSEAS MANAGERS}

TABLE 4.1

(For 'A' part of each question dealing with cultural factors)

\begin{tabular}{|c|c|c|c|}
\hline 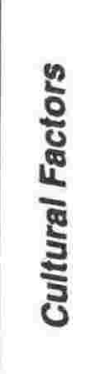 & 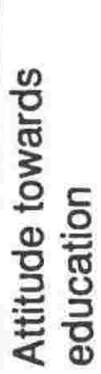 & 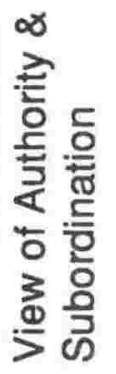 & 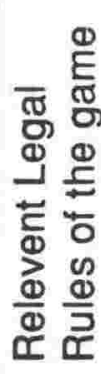 \\
\hline 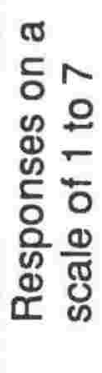 & $\begin{array}{l}- \\
- \\
- \\
- \\
- \\
- \\
n\end{array}$ & $\begin{array}{l}- \\
- \\
- \\
- \\
- \\
- \\
n\end{array}$ & $\begin{array}{l}- \\
- \\
- \\
- \\
- \\
- \\
n\end{array}$ \\
\hline
\end{tabular}

' $n$ ' represents the number of the U.S. overseas respondents in that cell. It can also be organised to show responses from each region. In each cell the responses are on a scale of 1 to 7 . Eventually, each cell would have a number between 1 to 7 representing the average perception of overseas managers for the cultural factors designated by that cell based on its pertinent ' $n$ '.

The Table 4.2 presents the data set that facilitates a descriptive comparison amongst foreign cultural factors' effects on selected aspects of managerial performance as well as the relative responsiveness of the specific aspects of performance to a foreign cultural factor both globally as well regionally. The averages appearing in horizontal cells would help accomplish the former comparison ( $\mathrm{H} 1)$ while the averages appearing in vertical cells the latter $(\mathrm{H} 2)$. 
TABLE 4.2

(For 'B' part of each question dealing with the impact of cultural factors on different aspects of performance)

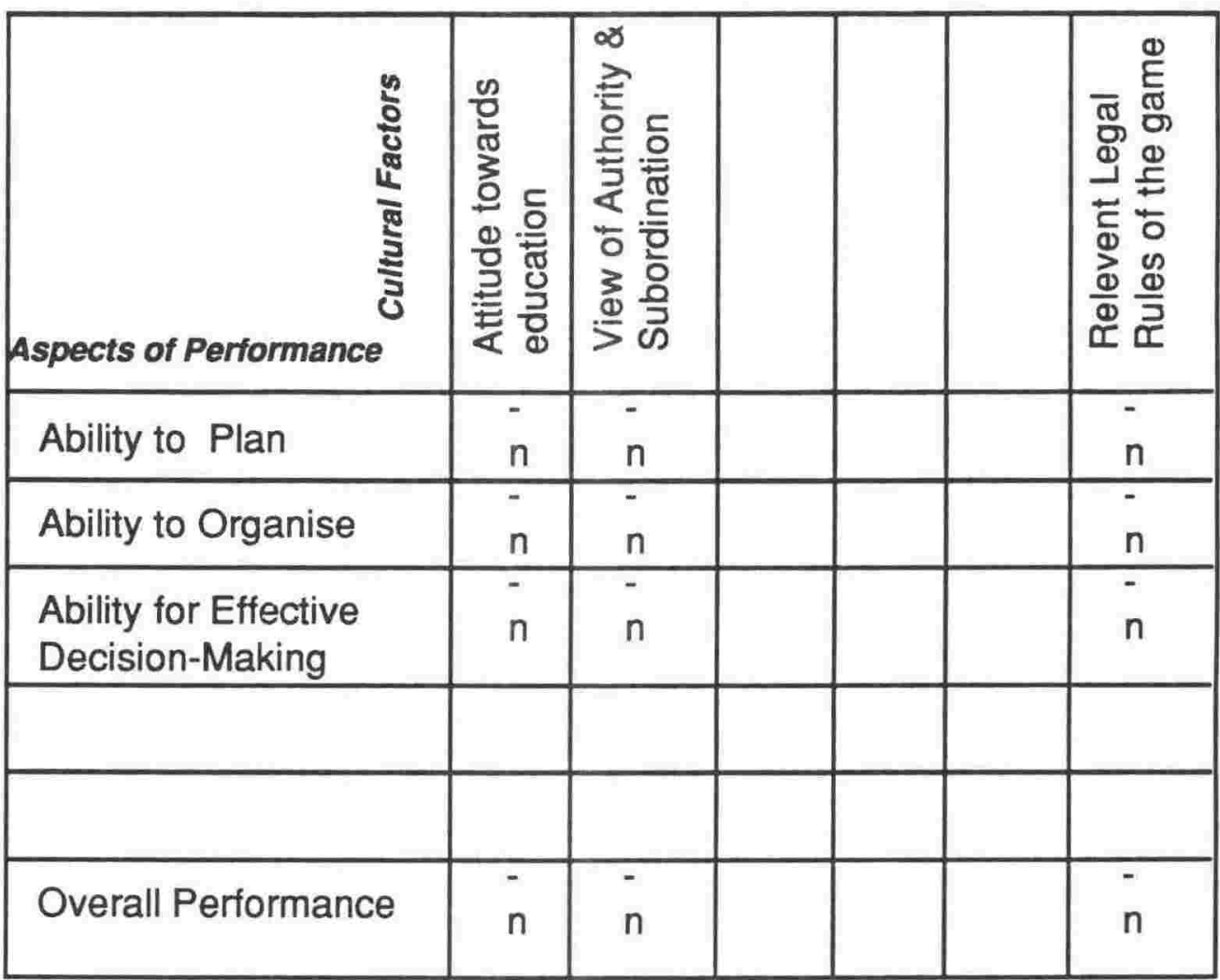

' $n$ ' represents the number of the U.S. overseas respondents. It can also be organised to show responses from each region. In each cell the responses are on a scale of 1 to 7 showing the perceived effect of a cultural factor on a specific aspect of managerial performance. Eventually, each cell would have a number between 1 to 7 representing the average response (perceived effect) for the cell based on its pertinent ' $n$ '.

Similar data sets were also obtained from the responses of the evaluator/s of performance of U.S. overseas managers.

The visual depiction provided in Tables 4.1 and 4.2 facilitates the grasp and appreciation of overall schema of comparisons and their ensuing importance. It also helped in weighing the appropriateness of statistical tools for the stated objectives and corresponding hypotheses. 
Data on specific environmental (cultural) factors as independent variables to find their effect on selected performance factors were collected on a Likert scale. This rating scale is usually ordinal in nature. Ordinal data provide an ordering of cases from the highest to lowest and best to worst. Ordinal data lack the desirable characteristics of equal intervals or absolute zero, and are not truly numerical. Although the data so obtained do not enjoy the characteristics of an interval or ratio unit of measurement, but the same may be used to permit a meaningful comparison of items so that one can determine which item is less than the other. Analysis of ordinal data provides comparisons in which we can have considerable confidence ${ }^{9}$ - although such data generally speaking are not as precise as interval data, which provides measures of how much higher one item is than the other. 10

There is an adequate justification in the research literature for treating the ordinal data as interval data. ${ }^{11}$ Under certain circumstances, ${ }^{12}$ one can

9 L.L. Thurstone,"The essential characteristic of the present measurement (ordinal) method is the scale of evenly graduated opinions so arranged that equal steps or intervals on the scale seem to most people to represent equally noticeable shifts in attitude," in "Attitudes Can be Measured," The American Journal of Seciology January 1928, pp. 529-54; cited in Francis J. Pribyle," The Image of the New Car Dealer as Perceived by the New Car Buyer: A Comparative Study of Differential Attitudes," (Unpublished Doctoral Dissertation, North Texas State University, 1975).

10 David K. Hildebrand, James D. Laing and Howard Rosenthal, Analysis of Ordinal Data, (London: Sage Publications, 1977), pp.1-5.

11 Norman H. Anderson, "Scales and Statistics: Parametric and Nonparametric," Psychological Bulletin.58, 1961, pp. 305-16 and Fred N. Kerlinger and Elazer J. Pedhazur, Multiple Regression in Behavioural Research (New York: Holt, Rinehart and Winston, Inc., 1973), pp. 437-41.

12 Though most psychological scales are basically ordinal, one can with considerable assurance often assume equality of interval. The argument is evidential. If one has, say, two or three measures of the same variable, and these measures are all substantially and linearly related, then equal intervals can be assumed. This assumption is valid because the more nearly a relation approaches linearity, the more nearly equal are the intervals of the scales. This applies, to some extent, to certain psychological measures like intelligence, achievement and attitudes. (Fred N. Kerlinger, Eoundations of Behavioral Research, New York, NY.: Holt, Rinehart And 
consider ordinal data to have interval scale properties. This is justified on the assumption that the ordinal scales used in this survey approximate interval equality quite well especially as the respondents happen to be senior managers of MNCs. Therefore, it was proposed to consider data as interval scale related (unless otherwise specified differently) for all the research objectives.

\section{STATISTICAL ANALYSIS AND TESTS}

It was proposed, as mentioned earlier, to send questionnaires to each subject - (overseas manager/s) of the study for his/her response. In other words, an attempt was made to solicit the responses from the entire population of U.S. overseas executives of the chosen MNCs in the specified regions.

It was proposed to use descriptive statistics given the fact that statistical methods need to be applied to a set of data which comprise a sample from the population of interest. These statistics would provide methods to organise, summarise, and describe sets of data which represent populations. All statistical methods are directed towards the description of a population. The population concept provides the frame of reference for all statistical methods. ${ }^{13}$

Winston, Inc., 1973, pp. 440-1). and Larry B. Christenson, Experimental Methodology, (Boston, Massachusetts: Allyn and Bacon Inc., 1977), pp. 331-4.

13 Sidney J. Armore, Introduction to Statistical Analysis and inference for Psychology and Education (New York: John Wiley \& Sons, 1966), pp. 8-11. 
To accomplish the stated research objectives and to test corresponding hypotheses it was proposed to employ the following statistics:

\section{A)}

For the first research objective no hypothesis is proposed. However, the arithmetic average and standard deviation for each question are computed and presented to highlight the general views of U.S. overseas managers about the specific cultural factors and the deviations amongst themselves on these views (pertinent data set Table 4.1). The graphs are prepared and presented on the basis of the mean responses from the overseas managers to provide a view of their general perception of the selected cultural variables and their perceived effect on the specific aspects of managerial performance, both from a global perspective as well as from a regional perspective.

\section{B)}

For the second research objective (and hypotheses 1 and 2), arithmetic averages and standard deviations are computed and presented. Stated hypotheses are tested by comparing the arithmetic means (descriptive statistics) of data cells representing the views of overseas managers about the impact of specific cultural factors on selected aspects of performance.

As the above hypotheses involve multiple means tests, it was decided to employ an $\mathbf{F}$ test in the repeated measures analysis of variance (ANOVA) using the GLM (General Linear Model). ${ }^{14}$ An $\mathbf{F}$ test in ANOVA tells if the

14 E. A. Maxwell, Introduction to Statistical Thinking. (Englewood Cliffs, New Jersey: Prentice-Hall, Inc., 1983), pp. 364-40 and SAS/STAT User's Guide, Release 6.03 Ed., (Cary, NC: SAS Institute Inc.), pp. 19-23 and Chapter 11. 
means are significantly different from each other, but it does not tell us which means differ from other means. The GLM procedure, however, also performs several multiple comparisons tests even with balanced as well as unbalanced designs. The multiple comparisons method gives more detailed information about the differences among the means and allow one to control error rates for a multitude of comparisons. The GLM procedure eliminates the possibility of incorrect results where analysis of variance involves unbalanced designs. In an analysis of variance, the variation in the response is separated into variation due to the classification variables and variation due to random error. An analysis of variance constructs tests to determine the significance of the classification variables. A typical goal in ANOVA is to compare means of the response variable for various combinations of the classification variables. The various procedures of the ANOVA fit model parameters that minimise the sum of squares of residual errors (that is mean squared error or MSE).

In order to achieve good statistical properties and simplify the statistical arithmetic, one may assign the same number of units to every cell in the design (i.e., balanced design). This is likely to enhance the generalisability of the results. However, the selected GLM procedure for the analysis will not compromise the benefits of balanced design in terms of generalisability. Care and caution need to be exercised as the data for the study is not strictly parametric.

When one has more than two means to compare, an F test in ANOVA tells if the means are significantly different from each other, but it does not tell which means differ from which other means. Multiple comparison methods give more detailed information about the differences among the means and allow you to control error rates for a multitude of comparisons. It was proposed 
to employ Fisher's least-significant-difference (LSD) test in this case which performs pairwise $t$ tests and highlights the means which are different, together with an indication about the size of the difference.

The above procedure helped test the first group of twelve hypotheses formulated to test the equality of a string of nine means, representing the responses for the general perception and perceived effect of a cultural factor on eight aspects of overseas managers' performance. The same procedure was employed to test the second group of eight hypotheses developed to test the equality of (twelve) means, representing the responses pertaining to the effects of all the twelve cultural factors on specific aspects of overseas managers' performance.

This helped us gauge the differences in impact of a cultural factor on different aspects of performance. Also, the differences in impact on one aspect of performance, as caused by different cultural factors would be gauged. This also highlighted which (if any) cultural factor's general perception is significantly different from those of others and also which aspect of performance is perceived to be more significantly affected than other aspects by a cultural factor.

The proposition to use ANOVA for the preceding was based on the main thrust of the research objective (No. 2) and hence the associated hypotheses ( $\mathrm{H} 1$ and $\mathrm{H} 2) .{ }^{15} \mathrm{In}$ the present study the focus of the research effort

15 'Analysis of Variance' (ANOVA) is used in studies in which we wish to determine whether two or more populations are equivalent in the sense that they have equal means. The same method is employed to assess the relative effects of different factors affecting observations by comparing the equality of the means of various (sample) groups (with or without the specific factor/s). The differences among the means tend to indicate that the chosen factor/s seem to exercise/have different effects on the subjects. These conclusions are valid for the 
was to determine whether different foreign cultural factors produce different effects (perceived or otherwise) on the selected aspects of managerial performance. ${ }^{16}$

In regression analysis, we do virtually the same thing. In many cases, it is often necessary to determine the nature of any quantitative relationships between the treatments and effects, if they exist, to be able to establish any general "trend," and to be able to predict values of one variable that would occur with specific values of another. However, in this study as the orientation was not to engage in the prediction of the outcome (performance) on a given a set of cultural factors for US overseas managers, the use of regression analysis was accordingly not proposed. Also, regression coefficients are not stable for interpretative purposes If the explanatory variables are interrelated. The estimated parameters change with addition or subtraction of independent variables which are correlated. There is no absolute way to interpret them because they do not have separate effects. For prediction purposes interrelationship/s between independent variables is not important. However for the purpose of interpreting relational coefficients it is very convenient and helpful if there is zero correlation between explanatory variables. The more the independent variables are interrelated, the more difficult the interpretation.

populations only if some assumptions about the populations are valid (e.g. populations all have the same form of probability/frequency curve, namely the normal distribution, that the populations variances are equal and the samples chosen were independent). The conclusions from ANOVA will still be valid if these assumptions are not exactly true, but they should be at least approximately true (E. A. Maxwell, Introduction to Statistical Thinking. op. cit., p. 367). In the analysis of variance an attempt is made to determine whether different "treatments" produce different effects (on the average). No attempt is made for prediction purposes to determine the form of any quantitative relationship between the treatments and effects which is, incidentally undertaken in regression (simple or multiple).

16 The search for association among variables is a basic activity in all the sciences. Regression is often used in an exploratory fashion for empirical relationship. However, one would need a controlled experiment to scientifically confirm a causal relationship. (Paul E. Green, Analyzing Multivariate Data, (Hinsdale, Illinois: The Dryden Press,1978), p.38. 
Among other things, one has greater difficulty telling the relative influence on the dependent variable of the independent variables. ${ }^{17}$

This study was carried out in an exploratory and descriptive mode in a vein of positivism, where there was no intention to see the relationship between cultural (independent) variables and performance (dependent) variables for predictive purposes. Primarily the effort was geared to gauge if there is any impact of foreign cultural factors on managerial performance. Can the causal relationship between foreign cultural variables and the specific aspects of managerial performance be meaningfully measured and interpreted?

\section{Multicollinearity}

As stated earlier the main thrust of this study was to ascertain and evaluate the existence of causal relationship between the performance of the U.S. overseas managers and their perception of the effects of foreign cultural factors. In order to have a meaningful interpretation of the relative (perceived) effects of the explanatory variables on the aspect of managerial performance one would like to be assured that these cultural variables are not interrelated. Because, if these independent (cultural) variables are significantly correlated, they would show overlapping explanatory power. The assignment of coefficient values to explanatory variables in this case would be unstable on account of this interrelationship, with the result the effort of including all of

17 Fred N. Kerlinger, op. cit., pp. 618-24 and R.Gordon, "Issues in Multiple Regression," Journal of Sociology, LXXIII, 1968, pp. 592-616. 
them for the stated research purpose would be a wasted effort. ${ }^{18}$ Therefore, it was proposed to ascertain the degree of multicollinearity. ${ }^{19}$ Also, since it refers to the condition of the explanatory variables that are assumed to be nonstochastic, it stays a feature of the sample not of the population This is not because that it may not be present in a population, but more so on account of the detailed and complete knowledge of the population which make its presence (if any) irrelevant. Therefore, in sample studies it is always prudent to 'test for multicollinearity' and measure the statistical significance of its degree.

The problem can be present in any kind of multivariate problem. Any situation in which data are collected on a naturalistic basis, without experimenter-intervention or control, has the potential for exhibiting multicollinearity among two or more predictor variables.

A classic symptom of multicollinearity is the presence of High $\mathrm{R}^{2}$ but few significant $t$ ratios (that is, showing that none or very few partial slope coefficients are statistically different from zero). Multicollinearity has the effect

18 For instance if there are three independent variables: A, B, and C and one dependent variable $X$ and one is interested in testing the relationship between three independent variables and $\mathrm{X}$. If $\mathrm{B}$ and $\mathrm{C}$ are perfectly correlated then the relationship between independent variables and dependent variable will not be much different whether you use B or $C$, that is one of these becomes superfluous.

19 Strictly speaking, the term multicollinearity refers to the existence of more than one exact linear relationship amongst independent variables, and the term collinearity refers to the existence of a single linear relationship. But this distinction is rarely maintained in practice, and multicollinearity refers to both the cases. If multicollinearity is perfect, the relational coefficients of independent variables are indeterminate and their standard errors are infinite. Where it is less than perfect, the relational coefficients of independent variables are determinate but possess large standard errors thus the estimation's accuracy of coefficients is seriously jeopardised. (Damodar N. Gujarati, Basic Econometrics, Singapore: McGraw-Hill Book Company, 1988, pp. 283-315). Also, it has been aptly posited that multicollinearity is a question of degree and not of kind (Jan Kmenta, Elements of Econometrics, (New York, NY: Macmillan Company, 1971), pp. 380-1). 
of increasing standard errors of the coefficients of the individual variables the result of which is that there is greater uncertainly about the underlying value of the coefficient of the individual independent variable/s. To diagonise multicollinearity it was proposed to use the 'eigenvalues and condition index' method. From these eigenvalues one can derive the condition number $k$ defined as:

$$
k=\frac{\text { Maximum eigenvalue }}{\text { Minimum eigenvalue }}
$$

and condition index $(\mathrm{Cl})$ defined as:

$$
\mathrm{Cl}=\sqrt{\frac{\text { Maximum eigenvalue }}{\text { Minimum eigenvalue }}} \quad=\sqrt{ } \mathrm{k}
$$

(Where the eigenvalues are of the matrix of products and cross products of the explanatory variables).

What constitutes serious multicollinearity is ambiguous, however, the evaluation of condition index $(\mathrm{Cl})$ follows a rule of thumb, that is if $\mathrm{Cl}$ is between 10 and 30 (i. e., $\mathrm{k}$ being between 100 and 1000), there is moderate to strong multicollinearity and if it exceeds 30 there is severe multicollinearity. 20 It was decided to drop a few co-linear (offending) variables (provided there is no serious specification bias/error) in the event multicollinearity is diagonised. 21

20 Damodar N. Gujarati, op. cit.

21 Essentially there are three basic procedures for dealing with multicollinearity: (a) ignore it; (b) delete one or more of the "offending" predictors; or (c) transform the set of predictor variables into a new set of predictor-variable combinations that are mutually uncorrelated. Ignoring multicollinearity need not be as cavalier as it might sound. First, one can have multicollinearity in predictor variables and still have strong enough effects that the estimating coefficients remain reasonably stable, i.e., have sharp variances. Moreover, multicollinearity may be prominent in only a subset of the predictors, a subset that may not contribute much to accounted-for variance anyway. A prudent procedure in checking one's predictor set for multicollinearity is to examine standard errors of the regression coefficients (which will tend to be large in the case of high multicollinearity and if the variable is not significant any way). Second, 
As the SAS output is in the desired format, it was decided to use the SAS package. ${ }^{22} \mathrm{Also}$, as the SAS output provides the results of regression analysis through which one could gauge the relative effect of cultural factors on the specific aspect/s of managerial performance and their associated statistical significance.

C)

For the research objectives (3) and (4), only a few responses for each region were expected, hence, it was decided to use the same few responses to compute arithmetic averages and standard deviations to provide the descriptive interpretation of the highlights of the evaluators' responses. Because of the limited number of responses from evaluator/s other measures have not been computed and accordingly no hypotheses were proposed to test for significant differences in their responses for their general perception of cultural factors and their effects on managerial performance. However, graphs were prepared and presented based on the mean responses of evaluators to highlight their view about the general perception of cultural variables and the consideration they assign to the perceived effect of the same on the specific

one may randomly drop some subset of the cases (perhaps 20 percent or so), rerun the regression, and then check to see if the signs and relative sizes of the regressions are stable. A number of recently developed regression routines incorporate checks for serious multicollinearity; if the program does not indicate this condition, the research can generally assume that it not acute).

If multicollinearity is "severe" one way is to drop one or more predictors that appear to be main offenders. On account of their high correlation the overall fit may not markedly change. Methods also exist, e.g. Principal component analysis etc. for transforming the original set of predictors to a mutually uncorrelated (orthogonal) set of linear combinations. If these components are interpretable in themselves one may retain these in regression analysis. If all components are retained, the predictive accuracy will be precisely the same as that obtained from the original set of predictors. Paul E. Green op. cit., and Damodar Gujarati ,op. cit.) 
aspects of performance in the evaluation of U.S. overseas managers' performance.

D)

For research objectives (5) and (6), in order to determine whether or not overall differences exist between two groups of overseas managers and evaluators of performance at headquarters, it was decided to use Hotelling's $T^{2}$. This is the multivariate extension of the student's $t$ statistic for testing the differences between the universe means of two groups* (hypotheses 3 and 4). The appropriate test statistic is: 23

$$
T^{2}=\frac{M 1 \times M 2}{M 1+M 2} \quad d^{\prime} C_{w}^{-1} d
$$

$$
\begin{aligned}
& \text { where } \mathrm{M1}=\text { the sample size of the overseas managers } \\
& \text { M2 = the sample size of the performance evaluators } \\
& \mathrm{d}=\text { the vector of differences between the mean } \\
& \text { responses of each group } \\
& \mathrm{C}_{\mathrm{W}}{ }^{-1}=\text { the pooled within - groups inverse covariance }
\end{aligned}
$$

"When there are two groups, Wilks' lambda $(\Lambda)$ can be interpreted as a measure of proportion of total variability not explained by group differences. The hypothesis that in the population there are no differences between the group means can be tested using Wilks' lambda. Lambda is transformed to a variable that has an $\mathrm{F}$ distribution. For two-group situation, the $\mathbf{F}$ value for Wilks' lambda is identical to that given by Hotelling's $\mathrm{T}^{2}$ (Marija J. Norusis, SPSS Advanced Statistics User's Guide, Chicago, Illinois: SPSS Inc., 1990, pp. 85-88).

23 Paul E. Green, op. cit., p.166 and Neil H. Timm, Multivariate Analysis With Applications in Education and Psychology (Monterey, CA: Brooks/Cole Publishing Co., 1975), pp. 203-6. 
Assuming there is an overall difference between the perceptions of overseas managers and performance evaluators, further analysis of individual variables on regional basis would be done with the help of " $\mathrm{t}$ " statistic.

E)

For research objectives (7) and (8), it was intended to explore the differences in views regarding specific foreign cultural factors and in perceptions about the impact of these specific foreign cultural factors on eight specific aspects of performance among five selected regions. The overseas managers of a region served as sample subjects for that region. The stated objective is achieved by employing multivariate significance test for more than two groups. It was proposed to use Wilks' likelihood criterion (Wilks' $\Lambda$ ) to test hypotheses 5 and 6 . This is defined as:

$$
\Lambda=\frac{|W|}{|T|}
$$

Where $\quad \mathbf{W}$ is the within groups sums of squares and cross products (SSCP) matrices for each of the groups,

and

T is the total sample sums of squares and cross products (SSCP) matrix. ${ }^{24}$

If the computed Wilks' lambda" is found to be significant then it can be concluded that the U.S. managers' views regarding the specific foreign

24 Maurice M. Tatsuoka, Multivariate Analysis (New York: John Wiley \& Sons, 1971), pp.85-6; and Paul E. Green, op. cit., pp. 291-4.

* It $(\Lambda)$ is the proportion of the total variance in the (discriminant) scores not explained by differences among groups. That is, the lambda $(\Lambda)$, to be significant should be as small as possible. A lambda of 1 occurs when the mean of discriminant scores is the same in all groups 
cultural factors and the perceived impact of these cultural variables on performance among different regions are significantly different.

Secondly, for the second part of objective (8) it was also proposed to isolate foreign cultural factors (if any) which may explain the differences in perceived impact on performance on a regional basis. For this purpose $\mathbf{K}$ group Multivariate Discriminant Analysis (MDA) was used. It is assumed that the relevant (predictor) variables have a multivariate normal distribution.

Descriptive statistics and univariate tests of significance provide basic information about the distributions of the variables in the groups and help identify some differences among the groups. However, in discriminant analysis and other multivariate statistical procedures, the emphasis is on analysing the variables together, not one at a time. By considering the variables simultaneously, one is able to incorporate important information about their relationships. 25

In multivariate discriminant analysis, a linear combination of the independent variables is formed and serves as the basis for assigning cases to groups. Thus, information contained in multiple independent variables is summarised in a single index. This is accomplished by finding a weighted average of those significant variables which can provide a score that will distinguish the members of one group from those of another. In MDA, the

and there is no between or among-oroup variability (Marija J. Norusis, op. cit., pp. 15 16).

25 Marija J. Nonusis, op. cit., pp. 5-7. 
weights are estimated so that they result in the "best" separation between (or among) the groups.

The use of $\mathrm{MDA}^{26}$ provided a means of discriminating amongst regions using regions as groups and cultural variables as predictors. This would be accomplished on the basis of measurements obtained about the perceived impact of cultural factors on the performance of U.S. managers working in the five selected overseas regions.

In the simple two-group multivariate discriminant case an attempt is made to find a single axis (linear composite) along with the groups that are maximally separated. Similarly, in K-group MDA the objective is to find an axis with the property of maximising among-groups to within-groups variability of projections on this axis. In the K-group case, in general, one axis does not exhaust the discrimination potential. Generally speaking, with $\mathbf{K}$ groups and $\mathbf{n}$ predictors, we can find $\min (\mathbf{k}-1, \mathbf{n})$ discriminant axes. ${ }^{27}$

The MDA would help find these axes with the property of maximising among groups to within-groups variability, subject to the scores on each new discriminant axis being uncorrelated with the scores on previously obtained discriminant axes, i.e., the second axis, maximising residual among groups to within-groups variability and so on. 28 4.

26 Maurice M. Tatsuoka, op. cit., pp. 85-6 and Paul E. Green, op. cit., pp.291-

27 Ben W. Bolch and Cliff J. Huang, Multivariate Statistical Methods for Business and Economics (New Jersey: Prentice Hall, 1974), pp. 231-4.

28 Formally stating the ratio of the among groups to within-groups of sums of squares of the linear composite $z^{*}$ is given by: 
In general, the centroids of K-groups will be in (at most) a K-1 space, as we need only $\mathrm{K}-1$ axes to account for all variability in the group centroids, assuming $n \geq K-1.29$

The procedure described above would help isolate the $\mathbf{p}$ predictors (cultural factors) to discriminate among the selected five overseas regions. It is intended to identify the cultural factors along with their perceived impact on performance variables which can significantly discriminate among the regions. However, it must be stated that this endeavour is not intended to calculate and identify the (K-1) discriminant axes (i.e., the dimensionality of the discriminant space) in a dimension reduction sense.

$$
\frac{\operatorname{SSA}(z)}{\operatorname{SSW}(z)}=\frac{k^{\prime} A k}{k^{\prime} W k}=\lambda
$$

"Fisher's discriminant function is given as:

$$
\mathrm{Z}=\mathrm{x}^{\prime} \mathrm{d} \mathrm{k}
$$

When $k$ is applied to the full data matrix, $X_{d}\left(X_{d}=m \times n\right.$ matrix of mean corrected scores on the original predictors) of mean corrected data one finds the linear composite:

$$
z=X_{d} k
$$
variability.

Which is the discriminant axis that maximises the ratio of between groups to within-groups

(Where numerator is a scalar based on the between - (among) groups SSCP matrix of Xd and the denominator is the other based on the pooled within-groups SSCP matrix of Xd).

Where $\lambda$ representing the ratio of two scalars, is itself a scalar. In order to find the discriminant axes, $\lambda$ needs to be maximised with respect to $\mathrm{k}$ (maximising $\lambda$ with respect to $\mathrm{k}$ will entail finding the partial derivative of $I$ with respect to $k$ and setting it equal to 0 ). The resulting matrices (after simplification) of eigen values and eigen vectors (normalised to unity) provide the values of discriminant criteria and sets of weights respectively. The first eigen vector provides a set of combining weights which have the largest possible discriminant criterion value (first eigen value) among all linear combinations of the $p$ predictor variables. The second eigen vector would similarly provide another set of weights uncorrelated with the first, giving second largest discriminant criterion value, and so on. (Maurice M. Tatsuoka, Discriminant Analysis: The Study of Group Differences, Illinois: Institute for Personality and Ability Testing, 1970, pp. 28-34) and Paul E. Green, op. cit, pp. 299-300.

29 Paul E. Green, op. cit, pp. 300-5. 
The preceding detailed description of the analyses to be employed for each of the stated research objectives, it is contended, would put the steps involved in statistical analyses in a clearer perspective. This would provide a clearer link between data, analyses and objectives.

\section{LIMITATIONS}

The validity of this study's findings may be limited for the following reasons:

The involvement of corporate headquarters in the distribution of questionnaires to the U.S. overseas managers may cause a perceived bias in their responses. These overseas managers might be inclined to provide responses which they perceive to be preferable to the executives at headquarters. The impact of this potential bias would be reduced to minimal as the responses would be addressed to the researcher directly.

Also, it is expected that the routing of questionnaires for overseas managers through corporate headquarters will eliminate the usual indifference that may be associated with a third party inquiry, and should evince more seriousness and increased commitment from the managers working overseas.

Further, the possibility of non-response is likely to be minimal because of the commitment and support of enterprise headquarters. Yet, one cannot guarantee the total absence of non-response. To this end, it is proposed to contact the officers currently working at headquarters who have had a working stint in that region wherein the non-response is significant, on a random basis 
to get their responses. The distribution of questionnaires for overseas managers through corporate headquarters may have some limiting impact on the validity of the findings of the study. However, with the precautions described, it is contended that such an impairing impact is negligible.

Study format: Because of the study format this research endeavour may seem to lack general validity. However, if the samples selected, although consisting of a few managers, are a good representative of the general group it should serve as an appropriate indicator of probable findings if the study were to be based on a larger sample of the group. It is contended that this format, though based on a fewer number of MNCs, would nevertheless provide valuable inputs for future research. 30

Construct validity: The study intended to analyse the impact of cultural variables on the performance. These variables however have not yet been operationalised, with the result that the validity of the findings is limited. ${ }^{31}$

30 Lawrance R. Jauch, Richard N. Osborn, and Thomas N. Martin, "Structured Content Analysis of Cases: A Complementary Method for Organizational Research," op. cit., pp. 51725 .

31 Very close to construct validity is external validity which requires that conclusions be true not only across people but also across conditions. External validity is similar to reliability which can be demonstrated both by repeating or replicating the findings. Louise $\mathrm{H}$. Kider, op. cit., pp. 6-7 and Julian L. Simon, Basic Research Methods in Social Science: The Art of Empirical Investigation, New York, NY.: Random House,1969), pp. 20-25. 


\section{QUESTIONNAIRES SOLICITING DATA}

As stated earlier, data was solicited through questionnaires. These questionnaires were developed following the guidelines given for their construction and design. 32 There were two sets of questionnaires: one for the overseas executives and the other to be completed by headquarters executive/s in charge of performance measurement and evaluation. Basically, the two sets were alike, as both were attempts to elicit responses relating to managers' and evaluators' views regarding the selected foreign cultural factors and the impact of these cultural factors on managerial performance.

Questionnaires were prepared on a comprehensive basis, including questions on the selected socio-cultural variables and their impact on the proposed aspects of manager's performance. To avoid different interpretations and appreciation of the selected cultural factors and to minimise the possibility of receiving unusable responses, definition of each cultural factor was provided in the relevant question itself. These definitions were based on prior studies. In part $\mathbf{A}$ of each question the respondent was asked a general type question with a view to elicit his common perception of the particular cultural factor. Part B of each question pertains to the application of that common perception to the eight specific aspects of managerial performance. Where the response sought was different, the explanation of the same was provided along with the question.

32 Donald P. Warwick and Charles A. Liniger, The Sample Survey Theory and Practice, (New York, NY: McGraw Hill Book Co., 1975), pp. 127-77 and Vernon Clover and Howard Balsley, Business Research Methods, (Columbus, Ohio: Grid Inc., 1974), pp. 110-55. 
Questionnaires for the performers (overseas executives) sought their views about the description of specific foreign cultural factors and their perceptions about the impact of cultural variables on the various aspects of performance on a 1 to 7 Likert scale. Questionnaires directed to evaluator/s (executives at headquarters) were geared to elicit their views about the description of specific foreign cultural factors and their responses to the considerations they assign to the impact of these specific cultural variables while measuring and evaluating the performance of overseas managers on a 1 to 7 Likert scale. It is contended that the scale of 1 to 7 would provide a more distinct measure of views about specific foreign cultural factors and their impact on performance. The decision to use the 1 to 7 scale instead of the 1 to 5 scale for soliciting their responses reflects purely a judgemental need for more refinement in classification.

Responses to questionnaires from the U.S. managers working overseas and performance evaluators at corporate/regional headquarters provided information regarding their views on the selected foreign cultural factors. The responses provided information regarding the impact of these specific foreign cultural factors on the selected aspects of performance as viewed by the overseas managers and the consideration accorded to the same by the performance evaluators. It is contended that this information would help show the relative impact of the selected cultural factors on the performance of the U.S. overseas managers.

\section{PRETEST AND PILOT STUDY}

Having received general agreement about the questionnaires from both colleagues and outside authorities it was decided the questionnaire 
should be pretested with a view to assess the understandability of questions and instructions and also, comprehension of the intended purpose. It is contended that pretesting provides not only a test of the clarity of the questions and of the correctness of the interpretation put upon them by the respondent, but it also affords the possibility of discovery of new aspects of the problems (proposed to be) studied but not anticipated in the planning stage. ${ }^{33} \mathrm{~A}$ pretest was conducted using colleagues who have spent some time in foreign countries. The participants were asked to comment on the difficulty of the response task and clarity of the instructions so that the reliability and validity of responses may be augmented. A few improvements were suggested and the same were incorporated in the questionnaire.

With the pretest favourably concluded, a pilot study was undertaken to refine and validate the questionnaire, using subjects (managers in MNCs) who have returned from foreign assignments, and their superiors in the enterprises under study. The pilot was also undertaken to test the sequence and the context of each question, to evaluate the response rate, and to assess informally the managers' abilities to handle the questions and the instructions. ${ }^{34}$ The questionnaires were sent to a few executives of a Minneapolis-based multinational enterprise who had worked at overseas offices and, also, to those colleagues who had taught overseas in Europe and Africa.

33 Pauline V. Young and Calvin F. Schmid, Scientific Social Surveys and Research. (Englewood Cliffs, New Jersey: Prentice Hall, Inc., 1966), pp. 205-6.

34 Thomas L. Burton and Gordon E. Cherry, Social Research Techniques for Planners, (London: George Allen and Unwin Ltd., 1970), pp. 55-8. 
Both the pilot and the survey were designed and administered according to Don A. Dillman's 'total design method' TDM). ${ }^{35}$ These comprehensive procedures are based on a compilation of research about mail surveys. His techniques are based significantly on the personalisation of the implementation of the survey. Respondents should be convinced that the research is important and that researcher is identified as an intermediary who will contribute to the solution.

Personalisation with a few modifications keeping in view the peculiarity of the participants was considered in all aspects of the pilot. A cover letter was sent with each questionnaire to introduce the participants to the nature and relevance of the research and acted as an appeal for their cooperation and participation. The involvement of the executives at headquarters was very critical to the success of this phase. Their cooperation, suggestions and the assurance for actual data collection were the main accomplishments of this phase of study. There was perfect concurrence to keep the questionnaire simple as it was designed to solicit quite a large number of responses. Additionally, it was felt that simplicity would actually improve the response rate and minimise the number of response errors and incomplete questionnaires. A simple questionnaire also helps in subsequent development of data sets and tabulation. ${ }^{36}$ The feedback provided by the executives involved in the pilot was very encouraging and detailed in terms of seriousness for the endeavour and quality and completeness of the responses. In the light of the thoroughness of the feedback from the pilot it

35 Don A. Dillman, Mail and Telephone Surveys: The Total Desian Method, (New York: John Wiley \& Sons, Inc., 1978).

36 v. Duoba and J.H. Maindonald, eds., Understanding Surveys, (Wellington: New Zealand Statistical Association Inc., 1988), pp. 9-12. 
was decided not to undertake the Kendall's coefficient of concordance ${ }^{*}$ in consultation with the supervisor and senior colleagues. The pilot study although undertaken in an informal manner yielded some valuable modifications in the sequencing and fine-tuning of questions and the cover letter was effectively concluded.

\section{SURVEY AND ADMINISTRATION OF QUESTIONNAIRES}

A few minor format-orientated changes were made to the questionnaire in response to some suggestions from the respondents/participants of the pilot study. Having successfully conducted and completed the pilot study with a response rate of approximately $80 \%$ (12 out of 15), the copies of the questionnaire were sent to corporate headquarters along with cover letters. Corporate headquarters then forwarded the questionnaires to overseas managers along with a covering letter stating the purpose and usefulness of the study in order to encourage overseas managers to participate in the study.

Five sets of questionnaires, one for each region, were sent to the evaluator/s. Also, these executives have agreed to provide time for the followup interviews to help supplement the survey findings.

* The coefficient of concordance helps study the tendency of the responses to agree or show concordance. By definition the $\mathrm{W}$ statistic of concordance cannot be negative and its maximum value is 1, Robert L. Winkler and William L. Hayes, Statistics: Probability. Inference, and Decision, (New York: Holt, Rinehart and Winston, 1975). 


\section{DATA COLLECTION AND RESULTS OF SURVEY}

An understanding was reached with the corporations selected for the survey that strict confidentiality with regard to their names and the exact number of their managerial personnel would be maintained. No attempt would ever be made to delve (probe) into their emoluments and other personal details, except those contained in the questionnaires. The need for this assurance was appreciated and honoured in the light of sensitivities of international business and other strategic considerations and, accordingly, the questionnaires were routed through the corporate headquarters to elicit and sustain their trust and consequent cooperation. The selected multinational corporations did encourage their overseas managers to return the duly filled questionnaires directly to the researcher in order to maintain the objectivity and the unbiased character of their responses.

A period of more than one year elapsed since the time of sending the questionnaires to the corporate headquarters and getting them back from overseas offices. A few corporations were cooperative enough to send reminders after the expiry of ten months. It is believed that a little more time if allowed would have gotten a few more responses, but this option was not pursued in view of the likely benefit and the cost in terms of (likely) time involved.

It must be mentioned that two corporations which initially agreed to cooperate in this research endeavour decided to withdraw from the survey after the questionnaires were mailed to them, purely on account of business reasons as they were undertaking serious restructuring in response to the sluggishness in their specific business area. At that late stage no attempt was 
undertaken to find another substitute corporation purely to complete this study in the appropriate amount of time.

The corporations selected for the survey though were of a diversified nature but mainly represented chemical, oil exploration, refining and marketing, heavy machinery, rubber and plastics, office equipment and computer, meat, dairy and frozen food, hotel, lodging and restaurant industries. The responses from their overseas managerial personnel and evaluators were directly received by this researcher.

The responses received from the overseas managers were from the countries representing all the selected five regions. In all 127 fully usable responses were received from managers working in the above mentioned 38 countries (Table 4.3).

Egypt although has always been considered as an important country of middle-east, however, for this survey it is classified in the African region. Similarly, Mexico has been included in Latin America for obvious similarities with the other countries of that region while locationally it is in the North American continent. This was done purely on the basis of personal judgement. 
TABLE 4.3

Region-wise and Country-wise Distribution of Responses

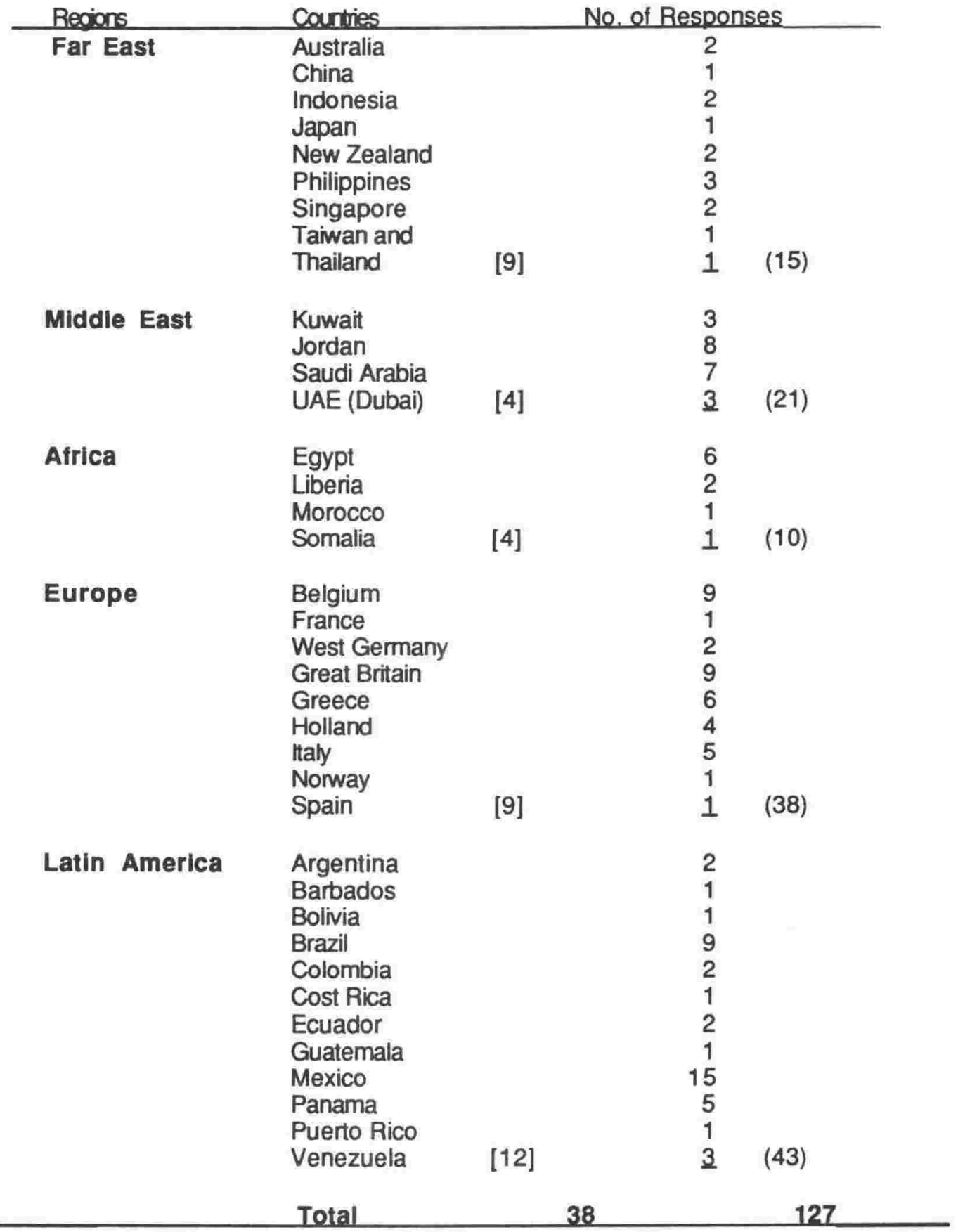

There was only one multinational corporation wherein the responses received pertain to only one region, while there were two corporations whose 
responses relate to two regions and the remaining corporations' responses represented at least four out of the five regions considered the under study. Overall, all five regions were represented in the responses received from the overseas respondents.

\section{TABLE 4.4}

\section{Response Distribution Amongst Multinational Corporations on the Basis of Number of Employees 37}

\begin{tabular}{cccc}
$\begin{array}{l}\text { Number of } \\
\text { Employees }\end{array}$ & $\begin{array}{c}\text { Number of } \\
\text { Comporations }\end{array}$ & $\begin{array}{c}\text { Number of } \\
\text { Responses }\end{array}$ & $\begin{array}{c}\text { Percent of } \\
\text { Total Respenses }\end{array}$ \\
\hline Less than 25,000 & 3 & 22 & 17 \\
25,001 to 50,000 & 1 & 16 & 13 \\
50,001 to 75,000 & 2 & 23 & 18 \\
75,001 to 100,000 & 1 & 8 & 6 \\
More than 100,000 & $\underline{3}$ & $\underline{58}$ & $\underline{46}$ \\
Total & 10 & 127 & 100 \\
\hline
\end{tabular}

The responses received from overseas represent a cross section of relatively small, medium and large multinational corporations (Table 4.4) on the basis of people employed. Overall the responses received pertain to corporations employing more than 540,000 employees globally.

\section{TABLE 4.5}

\section{Response Distribution Amongst Multinational Corporations on the Basis of Ranking Based on Sales 38}

\begin{tabular}{lccc}
$\begin{array}{l}\text { Forbes' Ranking } \\
\text { Based on Sales }\end{array}$ & $\begin{array}{c}\text { Number of } \\
\text { Corporations }\end{array}$ & $\begin{array}{c}\text { Number of } \\
\text { Responses }\end{array}$ & $\begin{array}{c}\text { Percent of } \\
\text { Total Responses }\end{array}$ \\
\hline $\begin{array}{l}\text { Top } 100 \\
101 \text { to } 200\end{array}$ & 4 & 37 & 29 \\
201 to 300 & 2 & 29 & 23 \\
301 to 400 & 1 & 39 & 31 \\
$\quad$ Total & $\underline{3}$ & $\underline{22}$ & 17 \\
& 10 & 127 & 100 \\
\hline
\end{tabular}

37 Forbes, April 28, 1986, pp. 231-260.

38 Ibid. 
The overseas managers who responded to the survey come from a cross section of very large, moderately large and large multinational corporations (Table 4.5). Among themselves they accounted for a total global sales volume of US $\$ 70$ billion.

TABLE 4.6

\section{Response Distribution Amongst Multinational Corporations on the Basis of Ranking Based on Assets Value 39}

\begin{tabular}{lccc}
$\begin{array}{l}\text { Forbes' Ranking } \\
\text { Based on Assets }\end{array}$ & $\begin{array}{c}\text { Number of } \\
\text { Comporations }\end{array}$ & $\begin{array}{c}\text { Number of } \\
\text { Responses }\end{array}$ & $\begin{array}{c}\text { Percent of } \\
\text { Total Responses }\end{array}$ \\
\hline $\begin{array}{l}\text { Top } 100 \\
101\end{array}$ to 200 & 2 & 25 & 20 \\
201 to 300 & 2 & 12 & 9 \\
301 to 400 & 2 & 13 & 10 \\
& 4 & 77 & 61 \\
$\quad$ Total & 10 & 127 & 100 \\
\hline
\end{tabular}

The distribution of responses on the bases of asset value, market value and the amount of net profit reported by these multinational corporations was fairly representative (Tables 4.6 to 4.8 ). Amongst themselves they controlled assets worth more than US\$58 billion, represented market value of more than US\$ 30 billion and accounted for a net profit in excess of US\$ 3 billion from their global operations. 40

39 lbid.

40 lbid. 
TABLE 4.7

Response Distribution Amongst Multinational Corporations on the Basis of Ranking Based on Market Value 41

\begin{tabular}{lccc}
$\begin{array}{l}\text { Forbes' Ranking } \\
\text { Based on Market } \\
\text { Value }\end{array}$ & $\begin{array}{l}\text { Number of } \\
\text { Corporations }\end{array}$ & $\begin{array}{l}\text { Number of } \\
\text { Responses }\end{array}$ & $\begin{array}{l}\text { Percent of } \\
\text { Total Responses }\end{array}$ \\
$\begin{array}{l}\text { Top } 100 \\
101 \text { to } 200\end{array}$ & 2 & 25 & 20 \\
201 to 300 & 4 & 67 & 53 \\
301 to 400 & 1 & 13 & 10 \\
$\quad$ & 3 & 22 & 17 \\
$\quad$ Total & 10 & 127 & 100 \\
\hline
\end{tabular}

TABLE $\mathbf{4 . 8}$

Response Distribution Amongst Multinational Corporations on the Basis of Ranking Based on Net Profit 42

\begin{tabular}{|c|c|c|c|}
\hline $\begin{array}{l}\text { Forbes' Ranking } \\
\text { Based on Net } \\
\text { Profi. }\end{array}$ & $\begin{array}{l}\text { Number of } \\
\text { Corporations }\end{array}$ & $\begin{array}{l}\text { Number of } \\
\text { Responses }\end{array}$ & $\begin{array}{l}\text { Percent of } \\
\text { Total Responses }\end{array}$ \\
\hline Top 100 & 3 & 29 & 23 \\
\hline 101 to 200 & 2 & 12 & 9 \\
\hline 201 to 300 & 2 & 55 & 43 \\
\hline 301 to 400 & 3 & $\underline{31}$ & 25 \\
\hline Total & 10 & 127 & 100 \\
\hline
\end{tabular}

The responses from evaluators totalled 18 and pertained to the five regions under study. However, some corporations provided only a few responses on evaluator's questionnaires stating that they did not use different criteria for different regions. In the light of their apparent reluctance it was decided not to press for those responses and use the ones which are specifically indicative of specific regions. The details of evaluators' responses also resemble those of overseas managers and also as their number is not very large, their detailed distribution analysis is not provided.
41 lbid.
lbid. 
The details about the personal profile of overseas managers and evaluators, their general perceptions relevant to the specific cultural factors in aggregate and within regions, the detailed statistical analyses to test the formulated hypotheses and the results obtained thereof are provided in the next chapter. 


\section{CHAPTER V}

\section{DATA ANALYSIS AND PRESENTATION OF RESULTS}

This chapter, which provides the results of the study, is divided into three sections. The first section is directed toward identification of U.S. Overseas managers' profiles and other pertinent characteristics. The second section is a descriptive account of overseas managers' perceptions of foreign cultural factors and their impact on the performance of managers. Concurrently, an attempt is also made to present the general profile of the evaluators of performance of overseas managers. A descriptive account of evaluators' perceptions relative to the foreign cultural factors and their impact on US overseas managers' performance is also provided. The last section relates to the tests of various hypotheses presented in this study.

\section{SECTION I}

\section{U.S. OVERSEAS MANAGERS' PROFILE AND OTHER CHARACTERISTICS}

\section{AGE DISTRIBUTION}

The majority of overseas managers seem to be clustered in the $36-50$ years age group, only 19 per cent of managers were above fifty years of age. Approximately 25 per cent of managers are in the 26-35 years age group. Managers assigned to African, European and Latin American regions seem to conform to the overall pattern in age distribution (Table 5.1). However, 48 per 
cent of managers in the Middle-East belong to the younger age group, while one third of the managers come from over the fifty years age group in the Far Eastern region. Managers assigned to the Middle East account for one third of the total overseas managers in the younger age group of our sample. The explanation for having 19 per cent managers in the more than fifty years age group is that around that age the MNE's overseas managers tend to either come back to the corporate headquarters or opt for retirement. A distinct feature pertaining to the Middle-east and Africa has been a strategy for business expansion especially in the hotel and tourism type services, which explains the induction of more young managers on account of their stamina, initiative and also as they would be undertaking the similar tasks elsewhere in the same region.

\section{EXPERIENCE PROFILE}

\section{Domestic Experience With Present Organisation}

From the point of view of experience with the present organisation 32 percent of U.S. overseas managers seem to have no work experience in domestic operations (Table 5.2). On the other hand 41 percent of the managers have more than five years of experience in domestic operations. In Far Eastern, European and Middle Eastern regions a relatively larger proportion (more than $30 \%$ of that region's managers) of overseas managers appear to be in the no experience group. The rationale sustaining such an outcome is to hire managers specifically for overseas assignment, thus developing a specialist core of young overseas managers. A relatively larger number of overseas managers with more than 5 years of domestic experience with the present organisation has been more in line with the corporations' general policy to man their overseas operations in the initial stages and later 
on to have them overseen by those who have an enhanced familiarity with corporations' domestic operations and policies. Overall, across all the regions, a majority of overseas managers seem to have worked in domestic operations of their respective present organisations.

\section{Overseas Experience With Present Organisation}

In case of overseas experience with the present organisation. The pattern seems to be consistent amongst the regions as well as in aggregate. The majority (61 per cent of total responded) of overseas managers are relatively new, that is, somewhat neophytes in their overseas exposure and experience. Only two-fifths of them seem to have more than five years of overseas experience (Table 5.3). Usually, those with a sizeable overseas experience are called back at the corporate headquarters to help manage and formulate new global and regional policies. Generally, the overseas assignment for managers is recommended and approved in recognition of their long tenure of service with the parent MNEs as this is taken to help bolster up their commitment for the MNEs unless they are recruited specifically for overseas assignment (Tables 5.2 and 5.3).

Only in Middle-East and Africa did the number of managers with up to five years experience far exceed than those with more than five years of experience. The phenomenon is more due to these two regions being relatively new commercially speaking where, in general corporations seem to be sending their younger staff more so as their first time placement. In European, Far Eastern and Latin American regions the managers are evenly distributed for their overseas experience with their respective organisations between less than five years and more than five years experience groups. 
This appears to be more on account of corporations' policy of putting the new manager with the well experienced one so as to smoothen the transition of the former into the new cultural environments.

\section{Domestic Experience With Other Organisations}

Approximately one half of those who responded did not have any domestic experience and from the same group four-fifths (close to 50) did not have any overseas experience with other organisations (Tables 5.4 and 5.5). Approximately 40 to 45 percent of managers have their careers started with their present organisations.

However, one-third of the overseas managers did have more than 5 years of domestic experience with other organisations. In the Far Eastern region the number of overseas managers with no experience (67 per cent) far exceeded those with up to five years (seven per cent) and those with more than five years (26 per cent). Generally, the overall trend with respect to domestic experience (Table 5.4) with other organisations is also reflected in the other four regions.

\section{Overseas Experience With Other Organisations}

Overseas managers with no foreign experience with other organisations $(65 \%)$ far exceeded those with up to five years (13\%) and with more than 5 years (22\%) in all the regions, except in Africa and Middle East where the numbers are somewhat even (Table 5.5). The number of managers with more than five years of experience is the highest (30 per cent) in Latin America, followed by the Middle East region (28 per cent). 
The change of employment by overseas managers amongst MNEs is neither contemplated nor favoured except under extraordinary circumstances. Additionally, if the move is warranted it is generally in the first few years. Only managers at very senior level and possessing long years of experience with other corporations (especially overseas) were considered for overseas placements according to the explanation given by the corporate headquarters (Tables 5.4 and 5.5).

\section{NUMBER OF ASSIGNMENTS}

The typical span of an overseas assignment varies between two to three years though in some cases it may stretch to six or more years. For approximately 40 per cent of overseas managers the current assignment is their "maiden" assignment. Only 11 per cent have been to five or more foreign assignments (Table 5.6). For fifty percent of respondents the present placement was their second, third or fourth assignment. The general familiarity of theEuropean region for U.S. managers is quoted to be the reason for the majority of them being sent there on their maiden assignment.

Approximately 60 percent of the surveyed U.S. overseas managers have had overseas assignments. The number of managers whose current assignment is their first foreign placement is relatively higher in Middle Eastern and European regions than in Far Eastern and African regions. (Table 5.6). Latin American region's pattern seems to conform with that of the total. The overseas managers in their eleventh or higher assignment are there because of their specific expertise and their proven rapport with subordinates and the government officials in general according to an informal telephonic conversation with the personnel manager for overseas placements. 


\section{NUMBER OF YEARS IN THE CURRENT ASSIGNMENT}

Twenty-five per cent of U.S. overseas managers have been in their assignment for five years or more, with eight per cent being there for more than eleven years (Table 5.7). For 48 per cent of managers the current year is either first or second year of current assignment. In the Middle East and Africa, the number of managers in their first two years of assignment is 57 per cent and 60 per cent respectively. On the other hand, in these two regions there is no manager with six or more years in their current assignment. The reasons for such a scenario, perhaps, are the major thrusts by hotel and tourism industry whose reliance on younger (not necessarily age-based) cadre of managers has been alluded to earlier. The percentage of overseas managers with five years or more in their current assignment is approximately 35 per cent in Europe and 32 per cent in Latin America due to perhaps their distinct expertise manifested in their excellent business connections and/or their ability to get the work moving/done in the respective regions.

From the preceding tables (5.1 to 5.7 ) it is observed that generally speaking, the tendency is not to slate younger managers (below 25) for overseas assignment and also to assign rather sparingly those with fifty plus years of age (except Far East). Further, a greater proportion (more than two thirds) of overseas managers have had some experience with their respective present organisations either in domestic operations or in overseas operations, while one third to half of those responded seem to have worked with other organisations as well. Those on foreign assignments seem to fall evenly between beginners and veterans and also from the point of view of number of years in their respective current assignments. Fifty per cent of managers 
seem to be in their first two years, while others have spent three years or more at the same overseas placement.

\section{PROFILE AND OTHER CHARACTERISTICS OF EVALUATORS OF U.S. OVERSEAS MANAGERS' PERFORMANCE}

\section{AGE DISTRIBUTION}

Evaluators like overseas managers appear to fall within the 36 to 50 years of age group in a distinct manner. Only a negligible number $(6 \%)$ belongs to 26-35 years age range and the reason is self evident. However, one third of evaluators are from the 51 and above age group (Table 5.8).

The same pattern seems to be valid across the regions. The similarity in the age pattern for Middle East and Africa is more on account of less number of responses rather than being indicative of some other phenomenon.

From the point of view of experience with the present organisation whether domestic or foreign, the predominance is greater of those with more than five years of experience for the obvious reasons (Tables 5.9 and 5.10).

\section{EXPERIENCE PROFILE}

Domestic Experience With Present Organisation

A long stretch of association with the present organisation is as a routine viewed as a general prerequisite for one to be placed in such positions. The period of association may cover both the overseas experience as well as domestic as it tends to enhance familiarity with corporations' 
strategies, style of policy formulation and implementation and general operations.

\section{Overseas Experience With Present Organisation}

Virtually no evaluator seems to be without overseas experience with his present organisation, though 11 per cent of evaluators do not posses any domestic experience. This suggests that the evaluator has been in an overseas location since he has been appointed (maybe to supervise the large scale overseas operations). As may be expected, keeping the tradition of efficient management, hence efficient performance evaluation, besides the execution of other functions, is to be entrusted to experienced personnel, the fact reinforced by the collected data (Tables 5.9 and 5.10). These people having spent many years and virtually grown up with the company supposedly possess a distinctly prudent stance and ability for coordinating placements (and evaluation) with overall strategy and the concomitant requirements. Evaluators with relatively less overseas experience i.e. up to five years constitute approximately two fifths of the total, may underscore a tendency on the part of corporate headquarters to empathise with younger overseas managers, especially in Europe.

Domestic and Overseas Experience with other Organisations

From the viewpoint of experience in general with other organisations only 22 per cent of evaluators seem to be without any domestic experience while the number devoid of any overseas experience is approximately thirty nine per cent (Tables 5.11 and 5.12). 
Overall, the evaluators in each of the three duration-related classes of overseas experience with other organisations seem to be evenly balanced. Evaluators in charge of the Far East region seem to have relatively less overseas experience with other establishments than those in charge of the Latin American region. The pattern is consistent with domestic experiencespans with other organisations. The data appertaining the evaluators need to be looked at keeping in view their relatively small sample size.

A typical evaluator of overseas managers' performance seem to come from 36 to 50 year of age group, has substantial overseas and domestic experience with the present corporation and also some experience with other organisations. Invariably, all of the evaluators have been to the regions they are currently responsible for, the fact which makes them better informed, their professional stance more compatible, their views relatively more realistic, and hence less likely to conflict with and contradict those of overseas managers.

\section{SECTION ॥}

\section{U.S. OVERSEAS MANAGERS' PERCEPTIONS OF FOREIGN CULTURAL FACTORS}

Section 2 of the questionnaire meant for overseas managers comprises of twelve questions, one each for the twelve specific cultural factors selected for the study. Each of the twelve cultural factors has two parts: ' $A$ ' pertaining to the general perception of the specific cultural factor and 'B' the other part contains a list of eight questions dealing with the eight specific aspects of managerial performance. 
In order to minimise the possibility of a specific cultural factors' meaning from being construed or understood or appreciated differently by respondents, it was decided to provide a definition of each cultural factor in the relevant question itself. These definitions were based on prior studies. In part $\mathbf{A}$ of each question the respondent was asked a general type question with a view to elicit his common perception on the lines of being highly unfavourable to being highly favourable on a likert scale of 1 to 7 . Part $\mathbf{B}$ of each question appertains the application of that common perception to the eight specific aspects of managerial performance on a similar scale of 1 to 7 . Where the response sought was different, the explanation of the same was provided along with the question.

Although no assurance can be given that overseas managers and evaluators responding to the questionnaires had identical understanding and appreciation of the cultural factors, the explanations provided with the questions were assumed to control variations in their perceptions of the cultural factors as much as was possible. The pretesting and the pilot part of the questionnaire testing too was undertaken with the same objective in mind. Nevertheless, results should be evaluated in the context of the definitions provided to the respondents and the above observations.

The views of U.S. overseas managers about the twelve specific cultural factors have been provided in two formats. The group of figures 5.1 to 5.6 and the group of tables 5.13 to 5.24 and 5.37 to 5.60 exhibit the general perceptions of overseas managers for the specific cultural factors both in graphical as well as in numerical (quantitative) form. An attempt has been made through the use of tables to present a comparative view of the average perceptions of cultural factors extant in each region and separately also of each of the twelve selected cultural factors across the five regions. It is 
contended that this tabular variety provides both the intra-regional as well as inter-regional comparison of the average perceptions of cultural factors and their influence on the selected aspects of managerial performance .

\section{GLOBAL (AGGREGATE) PERSPECTIVE}

Figure 5.1 and table 5.13 provide a global (aggregate) perspective of their perceptions of these cultural factors. The general perceptions of U.S. overseas managers about the cultural factors: attitude toward education, attitude toward work and achievement, attitude toward scientific method, communication and language and sense of self and space seem to be of slightly favourable tenor as against the others: view of authority and subordinates, interorganisational cooperation, class structure and individual mobility, attitude toward risk taking, attitude toward change, attitude toward time and time consciousness and legal rules where they seem to register a slight discomfort in their perception. Attitude toward time and time consciousness on a global (aggregate) basis seems to be an irritant for the overseas managers while the attitude toward education appears to be a positive feature. ${ }^{1}$ These perceptions are sustainable if one observes the commonly held views of U.S culture. The positive stance in perception for the attitude toward education is more due to the basic educational requirements for personnel working within the multinational organisations.

The impact of these cultural factors on the eight specific aspects of managerial performance on a global (aggregate) basis is not at a significant variant from their general perception. The intensity of negative and positive

1 Mark Mendenhall and Gary Oddou," Acculturation Profiles of Expatriate Managers: Implications for Cross-Cultural Training Programs," Columbia Joumal of World Business, Winter 1986, pp. 73-79. 
perceptions of cultural factors on the performance variables seems to be of a moderate stance, perhaps more on account of overseas managers' general proclivity for these managerial functions and environments.

\section{REGIONAL PERSPECTIVE}

On a regional basis, however, the perceptions of managers are relatively better focused than when viewed from a global (aggregate) perspective, a feature which has more to do with the averaging effect.

The overseas managers assigned to the Far East region have a distinctly favourable perception about the attitudes toward education and toward scientific method, communication and language, sense of self and space and legal rules extant there (Figure 5.2 and Table 5.14). Attitudes toward risk taking, toward change, toward work and achievement and view of authority and subordinates are perceived to be slightly negative by the U.S. overseas managers. The remaining cultural factors are viewed as marginally positive. The effect of these perceptions on the specific aspects of managerial performance tend to follow the pattern of initial perception, i.e., if a cultural attitude is viewed as positive its perceived effect on the performance variable too will be positive. The exceptions are in the case of attitude toward work and achievement and view toward authority and subordinates ${ }^{2}$ where the general perception is slightly negative while the effect on performance variables is marginally positive more so for the ability to understand and execute duties. For US managers a particular cultural trait may be slightly negative if it does

2 John A. Reeder," When West Meets East: Cultural Aspects of doing Business in Asia," Business Horizons, January-February, 1987, pp. 69-74; M.C. Schnitzer, M.L. Liebrenz and K.K. Kubin, International Business (Cincinnati: South-Western Publishing, 1985) ; G.W. Renwick, Malays and Americans: Definite Differences. Unique Opportunities (Yarmouth, ME: Intercultural Press, 1977 and Summer 1980. "If Australian are Arrogant, Are Americans Boring?" The Bridge, 
not conform to the trait they are accustomed to, ${ }^{3}$ but the same may expedite a particular facet of performance as is the case for the above two cultural attitudes.

In the Middle East region the general perception of U.S. overseas managers for the selected cultural factors is on the negative side (Figure 5.3 and Table 5.15). The attitude toward punctuality in particular is viewed distinctly negative and because of that overseas managers feel themselves somewhat constrained in their ability to plan, organise, motivate, and to get things done. ${ }^{4}$ The attitudes toward education and toward work and achievement, in general are perceived to be marginally supportive but their effects are not perceived as supportive on the managerial performance variables which may be more on account of a lag in their (local employees) appreciation and hence application or unconscious reluctance. Suffice it may be to say that the general perception appertaining the selected cultural factors is that of slight discomfort for the general managerial tasks.

The perceptions about the cultural factors extant in Africa is somewhat mixed. Some factors such as attitude towards time consciousness, interorganisational cooperation, view of authority and subordinates are perceived as moderately negative while the attitudes toward education, work and achievement, and toward self and space as positive (Figure 5.4 and Table 5.16). The prevalent legal rules in the region are perceived as slightly negative but their perceived effect on the performance variables is relatively more intense. The attitude about punctuality is viewed as negative and its

3 Philip R. Harris and Robert T. Moran, Managing Cultural Differences ( Houston, Texas: Gulf Publishing Co., 1983), pp. 387-434.

4 lbid., pp. 466-75. 
effect is glaringly focused on the manager's ability to get things done. The phenomenon has already been noticed by early researchers. ${ }^{5}$ Though there are variations in the cultural factors across the African continent, but the general tendencies from U.S. managers' perspective are as manifested by their responses. Time is not of the utmost importance to most Africans. As a matter of fact, time is viewed as being unlimited. Similarly respect for authority is linked more with age rather than the placement in the organisational structure. ${ }^{6}$ Although the attitude toward education is viewed slightly positively but its influence on manager's ability to organise and motivate is not, instead, it is slightly negative which may be on account of delayed manifestation of this attitude in the typical work habits (ethics). However, the fact that comments are based on fewer responses should be kept in mind while interpreting the numbers and comments thereof.

The average perceptions of U.S. overseas managers of cultural factors in Europe are somewhat between slightly negative and slightly positive (Figure 5.5 and Table 5.17). Attitudes toward education, and scientific method are marginally positive while those toward risk taking, change, punctuality and sense of self and space are slightly negative. One may wonder about the attitude toward punctuality in European region being perceived as slightly negative. But to appreciate the latent underpinnings of this perception one must appreciate that it is the group of U.S. overseas managers which is perceiving the attitude to be a bit uncomfortable which may mean that it is at a variant with that extant in the U.S.A. It does not in any way imply that the attitude towards time and time consciousness is good or bad. At times too

5 llid., pp. $482-90$

6 Ibid., and P.C. Gutkind and I. Wallerstein, eds. Political Economy of Contemporary Africa (Beverly Hills, CA: Sage Publications, 1985). 
much or too little insistence on punctuality may produce similar reactions and hence similar perceptions. The responses from overseas managers seem to suggest that interorganisational cooperation is marginally stifling and its effect is perceived to be negative in general on the selected aspects of managerial performance. The general pattern of the tone and tenor of managers' perceptions about these cultural factors seem to be symmetrically followed by their perceived influence on the selected input variables of managerial performance.

A larger number of cultural factors of the Latin American region are perceived slightly negative than those which are perceived slightly positive (Figure 5.6 and Table 5.18). The ability to get things done is negatively influenced by the extant legal rules and interorganisational cooperation (the case of Ludwig forestry endeavour in Brazil is a case in point). ${ }^{7}$ The attitude toward time consciousness is regarded as negative by the U.S. managers and its effect is perceived to be negative on all the chosen aspects of managerial performance. The attitudes toward sense of self and space and education are somewhat slightly positive and so are their perceived effects on the input variables of managerial performance from the overseas managers' perspective. This may be partially explained by an innate urge to (easily) emulate the U.S. counterparts as these imply a feeling of belonging to an elite group.

The foregoing paragraphs provide a brief description and interpretation of the U.S. overseas managers' perceptions of the foreign

7 P.A. Harrison, Behaving Brazilian: A Comparison of Brazilian and North American Social Behavior, (Yarmouth, ME: International Press, 1985); Allan Dodds Frank, ,"We Have Had Our Recession," Forbes, 3rd January 1983; Jeremy Man, " The Argentinian Web Trapping U.S. Lenders," Fortune, 20th August 1984, pp. 122-32 and Howard Banks, "Bankruptcy Without Pain," Forbes, 29th April, 1985, pp. 110-2. 
cultural factors in general and also in the selected five regions as was stipulated in the first two objectives of this study. An attempt has also been made to comment briefly on the perceived influence of these foreign cultural variables on selected aspects of managerial performance. The inter-regional comment on the perception of each of the cultural factors and their effect on the selected aspects of managerial performance was not attempted. The hypotheses proposed for the second objective would be dealt with in the last section of this chapter.

\section{EVALUATORS' (OF OVERSEAS MANAGERS' PERFORMANCE) PERCEPTIONS OF FOREIGN CULTURAL FACTORS}

Objectives three and four of this study intended to present evaluators' perceptions appertaining the twelve foreign cultural factors both from a global (aggregate) as well as regional perspective. The intended emphasis has been on the level of consideration given to the perceived influence of each of these cultural factors on the eight selected aspects managerial performance in the performance evaluation of US overseas managers.

The views of the evaluators of the U.S. overseas managers' performance about the twelve specific cultural factors too have been provided in similar formats. The group of figures 5.7 to 5.12 and the group of tables 5.25 to 5.30 and 5.61 to 5.72 exhibit the general perceptions of the evaluators of overseas managers' performance for the specific cultural factors both in graphical as well as in numerical (quantitative) form. An attempt has been made to maintain the similarity in presentation of data appertaining U.S. overseas managers and their evaluators in all relevant aspects. 


\section{GLOBAL (AGGREGATE) PERSPECTIVE}

Except for the attitude toward education, the evaluators seem to perceive in general the cultural factors to have slightly negative to no impact at all (Figure 5.7 and Table 5.25). The consideration they seem to be according to the influence of these cultural factors on the overseas managers' performance while evaluating their performance tends to follow the same general pattern as that of U.S. overseas managers except for the view of authority and subordinates which is perceived to be slightly negative while the consideration given to its influence on the manager's ability to executive duties is assuming it to be slightly positive. Similarly the attitude toward work and achievement is perceived to be slightly positive while the consideration placed for its perceived influence on the selected aspects of managerial performance treats it slightly negative on a consistent basis.

\section{REGIONAL PERSPECTIVE}

The figure 5.8 portrays the evaluators' overall perceptions of these cultural factors and the consideration they appear to attach to their influence on performance factors during performance evaluation of U.S. overseas managers in the Far East. Evaluators for the Far East region like U.S. overseas managers in that region seem to view the attitude toward scientific method to be slightly positive while the attitude toward change is perceived as slightly negative. Surprisingly the consideration given to the influence of attitude toward scientific method treats it as slightly negative for both initiative as well as ability to get things done. The attitude toward education is perceived to be of neutral favourableness while its influence is accorded relatively high favourable weightage on performance factors such as ability to organise, initiative and ability to plan in performance evaluation. 
The evaluators for the Middle East region perceive only attitude toward education and that toward work and achievement to be slightly positive, however their influence on the eight aspects of managerial performance is in general accorded a slight negative weightage in overseas managers' performance evaluation. All other remaining cultural variables extant in this region are in general perceived to be slightly to moderately negative. Attitudes toward change, punctuality, ${ }^{8}$ toward authority and subordinates, scientific method, class structure and individual mobility and legal rules are all perceived to be negative. The effect of these variables on various aspects of managerial performance in general, too, is accorded a negative consideration in the performance evaluation except the effect of general attitude toward self and space which according to evaluators' perception should favourably influence the managers' ability to execute duties. However, the fact that there were only two 'evaluator-responses' from this region should not be overlooked while attempting to generalise the findings.

The lines showing the general tone of the evaluators' average perceptions of the cultural factors for the African region in Figure 5.10 are quite expressive. Except for the attitudes toward education and work and achievement the average perceptions about the cultural factors in this region are from slightly to moderately negative, many perceptions hovering around the latter (Table 5.28). The recognition accorded to their influence on various facets of overseas managers' performance too rely on this negative perception by the evaluators. Overall, it may not be unreasonable to state that the cultural factors and their influence on various performance input factors

8 Shahid L. Ansari and Jan Bell, "Symbolism, Collectivism and Rationality in Organisational Control," Accounting. Auditing \& accountability Journal, vol. 4, No. 2, 1991, pp. 4-27 and Philip R. Harris and Robert T. Moran, op cit., pp. 475-78. 
are both perceived to be negative by the evaluators. Nevertheless, the same caveat needs to be exercised while generalising the comments as the number of 'evaluator-responses' was only two.

The mean responses from evaluators of their perceptions of the selected cultural factors and weightage given to their effects on the eight specific aspects of managerial performance in their evaluation of U.S. overseas managers in Europe are provided in the figure 5.11 and table 5.29. Except for the attitude toward risk taking and for sense of self and space all other cultural factors are perceived to be favourable which strengthens the notion of general affinity amongst European nations and the U.S. The conspicuously positive perception of legal rules and attitude toward education lends further support to the above remark. However, the influence of these positively perceived factors on performance factors is not accorded a commensurate weightage during performance evaluation for this region. This may underscore a slight uneasiness on the part of managers as well as evaluators in getting adapted to these variables prevalent in Europe.

Figure 5.12 and table 5.30 provide the average perceptions of evaluators appertaining the selected twelve cultural factors in Latin America and the weightage given to their effects on the eight aspects managerial performance in their evaluation of U.S. overseas managers working in that region. It may be suffice to state that in general the evaluators for this region seem to perceive the cultural factors in a very narrow bend of slightly negative to slightly positive with many being perceived as having no impact. The consideration assigned to their effects on the chosen aspects of managerial performance is also similar, in tone and tenor, to the that of general perceptions of these cultural factors. 
The preceding paragraphs present a brief commentary on the evaluators' perception of the selected cultural factors in the five regions along with the weightage assigned to the perceived effect of each on the eight aspects of managerial performance in their performance evaluation of managers of these regions as was stipulated in the third and fourth objectives. No attempt has been made to present an inter-regional comparison of each of the cultural factors for its general perception and the weightage assigned to its perceived effect on the aspects of performance for the group of evaluators. Accordingly, no effort is made to attempt and present a generalisation. Also, this researcher has desisted from making generalisations based on 'evaluator-responses' as the number of responses from them was quite small. 


\section{SECTION III}

\section{HYPOTHESES TESTING AND DATA ANALYSIS}

This section of the chapter provides the results of various hypothesis tests which have been undertaken to help achieve the research objectives of the study. Research objective no. 2 intended to determine the impact of the specific cultural factors as perceived by the U.S. managers working overseas on their performance. Accordingly two sets of hypotheses were formulated:

H1: There is no difference among the mean scores representing the general perception and impact of a specific cultural factor on eight different aspects of performance as viewed by the U.S. managers working overseas. (There are twelve hypotheses, one for each of the twelve foreign cultural factors).

H2: There is no difference among the mean scores representing the impact of twelve selected foreign cultural factors on an individual aspect of performance as viewed by the U.S. managers working overseas. (There are eight hypotheses, one each for the eight selected aspects of the performance).

That is, for $\mathrm{H} 1$

Ho: $\quad \mu C F 1 A=\mu C F 1 B 1=\mu C F 1 B 2$ $=\mu C F 1 B 8$ $\mu C F 2 A=\mu C F 2 B 1=\mu C F 2 B 2$ $=\mu C F 2 B 8$

$\mu C F 12 A=\mu C F 12 B 1=\mu C F 12 B 2$ $=\mu C F 12 B 8$

and $\mathrm{H} 2$

Ho: $\quad \mu C F 1 A=\mu C F 2 A=\mu C F 3 A=\mu C F 4 A$ $=\mu C F 12 A$ $\mu C F 1 B 1=\mu C F 2 B 1=\mu C F 3 B 1=\mu C F 4 B 1$ $=\mu C F 12 B 1$

CF1B8 $=\mu$ CF2B8 $=\mu C F 3 B 8=\mu C F 4 B 8$ $=\mu C F 12 B 8$

(where CF - cultural factor,$A=$ general perception, and $B=$ perceived effect of CF on a performance aspect). 
It was decided to employ an $\mathbf{F}$ test in the repeated measures analysis of variance (ANOVA) using the GLM (General Linear Model) as the above hypotheses involve multiple means tests. As remarked in the previous chapter, an $\mathbf{F}$ test in ANOVA(only) tells if the means are significantly different from each other, but it does not tell which means differ from which other means. The GLM procedure, however, performs several multiple comparison tests and gives more detailed information about the differences among the means and allows one to control error rates for a multitude of comparisons. The GLM procedure also eliminates the possibility of incorrect results where analysis of variance involves unbalanced design (as is the case here on account of unequal responses from the five regions). ${ }^{9}$

The first group of twelve hypotheses attempts to test the equality of (nine) $)^{10}$ means in a string (vector) as these are provided in the columns of table 5.13. Similarly, the second group of eight hypotheses attempts to test the equality of (twelve) means given in each row of the same table. Initially, it was proposed to test for the cultural factor's effect only on the eight aspects of managerial performance, but later the hypothesis for the general perception (part $\mathbf{A}$ of each question) of the cultural factor was also included and hence, nine hypotheses were tested instead of eight as was originally contemplated. The inclusion of the ninth factor does not in any way influence the general tone of the analysis.

9 SAS/STAT User's Guide, Release 6.03 Ed. (Cary, NC: SAS Institute Inc., 1990), pp. 1923. and Chapter 11.

10 An important point to remember in this is that the first mean represents the general perception of a specific cultural factor and the other eight means represent the perceived effect of that general perception on a various aspects of managerial performance. The first mean relates to a distinct issue. Besides comparing the nature of the effect of a cultural factor on the aspects of performance an attempt is also made to identify the symmetry between general perception and the extent of perceived effect of that general perception on the selected aspects of managerial performance. Accordingly, the interpretation of results should consider this feature as well. 
The initial testing of the above hypotheses was done on the aggregate data provided in tables 5.13 and $5.19^{\circ}$. The details of the results of the hypothesis tests are provided in table 5.37 for Group $\mathrm{H} 1$ hypotheses and table 5.38 for Group H2 hypotheses.

All the twelve null hypotheses that the column string of means (Table 5.13) are equal were rejected. Across regions there is a significant difference in the U.S. overseas managers' perceptions of these cultural factors and their impact on the selected aspects of managerial performance. However, the test has not identified any statistically significant difference in the perceived impact of the cultural factors on the selected aspects of managerial performance within a region except for attitude toward education at 0.0005 level, ${ }^{11}$ view of authority and subordinates at 0.05 level, and for attitude toward work and achievement at 0.005 level. The computed $\mathbf{F}$ values with appropriate degrees of freedom relating to the twelve hypotheses are all significant at the 0.0005 level (Table 5.37) but it appears that the differences are more pronounced amongst regions than within regions.

The second set consisting of all the nine null hypotheses that the string of means as shown in each row (Table 5.13) are equal were also rejected. The test has identified that within and amongst regions there are

* The data from other tables: 5.14-5-18 and 5.20-5.24 were used to highlight within region characteristics wherever deemed appropriate.

11 A null hypothesis can be rejected in a test with a level of significance alpha, i.e., one can have confidence of at least $100(1-$ alpha $) \%$ that the null hypothesis is false. However, the strength of a reject statement in a hypothesis test may also be indicated through the use of the empirical level of significance or p-level that a test statistic exhibits. The empirical level of significance is the level of significance for which a test statistic is just barely significant. In a hypothesis test, the empirical level of significance is referred to as the p-level. It measures how significant the observed sample test statistics actually is. Unlike the level of significance alpha, which is set by the experimenter, the p-level is determined by the data. (E. A. Maxwell, Introduction to Statistical Thinking, Englewood Cliffs, New Jersey: Prentice Hall, Inc., 1983), pp. 291-92. 
significant differences in the U.S. overseas managers' perceptions of the these (12) cultural factors and also of their perceived effects on the selected aspects of managerial performance. The computed $\mathbf{F}$ values with appropriate degrees of freedom relating to the nine hypotheses are all significant at the 0.0005 level (Table 5.38).

On account of the general absence of differential perceived effects of a cultural factor on the selected aspects of performance (Table 5.37), an attempt was made to see whether there exists some correlation in managers' perceptions for the aspects of performance on an overall (global) basis. The computed correlation matrices for the entire sample are provided in tables 5.39 and 5.40. The reliability alphas ( $\alpha$ 's) for these matrices are high showing the general consistency in the understanding of the U.S. overseas managers with respect to the questions and responses thereof, thus, sustaining and strengthening the internal validity.

The twelve correlation matrices (Table 5.39) show that there is a high degree of correlation among the perceptions of managers of the effects of individual cultural factor/s on the aspects of performance. This may partially explain why the statistical tests (for $\mathrm{H} 1$ ) could not identify any statistically significant difference in the impact of the cultural factors on the selected aspects of managerial performance within a region. The correlation matrices for the attitudes toward education, view of authority and subordinates and work and achievement show relatively smaller correlation coefficients and thus, tend to explain (at least partially) why some significant differences among the perceived effects of (these) cultural factors were identified.

Correlation matrices (nine) based on aggregate responses were also produced for the perceived effects of twelve cultural factors for each individual 
aspect of performance along with the question on general perception (Table 5.40). These correlation matrices also have high reliability alphas ( $\alpha$ 's) and consistently lower correlation coefficients. This may partially explain the identification of statistically significant differences on an overall basis amongst for $\mathrm{H} 2$ group of hypotheses.

The results of the second set of hypotheses and the associated nine correlation matrices indicate that there are significant differences in the perceived effects of the twelve cultural factors on individual aspects of managerial performance. However, it was proposed in the preceding chapter to explore whether or not any of these cultural variables are significantly interrelated with respect to their general perception, a test for multicollinearity was undertaken.

\section{Multicollinearity}

The 'Collin" option in REG Procedure (in SAS) was employed to diagonise multicollinearity for the aforementioned purpose. ${ }^{12}$ The procedure provided the eigenvalues, condition indices, and decomposition of the variance of the estimates with respect to each eigenvalue. The procedure also provided the $\mathbf{F}$ value, its associated $\mathbf{p}$ value with relevant degrees of freedom, $\mathbf{R}^{\mathbf{2}}$ and $\mathbf{t}$ values for the estimates of relational (regression) coefficients for each of the eight aspects of managerial performance.

The results so obtained confirmed the validity of the findings of the $\mathrm{H} 2$ set of hypotheses and also identified the existence of moderate to high multicollinearity as shown by the significant $\mathbf{F}$ statistics and their associated $\mathbf{p}$

12 Regression model being $\mathrm{B} 1=\mathrm{F}(\mathrm{CFA} 1+\mathrm{CFA} 2+\mathrm{CFA} 3+\ldots \ldots \ldots \ldots+\mathrm{CFA} 11+\mathrm{CFA} 12)$. SAS/STAT User's Guide, 4th Edition, version 6, volume 2, 1990, pp. 1416-8. 
values, high $\mathbf{R}^{\mathbf{2}}$, a few low $\mathbf{t}$ values and moderately large condition indices. In order to improve the robustness of the model and to provide a more precise relationship between cultural (explanatory) variables and aspects of performance (dependent variables) it was decided to drop those cultural variables whose associated $t$ values were less than 1 .

This procedure is a systematic but arbitrary way of exploring the importance of a subset of the cultural (explanatory) variables in explaining the differences in the perceived effects on the aspects of managerial performance. In the present case whenever the exclusion of variables, whose estimated coefficients had $t$ values less than 1 , significantly affected the magnitude of the re-estimated remaining coefficients, the fact has been highlighted and reported. The pretesting issues it introduces are recognised but have not been considered for further evaluation.

In case of all the eight aspects of managerial performance the cultural variables with $t$ value of less than 1 were dropped (Table 5.42). The exclusion of four cultural variables, namely, attitude toward education, view of authority and subordinates, attitude toward change and sense of self and space in the case of ability for effective decision making aspect of performance, did not have any significant effect on the $\mathbf{R}^{\mathbf{2}}$. The associated $\mathrm{F}$ statistic and condition index improved (Table 5.41). Similarly, in the case of the ability to motivate aspect of performance the deletion of attitude toward education, view of authority and subordinates, attitude toward work and achievement and attitude toward change did not have any effect on the overall relationship. The attitude toward change and view of authority and subordinates variables did not have much to contribute towards the relationship of the perception of cultural variables with seven out of eight aspects of performance. Similarly, 
the attitude toward education did not have any significant effect on five out of eight aspects of performance (Table 5. 42).

By way of facilitating the juxtaposition between before and after multicollinearity test the table 5.41 provides the estimated and re-estimated coefficients together with their respective $t$ values for the first dependent variable only. While, the details relating to the changed $\mathbf{F}$ statistics, $\mathbf{R}^{\mathbf{2}}$ and Adjusted $\mathbf{R}^{\mathbf{2}}$, condition indices and the re-estimated coefficients of independent variables together with their respective $t$ values are provided for all the dependent variables. The associated $t$ values of all the remaining variables have increased (but not much) thus underscoring the relative improvement in the reliability of their relational parameters.

The attitude toward change and view of authority and subordinates factors would have been totally dropped from the analysis of this study but for their relatively significant contribution toward explaining the differences in the perceived effects respectively, on 'initiative' and 'ability to plan' aspects of managerial performance. Accordingly, it was decided to keep all the twelve cultural factors and to make references of their relative lack of relevance in appropriate cases.

From a global perspective the preceding discussion of multicollinearity test and its results provide the comparative relevance of cultural factors for managerial performance and its specific aspects. However, looking at these individually one may still discern their differential effects on various aspects of managerial performance. The point to note is that they may have different levels of relevance in different regions and countries. The discussion of the issue of multicollinearity at the regional level has been provided in the section on inter-regional comparisons. 
An attempt has also been made to identify which particular aspect of performance differs significantly from the others in its perceived effect of a cultural factor for the entire sample. Data from tables 5.13 and 5.19 were used and the findings are provided in table 5.43. The table also provides the differences, if any, between the general perception of a cultural factor and its perceived effect on the eight aspects of managerial performance. The SAS/STAT procedures ${ }^{13}$ used for this is the Analysis of Variance (ANOVA) T Tests (LSD) which controls the type I comparison wise error. With alpha $(\alpha)$ of 0.05 the tests identified that no statistically significant differences exist between the mean responses for the general perception of a cultural factor and its perceived effect on the eight aspects of managerial performance for cultural factors: class structure and individual mobility, attitude toward risk taking, attitude toward change, communication and language and relevant legal rules of the game.

However, statistically significant differences have been identified for the other cultural variables, such as attitude toward education, view of authority and subordinates, attitude toward work and achievement, attitude toward scientific method and sense of self and space in the terms of their general perception (A) and their perceived effect on the eight aspects of managerial performance (Table 5.43). A cultural factor may be perceived in general as favourable or unfavourable, however the perception of its specific effect on an aspect of performance may or may not be significantly the same, the feature which may underscore its differential relevance for specific aspects of performance. op. cit., Chapter 11. 
This table (5.43) provides those specific cultural factors, the mean response of whose effect on a particular aspect of managerial performance is significantly different from the others which have been identified in the last column. The directionality ${ }^{14}$ of the significant differences have also been indicated accordingly with GT (greater than) or LT (less than) to show whether the pooled (aggregate) mean for a response is higher or lower than those for other responses (representing aspects of performance) so identified.

For example, for cultural factor -- interorganisational cooperation there is a significant difference (GT) in the overseas managers' perception of its effect on their ability to understand and execute duties (B4) and their perceptions for its effect on their ability to get things done (B7). In this analysis, the direction and extent of the differences are also highlighted (Table 5.43).

An attempt has also been made to identify which particular cultural factor's effect is significantly different from others on a particular aspect of performance in an aggregate sense for the entire sample. Data provided in tables 5.13 and 5.19 were used to accomplish this by employing procedures of

14 It may be appropriate to mention that the feature of 'directionality' and the 'degree' thereof should be understood and appreciated in a general sense rather than in a specific and precise vein. It is aptly remarked, "Cartography provides another example which is perhaps even more analogous to the above case. The maps of the world which cartographers produce using the conventional 'Mercator projection' are known to distort the apparent area of land masses at high latitudes; indeed, it is known to be impossible to produce a completely accurate flat map because of the impossibility of projecting an approximately spherical body (the planet) onto a flat surface. On the other hand, Mercator maps have a high representative accuracy with respect to direction, e.g., if city A is further east than city B on the globe, then city A will always appear to the right of the city B on a flat map. Thus, navigators find Mercator maps useful because of their accuracy in the 'direction' sense; it does not matter that they incorporate distortions in other ways because serious users of maps are aware of the restrictive assumptions under which they were prepared, and evolve their own tactics for dealing with any resulting deficiencies. By extension, it follows that management accounting models do not necessarily have to fully represent all aspects of decision situation in order to be useful. Other information sources and/or the exercise of managerial judgment can compensate for any restrictive assumptions of a model." John Currie, "The Role of Quantitative Models in Management Accounting Education," British Accounting Review ,1992 , pp. 3-16 (emphasis added). 
the Analysis of Variance (ANOVA) T Tests (LSD) which controls the type I comparison wise error and the results are provided in table 5.44. The table provides the specific aspects of managerial performance for which there exist statistically significant differences between the effects of specific cultural factors.

With alpha of 0.05 the tests identified that statistically significant differences exist between the mean responses for the twelve cultural factors in terms of their general perception (A) amongst U.S. overseas managers (research objective 1) and also in terms of their perceived effects on virtually all the eight aspects of overseas managers' performance (Table 5.44). The general direction (favourable and unfavourable perception) has also been identified with the use GT and LT for the aggregate (pooled) mean representing the perceived effect of the given cultural factor being higher or lower than those means representing the effects of the cultural factors identified in the last column.

The differences which are statistically significant at alpha of 0.005 and 0.001 for general perception for cultural variables and also for their perceived effects on the specific aspects of managerial performance have been appropriately identified in tables 5.43 and 5.44. However, while interpreting the results shown in table 5.44 for the performance evaluation of the U.S. overseas managers, the fact that a few of the cultural factors are interrelated with respect to their perceived effects on aspects of managerial performance must not be overlooked.

On account of relatively fewer responses from the evaluators of the U.S. overseas managers' performance no similar hypotheses were 
formulated. Therefore, no such elaborate attempt was undertaken to test (and interpret) for the statistically significant differences amongst the perceived effects of cultural factors on a single aspect of managerial performance or the perceived effects of a single cultural factor on various aspects of managerial performance either within or among the five selected. regions. ${ }^{15}$ For the same reason the test for multicollinearity was not undertaken.

The preceding paragraphs present the details of the statistical tests undertaken to test the proposed hypotheses. All the null hypotheses were rejected, however, the tests failed to identify any statistically significant differences in the perceived impact of the cultural factors on the selected aspects of managerial performance within a region except for attitude toward education, view of authority and subordinates, and for attitude toward work and achievement. The details also provide the directionality and relative extent of these differences.

\section{COMPARISON BETWEEN MANAGERS AND EVALUATORS}

Another set of comparisons proposed for this study was to identify the significant differences between groups of U.S. overseas managers and the evaluators of their performance in their general perceptions of the twelve cultural factors. Comparisons were also proposed between the overseas managers' perceptions of the effects of these factors on the eight specific aspects of performance and the consideration accorded to the impact of these

15 However, the pertinent information resulting from the identical hypothesis tests at various levels of alpha (e.g. $0.05,0.005$ and 0.001$)$ using the data presented in tables 5.255.36 for statistical significant differences among the effects of a cultural factor or the effects of cultural factors on a specific aspect of managerial performance on aggregate data have been summarised and presented in tables $5.47-5.52$ It must be stated that the results so obtained be accepted and used with the knowledge that these are based on comparatively fewer (18) responses. 
specific foreign cultural factors by the evaluators in evaluating the performance of U.S. executives working overseas.

The proposed hypotheses (that is no. 3 and 4) were:

Ho: There is no difference between the mean scores representing the view of the U.S. managers working overseas and performance evaluators regarding twelve selected foreign cultural factors.

Ho: There is no difference between the mean scores representing the views of the U.S. managers working overseas and performance evaluators regarding the impact of twelve specific foreign cultural factors on the selected eight aspects of performance.

To test for the equality of vectors of means representing the responses of overseas managers and their evaluators regarding their general perception of the cultural factors and the perceived and considered effect of these variables on the specific aspects of performance, the Hotellings $\mathbf{T}^{\mathbf{2}}$ test, the multivariate extension of the univariate $\mathbf{t}$ test was employed.

The results of comparisons of vectors of means representing the general perceptions ( row A, Table 5.53) of the twelve cultural factors between the two groups of managers and evaluators from the five selected regions (in aggregate) produced by Hotellings $\mathrm{T}^{2}$ test did not yield any statistically significant difference. Similarly, no statistically significant differences were identified between these two groups when the vectors of means representing their (aggregate) responses regarding the perceived effects of twelve selected cultural factors on the eight specific aspects of performance were compared (rows B1 to $\mathbf{B 8}$, Table 5.53).

An attempt was also undertaken to see whether there are any significant differences between these two groups in their views regarding the 
perceived effect of twelve cultural factors on individual aspects of managerial performance. The Hotellings $T^{2}$ test/s undertaken to test the similarities between managers and their evaluators on sectional (individual rows of means) basis, too, failed to identify any statistically significant differences. Hence, both the null hypotheses (no. 3 and 4 ) failed to be rejected by the statistical tests.

The consideration of the outcome of multicollinearity tests for the U.S. overseas managers while carrying out the above comparison tests was not undertaken as the similar tests for the evaluators were not carried out on account of fewer responses from the latter group.

On account of fewer responses from evaluators responsible for individual regions no attempt was undertaken to test for differences in the perceptions of U.S. overseas managers and their evaluators relating to the twelve cultural factors and their effect on the selected aspects of managerial performance on regional basis.

However, an attempt was also made to explore whether some statistically significant differences exist for some questions relating to cultural factors and their perceived effects on aspects of managerial performance within a specific region. Within Far east as well as Middle east, the tests failed to identify any significant difference in any of the pair-wise comparisons between overseas managers and their evaluators. While, in Africa, Europe and Latin America, on some pair-wise comparisons statistically significant differences were identified between overseas managers and their evaluators at 0.05 level (Tables 5.54 and 5.55 ). 
For example, in Africa managers and evaluators differ significantly in their general perception of a cultural factor relating to sense of self and space and its perceived effect on ability to motivate and ability to get things done. While in Europe they differ with regard to their general perception of view of authority and subordinates, class structure and mobility and relevant legal rules and their perceived effects on ability to organise, ability to motivate and ability to get things done. In Latin America, statistically significant differences were identified with regard to cultural factors; attitude toward time and time consciousness and extant attitude toward legal rules and the perceived effect of the latter on managers' ability to plan, to organise, for effective decision-making, to execute duties and overall performance. The perception also differs on the effect of punctuality on ability to get things done (Table 5.54-5.55).

The presence of some statistically significant differences between the views of groups of U.S. overseas managers and their evaluators regarding cultural factors and their effect on managerial performance within a region stems from a notion (belief) on the part of evaluators that cultural factors such as view of authority and subordinates, class structure and individual mobility, attitude toward punctuality, sense of self and space, and legal rules should become more acceptable, less cumbersome and less stifling over time. Other plausible explanations appear to be that the factors may be some what nonfacilitating (an irritant) when constantly being interfaced with versus from being observed from a vintage distance and accorded a moderate consideration only.

However, the fact that the groups compared were of unequal size in general (in aggregate) should be kept in mind to temper the generalisability of the results so obtained. The same comment can be made for specific regions. 
The phenomenon of pervasive similarities between the groups of the U.S.overseas managers and their evaluators in their general perception of the twelve cultural factors and also regarding the perceived effects of them on the specific aspects of managerial performance stems from the fact that virtually all the evaluators have been to those regions for whose managers' performance evaluation they were responsible for. The fact of their being familiar with the cultural variables extant in those regions made it possible (coincidentally rather than as a result of some policy action), it is assumed, for the presence of general similarity between managers and evaluators. From the informal talks held with the corporate headquarters, there was no evidence that some concerted effort might have been undertaken to incorporate these features in the managerial performance evaluation system.

Although separate hypotheses were not proposed to identify the differences in the perceptions of cultural factors and their effect on the aspects managerial performance for the evaluators but the tests run on their (aggregate) responses indicate the presence of (an uncanny) general similarity with the overseas managers' perceptions of cultural factors and their perceived effects on the aspects of managerial performance (Tables 5.475.52).

\section{INTER-REGIONAL COMPARISONS}

Although no specific hypothesis were initially formulated and proposed but in order to provide a brief prelude to the actual accomplishment of research objectives 7 and 8 (that is hypotheses 5 and 6 ) an attempt is made to present between (pairwise) regions comparisons by using the analysis of variance procedure T Tests (LSD). This procedure controls the type I 
comparison wise error and was performed on the twelve selected cultural factors as well as on the eight specific aspects of managerial performance using the data of tables 5.14-5.18 and 5.20-5.24 and the results are provided in tables 5.45 and 5.46 .

With alpha of 0.05 and using the pooled mean responses from the U.S. overseas managers statistically significant differences were identified for all the twelve cultural factors between and amongst the selected five regions, thus reinforcing the findings of the repeated measures analysis of variance for testing the string of means (Table 5.37 and 5.38). However, no statistically significant difference was identified between Africa and the Middle East for the following cultural factors:

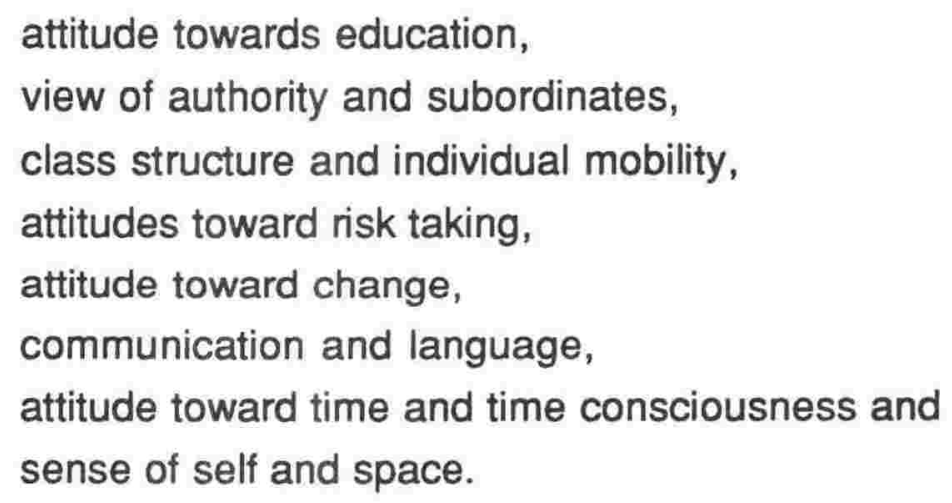

Similarly, no statistically significant differences were identified between Latin America and Europe for cultural factors:

view of authority and subordinates, interorganisational cooperation, class structure and individual mobility and communication and language.

Other statistically significant differences between other regions for other cultural factors are provided in table 5.45. 

mean scores representing the views of the U.S. overseas managers working in the five selected regions regarding the impact of twelve cultural factors on the selected eight aspects of performance is rejected. These tests not only underscored the rejection of the null hypotheses of equality of mean responses across five regions but also provided detailed information on pairwise comparisons between these regions for cultural factors as well as their perceived effect on the specific aspects of performance.

A panoramic view is provided in a consolidated format to highlight the inter-regional statistically significant differences among means of responses of the U.S. overseas managers about their perceptions of foreign cultural factors and their perceived effect on the aspects of managerial performance across regions (Table 5.56). The table provides information from a univariate perspective about the significant differences in cultural factors across the selected regions.

The tests for multicollinearity were also undertaken for the regional responses following the similar procedure (that is, to drop those variables whose estimated coefficients have a $t$ value of less than 1) as was adopted for the global responses. The test could not be run for the African region as the number of observations (responses) were less (ten) than the number of explanatory variables (twelve). The results so obtained are presented in tables 5.56-5.59 and 5.60-5.63. Cultural variables such as attitude toward risk taking and legal rules in the Far East seem not to have any significant effect on any of the aspects of managerial performance. This feature suggests that the U.S. overseas managers do not perceive these two variables to have any effect, that is, they do not find these variables to be different from those they have been exposed to in the United States. Similarly, in Latin America they do not perceive the attitude toward class structure and individual mobility to be 
affecting any aspect of their managerial performance. The tests failed to yield any meaningful results for the Middle Eastern region. Overall these findings tend to confirm the results of earlier hypotheses tests.

As mentioned earlier in chapter four descriptive statistics and univariate tests of significance provide basic information about the distributions of the variables in the groups and help identify some differences among the groups. However, in discriminant analysis as well as in multivariate statistical procedures, the emphasis is on analysing the variables togather, not one at a time. By considering the variables simultaneously, one is able to incorporate important information amongst their relations. ${ }^{16}$

The Wilks' likelihood $(\Lambda)$ criterion was used to accomplish research objective 7 , that is, hypothesis 5 , to ascertain the similarities and differences among the views of the U.S. overseas managers of the five selected regions regarding the twelve specific cultural factors. For research objective 8 (i.e. hypothesis 6) to explore the differences (if any) in the perceptions of U.S. overseas managers about the impact of cultural factors on the specific aspects performance on a regional basis, the Wilks' likelihood criterion $(\Lambda)$ was used. As mentioned in chapter four, Wilks' lambda $(\Lambda)$ is the likelihood ratio statistic for testing the hypothesis that the means of the classes on the selected variables are equal in the population. Wilks' lambda $(\Lambda)$ is close to zero if any two groups are well separated.

16 In discriminant analysis, a linear combination of the independent variables is formed and serves as the basis for assigning cases to groups. Thus, information contained in multiple independent variables is summarised in a single index. This is accomplished by finding a weighted average of those significant variables which can provide a score that will distinguish the members of one group from those of another. In discriminant analysis, the weights are estimated so that they result in the "best" separation between (or among) the groups. 
The hypotheses ( no. 5 and 6):

Ho: that there is no difference among the mean scores representing the views of the U.S. overseas managers working in the five selected regions regarding the twelve specific foreign cultural factors

and

Ho: that there is no difference among the mean scores representing the views of the U.S. overseas managers working in the five selected overseas regions regarding the impact of twelve specific foreign cultural factors on the selected eight aspects of performance.

The computed Wilks' lambda of 0.4094 , having an $F$ value of 2.3351 with appropriate degrees of freedom $(48,430)$ has a probability for $F$ of 0.0001 which means that based on all the twelve foreign cultural factors there are significant differences across regions (Table 5.65). Thus, the hypothesis no. 5 that there is no difference among the mean scores representing the views of the U.S. overseas managers working in the five selected regions regarding the twelve specific foreign cultural factors is rejected. However, it must be stated that the value of Wilks' lambda does not indicate that all the variance is explained by among group differences. The value of lambda should be as low as possible in order to be a good predictor. ${ }^{17}$

For the hypothesis no.6 the likelihood criterion $(\Lambda)$ was calculated based on 96 variables (12 cultural factors $\mathrm{x}$ eight aspects of performance). The computed value of Wilks' lambda 0.00107 , and the associated $F$ value of 1.3101 , with appropriate degrees of freedom $(384,110)$ have an associated probability level for $\mathrm{F}$ of $(0.0449)$. Which rejects the above-mentioned

17 It is important to remember that even though Wilks' lambda may be statistically significant, it provides little information about the discriminant function in the classification. It only provides a test of null hypothesis that the population means are equal. Small differences may be significant but, still not permit good discrimination among groups. 
hypothesis no. 6 that there is no difference among the mean scores representing the views of the U.S. overseas managers working in the five selected overseas regions regarding the impact of twelve specific foreign cultural factors on the selected eight aspects of performance.

The calculated statistic $(\Lambda)$ satisfies the usual condition to be a good predictor of significant differences across regions. The calculated likelihood criterion $(\Lambda)$ for each hypothesis indicates that the means representing the U.S. overseas managers' general perception of the selected cultural variables as well as of the perceived effect of these cultural variables on the specific aspects of managerial performance across five regions are significantly different. Both the tests were based on the respective entire groups of the variables submitted for the inclusion for the computation of Wilks' lambda..

An attempt has also been made to isolate foreign cultural factors which may explain the differences in impact on performance on a regional basis. For this purpose K-group Multivariate Discriminant Analysis (MDA) was employed.

The stepwise discriminant procedure ${ }^{18}$ was used but, discrimination was not found to be robust when general perception of only twelve cultural

18 In stepwise discriminant procedure variables are chosen to enter or leave the model according to one of the two criteria: (i) the significance level of an $\mathbf{F}$ test from an analysis of covariance, where the variables already chosen act as covariates and the variable under consideration is the dependent variable, or (ii) the squared partial correlation for predicting the variable under consideration from CLASS variables, controlling for effects of the variables already selected for the model. It is generally advised to specify a small significance level where the focus is on including only those variables with significant contributions to discriminatory power of the model rather than to maximise the probability of correct classification. The significance level and the squared partial correlation criteria select variables in the same order, although they may select different number of variables. Sample size may have some effect on the number of variables selected using significance level but no effect while using squared partial correlations. Under SAS packages the default value of significance level for adding or retaining variables in the model is 0.15 . A variables is entered only if its tolerance and the tolerance for variables in the model are greater than the value specified (default 1E-8).

The stepwise method is better than (simultaneous) when one wants to consider a relatively large number of independent variables for inclusion in the function. By sequentially selecting the next best discriminating variable at each step, variables which are not useful in 
variables was considered (Table 5.66-68). The computed value of Wilks' lambda based on the four discriminating variables out of 12 suggest the presence of significant discrimination (see $\mathrm{F}$ value and associated probability) but not a good one (0.56154). The same conclusion is confirmed with the results of table 5.67 showing the pairwise generalised squared distance between regions. The position of group centroids is not distinct on the selected four dimensions as is also proven by the poor hit ratio of $52.79 \%$ (classification error rate 0.4721 ). There is misclassification in every region which suggests substantial overlapping amongst regions.

To accomplish the second part of research objective no. 8 , the stepwise discriminant was employed to isolate the subset of quantitative variables (from 96) to produce a good discrimination model. The set of variables that make up each class is assumed to satisfy the assumptions for deriving discriminant functions, that is, multivariate normality of the distribution with an equal dispersion and covariance structures. ${ }^{19}$

The stepwise discriminant procedure identified after twelve iterations those cultural variables (Table 5.69) together with their perceived effect on specific aspects of managerial performance which provide a statistically significant discrimination among the selected five regions (listed in succeeding paragraph). The average squared canonical correlation (ASCC) if close to 1 indicates that all groups are well separated and in all or most directions in the discriminant space show a good separation for at least two

discriminating between the groups are eliminated and a reduced set of variables is identified. The reduced set typically is almost as good as, and sometimes better than, the complete set of variables. ( Joseph F. Hair, Polph E. Anderson, Ronald L. Talham and Bernie J. Grablowsky, Multivariate Data Analysis, Oklahoma:Petroleum Publishing Company, 1979, pp. 96-7).

19 There is however, evidence that discriminant analysis is not very sensitive to violation of these assumptions unless the violations are extreme. This is particularly true with large sample sizes. (R.J. Harris, A Primer of Multivariate Statistics, New York: Academic Press, 1975). 
groups. It is evident from the table that with every new variable selected for inclusion the separation amongst regions became better as is evident by $F$ statistic, Wilks' lambda, ASCC and their appropriate probabilities.

The effect of attitude toward education 'on overseas managers' ability for effective decision-making (CF1B3); interorganisational cooperation's effect on their ability to get things done (CF3B7); the effect of attitude toward work and achievement on their ability for effective decision-making, ability to understand and execute duties, and ability to motivate (CF4B3, CF4B4, CF4B5); the effect of attitude toward scientific method on their ability for effective decision-making, initiative, and ability to get things done (CF6B7, CF6B6, CF6B3); communication and language used in the region/s and its effect on managers' ability to get things done (CF9B7); the effect of attitude toward time and time consciousness on ability to get things done (CF10B7); sense of self and space extant in the region/s and its effect on managers' ability to motivate (CF11 B5) and legal rules prevailing in the region/s and their effect on overseas managers' ability to organise (CF12B2).

The group centroids (Table 5.70) are distinct although these are based on 12 dimensions. The robustness and significance of selected variables in discriminating across regions is further reinforced by the classification summary with a hit ratio of $99 \%$ (Table 5.71). Virtually, there is no overlapping in classification of subjects across regions. There is only one respondent which has been misclassified between Europe and Latin America. In the other regions the results of classification are perfect. Hence, it can be safely concluded that these 12 variables provide good and significant discrimination (predictors) amongst regions. 
Nevertheless, the results and conclusions must be accepted and used in the light of the fact that the sample size was relatively small in general as well as for a few regions. The findings of tests for multicollinearity between the U.S. overseas managers' perceptions of foreign cultural factors with respect to their effects on the aspects of managerial performance at the global level as well as at the regional level should be accorded a careful consideration in developing a comprehensive framework of their (overseas) performance evaluation. Also, the fact that this research endeavour relies on U.S. overseas managers' perception of foreign cultural factors which may (ought to) have something to do with their own culture should not be overlooked while evaluating the conclusions of this study. Further, care has consistently been exercised to desist from making any value-based remarks, instead the results and conclusions are based on statistical findings supported by the collected data.

The preceding paragraphs provide a brief discussion of those cultural factors which are significantly different across regions on the basis of their being so perceived by the U.S. overseas managers in general and/or on the basis of their perceived effect on managerial performance. In the testing of both the hypotheses (that is no. 5 and 6) cultural factors: interorganisational cooperation, attitude toward work and achievement, attitude toward time and time consciousness and sense of self and space (CF 3,4,10 and 11) are found to be statistically significant. These cultural factors distinctly (discriminatingly) influence the managers' ability to get things done and ability to make effective decisions. For hypothesis no. 6, perception of effects of four other cultural factors were identified to be discriminating among regions.

No attempt was either proposed or undertaken to identify linear discriminant functions based on the variables under study in the sense of 
dimension reduction (such as factor analysis, principal component analysis etc.). Typically, that exercise would have identified four uncorrelated discriminant functions $(k-1)$ which would have maximised the ratio of amonggroups to within-groups sums of squares.

This chapter had three purposes. The first was to identify the U.S. Overseas managers' profiles and other pertinent characteristics. The second purpose was to present a descriptive account of overseas managers' perceptions of foreign cultural factors and their impact on the performance of managers. Concurrently, an attempt was also made to present the general profile of the evaluators of performance of overseas managers. A descriptive account of evaluators' perceptions relative to the foreign cultural factors and their impact on US overseas managers' performance was also presented and discussed. Finally, the last section relates to the results of the tests of various hypotheses and presents the results and interpretation of data analysis. It also provides the discussion of the reliability and validity of the findings of this study.

This chapter was the culmination of the design, data collection, data analysis and findings of the research in relation to the stated objectives. The next chapter presents the summary of the conclusions reached and recommendations for further research. 


\section{CHAPTER VI}

\section{SUMMARY, CONCLUSIONS, AND RECOMMENDATIONS FOR FUTURE RESEARCH}

This chapter is a discussion of the implications of this research study. Before considering the significance of the results, a brief summary of the nature and purpose of the research is presented. The research results are then discussed and followed by recommendations for future research in the area of performance evaluation and cultural (environmental in a broader sense) variables in the context of multinational enterprises.

\section{Summary of the Nature and Purpose of the Research}

Many authors have been concerned with international business and the management of (American) interests abroad. Most of this literature deals with the utilisation of U.S. management philosophies and techniques abroad. With an ever increasing direct investment by U.S. corporations, there is a growing number of businesses becoming multinational, resulting in the assignment of a sizeable number of U.S. managers to overseas locations. While there are convincing arguments for employing local nationals, nonetheless there will still be an increasing number of Americans employed as more and more companies expand overseas. As a result, it has become more than ever necessary that American business leaders generally, and not merely those with specialised international responsibilities, learn to transcend their backgrounds and adopt a world view. 
These American expatriates occupy senior managerial positions of authority and responsibility because of which the degree of success achieved by the foreign subsidiary depends heavily on them and their performance. It is self evident that one of the more crucial determinants of efficient and effective conduct of ever-growing operations of U. S. multinational enterprises is the performance of the U. S. expatriates.

Multinational corporations and their subsidiaries are important players in the international game especially to cope with a fluid environment with potentials to influence various aspects of MNE's operations. Certainly, management behaviour is influenced by the technological characteristics of business, the attitudes and policies of government, and the type and level of economic development. The relationship between management and each of these systems is important. Even the most ardent Universalist advocating application of principles of management in all countries recognizes that cultural factors such as class structure, attitudes toward money and work, or the meaning of authority influence how management is or could effectively be conducted.

The complex and diverse nature of overseas environments has a significant influence on the effectiveness of managerial personnel and hence business operations. Consequently, the task of identifying, evaluating and predicting environmental variables assumes crucial and greater significance. Also, it is widely acknowledged that because of growing competition from nonAmerican multinational enterprises and dynamic underpinnings of international management, the performance of expatriates can no longer be measured against the criterion of their relevant knowledge and skills alone. 
Multinational business brings with it many unique problems in the management of resources, the most fundamental of which is the necessity for managers raised and experienced in one culture to play bicultural or multicultural roles. Often, managers of foreign subsidiaries play a middleman's role between two sets of cultural patterns.

Performance evaluation of overseas subsidiaries of MNE's and their managers are integral elements for the effective application of the philosophy of decentralisation. Several criteria have been used by enterprises in order to evaluate performance fairly and logically.

Even in a purely domestic setting most multi-unit companies face difficult problems in measuring and evaluating the performance of their subsidiaries and managers thereof. Dissatisfaction with budgets, standards, or any other performance criteria are voiced at one time or another in all companies; and human problems resulting from performance criteria, which are often perceived as "unfair", are well known to personnel managers and top management in all businesses.

In a multinational setting these problems have taken new dimensions and become more complex. There is not only the question what should be the "right" performance criteria, right accounting principles, or right psychological measures, but also such issues as whether or not domestic profit standards should be extended into the international realm; and whether affiliate executives should be judged in the context of their particular countries or some regionalisation of the worldwide operations should be adopted. 
Contributions of individuals represent a combination of circumstances, stimuli and actions. Each is significant in its impact on an individual's performance and hence should be evaluated for its impact in the measurement of performance. But until someone invents a valid single measure to effectively accomplish the task of performance evaluation, various yardsticks (surrogates) will have to be used, depending on the objectives, roles and activities within the purview of managers. Budgets, standard costs, and responsibility reports are financial measures that can be manipulated to fit most circumstances. Hence, non-financial measures become increasingly important as money loses its ability to serve as a common denominator, alone or in translation. Comprehensive financial measures, such as profit and return on investment, are constructed upon foundations containing flawed assumptions. They should be used with caution even in the best of circumstances and should only serve as starting points for more valid criteria. ${ }^{1}$

The need to maintain duality in foreign evaluations has been considered essential; that is knowing how efficiently the subsidiary uses its resources and what is the ability or effectiveness of its manager. Quantitative criteria (hitherto have been) used include both financial and non-financial measures. Each of the evaluation methods (e.g. profit or return on investment or comparative assessments with other subsidiaries, prior periods or budgets) was cited for a failure to maintain the necessary separation between, subsidiary's and the manager's performance.

${ }^{1}$ E.J. Kolde, The Multinational Company (Mass.: Lexington Books, 1974), pp. 100-78; "Report of the Committee on International Accounting" Supplement to the Accountina Review, (1974), pp. 250-69 and Sidney M. Robbins and Robert B. Stobaugh, "The Bent Measuring Stick for Foreign Subsidiaries," Harvard Business Review, Sept.- Oct., 1973, pp. 80-88. 
In the light of preceding comments regarding the persistent use of a few evaluation methods irrespective of the specific needs of the situation, and of the inadequate consideration being given to the factors affecting the performance of overseas personnel a need was felt for some other criterion. Often, qualitative criteria involving some environmental variables are recommended. It was at this point that an attempt to explore the extreme importance of cultural factors on account of their all-pervading effect on the overseas manager's performance was undertaken knowing full well that they are the most difficult to assess.

It was contended that by focusing on the impact of cultural factors the study should help in the analysis and evaluation of overseas managers on a more comprehensive basis than what was being seemingly done. Also, by attempting to measure the extent of similarities and differences in overseas managers' perceptions about the impact of foreign cultural factors on their performance and the consideration assigned to it the performance evaluation may constructively be pin pointed. It is also hoped that this endeavour may help achieve a better and more efficient utilisation of human resources. It may yield some indirect benefits in the area of recruitment, training, assignment, and relocation of overseas personnel. To quote Morsicato and Diamond, "it would contribute towards 'environmentalising' the performance evaluation system." 2

2 Helen G.Morsicato and Michael A. Diamond," An Approach to Environmentalizing Multinational Enterprise Performance Evaluation Systems," The International Journal of Accounting: Education and Research.vol. 16, No. 1, Fall 1980, pp. 248-66. 


\section{Summary of the Methodology Employed and Limitations}

To achieve the objectives of this research contacts were established with the U.S. multinational corporations to solicit their commitment and cooperation in the collection of the data. The questionnaires, fine-tuned and improved through the pretest and the pilot, were sent to the U.S. overseas managers of these multinational corporations through the corporate headquarters. The routing of questionnaires through the corporate headquarters was undertaken to maintain complete openness with them about the research and to insure an expedient completion and return of the questionnaires. All the questionnaires were returned to the researcher directly by the U.S. managers from their overseas locations.

In all 127 fully usable responses were received from the U.S. overseas managers of ten multinational corporations working in 38 countries of the five selected regions. The corporations which participated in the survey belong to a cross-section of industries in terms of employees, asset base, sales and net profit. The responses from evaluators totalled 18 and were fully usable and pertained to the selected five regions.

The involvement of corporate headquarters in routing the questionnaires to their overseas managers might have caused a perceived bias in their responses for they might have been inclined to give responses (supposedly) preferred by the headquarters. The impact of this potential bias, it is believed, must have been minimal as all the questionnaires were sent back directly to the researcher. 
The format of this study may seem to provide a less than robust general validity on account of the participants' selection and the number of responses. It is contended that the format of the study though based on a fewer number of MNCs, would nevertheless provide valuable support for the findings and future research. Further, it is also believed that the sample of respondents selected is a good representative of the general group.

The study intended to analyse the perceived impact of cultural variables (construct) on the performance, which have not been operationalised. Hence, this may limit the validity of the findings.

Also, because the variables may be construed differently by the respondents, the evaluation of their impact in general and in particular may vary depending upon an individual's understanding of the particular variable. Therefore, the respondents in this study were given a definition (general description) of each cultural variable in the beginning of each question. These definitions and descriptions were based on prior studies.

Although, no assurance can be given that the respondents to the questionnaires had identical understanding and appreciation of the cultural variables, the guide lines and descriptions given were assumed to control variations in their perceptions of the variables as much as was possible. This assumption is also supported by consistently high reliability alpha (given in correlation matrices). It is assumed that the findings do not lack construct and internal validity. 
It must be stated that the study's findings are limited because of its focus on a select sub-group of environmental factors, ${ }^{3}$ specific aspects of managerial performance, U.S. personnel and the selected five regions. Also, the study did not attempt to explore the relationship between age of the respondents and their perceptions of cultural factors. Similarly, no attempt was undertaken to investigate the causal relationship between the experience profile of the oveseas managers with the parent company and other organisations and their perceptions of foreign cultural factors. The information gathered from the A part of questionnaires was used for classification purposes only.

\section{Conclusions and Implications}

The data collected from the overseas respondents were used to run the statistical tests to test the hypotheses developed and formulated for this study. The results obtained identified statistically significant differences at $0.05,0.005$ and 0.001 levels and rejected the null hypothesis of equality of means of responses from the overseas managers regarding the general perception of the selected twelve cultural variables. The eight hypotheses appertaining the equality of means of responses appertaining the perceived effects of cultural factors on aspects of the managerial performance were rejected for each of the eight specific aspects of managerial performance. However, no statistically significant differences were identified among the general perception and perceived effects of a cultural factor on the eight aspects of managerial performance. This fact was also reinforced by a

3 Istemi S. Demirag," Multinational Performance Measures and Their Association with Contextual Variables," Accounting and Business Research, vol. 20 No. 80, Autumn 1990, pp. 275-85. 
significantly high degree of correlation among the general perception and eight specific aspects of performance. ${ }^{4}$

The two groups of (aggregate) responses from the evaluators and the overseas managers were compared to identify whether there exists any significant difference in their general perception of cultural factors. The vectors of means of responses of these two groups from the five selected regions were compared but did not yield any statistically significant difference. Similarly, no statistically significant differences were identified between these two groups when the vectors of means representing their (aggregate) responses regarding the perceived effects of twelve selected cultural factors on the eight specific aspects of performance were compared. Even when the individual aspects of performance were compared with respect to the perceived effects of twelve cultural factors on them for the two groups of overseas managers and evaluators, no statistically significant differences were identified.

However, an attempt was made using pair-wise comparisons (using univariate $t$ tests) to explore whether some statistically significant differences exist for some questions relating to cultural factors and their perceived effects on aspects of managerial performance on a regional basis. Within Far east and Middle east, too, the tests failed to identify any significant difference in any of the pair-wise comparisons between overseas managers and their evaluators. While, in Africa, Europe and Latin America, on some pair-wise comparisons statistically significant differences were identified between overseas managers and their evaluators at 0.05 level. For example, in Africa managers and evaluators differ significantly in their general perception of

${ }^{4}$ Tests for multicollinearity among the cultural variables at the global level did not identify any one variable which was correlated with others in case of all the eight aspects of managerial performance. However, in case of the Far Eastem and the Latin America regions three variables have been identified. 
cultural factor relating to sense of self and space and its perceived effect on ability to motivate and ability to get things done.

The presence of some statistically significant differences between the views of groups of U.S. overseas managers and their evaluators regarding cultural factors and their effect on managerial performance within specific regions stems from a notion (belief) on the part of evaluators that cultural factors such as view of authority and subordinates, class structure and individual mobility, attitude toward punctuality, sense of self and space, and legal rules that managers ought to get acclimatised with over a period of time so that these become more agreeable, and less stifling. Other plausible explanations appear to be that the factors may be some what non-facilitating (an irritant) when constantly being interfaced with versus from being observed from a distance and accorded a moderate consideration only.

However, the fact that the groups compared were of unequal size in general (in aggregate) should be kept in mind while evaluating the generalisability of the results so obtained. The same comment can be made for the specific regions.

The phenomenon of uncanny similarities between the groups of the U.S.overseas managers and their evaluators 5 in their general perception of the twelve cultural factors and also regarding the perceived effects of them on the specific aspects of managerial performance stems from the fact that virtually all the evaluators have been to those regions for whose managers' performance evaluation they were responsible for. The fact of their being

5 Although separate hypotheses were not proposed to identify the differences in the perceptions of cultural factors and their effect on the aspects managerial performance for the evaluators but the tests run on their (aggregate) responses indicate the presence of (an uncanny) general similarity with overseas managers' perceptions of cultural factors and their perceived effects on the aspects of managerial performance. 
familiar with the cultural variables extant in those regions made it possible (coincidentally rather than as a result of some policy action), it is assumed, for the presence of general similarity between managers and evaluators. From the informal talks held with the corporate headquarters, there was no mention ever made that some concerted effort might have been undertaken to incorporate these features in the managerial performance evaluation system.

Statistical tests undertaken to test for the presence of significance differences in the views of the U.S. Overseas managers about the foreign cultural factors and also with regard to the perceived effects these may have on the specific aspects of managerial performance came out positive. The tests were both: univariate as well as multivariate.

With alpha of 0.05 and using the pooled mean responses from the U.S. overseas managers statistically significant differences were identified for all the twelve cultural factors between and among the selected five regions. However, no statistically significant difference was identified between Africa and the Middle East for the following cultural factors:

attitude towards education, view of authority and subordinates, class structure and individual mobility, attitudes toward risk taking, attitude toward change, communication and language, attitude toward time and time consciousness and sense of self and space.

Similarly, no statistically significant differences were identified between Latin America and Europe for cultural factors: 
view of authority and subordinates, interorganisational cooperation, class structure and individual mobility and communication and language.

Statistically significant differences between the other regions for the foreign cultural factors are provided in table 5.45 .

Although similar statistically significant differences were identified in some of pooled means of responses for cultural factors across the selected five regions, however, with alpha of 0.05 the selected tests did not identify any statistically significant difference between Middle East and Africa and Europe and Latin America for the general perception of the twelve cultural factors among the U.S. overseas managers. Also, no differences of statistical significance were identified between Middle East and Latin America for the perceived effect of twelve cultural factors on aspects of performance such as,

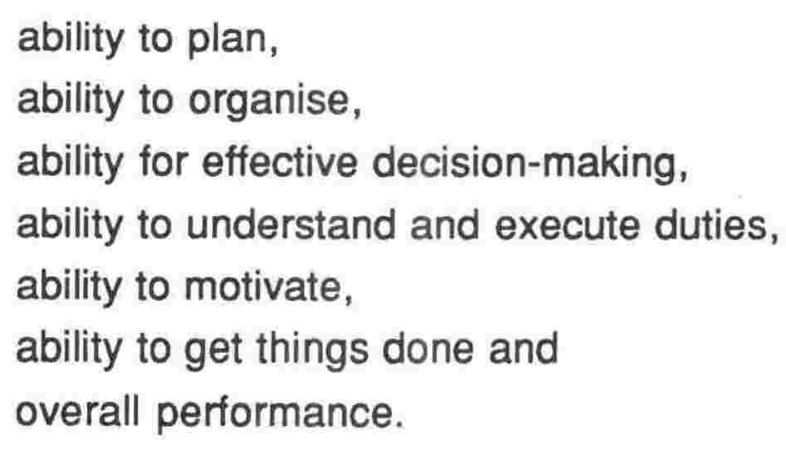

Not only that these tests underscored the rejection of the hypotheses of equality of mean responses across five regions, but also provided rich-indetails information on pair-wise comparisons between these regions for cultural factors as well as their perceived effect on the specific aspects of performance. 
In a summary form a bird's-eye view is presented to help gauge the inter-regional statistically significant differences among means of responses of the U.S. overseas managers about their perceptions of the specific foreign cultural factors and their perceived effect on the particular aspects of managerial performance across regions (Table 5.64).

Multivariate discriminant analysis was employed, to analyse all the variables simultaneously (rather than one at a time) in order to discern if there exists statistically significant differences in the perceptions of U.S. overseas managers about the selected twelve cultural factors the across regions. The Wilks' likelihood $(\Lambda)$ criterion was used to accomplish the stated objective, that is, to ascertain the similarities and differences among the views of the U.S. overseas managers of the five selected regions regarding the twelve specific cultural factors and also to explore the differences (if any) in the perceptions of U.S. overseas managers about the impact of cultural factors on the specific aspects performance on a regional basis. The computed Wilks' lambda for both the objectives confirmed the existence of statistically significance differences extant in the U.S. overseas managers' perceptions about cultural factors and the impact of the twelve specific foreign cultural factors on the selected eight aspects of performance across five regions.

An attempt was also made using the stepwise discriminant procedure to isolate foreign cultural factors which may distinctly explain the differences in impact on the performance on a regional basis. The procedure did not select good predictor variables (selected only four from out of twelve on the basis of the general perception of these cultural variables) to provide robust discrimination among regions when that was considered. 
However, the stepwise discriminant procedure identified twelve variables from out of ninety six variables (twelve cultural factors $\mathbf{x}$ eight aspects of managerial performance) after twelve iterations, which provided a statistically significant discrimination among the selected five regions. It is evident from the table that with every new variable selected for inclusion the separation amongst regions became better.

The robustness and significance of the selected (12) variables in discriminating across regions is further reinforced by the classification summary with a hit ratio of $99 \%$ (Table 5.71). Virtually, there is no overlapping in classification of subjects across regions. There is only one subject which has been misclassified between Europe and Latin America. In the other regions the results of classification are perfect.

This research endeavour has been exploratory in its orientation. It successfully accomplished its stated objectives that there are significant differences in the perceptions of U.S. overseas managers with regard to the selected cultural factors as well as their perceived effect on the specific aspects of managerial performance. The study also identified that the regions can be differentiated with varying degrees of robustness on the basis of U.S. overseas managers' general perceptions of the cultural factors present therein as well as on the basis of their (managers') perception of their effect on the aspects of their performance. However, the fact that the tests failed to identify any statistically significant differences in perceptions of foreign cultural factors between overseas managers and their evaluators should not diminish the relevance of the exercise. On the contrary, this finding underscores the fact that the perceptions of varying influences of the selected foreign cultural factors on managerial performance are being given serious recognition and consideration in overseas managers' performance evaluation. Undoubtedly, 
there may not be a serious difference between the perceived and considered view of cultural factors in performance evaluation, but the fact remains that these differ amongst themselves as well as across regions in their perceived effect on managerial performance. The realisation of this fact should encourage the MNCs to devote adequate resources for training and appropriate orientation of their managers slated for overseas assignments. The results obtained from the discriminant procedure would further help in effective focusing of resources for specific (those with discriminating ability) cultural factors extant in various regions. Acceptability of these foreign environments and efforts to impart training to potential overseas managers to conquer these (perceived) handicaps where feasible and to cope with them where these are unavoidable, without significantly affecting their performance will be a worthwhile investment both in short run as well as in long term for human resource development. A formal recognition and incorporation of the impact of the cultural variables in the managerial performance measurement criteria may be a welcome move to attend to the situation where the evaluators may themselves be foreign to the region in consideration.

It is believed that this study may provide in not that distant a future the explanation/s for observed behaviour and practices and may also endeavour to pave the way for predicting the unobserved practices, that is, it may supply and support the hypotheses about the attributes which may cause the occurrence of some specific behaviour. Thus, contributing toward the strengthening of the framework for performance evaluation systems.

Nevertheless, the results and conclusions of this study must be accepted and used in the light of the fact that the sample size was relatively small in general as well as for a few regions. Also, the fact that this research endeavour relies on U.S. overseas managers' perception of foreign cultural 
factors which may (ought to) have something to do with their own (both at micro as well as macro level) culture should not be overlooked while evaluating the conclusions of this study.*

\section{Recommendations for Future Research}

The genesis of this study is in the performance evaluation. Performance evaluation whether of subsidiary or its manager constitutes an integral element of the philosophy of decentralisation. The evaluation of work whether periodic or perpetual is an important hallmark of the ever-expanding scope of management (accounting) control system. It is through the framework of performance evaluation systems wherein budgets, standards or some other performance criteria play an important role and the activities are kept on desirable channels.

Several criteria have been used by enterprises in order to evaluate performance fairly and logically. Dissatisfaction with these criteria have been voiced at one time or other in all companies; and human problems resulting therefrom are not unknown to the personnel managers of the businesses. In a multinational setting these problems have taken new dimensions and become more complex. There is not only the question of "right" performance criteria, right accounting principles, or right psychological measures but whether overseas executives should be judged in the context of their particular countries (place of posting). And if the place of posting is to be accorded some consideration what should constitute the contextual variables, what

\footnotetext{
" It must be stated that a care has consistently been exercised to desist from making any value-based remarks instead the results and conclusions are based on statistical findings supported by the collected data.
} 
categories of social, economic, political, cultural factors together with their elaborate elements should be embraced by the evaluation system.

It has been observed that the traditional theories of control, such as the technical-rational or collectivist did not capture the subtle nuances of control in the context of MNCs. Culture prevalent in the host country has been found to provide explanation rather than economic rationality in certain key areas, e.g. rewards based on need not on performance, the bowing to family hierarchy in appointing a chairman etc. 6 Ansari rightly posits, "Culture has also been observed as a critique of existing models of control. Environments do dictate certain forms of accounting/control systems, but not in the deterministic fashion suggested by the environment-strategy-structure model of control. The way in which culture moulds and shapes control systems also calls into question the contingency theory idea of technological determinism. Control systems, it seems are not uniquely fashioned by either environment, or technology or... alone". 7

The present study has been exploratory in nature and the results and conclusions drawn from it are at best suggestive and they require further probe in many of its apparent and subtle dimensions before any generalisations can be made. However, in relation to the issues explored in this study, the following areas for further research are suggested.

A similar study may be undertaken with an enlarged coverage both in terms of cultural variables as well as aspects of performance to explore the overall effect on the measurement criteria. This may lend further credence to

\footnotetext{
6 Shaid L. Ansari and Jan Bell, "Symbolism, Collectivism and Rationality in Organisational Control," Accounting. Auditing \& Accountability Journal, vol.4 no.2, 1991, pp. 4-27.

7 llbid., p. 24.
} 
the findings of this study. Also, instead of focusing on a group of countries within a region it may be a worthwhile proposition to focus on individual countries of the region. The findings may yield tremendous insights for areas to focus on for the future human resource development. Research endeavours may also focus on other constituents and the interplay of environmental variables.

In order to obtain a more reliable comparison an attempt may be undertaken to, in the form of a case study, match the evaluator's consideration for cultural factors and their effect on managerial performance of an individual overseas manager with those of that particular overseas manger. Obviously, this would require the utmost cooperation and confidentiality, but the results would be a definite contribution to the discipline. This study may also provide insight into the consideration assigned to the effect of age, length of experience and other characteristics.

Future research efforts may be directed at delineating the perceived effects of organisation-specific culture from the perceived effects of foreign cultural factors on effectiveness of performance and its measurement. What consideration is/should be accorded to the effect of the expatriate family's inability to cope with the alien culture may form a subject for another research endeavour.

Also, as suggested by Professor Choi in his informal communication to this researcher that the same study should be undertaken for a foreign MNC with nationals working in the U.S. as this may pave the way for meta analysis wherein one can juxtapose the relative perceptions of each other's (U.S. versus Non-U.S.) cultural factors. An attempt can also be undertaken to study the perception of cultural factors and their effects on the managerial 
performance from the view point of transnational executives as that will highlight the interplay of the foreign cultural factors with organisation-specific cultural factors.

Research endeavours may also be undertaken to draw upon the findings by $\mathrm{Hofstede}^{8}$ in the realm of power distance and uncertainty avoidance characteristics observed in various cultures and the development of performance evaluation systems for MNCs. This may go a long way to instill perceived as well considered fairness in the evaluation systems.

Finally, as other researchers have attempted in the past to develop a framework for political risk consideration in the sphere of foreign direct investment appraisal, similar efforts may also be undertaken to explore the consideration given to political factors in foreign countries while evaluating overseas managers' performance.

8 Geert Hofstede, Culture's Consequences: International Differences in World Related Values, (Beverly Hills, CA: Sage Publications, 1980). 


\section{FIGURES}




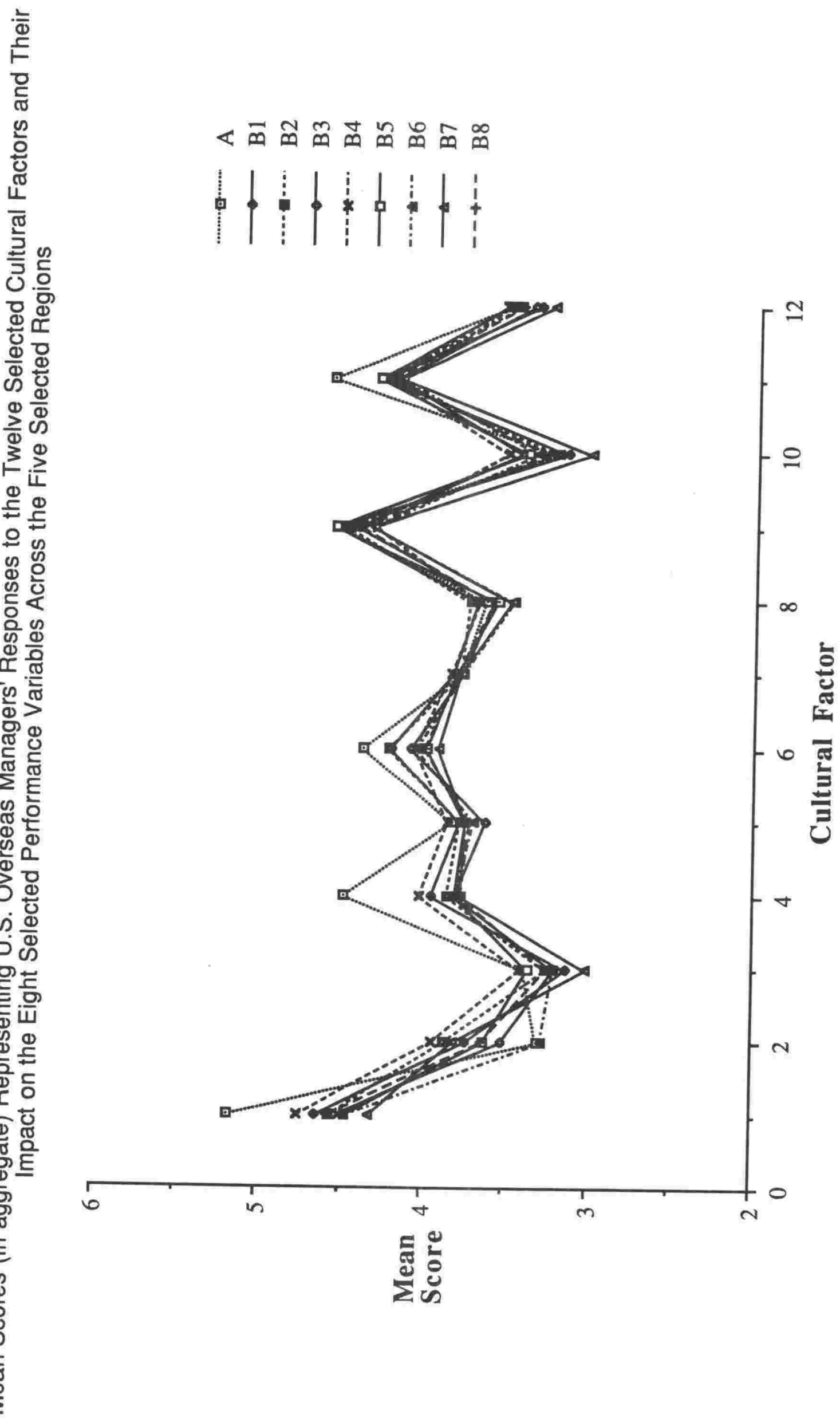




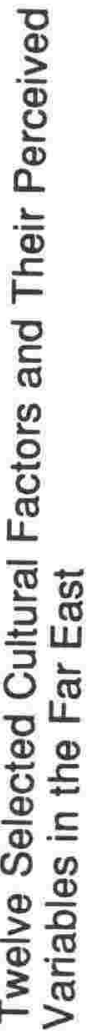

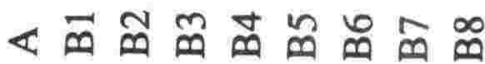

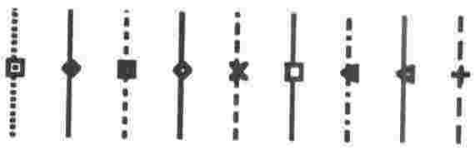

๙

ㄴํ 으 뜬

峁

혼

ㄴํㅇ

뭉뭉

ญ 웡

in $\frac{0}{\infty}$

㐘

등

$\sum^{\infty} i$

曲

象

离

О

के $\underline{E}$

$\supset$

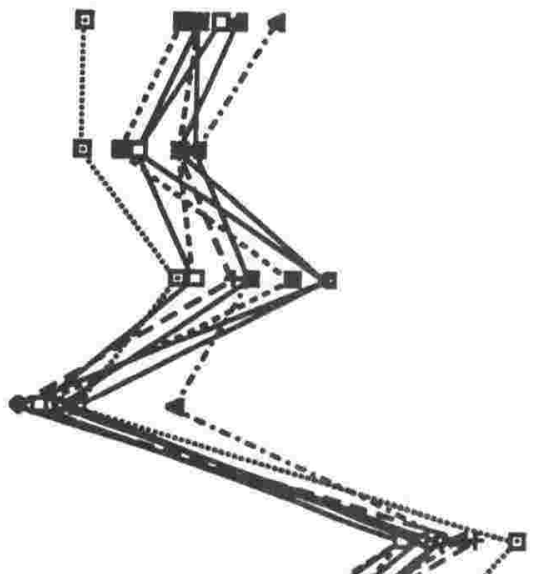

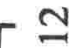

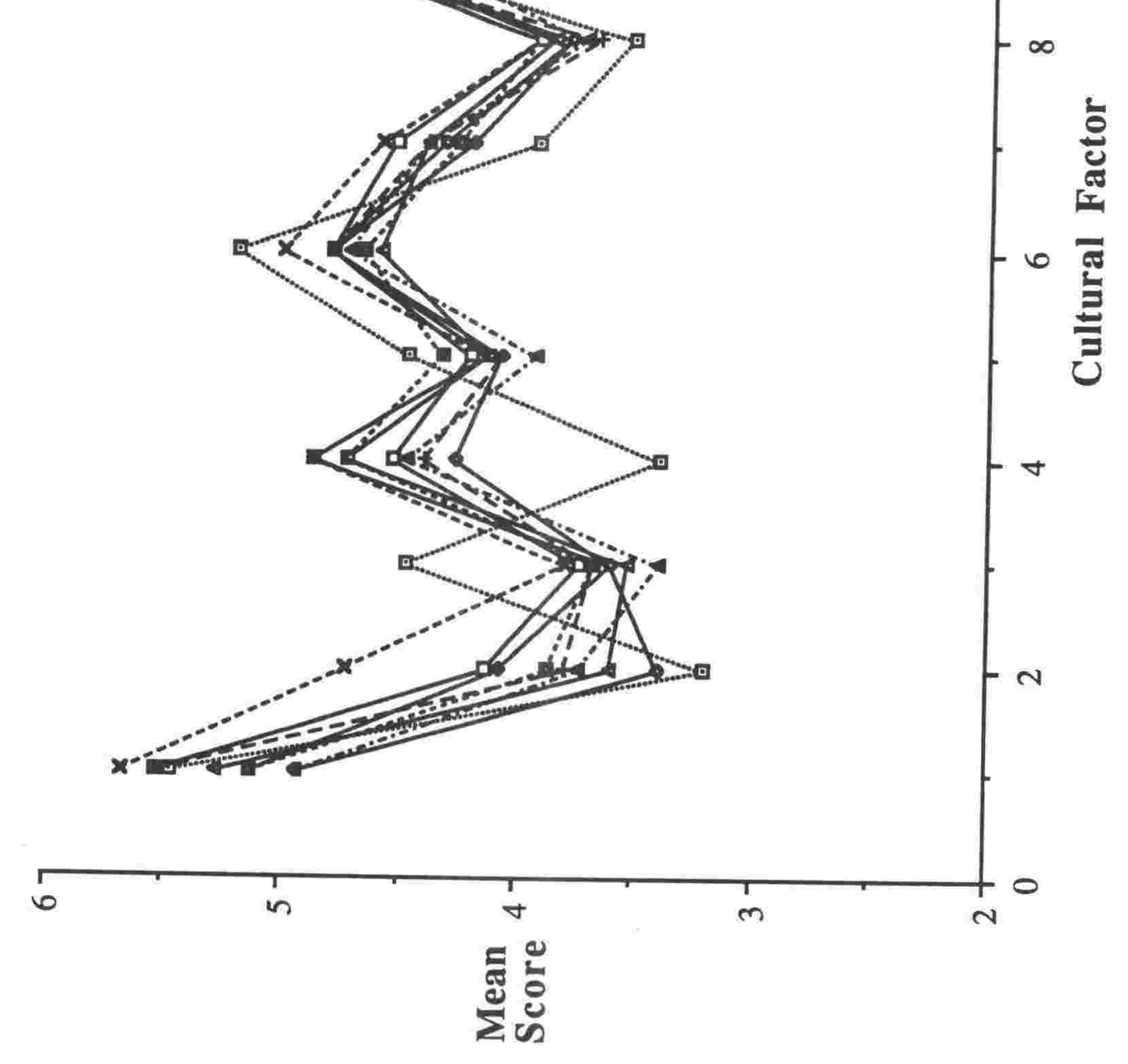

ఝ

ֻ 


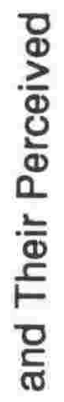

«

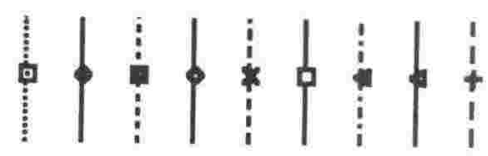

은

एँ

ธซ్

吾 원

을

过

․․

क ल

$\stackrel{\oplus}{\geq}$

ब.

$1 \frac{3}{7}$

๓.

เก

Ш

으 등

음ㅇ

똥

is $\frac{\Phi}{9}$

ठัต

ฮั

这

뽏

吃

\)

0 엄

ம를

읃

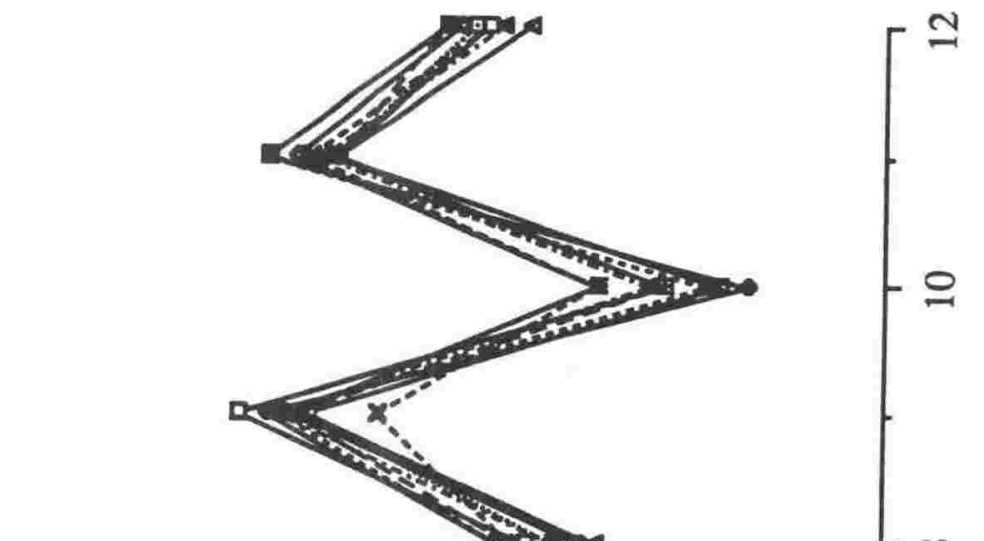

틀

क्

힝

ᄄ

Ф

ठ্

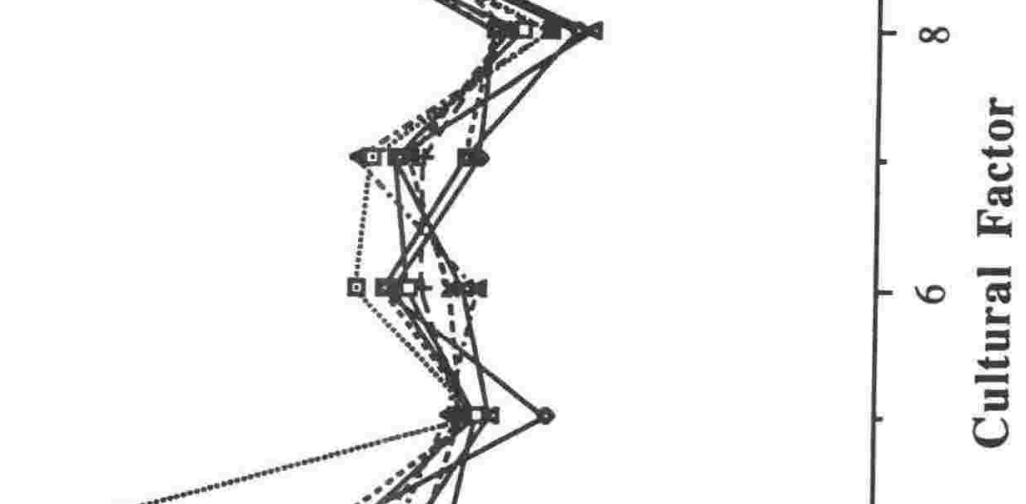

ֻ 


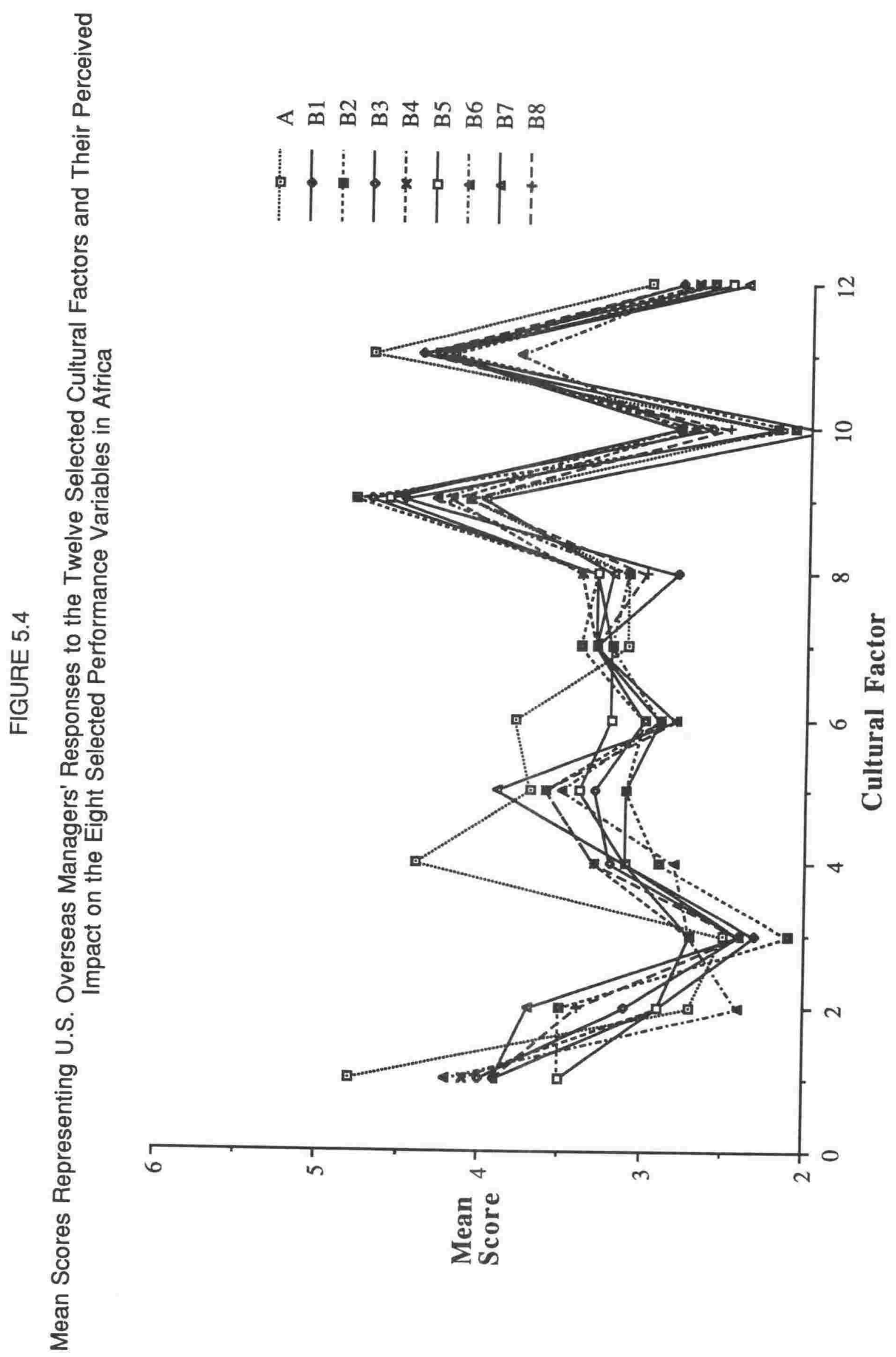




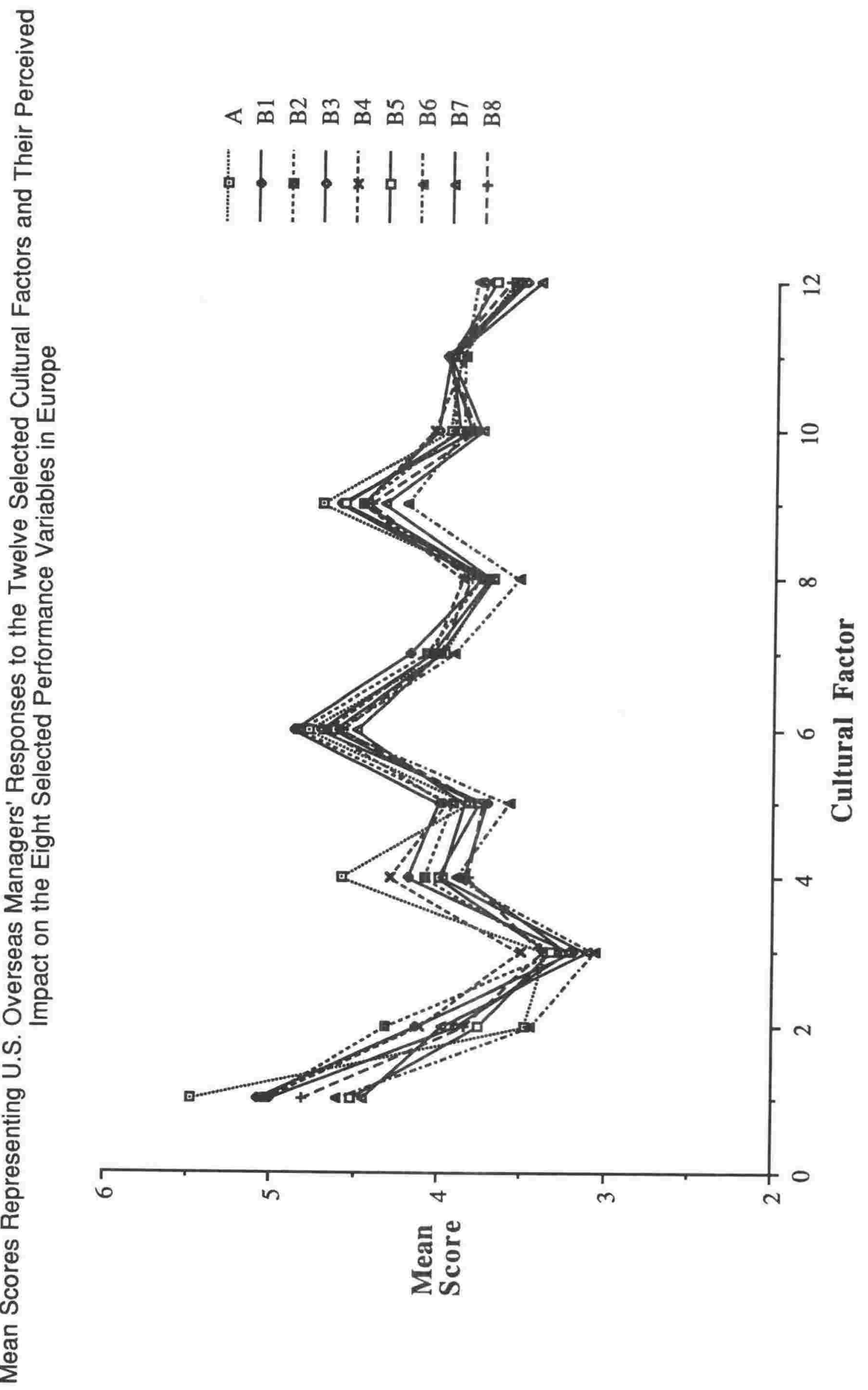


일

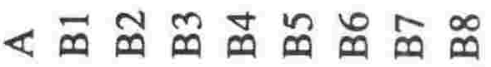

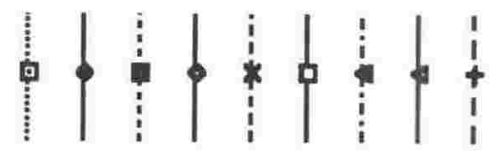

는

ㄴ.

๙

몷

$\frac{\Phi}{\Phi} . \subseteq$

œ

$\stackrel{0}{20}$

ऐ

0. 엉

เ⿵

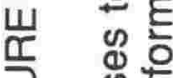

क⿻

음음

융음

$\llbracket$

in $\frac{6}{d}$

D心

ญ든

$\sum^{\pi}$

$\underset{c}{\infty} \stackrel{\Phi}{=}$

\%

Ð

○ జ

ம트

$\supset$

을
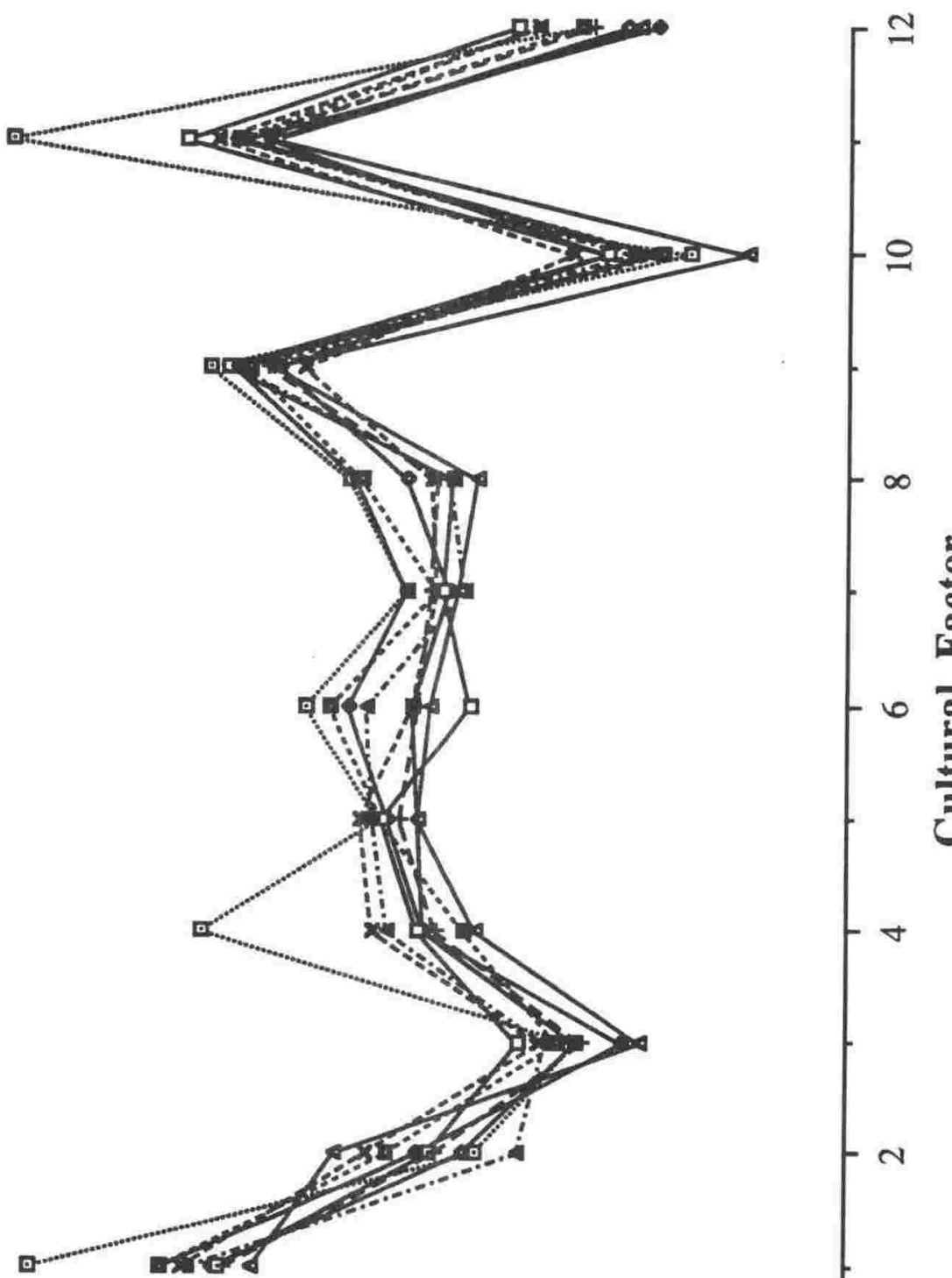

ॠ

힝

\%

¿ั.

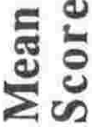

$\sum^{\mathbb{\Phi}}$ 
일

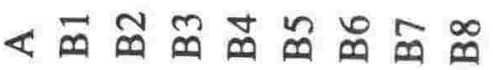

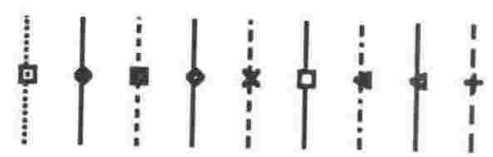

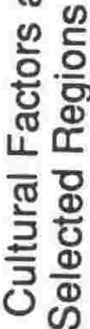

రัญ

ڤ Ф

\

$\wedge \quad \mathscr{\Phi}$

เก 은

山 प तٓ

5 ๑

는 동 응

๕ ह

is $\frac{1}{4}$

흠

㲾

岃

प्रफ

들 등

क्ष

흥은

등

Ф)

융

트

잠

드

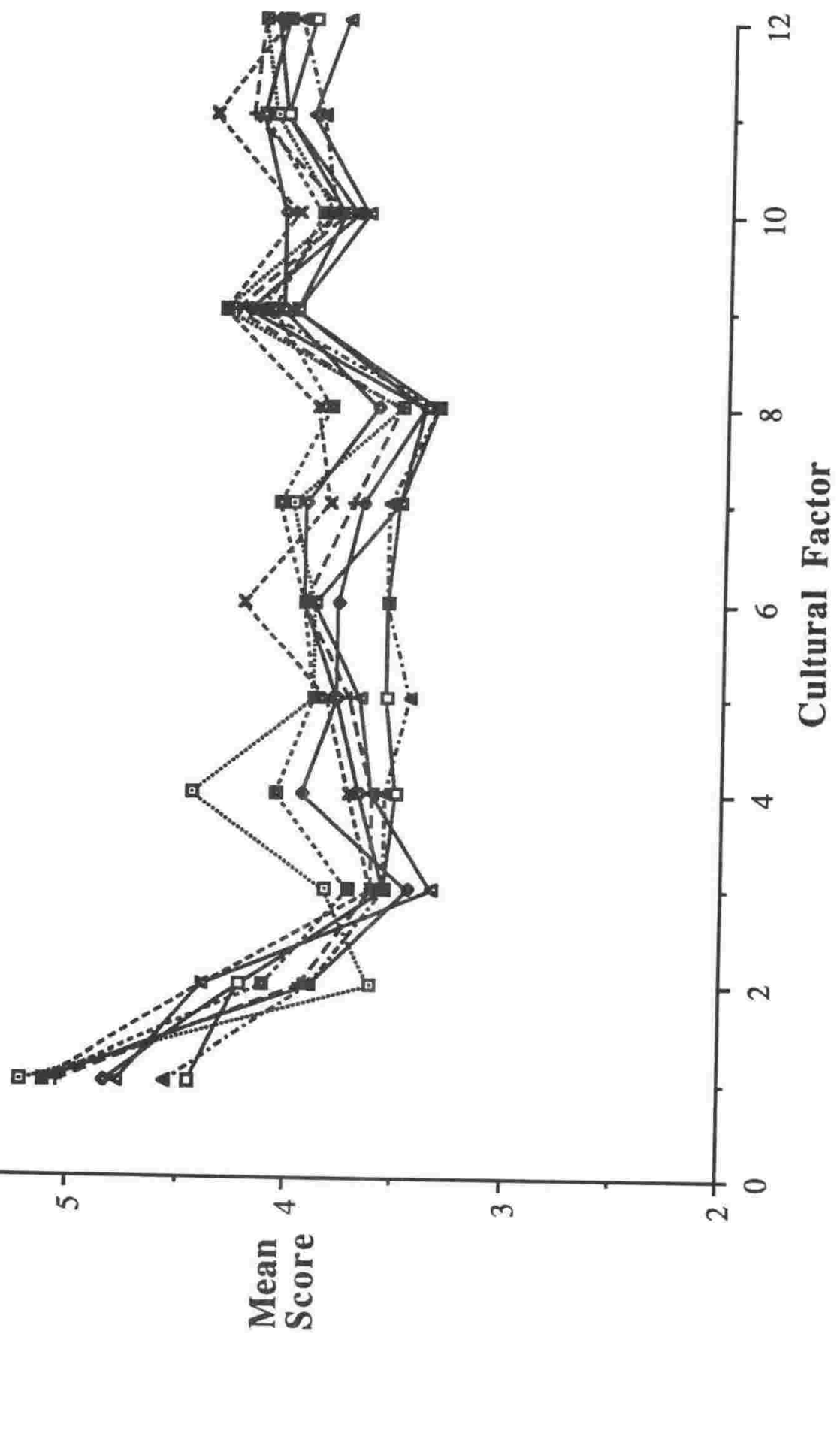


(2)

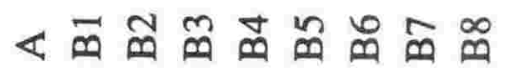

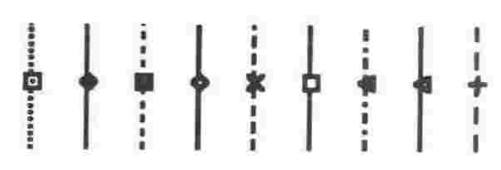

은

ษับ

สํำ

产递

U.

요

을

๘

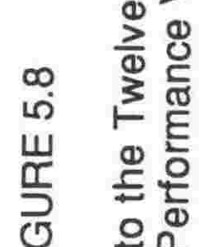

든 오뭄

¿

등

용

\%

는

元

귱

ш

워

을

क

잉

\%

ळ

ठั

㐫

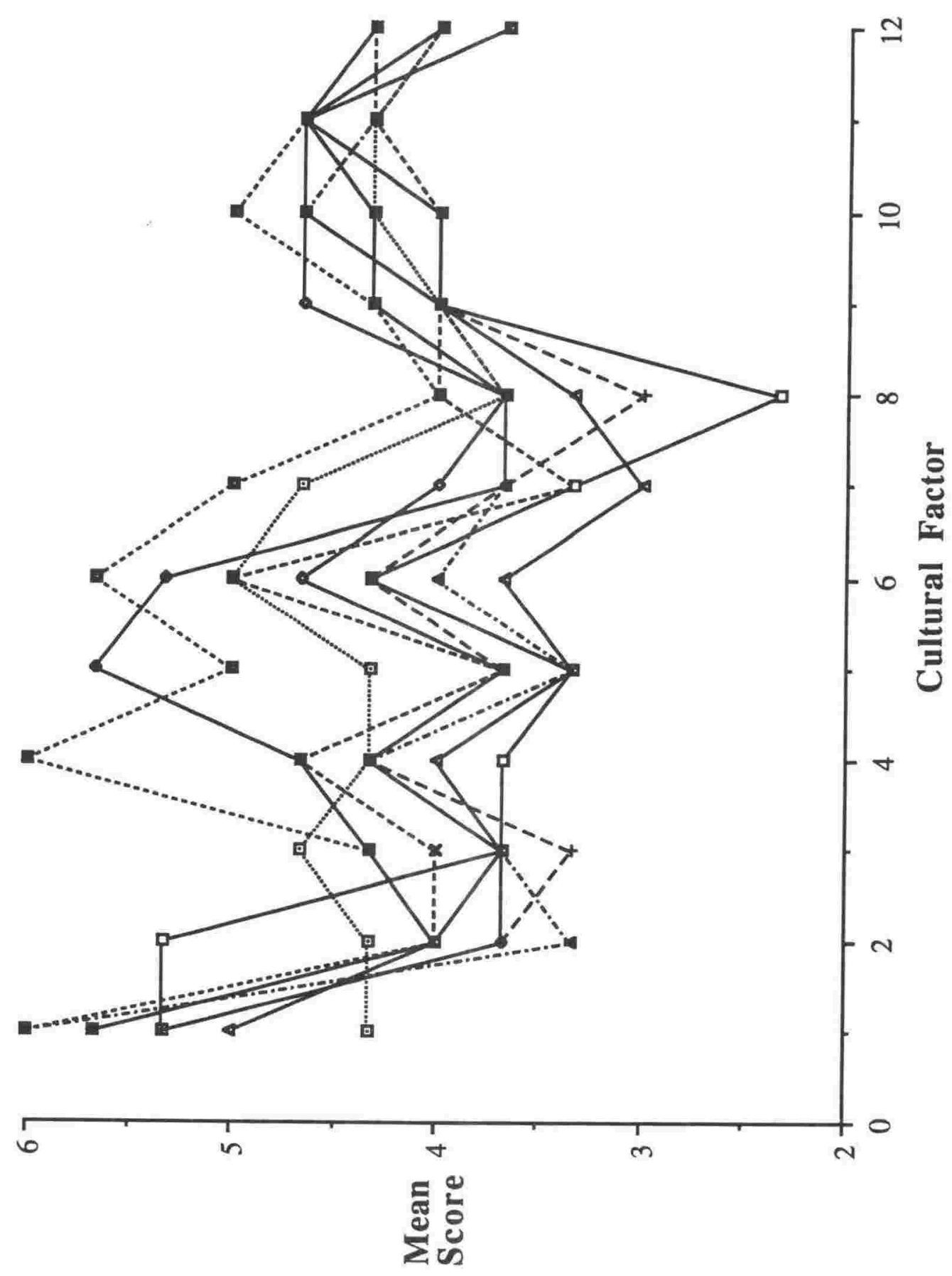




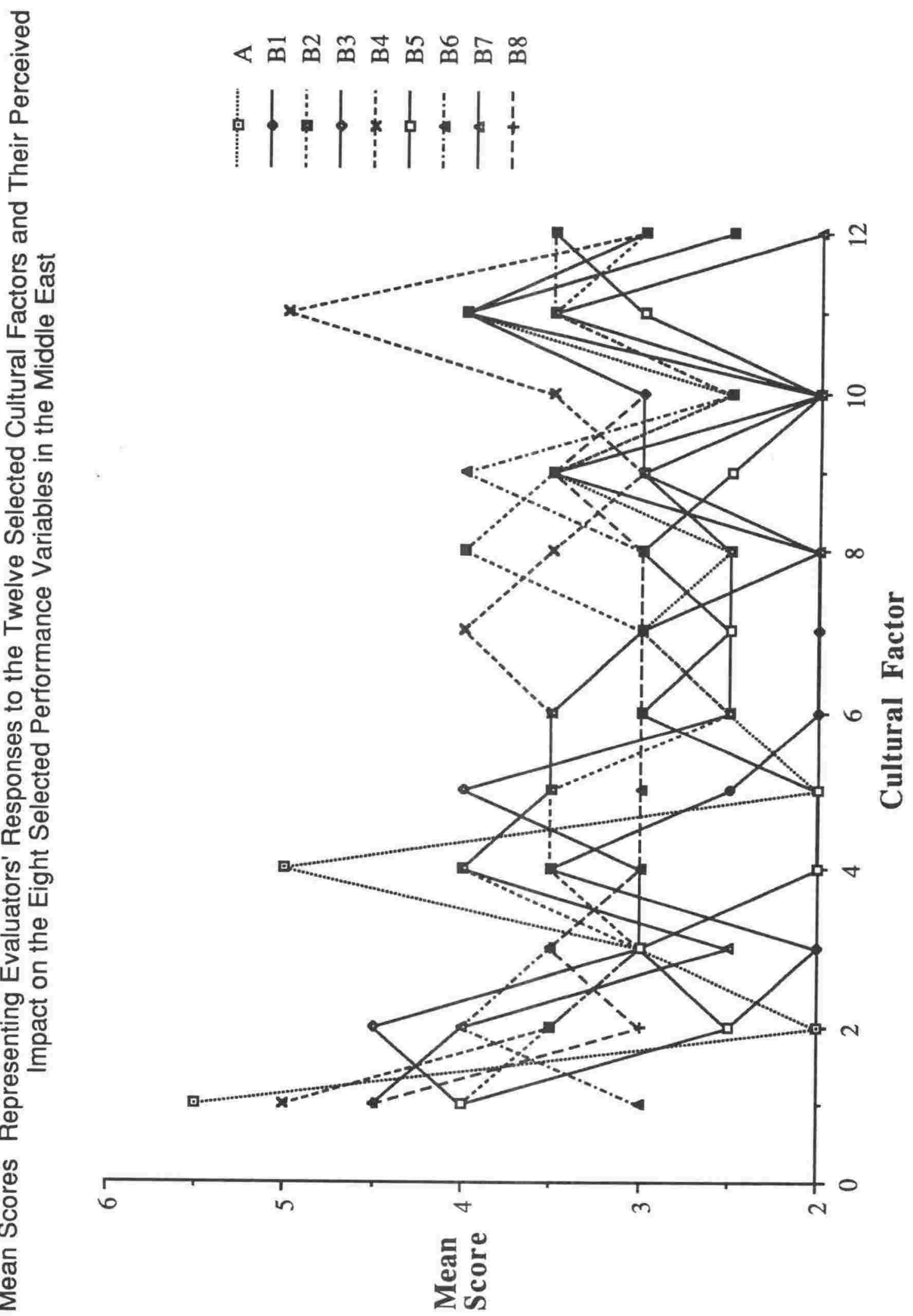




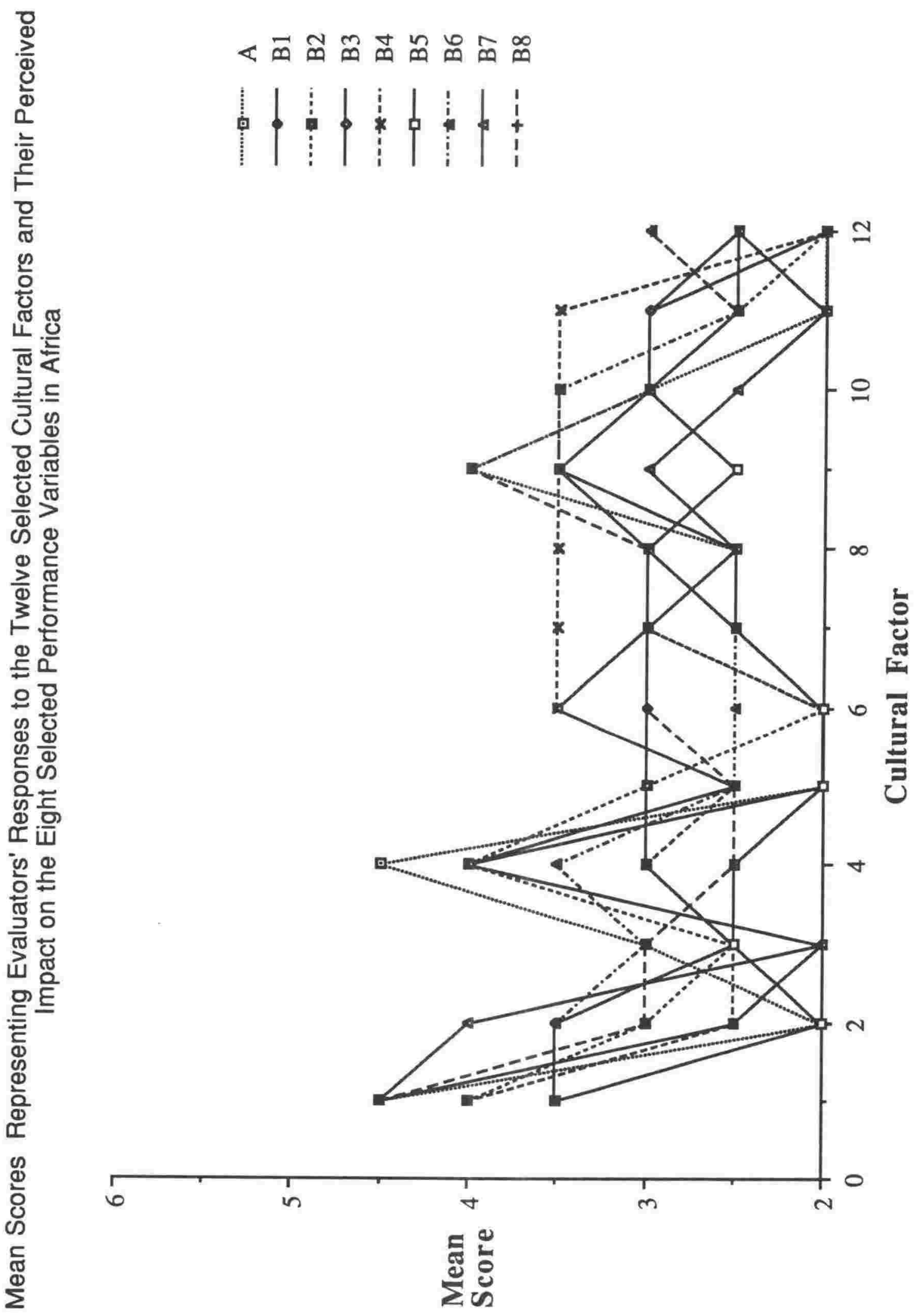




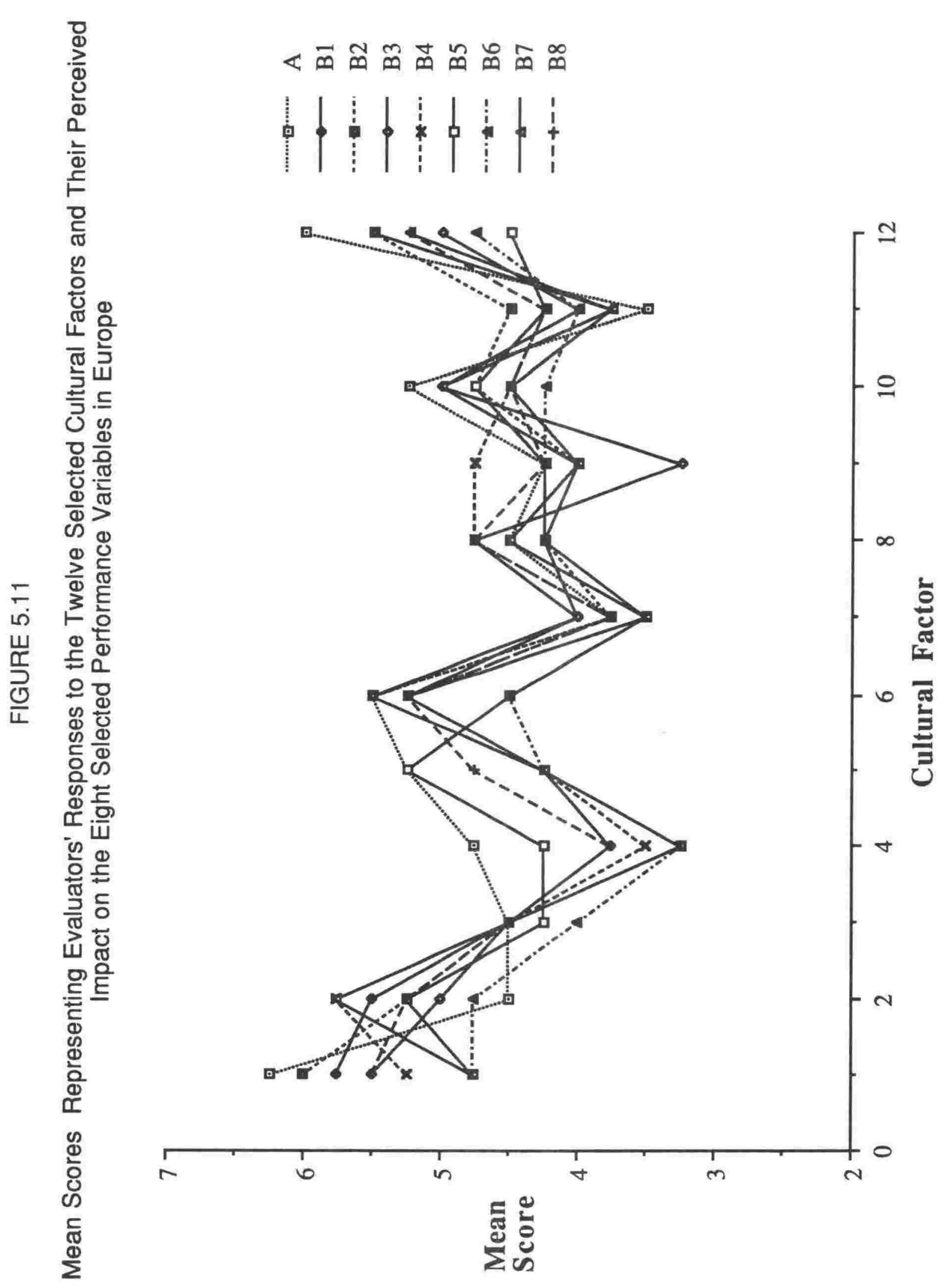




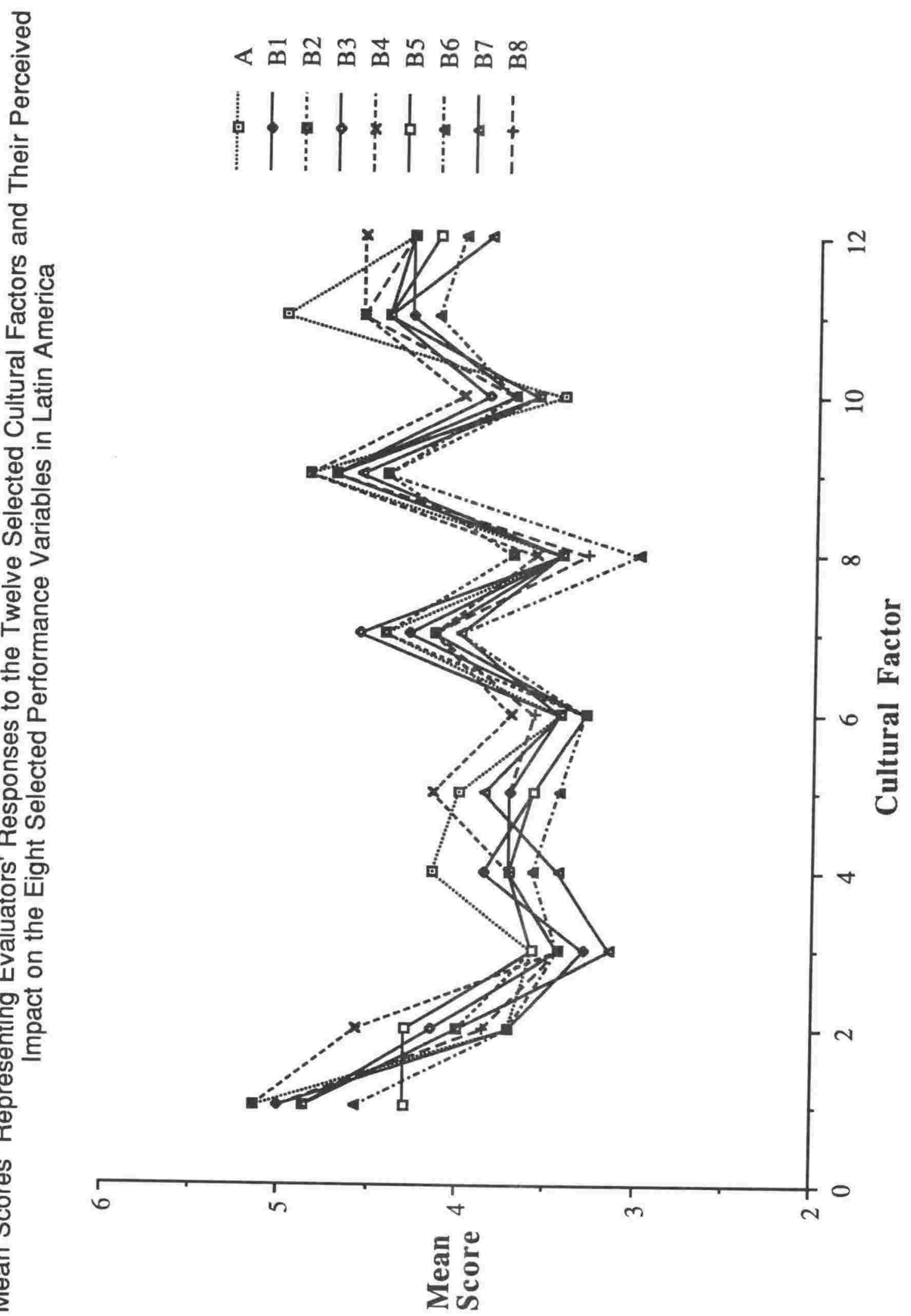


TABLES 

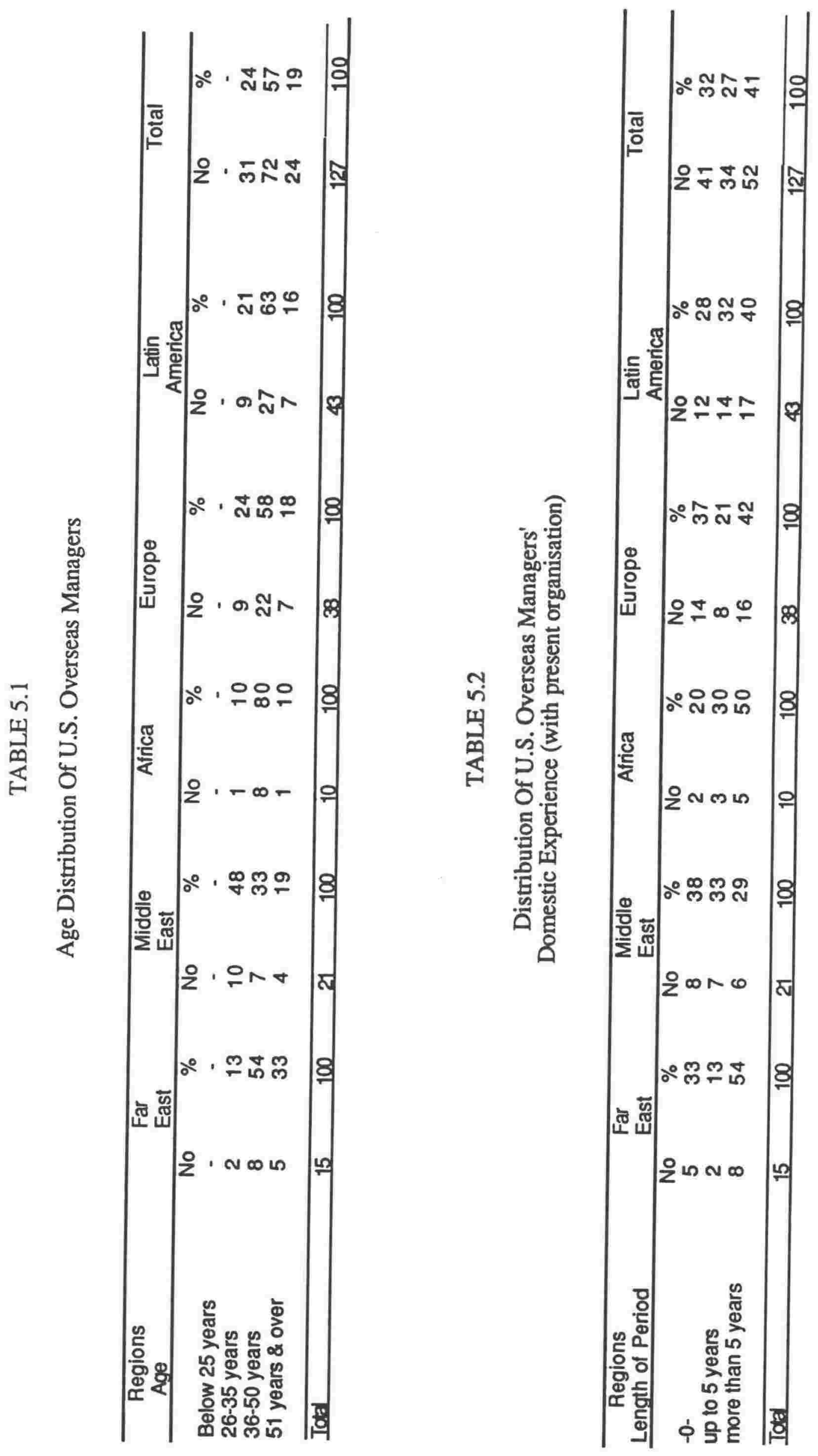

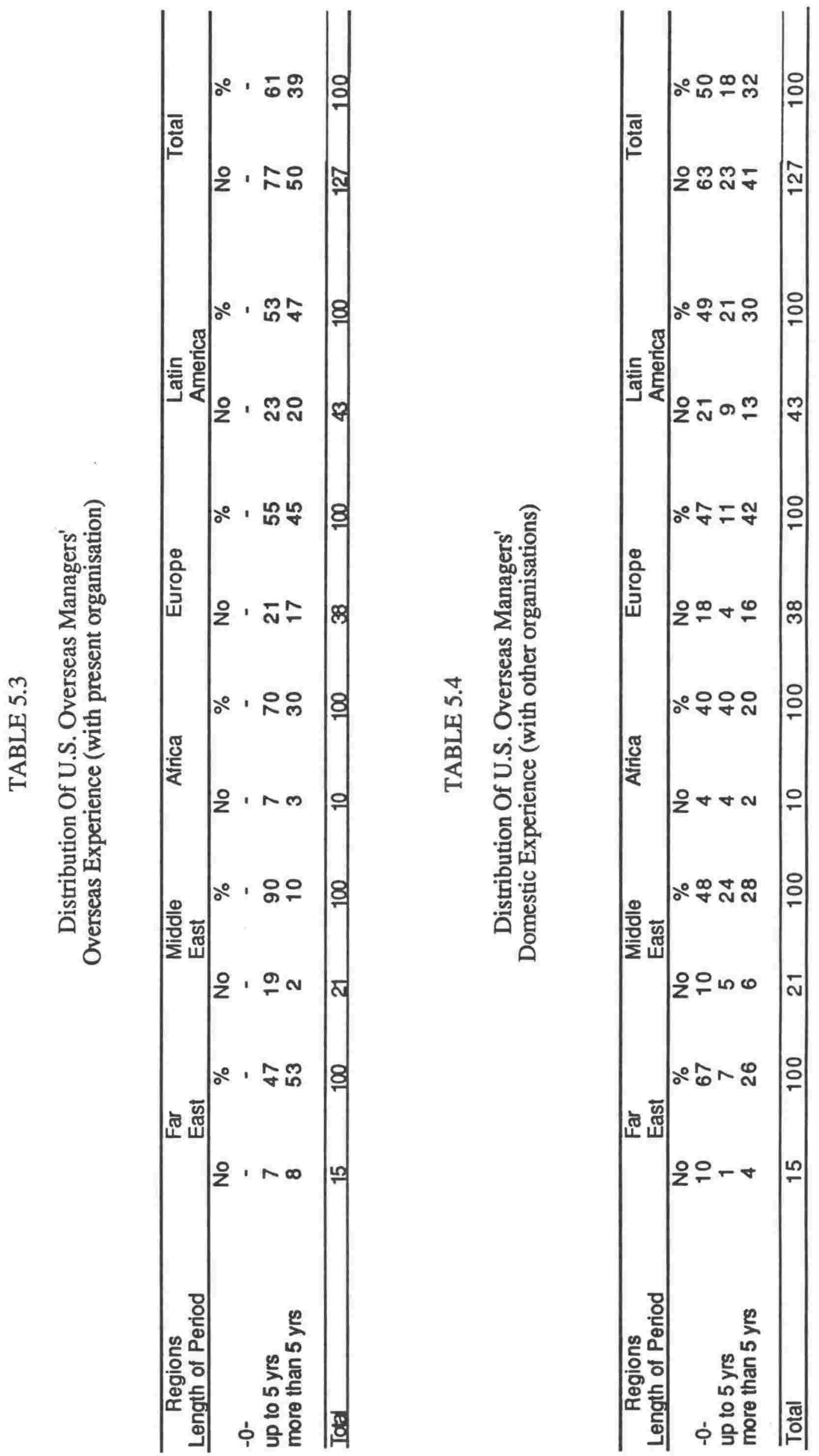


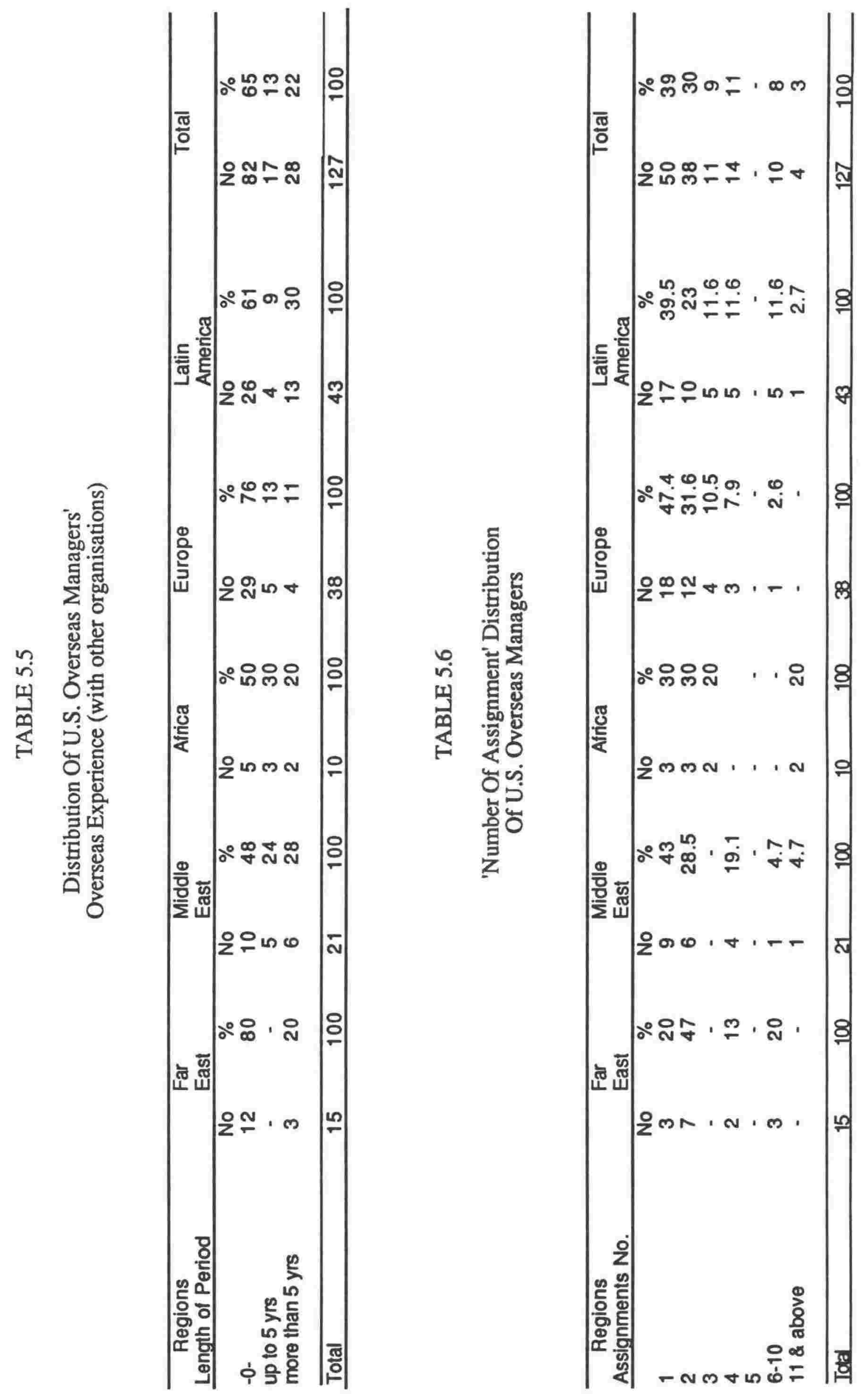



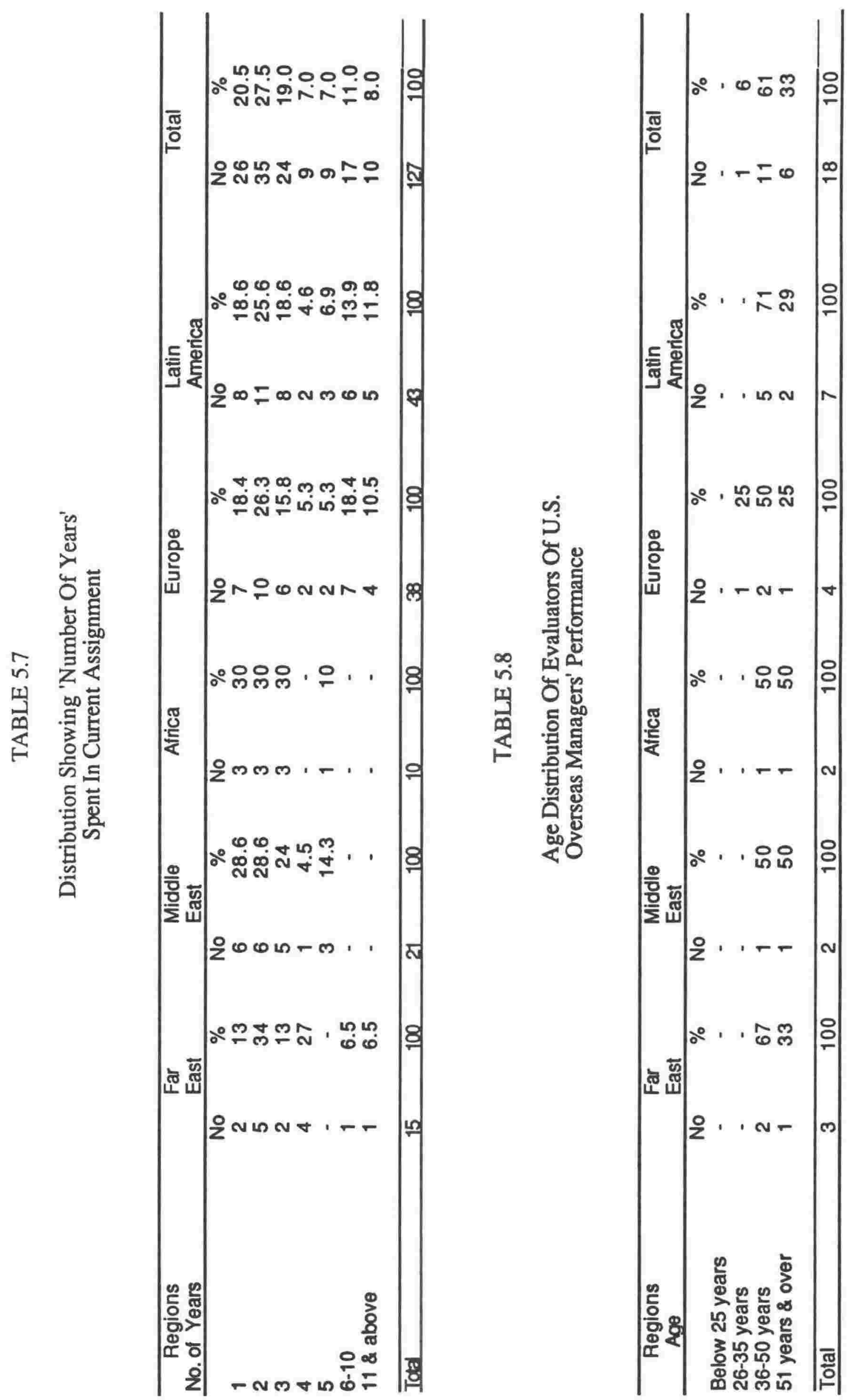

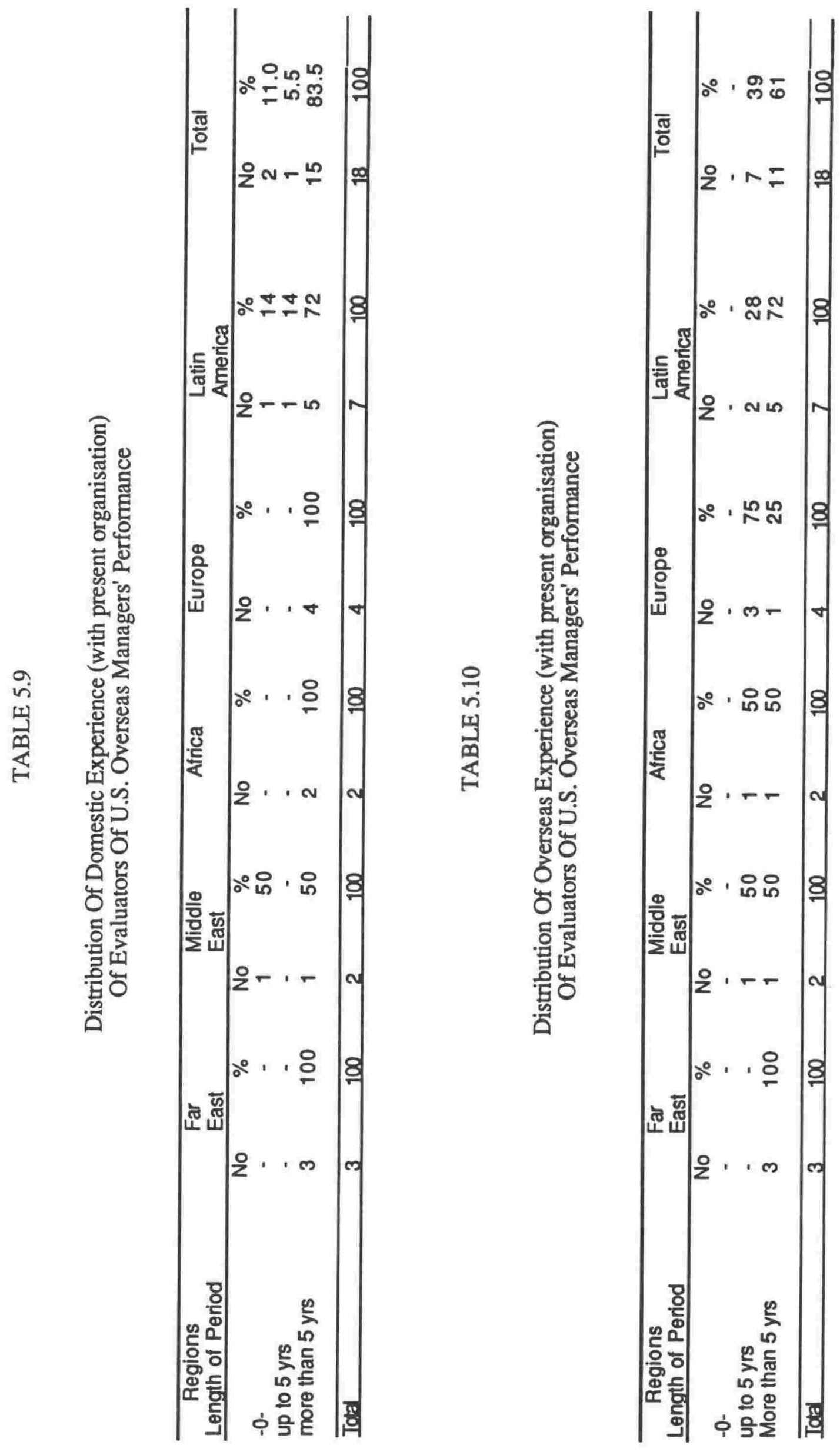


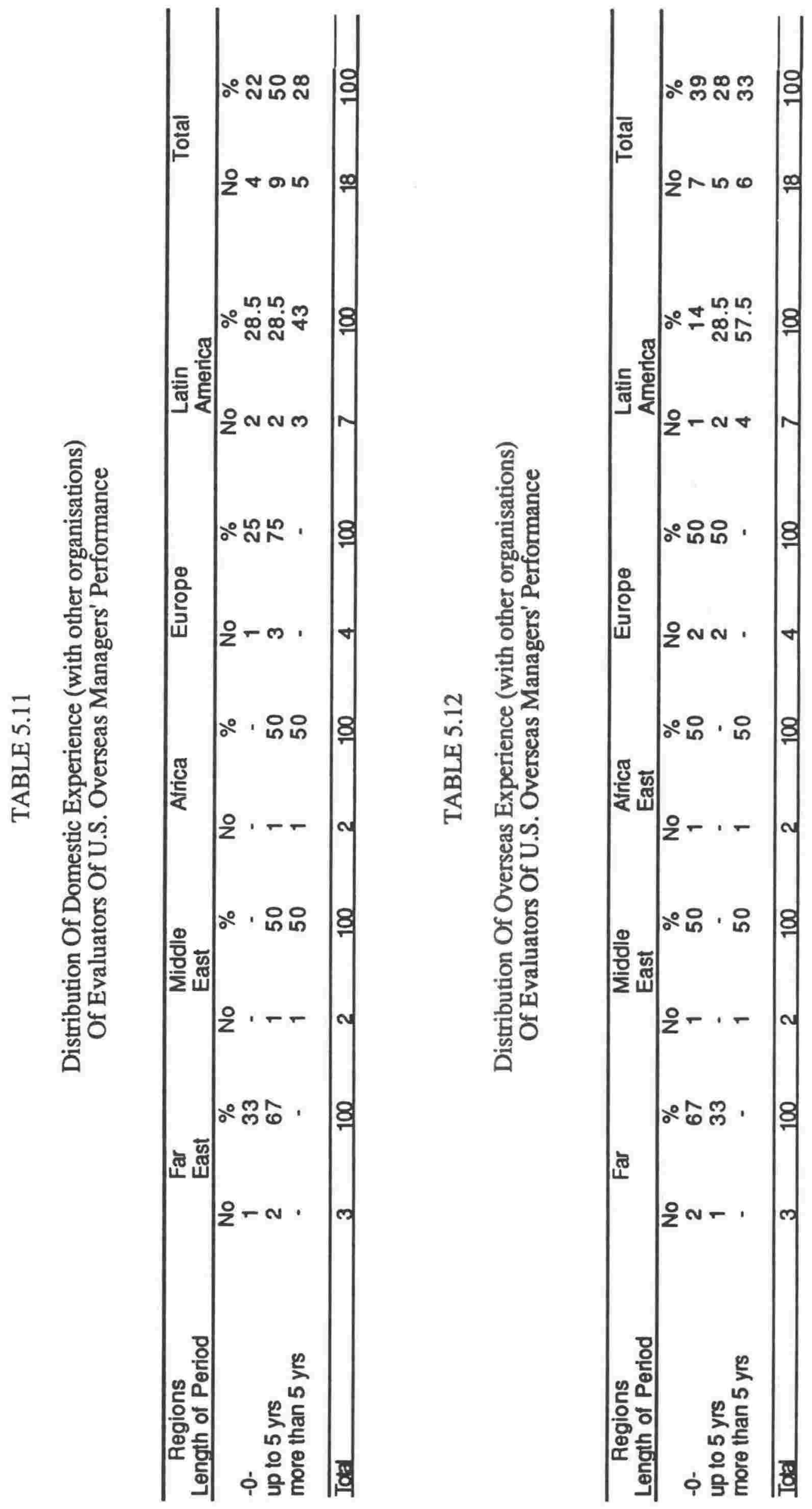




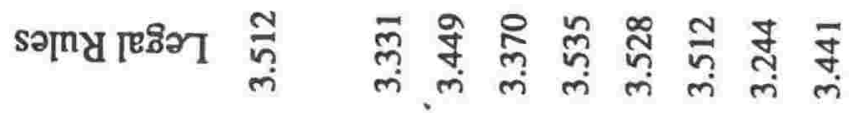

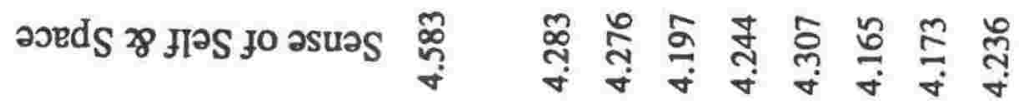

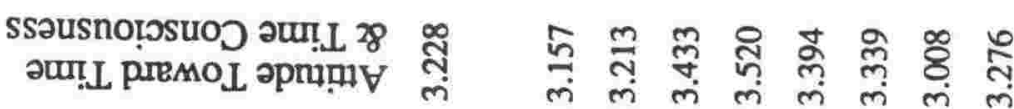

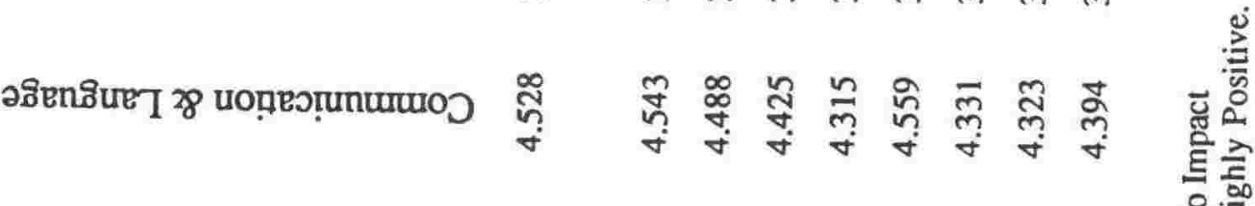

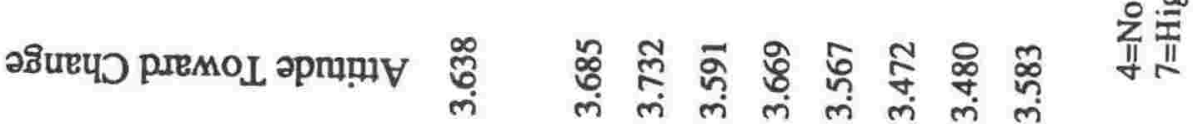

(

$\stackrel{1}{\geq}$

$\stackrel{\oplus}{ \pm}$

禹

은원

$\perp$

产哭

용

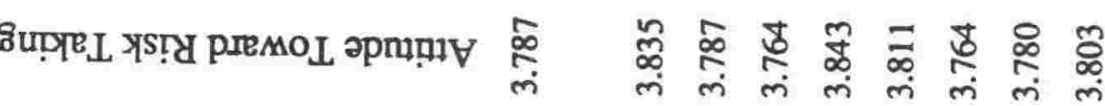

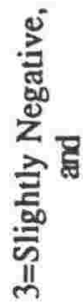

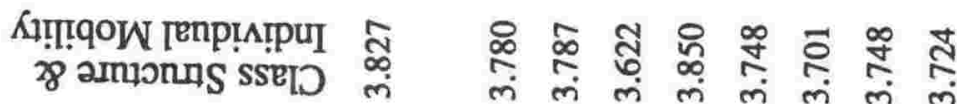

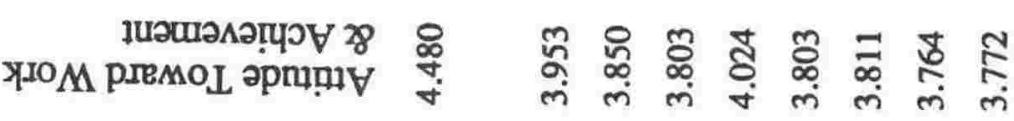

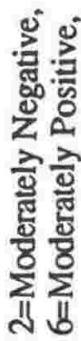

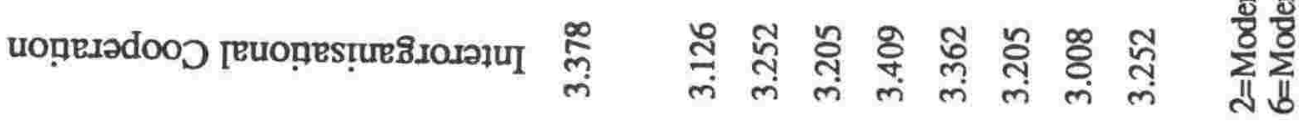

ம든

일

空

ळ్

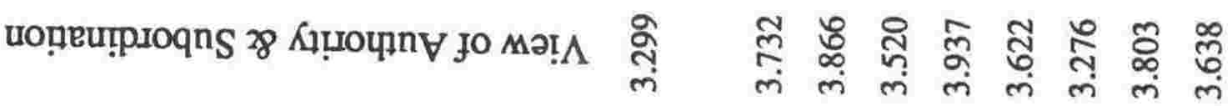

uomeonp

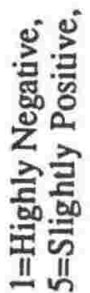

웡

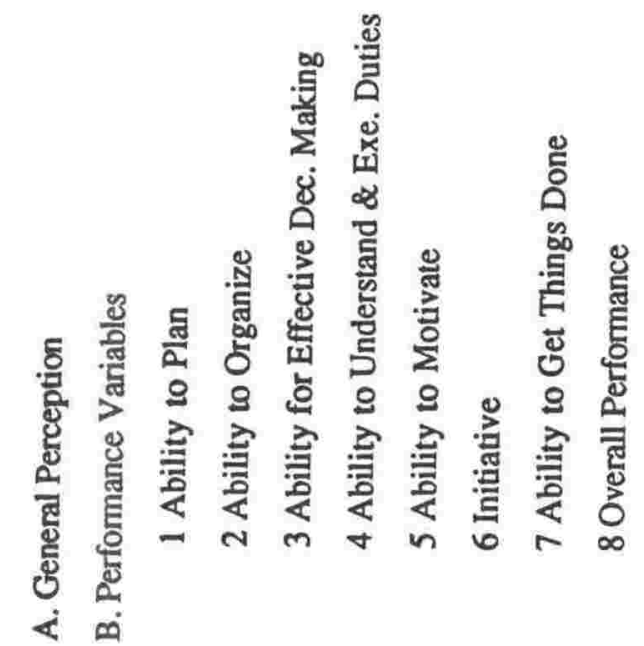

兽

옹 당

둉 


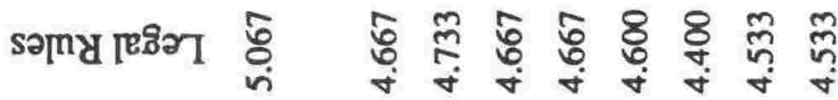

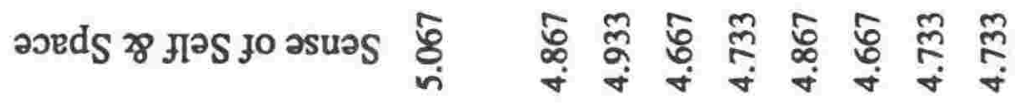

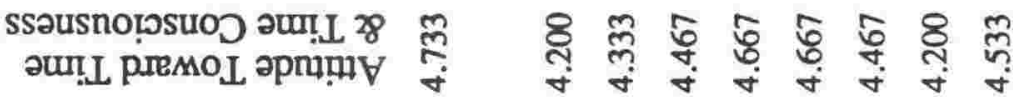

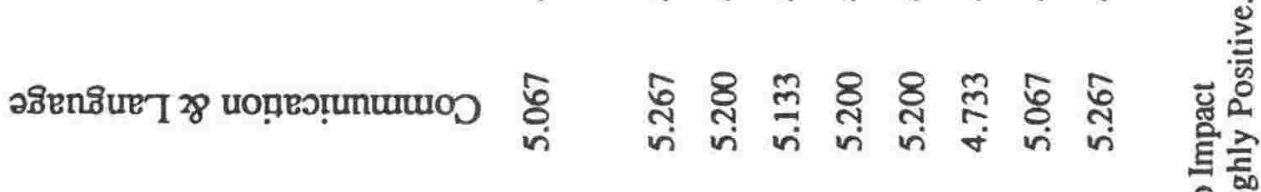

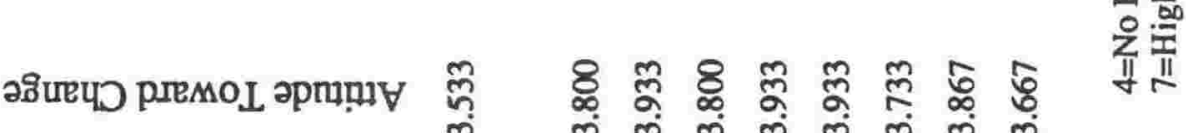

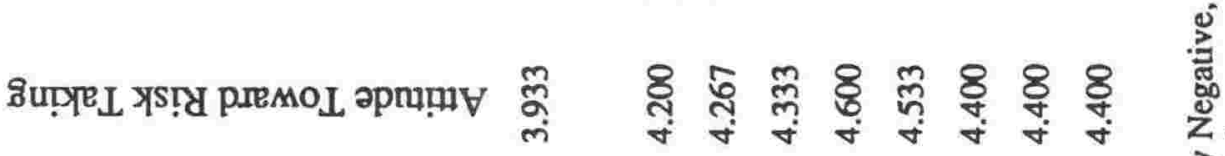

․ㅡ

\%

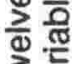

>

$\stackrel{0}{Ð}$

음

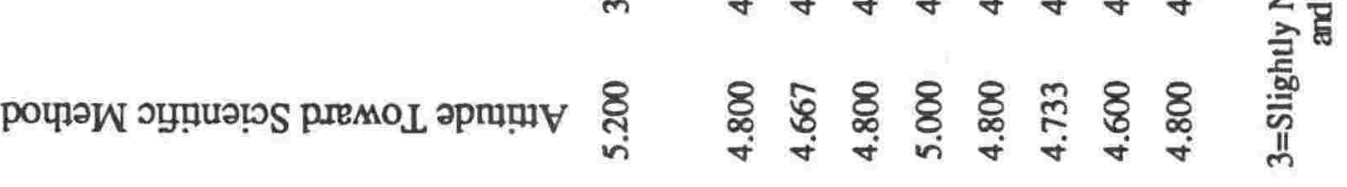

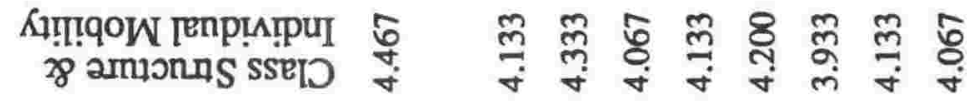

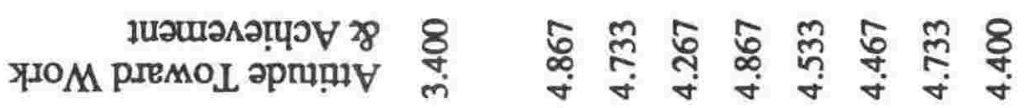

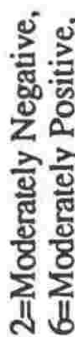

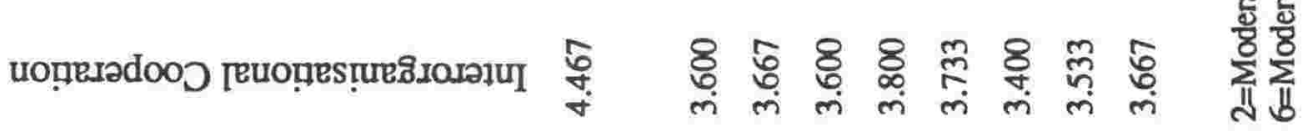

용

¿

뜽 둥

ठ․్ㅁ

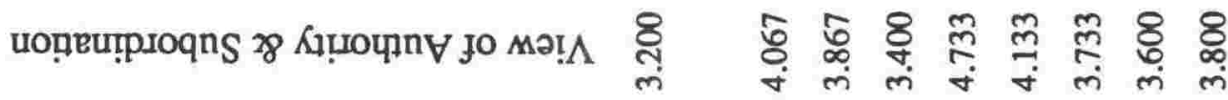

نํㅡㄹ

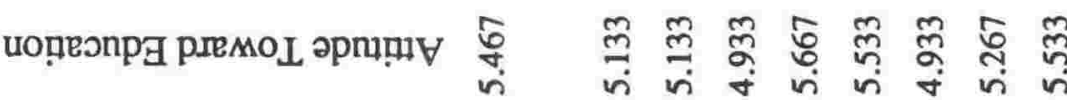

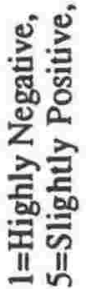




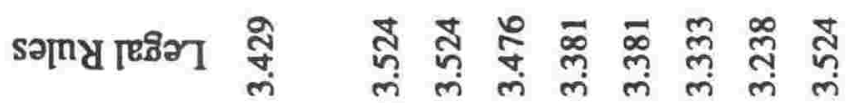

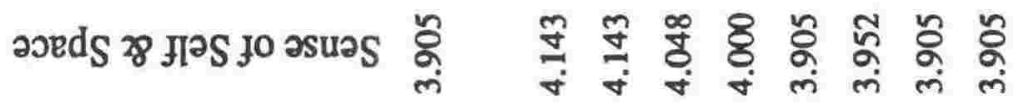

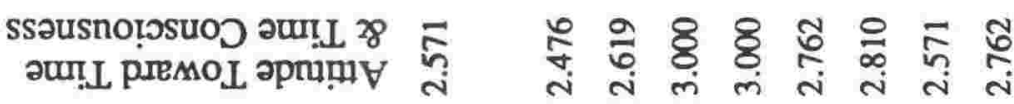

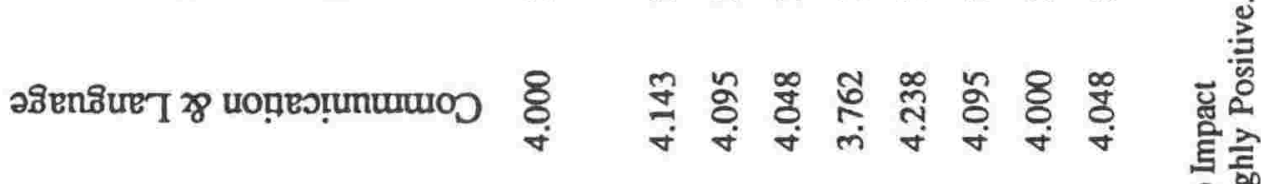

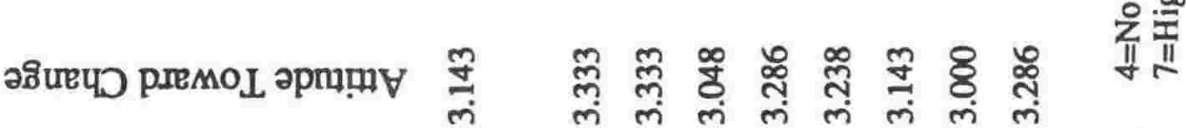

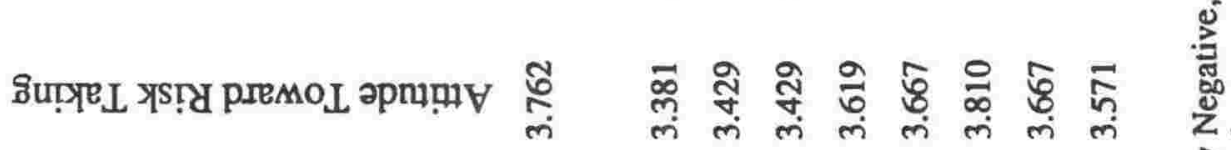

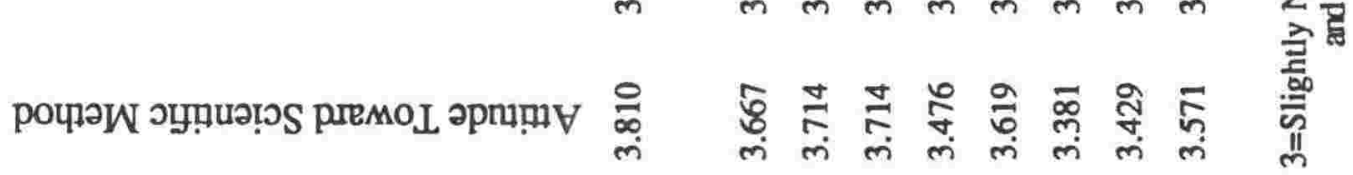

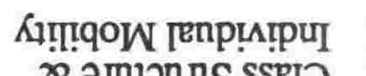
28 วmนnnS SSEID

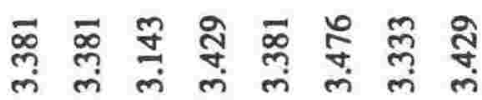

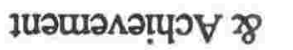
YIOM PREMOL כPm!̣

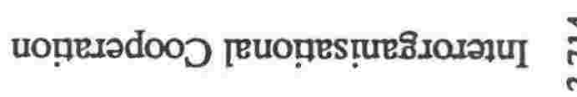

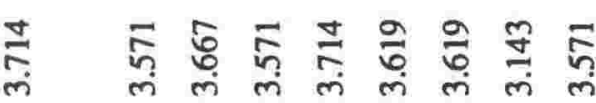

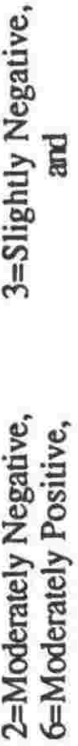

on

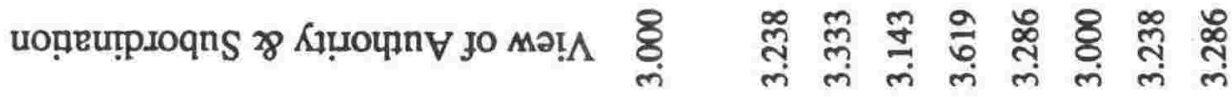

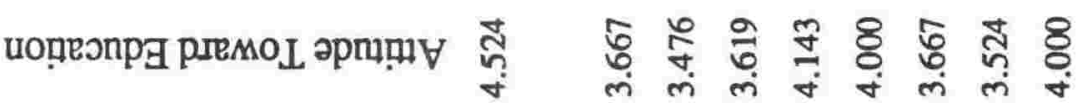

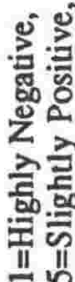

ம் 율

$\supset$ हᄐ

일

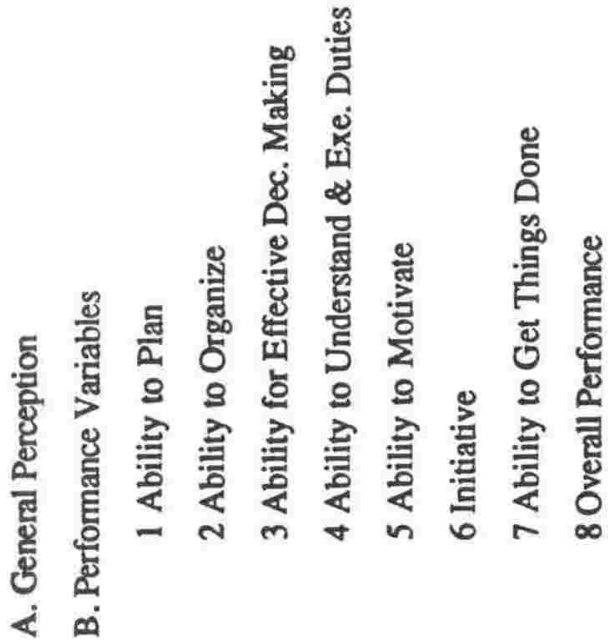




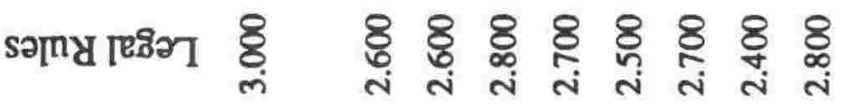

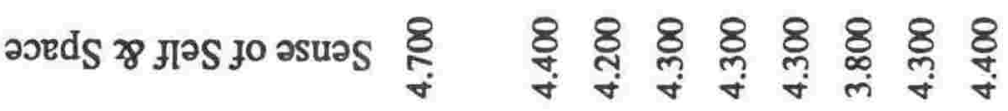

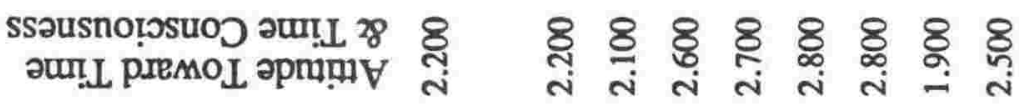

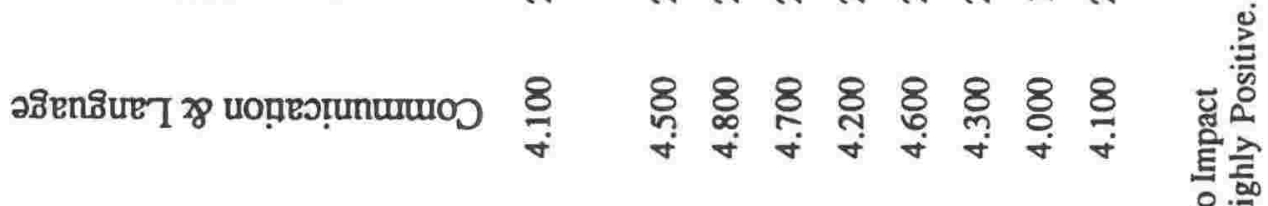

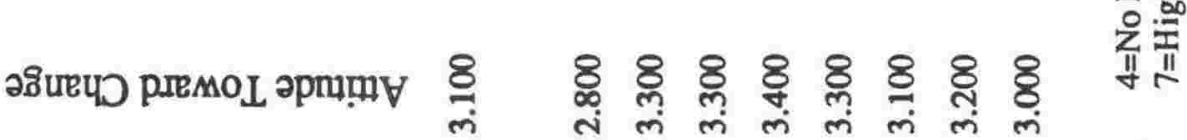

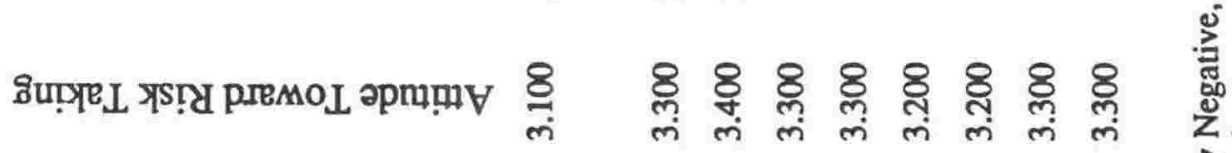

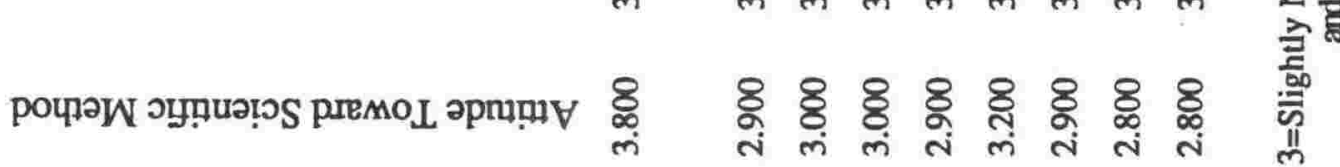

o

으음

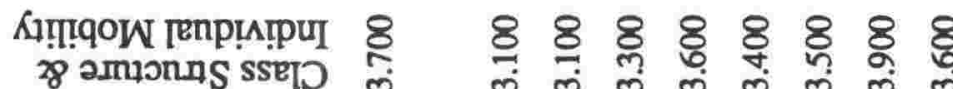

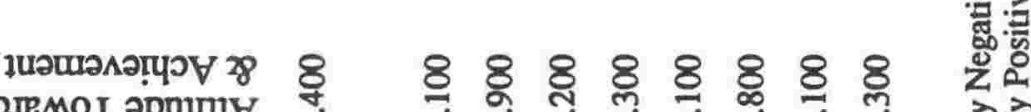

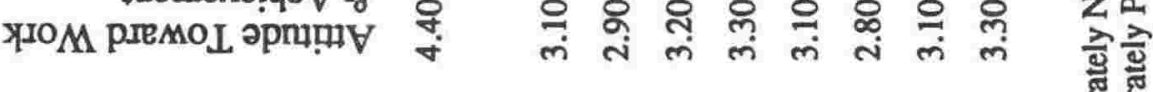

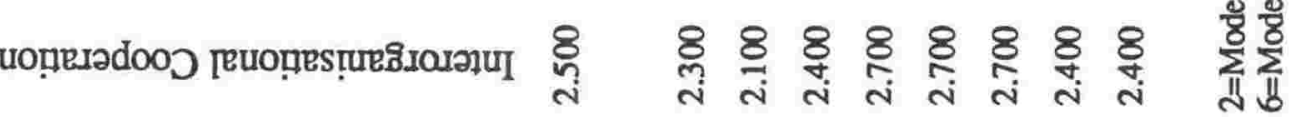

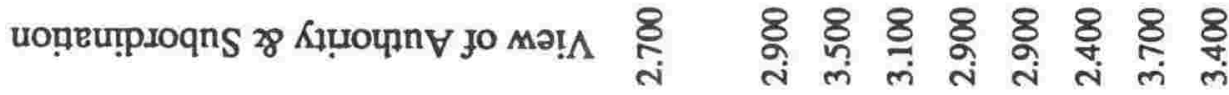

ن

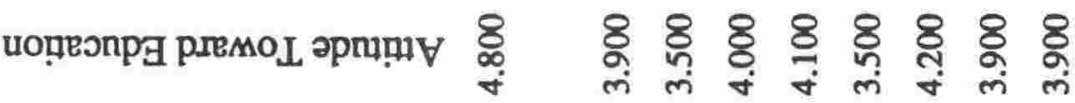

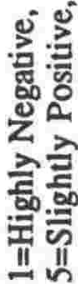

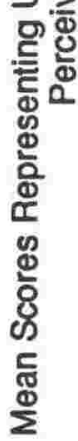

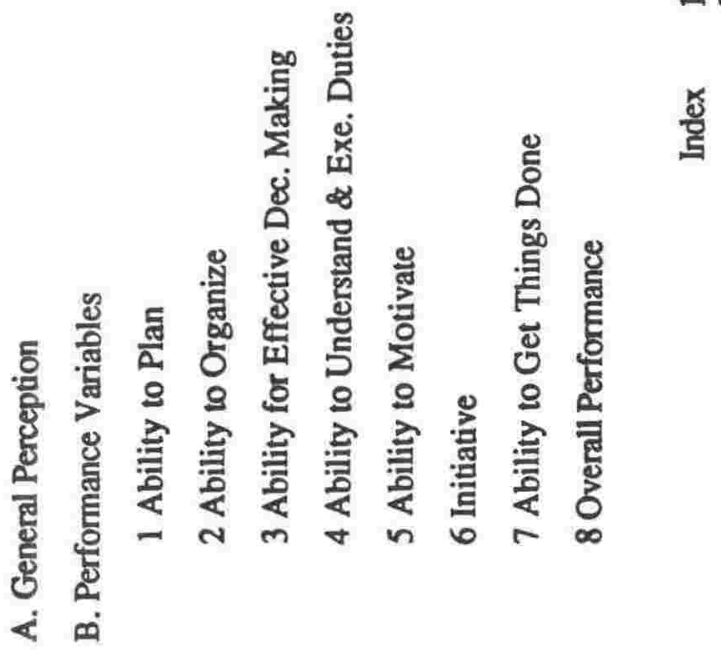




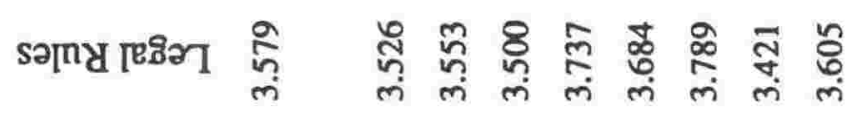

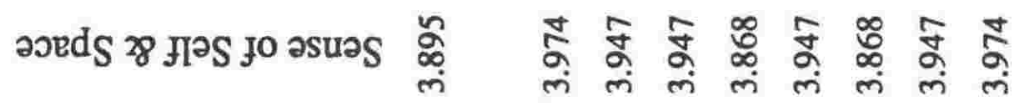

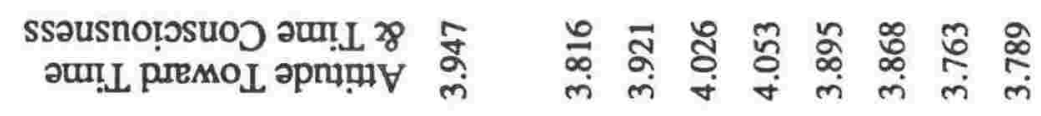

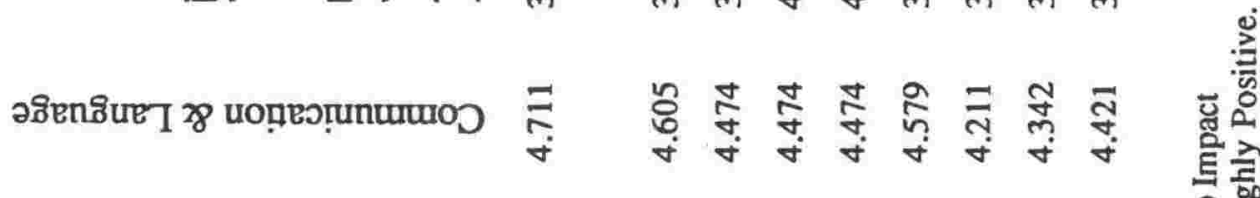

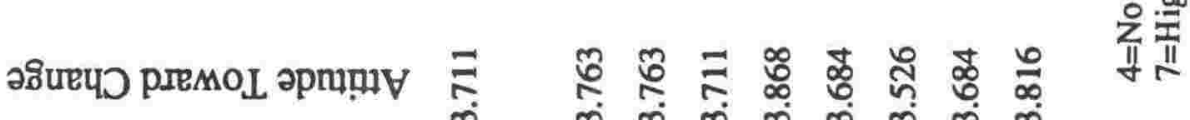

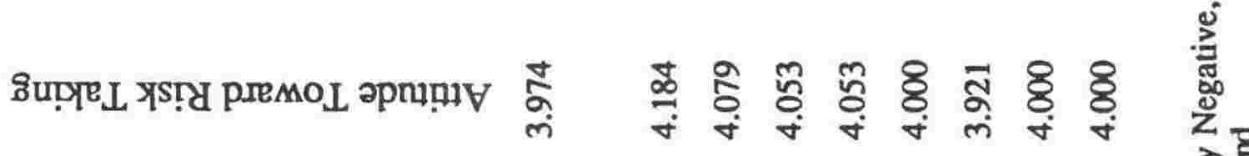

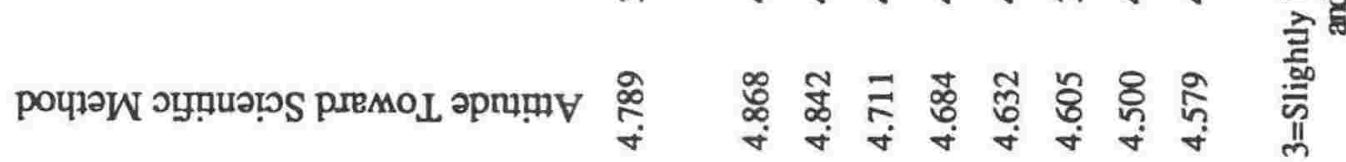

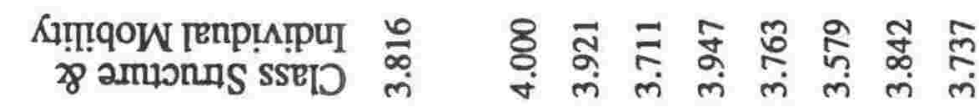

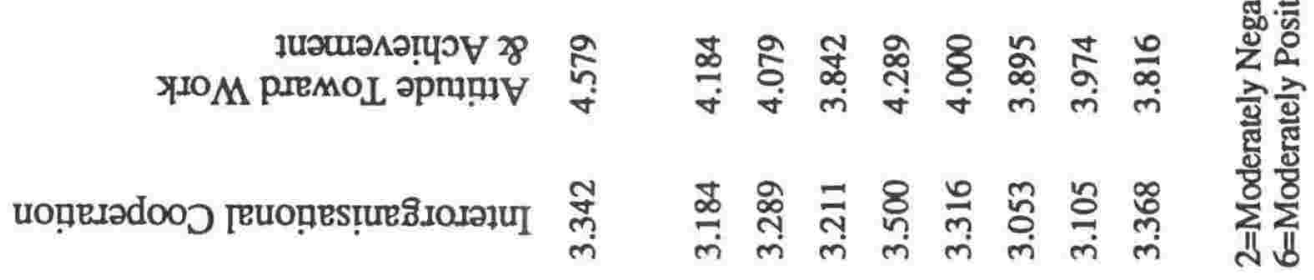

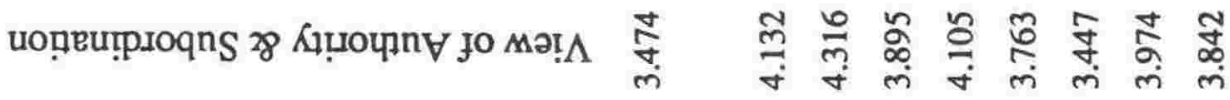

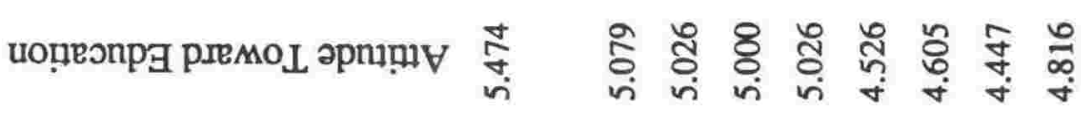

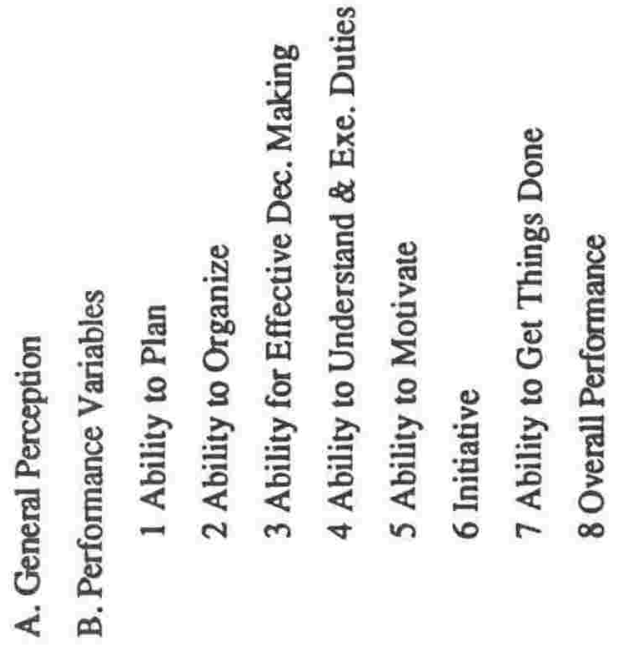




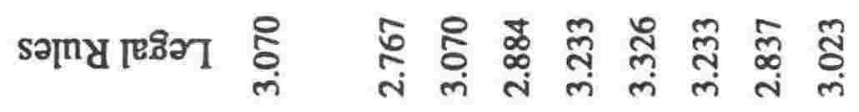

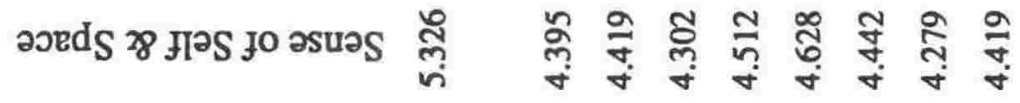

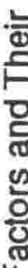

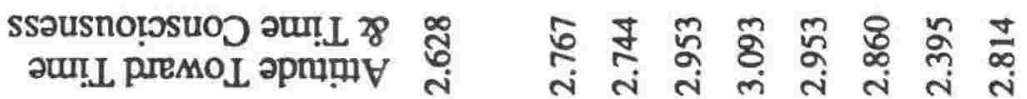

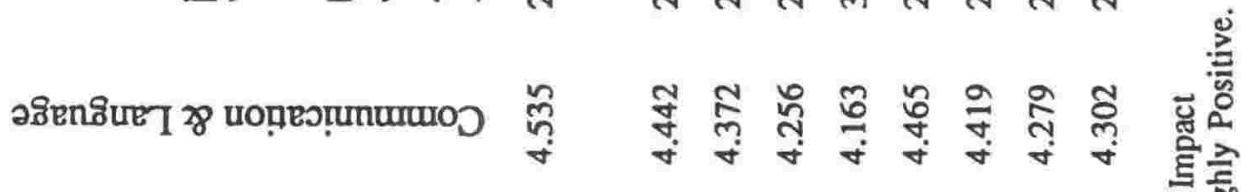

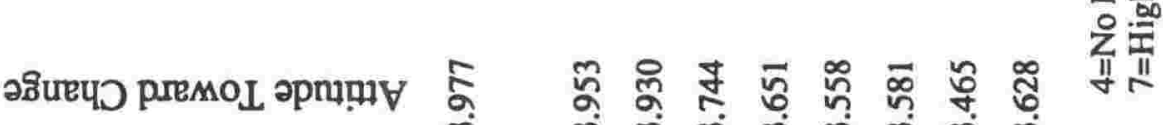

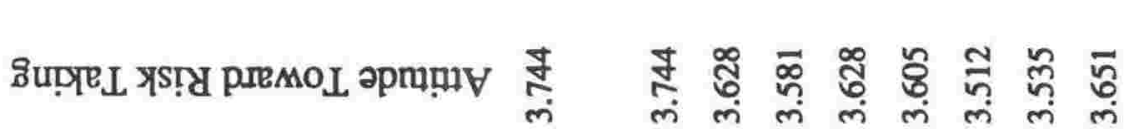

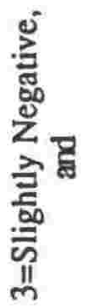

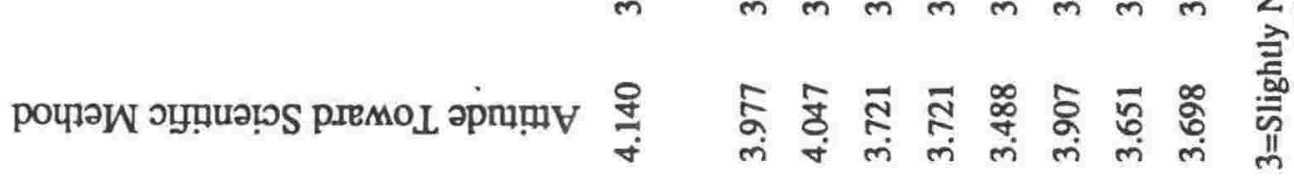

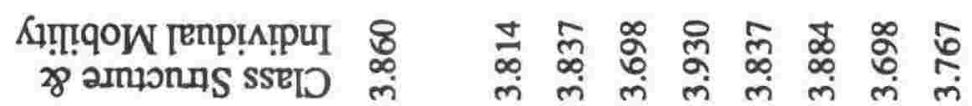

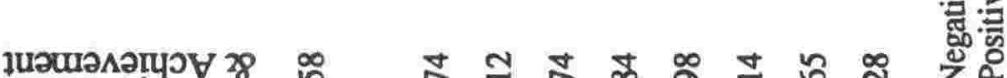

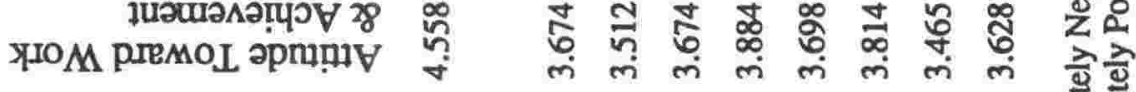

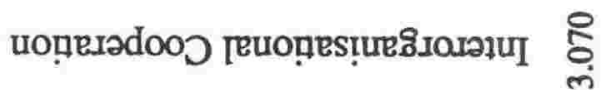

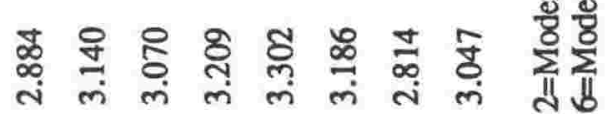

ฮั

o

uọ̣eutproqnS z8 Кำ

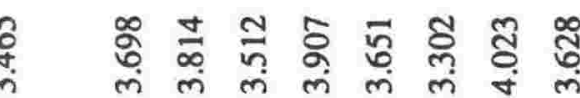

uop̣eonpg PremoL әpп!ฺ̣

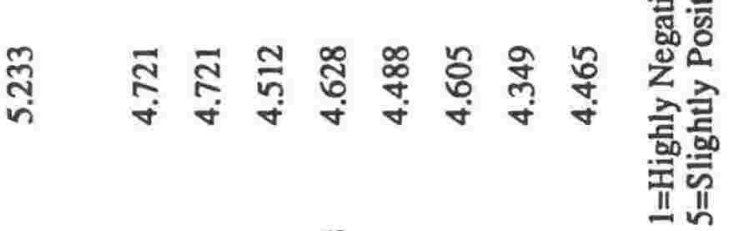

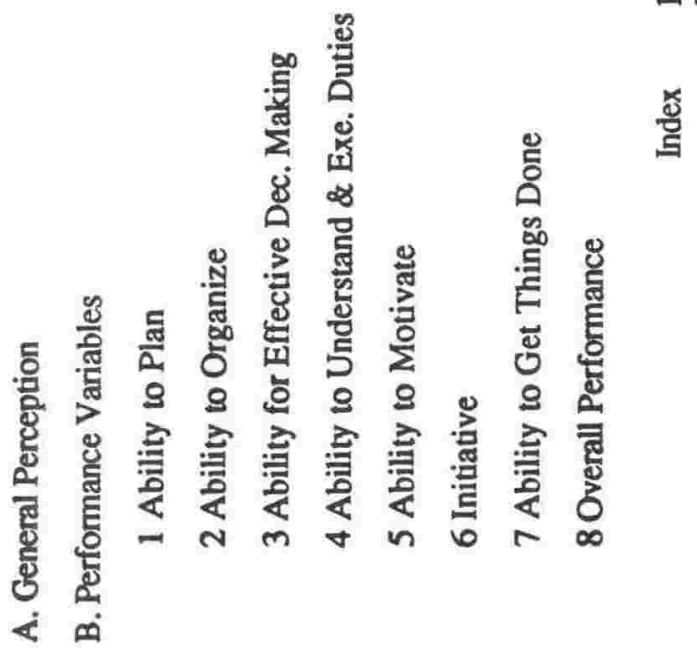




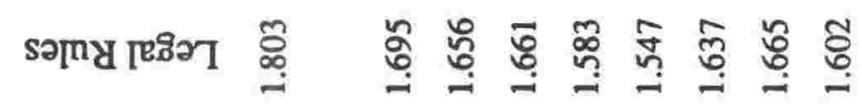

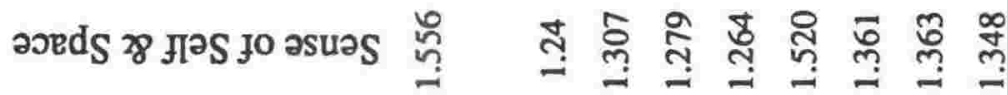

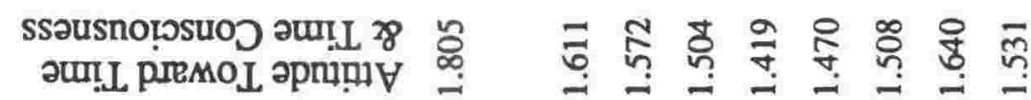

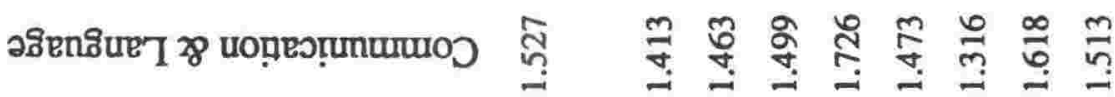

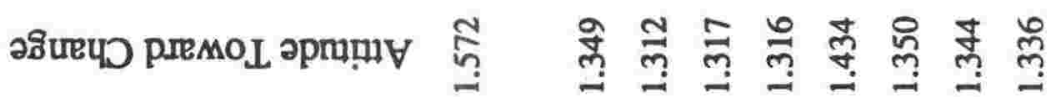

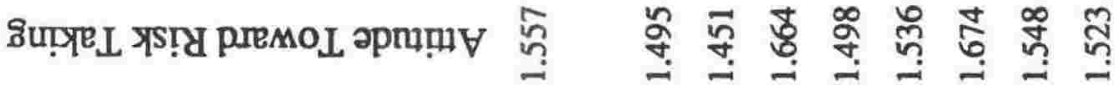

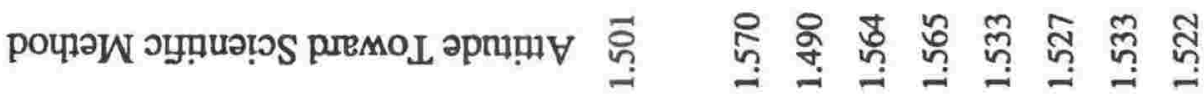

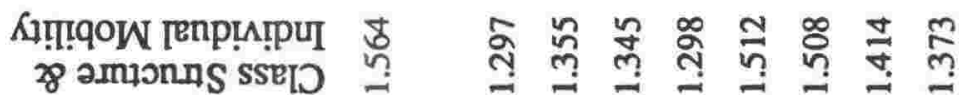

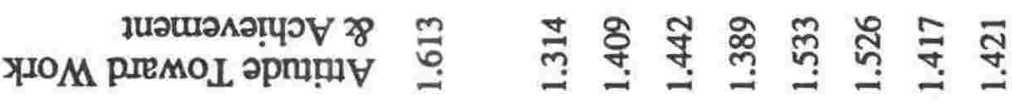

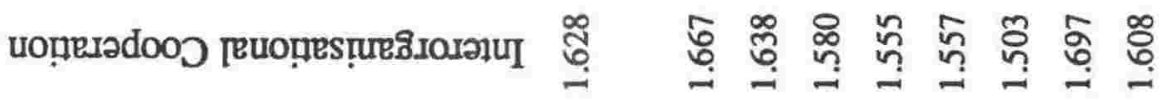

흔도

도

ळ잉

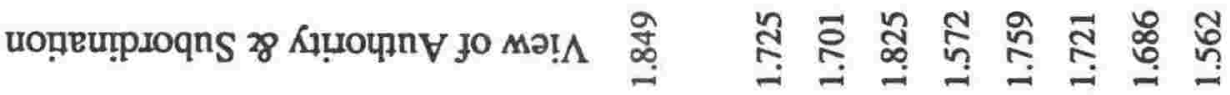

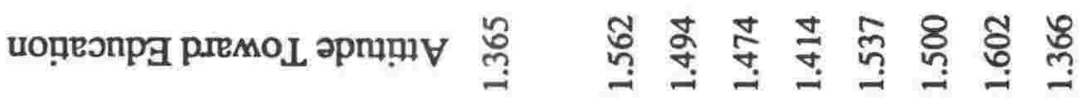

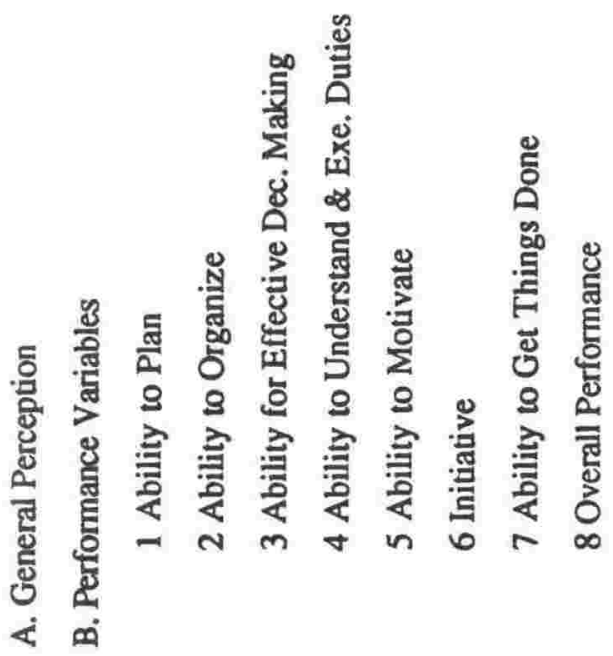




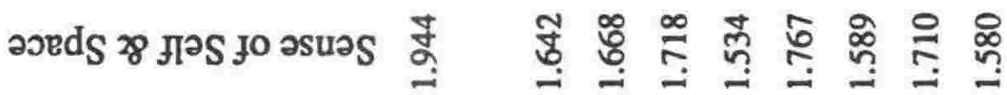

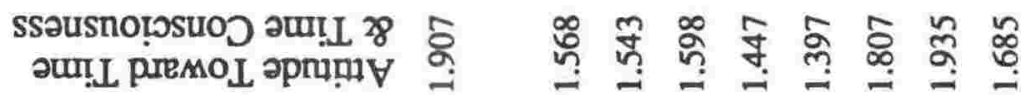

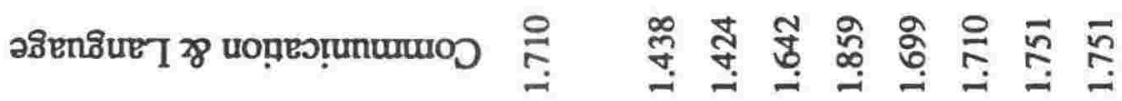

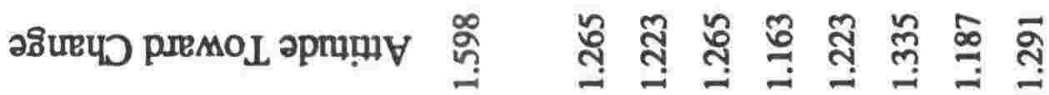

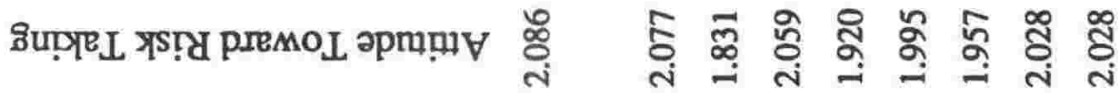

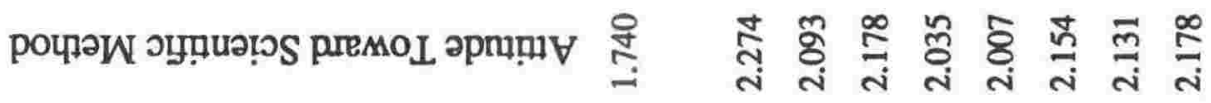

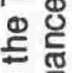

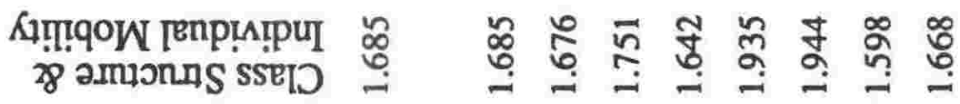

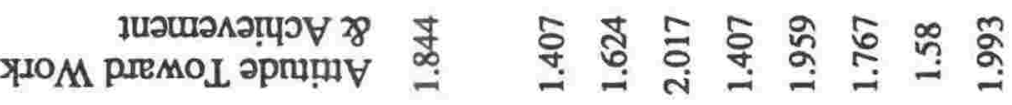

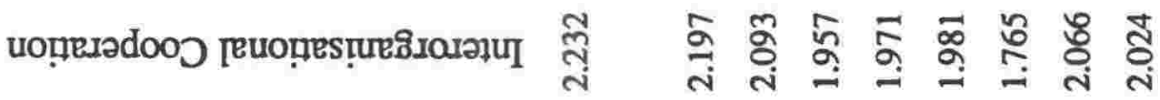

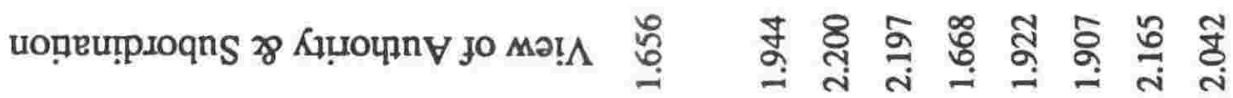

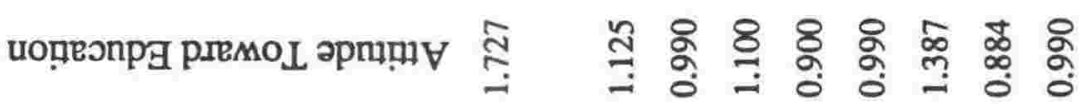

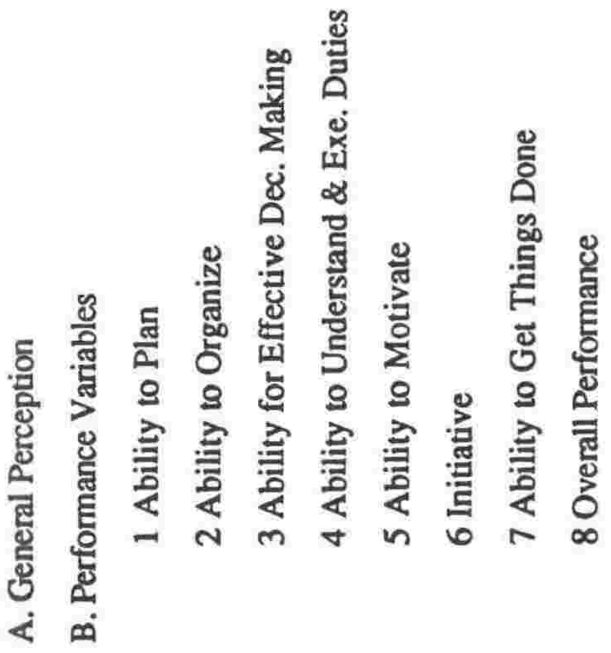


要

은

淽

띤

곡응

용

ब.

लs

$\stackrel{\infty}{\frac{0}{0}}$

崩

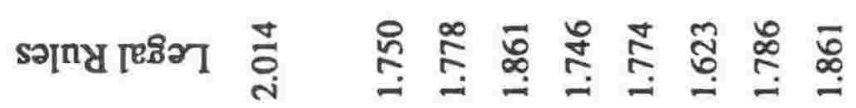

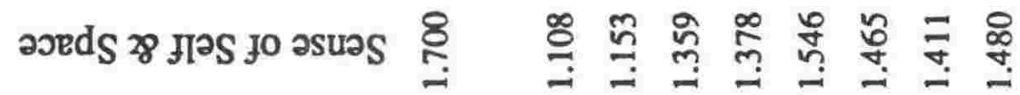

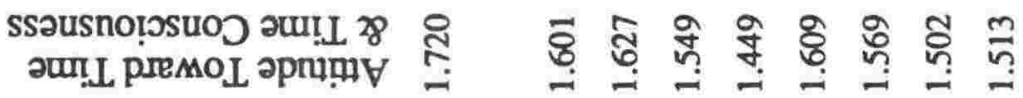

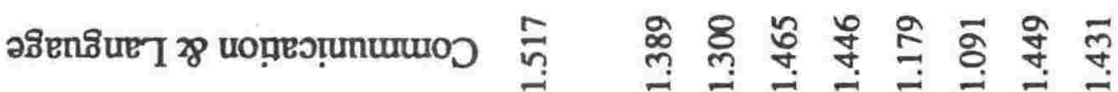

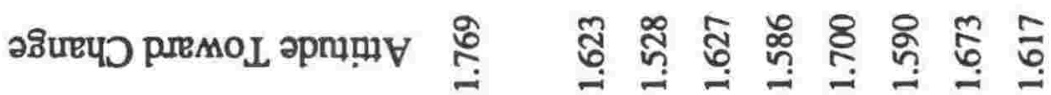

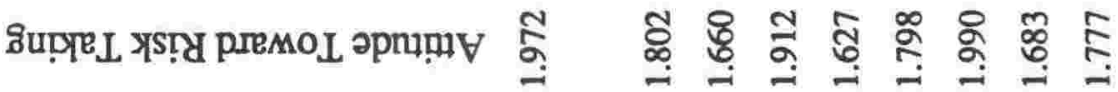

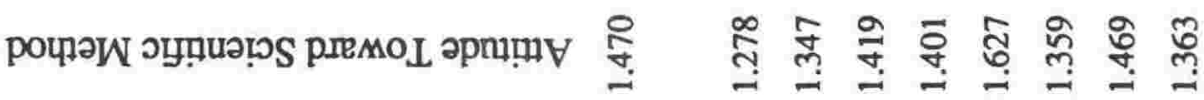

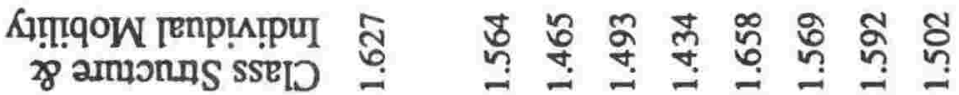

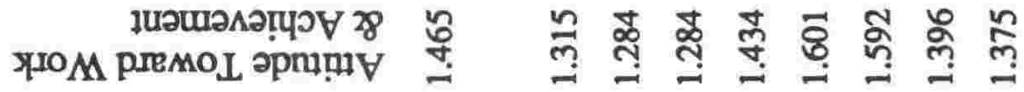

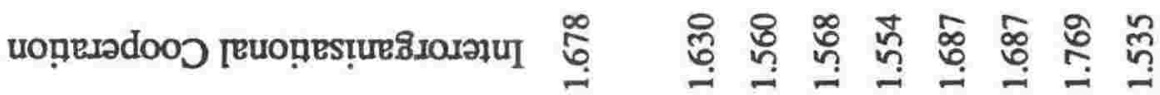

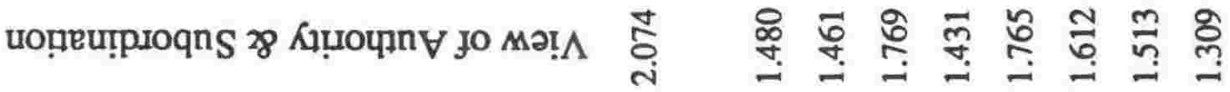

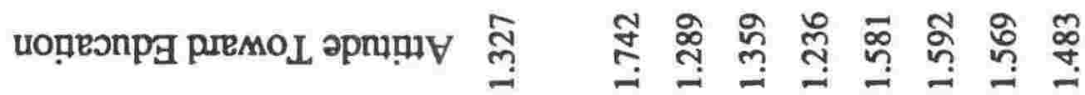

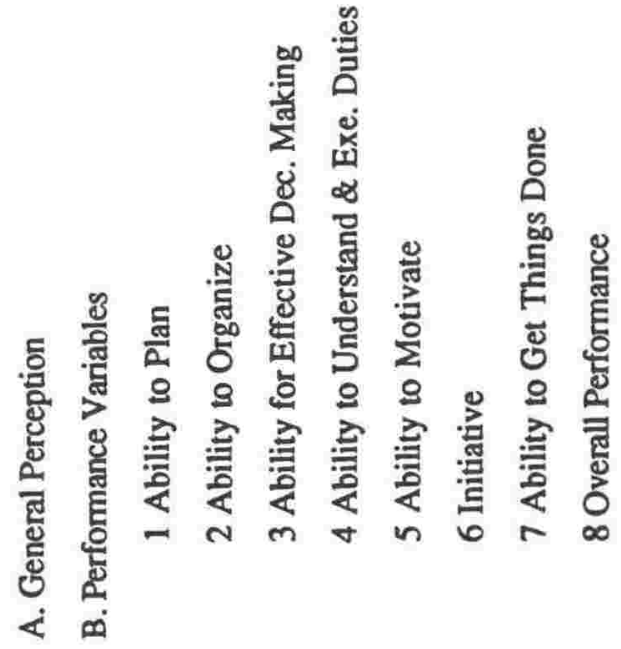




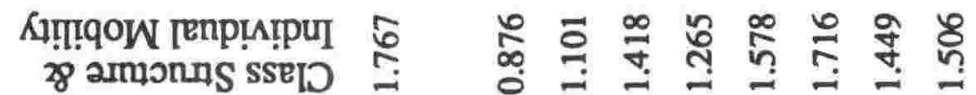

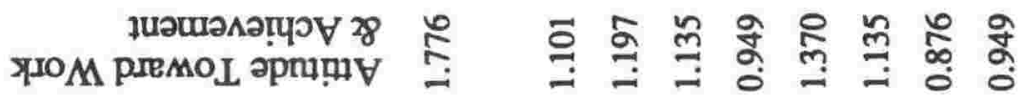

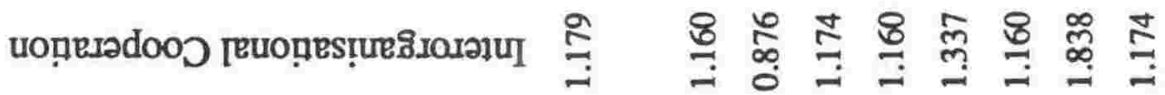

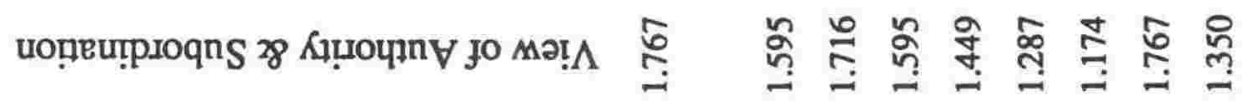

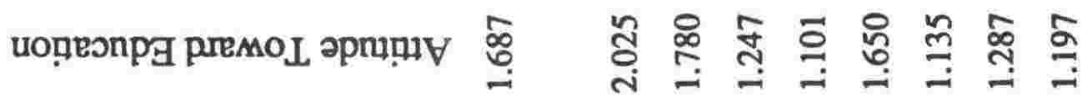

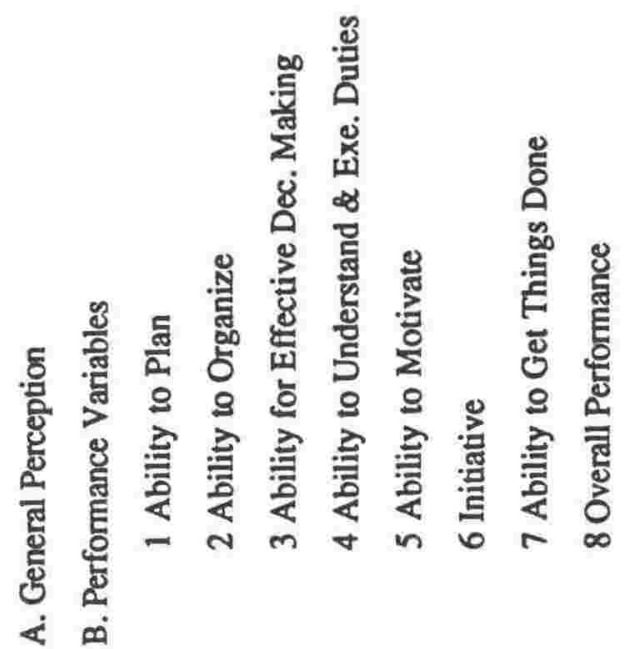

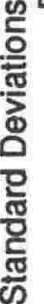




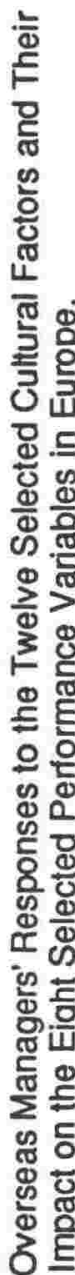

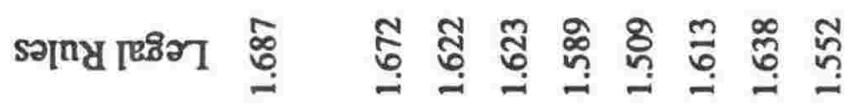

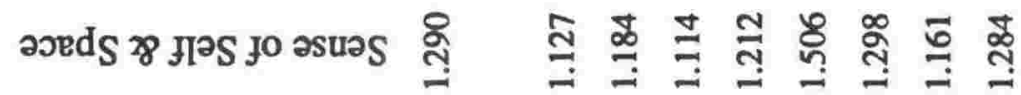

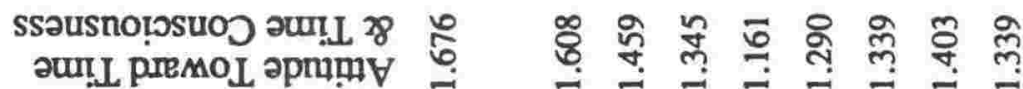

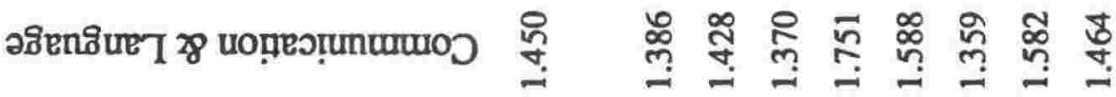

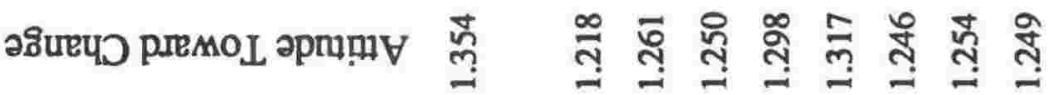

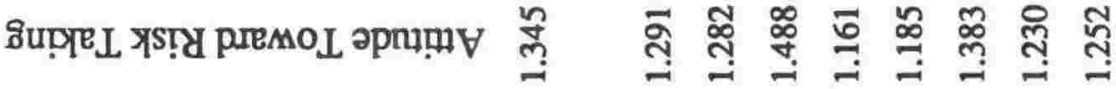

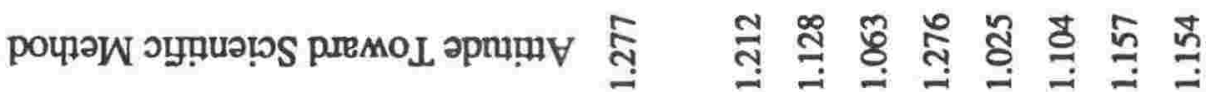

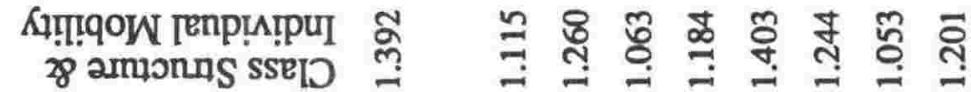

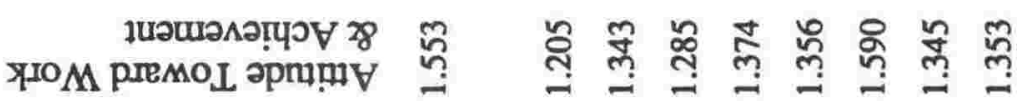

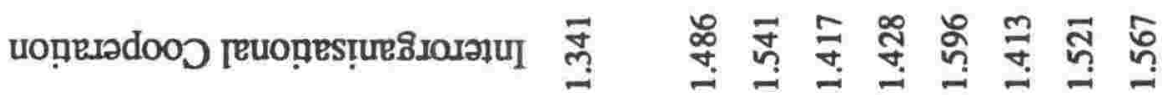

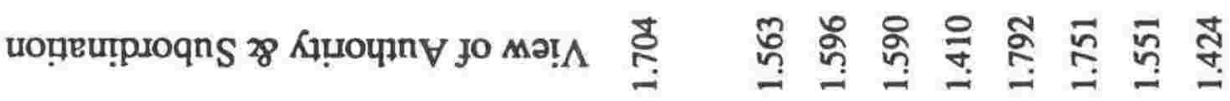
ค่.

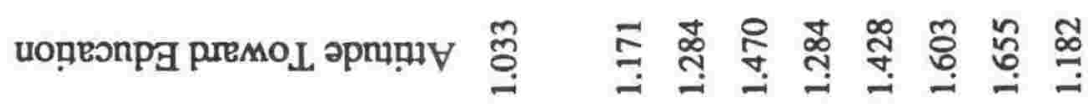




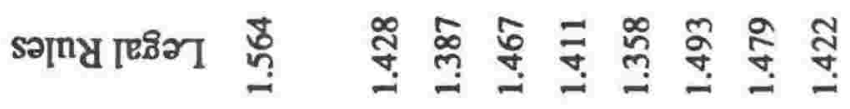

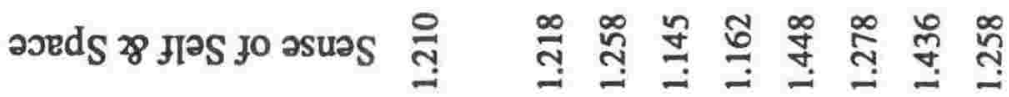

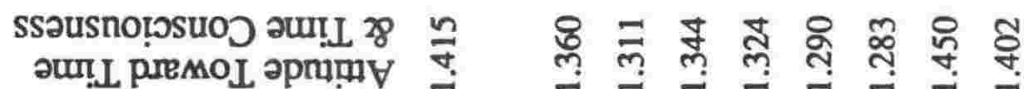

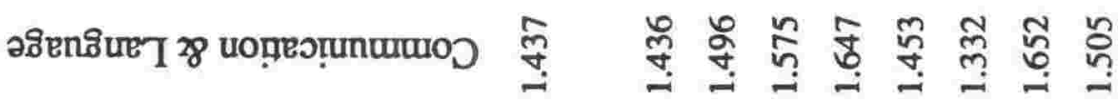

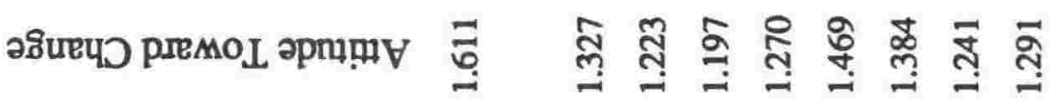

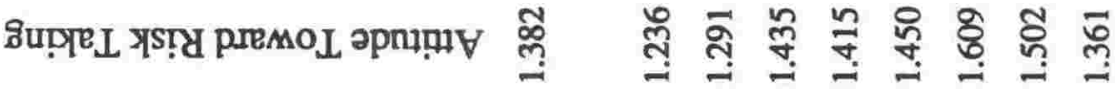

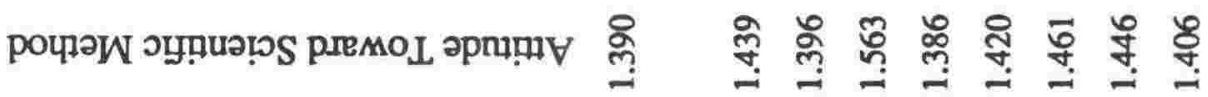

용

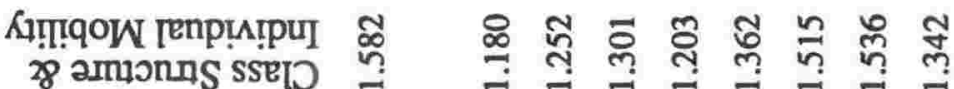

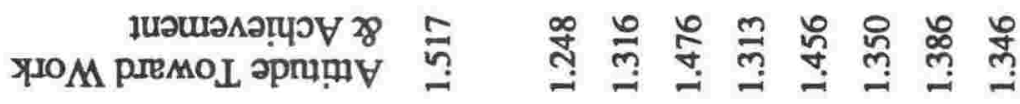

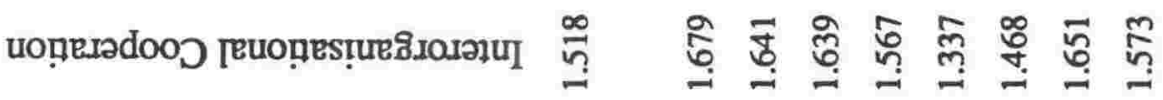

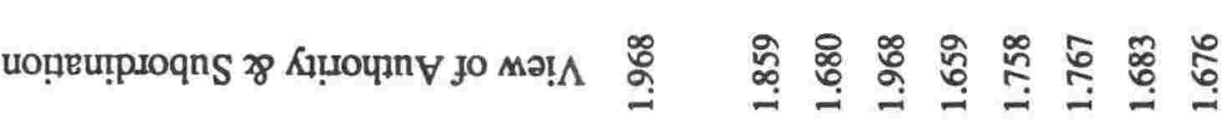




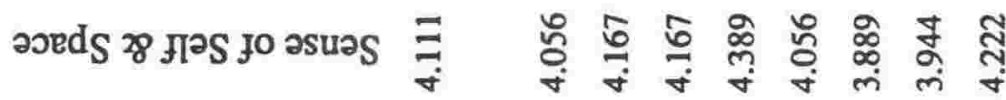

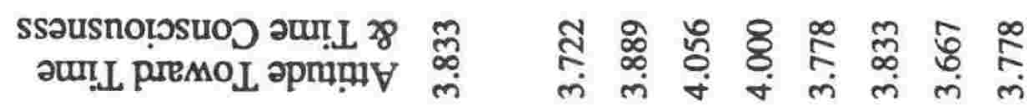

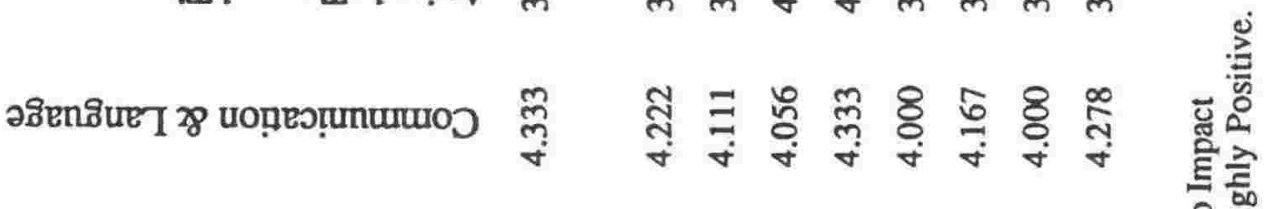

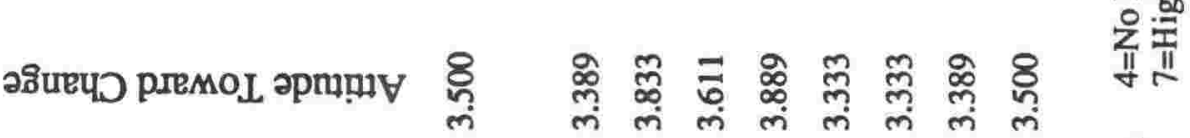

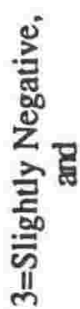

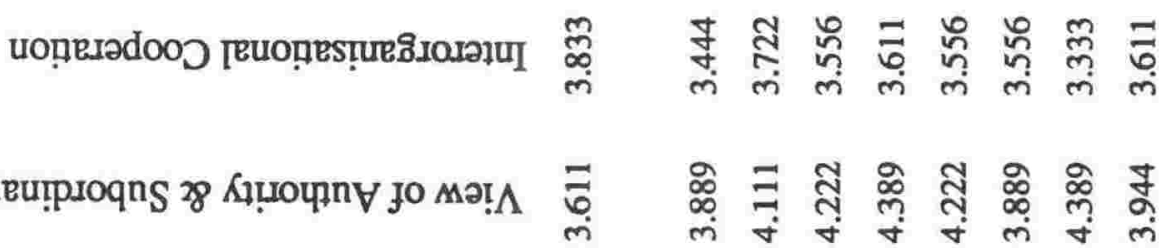




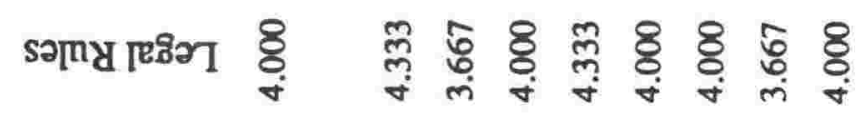

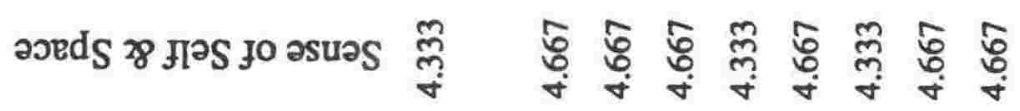

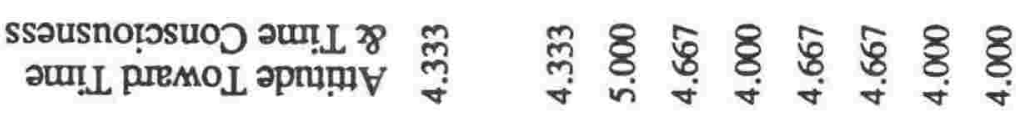

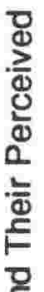

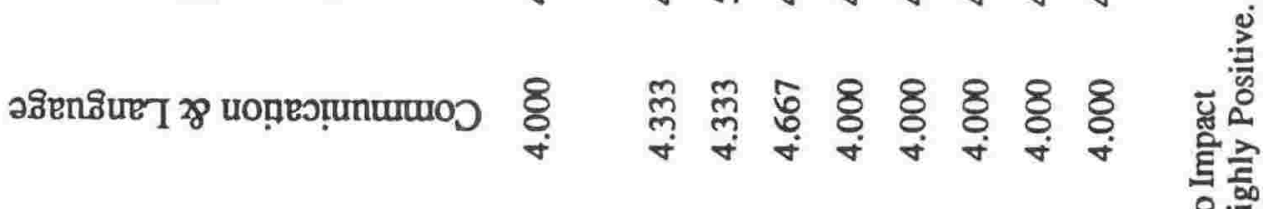

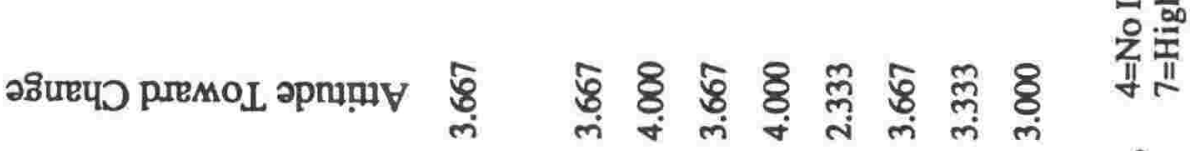

낭

in 으

응

\%

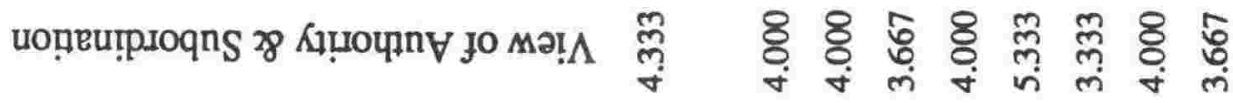

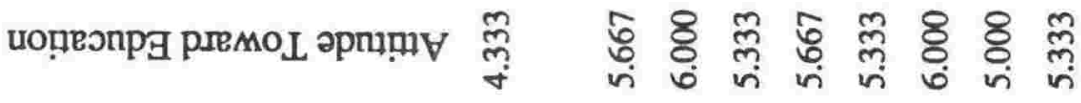

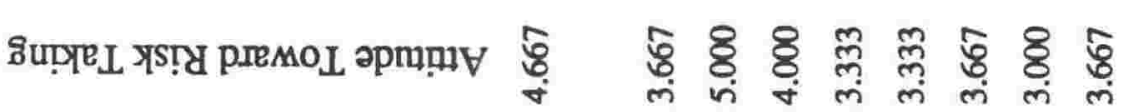

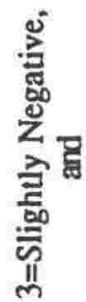

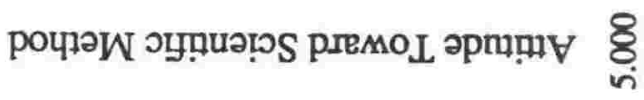

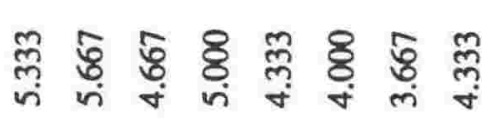

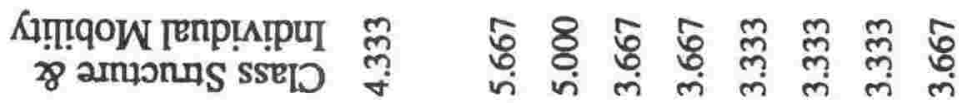

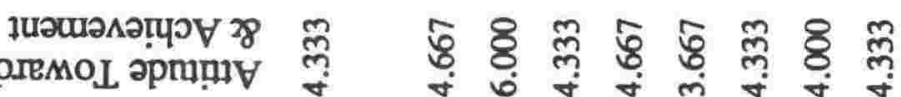

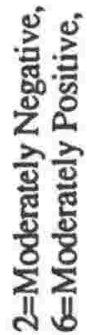

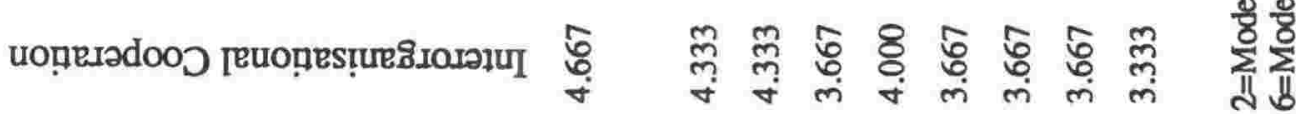

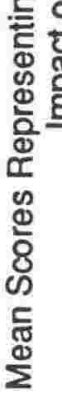
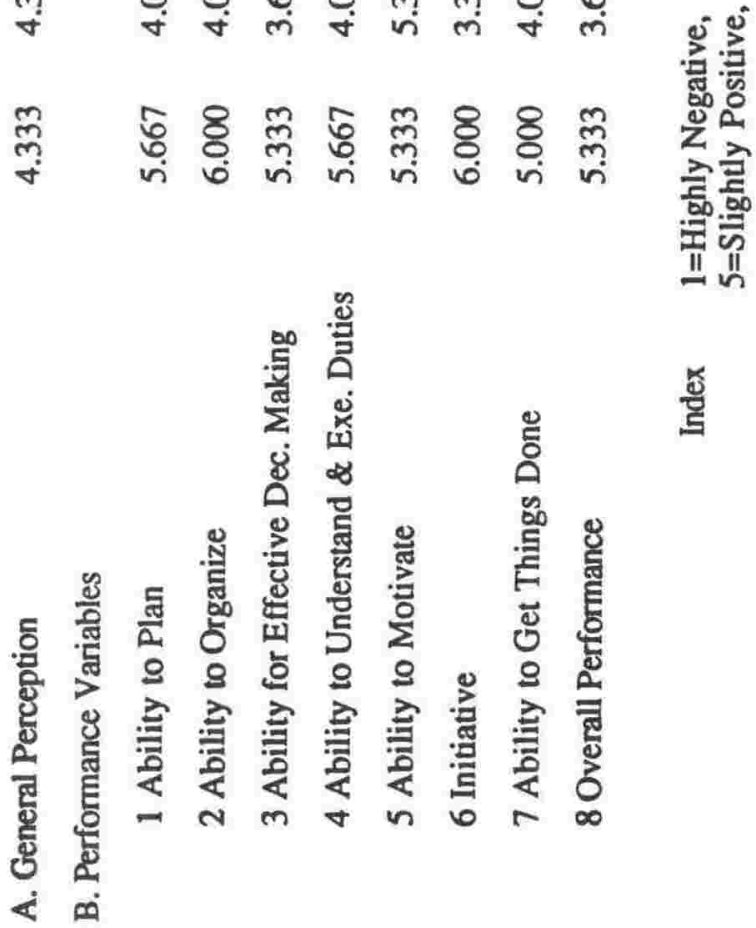

迺 


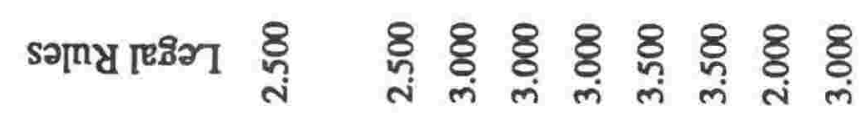

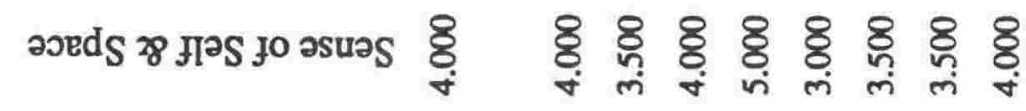

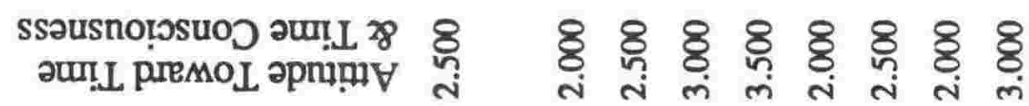

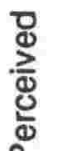

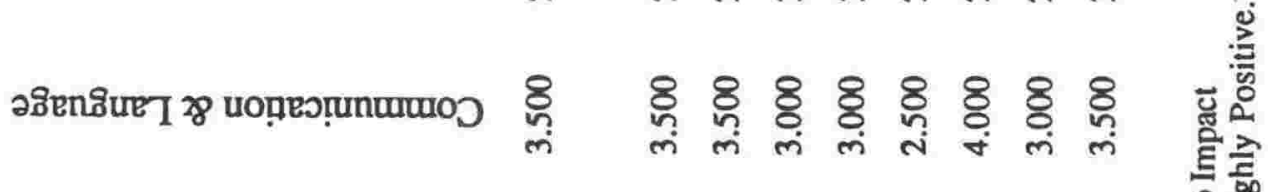

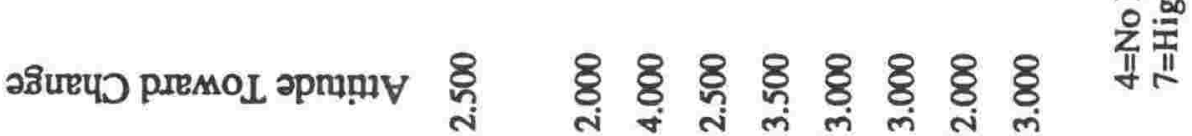

흘

응 음

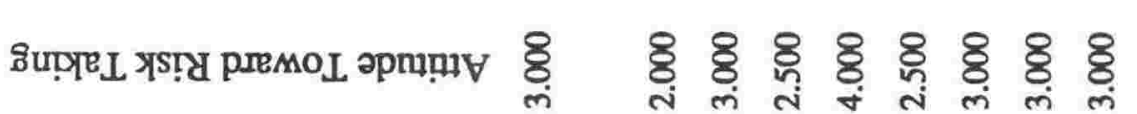

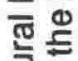

竞.

일

$3 \pi$

งิ

in

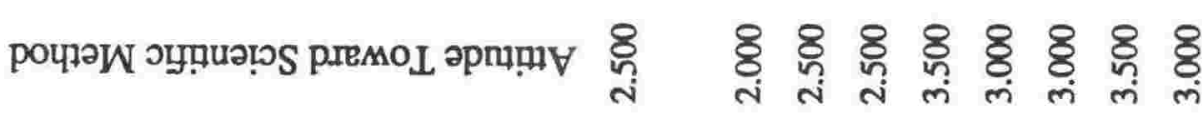

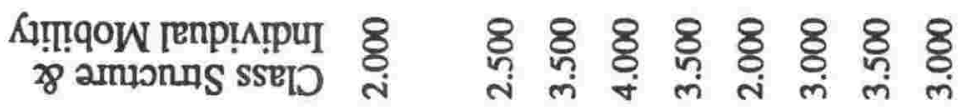

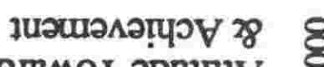

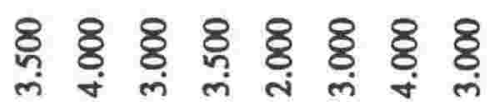

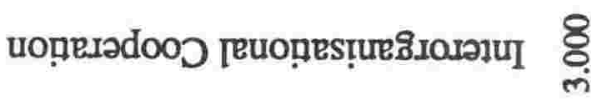

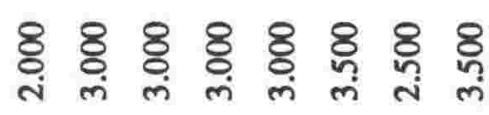

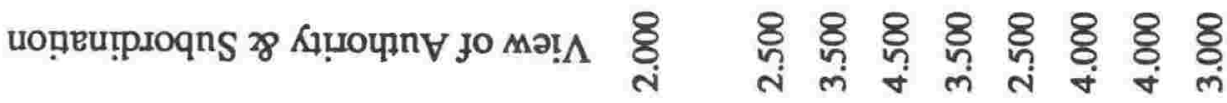

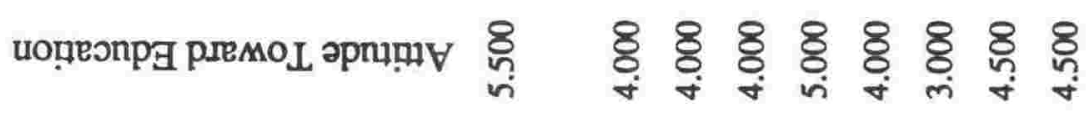




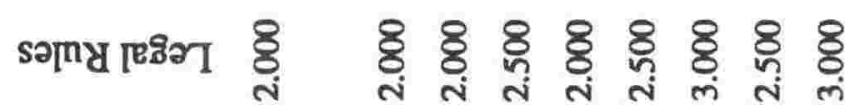

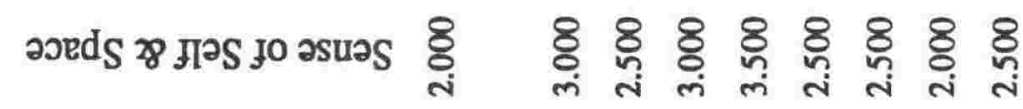

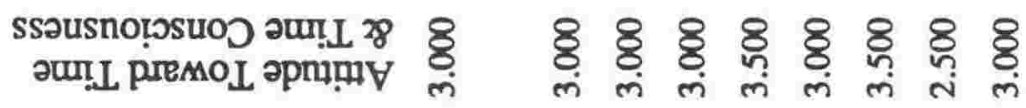

D

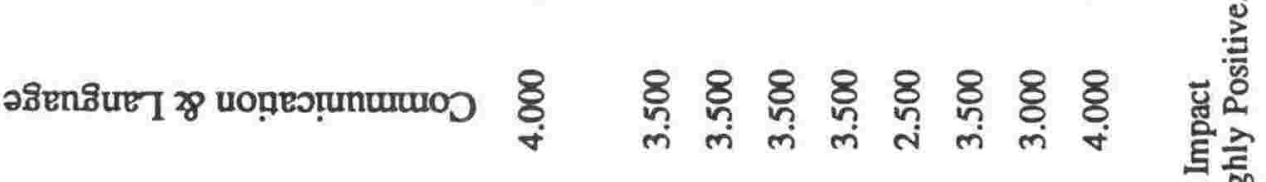

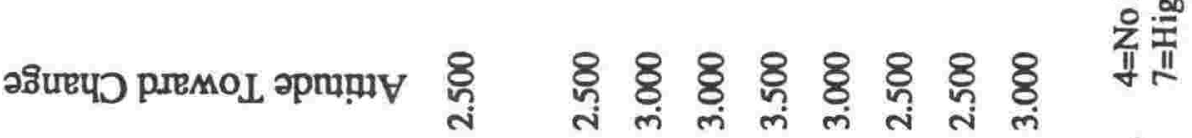

कิ

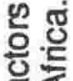

帘

뜬.

类造

จ

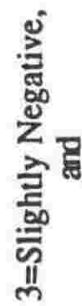

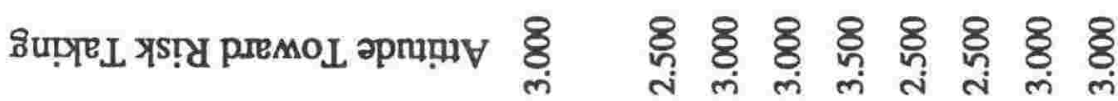

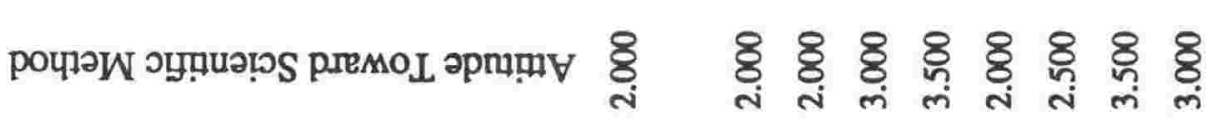

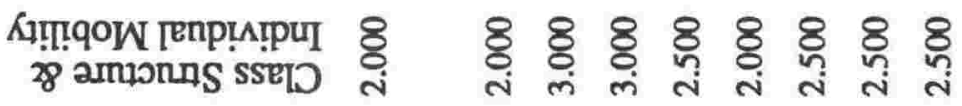

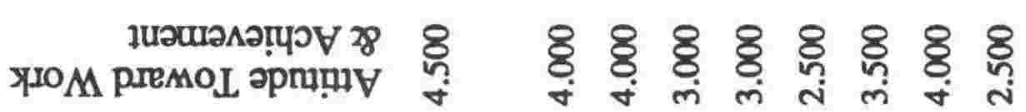

$\sum^{\infty}$

$\frac{2}{4}$

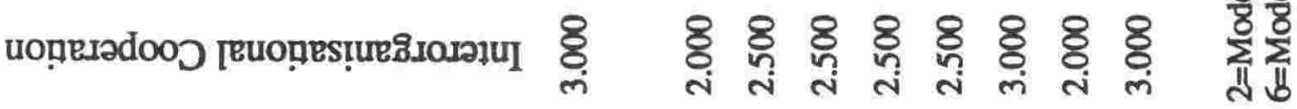

突蜜

능

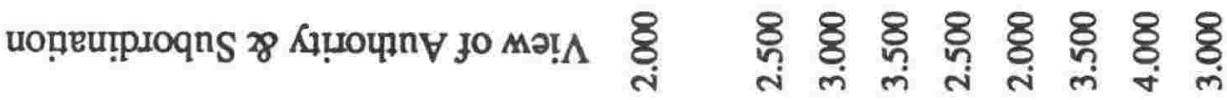

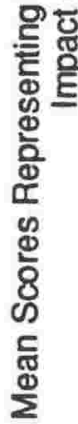

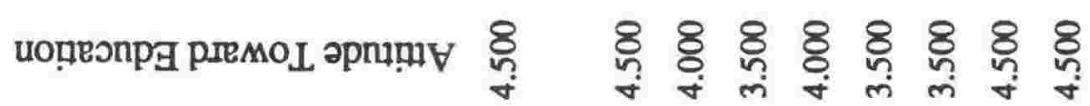
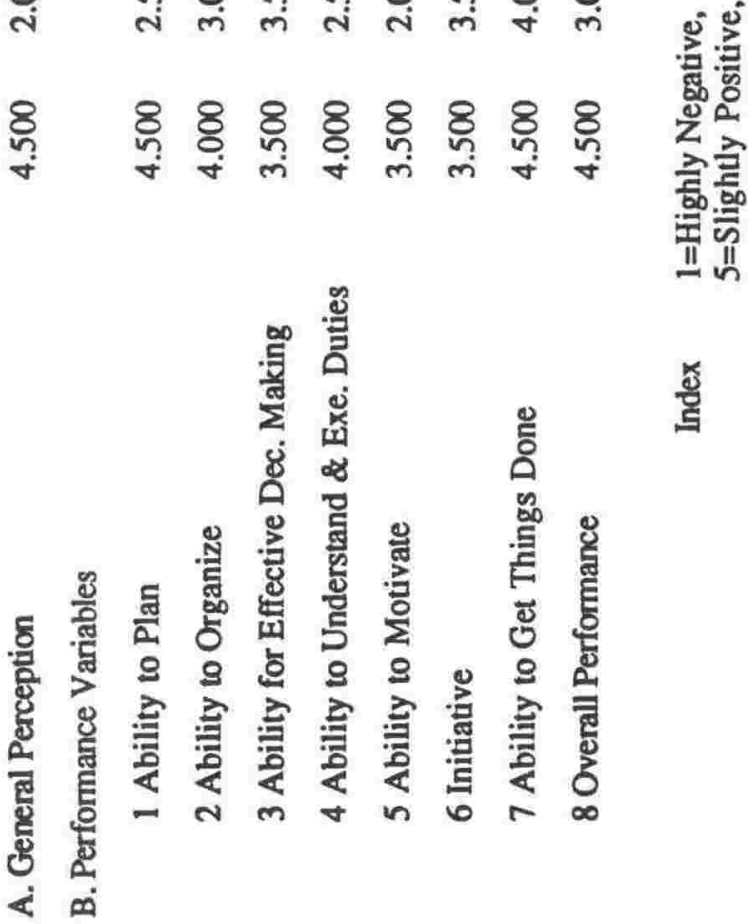

总 


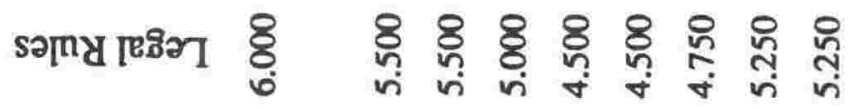

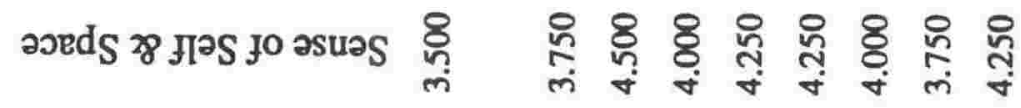

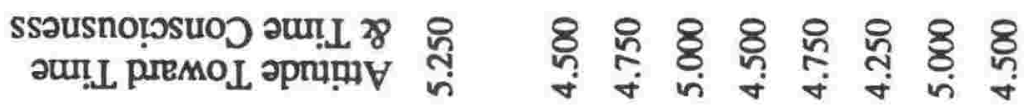



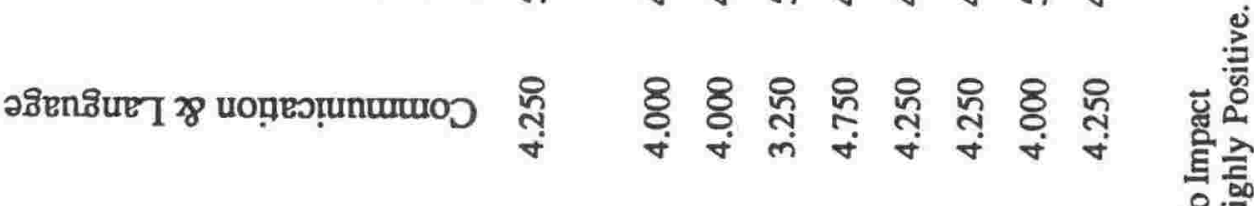

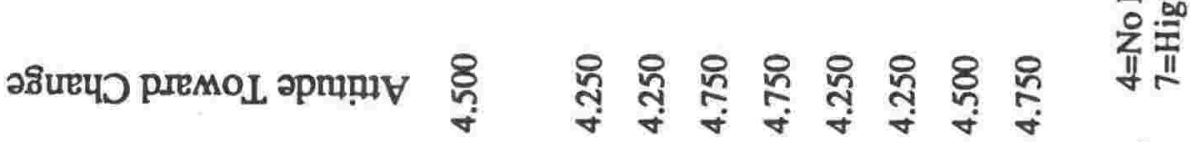

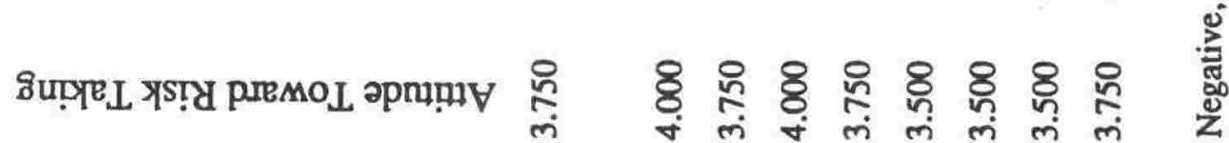

ัับ

뜬

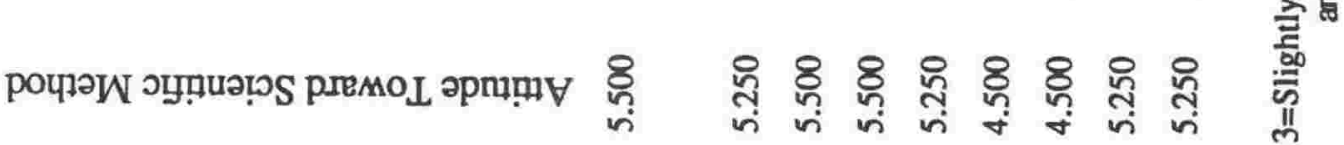

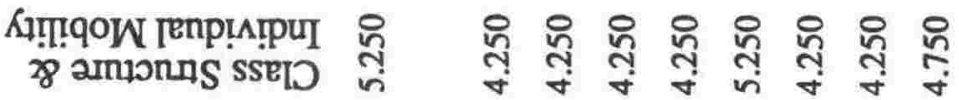

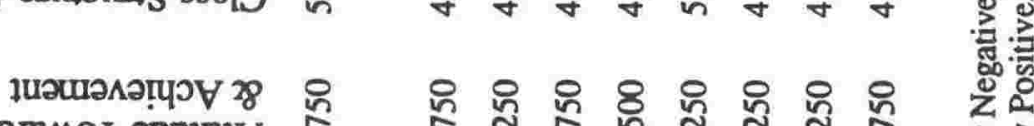

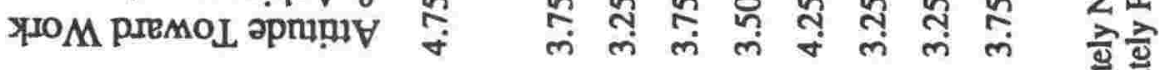

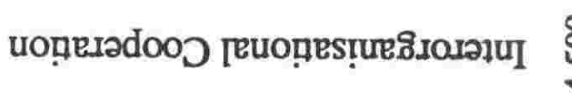




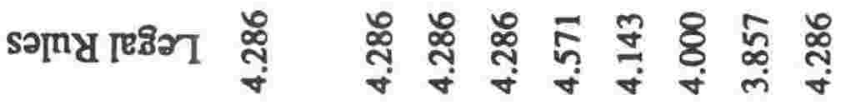

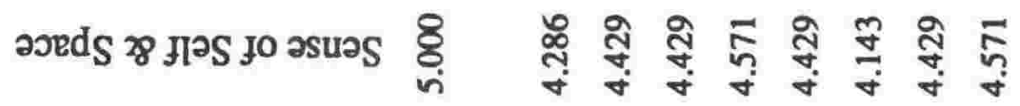

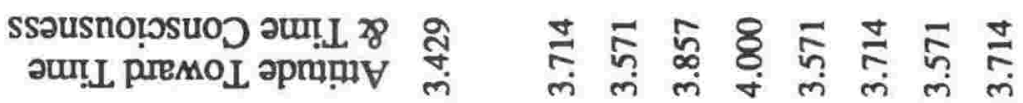

잉

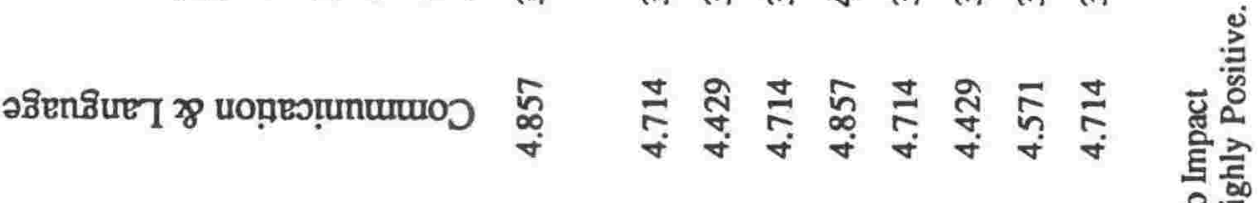

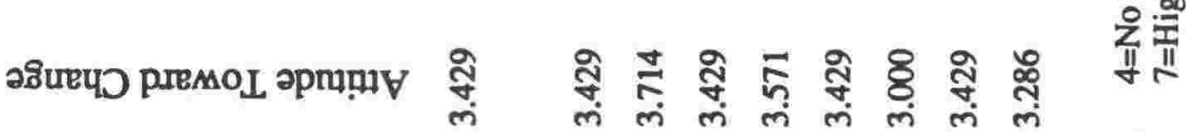

동

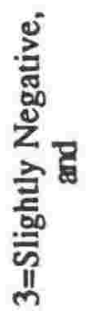

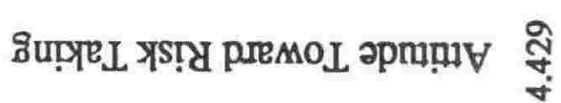

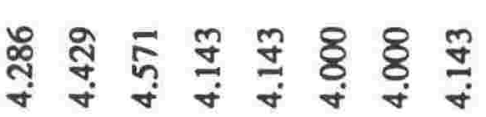

pочџ्W

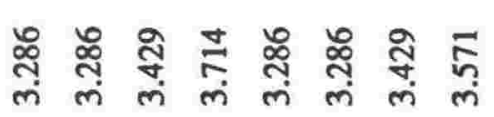

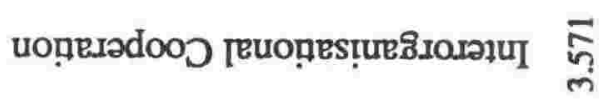

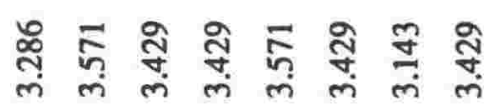

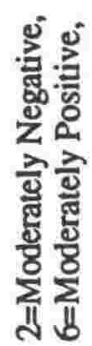

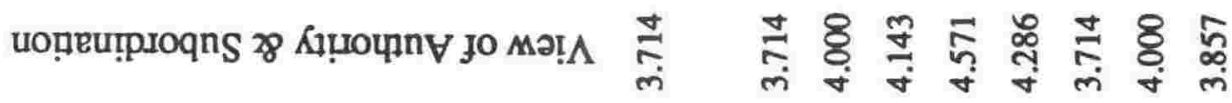

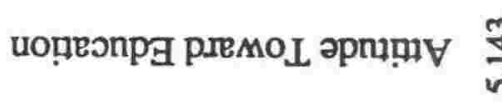

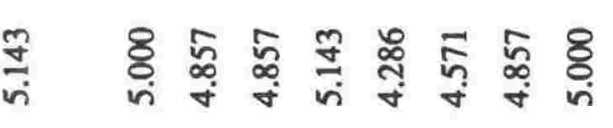
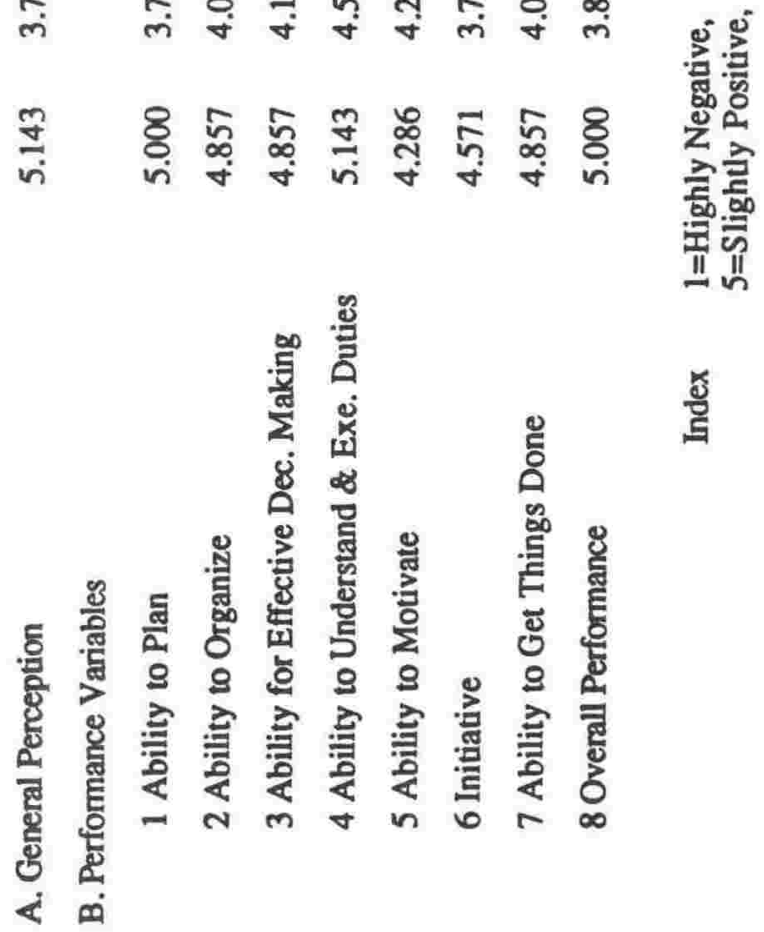


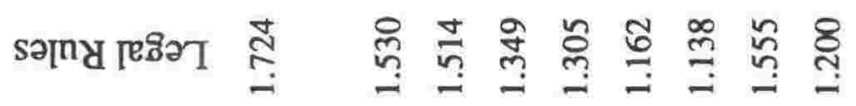

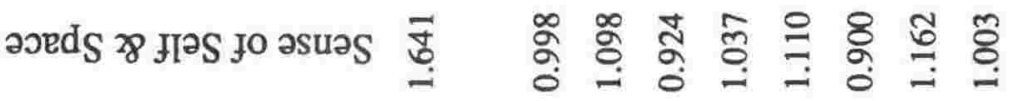

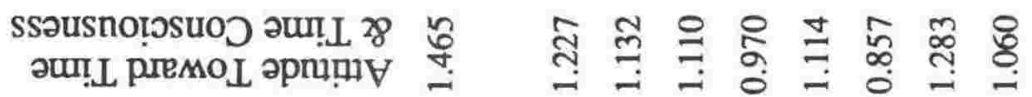

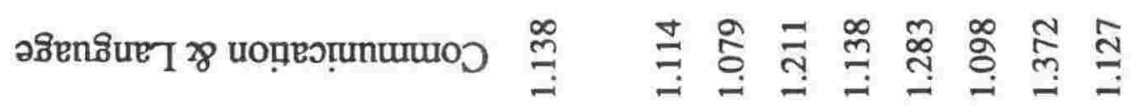

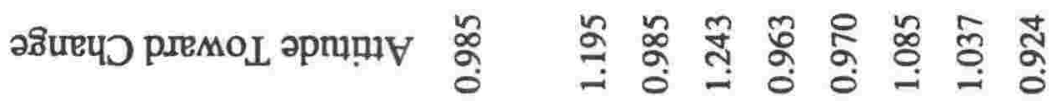

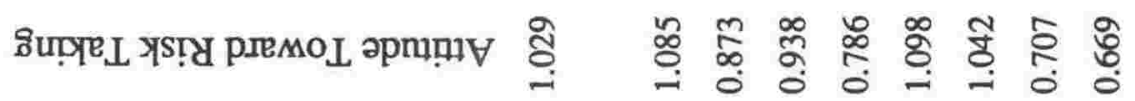

S)

里

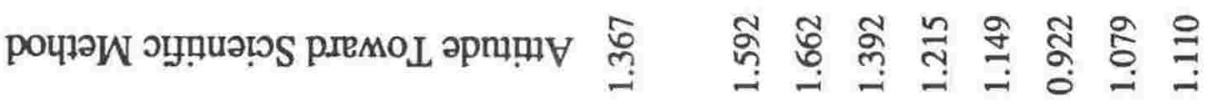

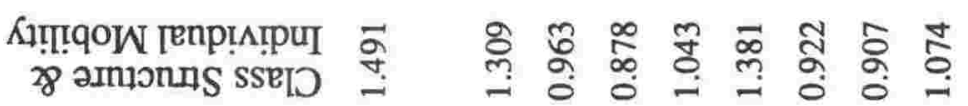

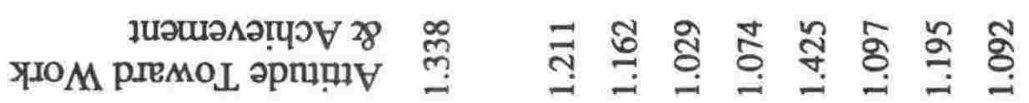

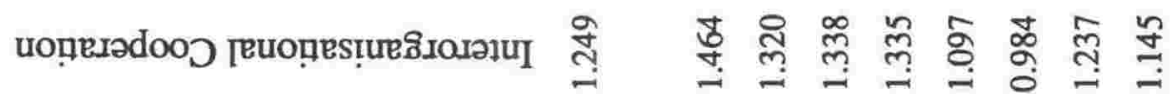

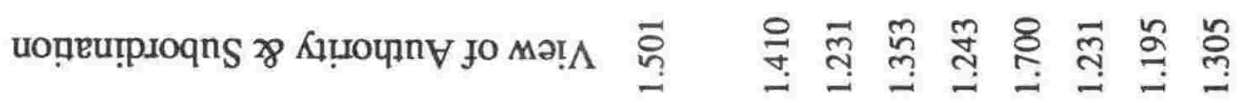

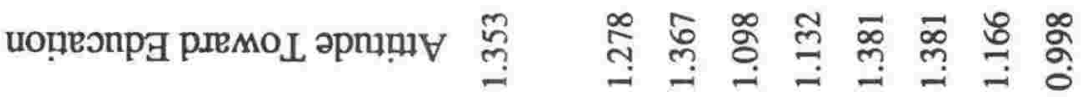

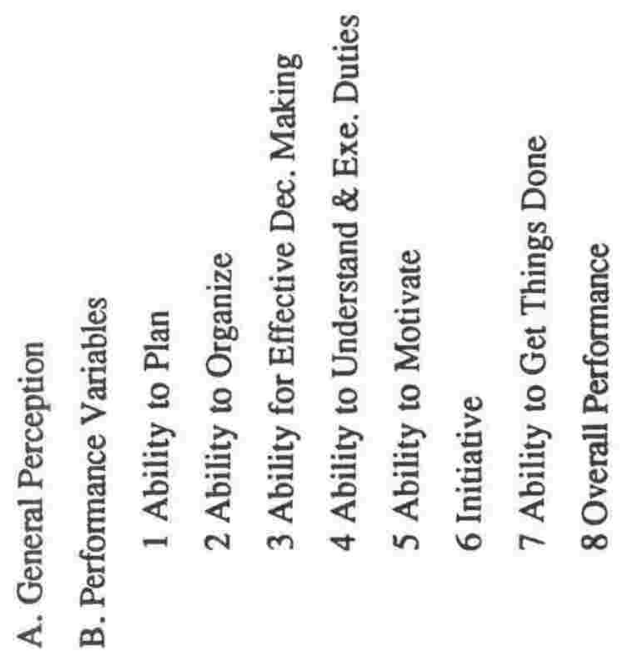




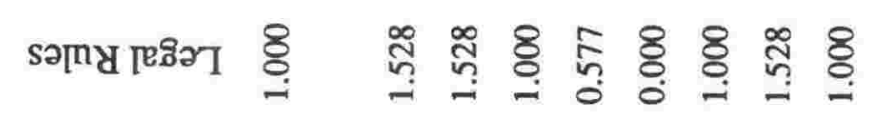

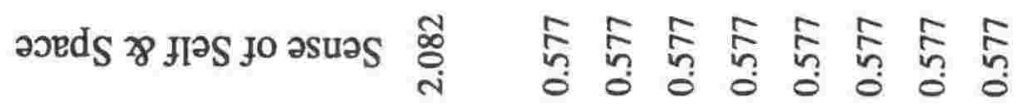

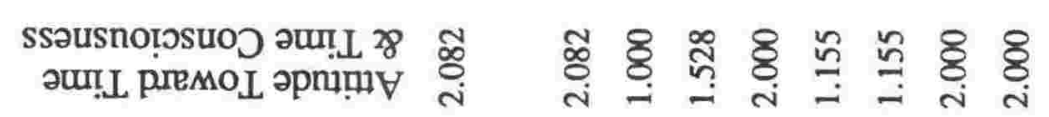

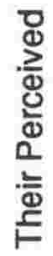

礛

을

这产

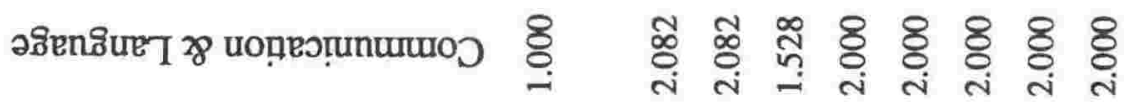

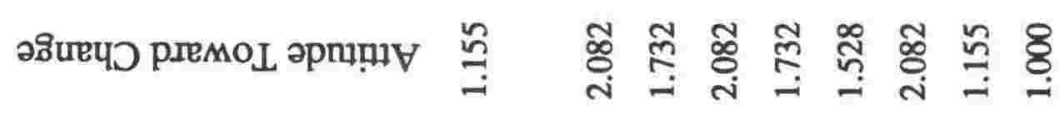

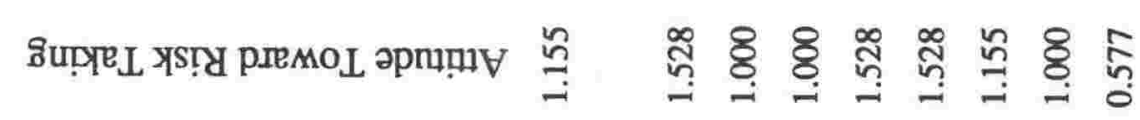

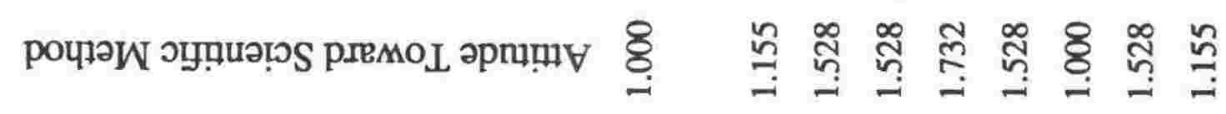

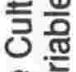

$\stackrel{0}{\longrightarrow}$

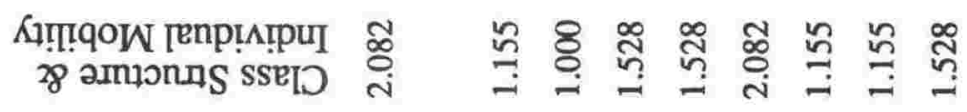

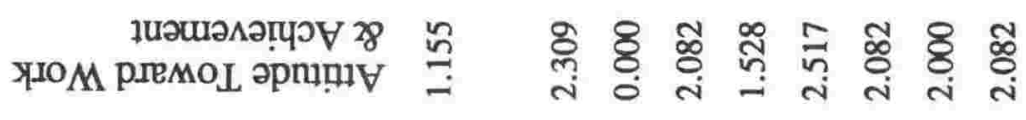

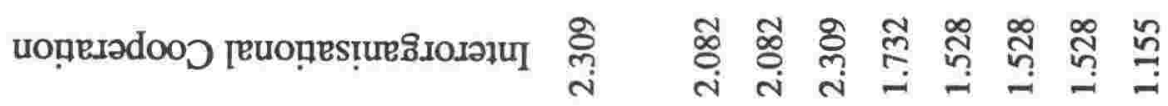

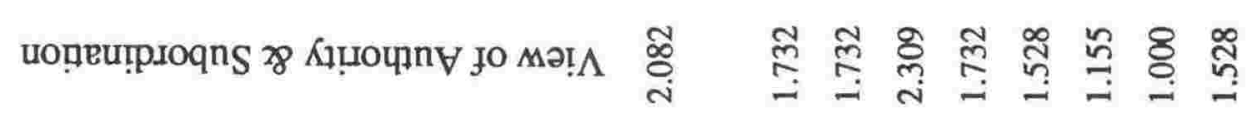

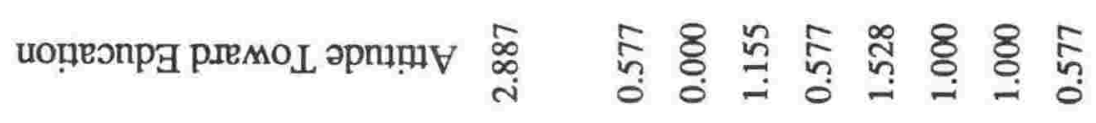

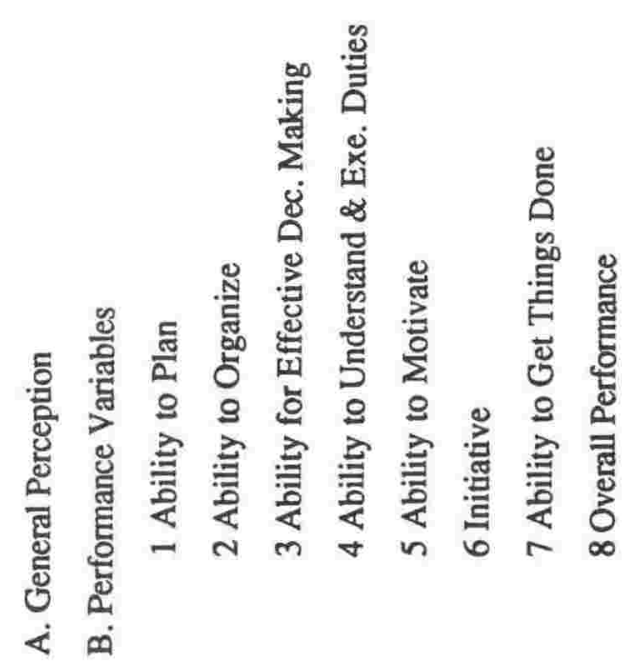




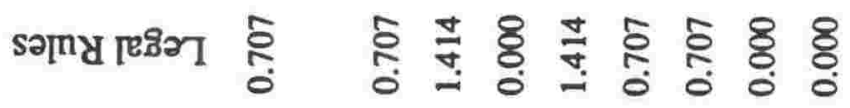

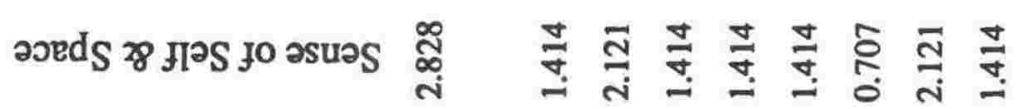

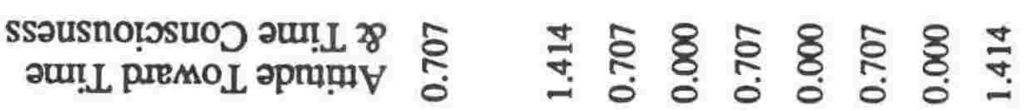

$\stackrel{\square}{\frac{\Phi}{\infty}}$

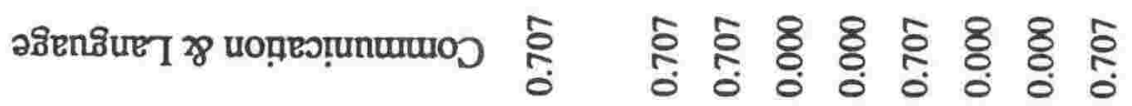

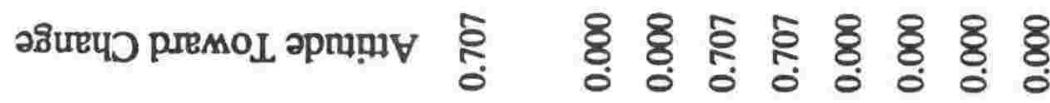

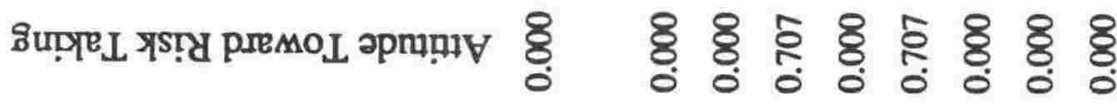

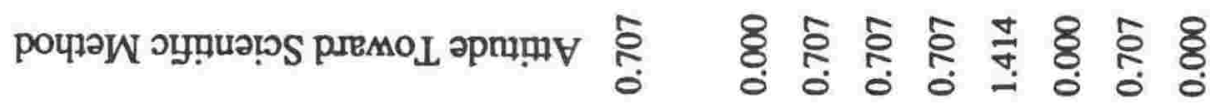

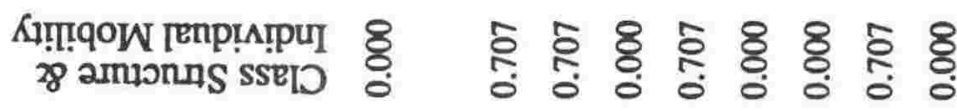

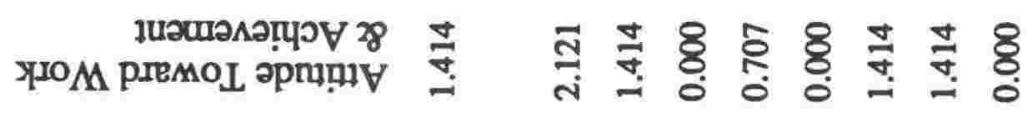

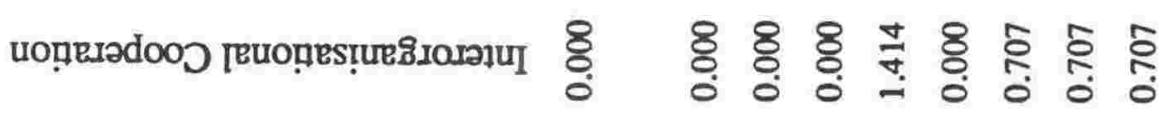

uореuтproqn

드

능

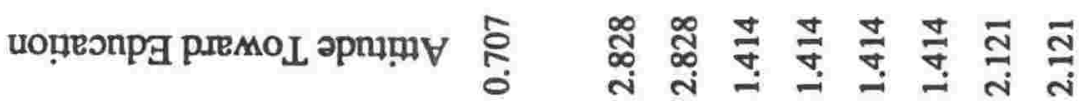

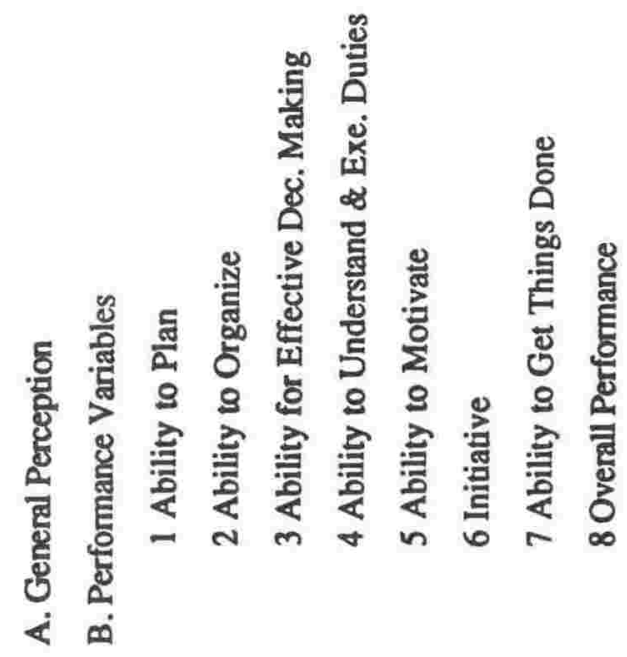




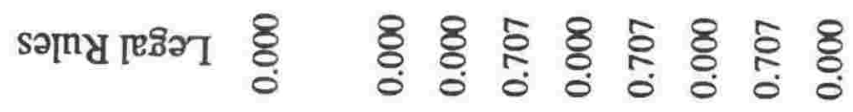

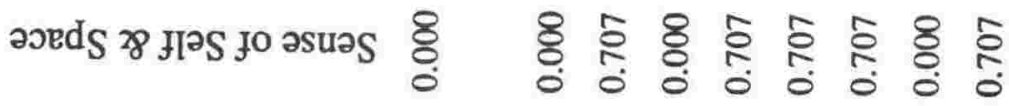

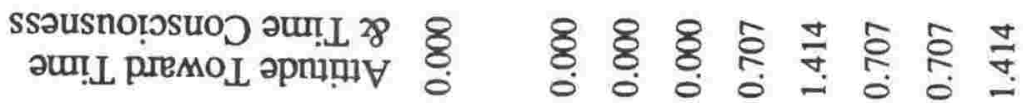

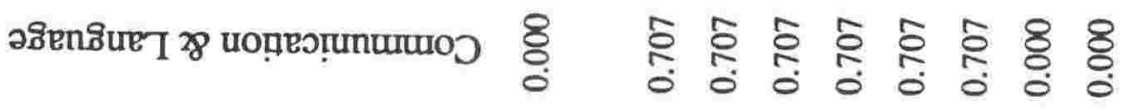

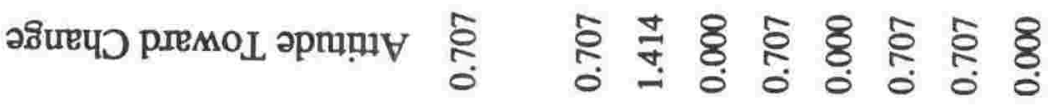

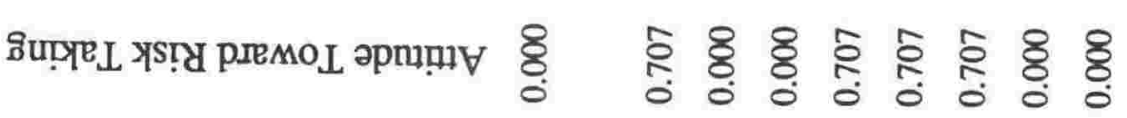

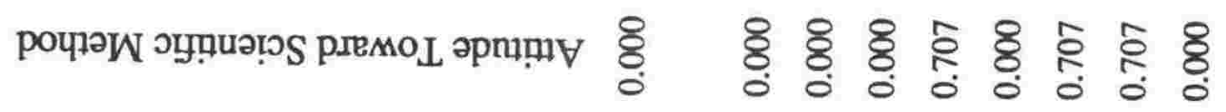

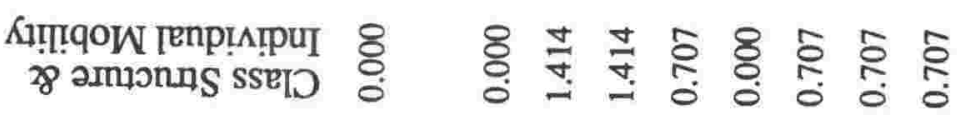

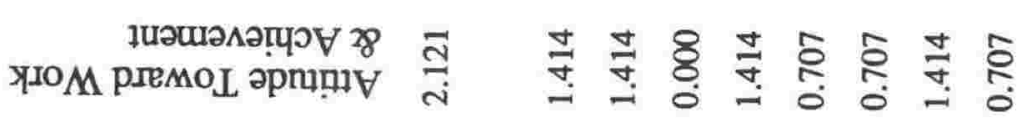

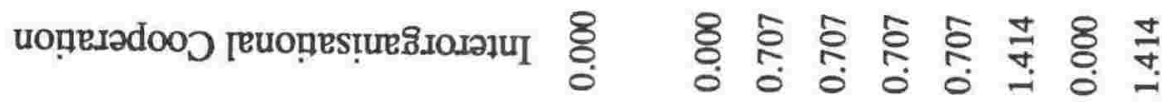

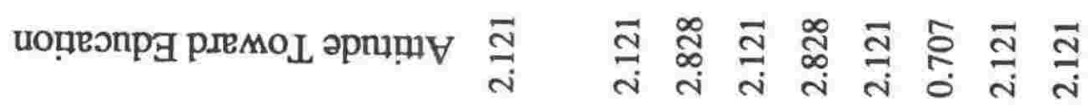

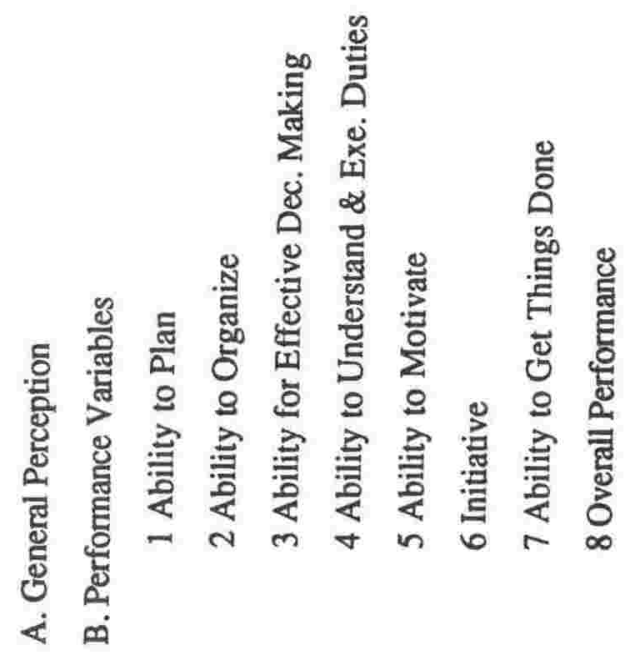




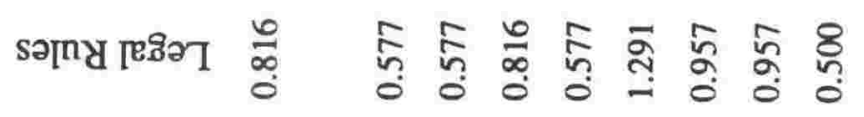

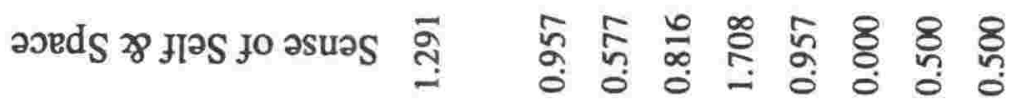

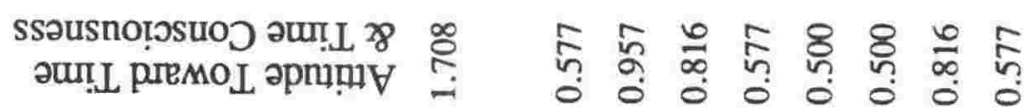

离

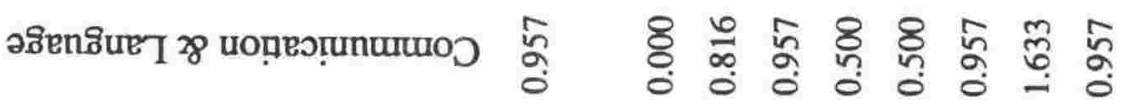

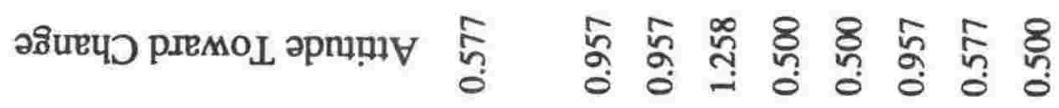

듕 응

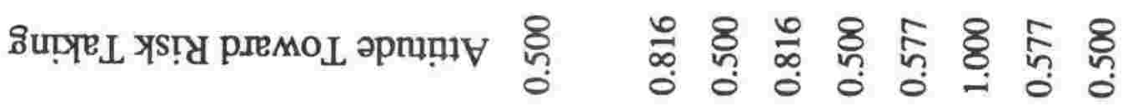

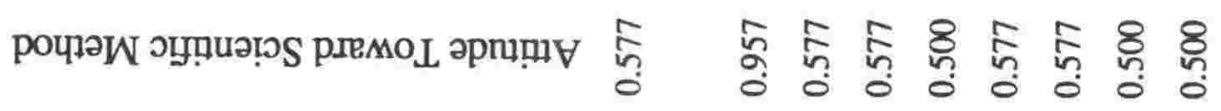

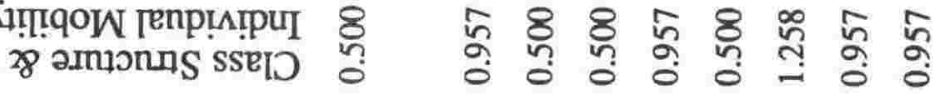

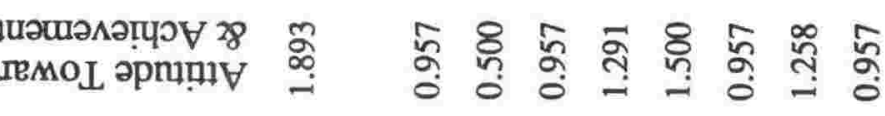

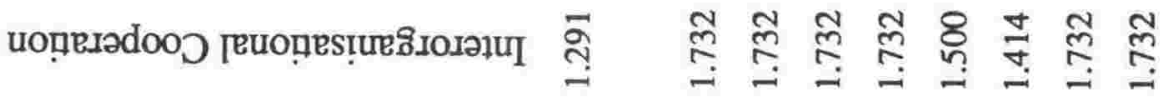

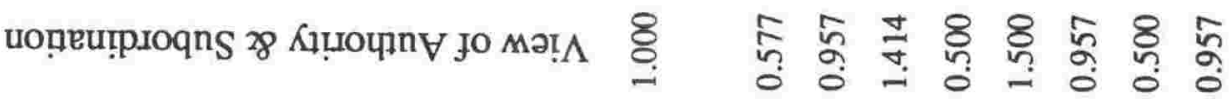

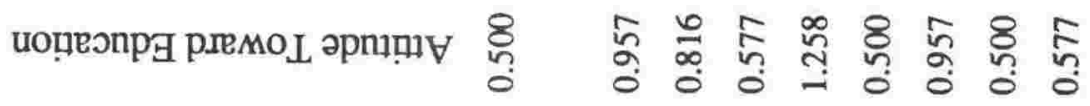

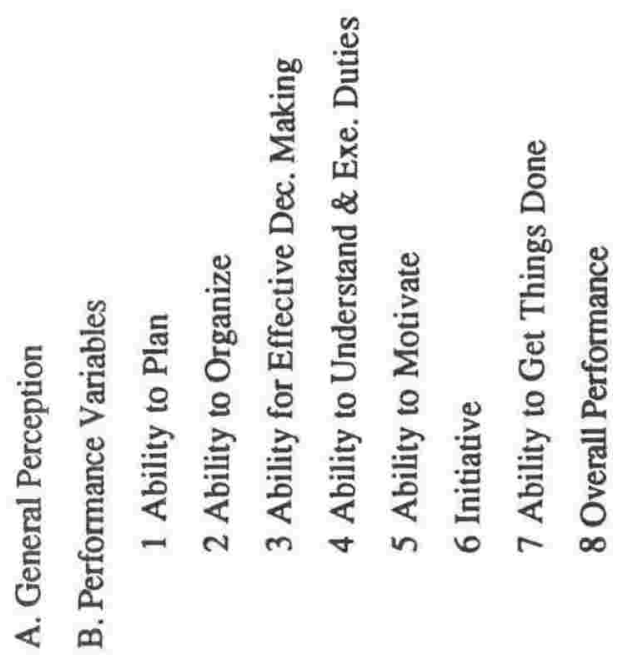




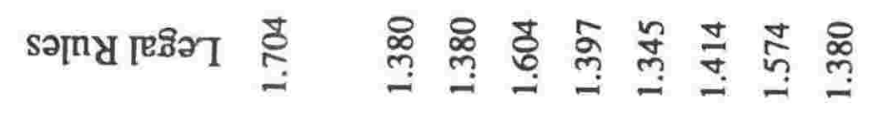

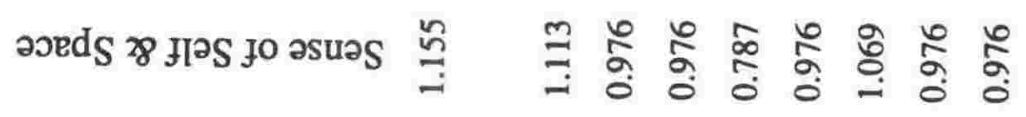

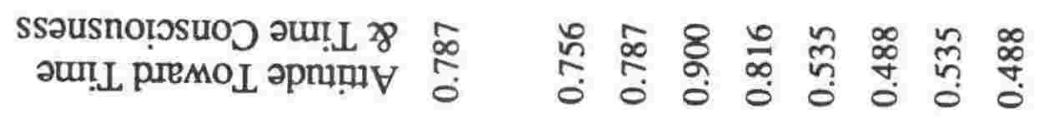

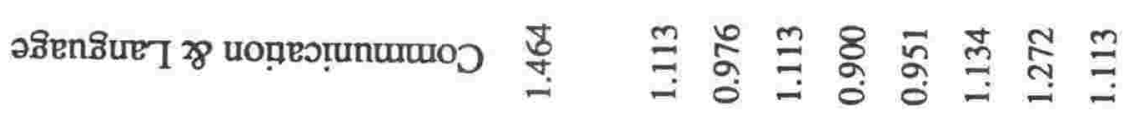

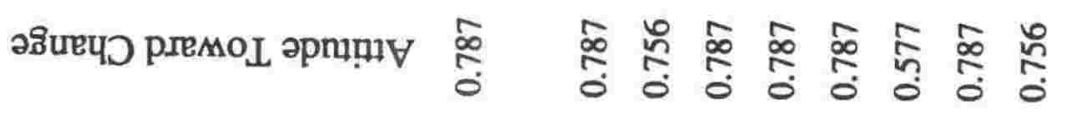

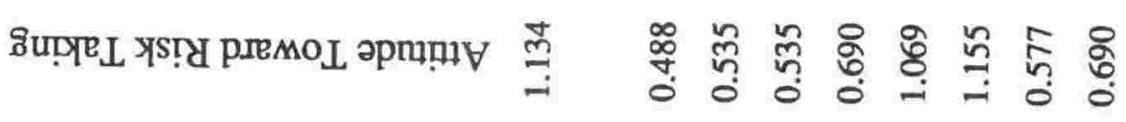

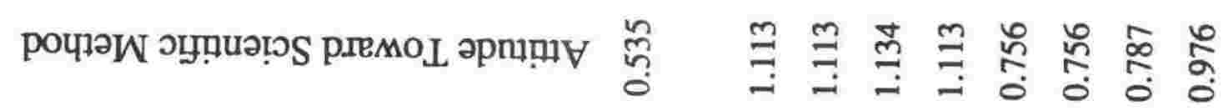

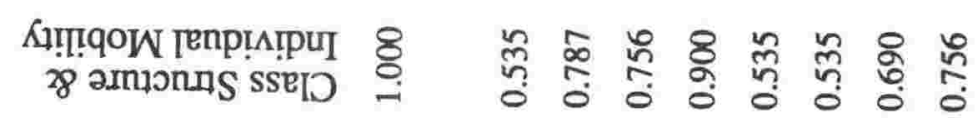

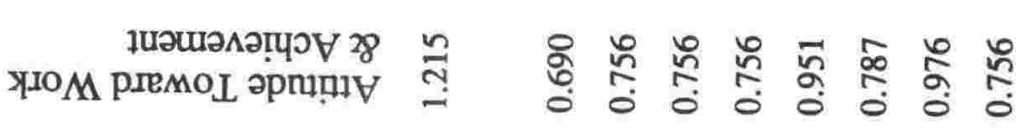

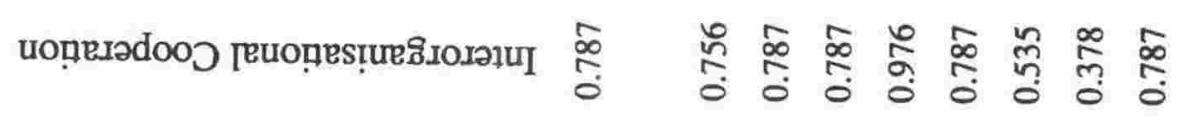

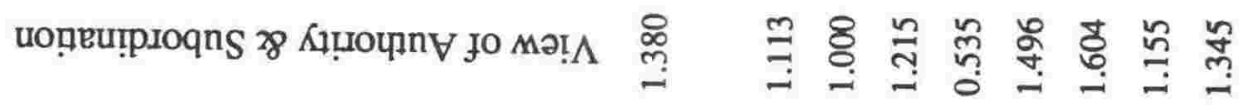

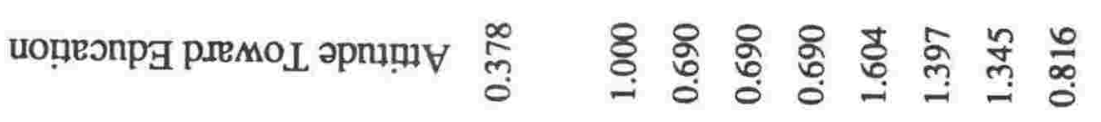

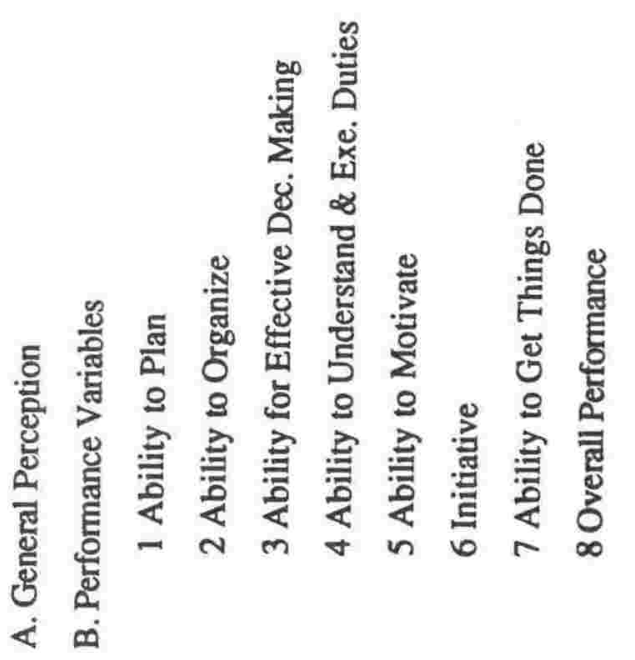




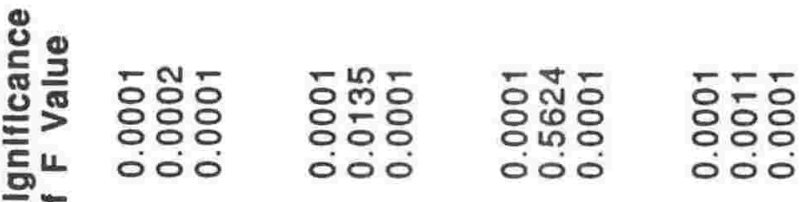

을 홍으

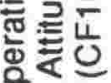

ํํㅇ

던든

잉

8

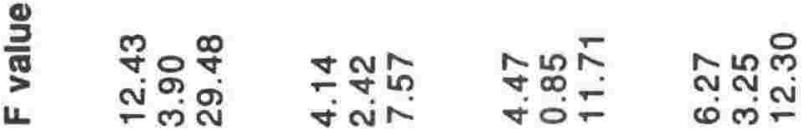

을 믕은

के

E 잉

흔을

드이

论

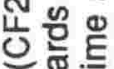

(3)

\&은

드워ํㅇ

名琵

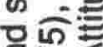

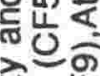

츤인

응 용

흐밈

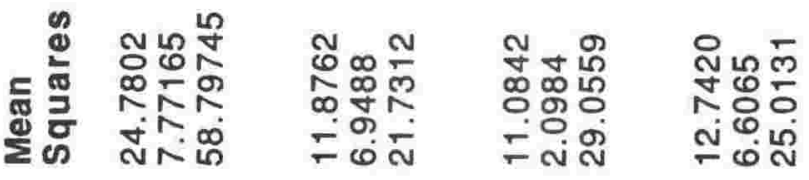

믕

흐뭉

드 등

넌듬든 뜬

등 응

융흐ㅇㅝㅗ

号起焉

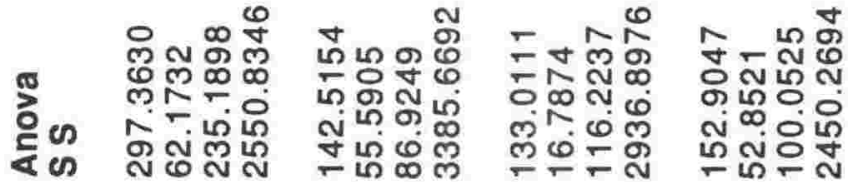

밍요

言皆

허ㅇㅝㅡ

은

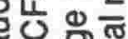

듕

ij 3 은

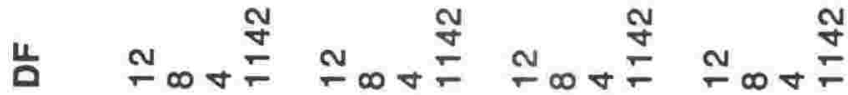

뭉

은 는

을 으모

을

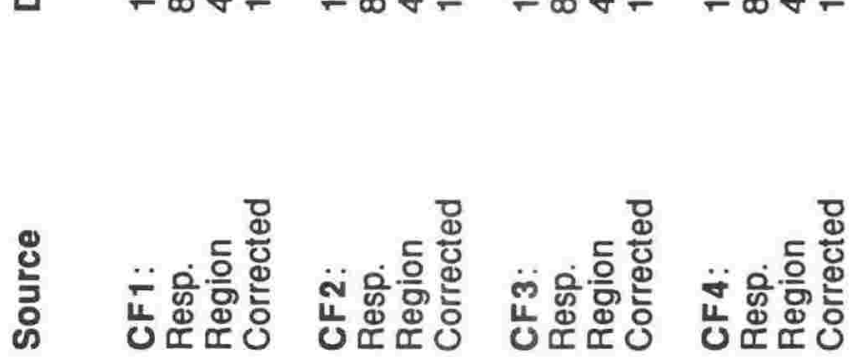

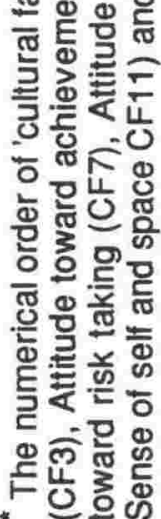




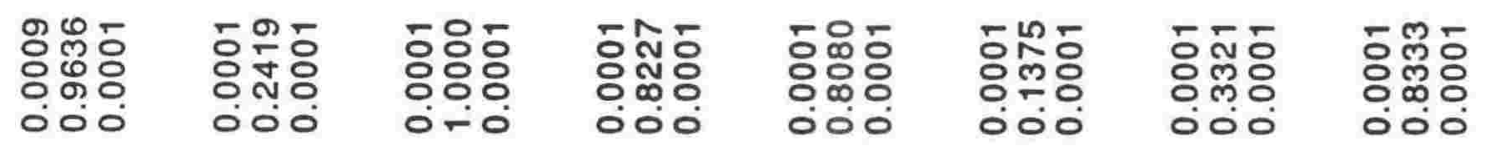

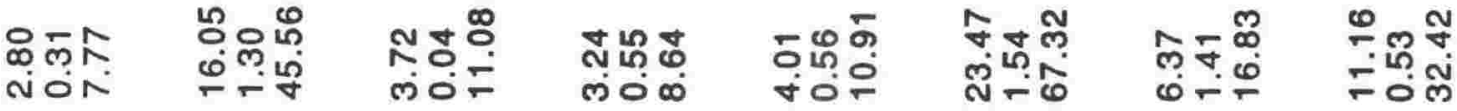

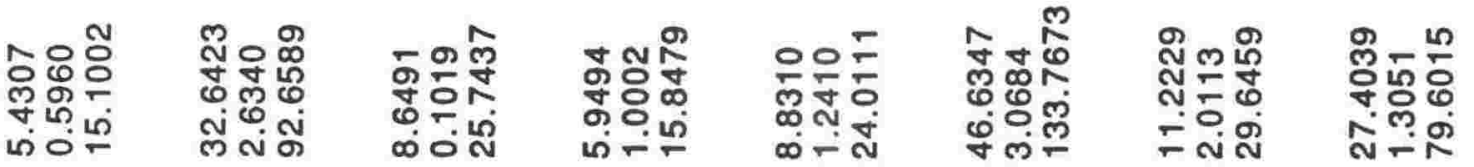

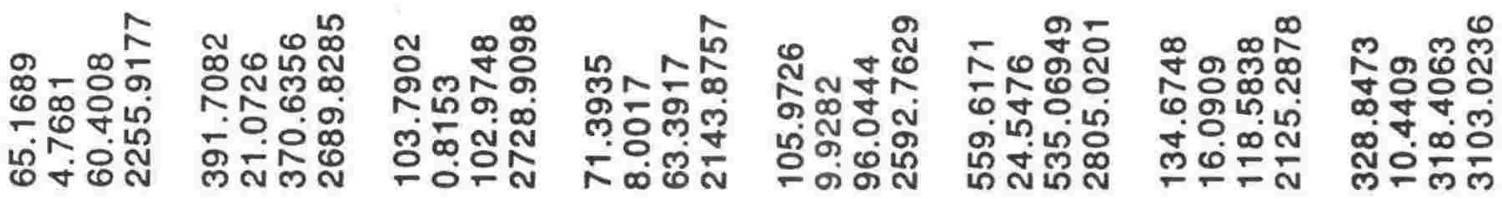

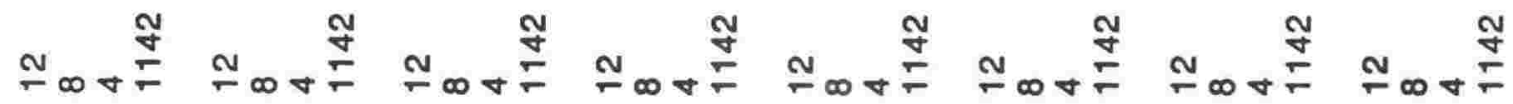

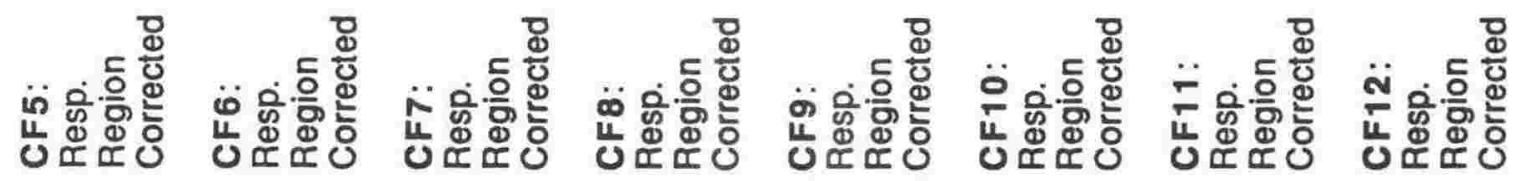




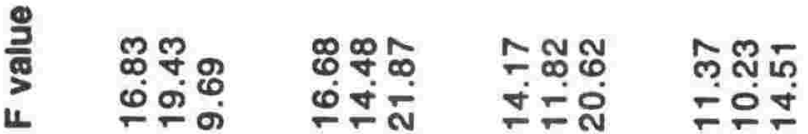

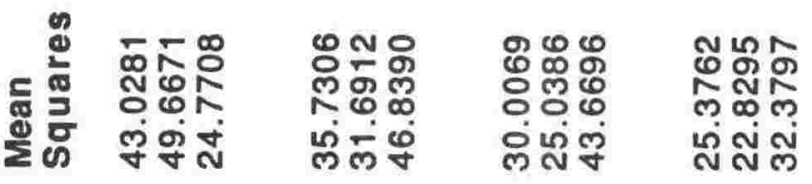

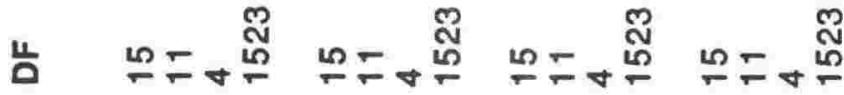

$\frac{\frac{0}{20}}{\frac{20}{20}}$

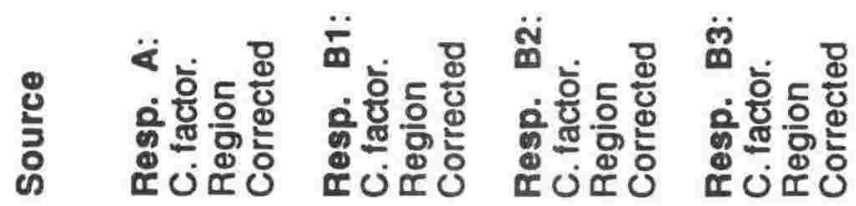




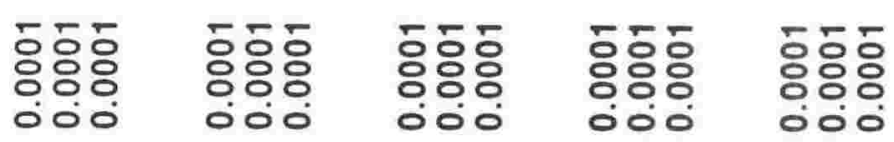

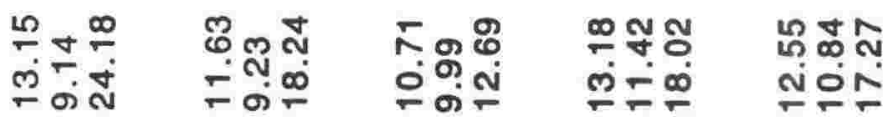

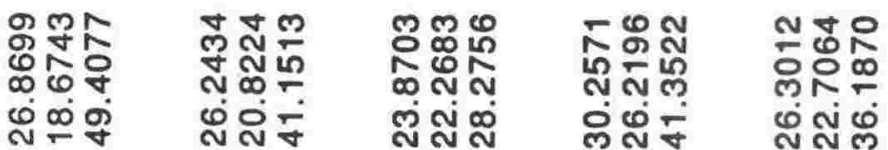

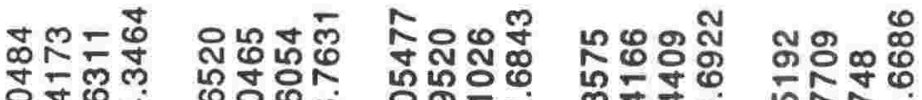

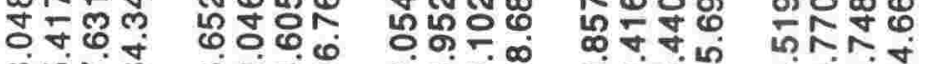

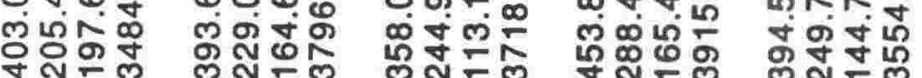

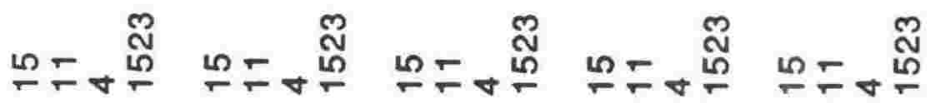

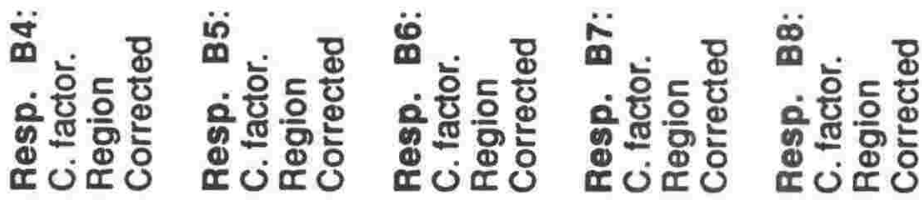




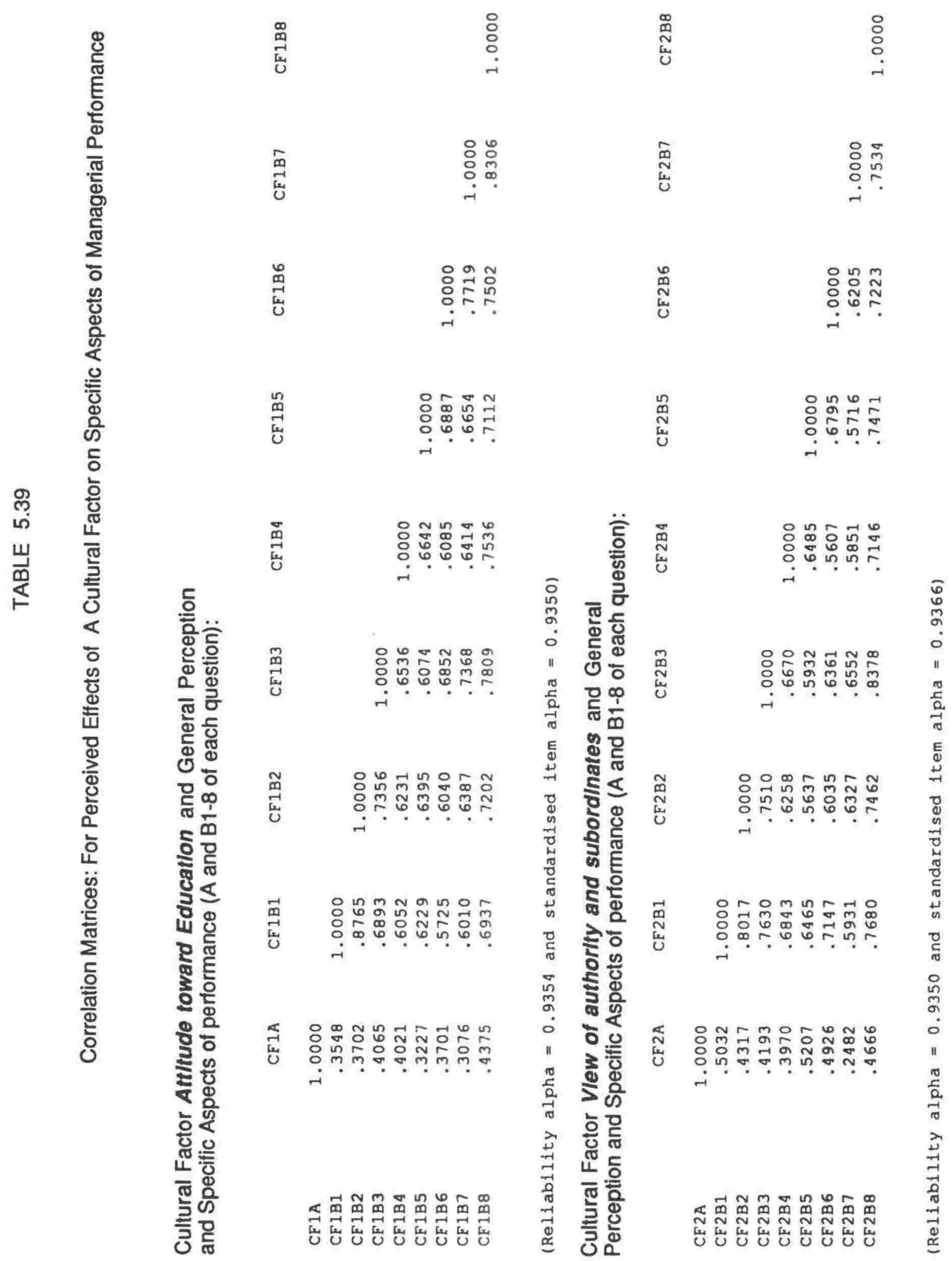


品

兽

응

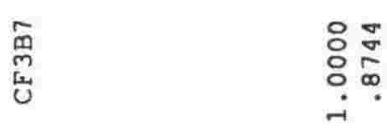

息

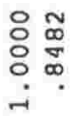

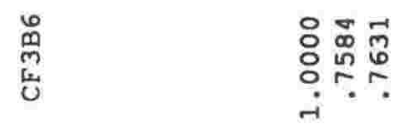

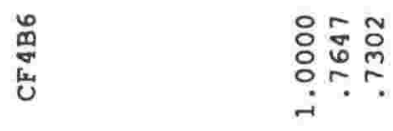

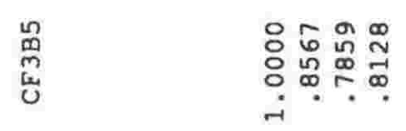

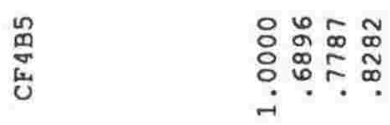

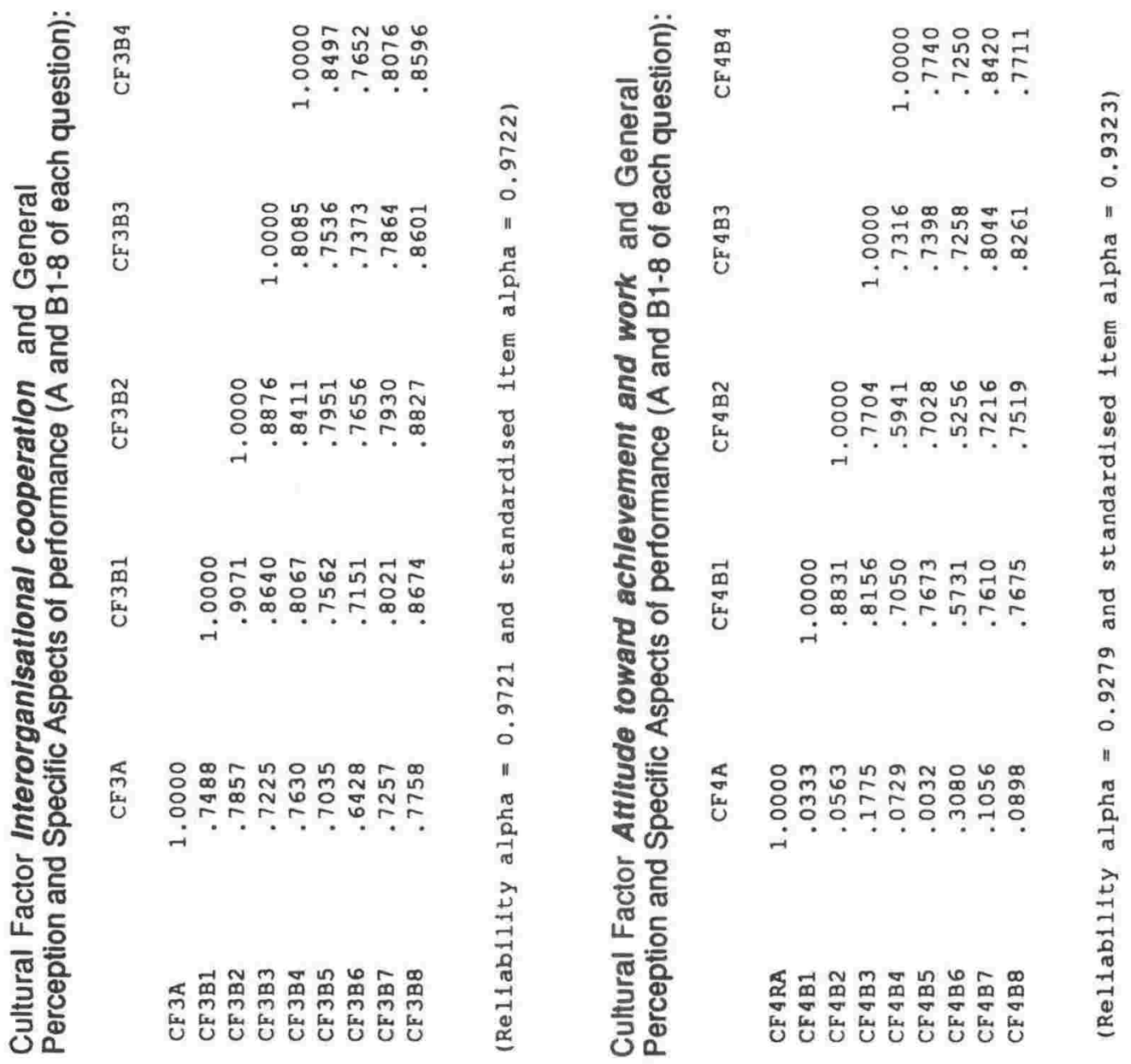


$\underset{\substack{\infty \\ 0 \\ 0}}{\stackrel{0}{0}}$

:

D
0
0
닌

$\stackrel{\circ}{\circ}$

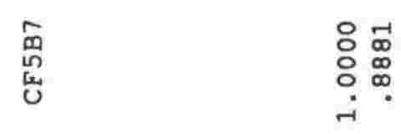

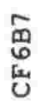

范

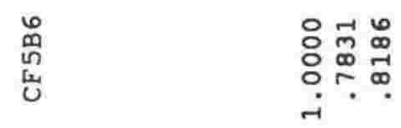

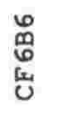

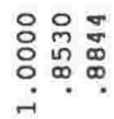

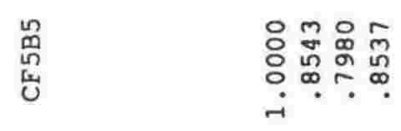

兽

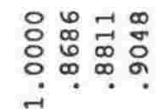

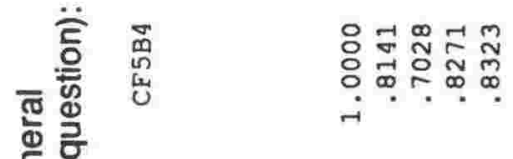

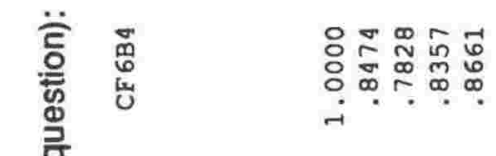

ऽั 듐

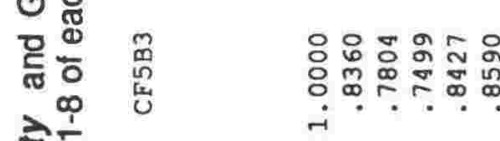

ڤัต

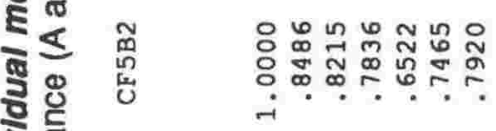

동

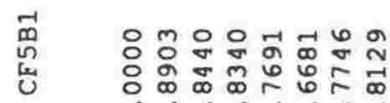

징 듐

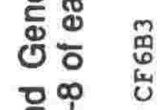

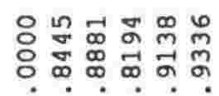

⿳亠口冋.

둥

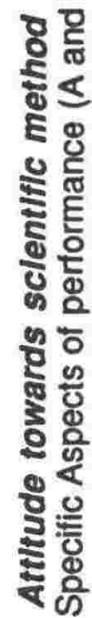

동

รับ

รัฐ

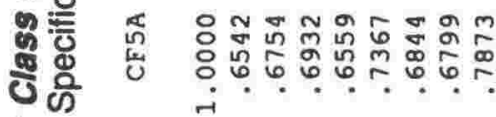

흥 뭉

흥 믇

푼들

힐 응

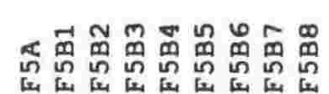

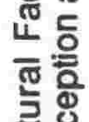

穹迹

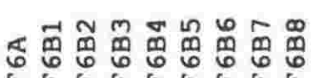

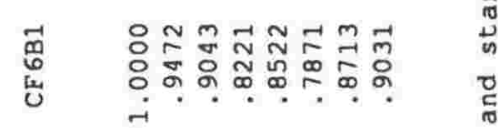

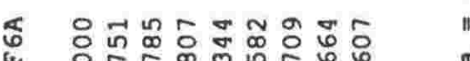

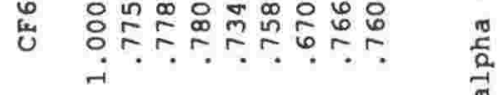




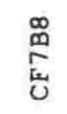

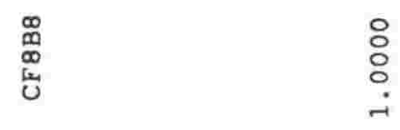

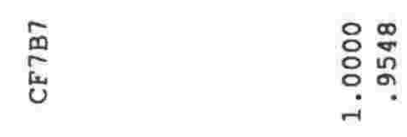

恕

.

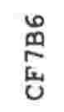

苗点.

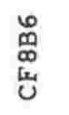

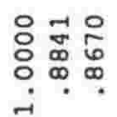

辠

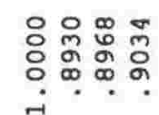

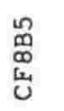

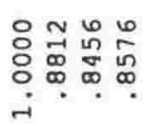

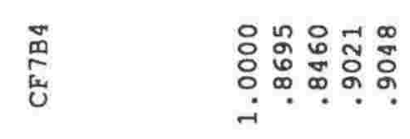

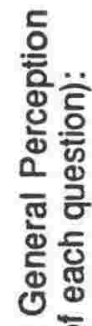

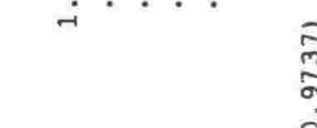

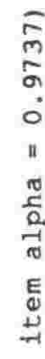

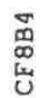

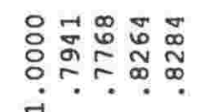

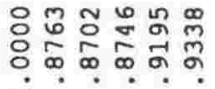

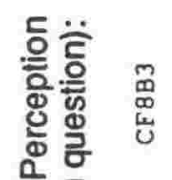

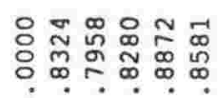

뜡

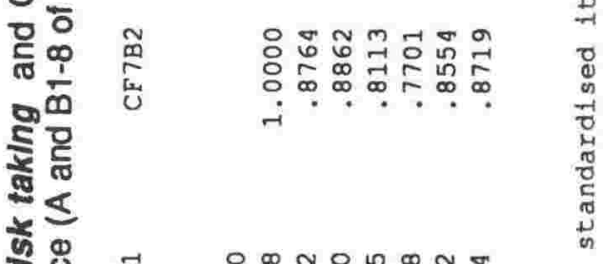

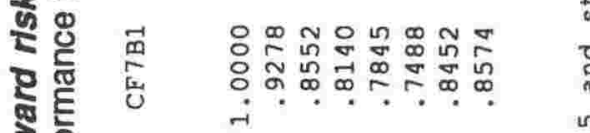

옹

음

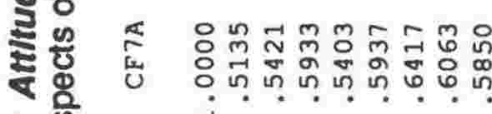

흘

兽:

त्ञ के

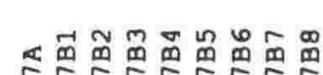

卷 $\frac{0}{\mathrm{C}}$

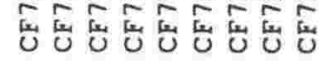

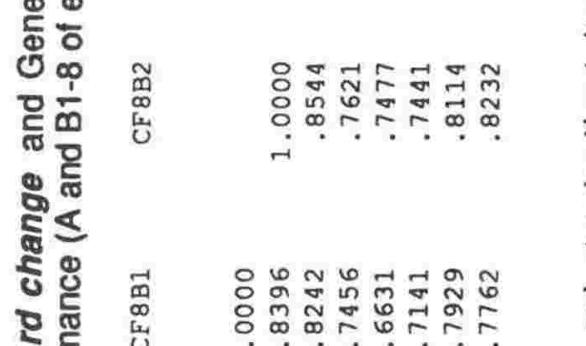

놇

‥

은 능

ํㅡㅇ

II

帘哭

×

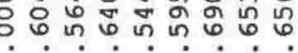

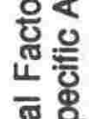

닉유

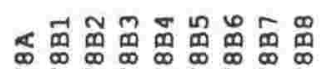

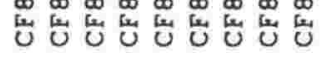

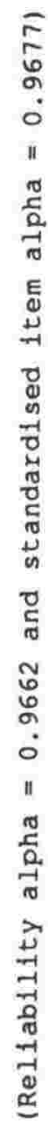


$\infty$
品
년

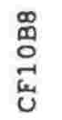

$$
\stackrel{\circ}{\circ}
$$

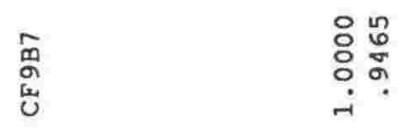

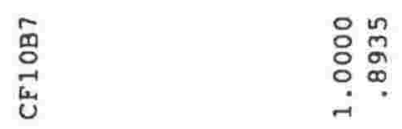

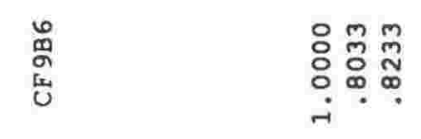

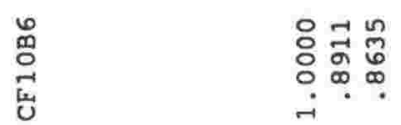

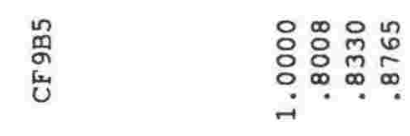

哭

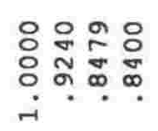

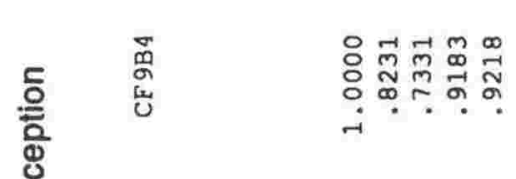

핀

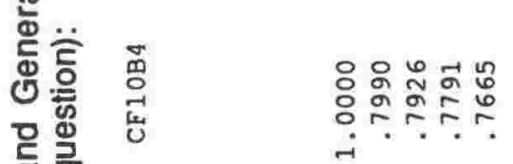

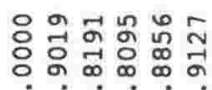

ฮ

\%

ㄱำ?

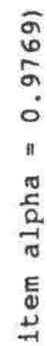

옹듀

융 ్ㅜㄴㅠㅠ용유

-

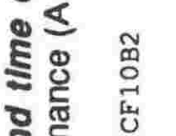

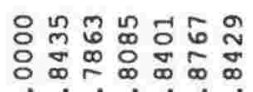

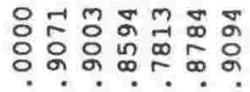

ฐัฒ

$\stackrel{ \pm}{ \pm}$

0
0
0
0
0
$\frac{\pi}{7}$
0
0
0
0

은

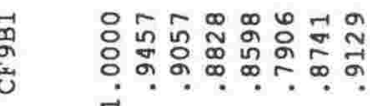

은 है

옳응

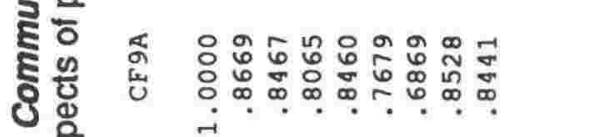

훈

윰

쥰유

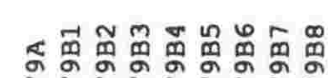

록은

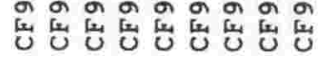

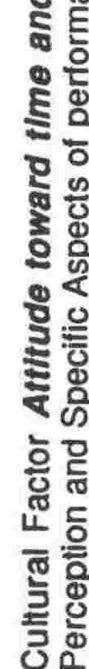

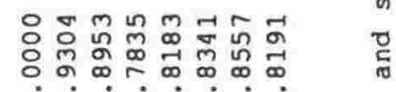

0
0
0
0
0
11
0
0

D
-1
-1
0
01
-10
0

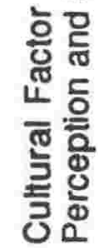

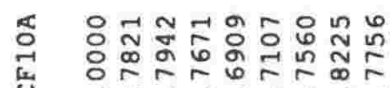

ㄴ.?

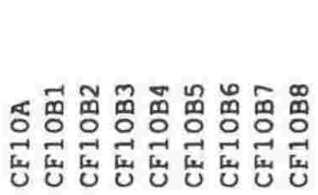


兽

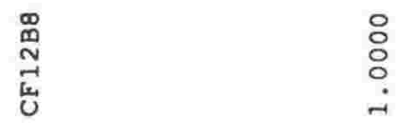

商

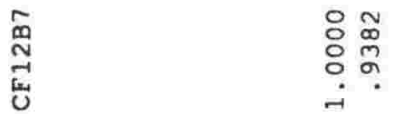

兽

兽

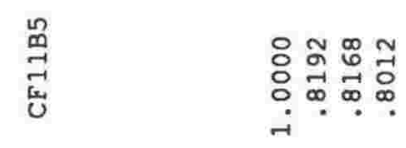

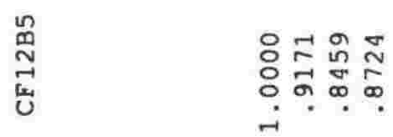

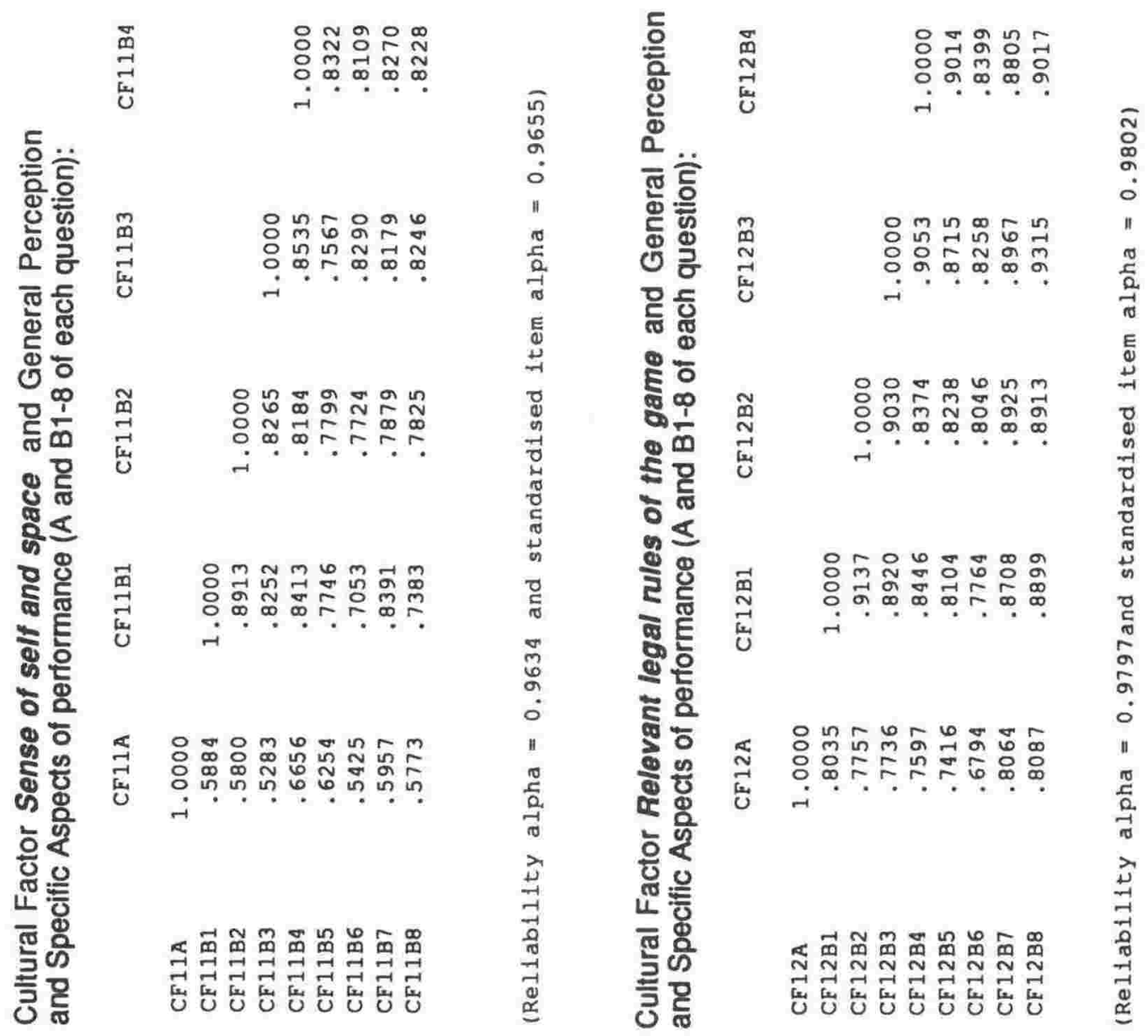




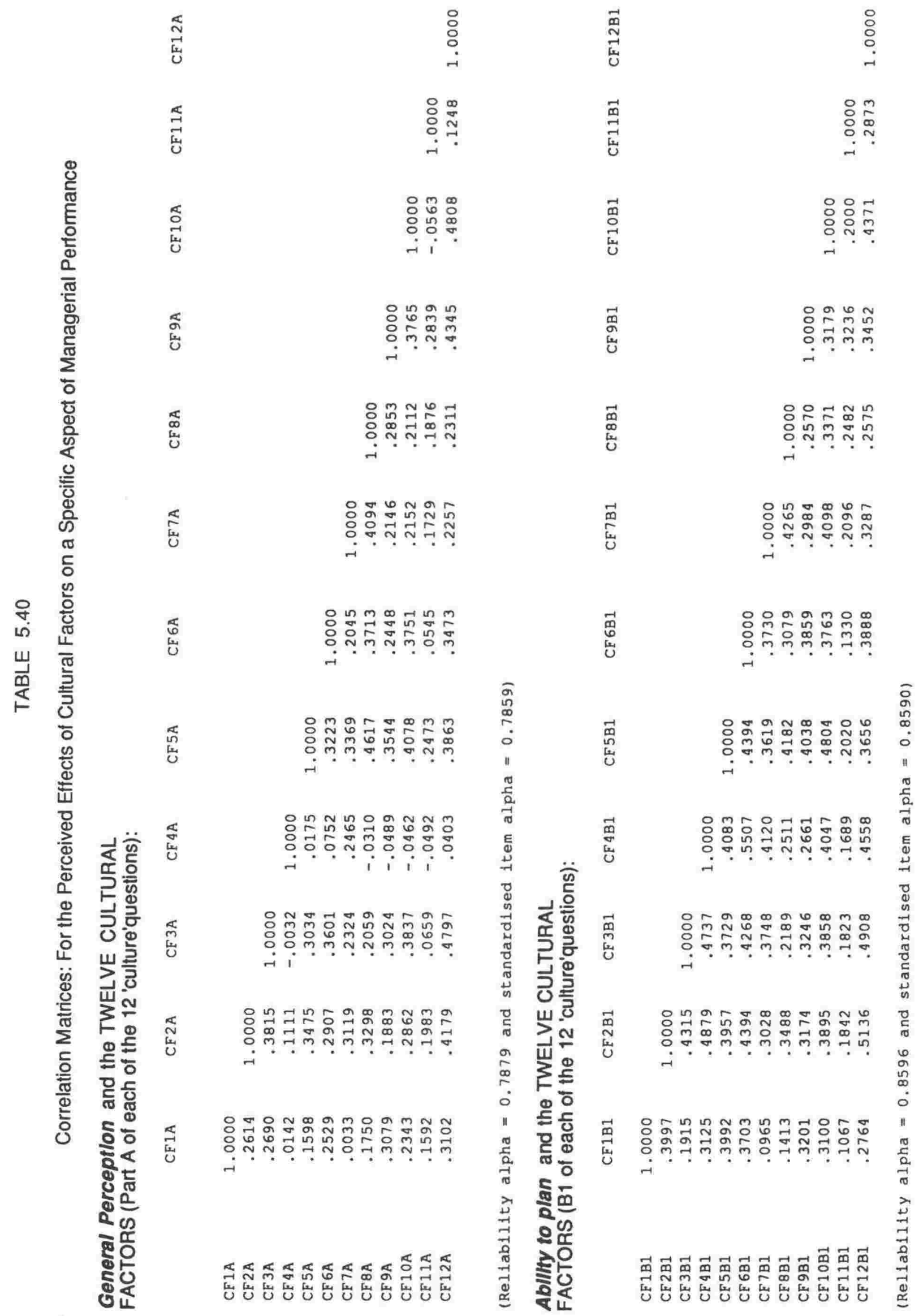




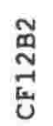

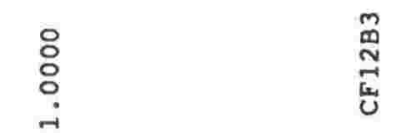

$\stackrel{\circ}{\circ}$

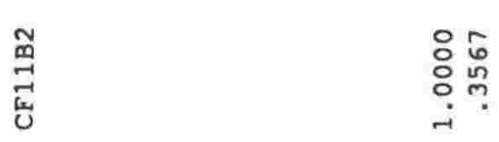

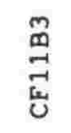

:

畄

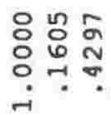

兽

㝵芌芯

圝

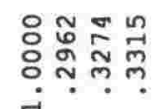

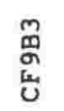

융ํํ워ำ

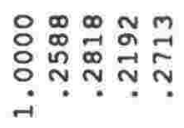

요유 ํํำ ํ. ํ. ํ.

兽

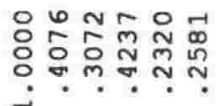

监

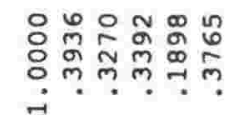

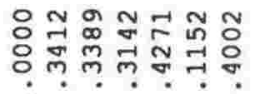

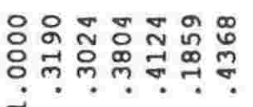

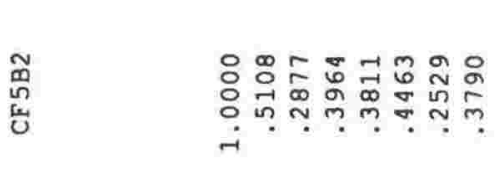

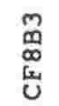

$\rightarrow$

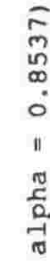

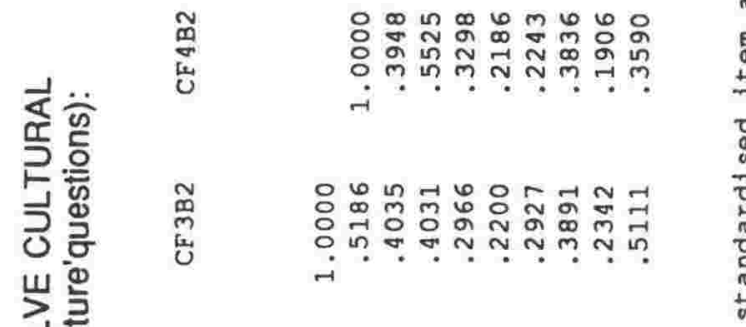

岂壱

은

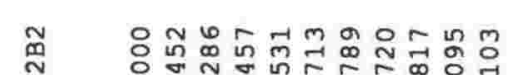

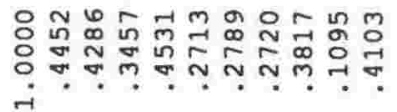

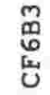

㠃

算

灾

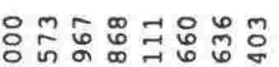

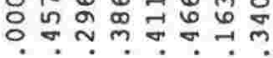

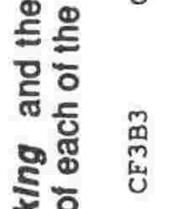

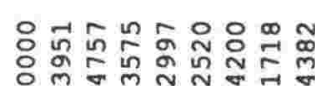

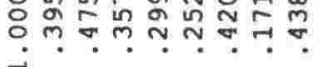

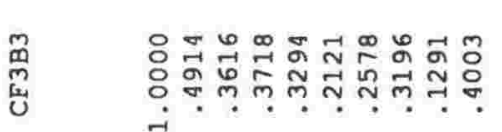

है

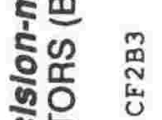

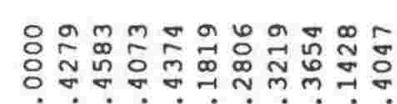

ชับ

믄

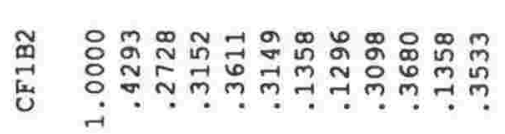

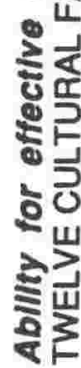

急 


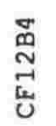

:

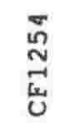

응

: $\frac{7}{0}$

$\stackrel{\text { 兽 }}{\text { 㟧 }}$

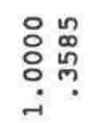

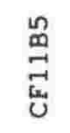

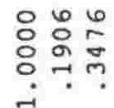

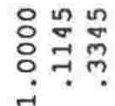

哭

0
$:$
0
0

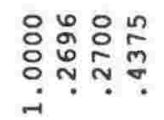

品
ô
है

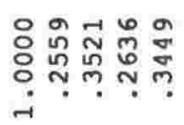

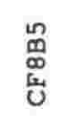

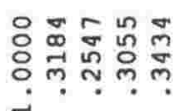

兽

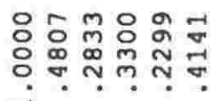

兽

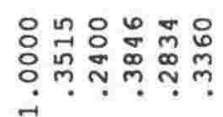

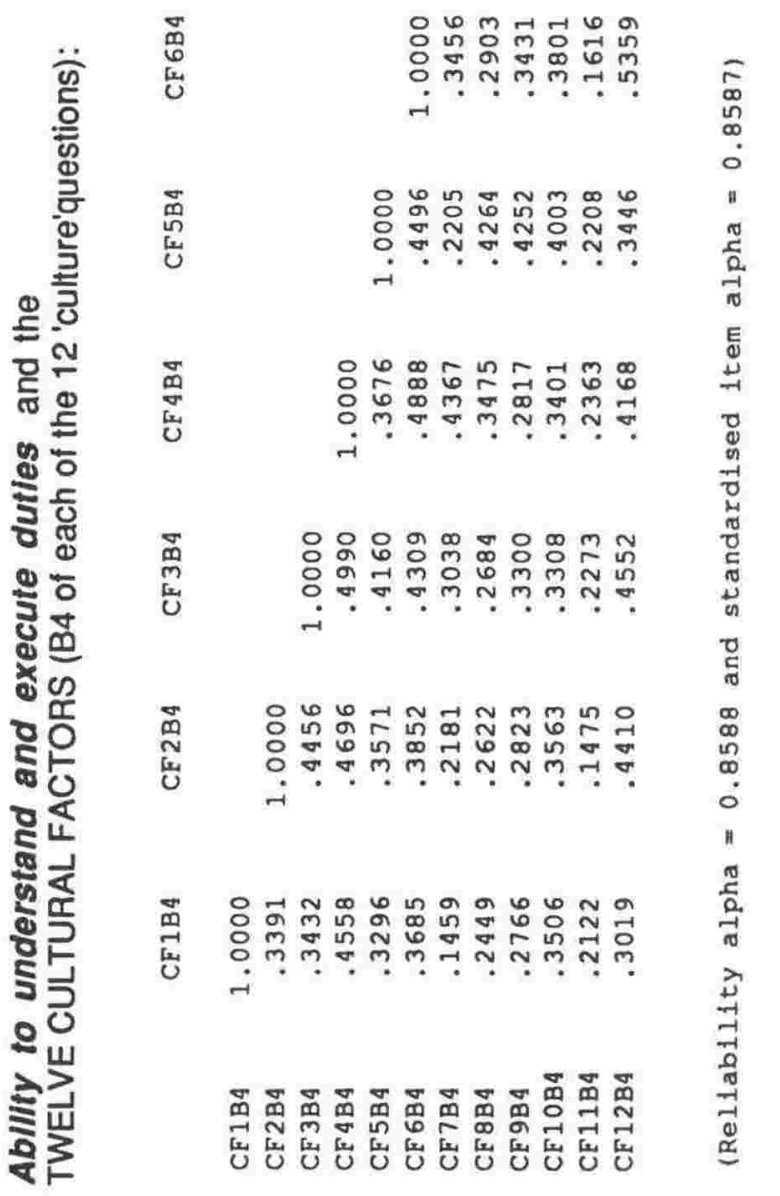

足
0
0
岕

잉ํำ

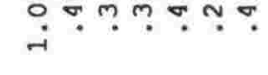

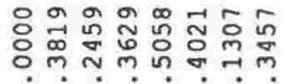

总

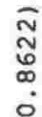

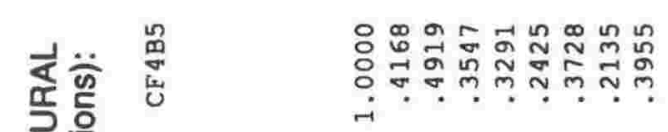

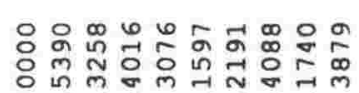

어웜

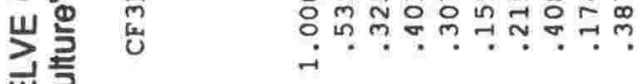

ш 。

赵

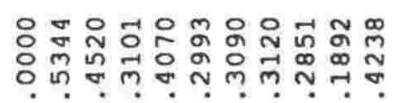

뭉

ㅎํㅇ ङ

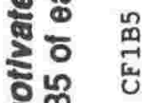

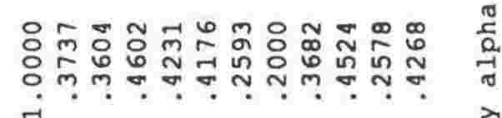

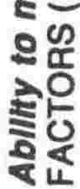

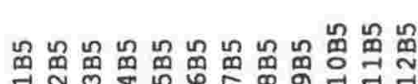

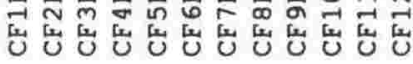




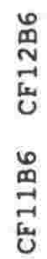

$\stackrel{\circ}{\circ}$

学第

过

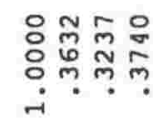

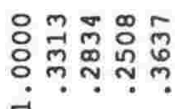

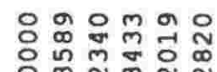

息

促

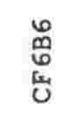

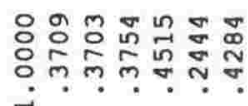

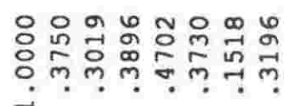

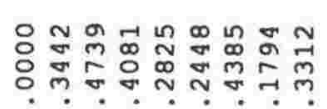

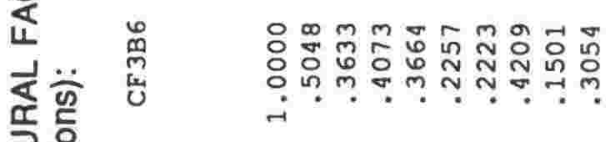

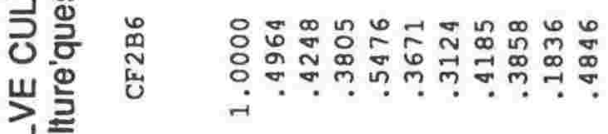

픙

等

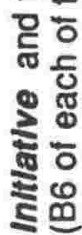

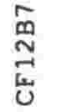

息

䍃

赵

孚

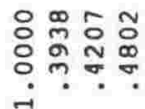

品
o
过

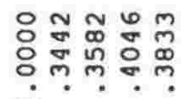

雚

ํ.

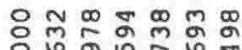

苗

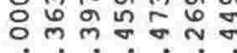

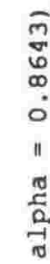

$\stackrel{E}{ \pm}$

ช

$\underset{3}{\mathrm{D}}$

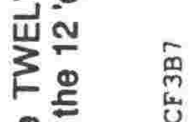

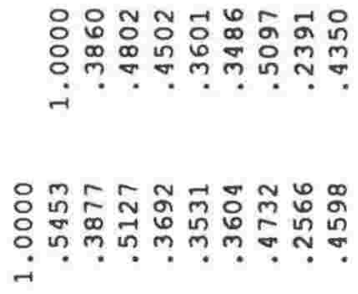

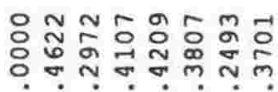

믄

竞

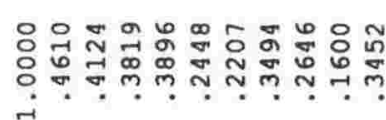

ธิธิ์

究皆

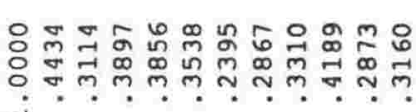

告

ฐ

oิ

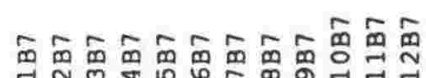

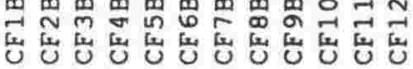




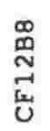

$\circ$
$\circ$
$\circ$
-

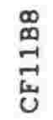

ํ.

离

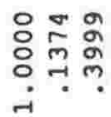

罟

:

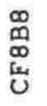

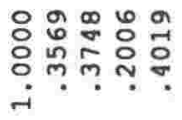

兽

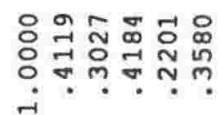

$\infty$
0
0
岳

:

点

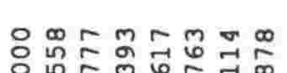

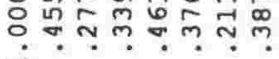

0
$0-1$
0
0
0
0
11

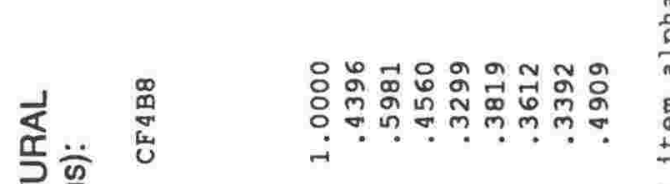

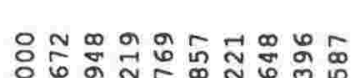

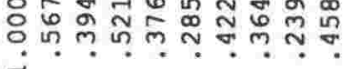

플

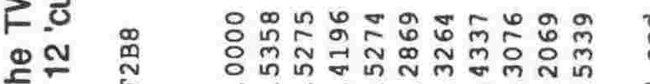
E 


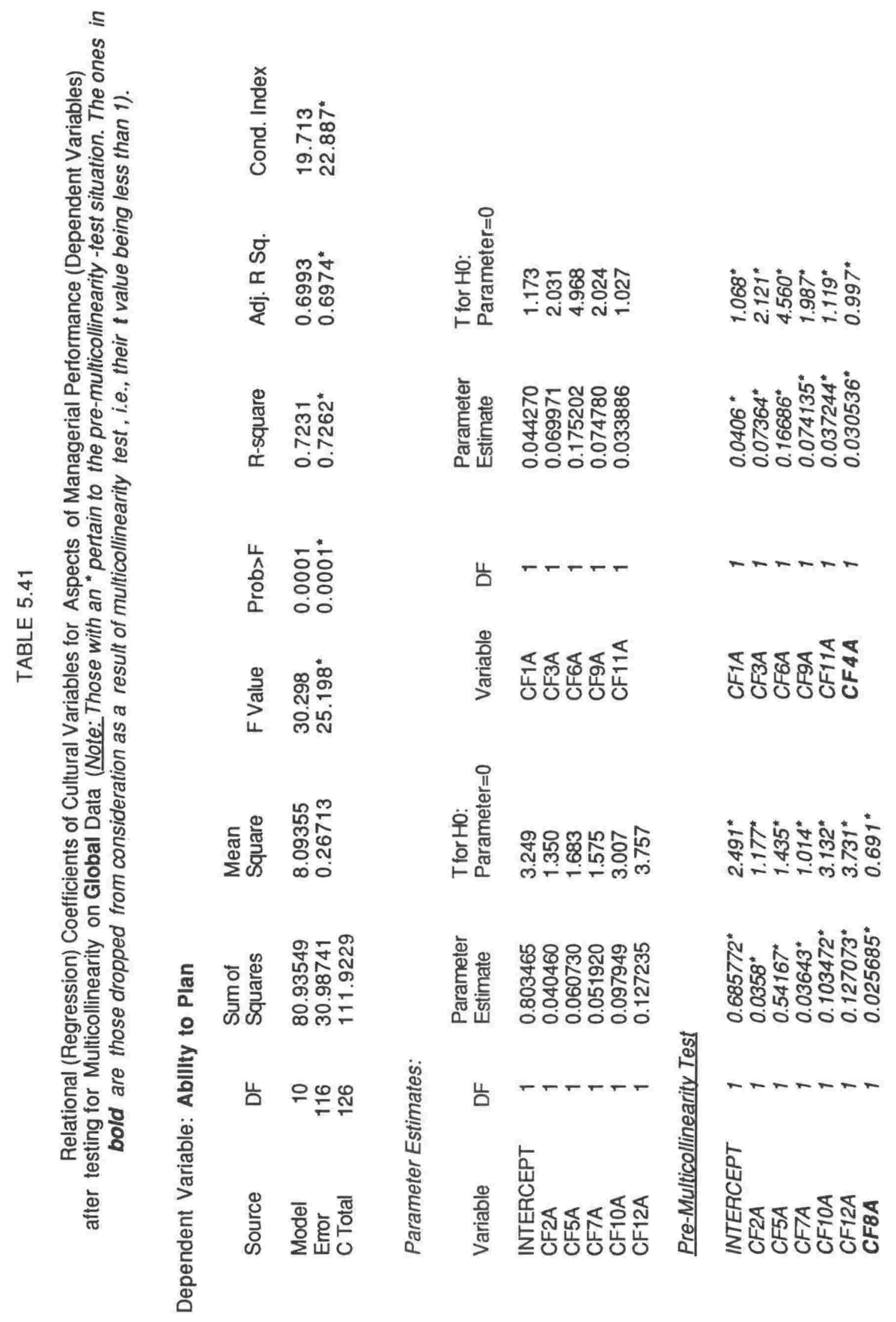




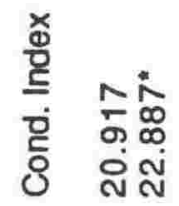

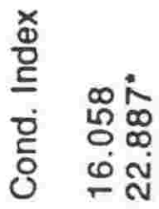

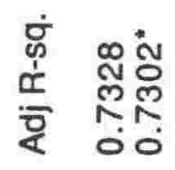
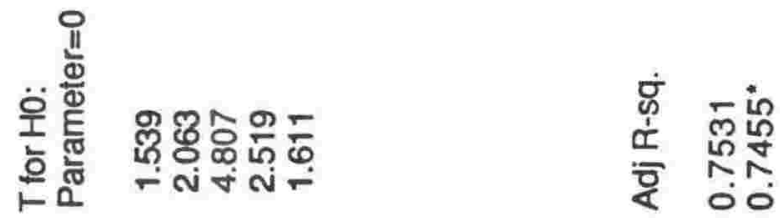

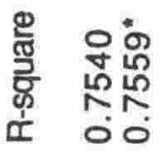
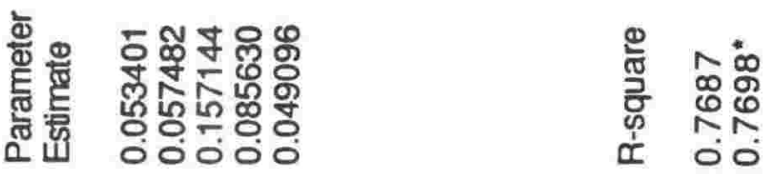

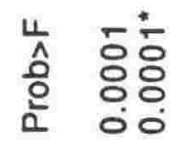<smiles>[13CH3][13CH3]</smiles>

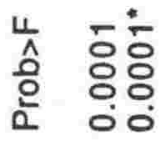

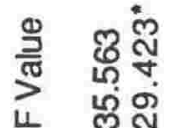

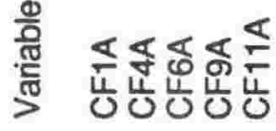

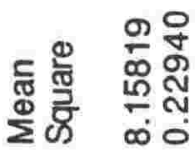

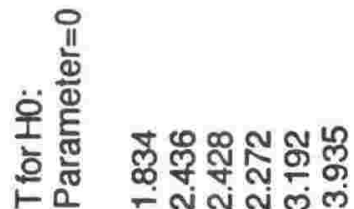

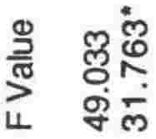

$\frac{\text { 일 }}{\frac{\mathrm{x}}{\mathrm{J}}}$

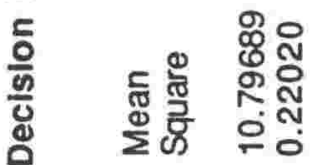

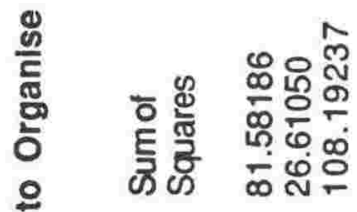

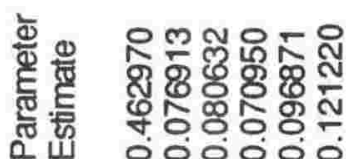

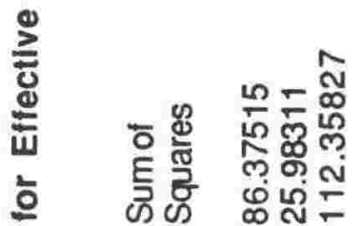

言

है

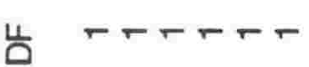

言

늠 우유유

㟔 r- -

㟔 $\quad \infty \stackrel{\oplus}{\underline{N}}$

$\frac{\dddot{0}}{\frac{0}{\frac{\pi}{2}}}$

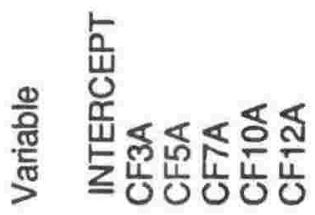

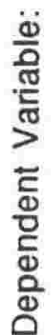

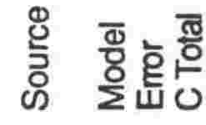




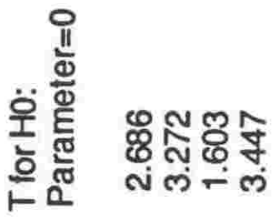
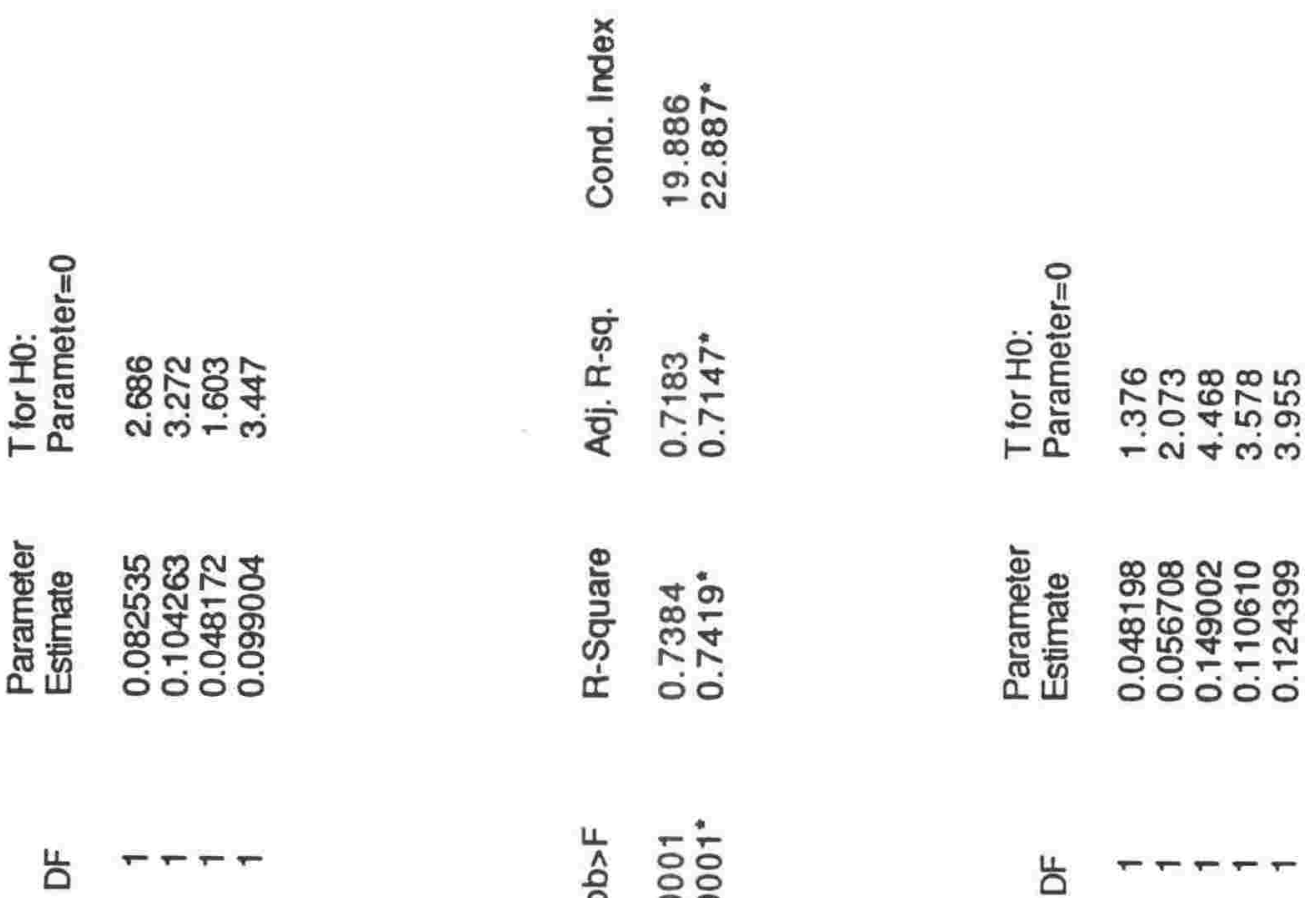

$$
\text { 논 }
$$<smiles>[13CH2][13CH3]</smiles>

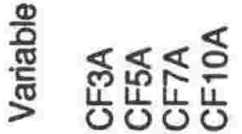

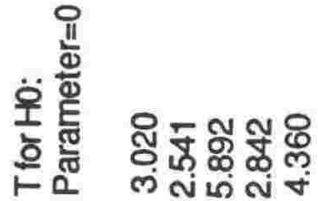

$\stackrel{0}{5}$

敢

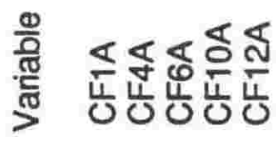

芯

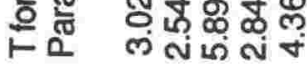

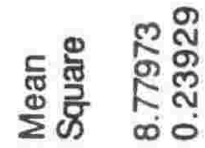

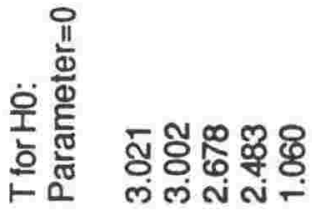

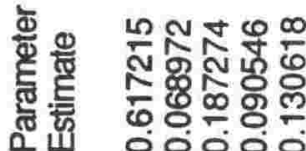

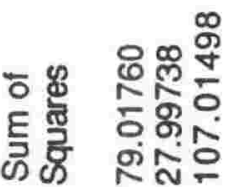

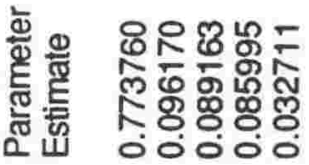<smiles>[13CH3][13CH3]</smiles>

แU

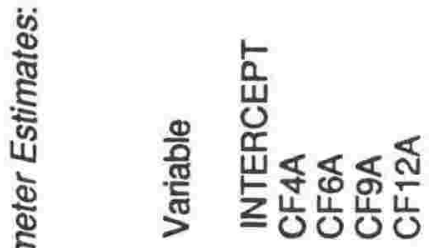

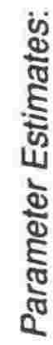

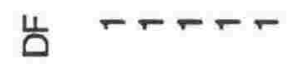

응

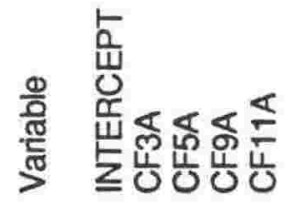



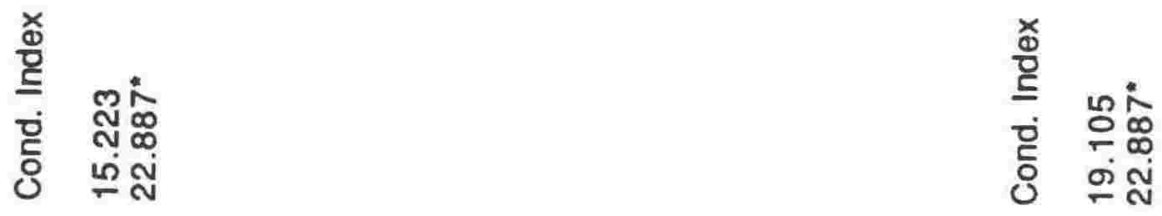

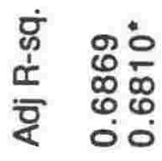

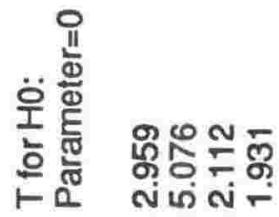

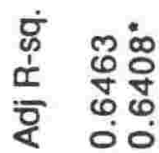
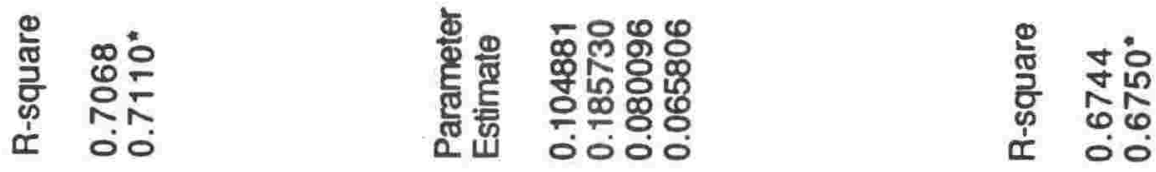

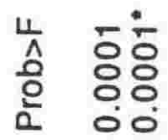

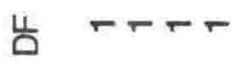

능ㅎㅇㅇ
응 융

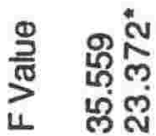

产 峁岕岕崩

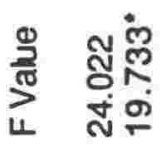

돓

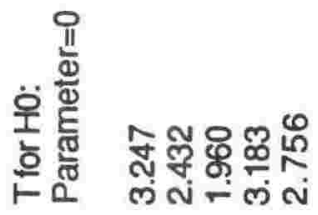

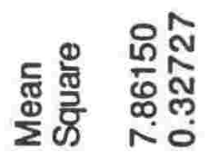

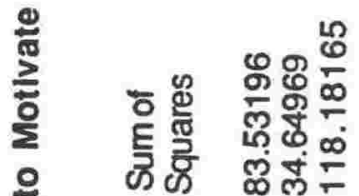

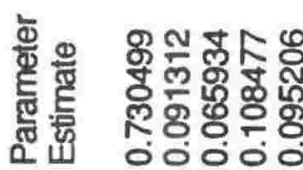

产

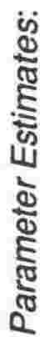

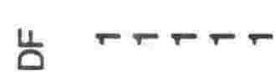

늠 우뜬오

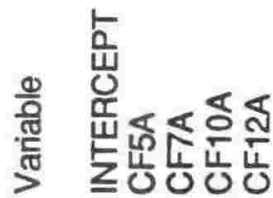

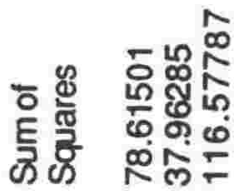

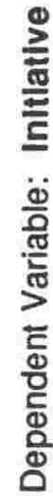

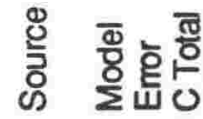



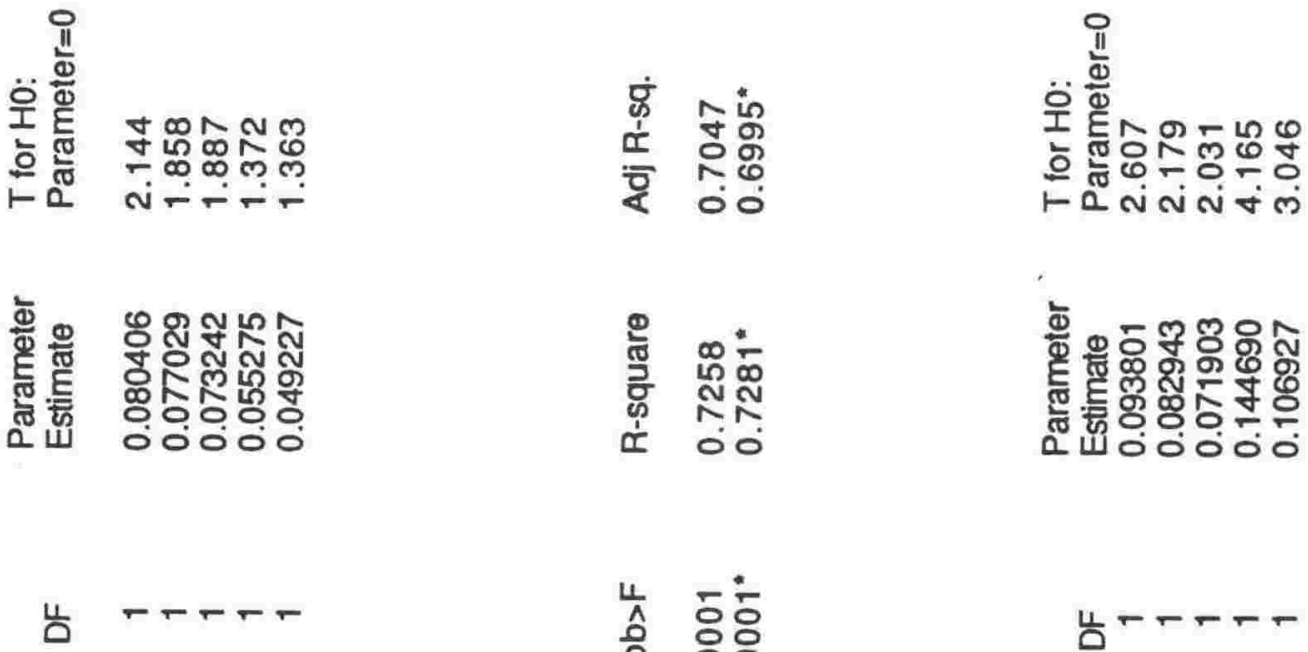

능
응응
은

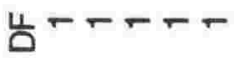

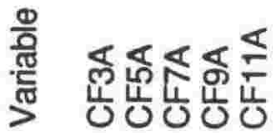

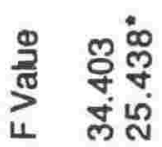

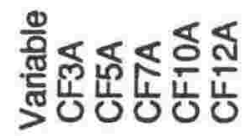

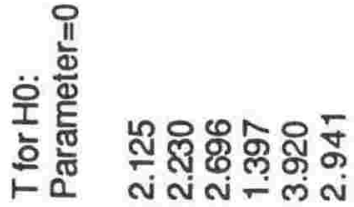

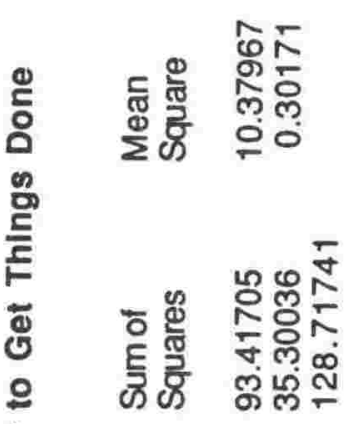

全总

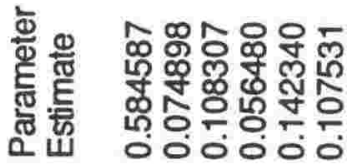

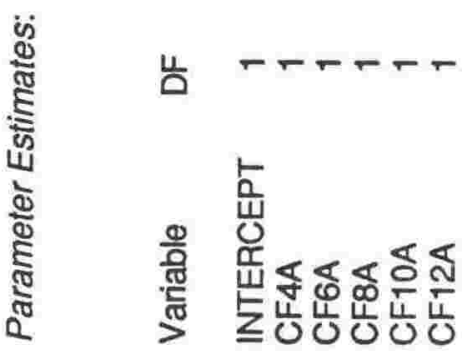

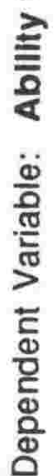

㟔 $9 \cong$

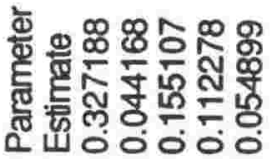

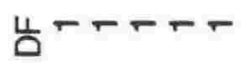

ஓ ฐ

ญे

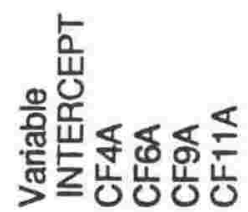




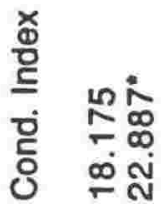

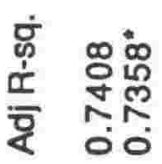

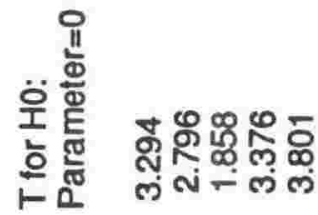

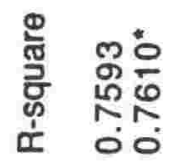

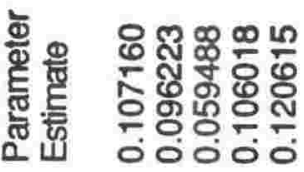

능ㅎㅇ융

㟔

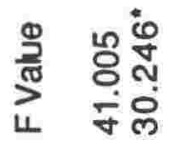

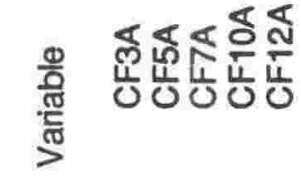

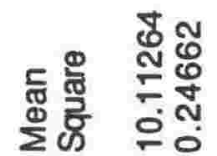

全总

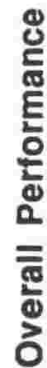

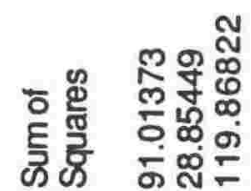

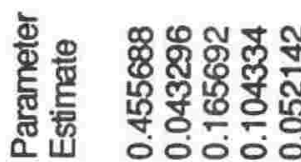

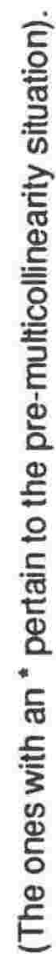

䓃

ï

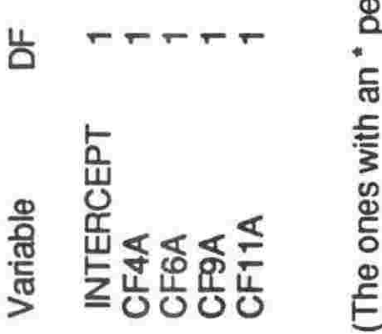

ํํํ 


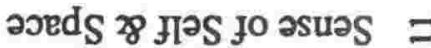

Ssausnoţsuo วuा!L 28

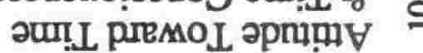

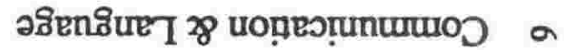

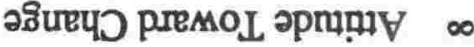

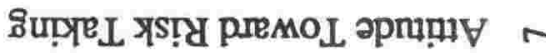

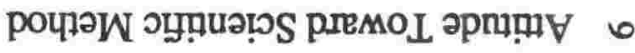

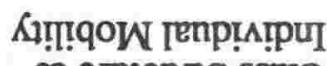

28 ampnas SSElT

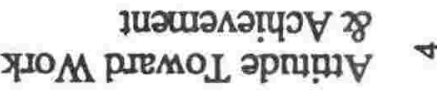

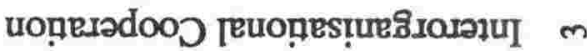

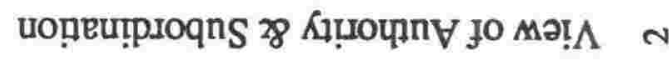

N

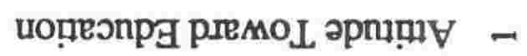

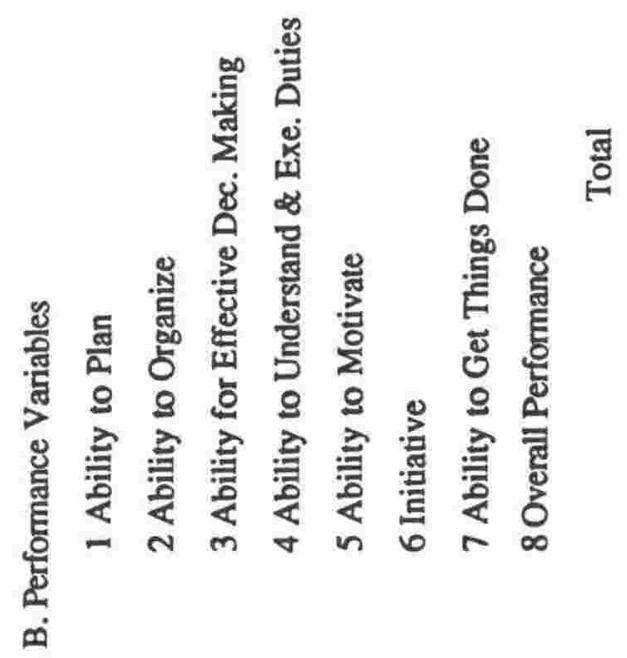




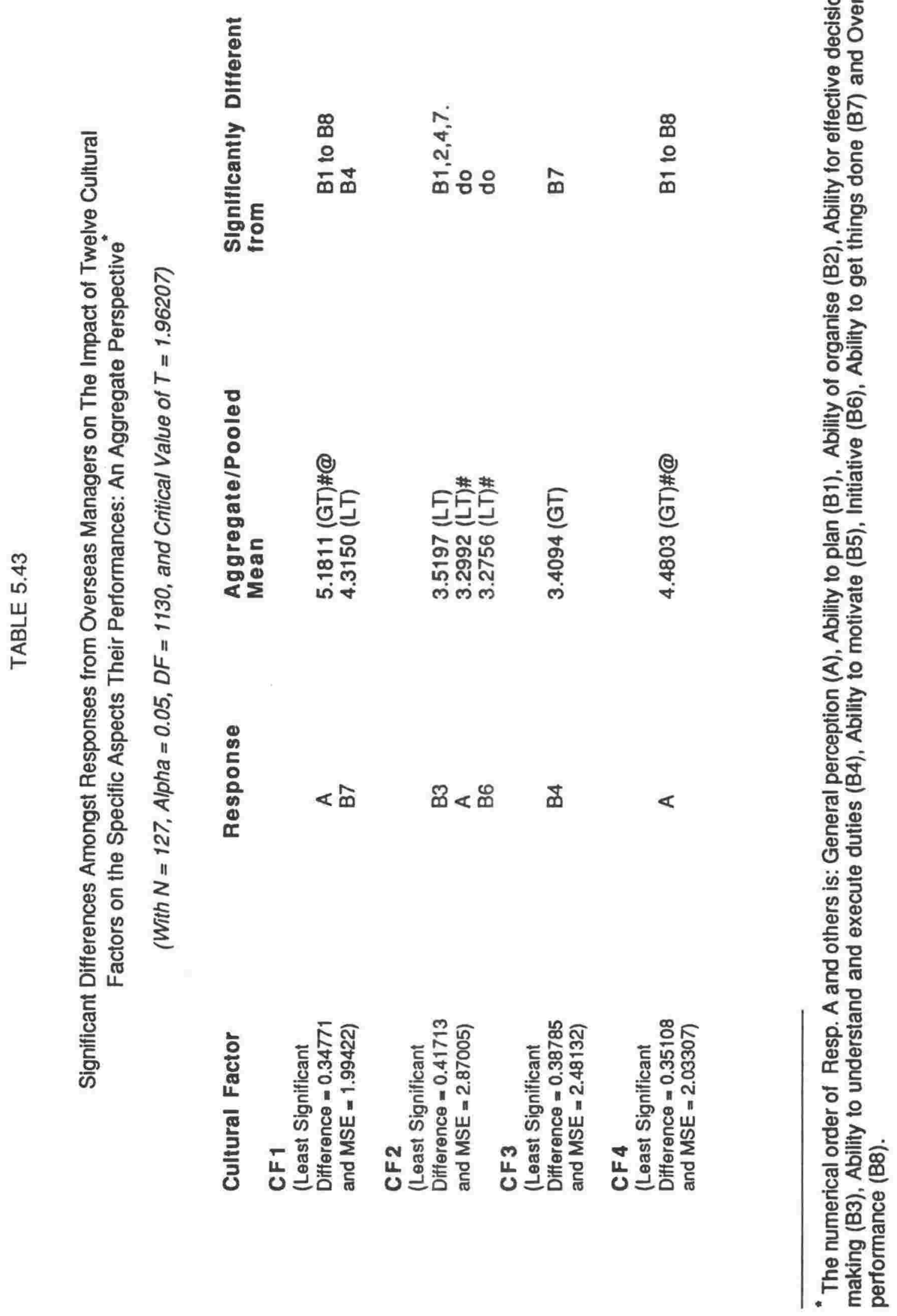


กั
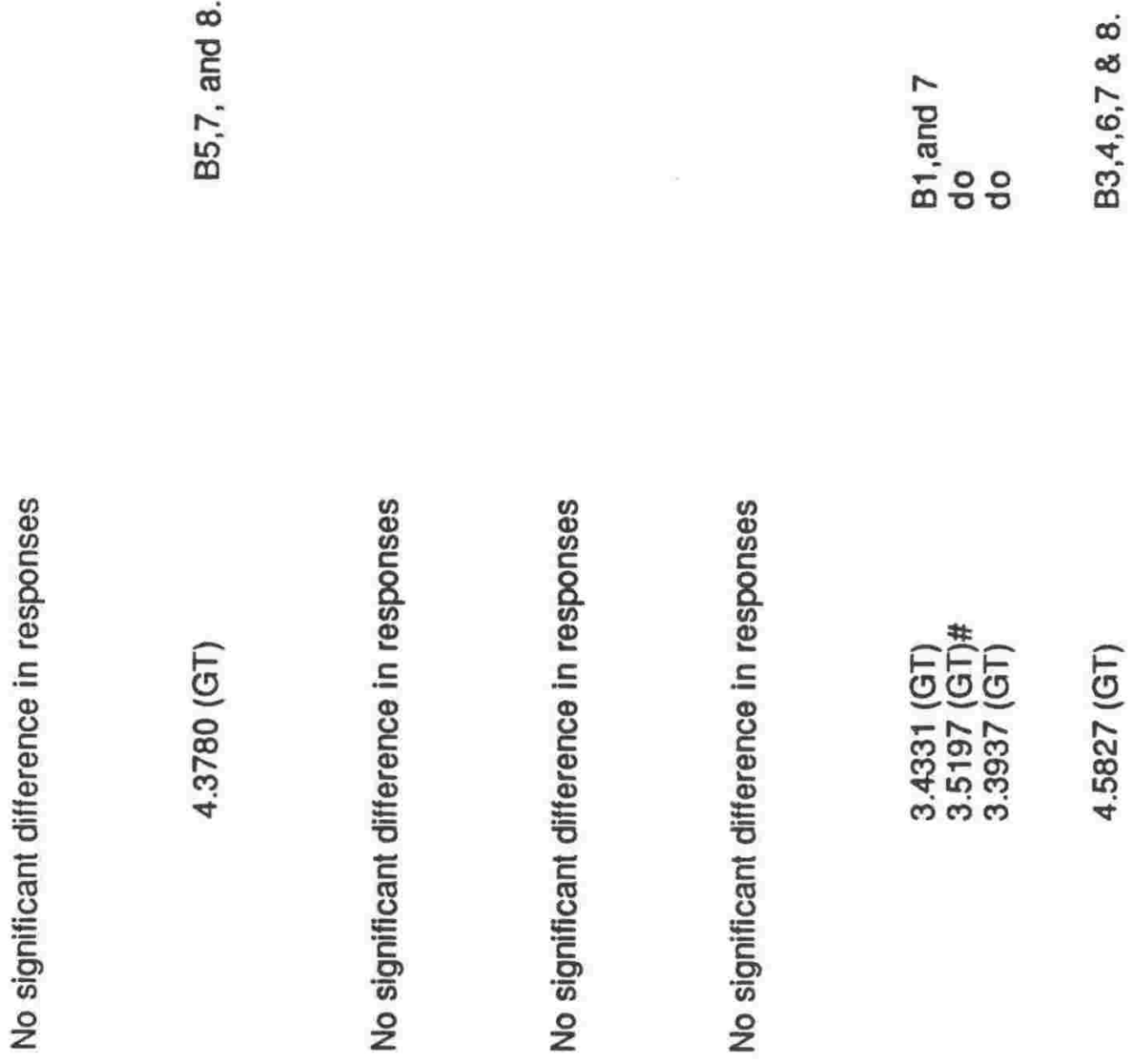

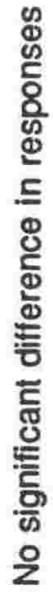

ลิ-

$<$

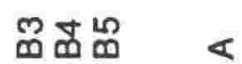

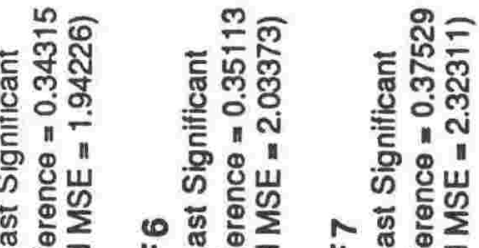
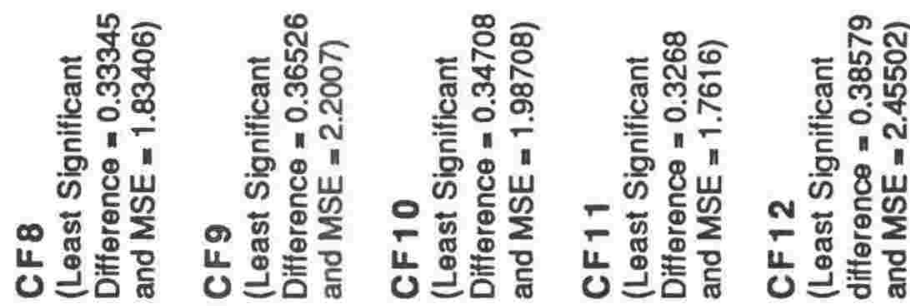

言

$\frac{\pi}{\frac{1}{2}}$

()

$\gamma$

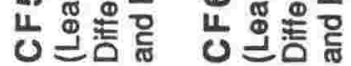

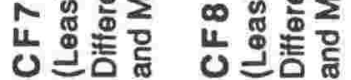

연

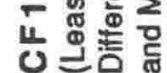

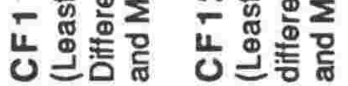

능

$\circ$ 밀 

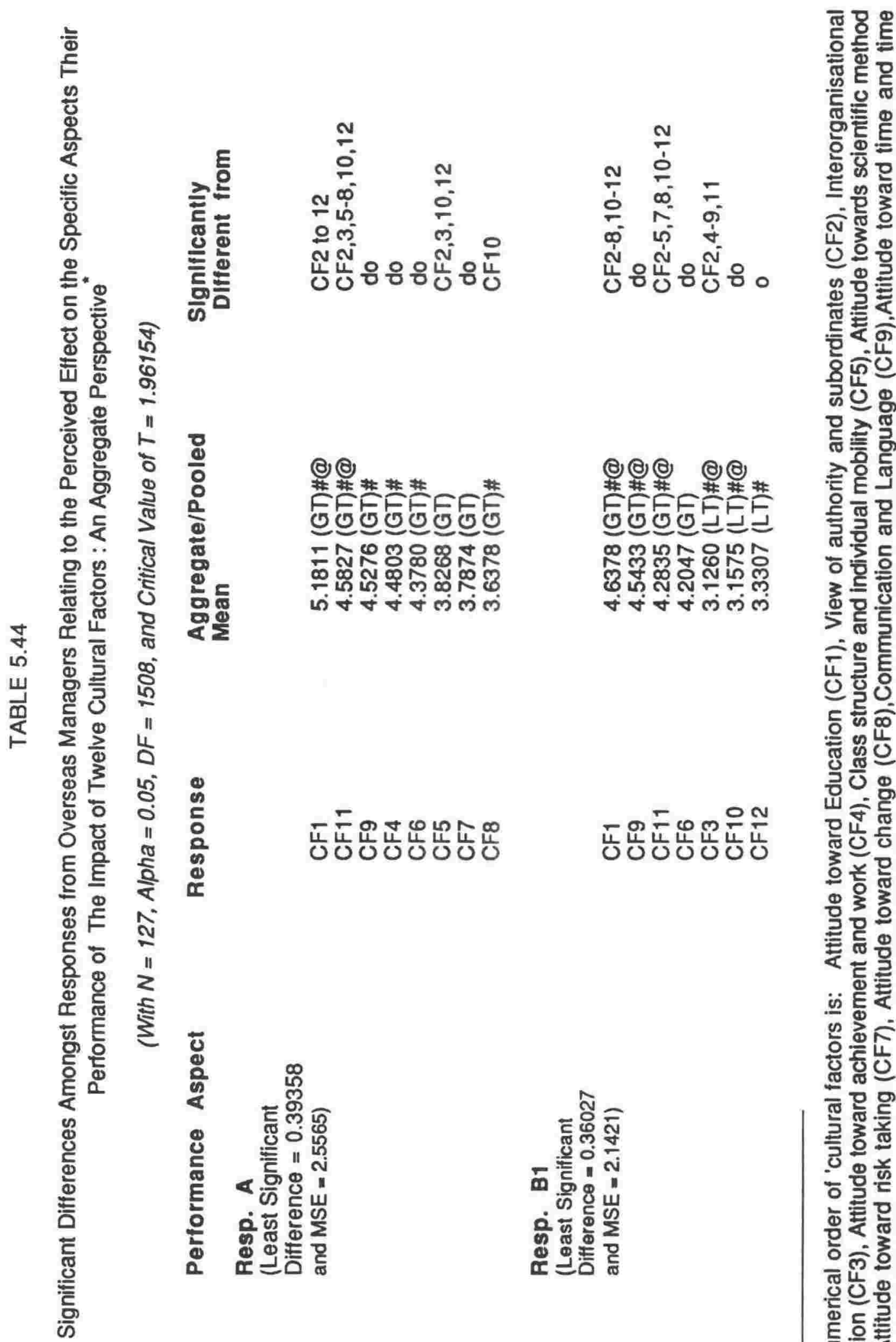

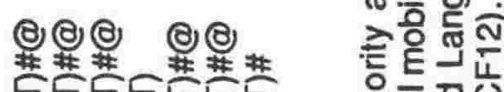

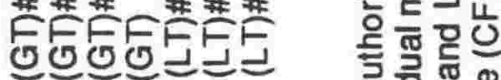

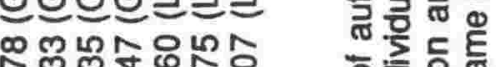

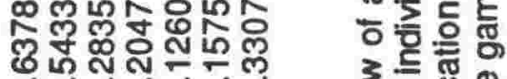

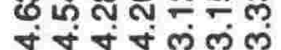
은 을을 원 호 들 है응 잉ํำ 등죠 옹느 U Uี

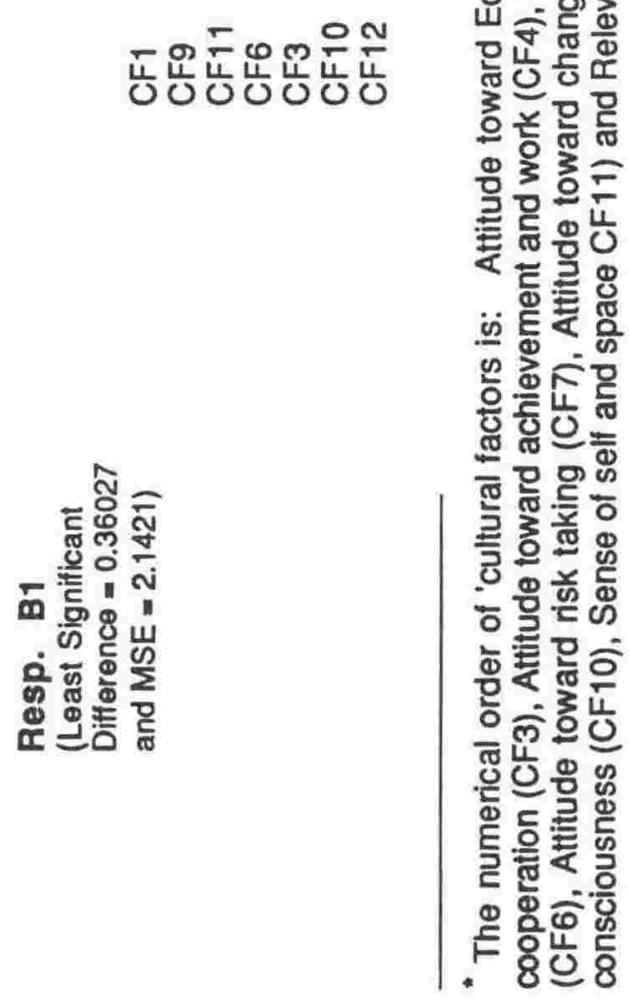




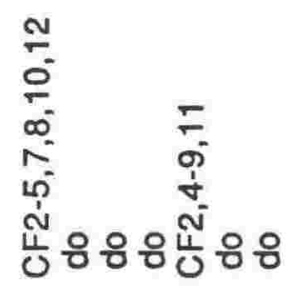

(항항ㅎㅇ

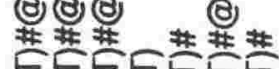

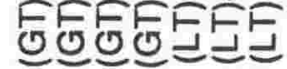

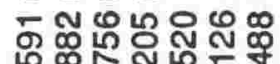

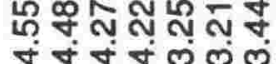

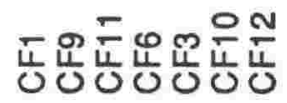

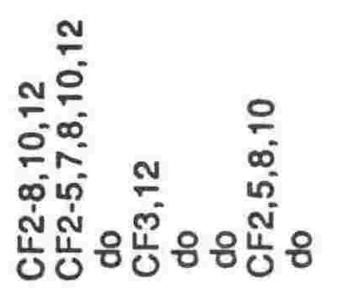

하요용

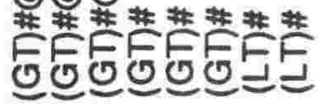
성요용

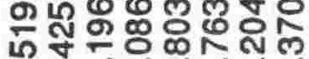
मं अंषल लं

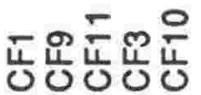
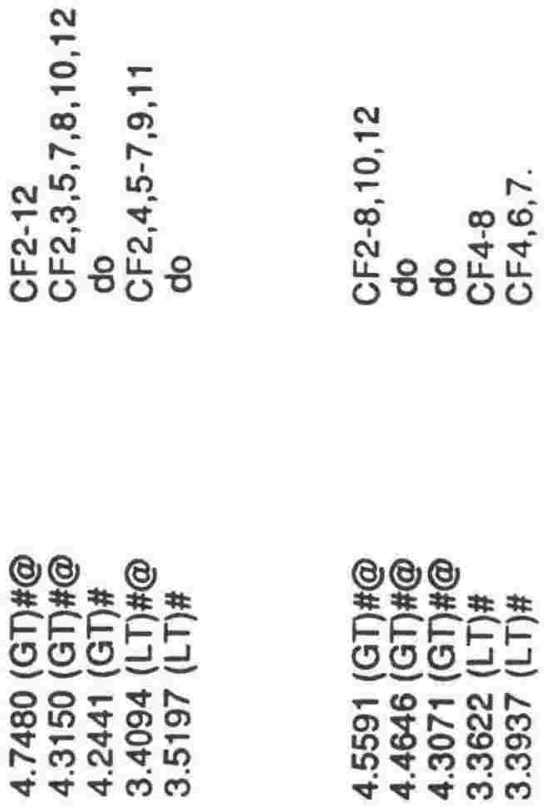

아아유)

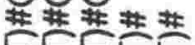
엉ㄹㄹ -은 웡 종 유아일 षंष्म ल
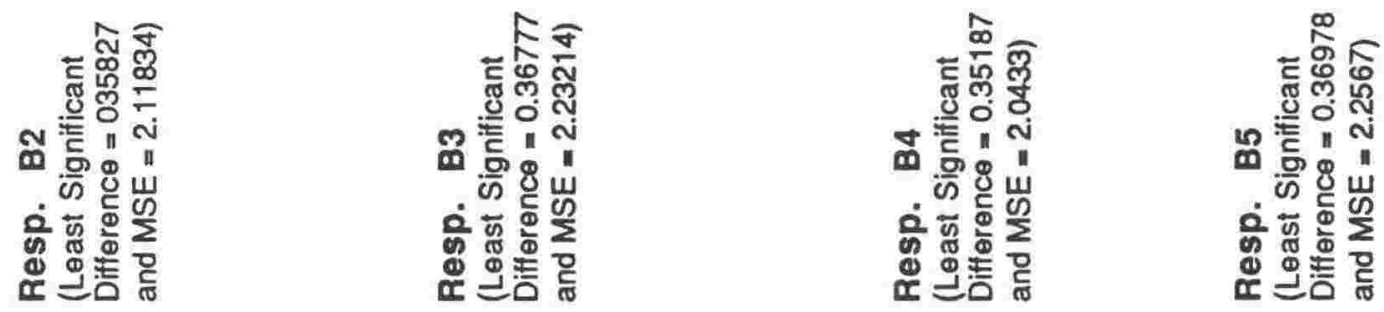

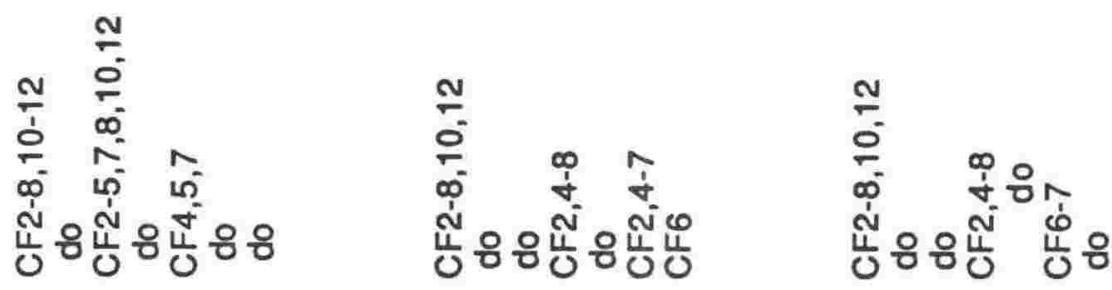

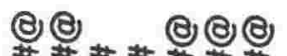

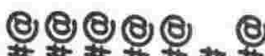

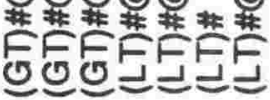

可可手

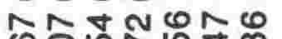
कㅇำ

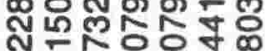

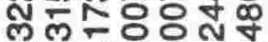

ᄂ? ल्ల의

$\dot{\forall} \dot{\forall}$ ल ल

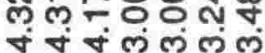

(ㄷ) (하웅

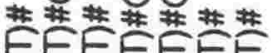

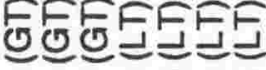

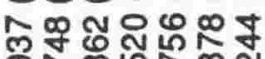

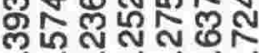

षणषं लं लं

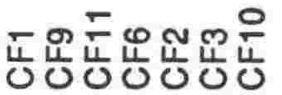

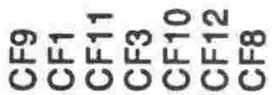

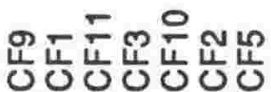
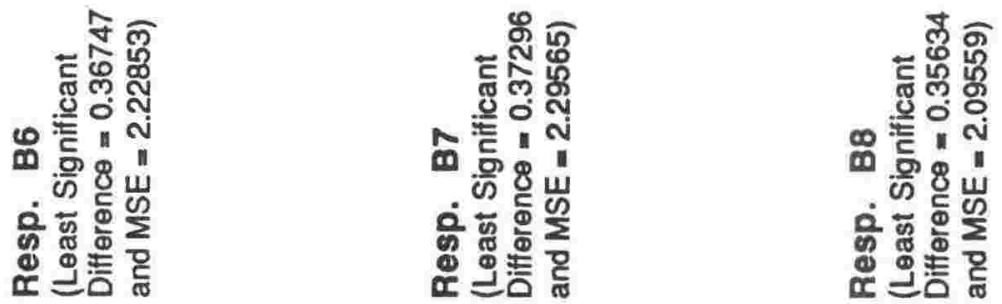

in 동

$\therefore \circ$

의

อุ

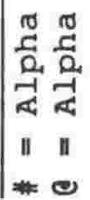




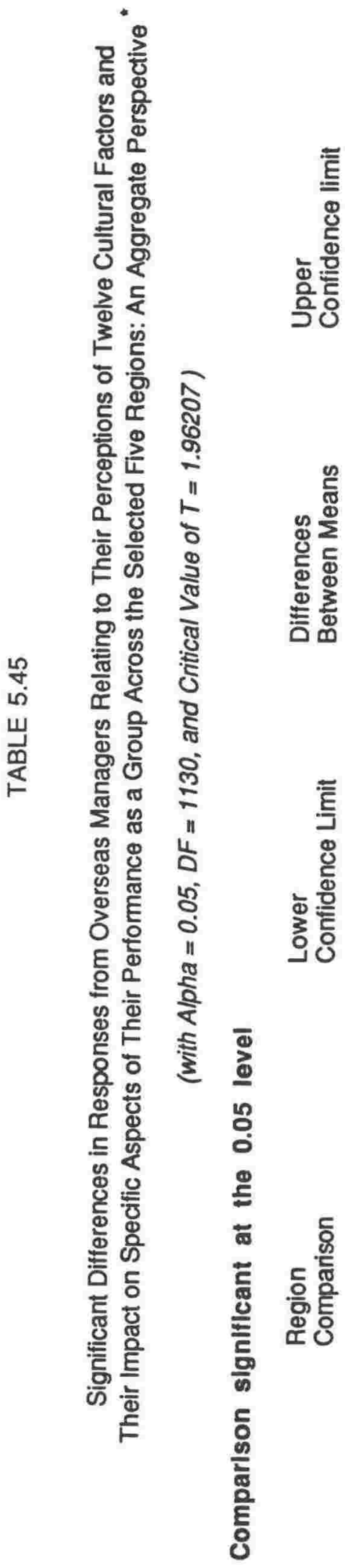

๒ ํํำ

๒

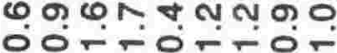

造

응ํㅆำ

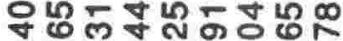

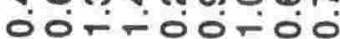

응

Ш

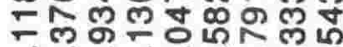

온

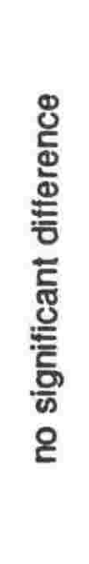

๓⿴囗十 ०00

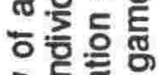

긍든을

๙

는 흥 일

든

을 \&닝

을

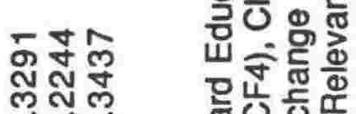

○ं० ₹

흔 몽 흔

ㅇํㅇำ

롤 옹

$<$ 돌잉

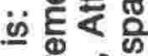

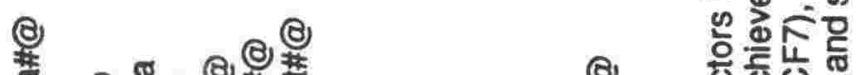

สิธ

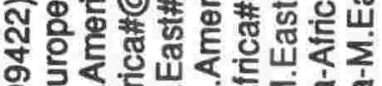

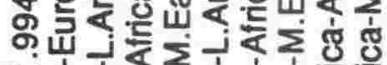

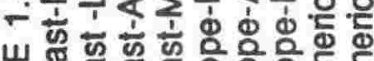
ᄂ

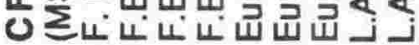
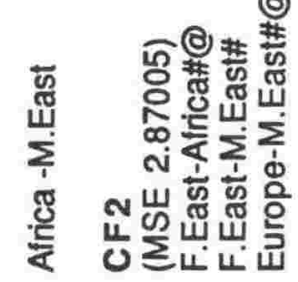

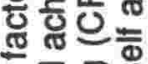
뜬 믄

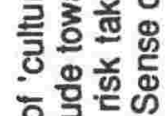
㐫还 은 के ले 중느용 능 톨을을 듄

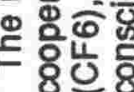


m.

ํํㅇ

NON

$\because \div 0$

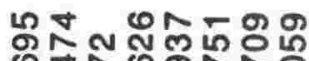

ナNOONR。

0ं0-

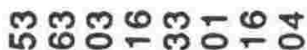

$\infty \infty$ 舟

क 6 का एक $\infty$

०0-00-0

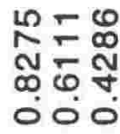

ले लै

ल N

$000^{\circ}$
ப்

นึำ 00-0000-

Ð 용 용

힝ㅎㅀ 힝

言语害

: $E$ E

త్ర ల్ల

드읃ㄷㄷㅡ

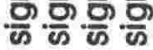

은 올읃은
N

Ұ

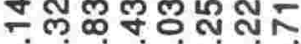
0000000
옹

등

든든

오오

읍ํํํํํํำ

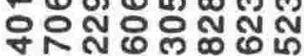
00-0000

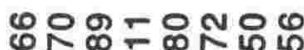

은 은

ㄴํㄱ용

0000000
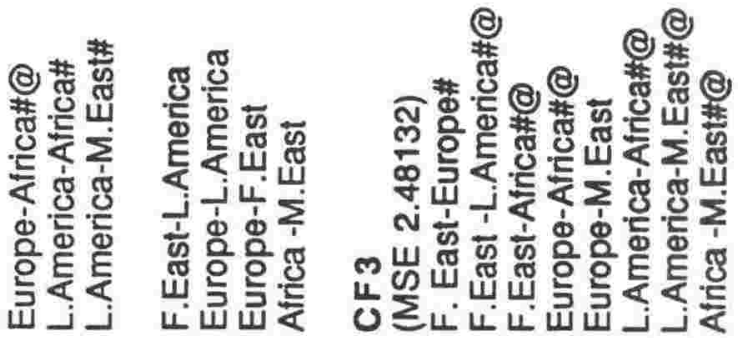

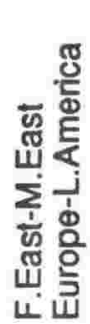
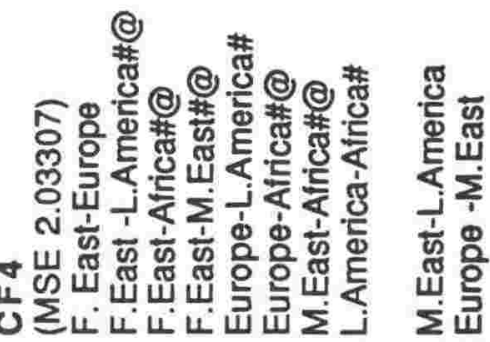


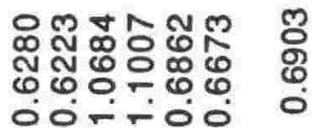

ㄴํํํำํํำํำ

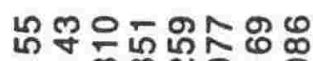

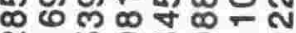

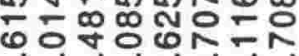

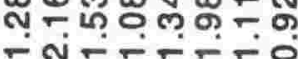

$0-\div 00$

โ유ํํำำำ

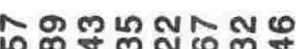

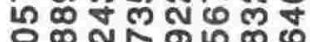

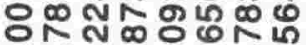

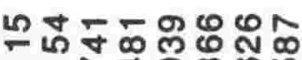

फुले ब्र

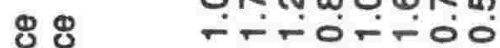

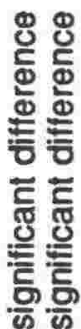

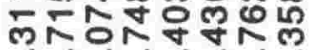

0000000

00-00000

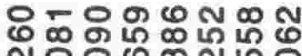

옹으

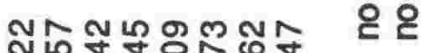

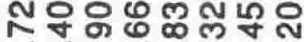

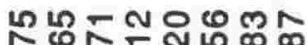

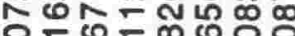

oró0-0

0000000

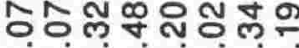

0000000
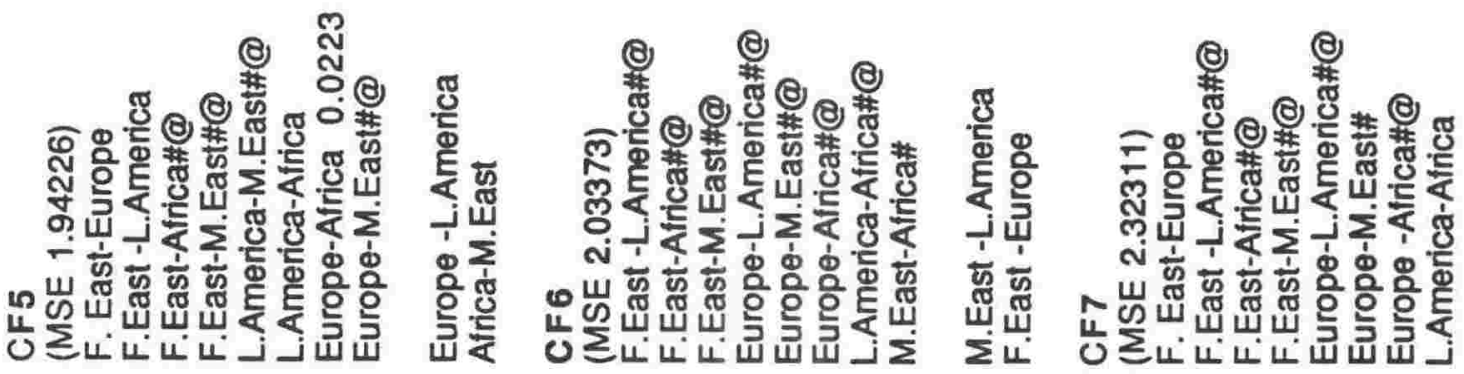
ต

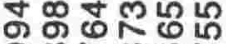

누요

ำกำㅇำ

는ㄴㅇㅇㅇㅛ

000

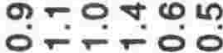

แก บ

กำ

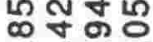

०ัพ

๓

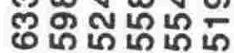

๓๓๓ ๓

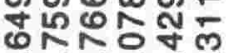

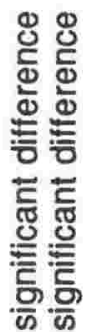

웡요용

000-00

8. 8 ㅇำ-

붕요 유

10

000000

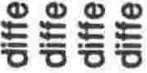

든 든 인

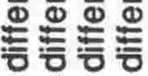

댏 ญ

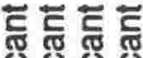

든흔흔은

는흔흔은

읃을은은

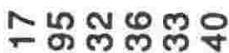

下

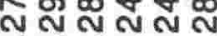

000000

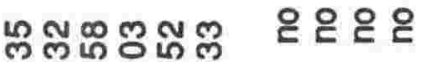

ำนกำ

लंर्षㅇ

ํㅐ융

000000

o--
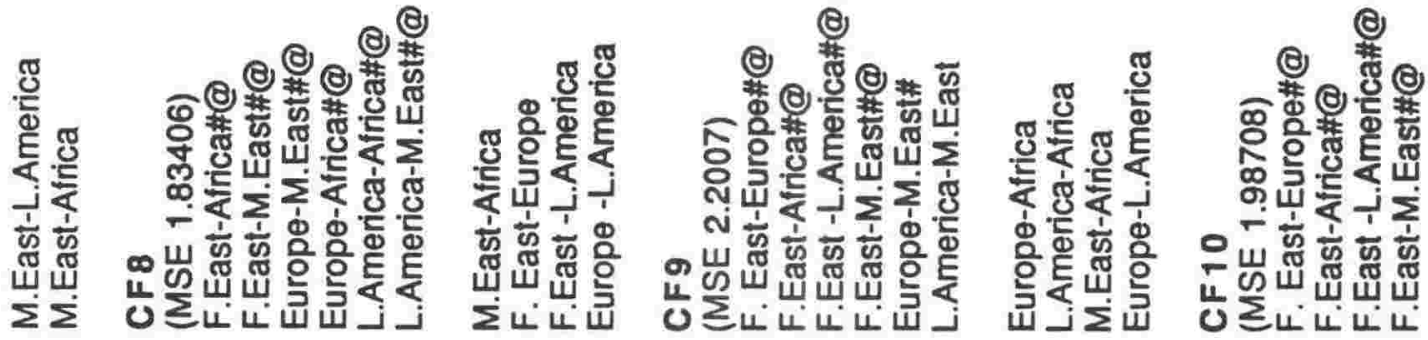
ตำ พ

애융ำ

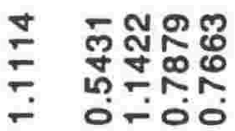

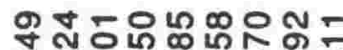

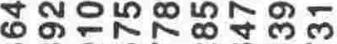

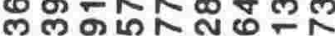

- $\mathrm{N}-0-0-0$

ஜㄴㅁㅇㅛ

ำํำ

ชำ

-

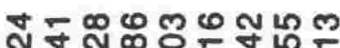

$-\div 0$

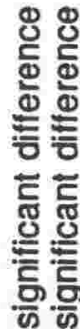

000000

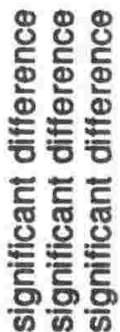

นกㅇํำ

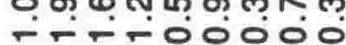

$\nabla \infty \infty-\quad$ 웅

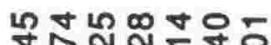

오오올

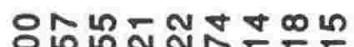

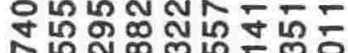

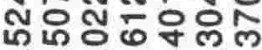

0ั-00000

क क़

0000000
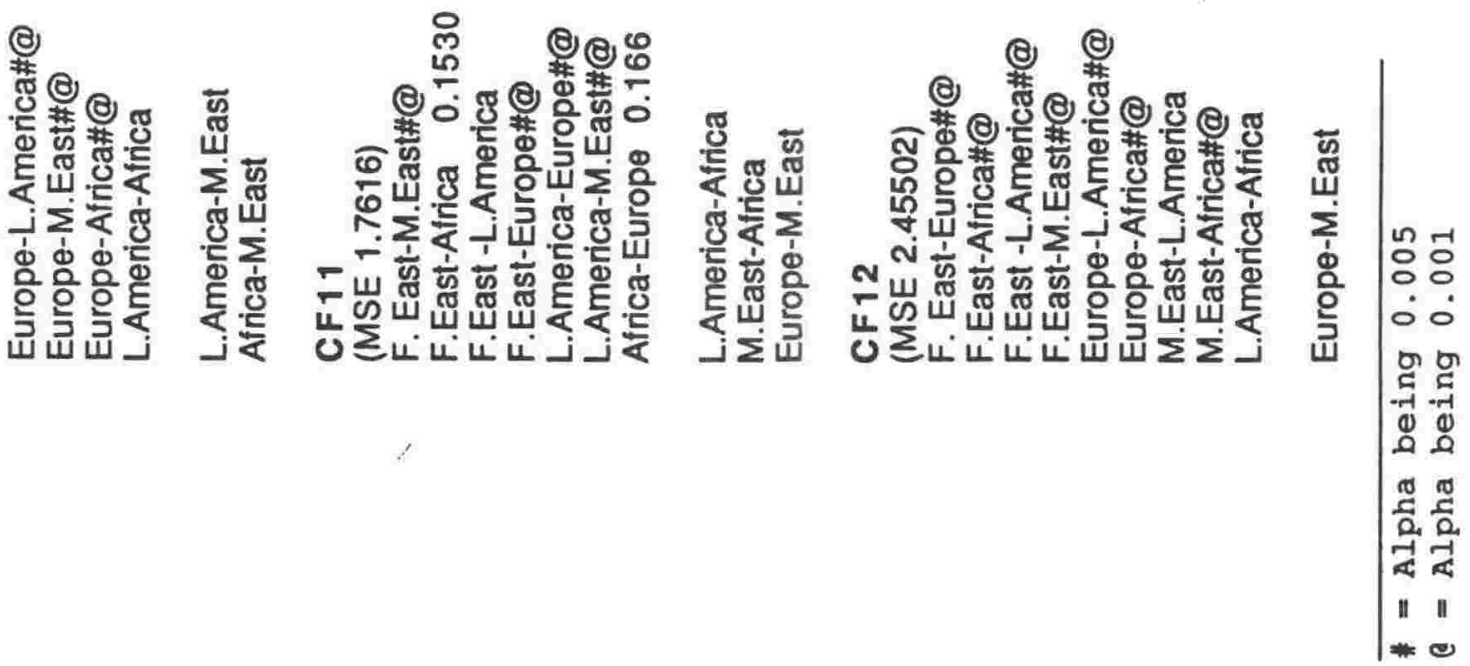
巳ัญ

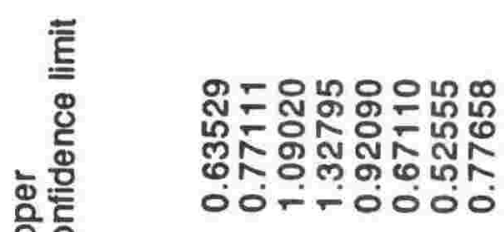

MN

흥

ㄴ.
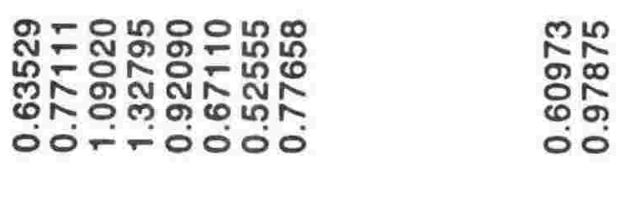

๒ั ์

등 둔

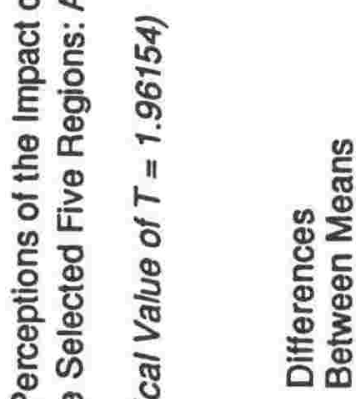

พัพ

승 0000000

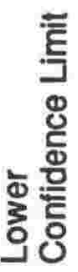

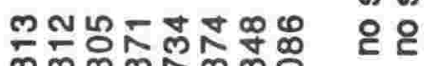

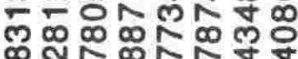
ชับ์ 0000000

लํ.

छิธ

Ф웅

흠ㅇㅁㅁ

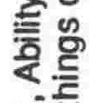

สิ๊

오은

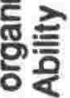

ㅎํ

言

뜨르를

들

交要

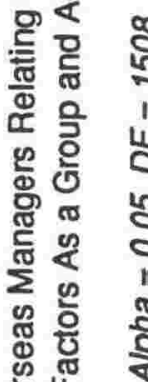

$\leq 2$

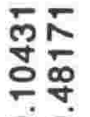

든 흫

융

음

진

동휴

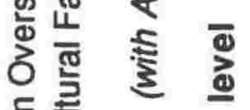

튼 吾

\& 웜

¿ $\frac{\mathrm{d}}{5}$

क

드

\& 3

它

Фั

更

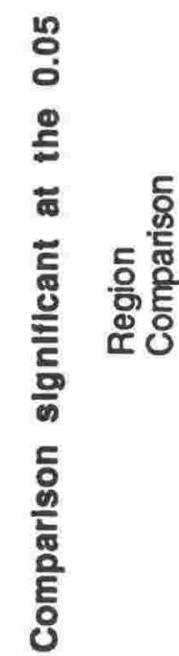

(ㄷ)

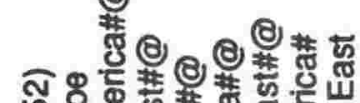

승응ㅎㅀ

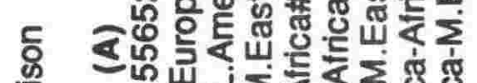

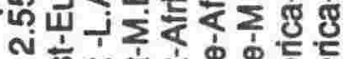

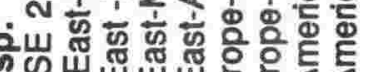

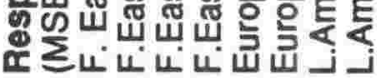

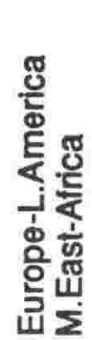

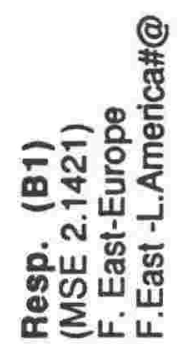

i்

잉

ธิ

동

한

응

๘ ㅎㅀ

온

혼

흘

产怘

들 울

농은 
คำกำกำ

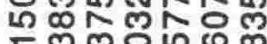
N -T000
ஸோழா ल-ㅜ

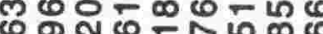

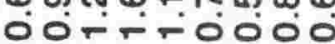

๓ำกㄴำ

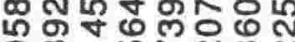
ब $-1 N \mathrm{~N}$ ल मून की $00-1000$
능ㅁㅇㅇํำ ษㅇํㅇำ लํํㄴำ 0.0000

부붕 $\forall-\infty N \infty \infty$ ๒ึ 000000

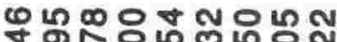

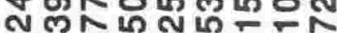
๓

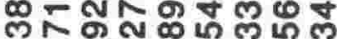
000-0000

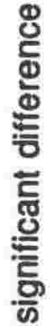

은

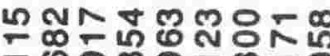
๓๐ ๘ 0ं000000
ஸิ ณ ผ 내 $\infty$ लื ०0ं0-000

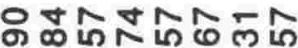
- 10 N

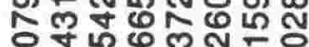
00000000

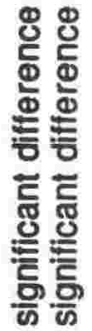

오우
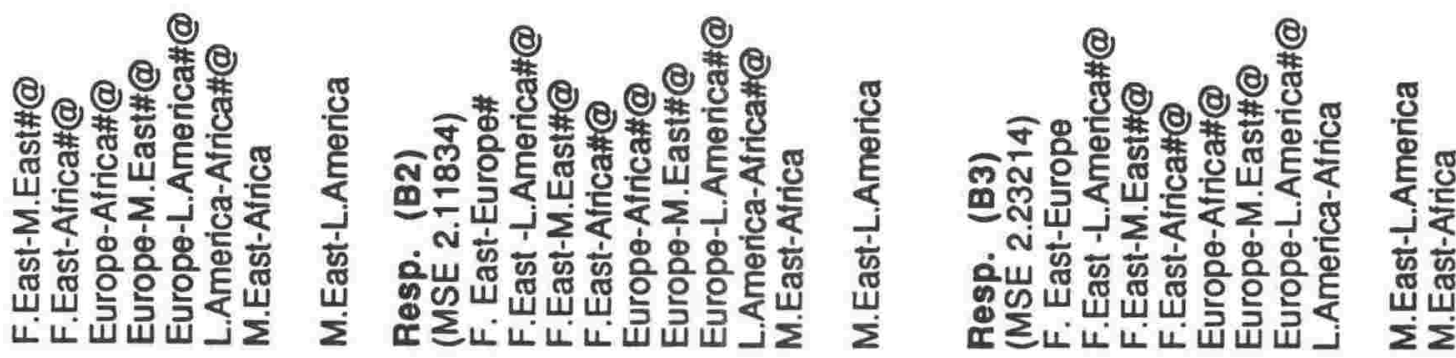
エ बิ NEL

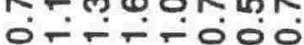

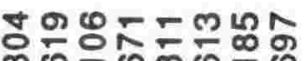
$00-6$ ต लొழ당 மீ-

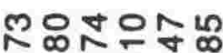
以舟的方 ம 00-

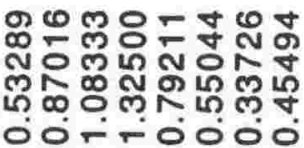

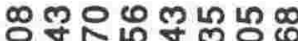
फ̃

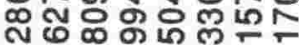
0000000
누윰ํำ ฌ 둥ำ 00

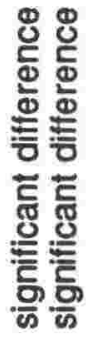

울울

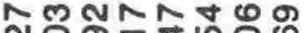
大ํํㅇํำ ตํํำ స్ํำ 0000000
ต ํํㅇㅇㅇㅇㅇㅇ 등ㅇㅇ

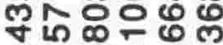

\& 000 0

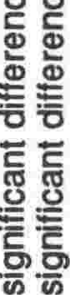

올 을

ㅇㅠㄸ엉ㅇํ은

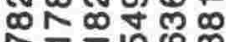
픈 000000
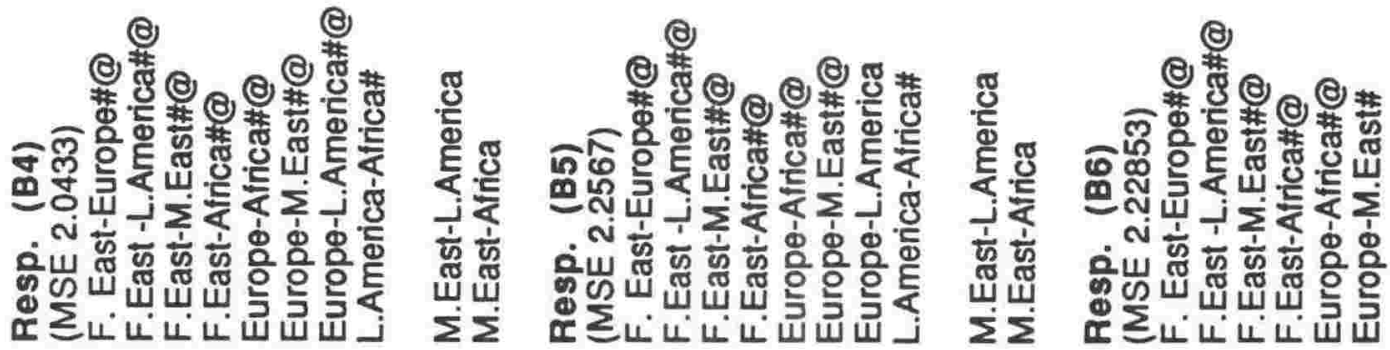


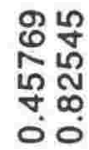

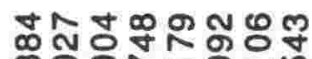

잉스는

ल원중

쮸뮴쬬유융

क ल주요

下

○- -0000

0--

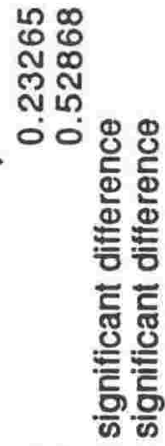

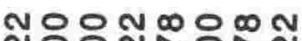

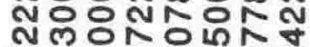

Nलํㅇㅇํํำ

$\checkmark \infty 0-\mathrm{m} \omega \mathrm{n}$

00- 0000

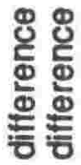

땡ํำ

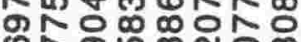

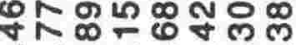

०00-0000

ธำ 욷음

응 लำ

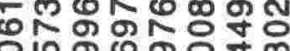

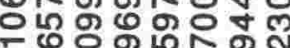

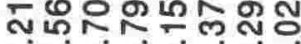

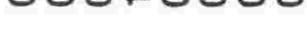

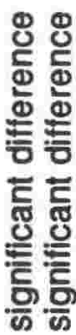

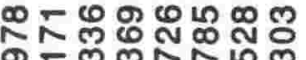

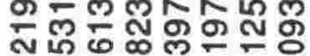

00000000

0.

0000000
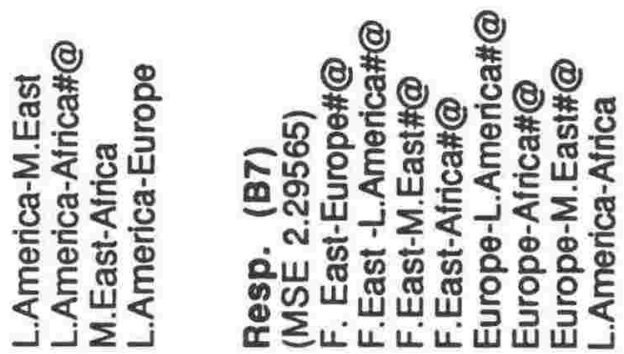

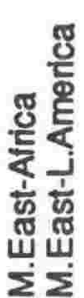

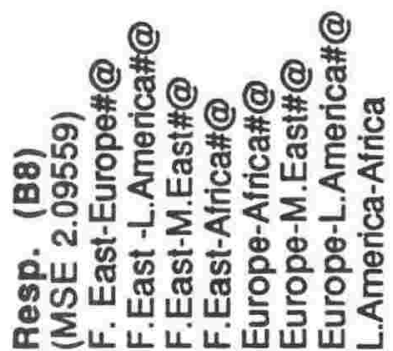

岁

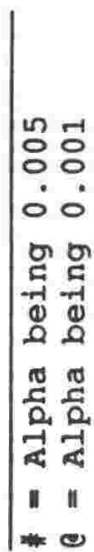




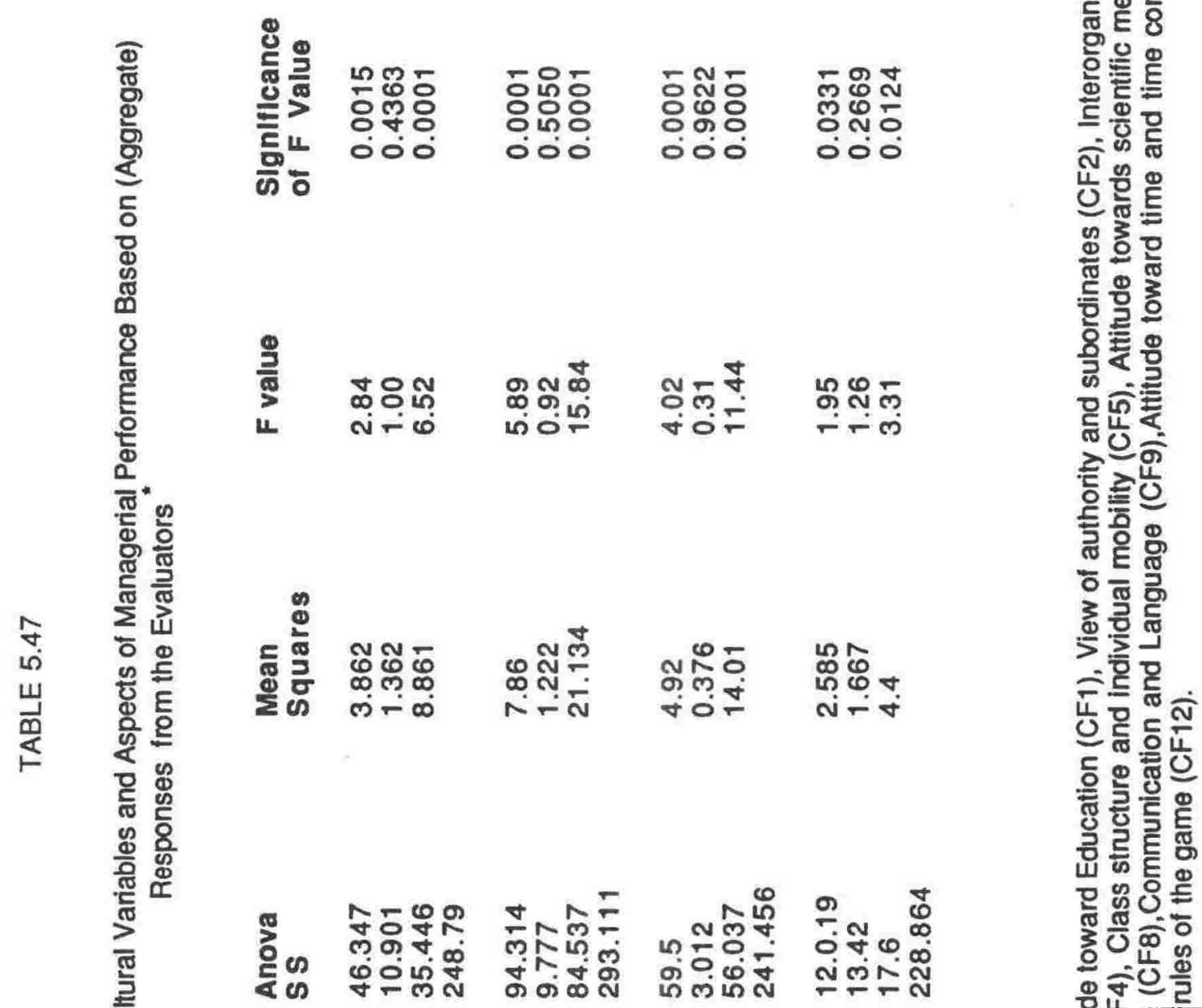

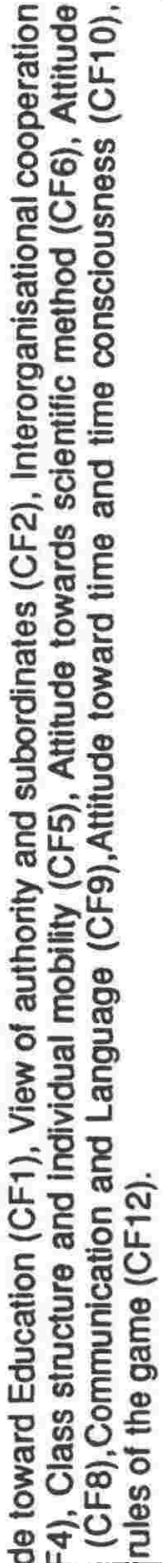

"II"

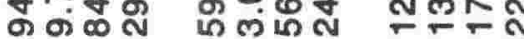




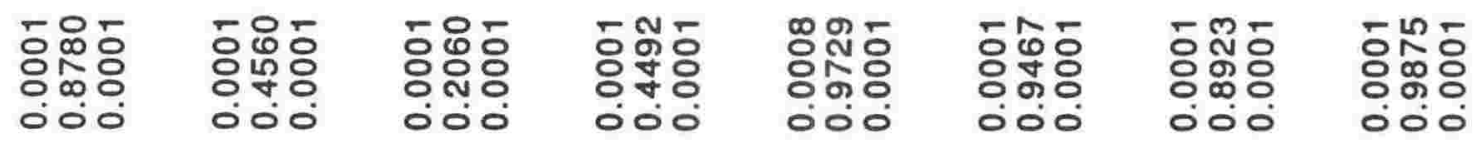

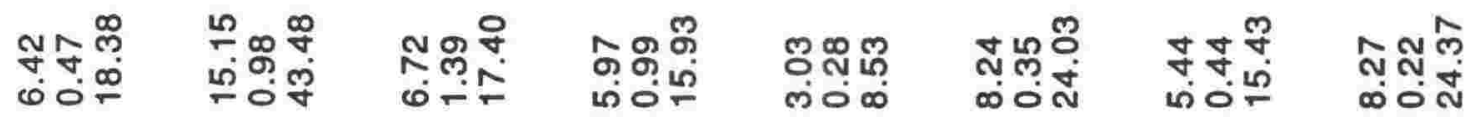

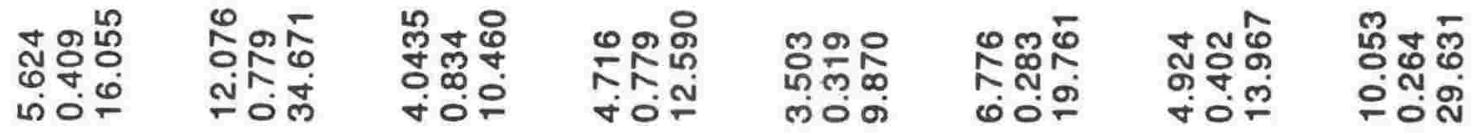

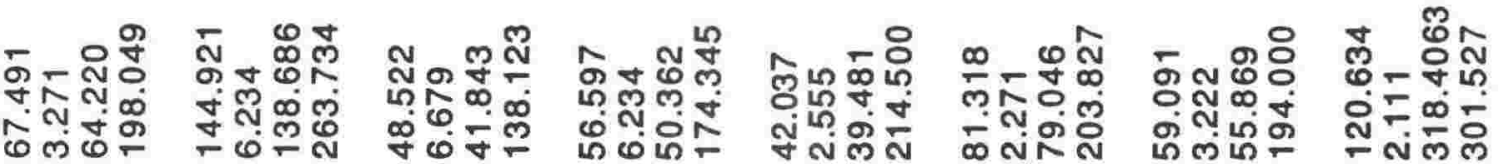

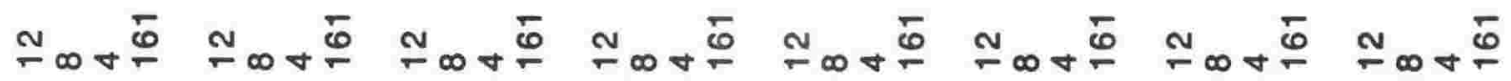

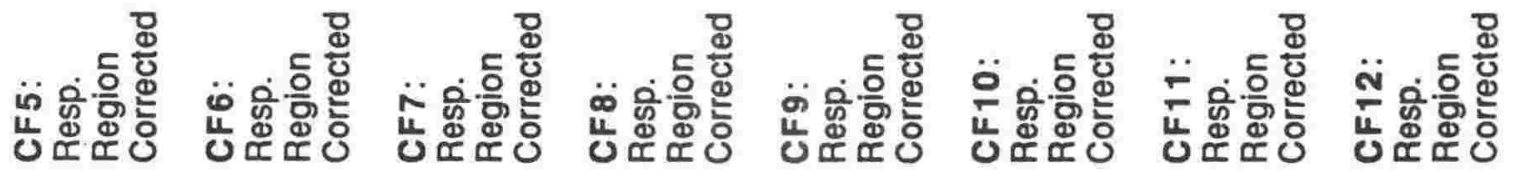




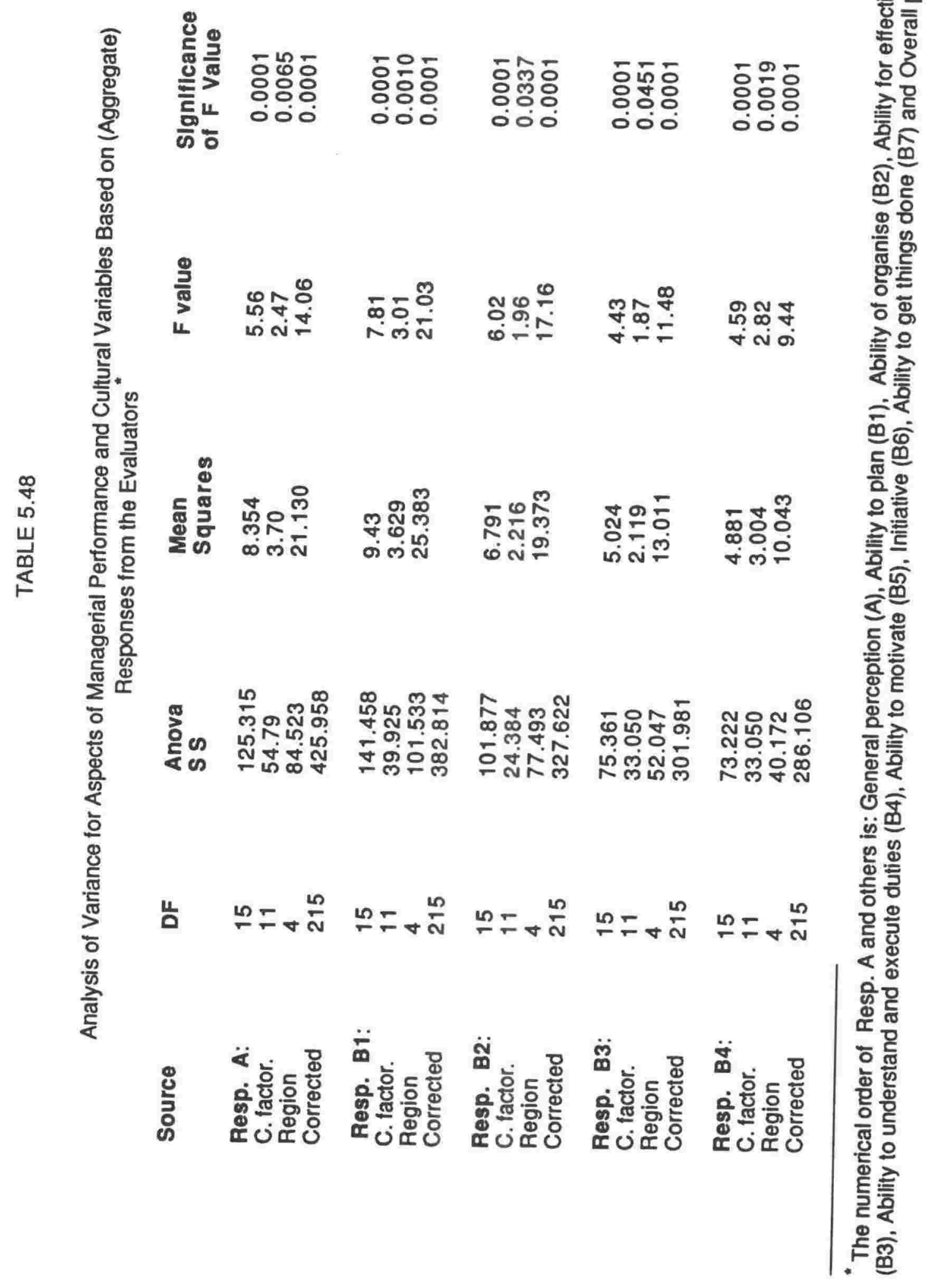




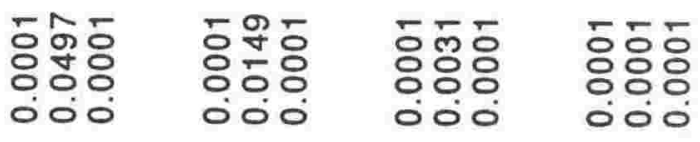

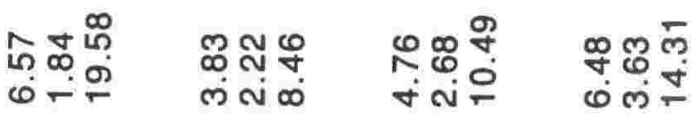

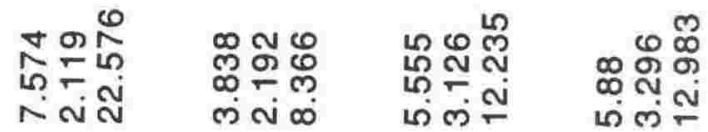

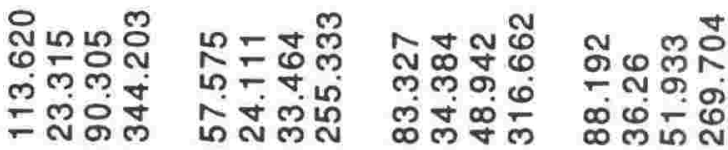

Lก:

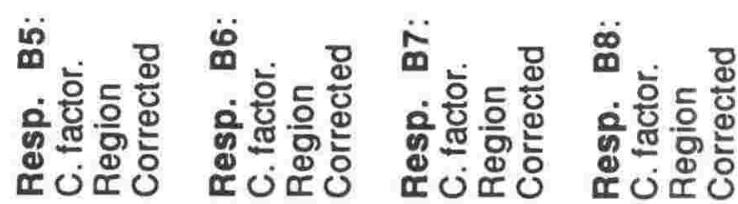



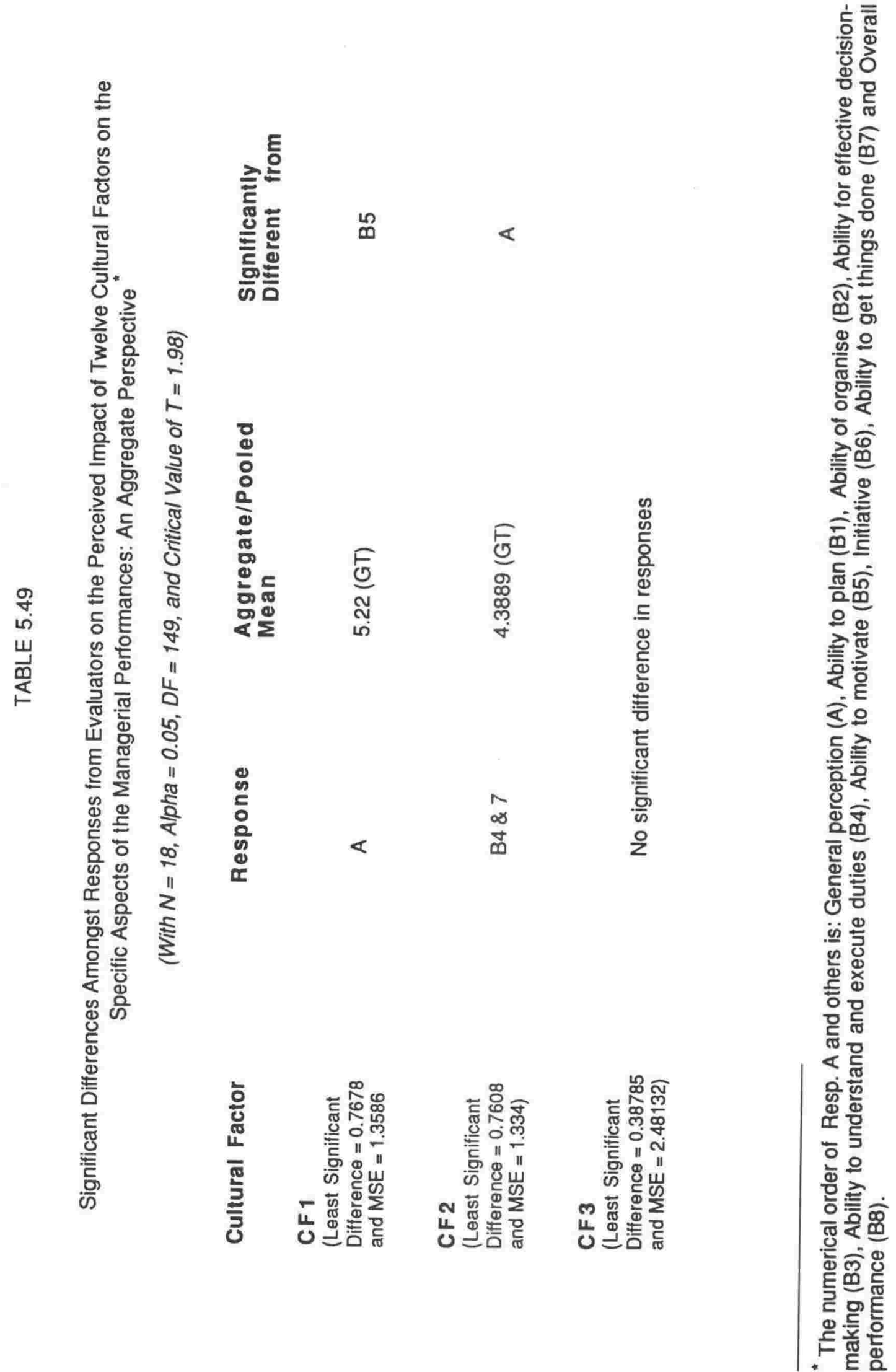
을

$\stackrel{\oplus}{\infty}$ in
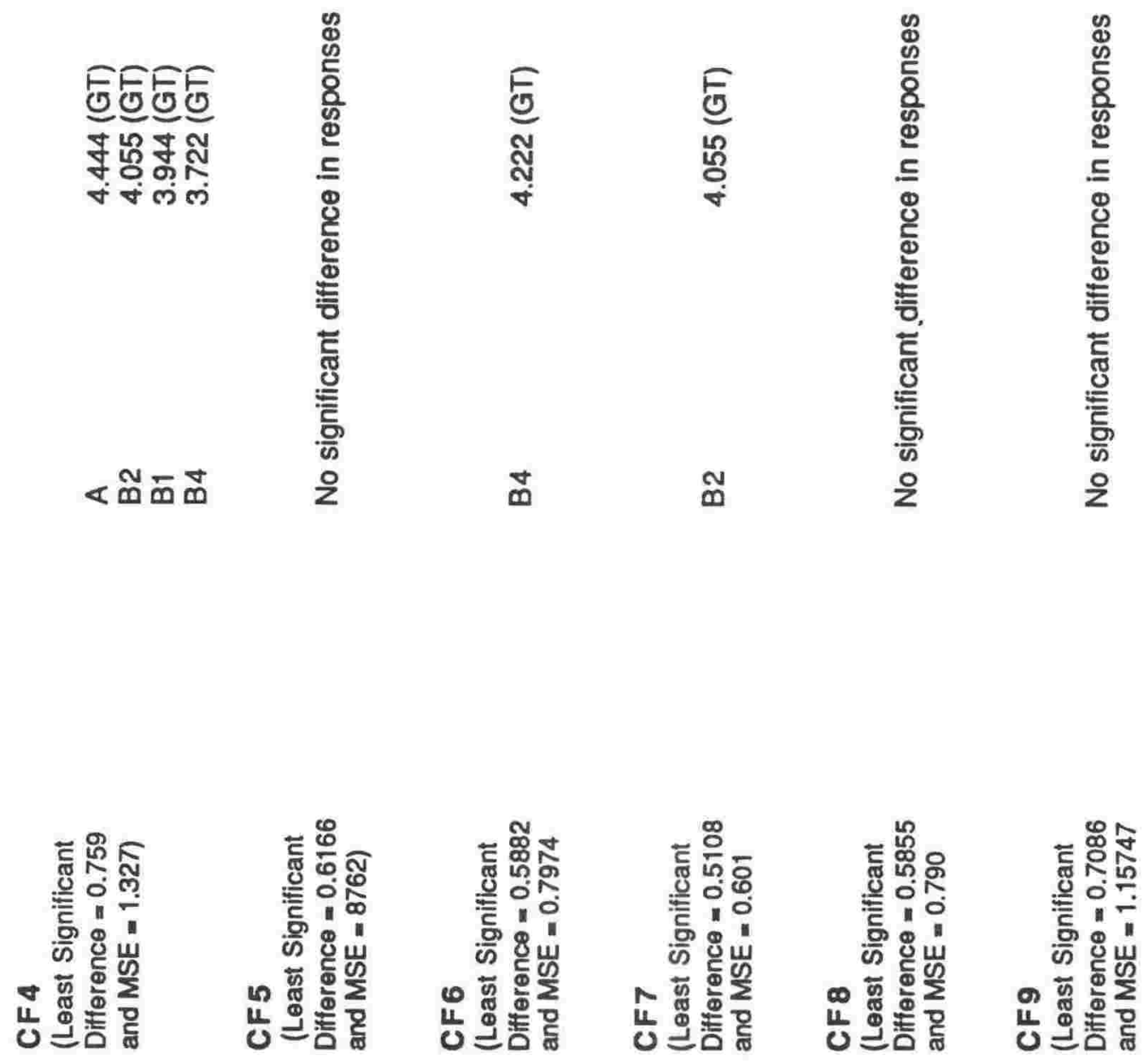

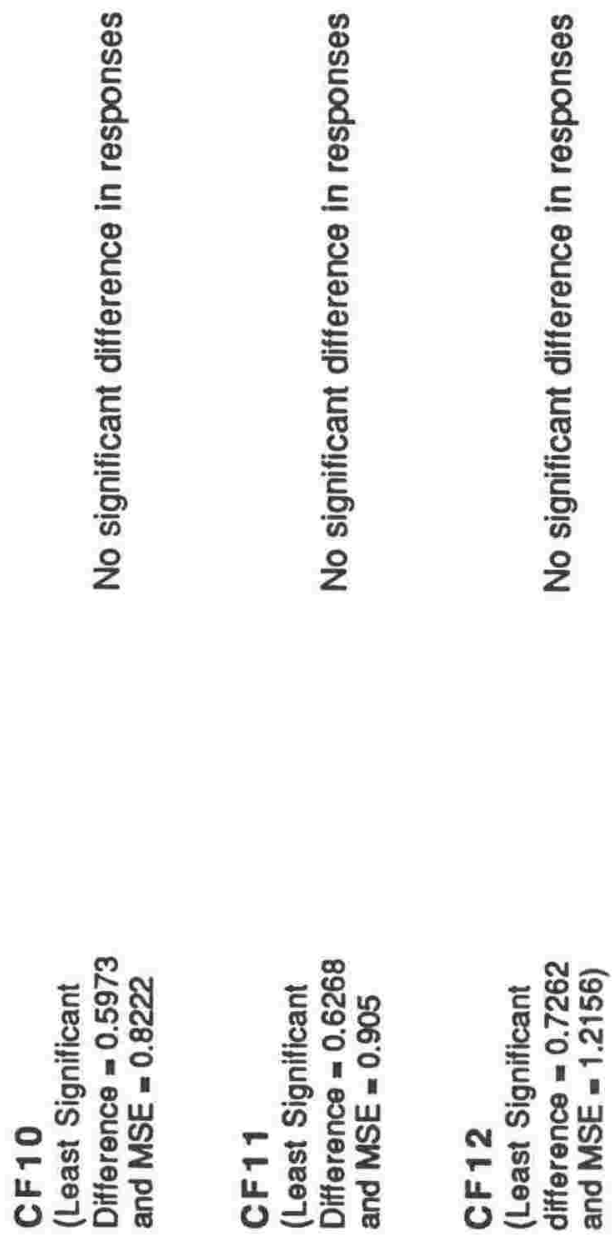


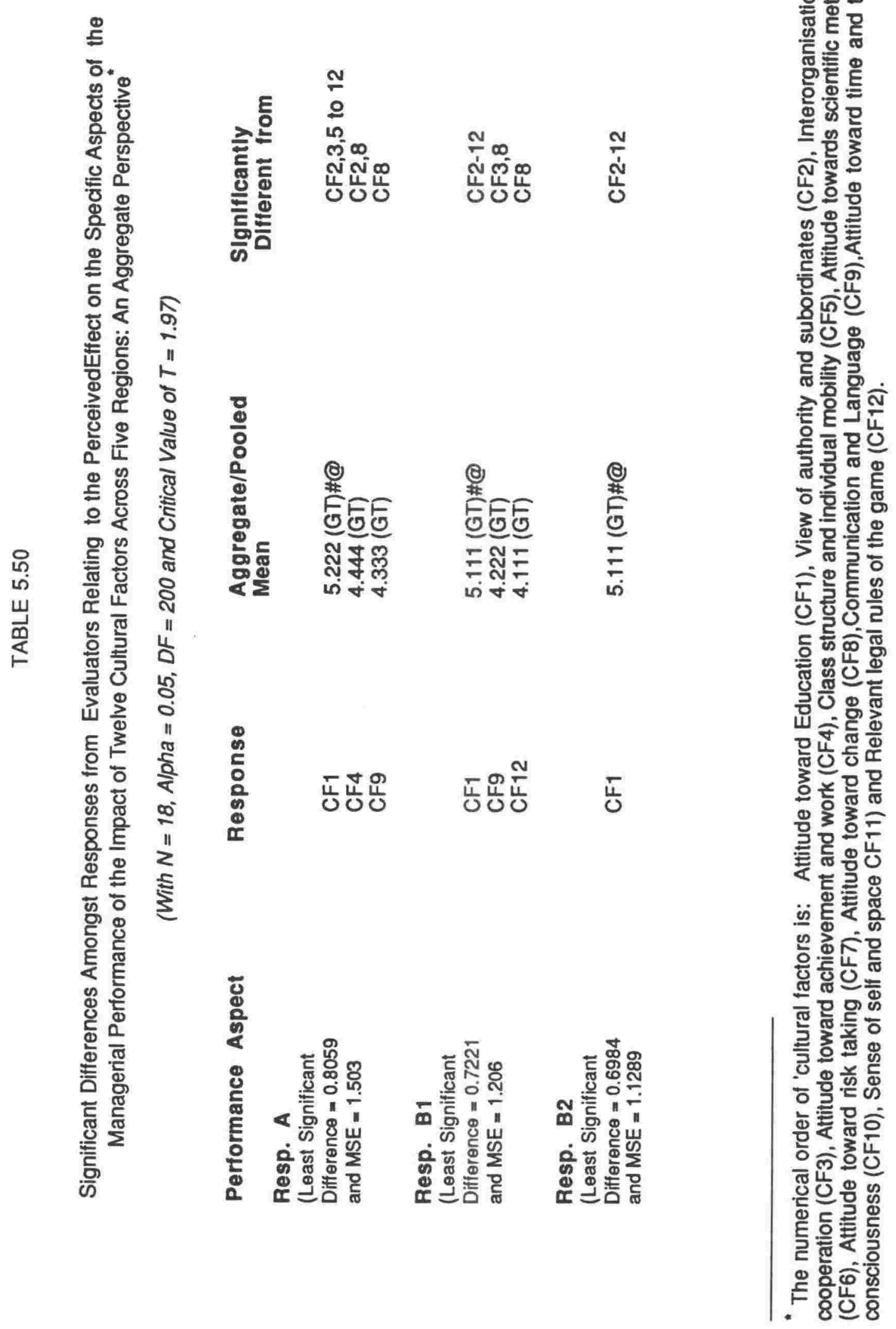



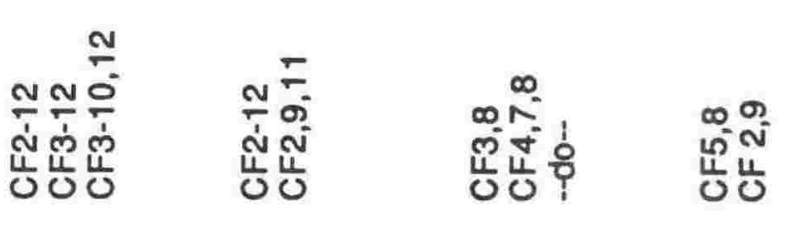

赵
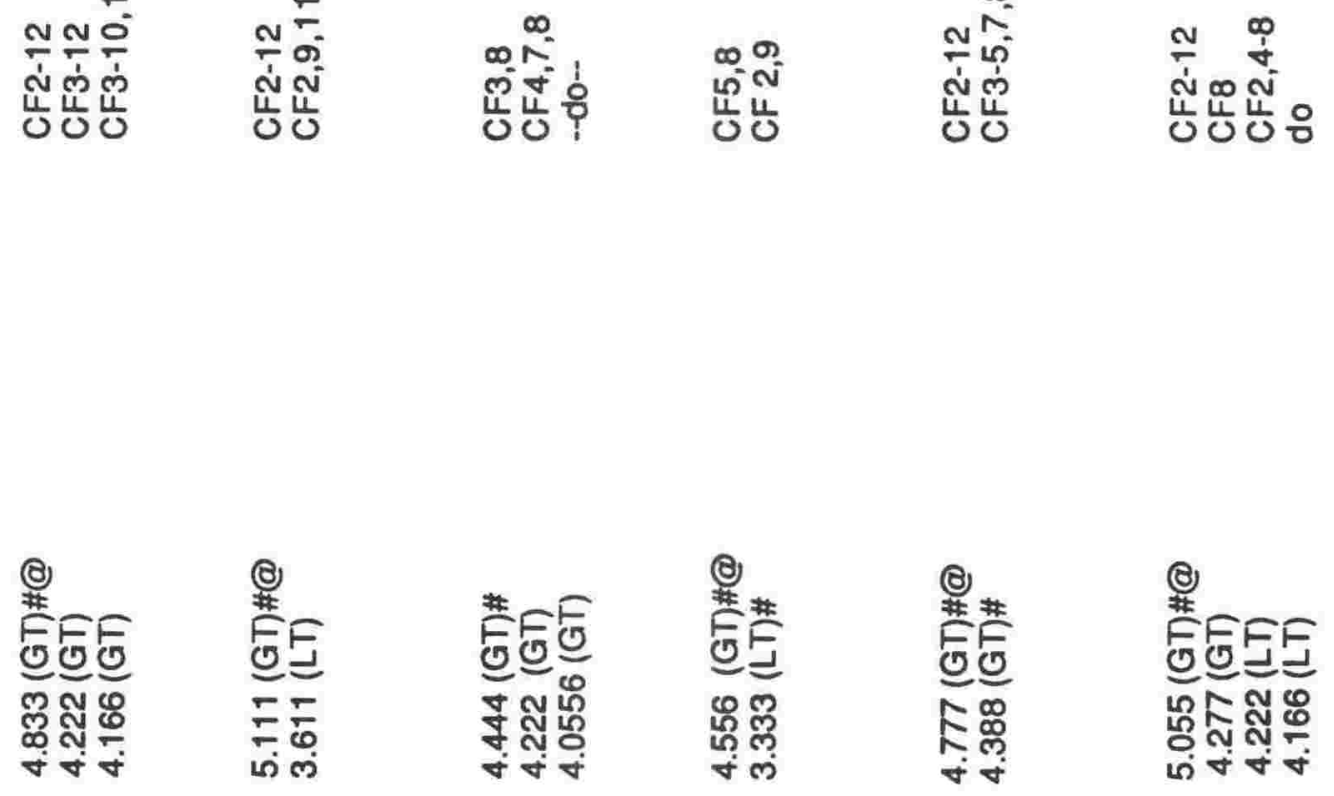

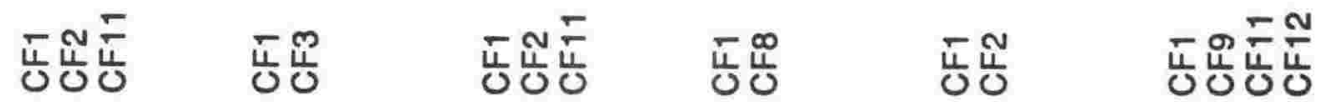
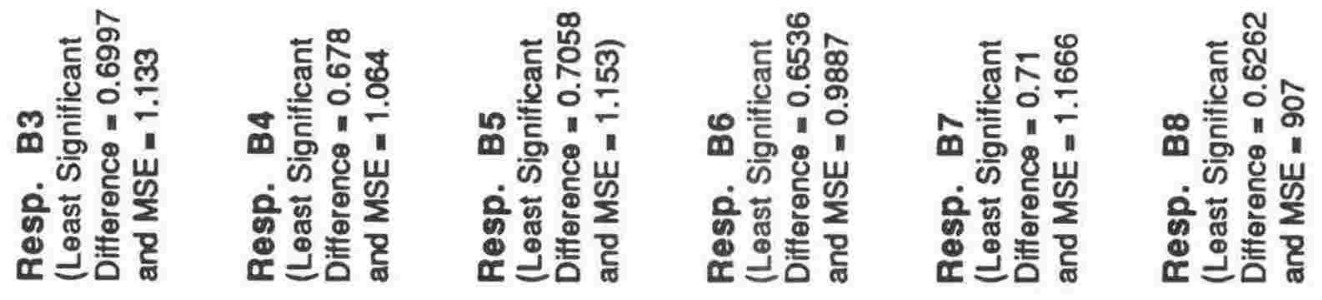


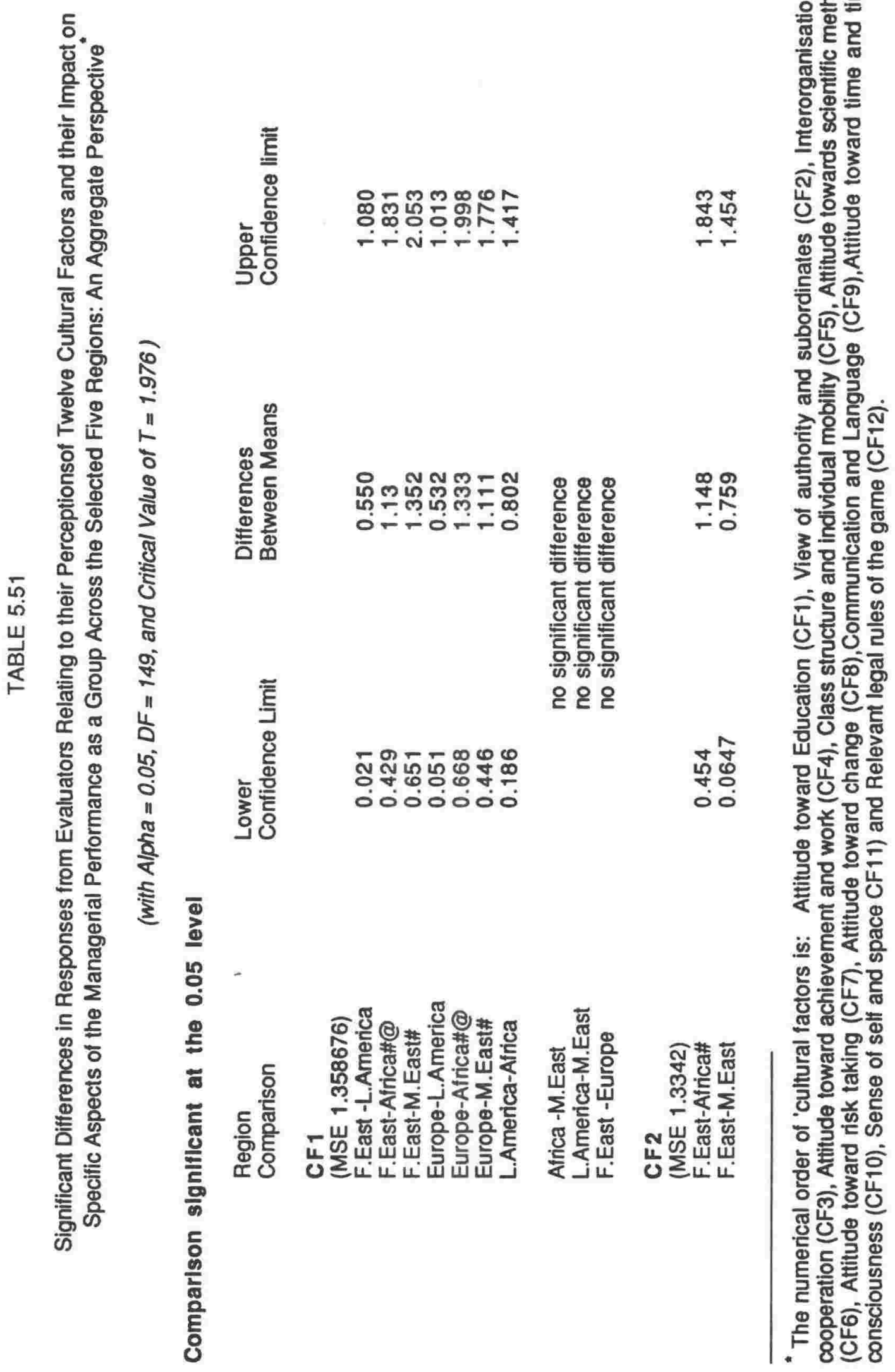


ำกำำ

ชัดธำ

-

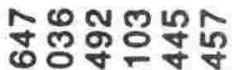

- लं लं - of in

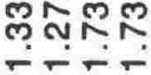

N $M \forall \leftarrow \infty=N$ ำ लื - N- -

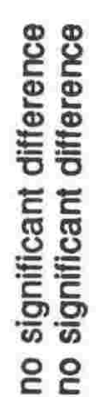

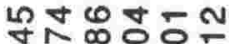

퉁ํํ유:-

0- -000
운 ஸN ఏ

$\approx \approx * E$

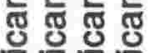
든

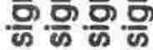
옫ㅇㅇㅇㅇ

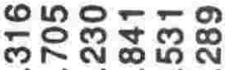
00-000

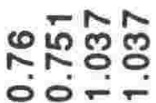

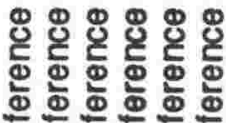

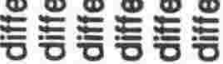
르를ㅌ틀

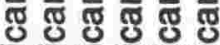
든등등드응

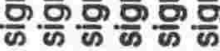
옫옫ㅇㅇㅇㅇ $\infty \stackrel{\text { N }}{\mathcal{N}} \mathbb{\Psi}$ ०000
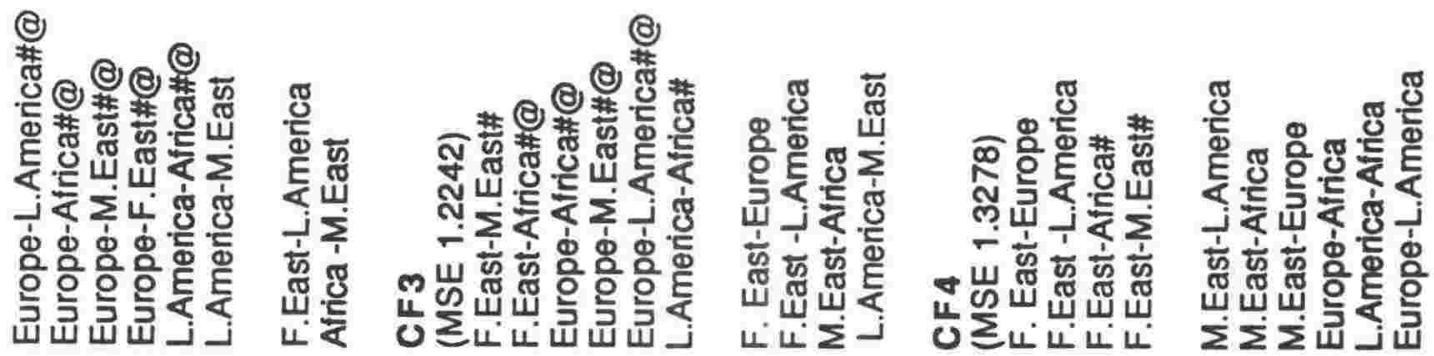


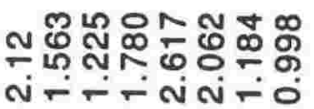

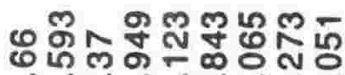

กำํำ옹ํำ

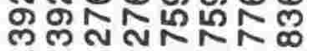

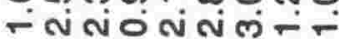

范

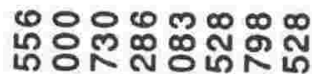

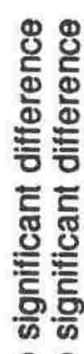

부윰ำำ

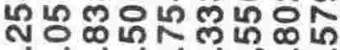

-

- N-O- Nió

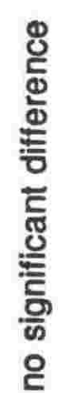

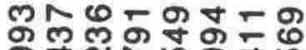

守 लำ

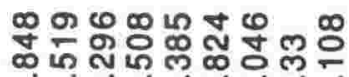

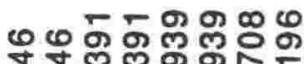
O--

부요요웅

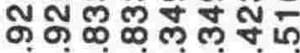
000ั-00

0000000
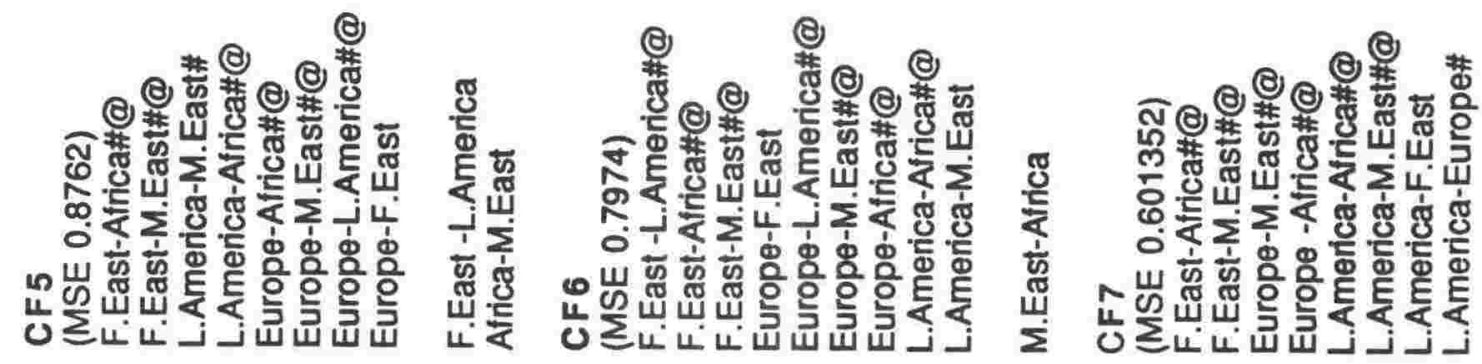


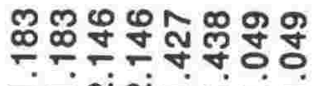

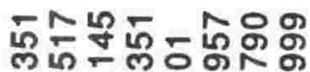

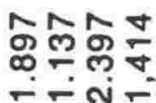

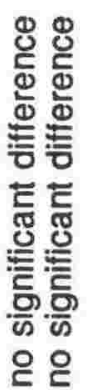

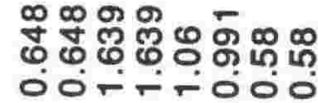

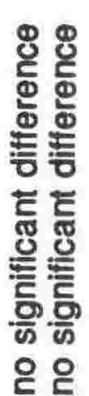

후유ํำำำ

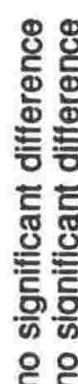

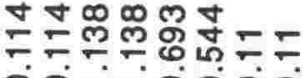

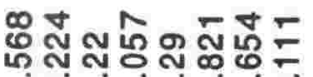
0000000

홍ํㅇ융

ㄴำ 는

ผึనผ -0 ஸ்
(2)

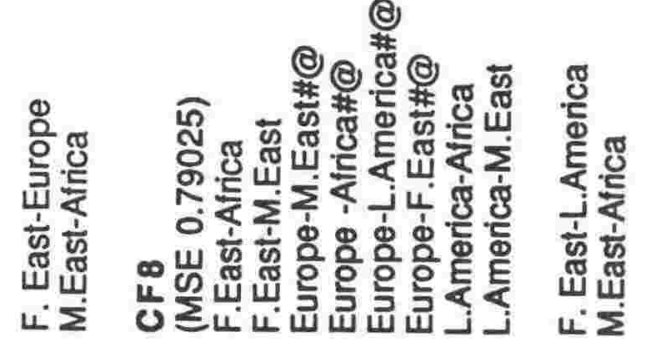

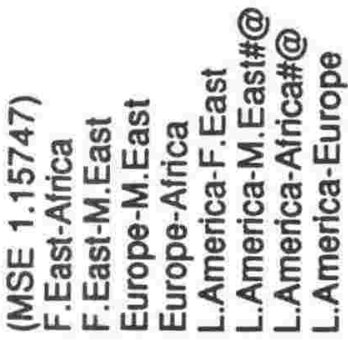

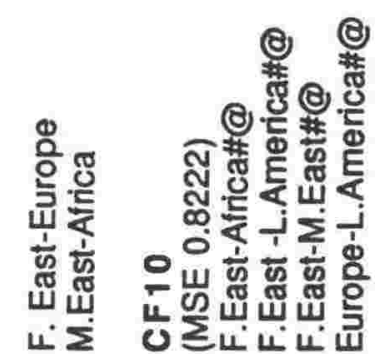




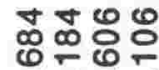

N่

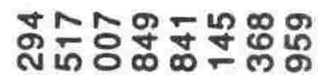

लำ

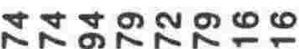

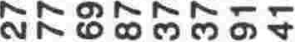
ल-

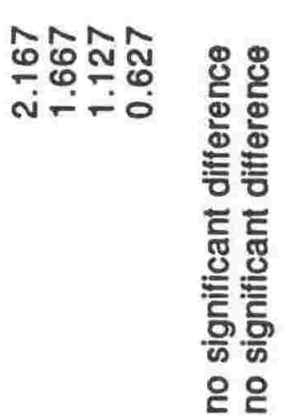

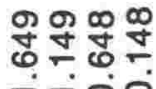

ิำณำก Nับํำ 0-0-00-

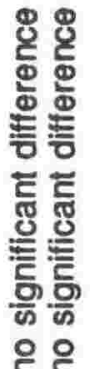

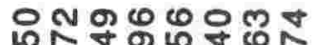

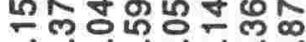
0-0000-0

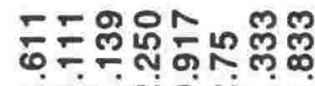

응 옹

泫

듀ํ 튬

흠ํํํ

을 읃
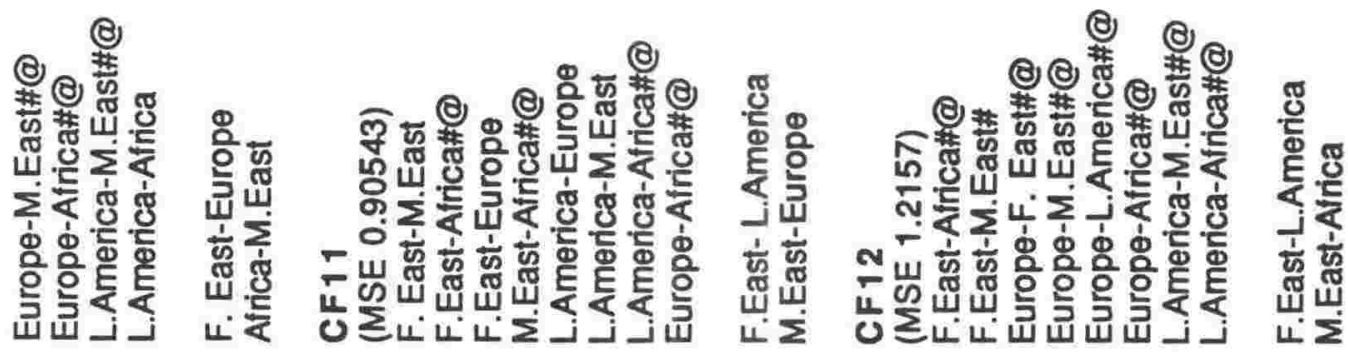

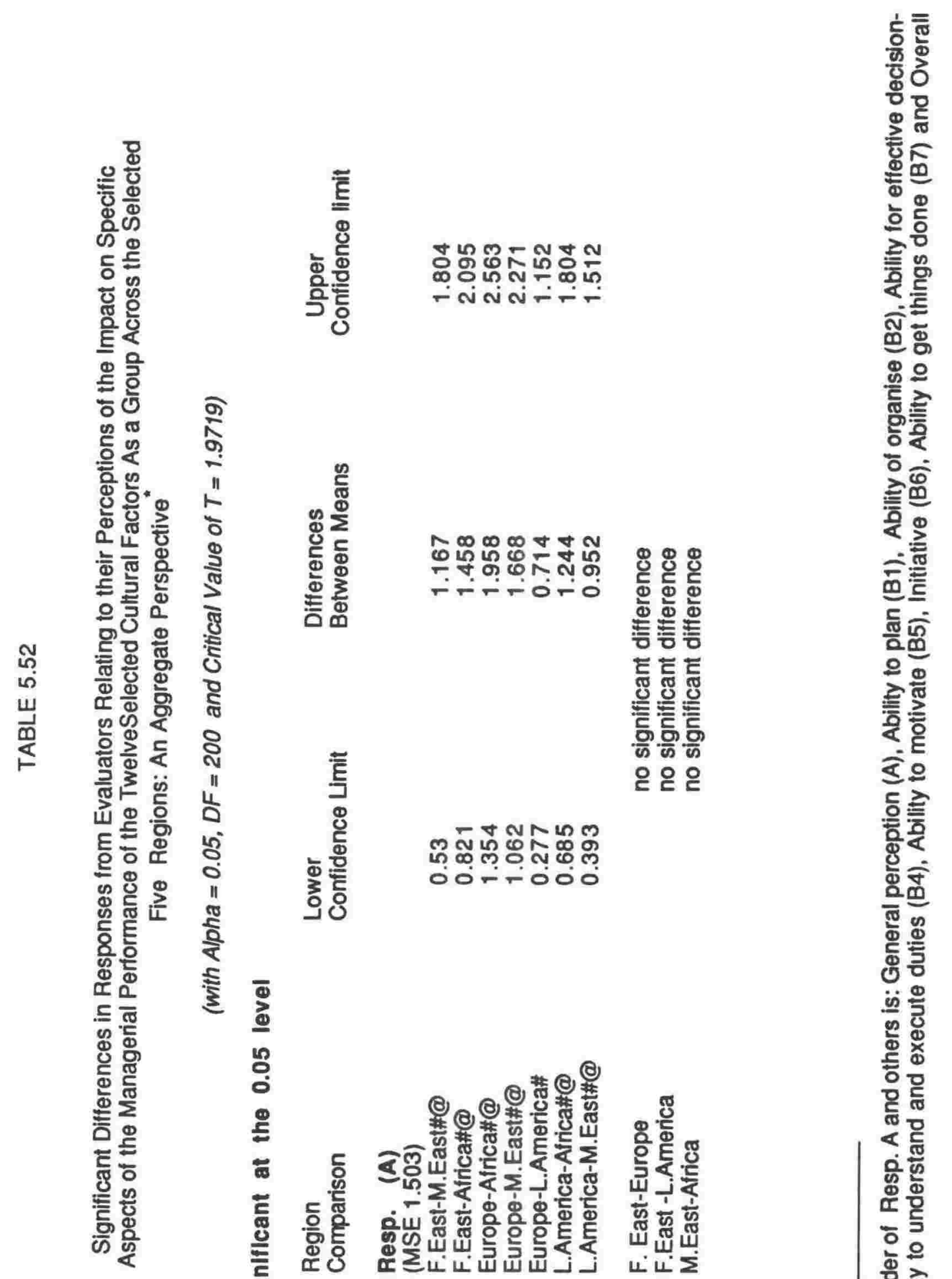

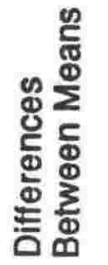

옹ㅇ

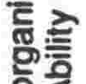

후

룽

운

它要

동

응

흥

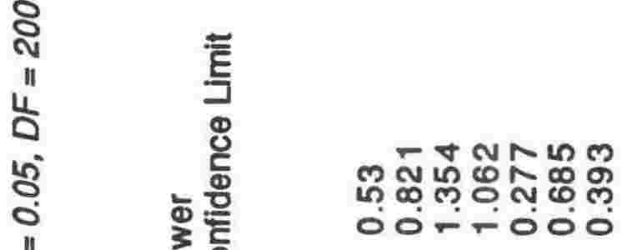

ธิ요

드ㅇㅡㅡ

응훙

递

๕ัษ

중요

ษ

옹

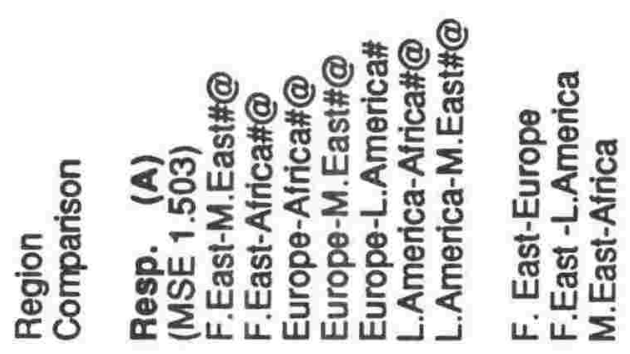

응 옹

중

응드

동

ธ

태을

<은

응 는

뚱

응

홍ㅇ

응

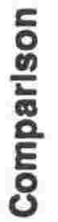

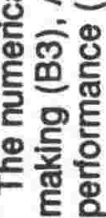


ผีఱ ભ ભ

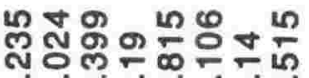

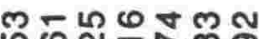

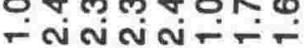

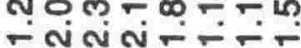

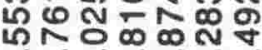

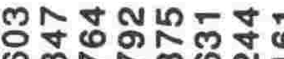

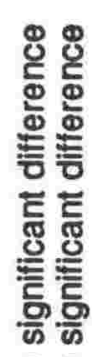

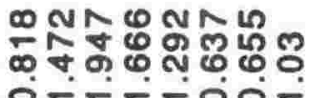

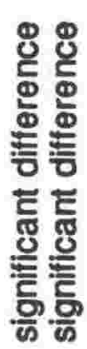

읃읃

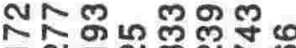

스뉴 ललㅠ

o- - 000

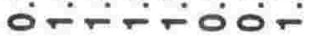

옹ㅇ

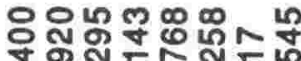
$00-0000$

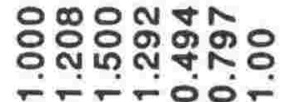

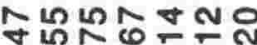
ป 0000000
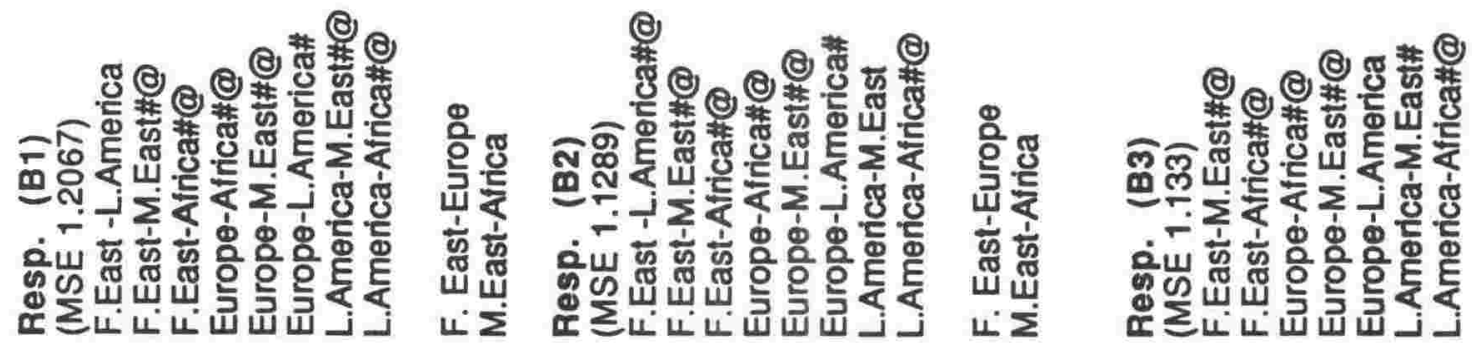
ะับังินค์

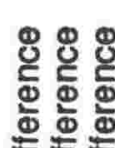

o-

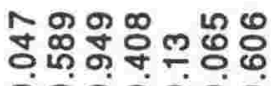

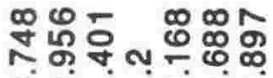

ำํํำ 000000
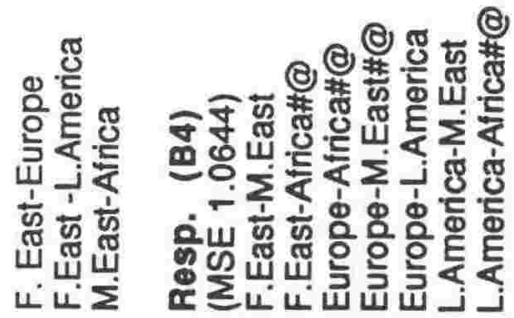
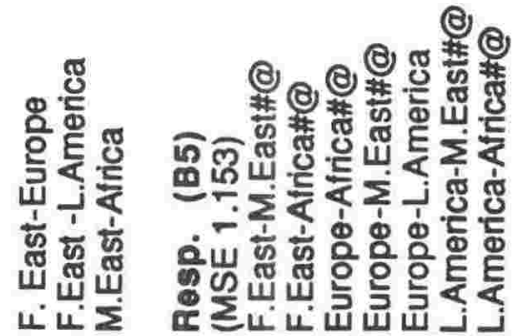
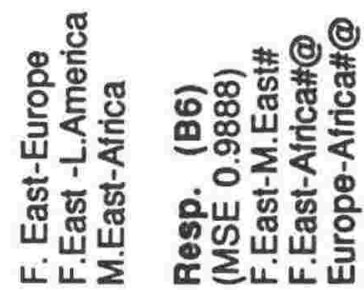


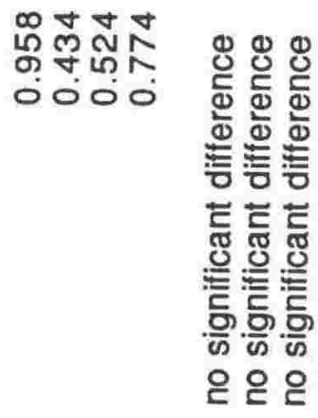

ஜฒำ ำ $00^{\circ} 0^{\circ}$
유ำ

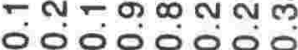

以ே $000-100$

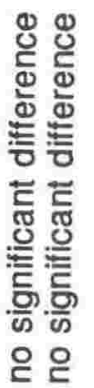

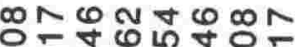
बढ़ लिख $000-5000$

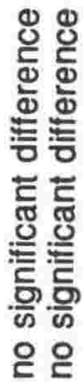

m N ড় $000-0000$
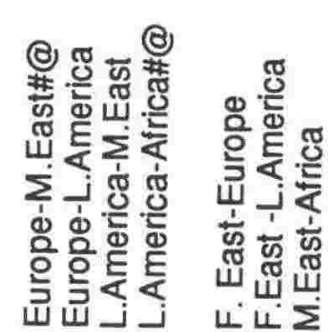

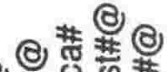
(ㄷ) \#.을

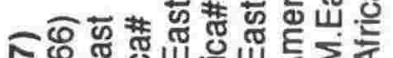
๓ - $\sum \frac{1}{1}<\sum_{1}$

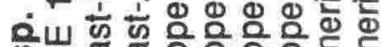

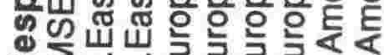

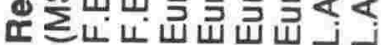

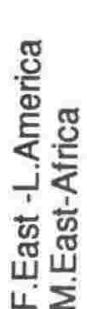

(8)

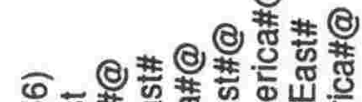

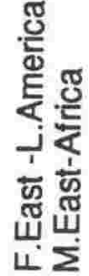




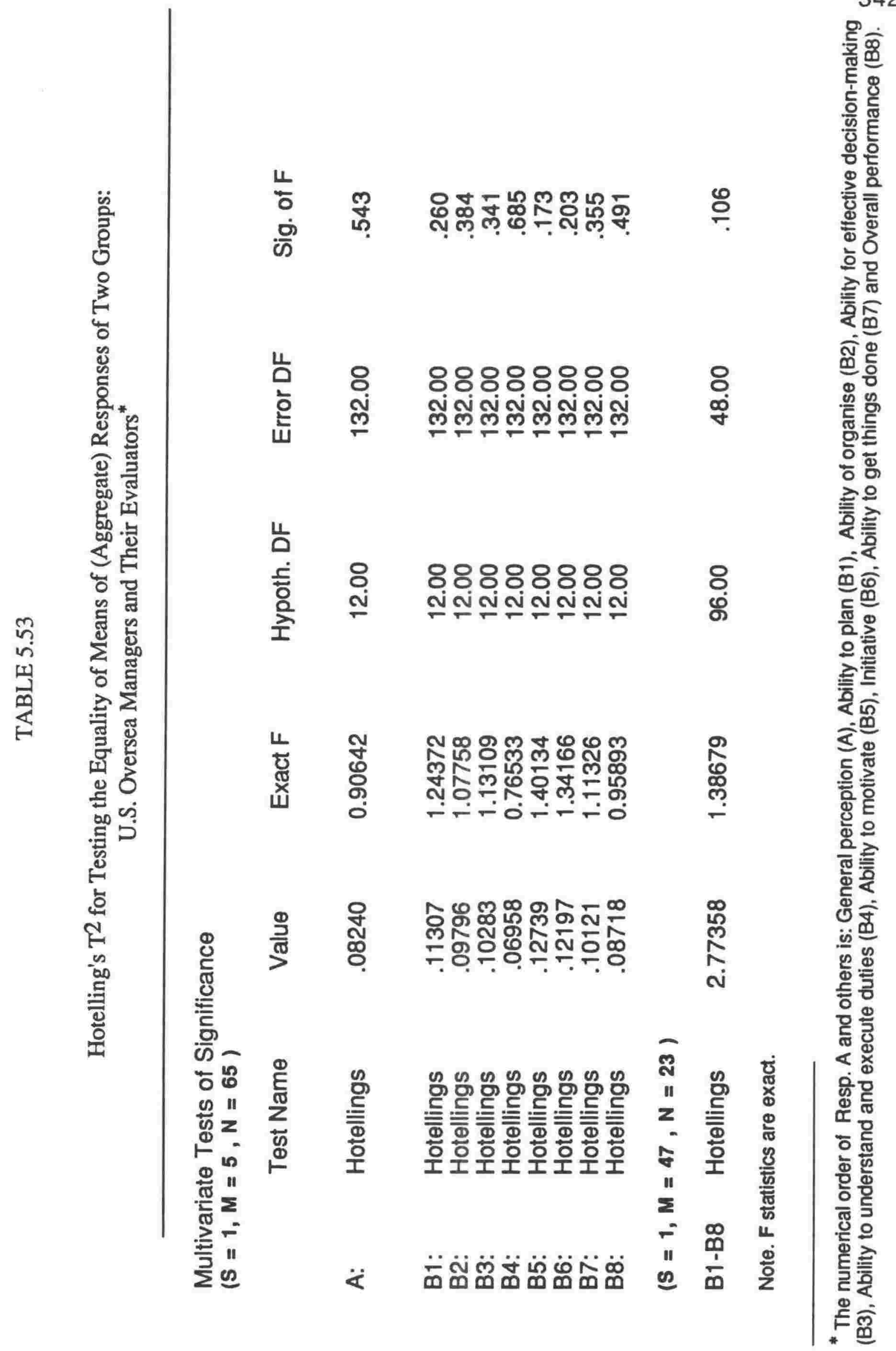




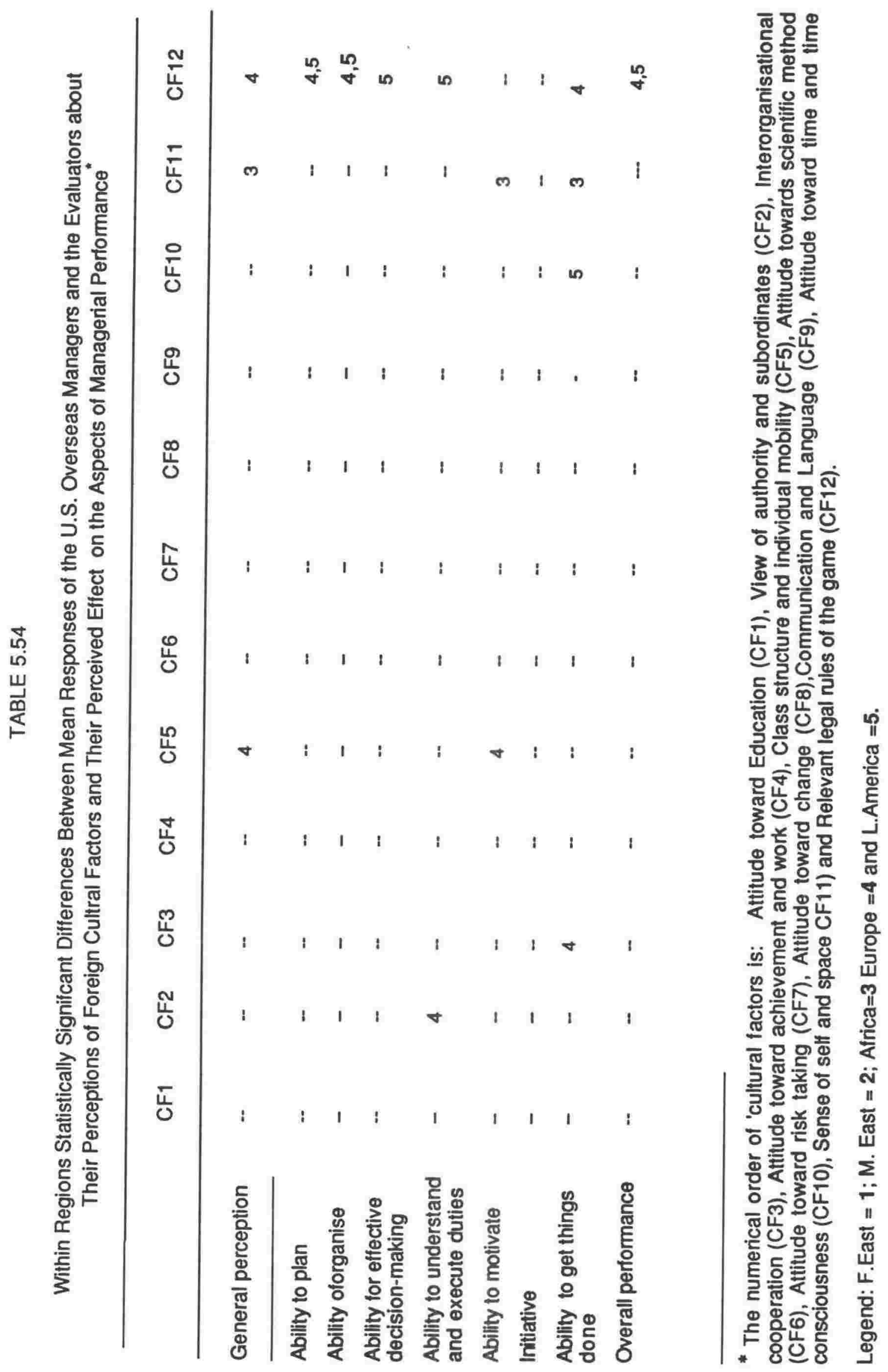




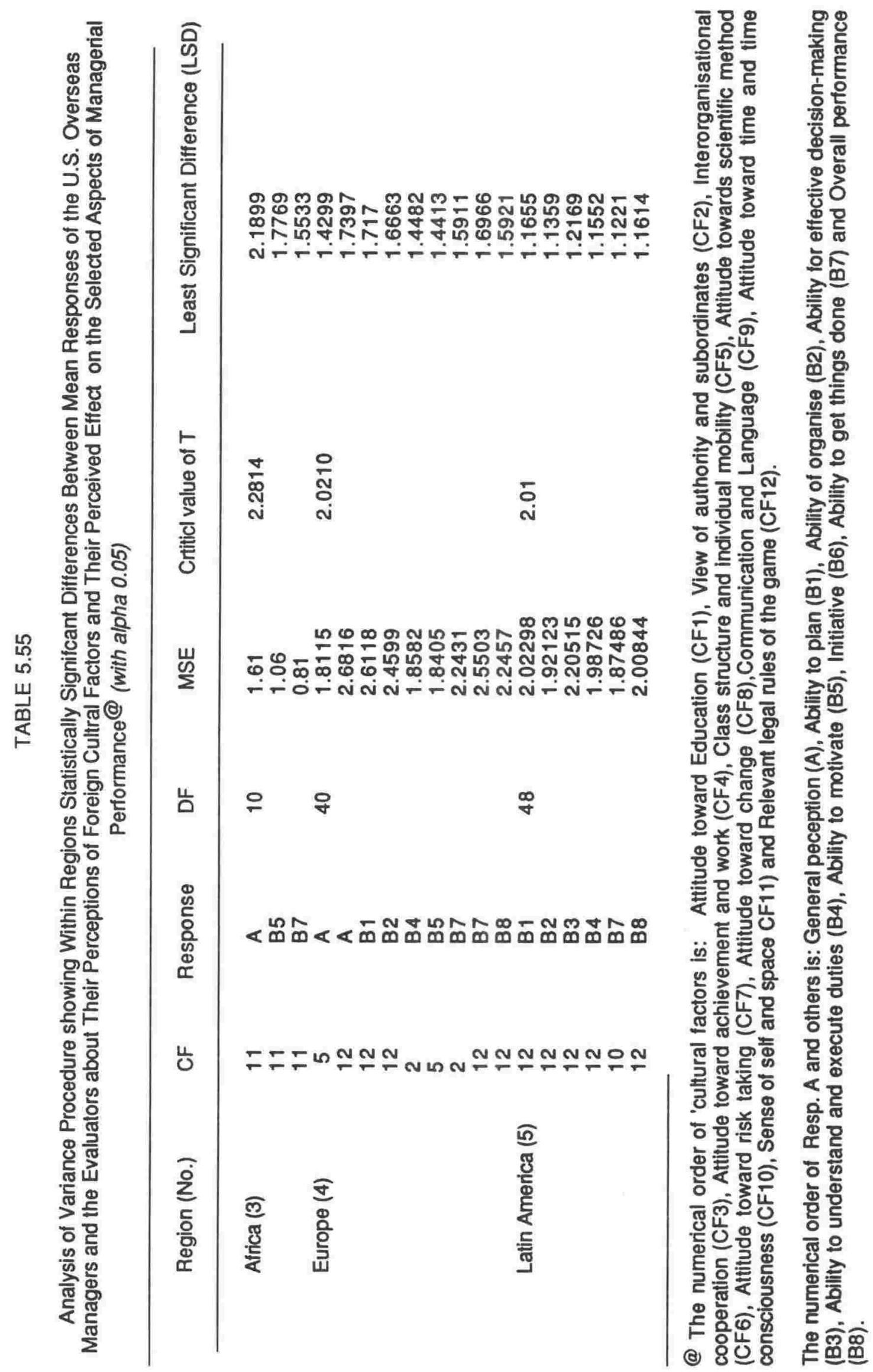




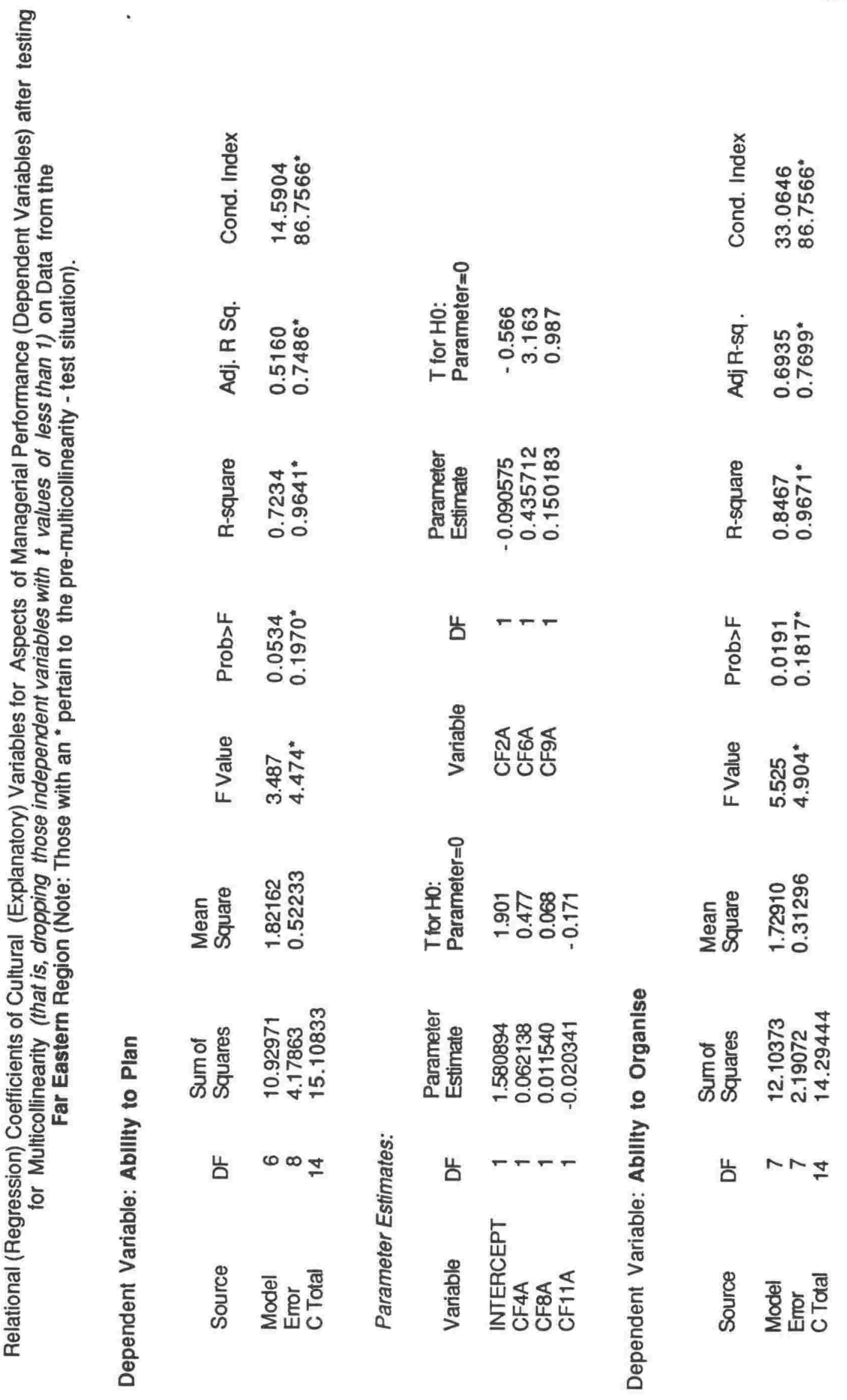




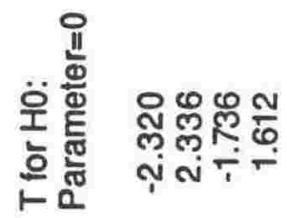
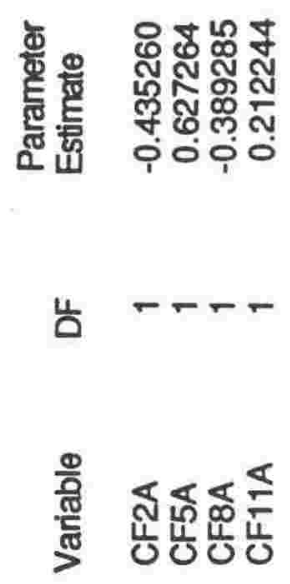

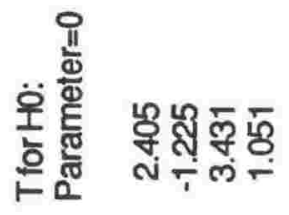
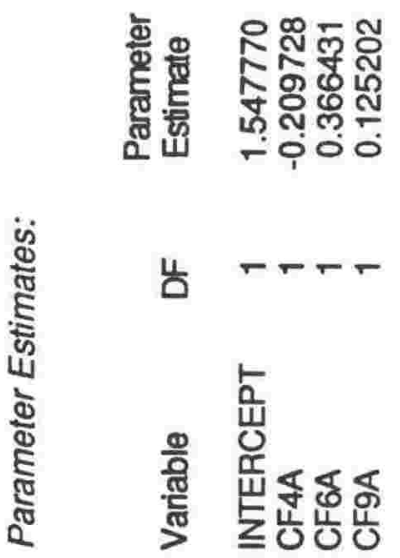

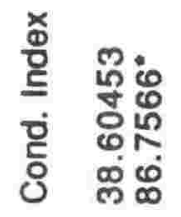

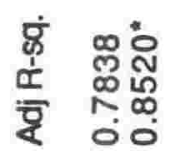
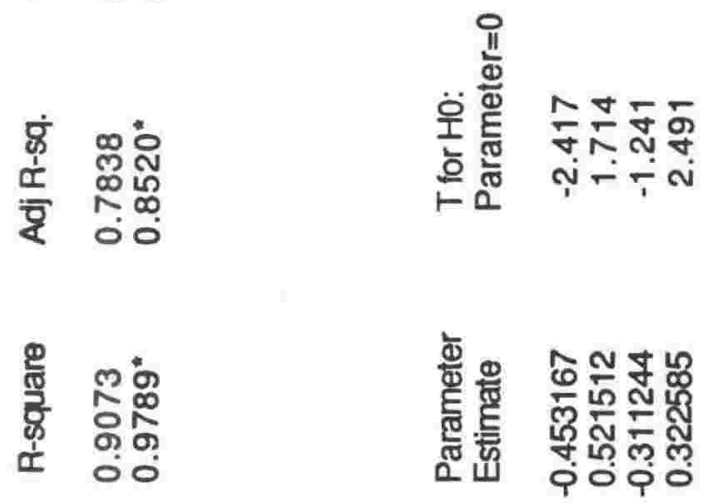

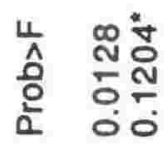

㟔

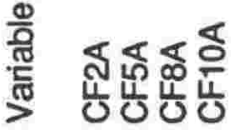

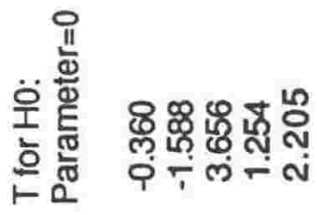

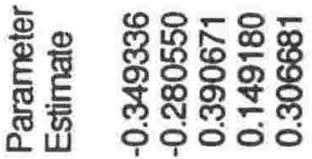

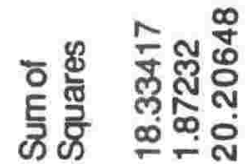

䓃 $\infty 0_{\square}$

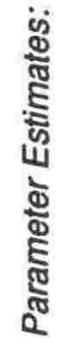

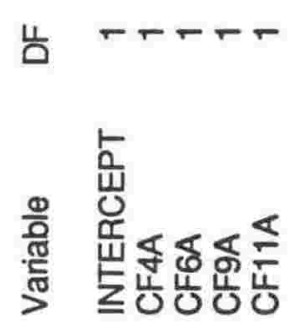




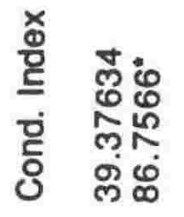

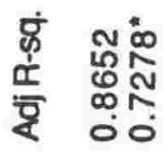
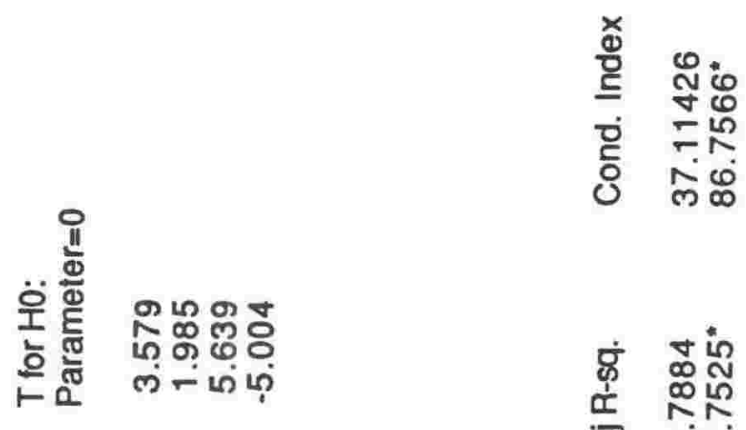

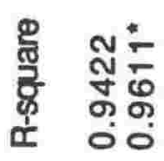

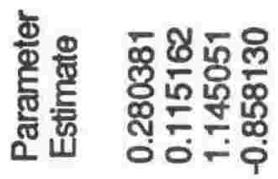

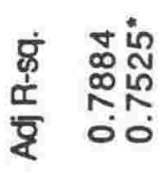

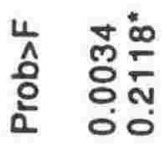

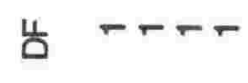

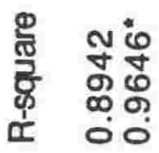

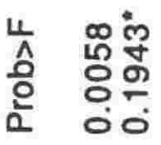

ฏ

产

$\sum_{4}^{\frac{10}{10}}$

บัّ

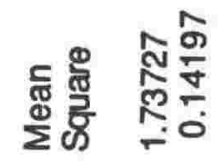

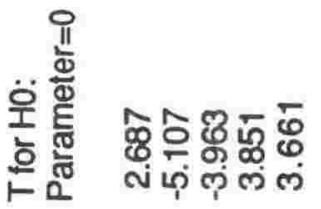

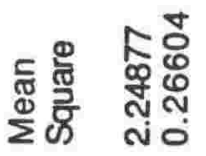

를

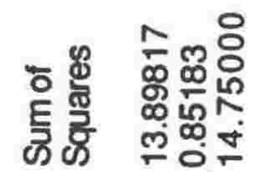

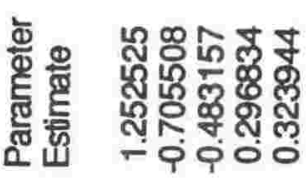

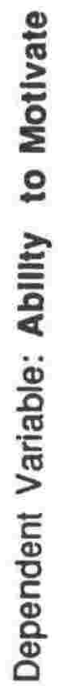

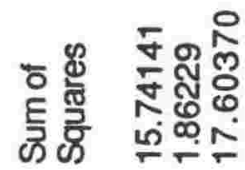

㟔 $\infty 0 y$

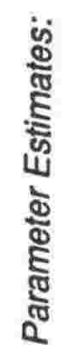

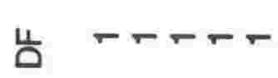

㟔 Nー

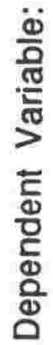

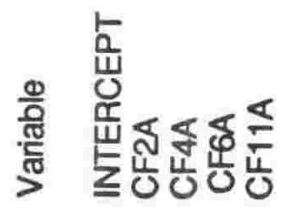

\& 홍 혼흔

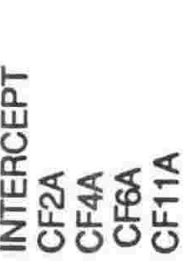




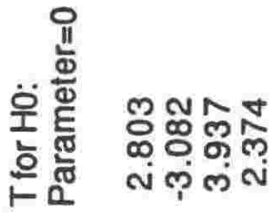
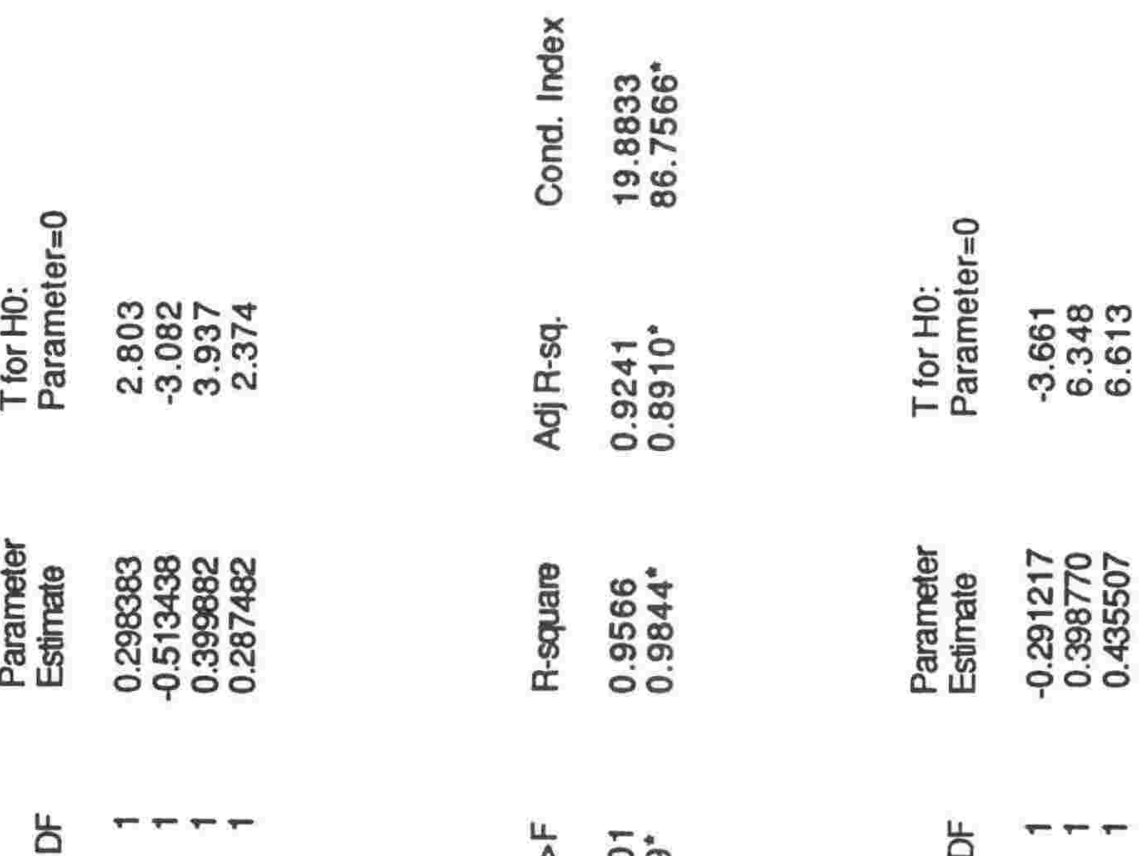

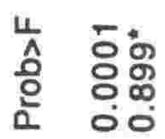

产

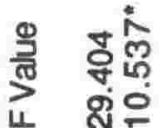

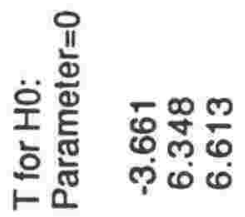

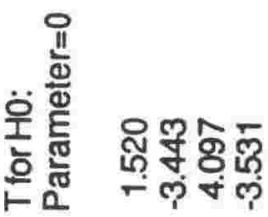

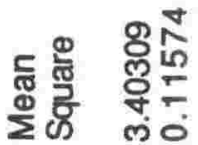
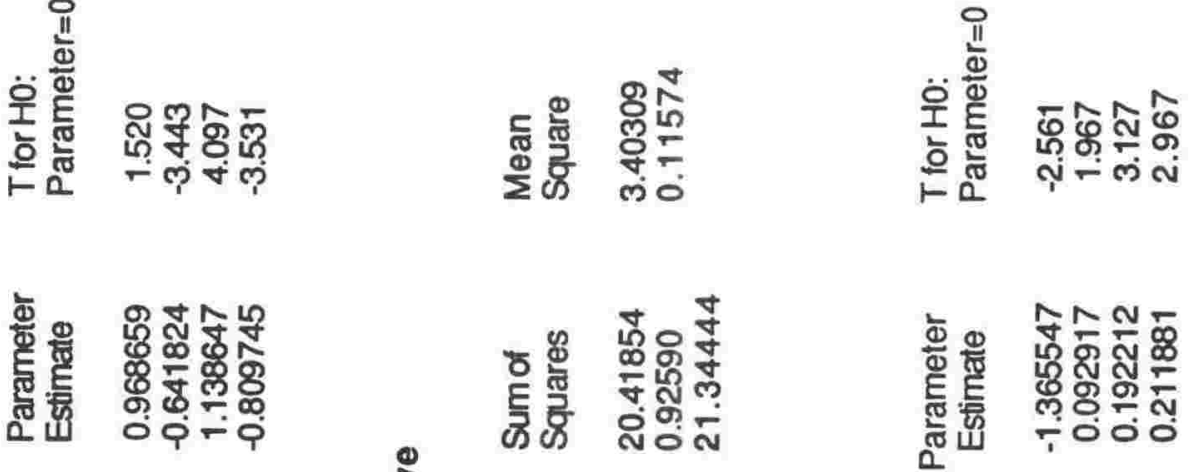

岁 $-\pi$

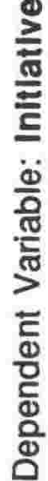

$400 \%$

ญ்

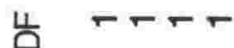

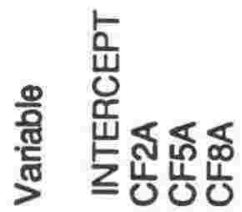

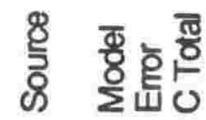

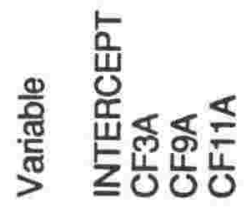




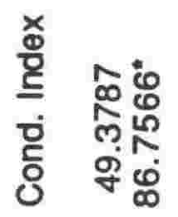

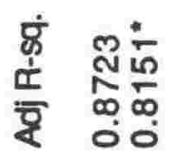

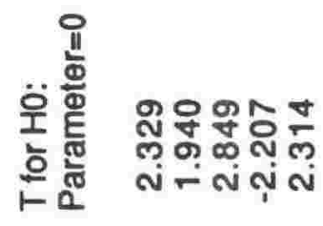

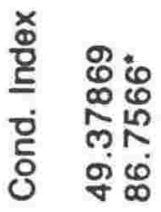
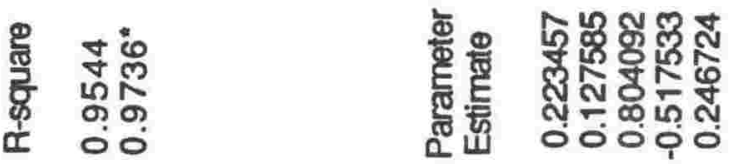

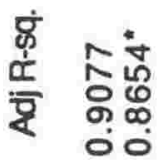

总

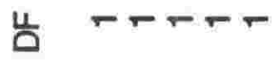

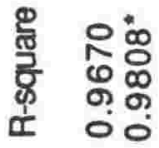

楚

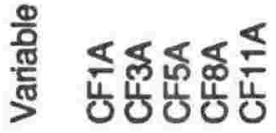

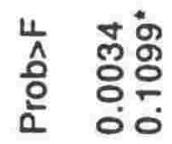

疍

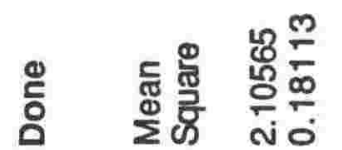

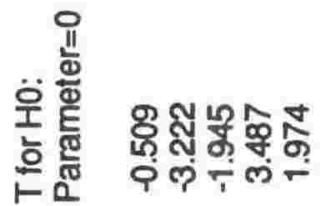

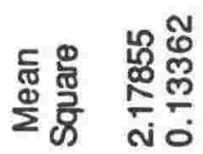

煦

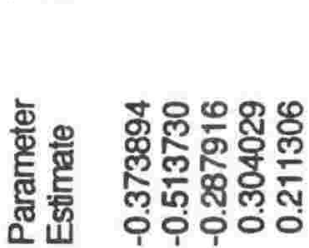

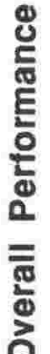

பั口 のே

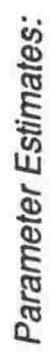

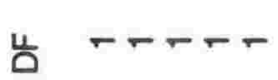

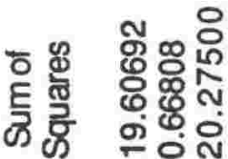

ऊँ ळ\%

แั

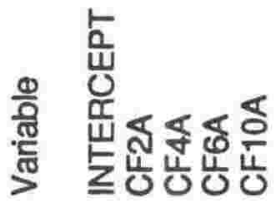

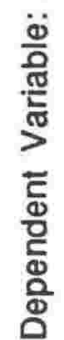

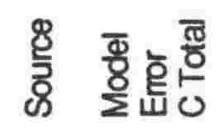




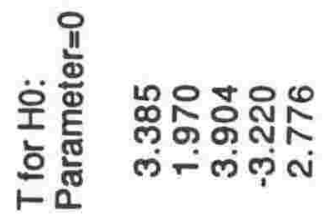

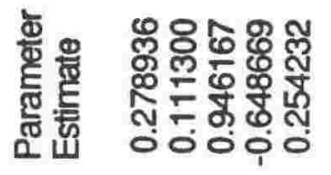

㟔

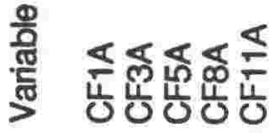

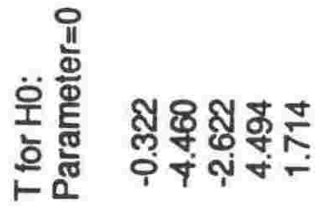

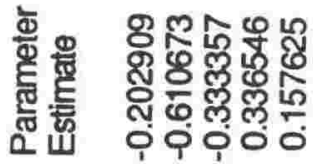

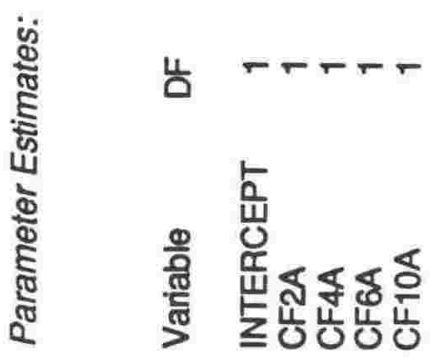


을

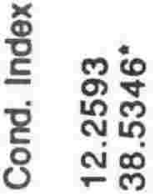

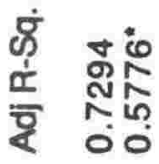

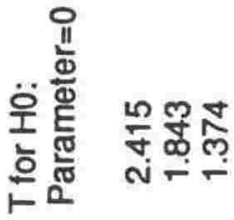

产

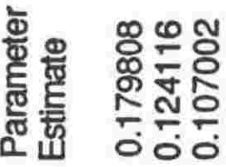

둥

호응

os

응으

in 8

i 흔형

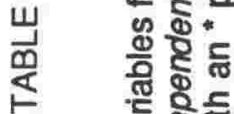

离 융

政:

은 온

응

뚱형

옹등

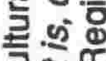

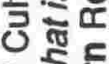

응등

옹류

ट्亏

응흐

응

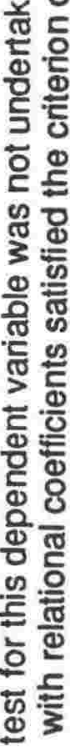

놓

4

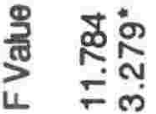

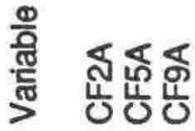

듬 害

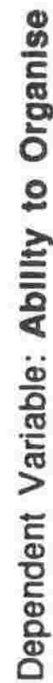

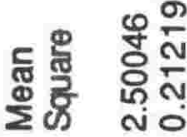

全竞要

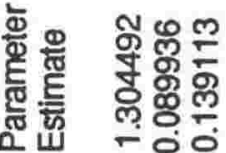

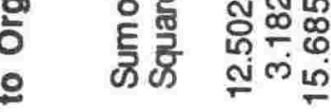

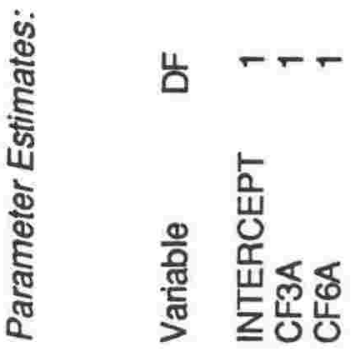



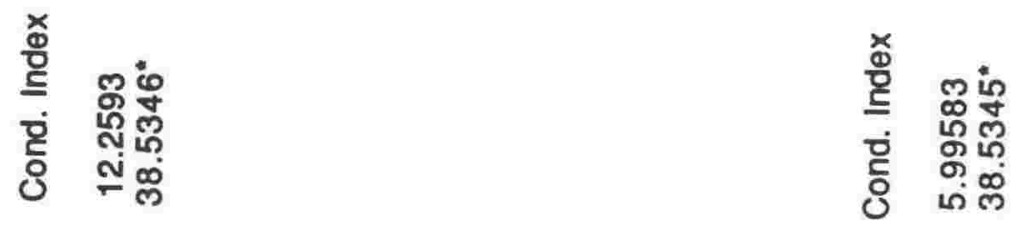

要
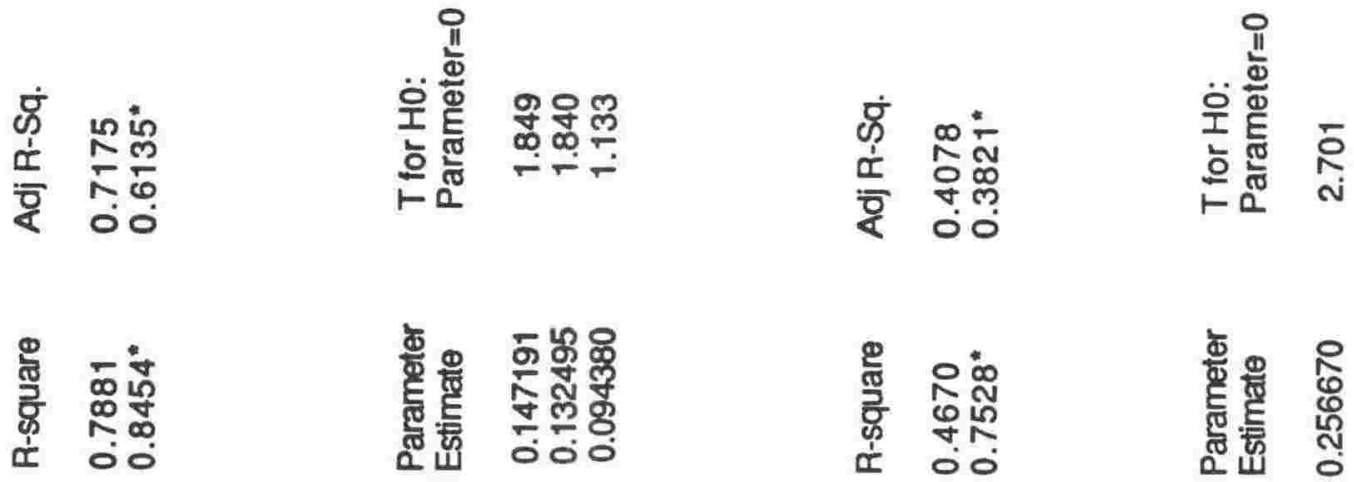

능 융

㟔

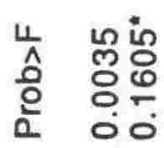

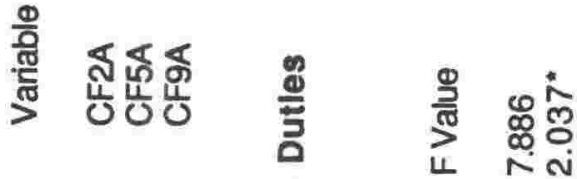

产 缶

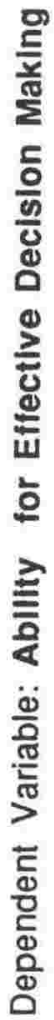

แ

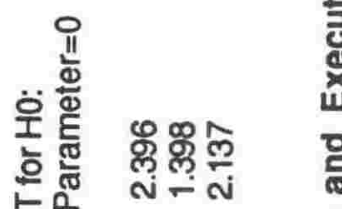

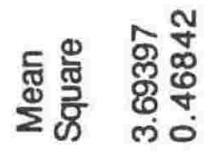

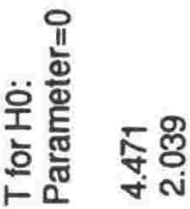

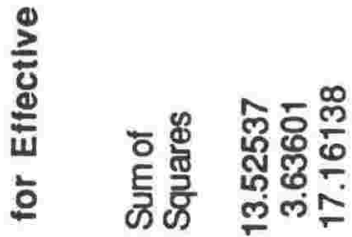

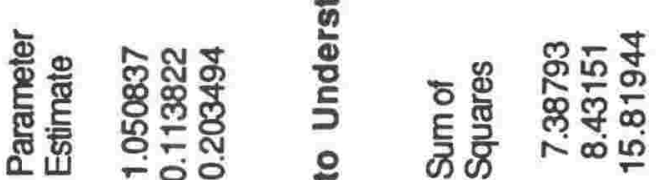

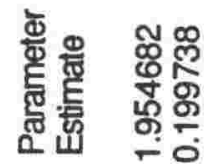

ㄴำำ

के

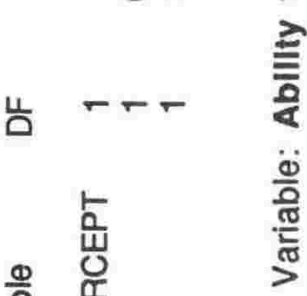

\&

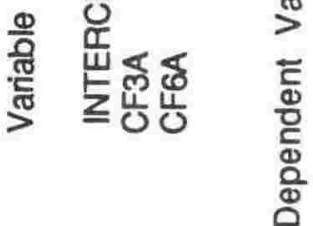

\&

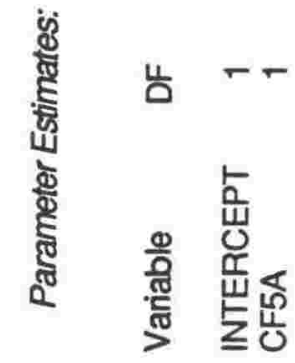




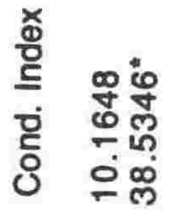

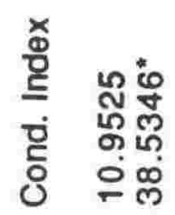

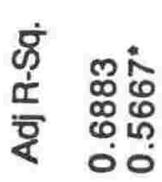

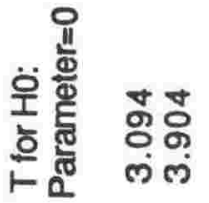

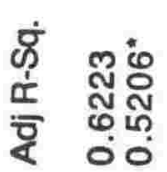

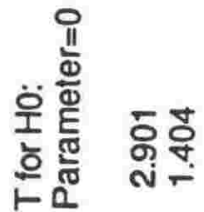

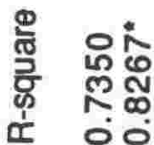

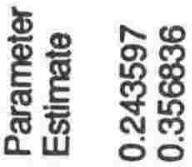

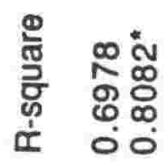

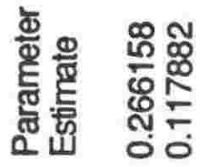

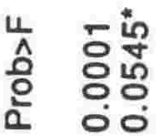<smiles>[CH-][AsH]</smiles>

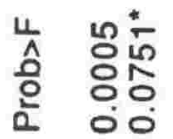

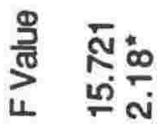

黄 感岌

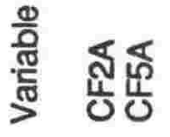

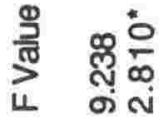

㟔 -

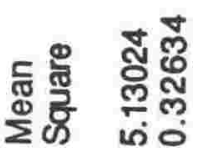

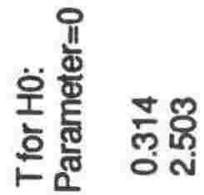

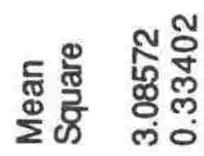

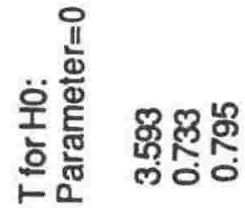

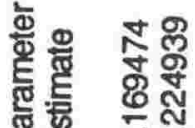

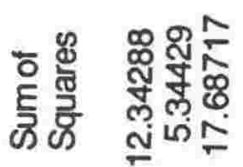

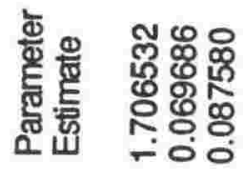

कर फ़ं

○出 ธ。

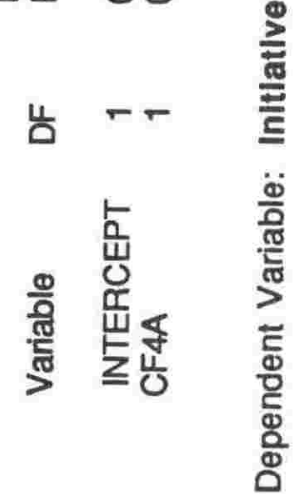

u - 离

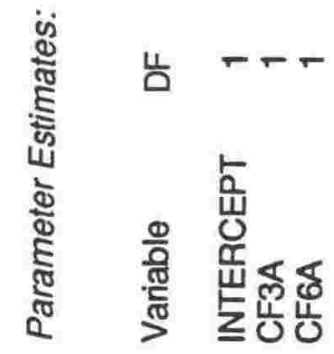

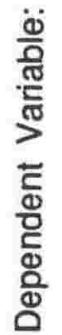

แ

\& 

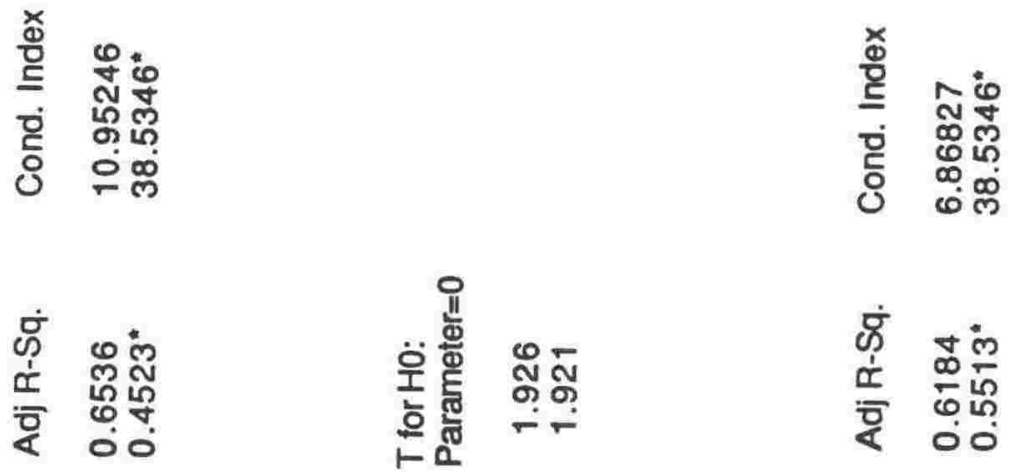

委

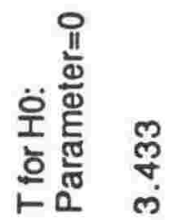

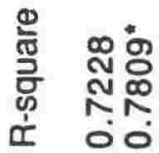
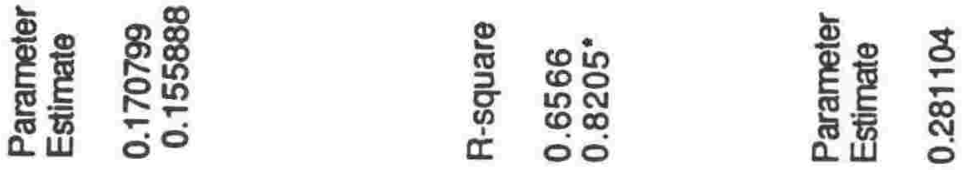

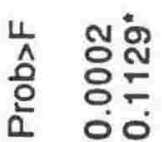

4

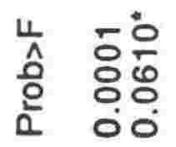

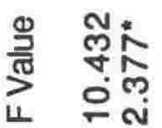

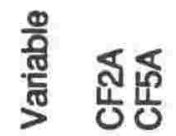

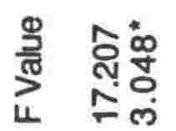

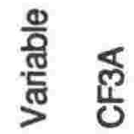

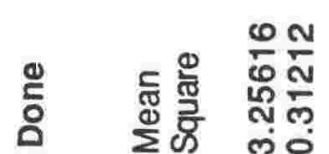

全璦

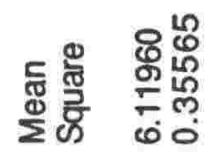

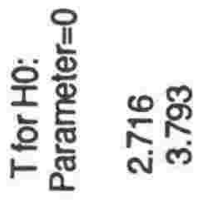

을

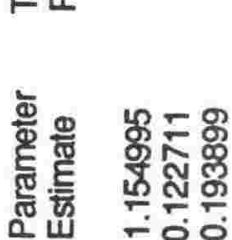

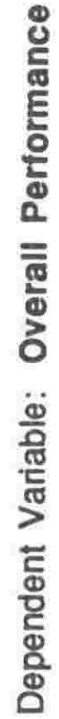

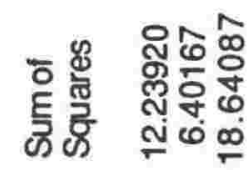

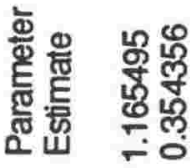

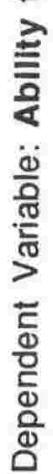

แั

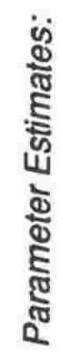

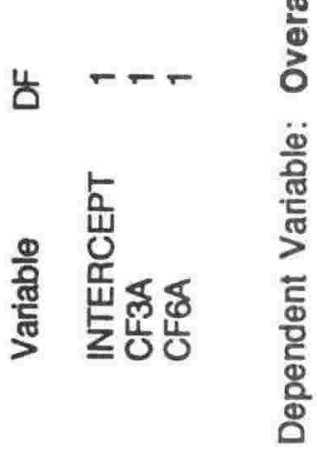

แับ

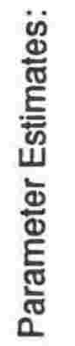

告 -

\&

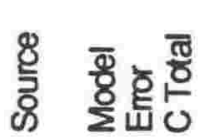

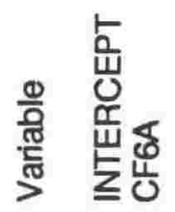



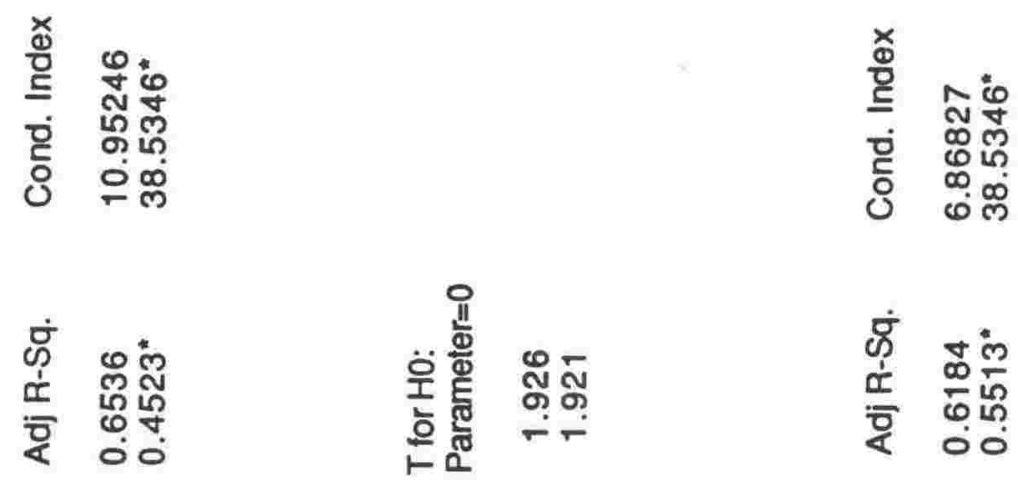

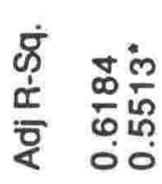

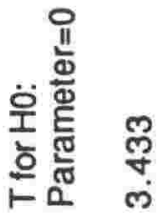

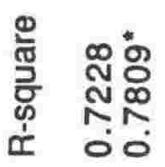
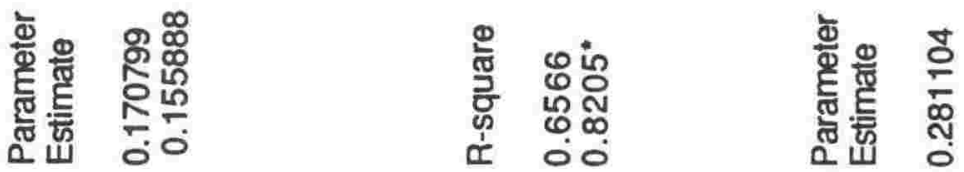

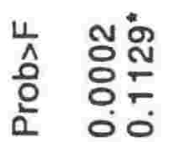<smiles>[13CH3]I</smiles>

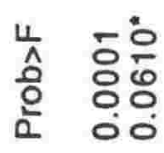

告 -

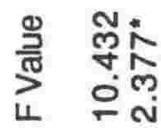

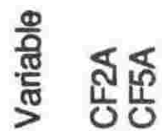

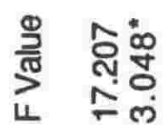

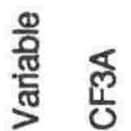

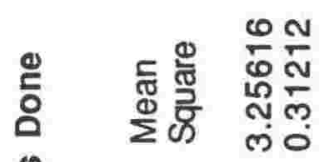

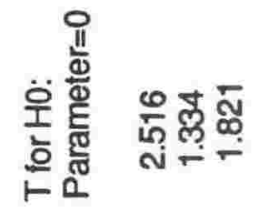

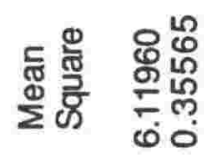

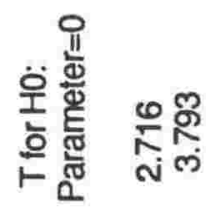

을

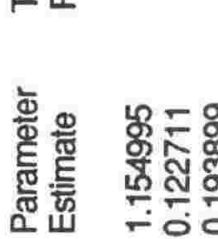<smiles>O=C=C=[Os]</smiles>

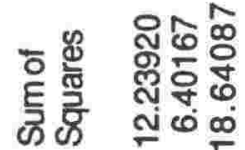

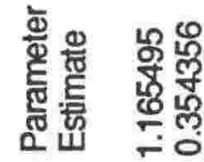

2

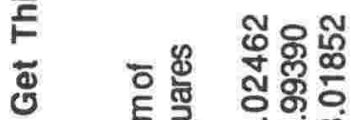

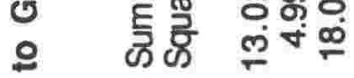

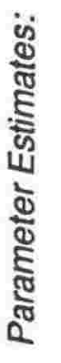<smiles>[13CH]=[13CH][Se]</smiles>

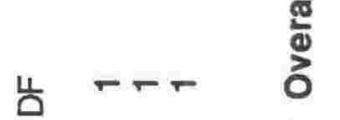

แน Nœ요

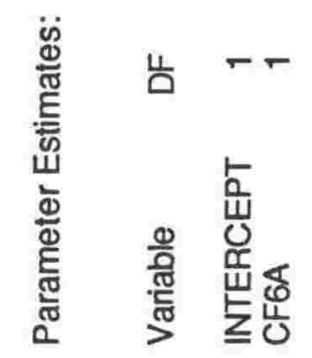

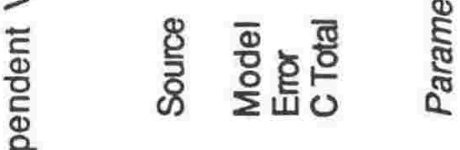

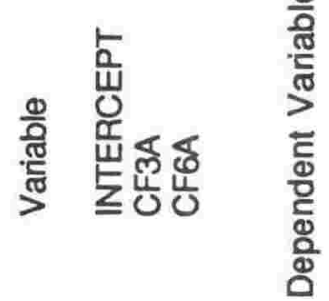

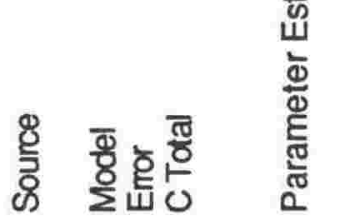


옿

ङ

क

들

홍

ญั้

등흐

政

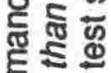

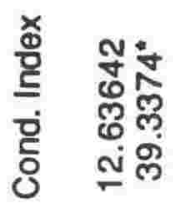

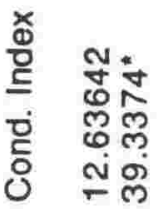

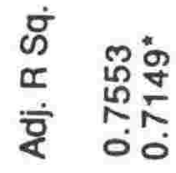

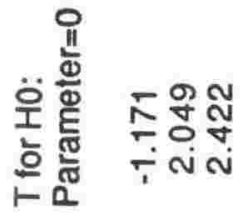

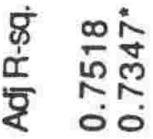

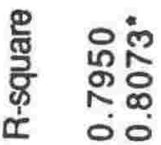

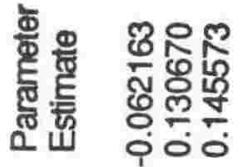

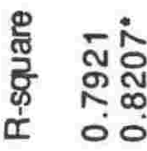

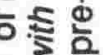

용

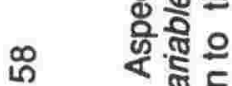

เก 흔

山 츙

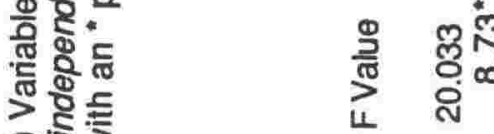

능

告

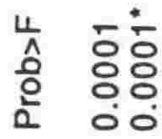

产

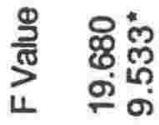

응요

뜽 은

씅흐응

त 음

흑 는흥

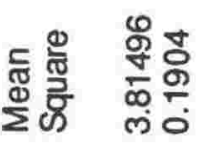

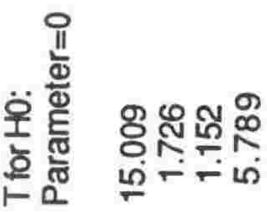

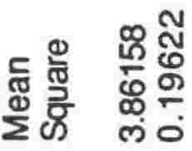

응 꼰

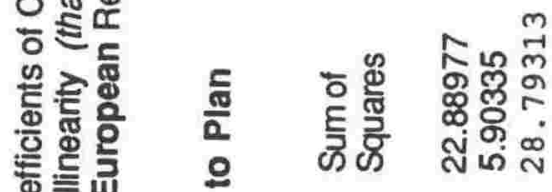

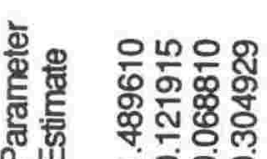

兽

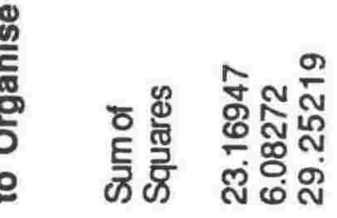

ठํ.

든

㟔 बह

- 000

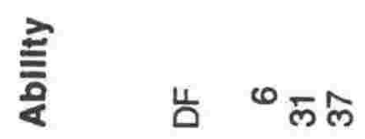

옹

نे

㟔 - - ミ

㟔

을

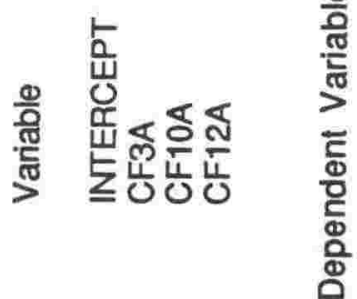

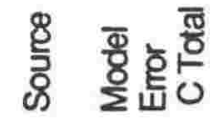




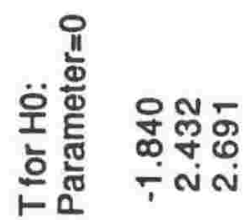

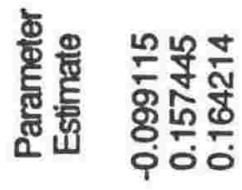

告

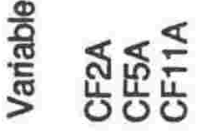

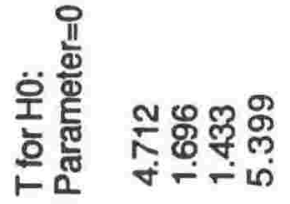

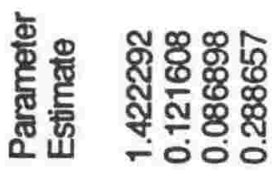

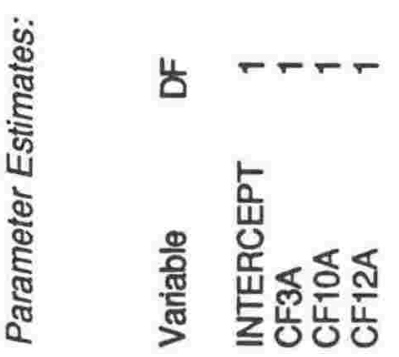

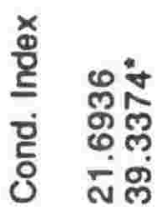

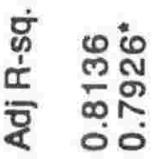

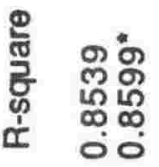

능

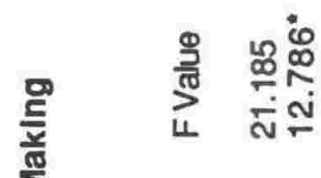

흔

竎

흔

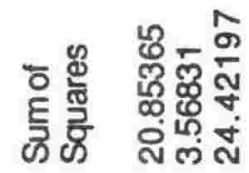

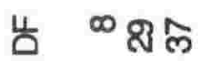

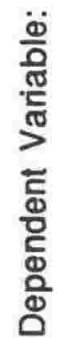
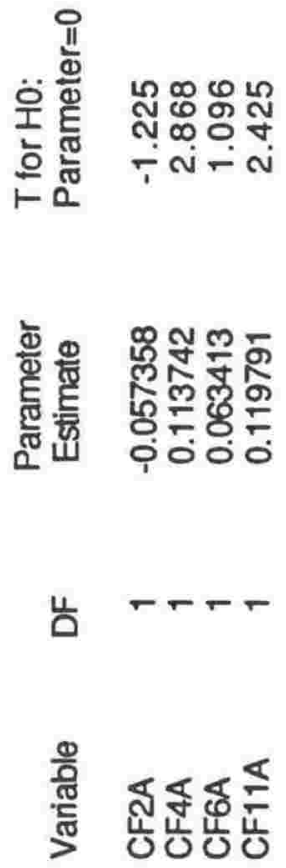

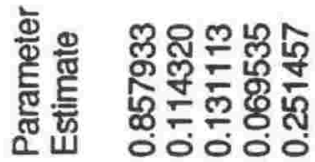

言

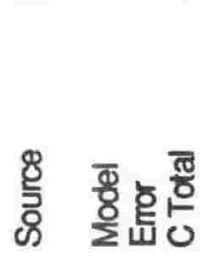

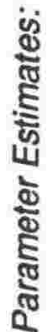

㟧

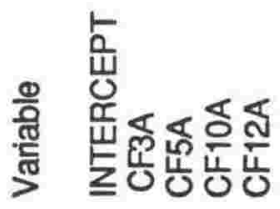




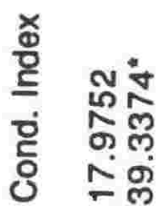

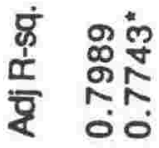

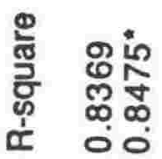

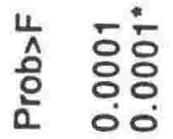

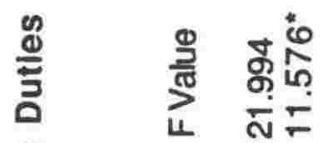

苛

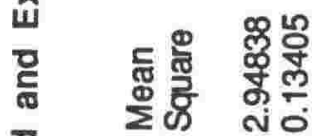

흘

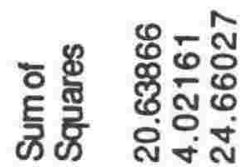

पू ग्लेल

\&

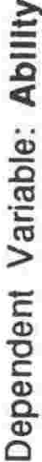

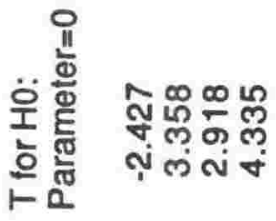

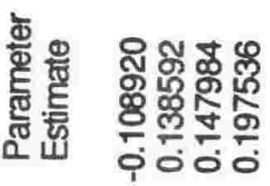<smiles>[Te][As]=[Te]</smiles>

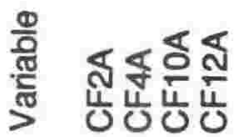

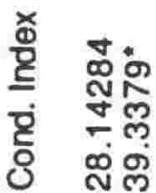

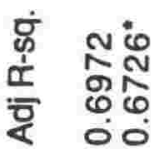

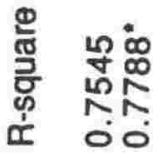

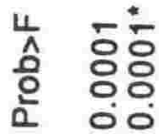

\.

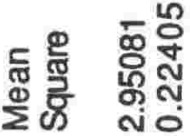

产

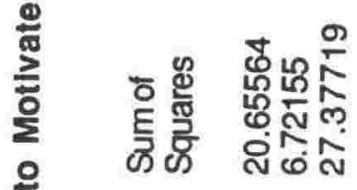

㟔 --

㟔 유요

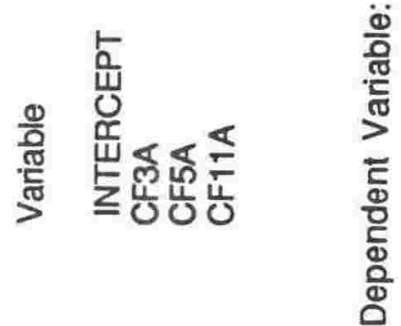




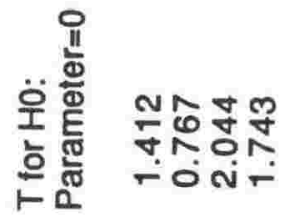
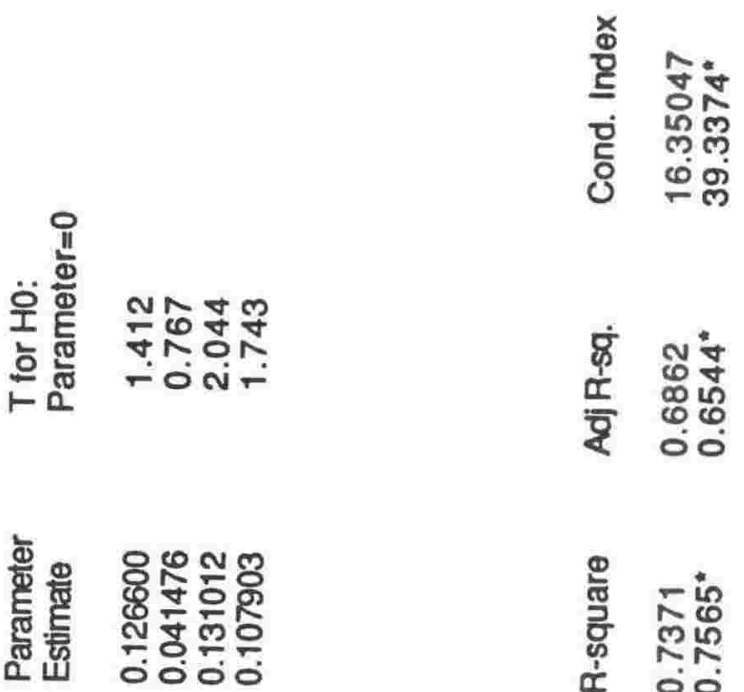

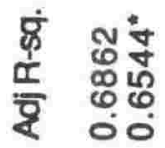
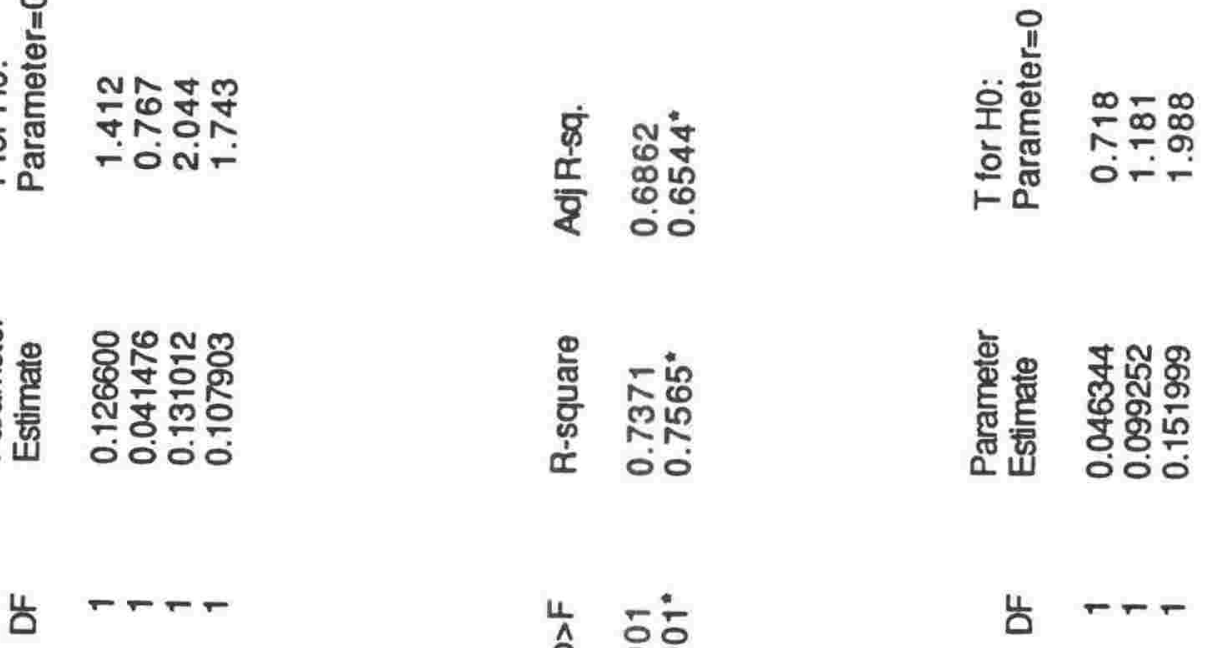

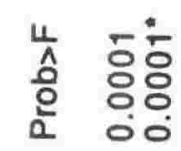

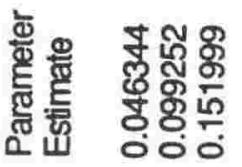

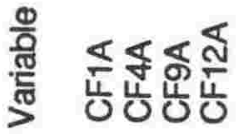

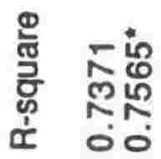

㟔

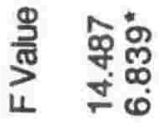

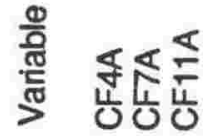

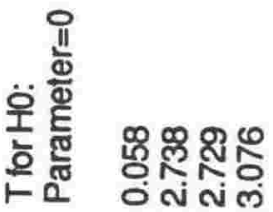

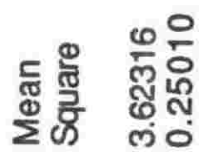

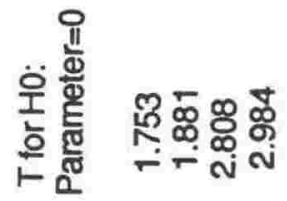

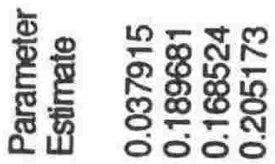

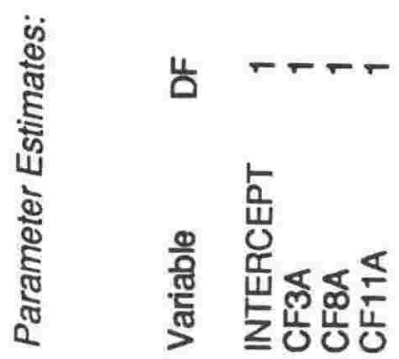
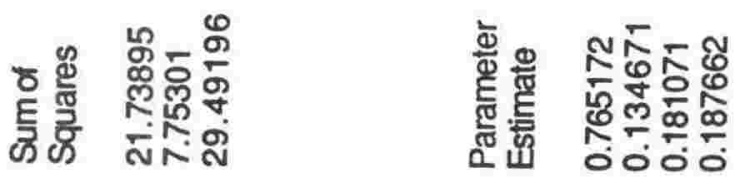

㟔 एहल

के

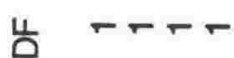

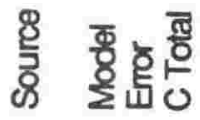

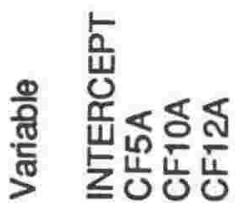



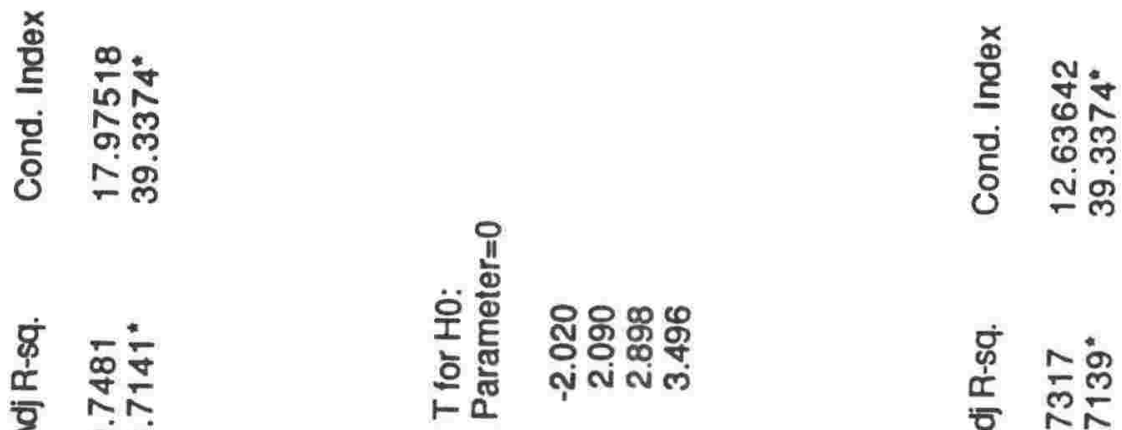

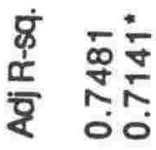

ำ ํํำ

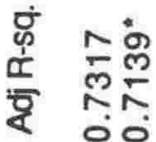

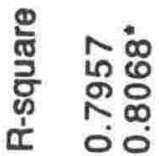

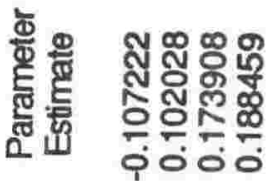

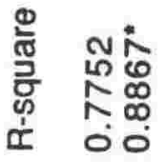

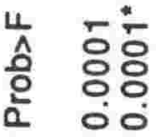

㟔

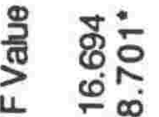

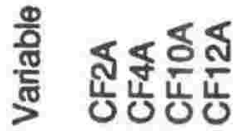

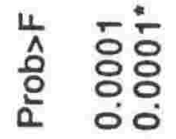

疍 N

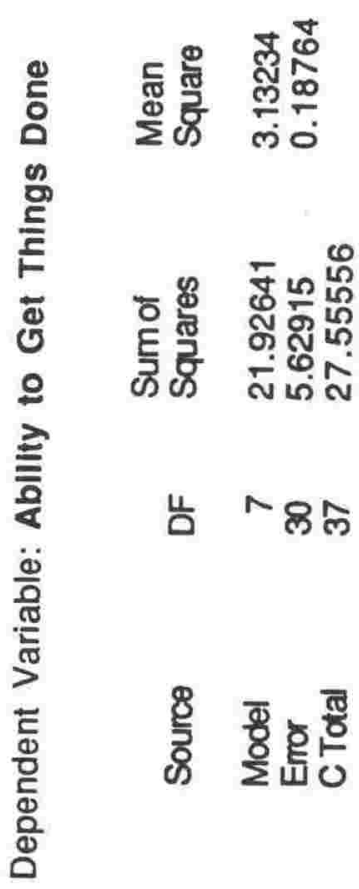

운

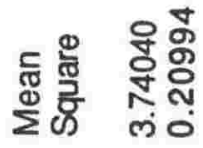

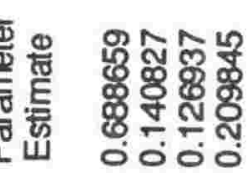

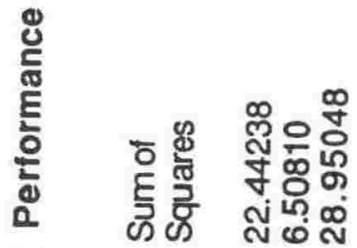

㟔

पू हले

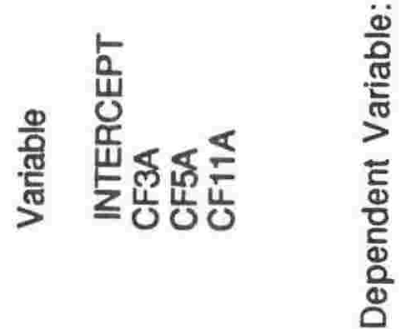

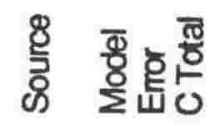




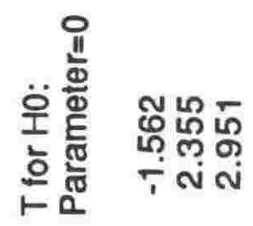

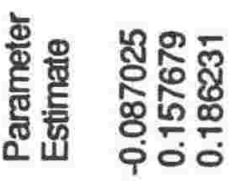

u $\cdots$

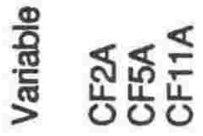

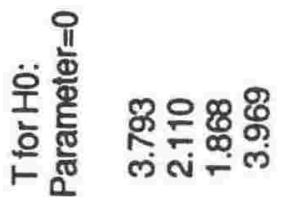

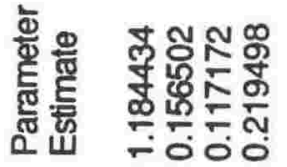

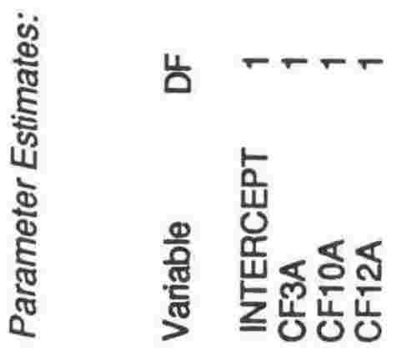




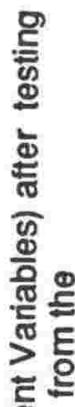

ه

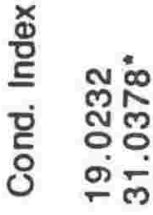

๑ั

응흫

주

듕

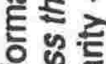

ㅇㅗㅇㅀㅀ

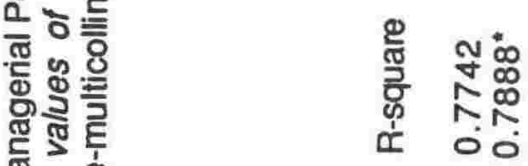

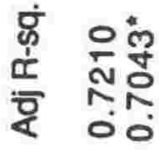

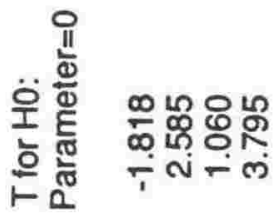

$\sum^{\pi}-0$

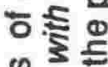

융

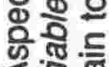

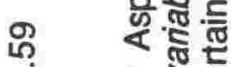

i 흥

山 홍휴

.

$>$.

ริㅇㅇㅇ

施

뜸 웡

뜽흔

진

姜这

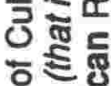

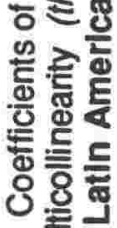

능 융융

㟔 r-

ए

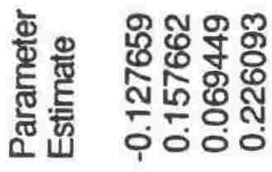

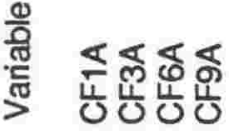

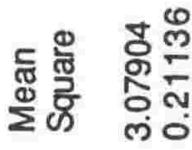

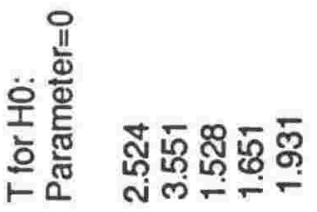

들

क응

:

들

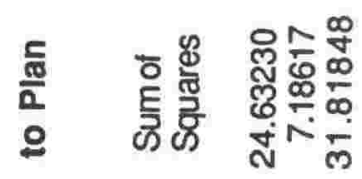

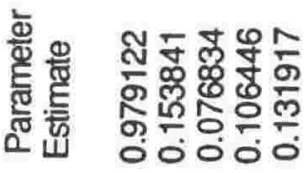

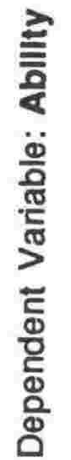

㟔 $\infty$ ॠ

कू

㟔

\&

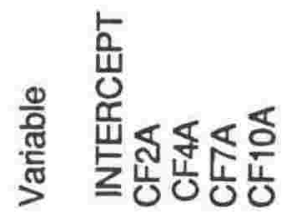




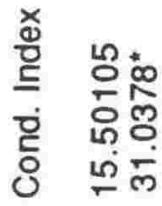

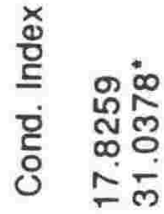

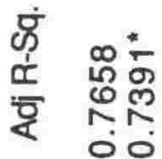

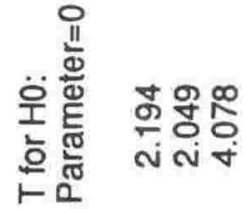

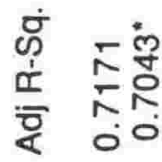

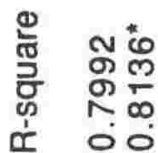
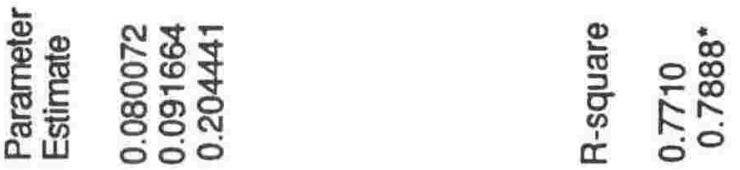

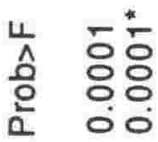

แ

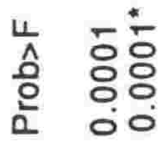

\.

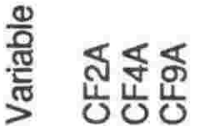

य

을

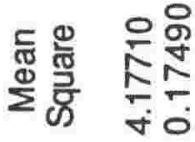

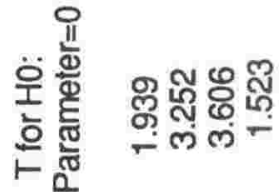

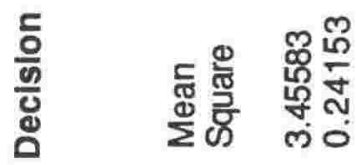

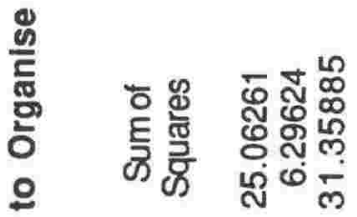

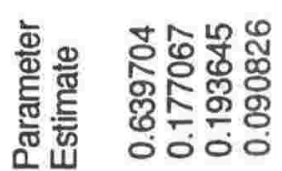

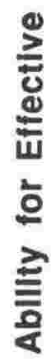

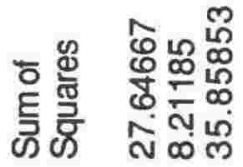

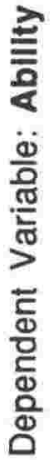

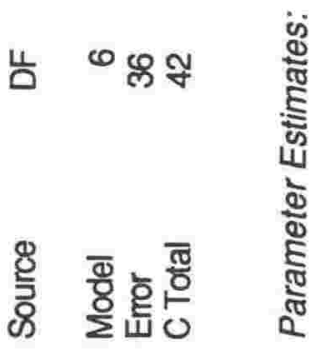

㟔 - - -

பั口 $\infty$ ॠ

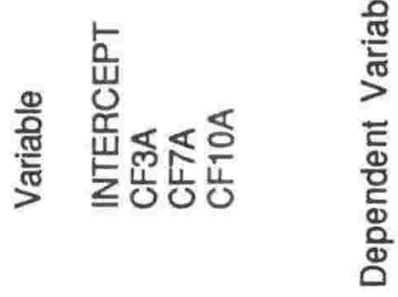

\& 

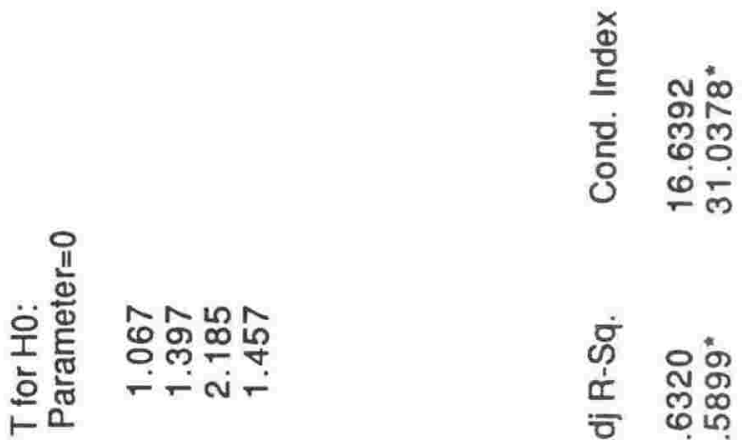

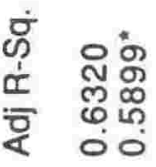
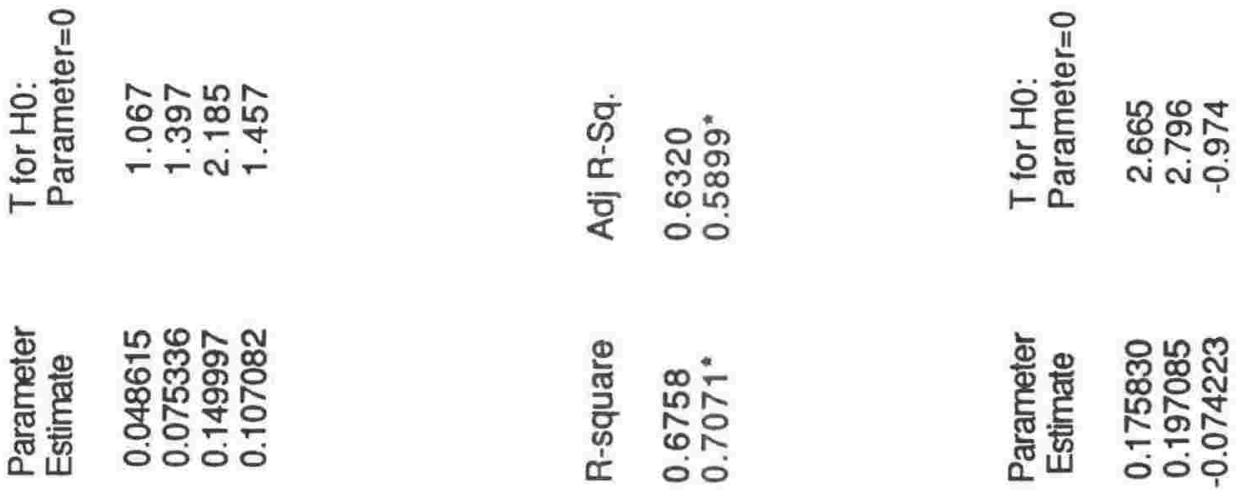

㟔

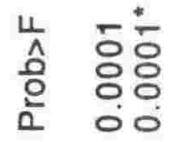

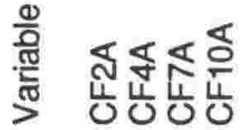

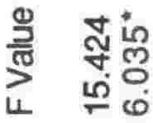

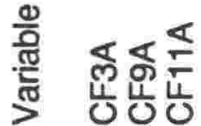

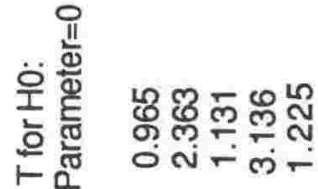

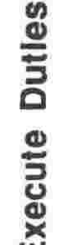

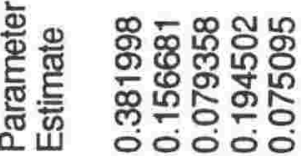

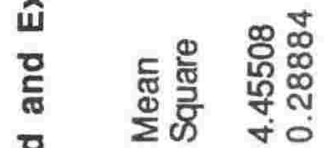

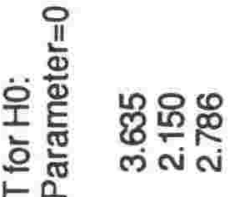

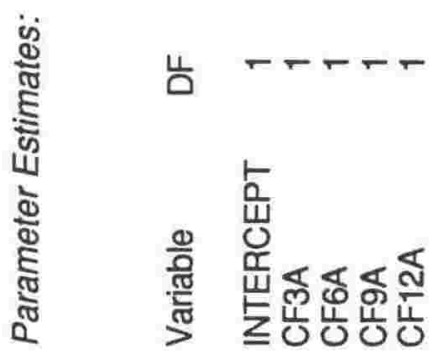

㟔 - -

등

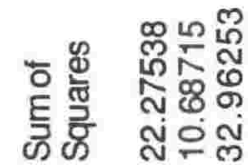

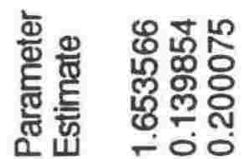

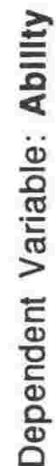

告 ผ ल พ

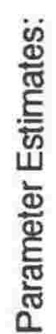

㟔

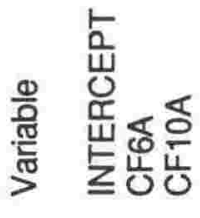



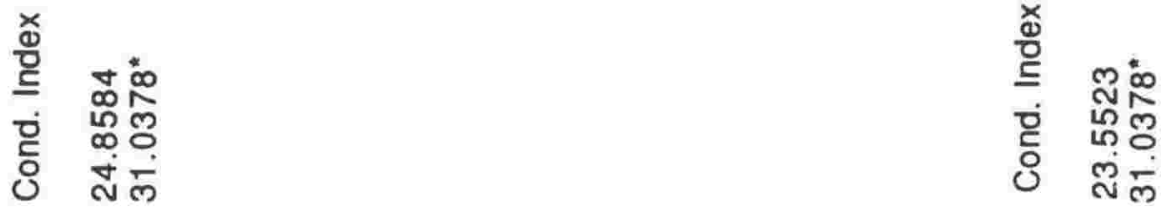

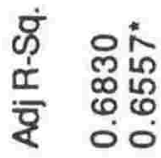

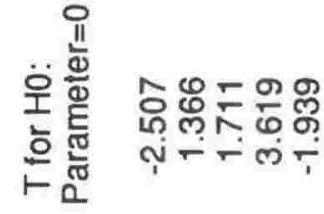

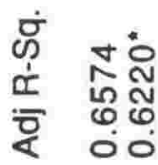
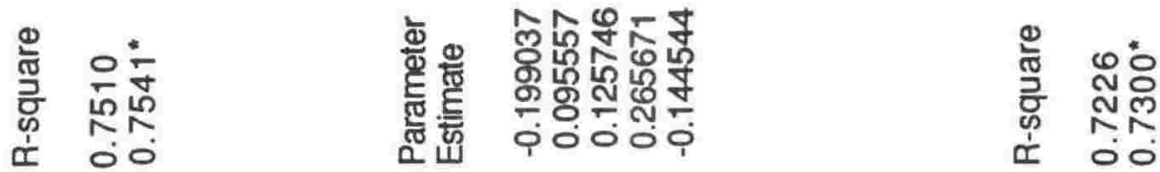

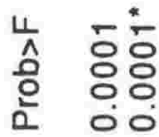

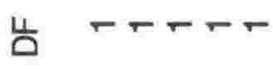

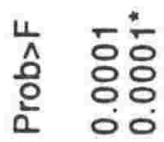

य
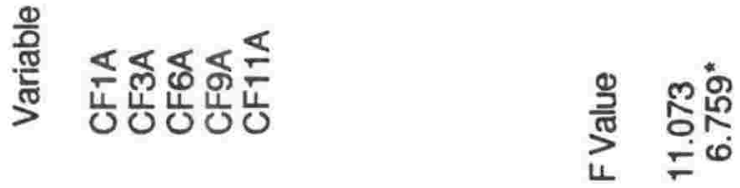

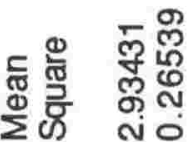

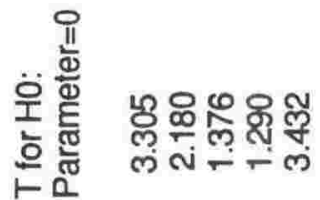

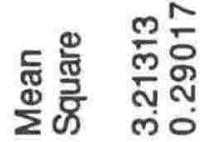

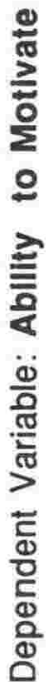
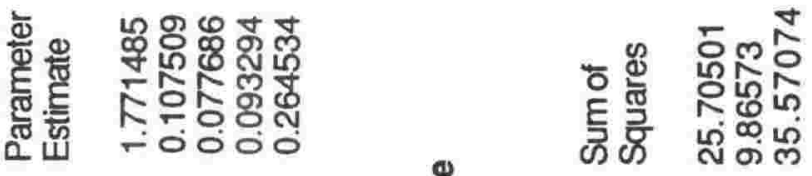

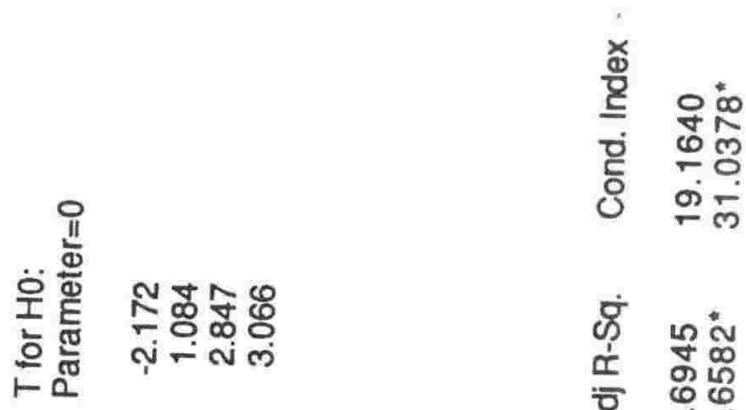

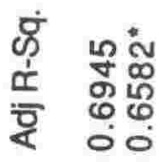

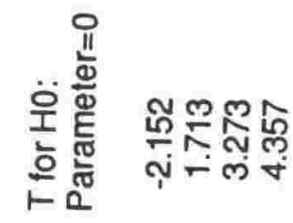

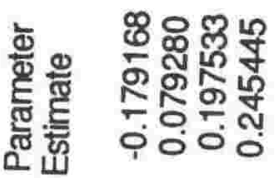
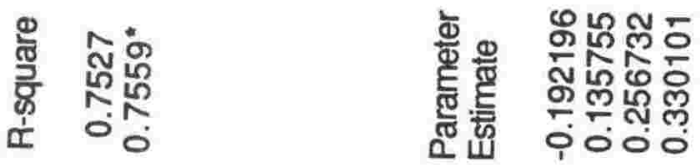

告 r.

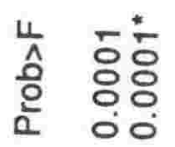<smiles>[Te][Te][Te]</smiles>

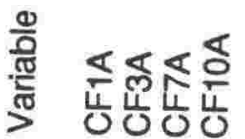
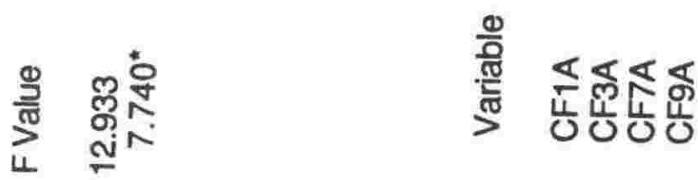

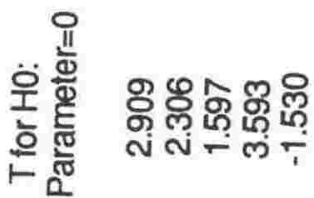

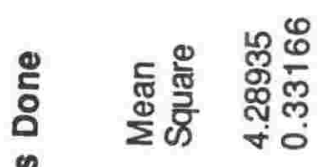

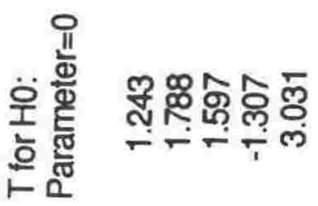

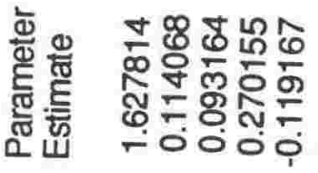

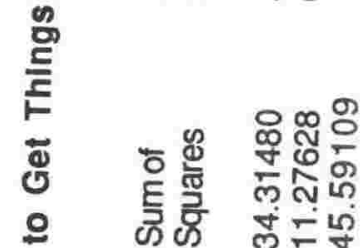

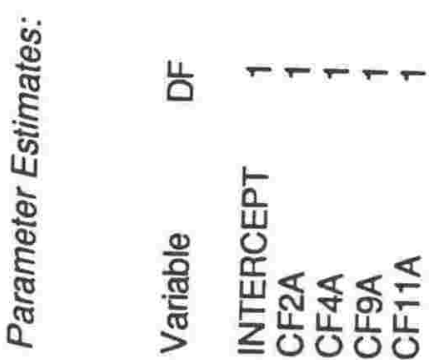

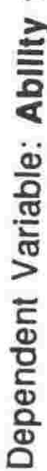

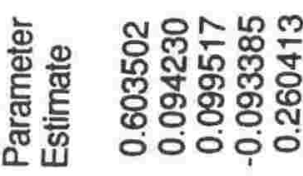

㟔 $\infty$ ल भ

ฏ

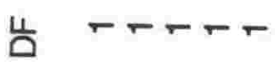

\&

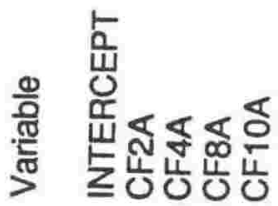




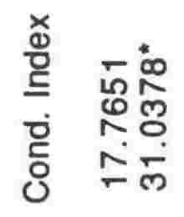

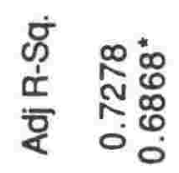

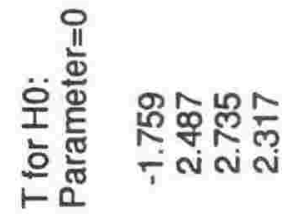

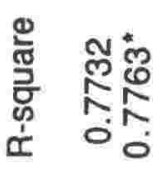

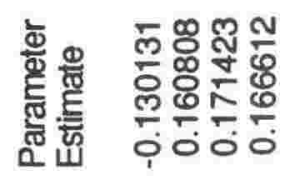

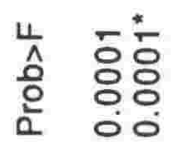

㟔

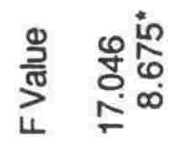

造

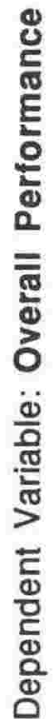

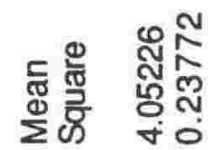

产产幖

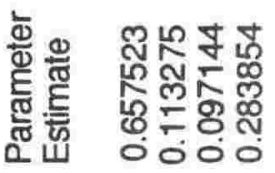

告 ヘே

离

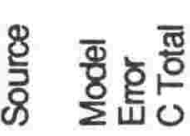

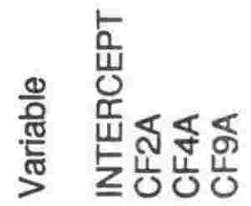




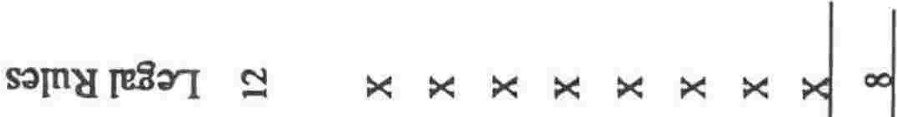

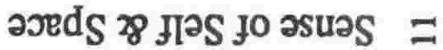

Ssəusnotosuo วuा!

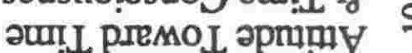

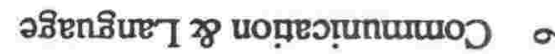

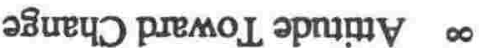

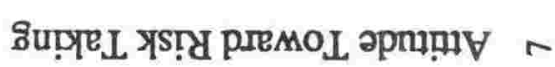

$x \times x \times x \times x x$

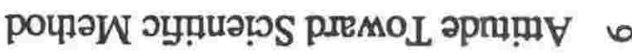

密

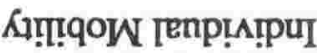

zo ampnns SSEโD

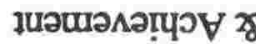

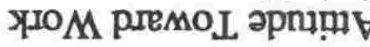

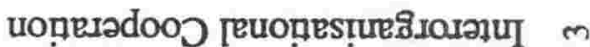

$x \times x, x$

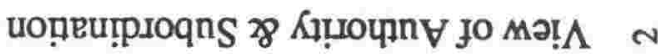

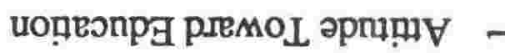

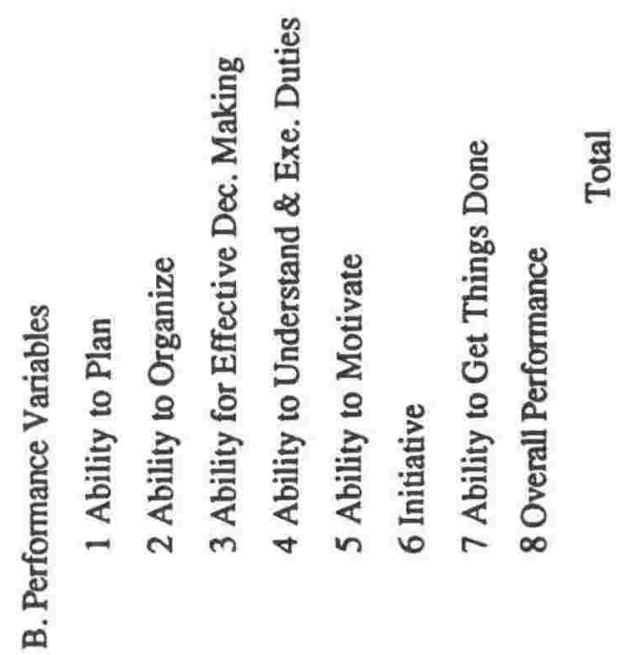




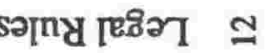

$x \times x \times x \times x+$

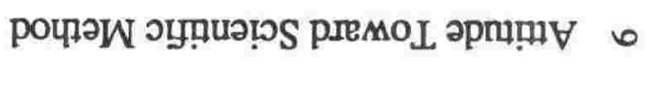

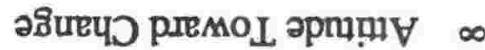

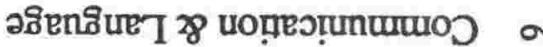

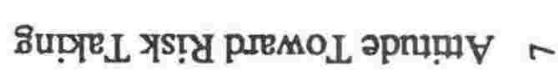

К!़ा!qoW [enp!̣ı!pu

28 amunns sse[D

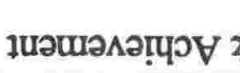

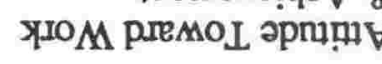

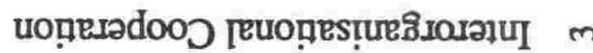

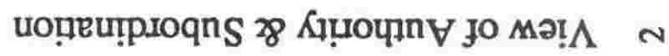

uọ̣eonpg premoL әрп!̣ -

in $x \times x \times x \times x$. 䒕

ญ.

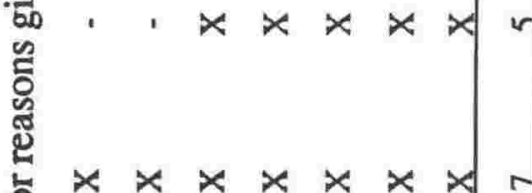

कू

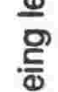

ฏ

늘
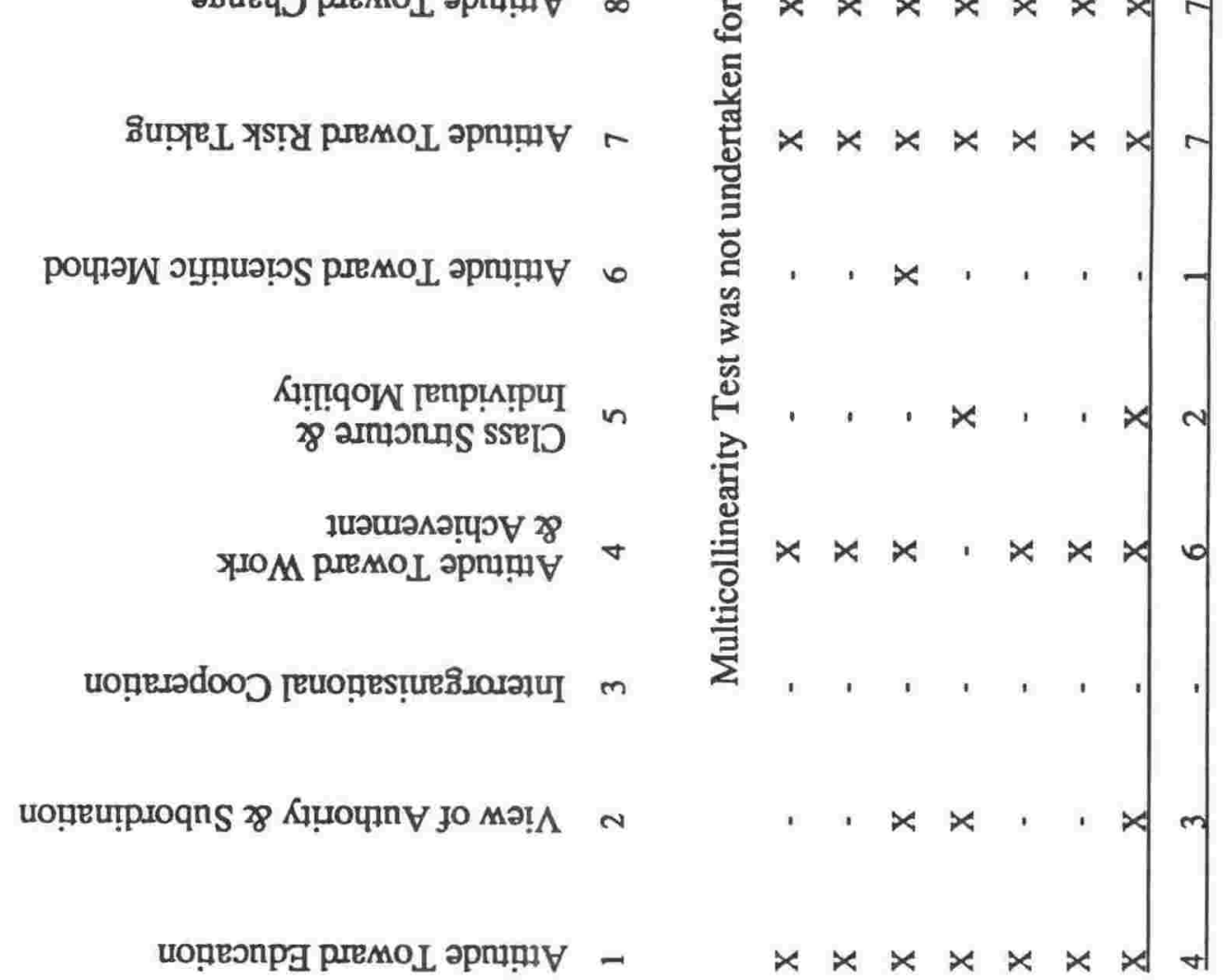

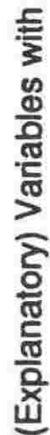

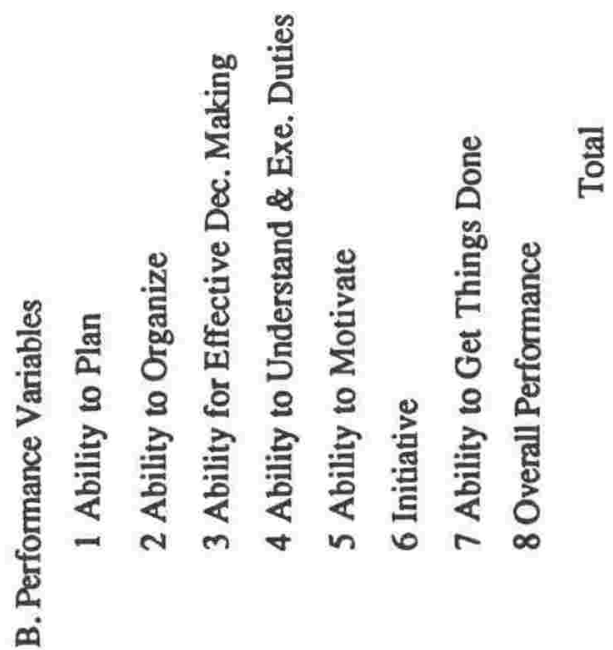




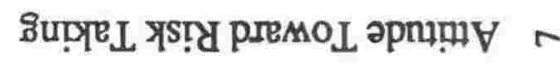

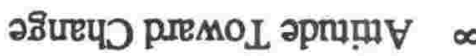

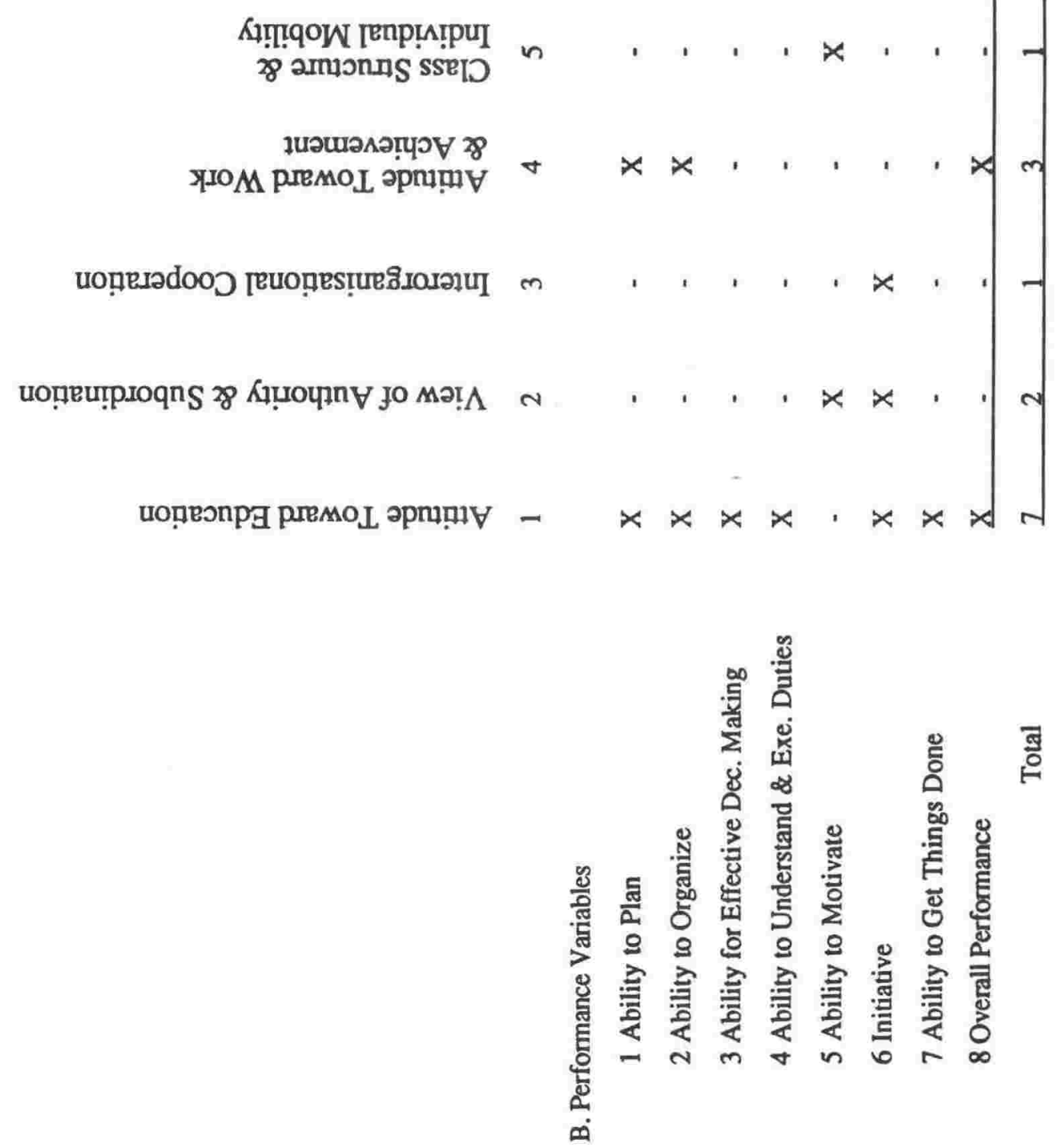




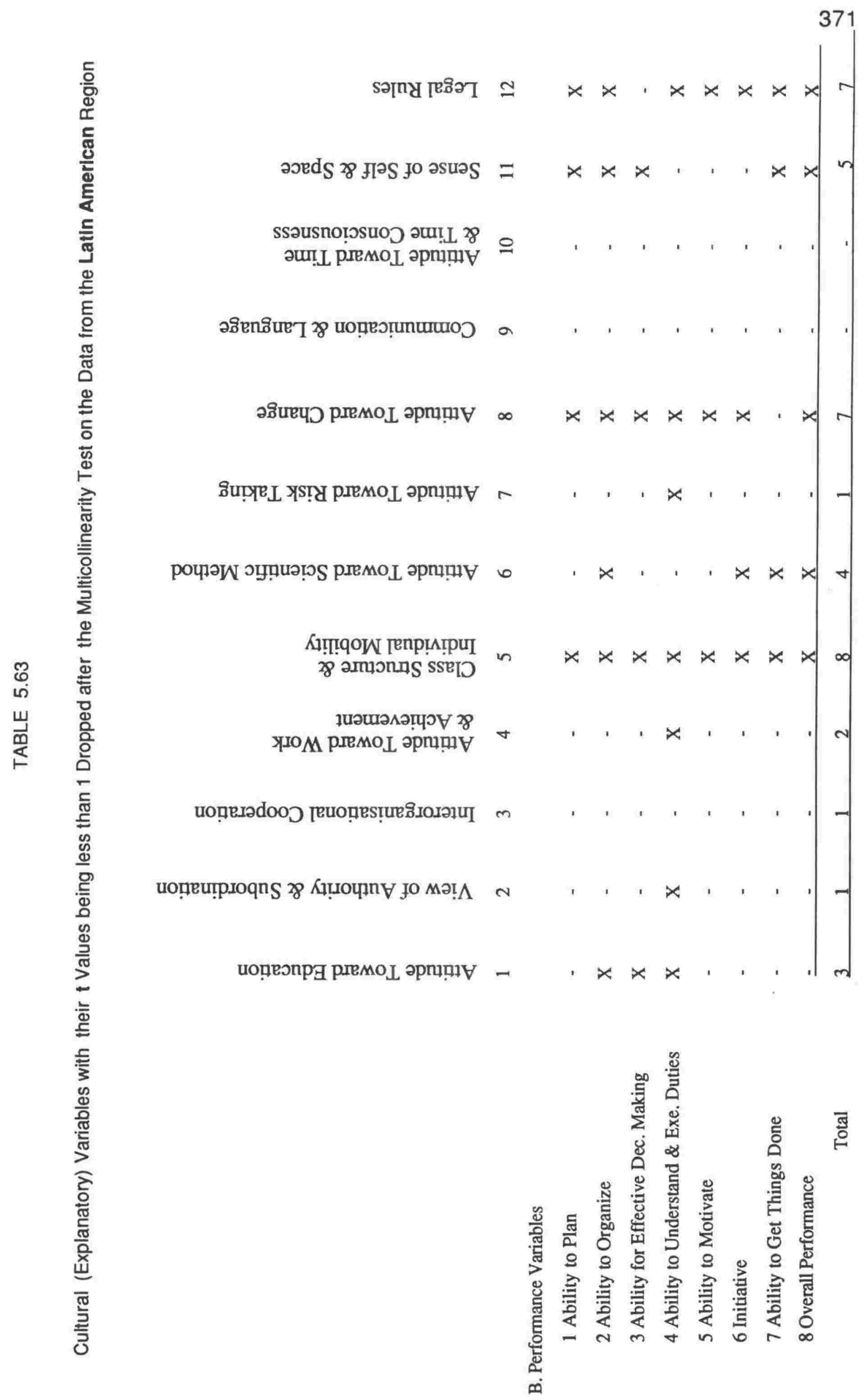




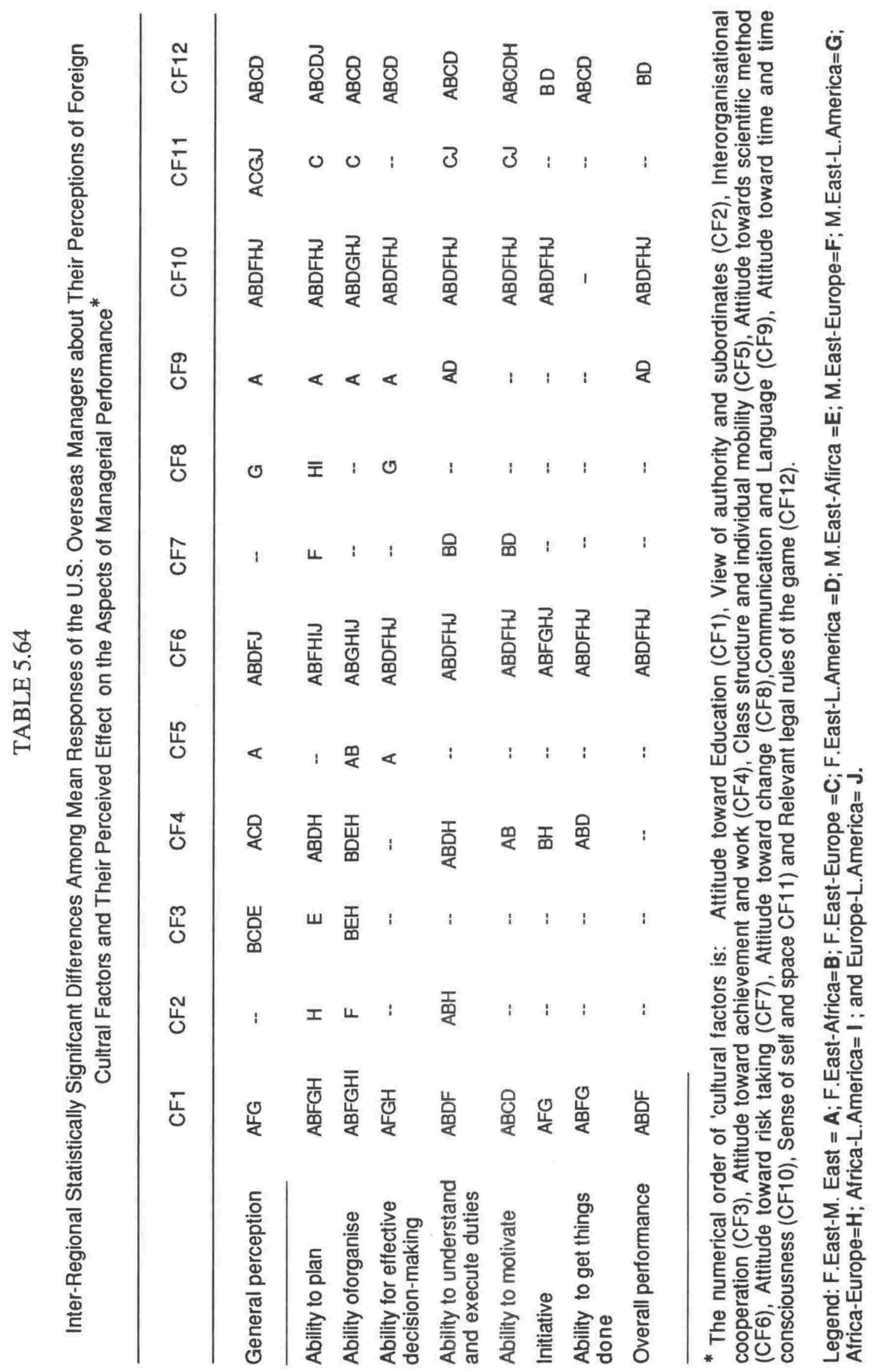



$\begin{array}{ll}\Perp & \overline{0} \\ & 0 \\ & 0\end{array}$

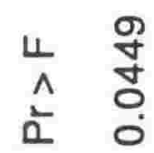

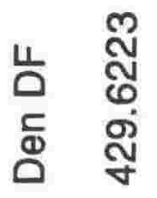

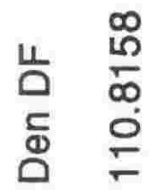

㟔

E

㟔 岕

in

ᄂ $\stackrel{\sqrt[一]{~}}{\text { N }}$

ᄂ $\stackrel{5}{\stackrel{0}{?}}$

$\frac{0}{\frac{0}{5}}$

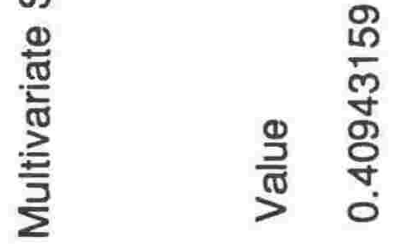

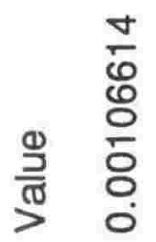

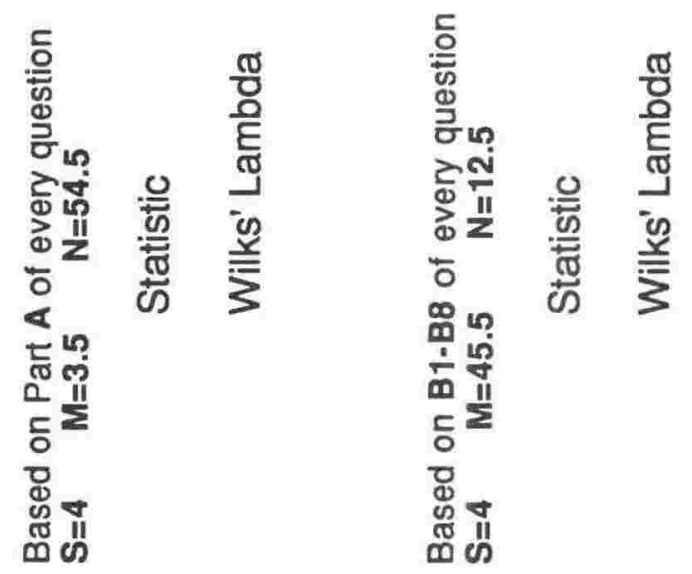




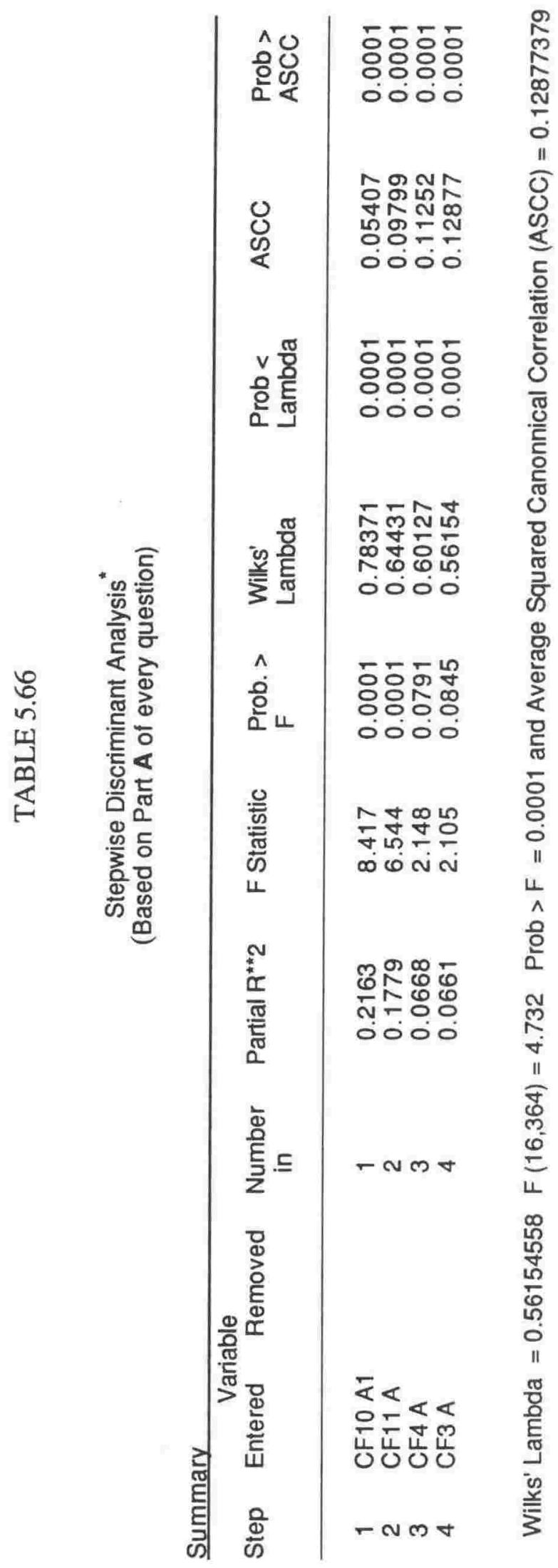

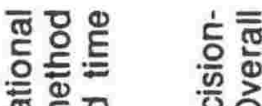

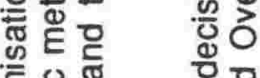

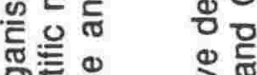

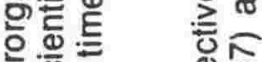

论 包

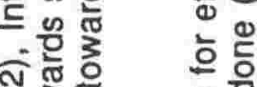

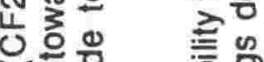

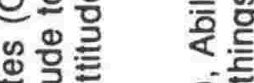

要灵

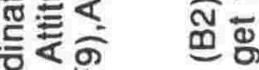

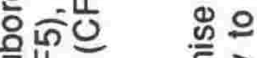

ज药

웜원

$>$ 등 후

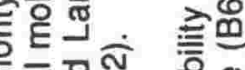

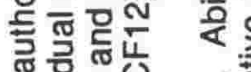

훟ㄷㅇㅇ

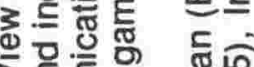

可.

인튼 20

능잉

는흘

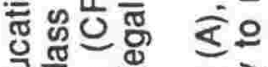

可吅

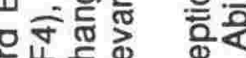

는등

उ

능 문

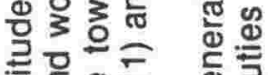

妾婇㐘

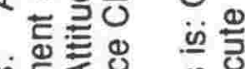

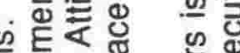

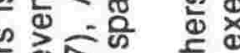

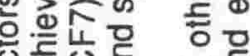

융이듀

문워

告的《

可용요

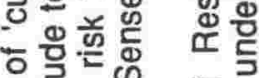

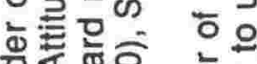

눈

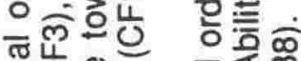

어웡

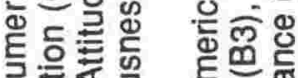

כ征鸟

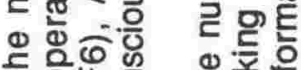

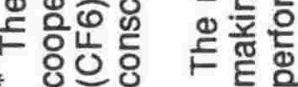




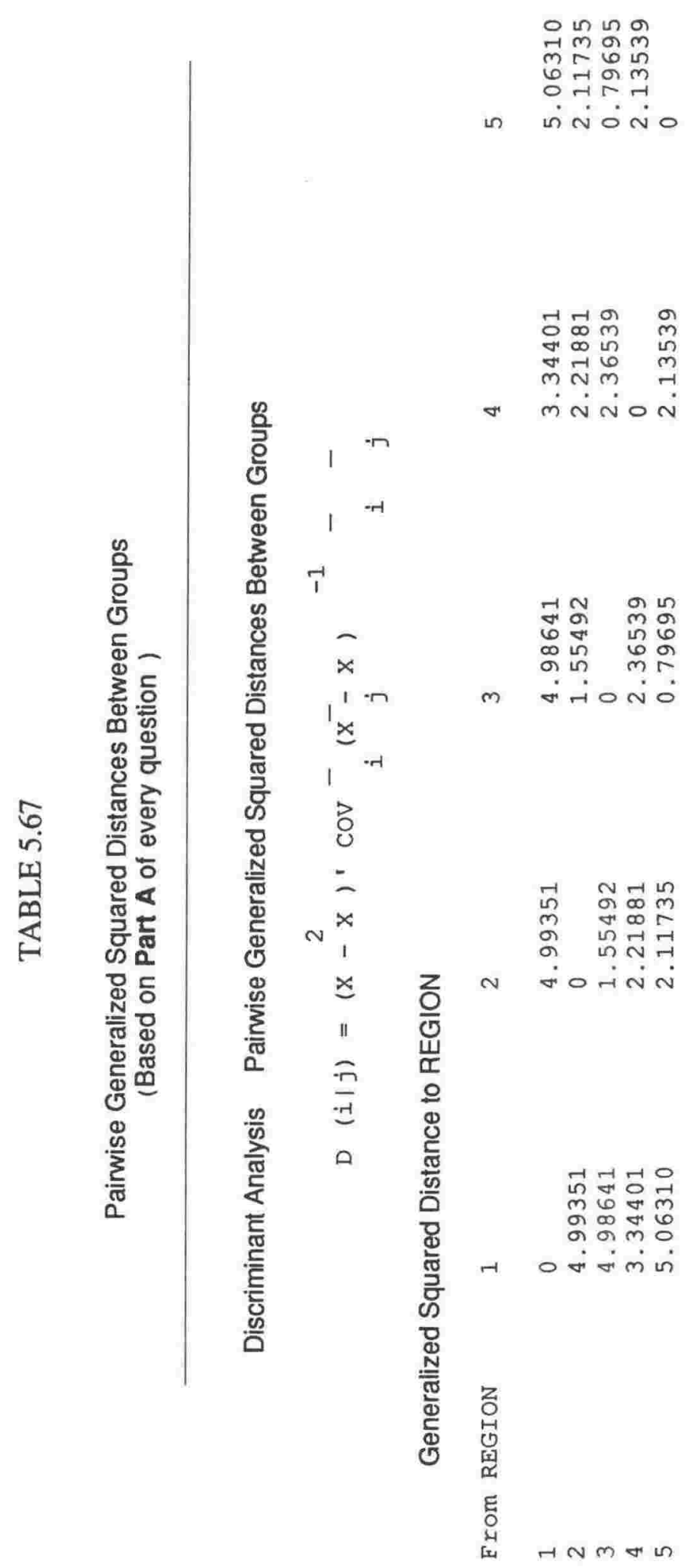




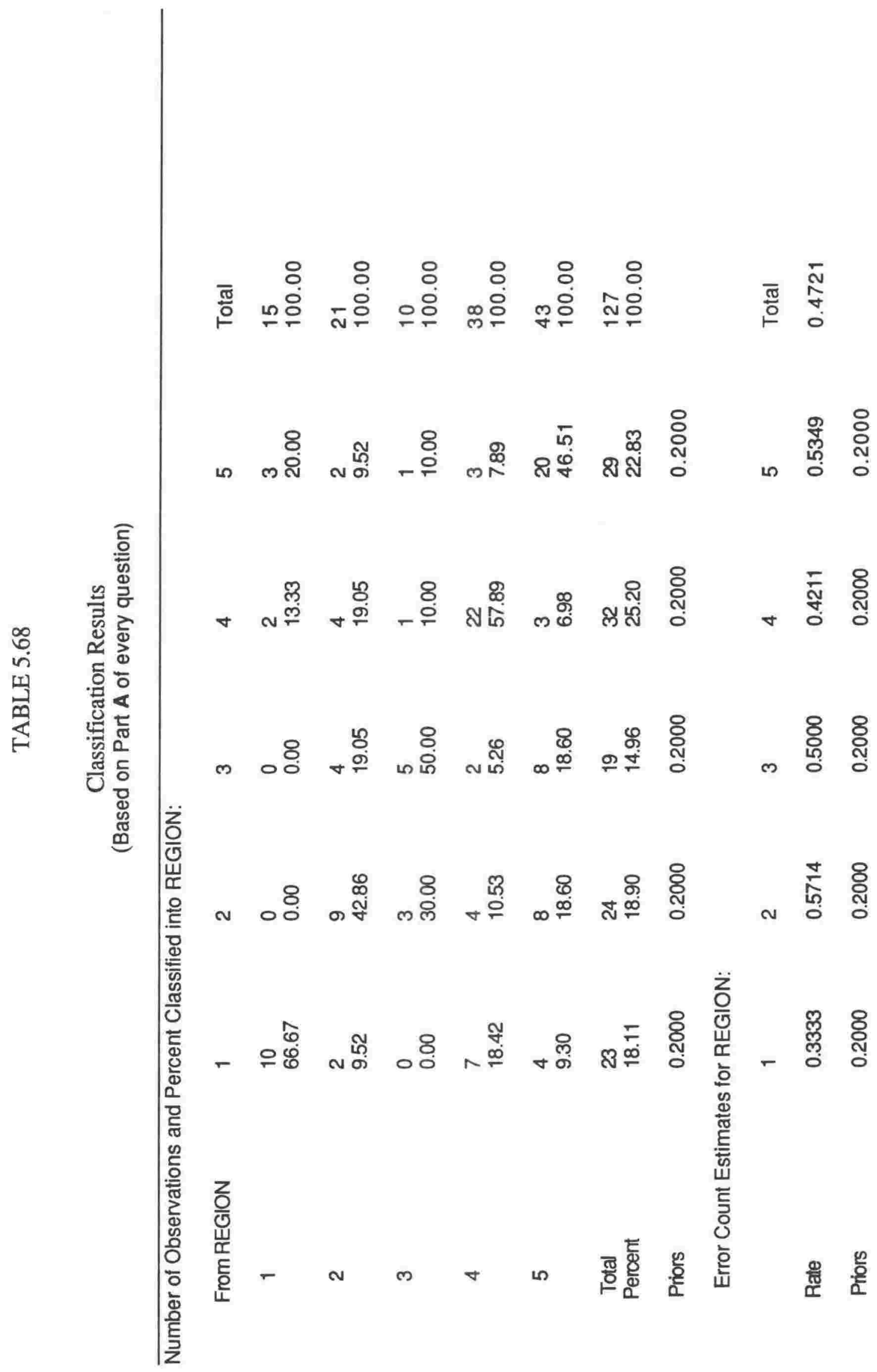




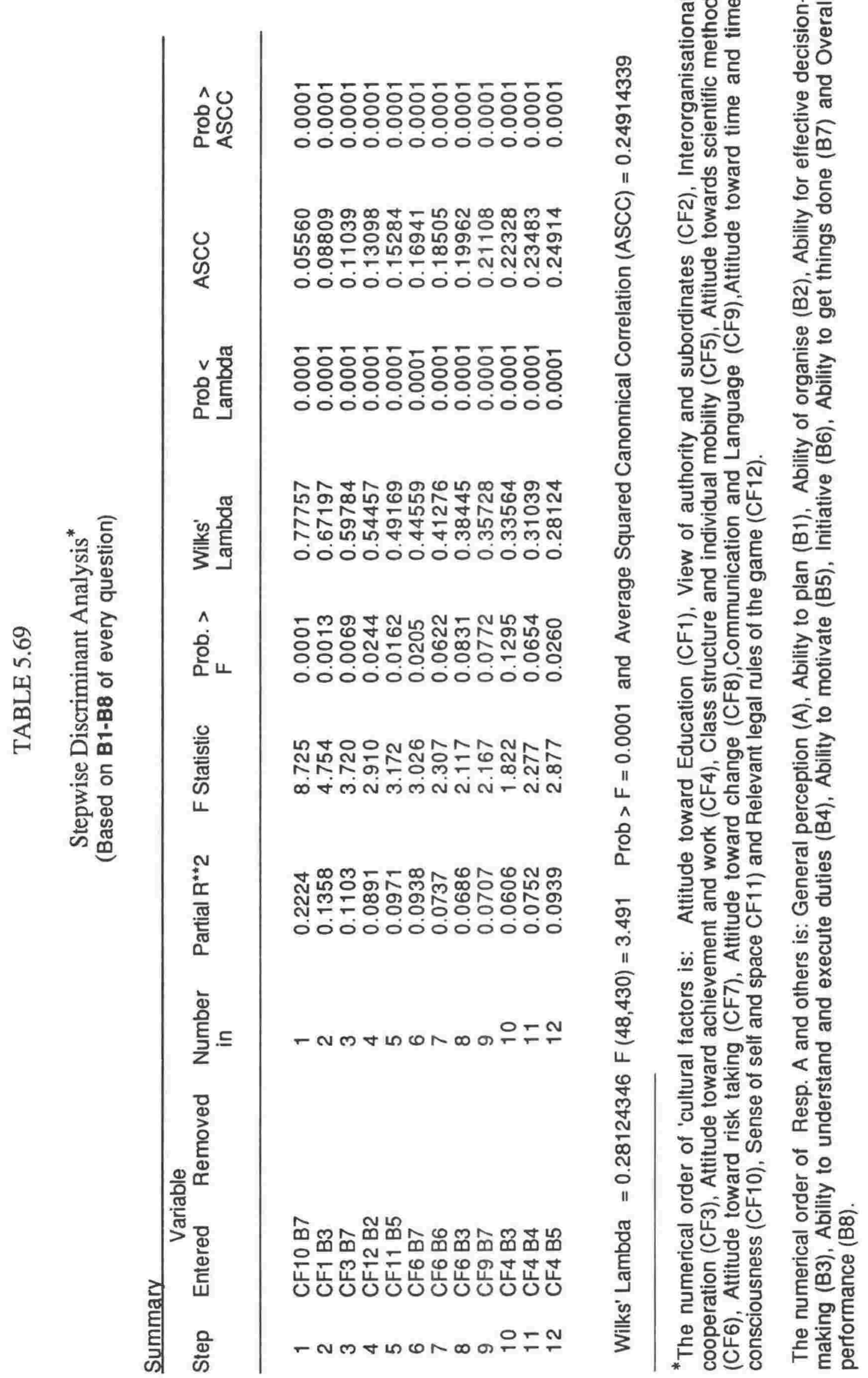




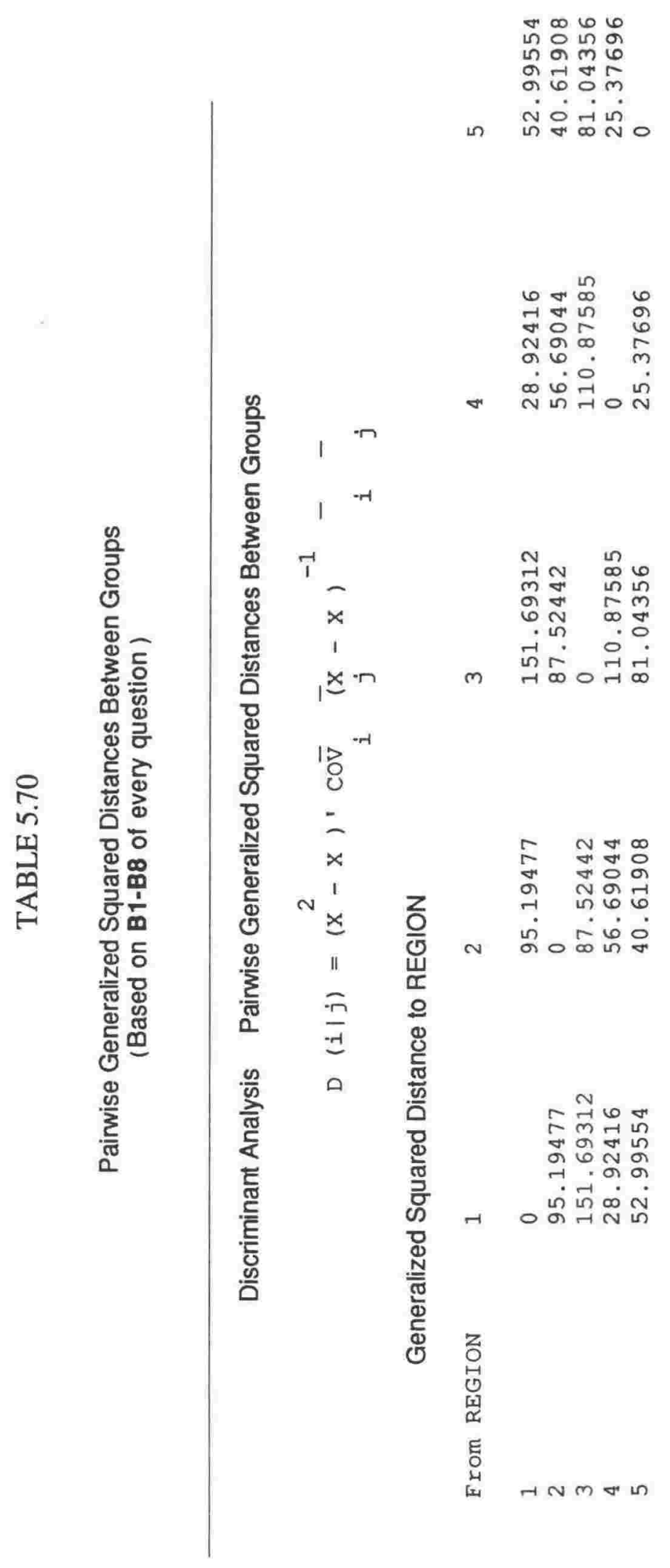




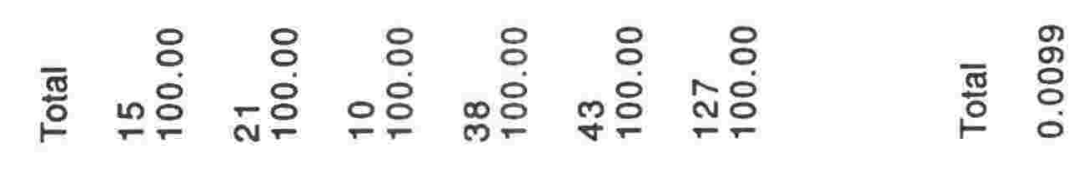

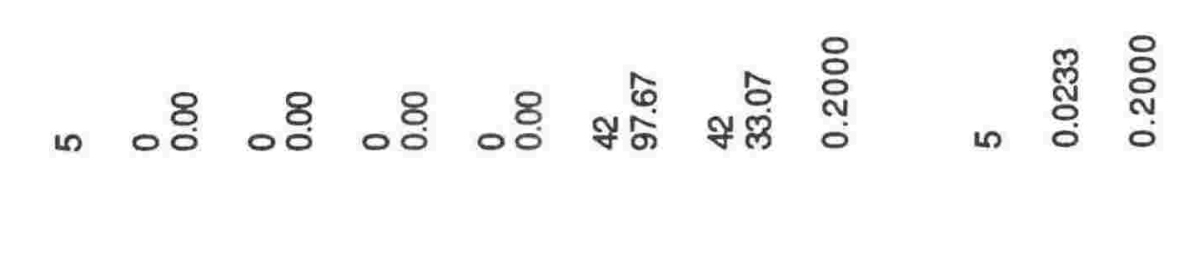

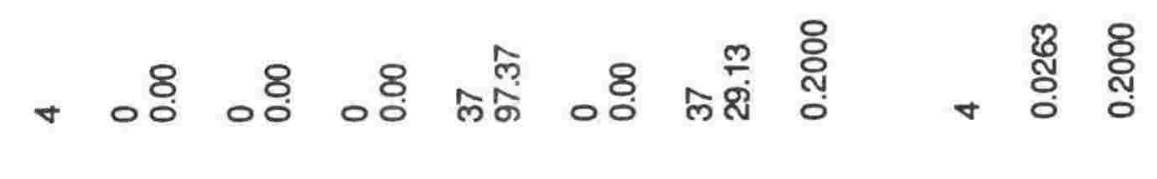

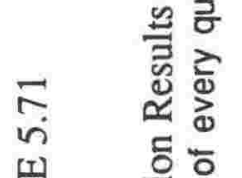

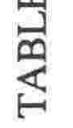

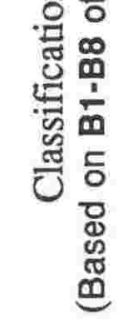

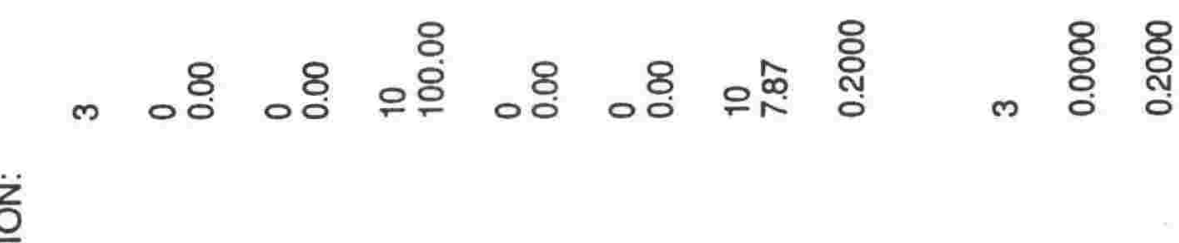

总

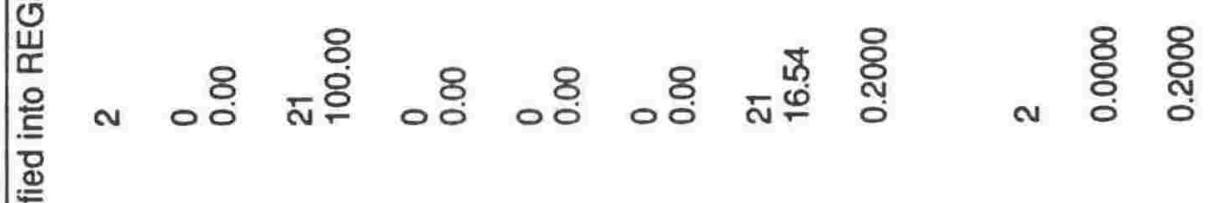

-

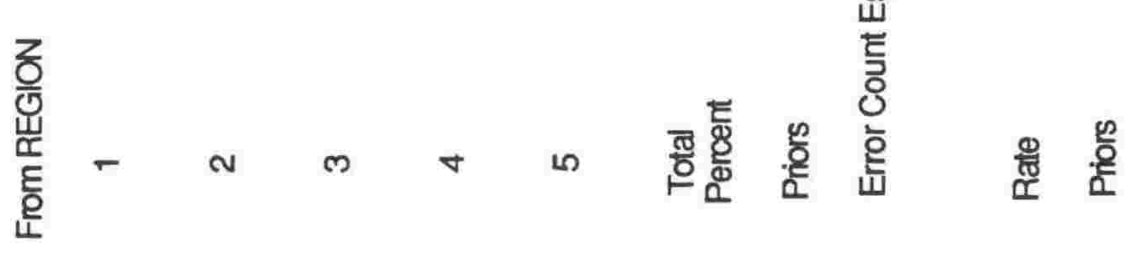


APPENDICES 


\section{APPENDIX A}

(Reasons for Sending Home Country Managers Overseas) 
REASONS FOR SENDING HOME COUNTRY MANAGERS OVERSEAS

1. The foreign enterprise is just being established (start-up phase).

2. The parent firm wishes to develop an internationally orientated management for the headquarters (foreign assignments are seen essentially as management development).

3. The foreign enterprise is seen as short-lived.

4. The parent firm has surplus managerial personnel toward which it feels responsible. (This reason, if relevant, should be examined with care if it implies pushing the least capable managers abroad.)

5. The parent firm has no one sufficiently familiar with the foreign environment to interpret communications for a non-parent country management, and therefore needs to develop area expertise.

6. Virtually no autonomy is possible for the foreign enterprise because it is integrated so closely with operations elsewhere.

7. High-level technical knowledge and skill of a nature that cannot be protected legally is carried by top management (in a research oriented, service firm).

8. No adequate management is available from other sources.

9. The host society is multiracial (or multireligious), and a local manager of either racial origin (or religion) would make the enterprise politically vulnerable or lead to an economic boycott.

10. There is a compelling need to maintain a foreign image.

11. The parent firm will be serving largely other firms of the same nationality operating abroad, most of which are directed by parent country nationals.

12. It is felt desirable to avoid involving particular local nationals or families (former distributors or agents) in management, and the use of other local nationals would create dangerous animosities. (For example, U.S. executives are reported to be in demand in Europe to manage multicountry operations involving the supervision of managers of different European nationalities.)

13. Local nationals are not mobile and resist assignment elsewhere. 
14. A parent-country national is simply the best man for the job, all things considered.

15. Control is weak, particularly in cases where local nationals are highly nationalistic (patriotic) and more responsive to government appeals than would be an expatriate (but an expatriate may be less able to influence the government).

SOURCE: Richard D. Robinson, International Business Management. (Hinsdale, Illinois: The Dryden Press, 1978), pp.293-94. 
APPENDIX B

(Cultural Universals) 


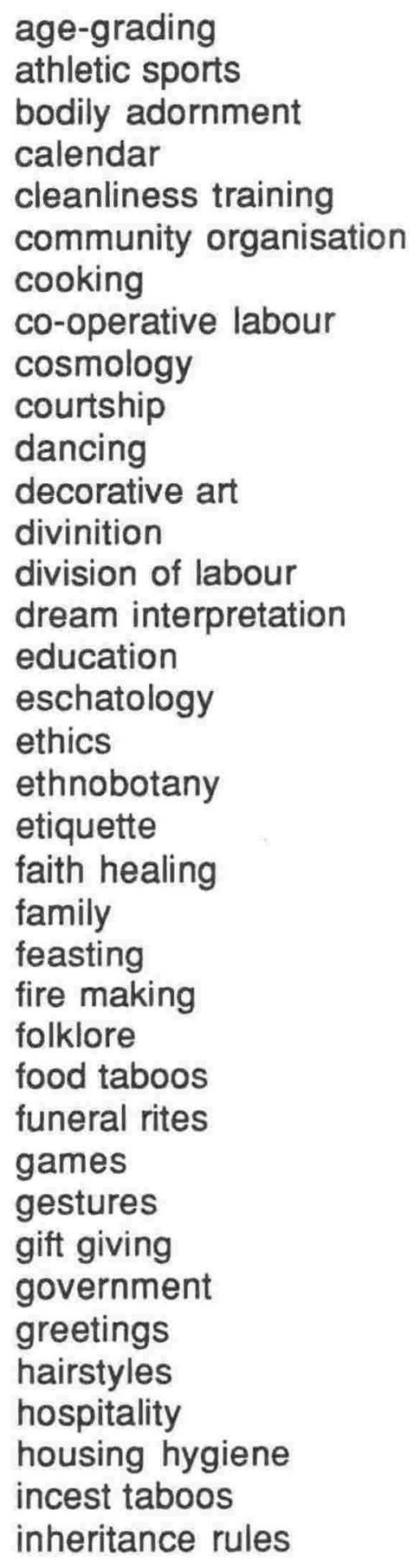

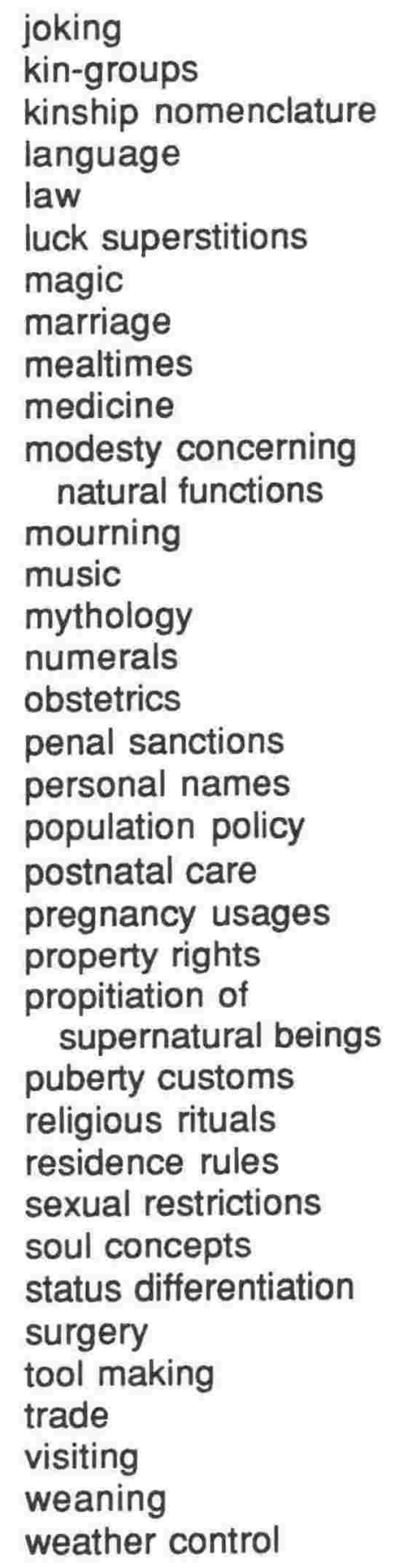

SOURCE: George P. Murdock - "The Common Denominator of Cultures", in the Science of Man in the World Crises, ed. Ralph Linton, (New York: Columbia University Press, 1945), pp.123-26. 
APPENDIX C

(U.S. Values and Possible Alternatives) 


\section{U.S. VALUES AND POSSIBLE ALTERNATIVES}

\begin{tabular}{|c|c|c|}
\hline $\begin{array}{l}\text { Aspects" of } \\
\text { U.S. Culture }\end{array}$ & Alternative & $\begin{array}{l}\text { Examples of } \\
\text { Management } \\
\text { Function Affected }\end{array}$ \\
\hline
\end{tabular}

The individual can influence the future (where there is a will there is a way)

The individual can change and improve the environment.

An individual should be realistic in his aspirations

We must work hard to accomplish our objectives (Puritan ethic)

Commitments should be honoured (people will do what they say they will do)

One should effectively use one's time (time is money which can be saved or wasted)

A primary obligation of an employee is to the organisation

The employer or employee can terminate his or her relationship
Life follows a preordained course and human action is determined by the will of God.

People are intended to adjust to the physical environment rather than to alter it.

Ideals are to be pursued regardless of what is "reasonable"

Hard work is not the only prerequisite for success. Wisdom, luck and time are also required

A commitment may be superseded by a conflicting request or an agreement may only signify intention and have little or no relationship to the capacity of performance

Schedules are important but only in relation to other priorities

The individual employee has a primary obligation to his family and friends

\section{Employment is for a} life-time
Planning and scheduling

Organisational environment, morale, and productivity

Goal setting and career development

Motivation and reward system

Negotiating and bargaining

Long and short range planning

Loyalty, commitment, and motivation

Motivation and commitment to the company_

"Aspect here refers to a belief, value, attitude or assumption which is a part of culture in that it is shared by a large number of persons in any culture. 
Aspects of

U.S. Culture
Alternative

Personal contributions to

A person can only work for one company at a time (man cannot serve two masters)

The best qualified persons should be given the positions available

A person can be removed if he does not perform well

All levels of management are open to qualified individuals (an office boy can rise to become company president)

Intuitive aspects of decisionshould be reduced and efforts should be devoted to gathering relevant information. Data should be accurate.

Company information should be available to anyone who needs it within the organisation.

Each person is expected to have an opinion and to express it freely even if his views do not agree with his colleagues.

\author{
A decision-maker is \\ expected to consult persons \\ who can contribute useful \\ information to the area \\ being considerd
}

an enterprise are

acceptable

Family considerations, friendship, and other considerations should not determine employment practices

The removal of a person from a position involves a great loss of prestige and will be rarely done

Education or family ties are the primary vehicles for mobility

Decisions are expressions of wisdom by the person in authority and any questioning would imply a lack of confidence in his judgment. Accurate data is not as highly valued.

Withholding information to gain or maintain power is acceptable.

Deference is to be given to persons in power or authority and to offer judgment that is not in support of the ideas of one's superiors is unthinkable

Decisions may be made by those in authority and others need not be consulted.

Examples of Management Function Affected

Ethical issues and conflict of interest

Employment, promotions, recruiting, selection, and reward

Promotion

Employment practices and promotion

Decision-making process

Record-keeping

Organisation, communication, managerial style.

Communications, organisational relations

Decision-making, leadership 
Aspects of

U.S. Culture
Alternative

Decisions may be made by those in authority and others need not be consulted.

Personal ambition is frowned upon.

Competition leads to imbalances and leads to disharmony.

Various kinds of work are accorded low or high status and some work may be below one's "dignity" or place in the organisation

Tradition is revered and the power of the ruling group is founded on the continuation of a stable structure.

Symbols and the process are more important than the end point.

Persons are evaluated but in such a way that individuals not highly evaluated will not be embarrassed or caused to "lose face".
Examples of Management Function Affected

Decision-making, leadership

Selection and promotion

Career development and marketing.

Assignment of tasks performance, and organisational effectiveness.

Planning, morale, and organisation development

Communication, planning, quality control.

Rewards and promotion, performance evaluation and accountability.

SOURCE: Philip R. Harris and Robert T. Moran, Managing Cultural Differences (Houston, Texas: Gulf Publishing Co., 1987), pp.76-7. 
APPENDIX D

(Selected Cultural Factors) 
(with explanations)

1. Attitude toward education: The general or dominant cultural attitude toward education and the acquisition of knowledge, in terms of their presumed desirability; the general attitude toward different types of education.

2. Attitude toward industrial managers and management: The general or dominant social attitude toward industrial and business managers of all sorts, and the way that such managers tend to view their managerial jobs.

3. View of authority and subordinates: The general or dominant cultural attitude toward authority and persons in subordinate positions, and the way that industrial managers tend to view their authority and their subordinates.

4. Interorganisational co-operation: Extent and degree to which business enterprises, government agencies, labour unions, educational institutions, and other relevant organisations co-operate with one another in ways conducive to industrial efficiency and general economic progress.

5. Attitude toward achievement and work: The general or dominant cultural attitude toward individual or collective achievement and productive work in industry.

6. Class structure and individual mobility: The extent of opportunities for social class and individual mobility, both vertical and horizontal, in a given country, and the means by which it can be achieved.

7. Attitude toward wealth and material gain: Whether or not the acquisition of wealth from different sources is generally considered socially desirable, and the way that persons employed in industry tend to view material gain.

8. Attitude toward scientific method: The general social and dominant individual attitude toward the use of rational, predictive techniques in solving various types of business, technical, economic and social problems.

9. Attitude toward risk taking: Whether or not the taking of various types of personal, collective, or national risks is generally considered acceptable, as well as the dominant view toward specific types of risk taking in business and industry; the degree and extent to which risk taking tends to be a rational process in a particular country. 
10. Attitude toward change: The general cultural attitude toward social changes of all types which bear directly on industrial performance in a given country, and the dominant attitude among persons employed in industry toward all types of significant changes in enterprise operations.

11. Communication and language: The general features of communication process with regard to gestures, symbols, verbosity of style and degree of impliedness in the language used in oral and written communication.

12. Attitude toward time and time consciousness: The general attitude toward punctuality and the prevalence of difference time-systems.

13. Sense of self and space: Self identity and appreciation can be manifested by humble bearing in one place, while another calls for macho behaviour. Some cultures require more distance between the individuals, while other - Latins, Orientals - want to get closer.

14. Mental process and learning: Some cultures encourage learning for the sake of information, while some favour abstract thinking and conceptualisation, and still others prefer rote memory.

15. Relevant legal rules of the game: Quality, efficiency, and effectiveness of the legal structure in terms of general business law, labour law, tax law, and general law relevant to business, degree of enforcement, reliability, and so on.

SOURCE: R.N. Farmer and B.M. Richman, Comparative Management and Econemic Progress; (Bloomington, Ind., Cedanwood Press, 1970), pp.26-35. 
APPENDIX E

(Details of the Survey with Candidates of Executive MBA and Advanced Management Programs at Georgia State University, Atlanta, Ga, USA.) 


\section{Details of the Survey with Candidates of \\ Executive MBA and Advanced Management Programs \\ at Georgia State University, Atlanta, Ga. USA.}

It was decided to carry out a mailed questionnaire survey with a view to identify the more important aspects of performance that affect the measurement of managerial performance in context of multinational enterprises. For the purpose of this survey, the middle level and senior level executives enrolled in the Executive MBA and Advanced Management Programs at Georgia State University were selected. A list comprising 14 aspects of performance was (adapted from R.J. Fleming's list ${ }^{1}$ ) provided to these participants asking them to assign weights and ranks to these aspects in order of their importance. A letter explaining the intent of the survey and a questionnaire (enclosed) were sent to each of the sixty (60) executives. Responses were received from thirty-seven (37) executives, giving a response rate of $62 \%$, and all responses were useable. The responses were examined to see the extent of similarity of the rankings: i.e., the tendency of the rank orders to agree or show concordance. A high degree of concordance provides some evidence that respondents had reasonably congruent perceptions of the research item. The examination was accomplished by application of Kendall's coefficient of concordance. The coefficient is based on the idea of the extent of variability among respective sums of ranks ${ }^{2}$ and is given as:

$$
\text { * } W=\frac{\text { variance of ranks sums }}{\text { maximum possible variance of rank sums }}
$$

1 R.H. Fleming, Cultural Determinants of the Effectiveness of American Executives Abroad, (Ph.D. Dissertation, Louisiana State University, 1966).

2 Robert L. Winkler and William L. Hayes, Statistics: Probability, Inference and Decision, (New York: Holt Rinehart and Winston, 1975), pp.870-76. 
By definition, $W$ cannot be negative and its maximum value is 1 ; thus, a statistic of approximately .6 would show a moderately high degree of concordance $^{3}$. Responses about ranks received from 37 executives were used to compute the W statistic, which in this case is $.755^{\star *}$, indicating a high degree of concordance among the respondents.

Next, the weights (percentage) given to each of the performance aspects by the respondents were added to obtain a total for individual aspects of performance. The totals obtained are as follows:

*This can be expressed as

$w=\frac{12 \quad W_{j}^{2}}{m 2 n\left(n^{2}-1\right)}-\frac{3(n+1)}{n-1}$

where $\mathrm{m}=$ number of respondents

$\mathrm{n}=$ number of items to be ranked

$W_{j}=$ total of ranks given to each item

** $\quad W=\frac{12(1313077)}{37^{2}(14)\left(14^{2}-1\right)}-\frac{3(14+1)}{14-1}$

$$
=\frac{15756924}{3737370}-\frac{45}{13}
$$

$$
.755=4.216-3.416
$$

3 Ibid., p.875. 
1. Ability to understand and execute duties 242

2. Ability to organise

3. Ability to carry out company's policies

4. Ability to plan

5. Ability to get things done

6. Ability to motivate $\underline{\underline{219}}$

7. Ability for effective Decision-making

8. Initiative $\underline{\underline{223}}$

9. Ability to develop people

10. Ability to socialise

11. Control (ability to establish criteria to measure subordinates and departmental effectiveness in attaining objectives) $\quad 130$

12. Overall performance

13. Contribution toward market share

14. Contribution toward consolidated profits

It was thought prudent to omit those factors whose average weights were around 5 percent. This step helped delete all those factors which has aggregarte weights of less than 185 (respondents $(37) \times(5 \%)=185)$. This step was deemed appropriate, especially after obtaining a relatively high degree of coefficient of concordance. Consequently, the following eight factors were selected:

1. Ability to plan

2. Ability to organise

3. Ability for effective decision making

4. Ability to understand and execute duties

5. Ability to motivate

6. Initiative

7. Ability to get things done

8. Overall performances

It was proposed to carry out the main research work with these eight (8) factors representing the performance of overseas executives. 
APPENDIX F

(Letters to Respondents) 
Letter to the Overseas Managers

Date:

Dear Sir:

SUBJECT: SURVEY TO INQUIRE INTO THE IMPACT OF FOREIGN CULUTRAL FACTORS ON U.S. MANAGERS WORKING OVERSEAS

I am presently conducting a reseach. This study pertains to the perceived impact of foreign cultural factors on the performance of American executives working in the overseas offices of U.S. multinational enterprises.

The purpose of this survey is to solicit your opinion about the specific cultural factors observed (explained at the beginning of each set of enclosed questions) and their perceived impact on the selected aspects of performance on a scale of 1 to 7 in the place of your current assignment.

I am requesting your help in completing the enclosed questionnaire. You are requested to cross or circle the statements which you consider to be most expressive of your opinion.

Your response is particularly important to me because of its value and representativeness stemming from your overseas experience. Your opinions about the impact of foreign cultural factors on the performance would help provide a deep insight for my study. Your support and contribution to this effort is sincerely appreciated.

This is study is completely ananymous, and in no case would the information tendered be made public.

I would appreciate if you could please complete the questionnaire at your earliest convenience and send it to me at the given address.

Thanks you

Sincerely,

B.S. Khanna 
Letter to the Evaluators

Date:

Dear Sir:

\section{SUBJECT: SURVEY TO INQUIRE INTO THE IMPACT OF FOREIGN CULUTRAL FACTORS ON U.S. MANAGERS WORKING OVERSEAS}

This is in continuation of the telephone conversation regarding the research study I am currently engaged in. It is an exploratory research, whose purpose is to study the impact of foreign cultural factors on the performance of U.S. nationals working as managers in different countires/regions, as perceived by them. Intertwined with it is the consideration given to the impact of these cultural factors on the overseas mangers' performance, by the performance evaluators at the regional/corporate headquarters.

I would highly appreciate if the questionnaires meant for overseas managers may please be routed through your office to the U.S. nationals working as overseas managers in different countries/regions. The completed questionnaire may be returned directly to $\mathrm{me}$ at the given address. Your cooperation and help is of very great significance to me in getting these questionnaires mailed to them. You may write a note to them, encouraging them to respond to the questionnaire.

The questionnaires meant for evaluators need to be filled in by all those associated with the performance evaluation of the overseas managers at the headquarters.

This is study is completely ananymous, all the responses provided will be treated as strictly confidential; and in no case would the information tendered be made public. No reference will be made of any person, office or your firm in this study.

I will be more than happy to share the findings of my study with you and your office. I look forward to your cooperation in helping me to obtain this information from yoru overseas managers.

Thank you

Sincerely,

B.S. Khanna 
APPENDIX G

Questionnaire for U.S. Overseas Managers 
TO STUDY THE IMPACT

OF FOREIGN CULTURAL FACTORS ON

MANAGERIAL PERFORMANCE

\section{QUESTIONNAIRE FOR OVERSEAS MANAGERS}

After completing, please return the questionnaire to :

Bhagwan S. Khanna 


\section{Section 1}

General Information:

I. Age:
A) Below 25 years
B) 26-35 years
C) $36-50$ years
D) 51 and above

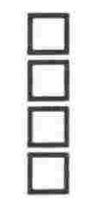

II. Experience: A) With the present organisation:

1) Domestic up to 5 years $\square$ more than 5 years

2) Overseas up to 5 years $\square$ more than 5 years

B) With other organisations:

1) Domestic up to 5 years $\square$ more than 5 years

2) Overseas up to 5 years $\square$ more than 5 years assignment (first, second,......)

assignment (first, second,.......)

III. Present Placement

(Name of the Country ) 
I. Attitude toward education: The general or dominant cultural attitude toward education and the acquisition of knowledge, in terms of their presumed desirability; the general attitude toward different types of education.

A. Where would you place the attitude toward education in the country of your present assignment on a scale of 1 to 7,1 being highly unfavorable, and 7 being highly favorable?

$\begin{array}{lllllll}1 & 2 & 3 & 4 & 5 & 6 & 7\end{array}$

B. Where would you place the impact of this attitude, on the following on a scale of 1 to 7 ?

- Ability to plan

- Ability to organise

- Ability for effective decision-making

- Ability to understand \& execute duties

- Ability to motivate

- Initiative

- Ability to get things done

- Overall performance

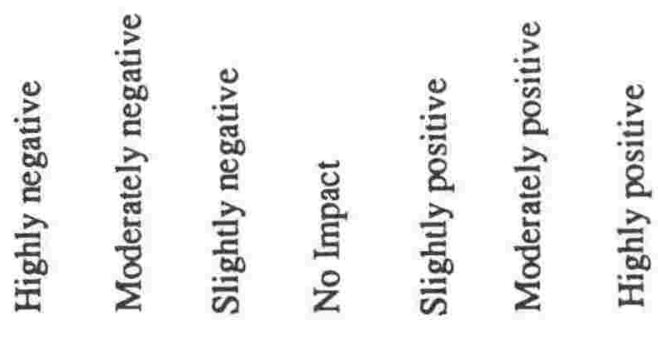

II. View of authority and subordinates: The general or dominant cultural attitude toward authority and persons in subordinate positions, and the way that industrial managers tend to view their authority and their subordinates.

A. Where would you place the attitude toward authority in the country of your present assignment on a scale of 1 to 7,1 being highly authoritarian, and 7 being highly democratic (participation)?

$$
\begin{array}{lllllll}
1 & 2 & 3 & 4 & 5 & 6 & 7
\end{array}
$$

B. Where would you place the impact of this attitude, on the following, on a scale of 1 to 7 ?

- Ability to plan

- Ability to organise

- Ability for effective decision-making

- Ability to understand \& execute duties

- Ability to motivate

- Initiative

- Ability to get things done

- Overall performance
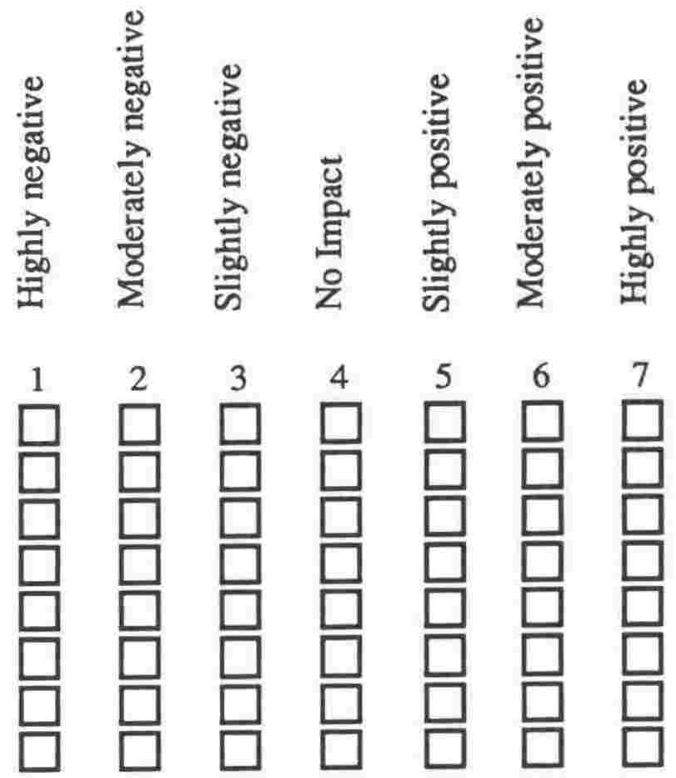
III. Interorganisational co-operation: The extent and the degree to which business enterprises, government agencies, labour unions, educational institutions, and other relevant organisations co-operate with one another in ways conducive to industrial efficiency and general economic progress.

A. How would you characterise the inter-

organisational co-operation in the country of your present assignment on a scale of 1 to 7,1 being highly unsatisfactory, and 7 being highly satisfactory?

$\begin{array}{lllllll}1 & 2 & 3 & 4 & 5 & 6 & 7\end{array}$

B. Where would you place the impact of this feature on the following, on a scale of 1 to 7 ?

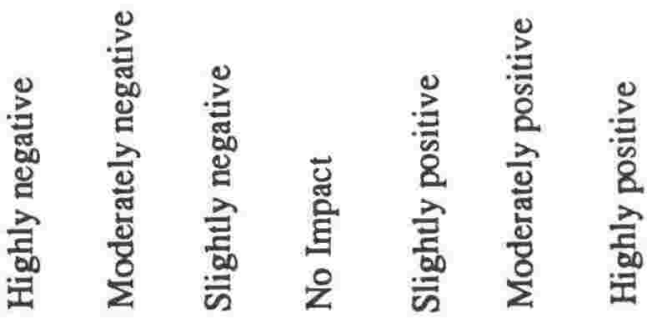

- Ability to plan

- Ability to organise

- Ability for effective decision-making

- Ability to understand \& execute duties

- Ability to motivate

- Initiative

- Ability to get things done

- Overall performance

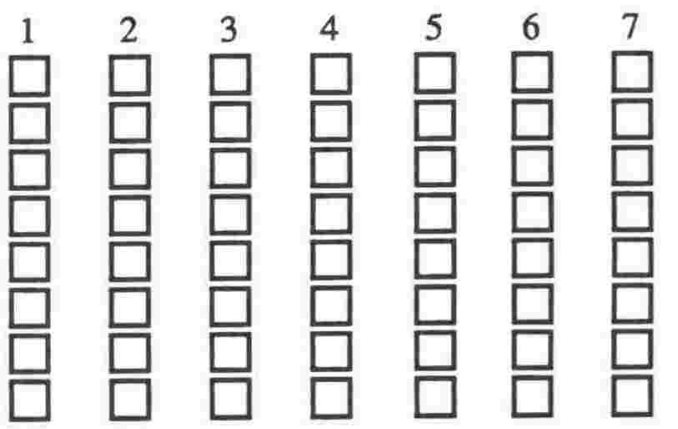

IV. Attitude toward achievement and work: The general or dominant cultural attitude toward individual or collective achievement and productive work in industry.

A. How would you characterise the cultural attitude toward productivity in the country of your present assignment on a scale of 1 to 7,1 being highly collective achievement, 7 being highly individualistic?

$\begin{array}{lllllll}1 & 2 & 3 & 4 & 5 & 6 & 7\end{array}$

B. Where would you place the impact of this attitude on the following on a scale of 1 to 7 ?

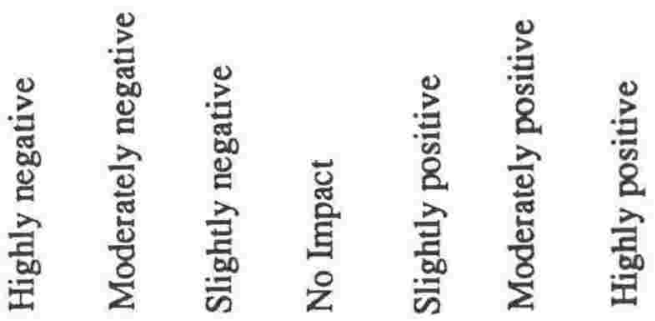

- Ability to plan

- Ability to organise

- Ability for effective decision-making

- Ability to understand \& execute duties

- Ability to motivate

- Initiative

- Ability to get things done

- Overall performance
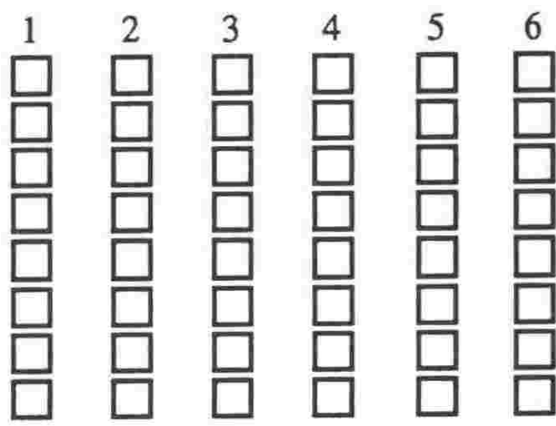
V. Class structure and individual mobility: The extent of opportunities for social class and individual mobility, both vertical and horizontal, in a given country, and the means by which it can be achieved.

A. Where would you place the opportunity for social class and individual mobility in the country of your present assignment on a scale of 1 to 7 , where 1 stands for highly unsatisfactory, and 7 for highly satisfactory?

$\begin{array}{lllllll}1 & 2 & 3 & 4 & 5 & 6 & 7\end{array}$

B. Where do you place the impact of this feature on the following on a scale of 1 to 7 ?

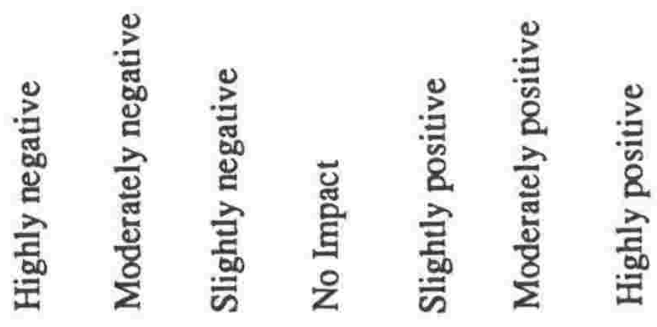

- Ability to plan

- Ability to organise

- Ability for effective decision-making

- Ability to understand \& execute duties

- Ability to motivate

- Initiative

- Ability to get things done

- Overall performance

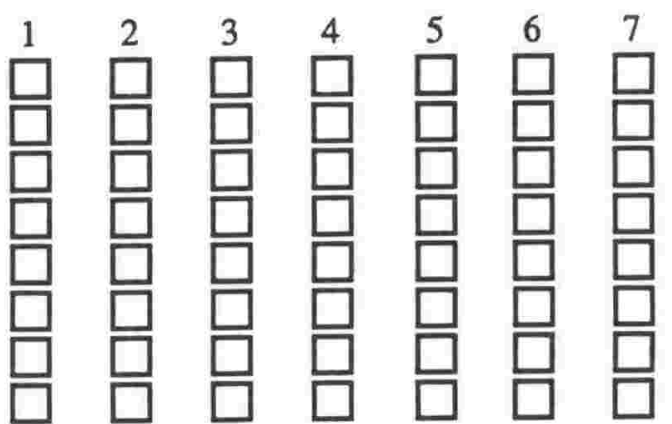

VI. Attitude toward scientific method: The general social and dominant individual attitude toward the use of rational, predictive techniques in solving various types of business, technical, economic, and social problems.

A. Where would you place the attitude toward scientific method in the country of your present assignment on a scale of 1 to 7,1 being highly unfavorable, and 7 being hightly favorable?

$\begin{array}{lllllll}1 & 2 & 3 & 4 & 5 & 6 & 7\end{array}$

B. Where would you place the impact of this attitude on the following on a scale of 1 to 7 ?

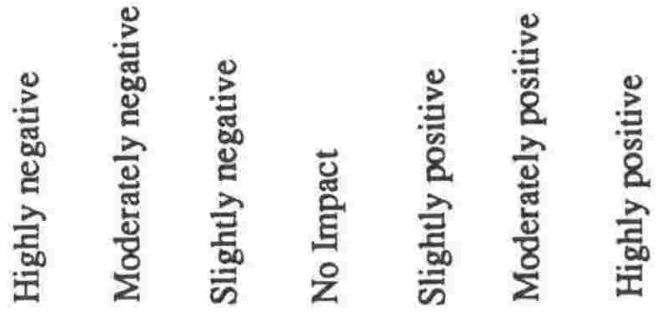

- Ability to plan

- Ability to organise

- Ability for effective decision-making

- Ability to understand \& execute duties

- Ability to motivate

- Initiative

- Ability to get things done

- Overall performance

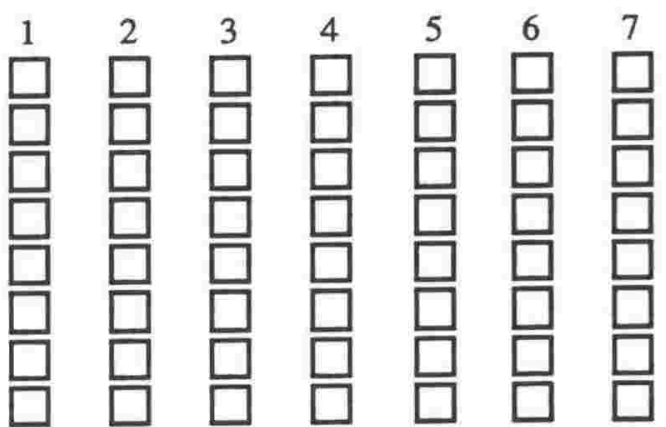


VII. Attitude toward risk taking: Whether or not the taking of various types of personal, collective or national risks is generally considered acceptable, as well as the dominant view toward specific types of risk taking in business and industry; the degree and extent to which risk taking tends to be rational process in a particular country.

A. Where would you place the attitude toward

risk taking in the country of your

present assignment on a scale of 1 to 7,1

being highly uncommendable, and 7

being highly commendable?

$\begin{array}{lllllll}1 & 2 & 3 & 4 & 5 & 6 & 7\end{array}$

B. Where would you place the impact of there attitude on the following on a scale of 1 to 7 ?

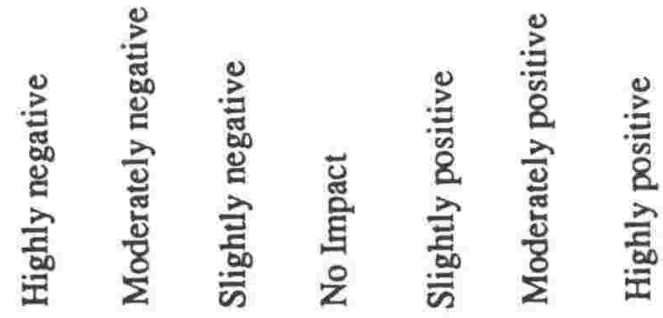

- Ability to plan

- Ability to organise

- Ability for effective decision-making

- Ability to understand \& execute duties

- Ability to motivate

- Initiative

- Ability to get things done

- Overall performance
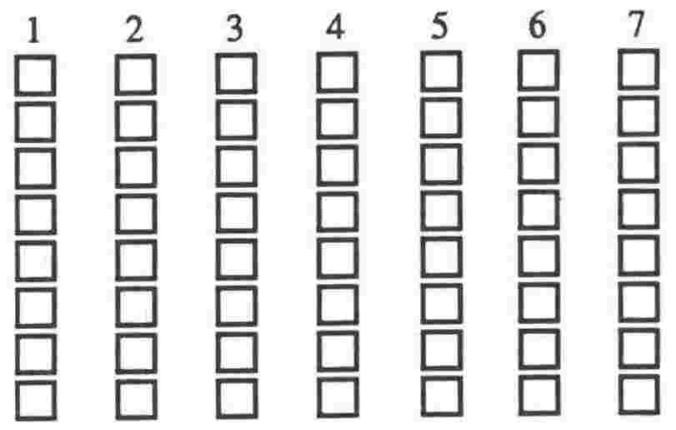

VIII Attitude toward change: The general cultural attitude toward social changes of all types which bear directly on industrial performance in a given country, and the dominant attitude among persons employed in industry toward all types of significant changes in enterprise operations.

A. Where would you place the attitude of people in the country of your present assignment toward change on a scale of 1 to 7,1 being highly unfavorable, and 7 being highly favorable?
12
4
56
7

B. Where would you place the impact of this attitude on the following on a scale of 1 to 7 ?

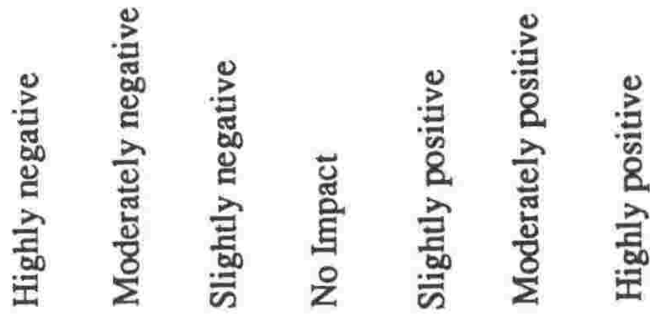

- Ability to plan

- Ability to organise

- Ability for effective decision-making

- Ability to understand \& execute duties

- Ability to motivate

- Initiative

- Ability to get things done

- Overall performance

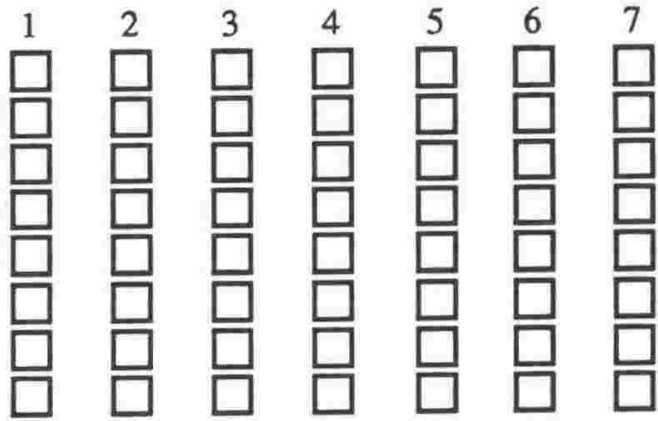


IX. Communication and language: The general features of communication process with regard to gestures, symbols, verbosity of style and degree of impliedness in the language used in oral and written communication.

A. How would you rate the communication process and language as practice in the country of your present assignment on a scale of 1 to 7,1 being highly unfavorable for working and 7 being highly favorable for working effectively?

$\begin{array}{lllllll}1 & 2 & 3 & 4 & 5 & 6 & 7\end{array}$

B. How does communication and language of the country of your present assignment influence the following ?

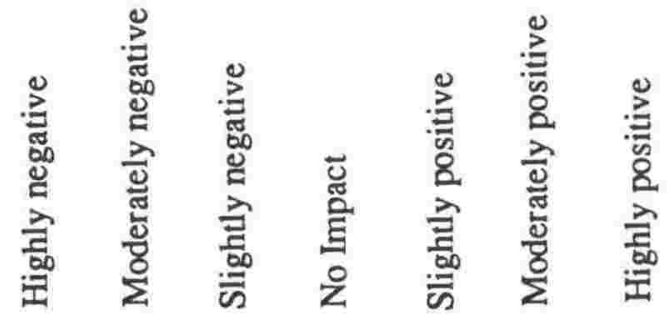

- Ability to plan

- Ability to organise

- Ability for effective decision-making

- Ability to understand \& execute duties

- Ability to motivate

- Initiative

- Ability to get things done

- Overall performance

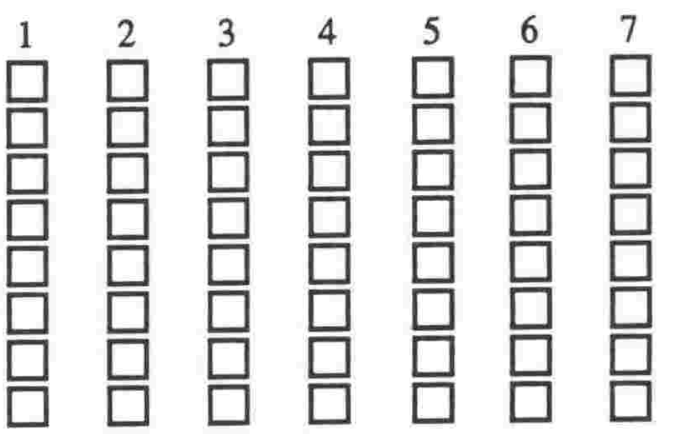

$\mathrm{X}$ Attitude toward time and time consciousness: The general attitude toward punctuality and the prevalence of difference time systems.

A. How would you rate the time

consciousness and punctuality of the

employees at your country of present

assignment on a scale of 1 to 7,1 being

highly unconcerned and 7 being highly concerned?

$\begin{array}{lllllll}1 & 2 & 3 & 4 & 5 & 6 & 7\end{array}$

B. Where do you place the impact of this attitude on the following on a scale of 1 to 7 ?

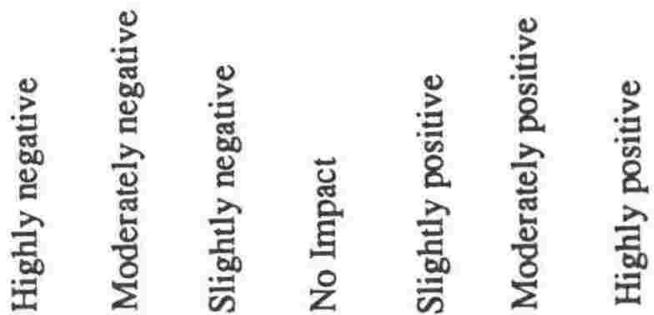

- Ability to plan

- Ability to organise

- Ability for effective decision-making

- Ability to understand \& execute duties

- Ability to motivate

- Initiative

- Ability to get things done

- Overall performance
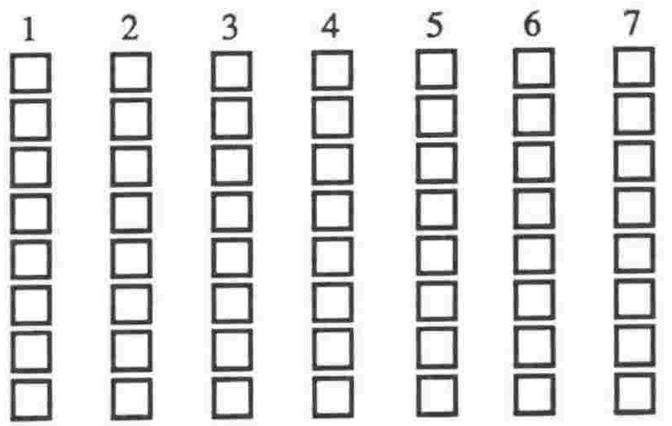
XI. Sense of self and space: Self identity and appreciation can be manifested by humble bearing in one place, while another calls for macho behavior. Some cultures require more distance between individuals, while othes - Latin, Orientals - want to get closer.

A. How would you characterise the feature of sense of self and space in the country of your present assignment on a scale of 1 to 7,1 being highly aloof, and 7 being highly cordial?

$\begin{array}{lllllll}1 & 2 & 3 & 4 & 5 & 6 & 7\end{array}$

B. Where do you place the impact of this feature on the following on a scale of 1 to 7 ?

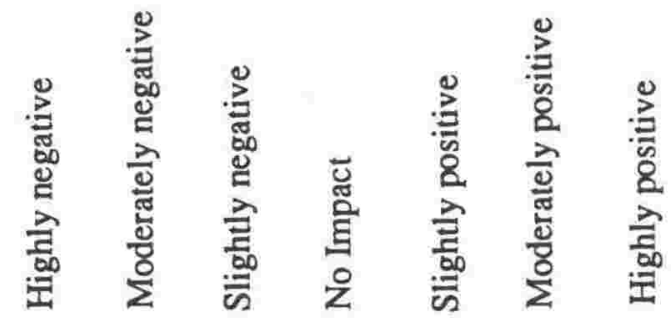

- Ability to plan

- Ability to organise

- Ability for effective decision-making

- Ability to understand \& execute duties

- Ability to motivate

- Initiative

- Ability to get things done

- Overall performance

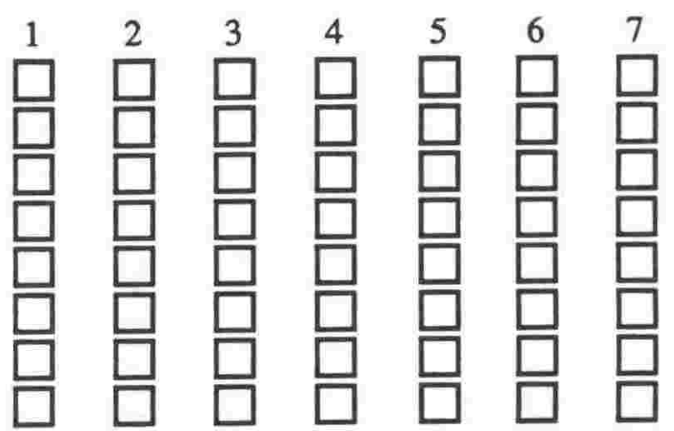

XII. Relevant legal rules of the game: Quality, efficiency, and effectiveness of the legal structure in terms of general business law, labour law, and general law relevant to business, degree of enforcement, reliability and so on.

A. Where would you place the above feature in the country of your present assignment on a scale of 1 to 7,1 being highly unsatisfactory and 7 being highly satisfactory?

$\begin{array}{lllllll}1 & 2 & 3 & 4 & 5 & 6 & 7\end{array}$

B Where do you place the impact of the above on the following on a scale of 1 to 7 ?

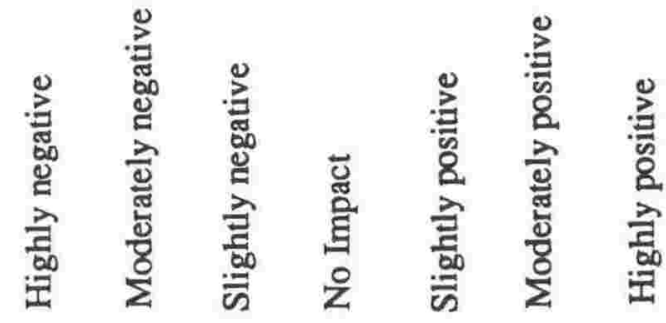

- Ability to plan

- Ability to organise

- Ability for effective decision-making

- Ability to understand \& execute duties

- Ability to motivate

- Initiative

- Ability to get things done

- Overall performance

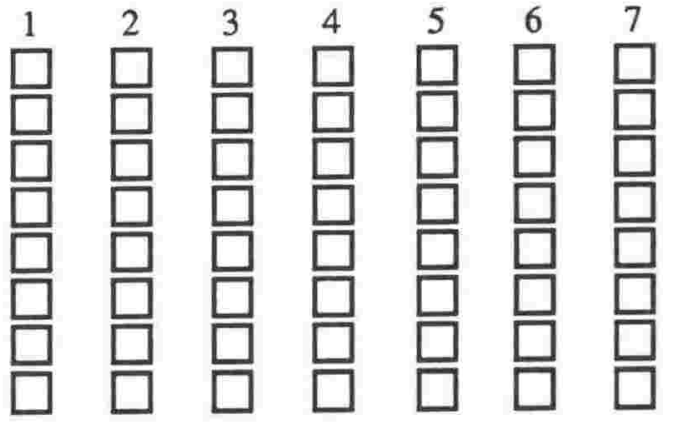


APPENDIX H

Questionnaire for Evaluators 
TO STUDY THE IMPACT

OF FOREIGN CULTURAL FACTORS ON

MANAGERIAL PERFORMANCE

\section{QUESTIONNAIRE FOR EVALUATORS}

After completing, please return the questionnaire to :

Bhagwan S. Khanna 


\section{Section 1}

General Information:

I. Age:
A) Below 25 years
B) $26-35$ years
C) $36-50$ years
D) 51 and above

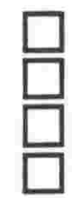

II. Experience: A) With the present organisation:
1) Domestic up to 5 years
2) Overseas up to 5 years
more than 5 years
more than 5 years

B) With other organisations:

1) Domestic up to 5 years

2) Overseas up to 5 years

more than 5 years

more than 5 years

This questionnaire relates to the evaluation criteria used for region.

(Take one at a time for the following)
A. Far East
B. Middle East
C. Africa
D. Latin America
E. Europe

All the subsequent questions relate to the above region.

Have you ever been in the above-mentioned region? Yes $\square$ No $\square$

If yes, how long months, longest stay months. 


\section{Section 2}

I. Attitude toward education: The general or dominant cultural attitude toward education and the acquisition of knowledge, in terms of their presumed desirability; the general attitude toward different types of education.

A. Where would you place the attitude toward education in the previously mentioned region on a scale of 1 to 7,1 being highly unfavorable, and 7 being highly favorable?

$$
\begin{array}{lllllll}
1 & 2 & 3 & 4 & 5 & 6 & 7
\end{array}
$$

B. Where would you place the impact of this attitude, in evaluating managerial performance, on a scale of 1 to 7 ?

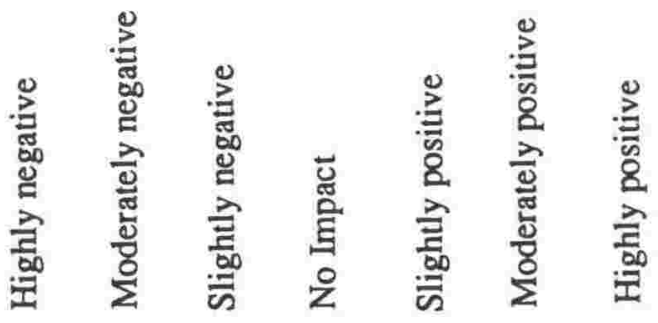

- Ability to plan

- Ability to organise

- Ability for effective decision-making

- Ability to understand \& execute duties

- Ability to motivate

- Initiative

- Ability to get things done

- Overall performance

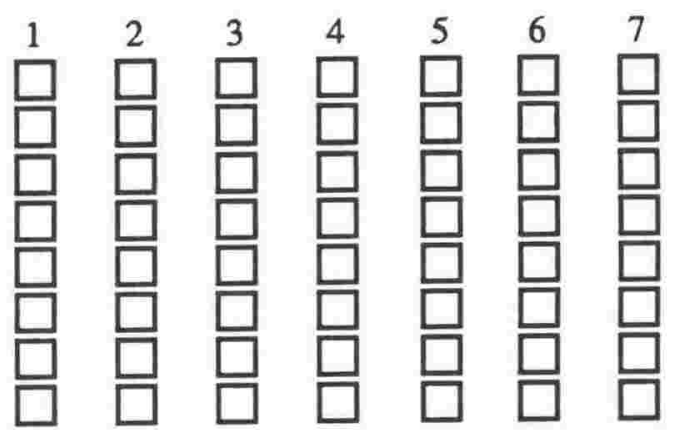

II. View of authority and subordinates: The general or dominant cultural attitude toward authority and persons in subordinate positions, and the way that industrial managers tend to view their authority and their subordinates.

A. Where would you place the attitude toward authority inthe previously mentioned region on a scale of 1 to 7,1 being highly authoritarian, and 7 being highly democratic (participation)?

$$
\begin{array}{lllllll}
1 & 2 & 3 & 4 & 5 & 6 & 7
\end{array}
$$

B. Where would you place the impact of this attitude, in evaluating managerial performance, on a scale of 1 to 7 ?

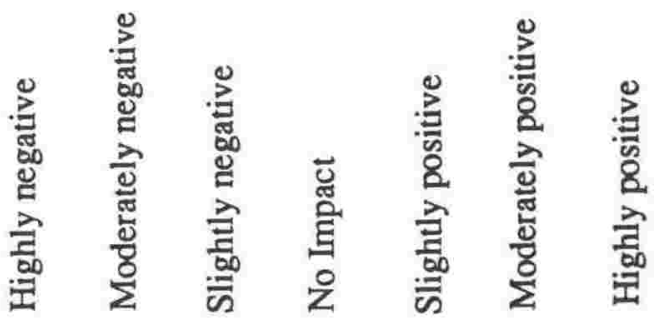

- Ability to plan

- Ability to organise

- Ability for effective decision-making

- Ability to understand \& execute duties

- Ability to motivate

- Initiative

- Ability to get things done

- Overall performance

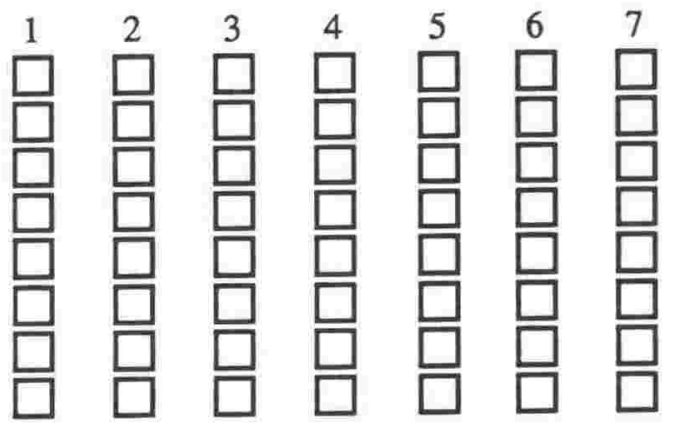


III. Interorganisational co-operation: The extent and the degree to which business enterprises, government agencies, labour unions, educational institutions, and other relevant organisations co-operate with one another in ways conducive to industrial efficiency and general economic progress.

A. How would you characterise the inter-

organisational co-operation in the

previously mentioned region on a scale of

1 to 7,1 being highly unsatisfactory, and

7 being highly satisfactory?

$\begin{array}{lllllll}1 & 2 & 3 & 4 & 5 & 6 & 7\end{array}$

B. Where would you place the impact of this attitude, in evaluating managerial performance, on a scale of 1 to 7 ?

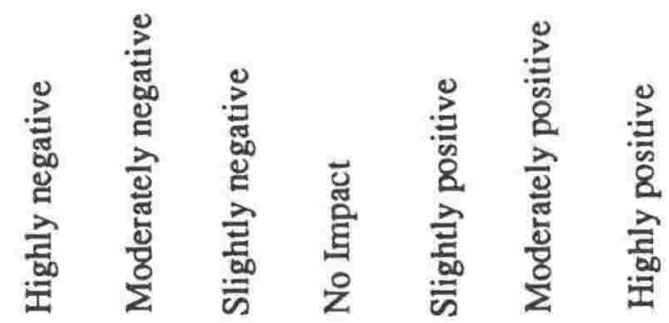

- Ability to plan

- Ability to organise

- Ability for effective decision-making

- Ability to understand \& execute duties

- Ability to motivate

- Initiative

- Ability to get things done

- Overall performance

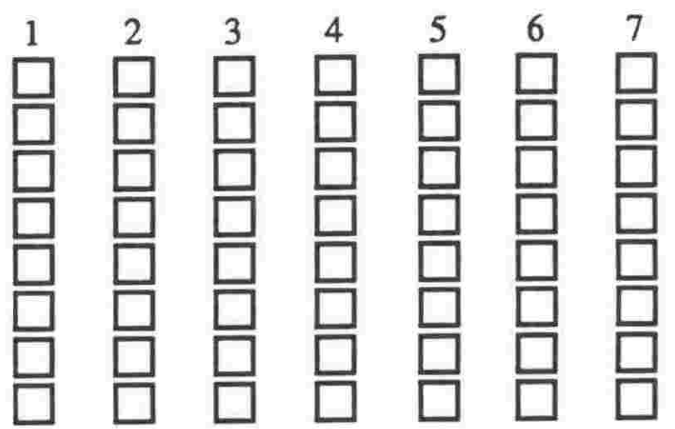

IV. Attitude toward achievement and work: The general or dominant cultural attitude toward individual or collective achievement and productive work in industry.

A. How would you characterise the cultural

attitude toward productivity in the

previously mentioned region on a scale of

1 to 7,1 being highly collective

achievement, 7 being highly

individualistic?

$$
\begin{array}{lllllll}
1 & 2 & 3 & 4 & 5 & 6 & 7
\end{array}
$$

B. Where would you place the impact of this attitude, in evaluating managerial performance, on a scale of 1 to 7 ?

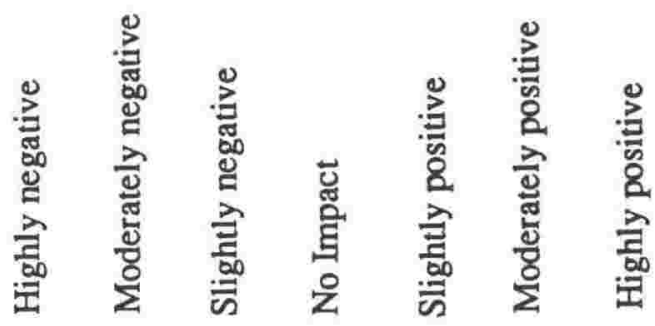

- Ability to plan

- Ability to organise

- Ability for effective decision-making

- Ability to understand \& execute duties

- Ability to motivate

- Initiative

- Ability to get things done

- Overall performance

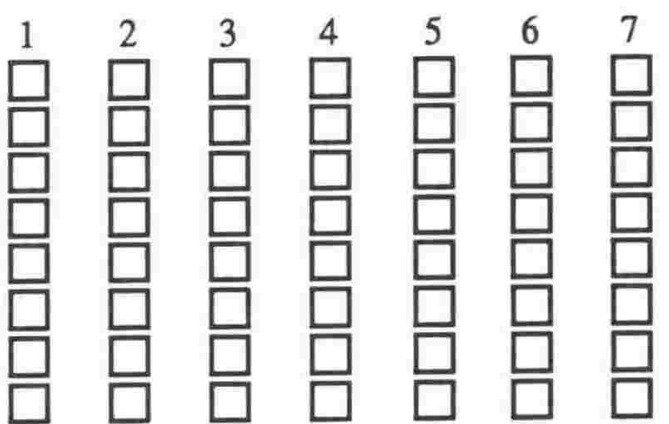


V. Class structure and individual mobility: The extent of opportunities for social class and individual mobility, both vertical and horizontal, in a given country, and the means by which it can be achieved.

A. Where would you place the opportunity for social class and individual mobility in the previously mentioned region on a scale of 1 to 7 , where 1 stands for highly unsatisfactory, and 7 for highly satisfactory?

$\begin{array}{lllllll}1 & 2 & 3 & 4 & 5 & 6 & 7\end{array}$

B. Where do you place the impact of this attitude, in evaluating managerial performance, on a scale of 1 to 7 ?

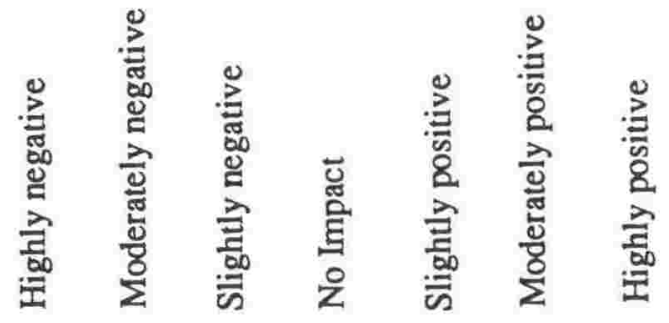

- Ability to plan

- Ability to organise

- Ability for effective decision-making

- Ability to understand \& execute duties

- Ability to motivate

- Initiative

- Ability to get things done

- Overall performance

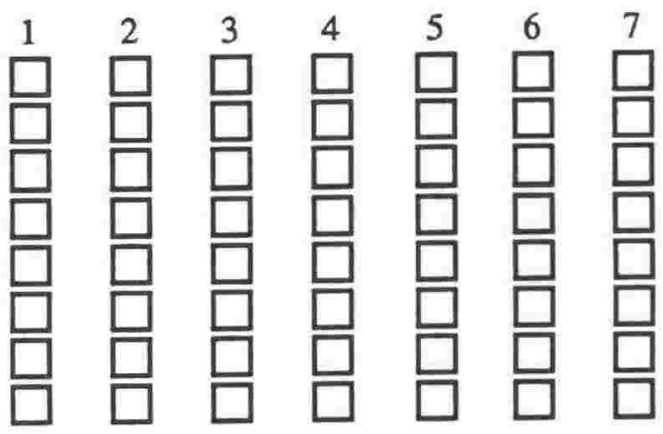

VI. Attitude toward scientific method: The general social and dominant individual attitude toward the use of rational, predictive techniques in solving various types of business, technical, economic, and social problems.

A. Where would you place the attitude toward scientific method in the previously mentioned region on a scale of 1 to 7,1 being highly unfavorable, and 7 being hightly favorable?

$\begin{array}{lllllll}1 & 2 & 3 & 4 & 5 & 6 & 7\end{array}$

B. Where do you place the impact of this attitude, in evaluating managerial performance, on a scale of 1 to 7 ?

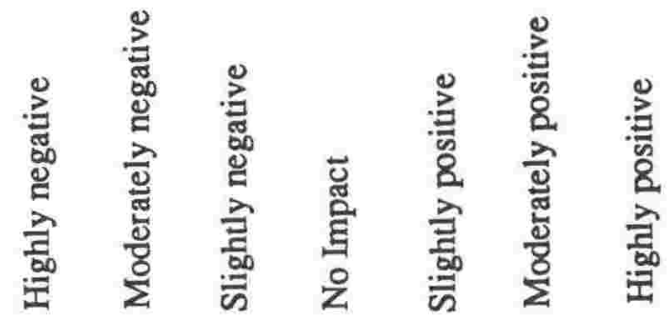

- Ability to plan

Ability to organise

- Ability for effective decision-making

- Ability to understand \& execute duties

- Ability to motivate

- Initiative

- Ability to get things done

- Overall performance

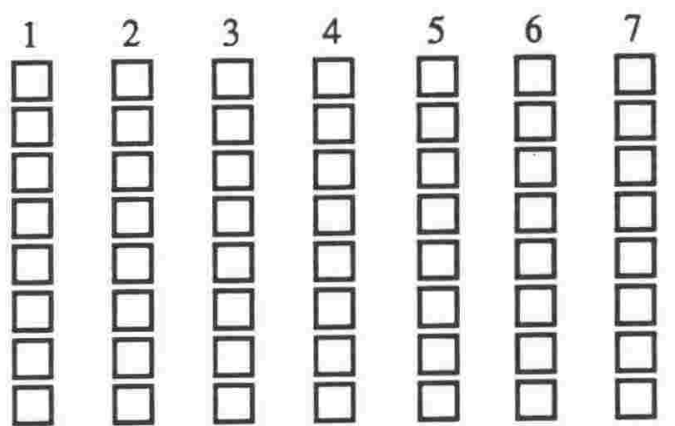


VII. Attitude toward risk taking: Whether or not the taking of various types of personal, collective or national risks is generally considered acceptable, as well as the dominant view toward specific types of risk taking in business and industry; the degree and extent to which risk taking tends to be rational process in a particular country.

A. Where would you place the attitude toward risk taking in the previously mentioned region on a scale of 1 to 7,1 being highly uncommendable, and 7 being highly commendable?

$\begin{array}{lllllll}1 & 2 & 3 & 4 & 5 & 6 & 7\end{array}$

B. Where would you place the impact of this attitude, in evaluating managerial performance, on a scale of 1 to 7 ?

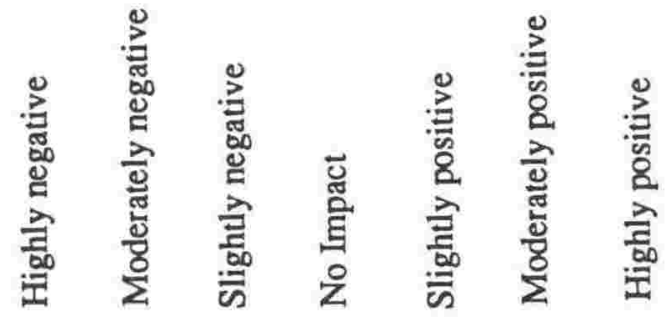

- Ability to plan

- Ability to organise

- Ability for effective decision-making

- Ability to understand \& execute duties

- Ability to motivate

- Initiative

- Ability to get things done

- Overall performance

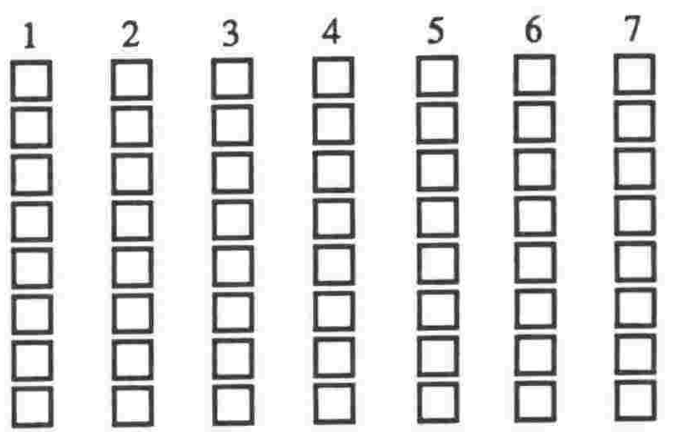

VIII. Attitude toward change: The general cultural attitude toward social changes of all types which bear directly on industrial performance in a given country, and the dominant attitude among persons employed in industry toward all types of significant changes in enterprise operations.

A. Where would you place the attitude of people in the previously mentioned region toward changer on a scale of 1 to 7 , 1 being highly unfavorable, and 7 being highly favorable?
12
4
5
7

B. Where would you place the impact of this attitude, in evaluating managerial performance, on a scale of 1 to 7 ?

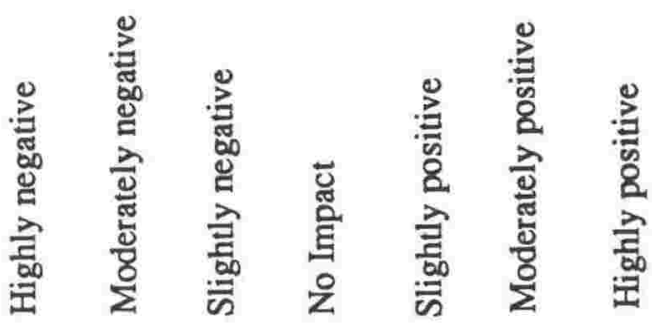

- Ability to plan

- Ability to organise

- Ability for effective decision-making

- Ability to understand \& execute duties

- Ability to motivate

- Initiative

- Ability to get things done

- Overall performance

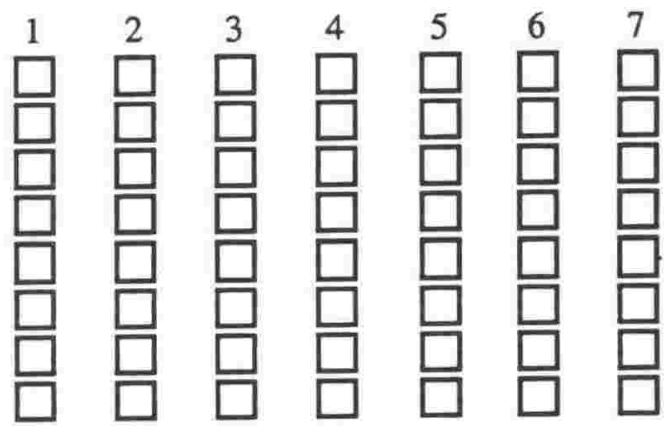


IX. Communication and language: The general features of communication process with regard to gestures, symbols, verbosity of style and degree of impliedness in the language used in oral and written communication.

A. How would you rate the communication process and language as practice in the previously mentioned region on a scale of 1 to 7,1 being highly unfavorable and 7 being highly favorable for working effectively?

$\begin{array}{lllllll}1 & 2 & 3 & 4 & 5 & 6 & 7\end{array}$

B. Where do you place the impact of this attitude, in evaluation managerial performance, on a scale of 1 to 7 ?

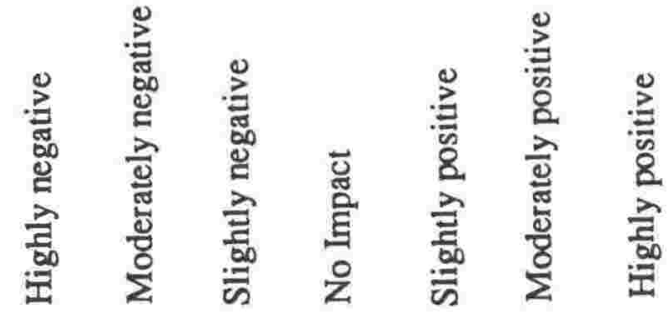

- Ability to plan

- Ability to organise

- Ability for effective decision-making

- Ability to understand \& execute duties

- Ability to motivate

- Initiative

- Ability to get things done

- Overall performance

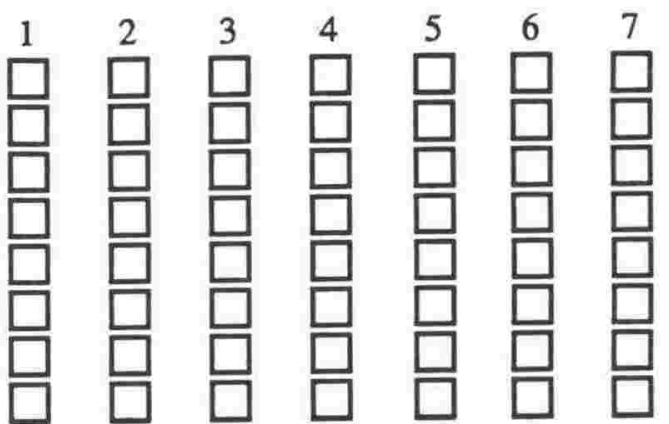

$\mathrm{X}$ Attitude toward time and time consciousness: The general attitude toward punctuality and the prevalence of difference time systems.

A. How would you rate the time

consciousness and punctuality of the employees at the previously mentiond region on a scale of 1 to 7,1 being highly unconcerned and 7 being highly concerned?

$\begin{array}{lllllll}1 & 2 & 3 & 4 & 5 & 6 & 7\end{array}$

B. Where do you place the impact of this attitude, in evaluating managerial performance, on a scale of 1 to 7 ?

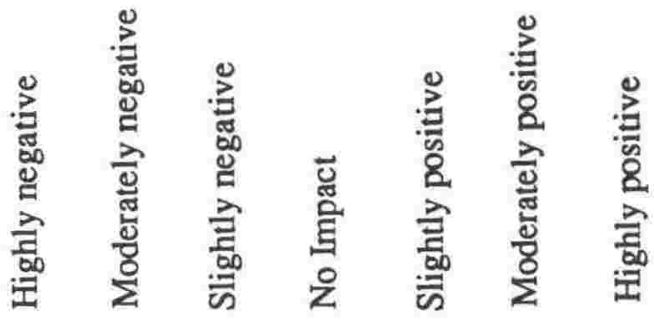

- Ability to plan

- Ability to organise

- Ability for effective decision-making

- Ability to understand \& execute duties

- Ability to motivate

- Initiative

- Ability to get things done

- Overall performance

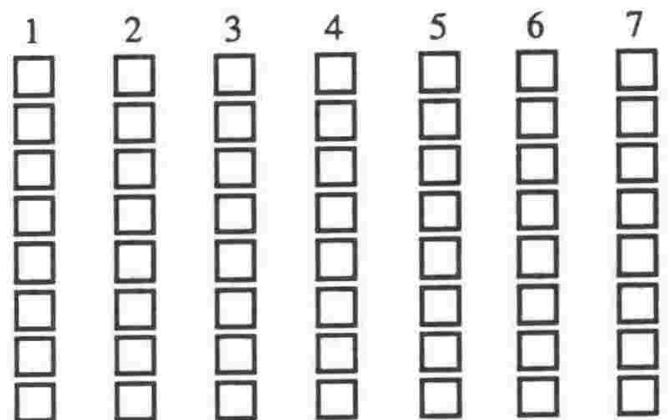


XI. Sense of self and space: Self identity and appreciation can be manifested by humble bearing in one place, while another calls for macho behavior. Some cultures require more distance between individuals, while othes - Latin, Orientals - want to get closer.

A. How would you characterise the feature of sense of self and space in the previously mentioned region on a scale of 1 to 7,1 being highly aloof, and 7 being highly cordial?

$\begin{array}{lllllll}1 & 2 & 3 & 4 & 5 & 6 & 7\end{array}$

B. Where do you place the impact of this attitude, in evaluation managerial performance, on a scale of 1 to 7 ?

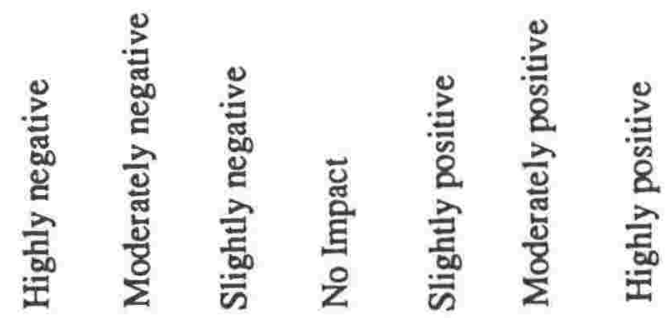

- Ability to plan

- Ability to organise

- Ability for effective decision-making

- Ability to understand \& execute duties

- Ability to motivate

- Initiative

- Ability to get things done

- Overall performance

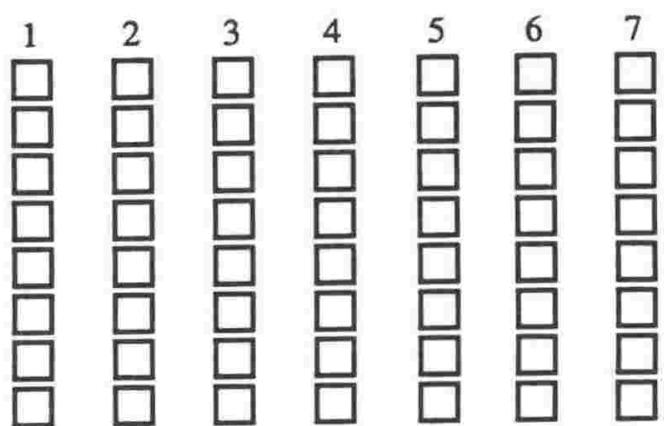

XII. Relevant legal rules of the game: Quality, efficiency, and effectiveness of the legal structure in terms of general business law, labour law, and general law relevant to business, degree of enforcement, reliability and so on.

A. Where would you place the above feature in the previously mentioned region on a scale of 1 to 7,1 being highly unsatisfactory and 7 being highly satisfactory?

$\begin{array}{lllllll}1 & 2 & 3 & 4 & 5 & 6 & 7\end{array}$

B. Where do you place the impact of this attitude, in evaluating managerial performance, on a scale of 1 to 7 ?

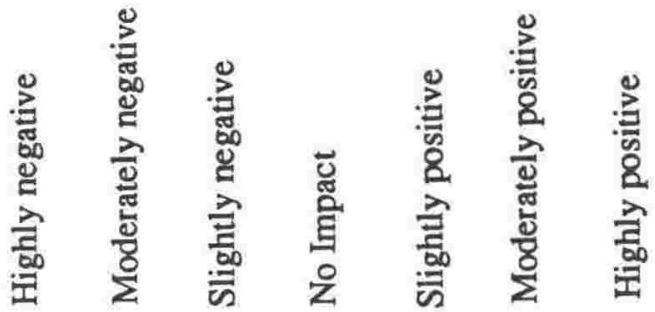

- Ability to plan

- Ability to organise

- Ability for effective decision-making

- Ability to understand \& execute duties

- Ability to motivate

- Initiative

- Ability to get things done

- Overall performance

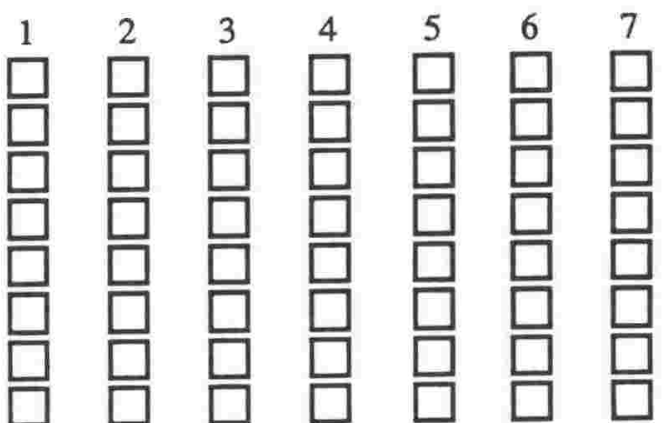




\section{BIBLIOGRAPHY}




\section{BOOKS}

Abdallah, Wagdy M., Internal Accountability: An International Emphasis. Ann Arbor, Michigan: UMI Research Press, 1984.

Adler, Nancy J., International Dimensions of Organisational Behaviour, Boston, Massachusetts: Kent Publishing 1986.

AlHashim Dhia D. and Arpan Jeffrey S, International Dimension of Accounting, 2nd Ed., Boston, Mass.: PWS-Kent Publishing Company, 1988.

Alland, A., The Human Imperative, New York: NY:, Columbia University Press, 1972.

, Evolution and Human Behaviour, 2nd Ed., New York, NY: Doubleday, 1973.

Appley, L. A., Management in Action, New York, NY.: American Management Association, 1956.

Armore, Sidney J., Introduction to Statistical Analysis and Inference for Psvchology and Education, New York, NY.: John Wiley \& Sons, Inc. , 1966.

Arensberg, Conrad M. and Niehoff, Arthur M. , Introducing Social Change: A Manual for Americans Overseas, Chicago, Illinois: Aldine Publishing Co., 1964.

Arpan, Jeffrey S. and Radebaugh, Lee, International Accounting and Multinational Enterprises, New York, NY.: Warran, Gorham and Lamont, 1981.

Bailey, F., Stratagems and Spoils: A Social Anthropology of Politics, New York, NY.: Schocken, 1969.

Bascom, W. R. and Herskovits, M. J., ed., Continuity and Change in African Cultures, 1958.

Bass, Bernard M., The American Adviser Abroad, Technical Report 27, Management Research Center of the College of Business Administration, Rochester, New York, NY.: University of Rochester, August, 1969.

Bates, Marston, Gluttons and Libertines: Human Problems of Being Natural, New York: Random House Inc., 1968.

Beals, Ralph L. and Hoijer, Harry, An Introduction to Anthropology, New York, NY.: The Macmillan Co., 1959. 
Belkaoui, Ahmed, Inquiry and Accounting: Alternate Methods and Research Perspectives, Westport, Connecticut: Quorum Books, 1987.

Benedict, Dr. Ruth, Patterns of Culture, Boston, Massachusetts: HoughtonMiffin Co., 1934.

Bennet, Spencer and Bowers, David, An Introduction to Multivariate Techniques for Social and Behavioral Sciences, New York, NY.: John Wiley \& Sons, Inc., 1976.

Berelson, Bernard and Steiner, Gary A., Human Behaviour: An Inventory of Scientific Findings, New York, NY.: Harcourt, Brace \& World, Inc., 1964.

Bernard, Chester I., The Functions of the Executive, Cambridge, Massachusetts: Harvard University Press, 1938, especially chapters 6 \& 7.

Blau, Peter M., The Dynamics of Bureaucracy, Chicago, Illinois: University of Chicago Press, 1963.

Blough, Roy, International Business: Environment and Adaptation, New York, NY.: McGraw-Hill Book Co., 1966.

Bolch, Ben W. and Huang, Cliff J., Multivariate Statistical Methods for Business and Economics, New Jersey: Prentice Hall, 1974.

Bonner, Hubert, Psychology of Personality, New York, NY.: Ronald Press Co., 1961.

Broom, Leonard and Selznick, Philip, Sociology: A Text with Adapted Readings, 3rd Ed., New York, NY.: Harper \& Row Publishers, 1963.

Burrell, Gibson and Morgan, Gareth, Sociological Paradigms and Organisational Analysis : Elements of the Sociology of Corporate Life, London: Heine-mann Educational Books Ltd, 1979.

Bursk, Edward C., Dearden, John , Hawkins, David F., and Longstreet, Victor M., Financial Control of Multinational Operations, New York, NY.: Financial Executive Research Foundation, 1971.

Burton, Thomas L. and Cherry, Gordon E., Social Research Techniques for Planners, London: George Allen and Unwin Ltd., 1970.

Caplan, Edwin H. and Champoux, Joseph E., Cases in Management Accounting: Context and Behavior, New York, NY.: National Association of Accountants, 1978.

Caves, Richard E., Multinational Enterprise and Economic Analysis Cambridge, London: Cambridge University Press, 1982. 
Ceram, C.W., Graves. Gods and Scholars, New York: Alfred A. Knopf, Inc, 1967.

Choi, Frederick D.S. and Mueller, Gerhard G., International Accounting, New Jersey, Prentice-Hall, Inc., 1984.

Christenson, Larry B., Experimental Methodology, Boston, Mass.: Allyn and Bacon Inc., 1977.

Clover,Vernon and Balsley, Howard, Business Research Methods, Columbus, Ohio: Grid Inc., 1974.

Cochrane, Glynn, The Cultural Appraisal of Development Projects, New York, NY.: Praeger Publishers, 1979.

Cunningham, G.M., An Accounting Research Framework for Multinational Enterorise, Ann Arbor, Michigan: UMI Research Press, 1978.

Czechowicz, James I., Choi, Frederick D.S. and Bavishi, Vinod B., Assessing Foreign Subsidiary Performance, New York, NY.: Business International Corporation, January, 1982.

Davis, Ralph C., Industrial Organisation and Management, New York, NY.: Harper \& Brothers, 1940, first published in 1928.

Davis, Stanley M., Comparative Management: Cultural and Organizational Perspetives, Englewood Cliffs, NJ: Prentice-Hall, Inc., 1971.

DeGreene, Kenyon B., Sociotechnical Systems: Factors in Analysis, Design and Management, Englewood Cliffs, N.J.,: Prentice Hall, 1973.

Dillman, Don A., Mail and Telephone Surveys: The Total Design Method, New York, NY.: John Wiley \& Sons, Inc., 1978.

Directory of American Firms Operating in Foreign Countries, 9th ed., New York, NY.: World Trade Academy Press, Inc. 1984.

Directory of American Firms Operating in Foreign Countries, 11th ed., New York, NY.: World Trade Academy Press, Inc., 1987.

Duoba, V. and Maindonald, J.H., eds. Understanding Surveys, Wellington: New Zealand Statistical Association Inc., 1988.

Evans, Thomas G., Taylor Martin E., and Holzmann Oscar, International Accounting and Reporting Boston, Mass.: PWS-Kent Publishing Company, 1988.

Farmer, R.N. and Richman, B.M., Comparative Management and Economic Progress, Bloomington, Ind.: Cedarwood Press, 1970, 1965.

, International Business.2nd Ed., Bloomington, Ind.: Cedarwood Press, 1974. 
, International Business.3rd Ed., Bloomington, Ind.: Cedarwood Press, 1980.

Geertz, C. , The Interpretation of Culture, New York, NY: Basic Books, 1973.

, "Person, Time and Conduct in Bali: An Essay in Culutral Analysis," Yale Southeast Program, Cultural Rep. Series No. 14, 1966.

Glenn, E., Man and Mankind: Conflict and Communication Between Cultures, Norwood, New Jersey: Ablex Publishing, 1983.

Goodenough, W. H., "Cultural Anthropology and Linguistics", in Report of the Seventh Annual Round Table Meeting on Linguistics and Language Study, ed. P Garvin, Monogr. Series No. 9, Washington D.C.: Georgetown University, 1957.

, "Culture, Language and Society," McCalb Module in Anthropology, Reading, Massachusetts: Addison-Wesley, 1971.

Green, Paul E., Analyzing Multivariate Data, Hinsdale, Illinois: The Dryden Press, 1978.

Gross, J. L. and Rayner S., Measuring Culture: A Paradiom for the Analysis of Social Organization, New York, NY.: Columbia Press, 1985.

Gudykunst, W. and Kim Y.Y., (eds.) Methods for Intercultural Communication Research, Beverly Hills, CA.: Sage Publications, 1984 (annual).

Gujarati, Damodar N. , Basic Econometrics, Singapore: McGraw-Hill Book Company, 1988.

Gutkind, P.C. and Wallerstein I., eds. Political Economy of Contemporary Africa Beverly Hills, CA: Sage Publications, 1985.

Hair, Joseph F., Anderson, Polph E., Talham, Ronald L. and Grablowsky, Bernie J., Multivariate Data Analysis, Oklahoma:Petroleum Publishing Company, 1979.

Haire, M., Ghiselli, E.E. and Porter, L.W., Managerial Thinking: An International Study, New York, NY.: John Wiley \& Sons, Inc., 1966.

Hall, Edward T., The Hidden Dimension. The Silent Language, Garden City, New York: Doubleday \& Company, Inc., 1966, 1959.

Harbison, Frederick and Myers, Charles A., Management in the Industrial World, New York, NY.: McGraw-Hill Book Co., 1959.

Harris, M. , The Rise of Cultural Theory, New York, NY: Crowell, 1929.

Harris, Philip R., " Management in Transition: Transforming Managerial Practices and Organizational Strategies for a New Work Culture, San Fransisco, CA.: Jossey-Bass, 1985. 
and Moran, Robert T., Managing Cultural Differences, 1 st Ed. Houston, Texas: Gulf Publishing Company, 1979.

Managing Cultural Differences, 2nd ed. Houston, Texas: Gulf Publishing Co., 1987.

Harris, R.J., A Primer of Multivariate Statistics, New York: Academic Press, 1975.

Harrison, P.A., Behaving Brazilian: A Comparison of Brazilian and North American Social Behavior, Yarmouth, ME: International Press, 1985.

Henle, Paul, Language. Thought. and Culture, Ann Arbor, Michigan: University of Michigan, 1958.

Herskovits, Melville J., Cultural Anthropology, New York, NY.: Alfred A. Knopf, Inc., 1963.

Hildebrand, David K., Laing, James D. and Rosenthal, Howard, Analysis of Ordinal Data, London: Sage Publications, 1977.

Hofstede, Geert, Culture's Consequences: International Differences in WorkRelated Values, Beverly Hills, California: Sage Publications, 1980.

Honigmann, John H., The World of Man, New York, NY.: Harper \& Brothers, 1959.

, Personality in Culture, New York, NY.: Harper \& Row Publishers, 1967.

Hsu, Francis L.K. (ed.), Aspects of Culture and Personality, New York, NY.: Abelard-Schuman, 1954.

Itami, H., Adaptive Behavior: Management Contrast and Information Analysis Sarasota, Fla., American Accounting Association, 1977.

Jerome, William Travers, Executive Control - The Catalyst, New York, NY.: John Wiley \& Sons, Inc., 1970.

Kmenta, Jan, Elements of Econometrics, New York, NY: Macmillan Company, 1971.

Kardiner, Abraham, The Individual and His Society and Psychodynamics of Primitive Social Organizations, New York, NY.: Columbia University Press, 1939.

Kaplan, A., Culture Theory, Englewood Cliffs, New Jersey : Prentice Hall, 1972.

Kaplan, Robert S., Advanced Management Accounting,Englewood Cliffs, New Jersey: Prentice-Hall, Inc., 1982, pp. 438-342. 
Kazdan, Alan E. , Research Design in Clinical Psychology, New York, NY.:Harper \& Row, Publishers, 1980.

Kerlinger, Fred N. Foundations of Behavioral Research, New York, NY.: Holt, Rinehart And Winston, Inc., 1973.

, and Elazer J. Pedhazur, Multiple Regression in Behavioural Research, New York, NY.: Holt, Rinehart and Winston, Inc., 1973.

Kidder, Louise H. , Research Methods in Social Relations, 4th Ed., New York,NY.: Holt, Rinehart and Winston, 1981.

Kitzinger, U.W., The Challenge of the Common Market, Oxford: Basil Blackwell, 1961.

Kluckhuhn, Clyde, Mirror for Man: A Survey of Human Behaviour and Social Attitudes, Greenwich, Connecticut: Fawcett Publications Inc., 1959.

Kluckhohn, Florence Rockwood and Strodtbeck, Fred L., Variations in Value Orientations, Evanston, Illinois: Row, Peterson \& Company,1961.

Kmenta, Jan, Elements of Econometrics, New York, NY: Macmillan Company, 1971.

Kochman, T., Black and White-Styles in Conflict, Chicago: University of Chicago Press, 1981.

Kojima, Kiyoshi, Direct Foreign Investment, London: Croom Helm Ltd., 1978.

Kolde, E.J., The Multinational Company, Massachusetts: Lexington Books, 1974.

Koontz, Harold ," The Management Theory Jungle," Academy of Management Journal, IV, No. 3, (December 1961, pp. 174-5.

Krech, D. and Crutchfiled, R.S., Theory and Problems of Social Psychology, New York, NY.: McGraw-Hill Company, Inc., 1948.

Kuhn, Alfred, The Study of Society: A Unified Approach, Homewood, Illinois: Richard D. Irwin and The Dorsey Press Inc., 1963.

Kroeber, A. L. and Kluckhohn, C., Culture: A Critical Review of Concepts and Definitions, New York, NY.: Random House/Vintage Books 1985.

Kumar, K., Social and Cultural Impact of Multinational Corporations, Hawaii: East-West Centre, 1978. , Iransnational Enterprises: Their Impact on Third World Societies and Cultures, Boulder, Colorado: Westview Press, 1980.

Levi-Strauss, C., Mythologiques, IV: L'Homme Nu, Paris, France: Plon, 1971. 
Lewis, Oscar, Five Families: Mexican Case Studies in the Culture of Poverty, New York, NY.: Basic Books, Inc., 1959.

Lienhardt, Godfrey, Social Anthropology, 2nd Ed., Oxford, U.K.: Oxford University Press, 1966.

Linton, Ralph, The Study of Man, New York, NY.: Appleton-Century, 1936.

Long Phil, Performance Appraisal Revisited London: Institute of Personnel Management, 1986.

March, J. G. and Simon, H. A. , Organizations, New York, NY.: John Wiley \& Sons, 1958.

Maxwell, E. A., Introduction to Statistical Thinking, Englewood Cliffs, New Jersey: Prentice Hall, Inc., 1983.

McClelland, David C., The Achieving Society, Princeton, New Jersey: D. Van Nostrand Co., 1961.

Miller, Elwood L., Accounting Problems of Multinational Enterprises, Massachusetts: Lexington Books, 1979.

, Responsibility Accounting and Performance Evaluation. New York, NY.: Van Nostrand Reinhold Company, 1982.

Millar, Jean, British Management versus German Management. Hampshire, England: Saxon House, 1979.

Mintzberg, Henry, The Nature of Managerial Work, New York, NY.: Harper \& Row, 1973.

Moran, Robert T. and Harris, Philip R., Managing Cultural Synergy, Houston: Gulf Publishing Company, 1982.

Morsicato, Helen G., Currency Translation and Performance Evaluation in Multinationals, Ann Arbor, Michigan:UMI Research Press, 1980.

Mueller, Gerhard G., An Introduction to International Accounting, Englewood Cliffs, New Jersey: Prentice Hall, 1965.

Norusis, Marija J. , SPSS Advanced Statistics User's Guide, Chicago, Illinois: SPSS Inc., 1990.

NeGandhi, A. R. and Prasad, B., Comparative Management. New York, NY.: Appleton-Century-Crofts, 1971.

Ouchi, William, Theory Z, Reading, MA.: Addison-Wesley,1981.

Parsons, Talcott, Theories of Society, New York, NY.: Free Press, 1961.

Pareto, Vilfredo, The Man and Society, translated and edited by Arthur Livingston, New York, NY.: Harcourt, Brace and Co., 1935. 
Pascale, Richard Tanner and Athos, Anthony G., The Art of Japanese Manage-ment ,New York, NY.: Simon and Schuster, 1981.

Persen, William and Lessig, Van, Evaluating the Financial Performance of Over-seas Operations, New York, NY.: The Financial Executives Research Foundation, 1978.

Phatak, Arvind V., Managing Multinational Corporations, New York, NY.: Praeger Publishers, 1974.

Popper Karl R., The Logic of Scientific Discovery, London: Hutchinson of London, 1969).

Poulantzas, Nicos, Political Power and Social Class, Translated by Timothy O'Hagan, London: U.K.: NLB and Sheed and Ward, 1973.

Redfield, Robert, The Primitive World and Its Transformations, Ithaka, NY.: Cornell University Press, 1953.

Renwick, G.W., Malays and Americans: Definite Differencs. Unique Opportunities, Yarmouth, ME: Intercultural Press, 1977.

Reynolds, Calvin, 1968-1973 Policy Changes Which Affect the Income of Americans Working Abroad - Preliminary Results, New York, NY.: National Foreign Trade Council, 1973.

Rich, Andrea L., Interracial Communications, New York, NY.: Harper \& Row,1974.

Robertson, Thomas S., Consumer Behavior, Glenview, Illinois.: Scott, Foresman \& Co., 1970.

Robbins, Stephen P. and Mukerji, Debu, Managing Organisations: New Challenges and Perspectives, Sydney, Australia: Prentice Hall,1990.

Robinson, Richard D., International Business Management, 2nd Ed., Hinsdale, Illinois: The Dryden Press, 1978.

Robock, Stefan M., Simmonds, Kenneth and Zwick, Jack, International Business and Multinational Enterprises, Homewood, Illinois: Richard D. Irwin, Inc., 1977.

Rugman, Alan M., Multinational in Canada: Theory. Performance, and Economic Impact. Boston, Mass.: Martinus Nijhoff Publishing, 1980.

Sapienza, Alice M., "Organisational Culture and Leadership, San Francisco, CA.: Jossey-Bass, 1985.

Sapir, Edward, Selected Writings in Language. Culture and Personality, ed. by David Goodman Mandelbaum, Berkeley, CA.: University of California Press, 1949. 
SAS/STAT User's Guide, Release 6.03 Ed., (Cary, NC: SAS Institute Inc.), pp. 19-23 and Chapter 11.

SAS/STAT User's Guide, version 6, fourth Edition, 1990, pp. 1418.

Schaupp, Deitrick L., A Cross-Cultural Study of a Multinational Company, New York, NY.: Praeger Publishers Co., 1978.

Schneider, D., American Kinship : A Cultural Account, Englewood, NJ.: Prentice Hall, 1968.

Schnitzer, M.C., Liebrenz, M. L. and Kubin, K. K., International Business, Cincinnati, Ohio: South-Western Publishing, 1985.

Schoenfeld, Hanns-Martin W., "The Present State of Performance Evaluation in Multinational Companies," in Managerial Accounting and Analysis in Multinational Enterprises eds. H.P. Holzer and H.M. Schoenfeld, New York: Walter de Gruyter 1986.

Scott, William G., Organisation Theory: A Behavioral Analysis for Management, Homewood, Illinois: Richard D. Irwin, Inc., 1967.

Selvarajah, Christopher T. and Cutbush-Sabine, Katrin, eds., International Business, Melbourne: Longman Cheshire, 1991.

Shapiro, A. C., Multinational Financial Management, Boston, Massachusetts: Allyn and Bacon, Inc.,1982.

Shea, G.F., Managing a Difficult or Hostile Audience, Englewood Cliffs, N.J.: Prentice Hall, 1984.

Simon, Julian L. , Basic Research Methods in Social Science: The Art of Empirical Investigation, New York, NY.: Random House,1969.

Solomons, David, Division Performance: Measurement and Control, Homewood, Illinois.: Richard D. Irwin, 1968.

Spengler, Oswald ," On the Style-Patterns of Culture," in Theories of Society: Foundations of Modern Sociological Theory, Vol. II, ed. Talcott Parsons, Edward Shils et. al., New York, NY.: The Free Press of Glencoe, Inc., 1961.

Stopford, John M. and Dunning John H., Multinational Company Perfor-mance and Global Trends, London: Macmillan Publishers Ltd., 1983.

Tatsuoka, Maurice M., Multivariate Analysis, New York, NY.: John Wiley \& Sons, Inc., 1971.

, Discriminant Analysis: The Study of Group Differences, Illinois: Institute for Personality and Ability Testing, 1970.

Taylor, Edward B., Primitive Culture: Researches into the Development of Mythology. Philosophy. Religion. Lanquage. Art and Custom, New York, NY.: Henry Holt \& Co., 1977. 
Terpstra, V., The Cultural Environment of International Business, Cincinnati, Ohio: South-Western Publishing Co., 1978.

Thiagarajan, K.M., A Cross-Cultural Study of the Relationships Between Personal Values and Managerial Behavior, Technical Report 23, NONR N00014-67A, Rochester, NY: University of Rochester, Management Research Center, 1968.

Thompson, Laura, Toward a Science of Mankind, New York, NY.: McGraw Hill, 1961.

Timm, Neil H., Multivariate Analysis With Applications in Education and Psychology, Monterey, CA: Brooks/Cole Publishing Co., 1975, pp. 203-6.

Torgersen, Paul E. and Weinstock, Irwin T., Management: An Integrated Approach, Englewood Cliffs, New Jersey: Prentice-Hall, Inc., 1972.

Tucker, W.T., Foundations for a Theory of Consumer Behaviour, New York, NY.: Holt Rinehart and Winston, 1967.

Wadia, Maneck S., Management and the Behavioural Sciences, Boston, Mass. : Allyn and Bacon, Inc., 1968.

Warwick, Donald P. and Liniger, Charles A., The Sample Survey Theory and Practice, New York, NY. : McGraw Hill Book Co., 1975.

Watt, G., Hammer, R. and Burge, M., Accounting for Multinational Corporation, New York, NY.: Financial Executives Research Institute, 1977.

Webber, Ross A., Culture and Management, Homewood, Illinois: Richard D. Irwin,1969.

White, Leslie A., The Science of Culture: A Study of Man and Civilisation, New York, NY.: Farrar, Straus and Cudahy, 1949.

Wilkins, Mira, The Maturing of Multinational Enterprise: American Business Abroad from 1914 to 1970 , Boston, Mass.: Harvard University Press, 1974.

Winkler, Robert L. and Hayes, William L., Statistics: Probability, Inference, and Decision, New York, NY.: Holt, Rinehart and Winston, 1975.

Young, Pauline V. and Schmid, Calvin F., Scientific Social Surveys and Research, Englewood Cliffs, New Jersey: Prentice Hall, Inc., 1966. 


\section{ARTICLES}

Abegglen, J.C., "Subordination and Autonomy Attitudes of Javanese Workers," American Journal of Scoiology, Vol. 63, No. 1, 1957, pp. 181-9.

Adler, Nancy J., "A Typology of Management Studies Involving Culture," Journal of International Business Studies, Fall 1983, pp. 29-47.

Adler, Nancy J., "Cross-Cultural Management: The Ostrich and the Trend," Academy of Management Review, vol. 8, No.2, April 1983, pp. 22632.

"Expecting International Success: Female Managers Overseas," Columbia Journal of World Business, vol. 19, No. 3, Fall 1984, pp. 7986.

. and Jelinek, Mariann, " Is Organization Culture" Culture Bound?" Human Resource Management. vol. 25, No.1, Spring 1986, pp.73-90.

Ajiferuke and Boddewyn, J., "Culture and Other Explanatory Variables in Comparative Management Studies," Academy of Management Journal, June 1970, pp. 153-78.

Anderson, Lynn R., Self-Monitoring and Managerial Effectiveness, Working Paper No. 7, The Department of Management Studies, The University of Auckland, Auckland, New Zealand, 1981, pp. 1-22.

Anderson, Norman H., "Scales and Statistics: Parametric and Nonparametric," Psychological Bulletin. 58, 1961, pp. 305-16.

Ansari, Shahid L. and Bell, Jan "Symbolisim, Collectivism and Rationality in Organisational Control, "Accounting. Auditing \& Accounability Journal, vol. 4, No. 2, 1991, pp. 4-27.

Baker, James C. and Ivancevich, John M., "A Comparative Study of the Satisfaction of Domestic United States Managers and Overseas United States Managers," Academy of Management Journal, March 1970, pp. 69-77.

Banks, Howard, "Bankruptcy Without Pain, " Eorbes, 29th April, 1985, pp. 1102.

Barrett, G.V. and Bass, B. M., "Comparative Surveys of Managerial Attitudes and Behavior," in Comparative Management: Teaching. Research and Training, ed. J. Boddewyn, New York: Comparative School of Business Administration, 1970, pp. 170-207.

Bateson, Gregory, "Cultural Determinants of Personality" in Personality and the Behavior Disorders, ed. J. McV. Hunt, New York, NY: Ronald Press, 1944, p. 273. 
Binford, L.R., "Post-Pleistocene Adaptations", in New Perspectives in Archaeology, ed. L.R. Binford and S.R. Binford, Chicago, Illinois: Aldine, 1968, p. 311.

Birenberg, J.G. and Raghunath," Implications of Behavioral Science for Managerial Accounting," Accounting Review, July 1967, pp. 468-79;

Boddewyn, Jean J., "Political Aspects of MNE Theory," Journal of International Business Studies, Fall 1988, pp. 341-63

Brandt, William K. and Hulbert, James M., "Patterns of Communications in Multinational Corporations: An Empirical Study", Journal of International Business Studies, Spring, 1976, pp. 55-8.

Bruns, William J. Jr., "Accounting Information and Decision Making: Some Behavioural Hypotheses," Accounting Review , July 1968, pp. 469-80.

Buckley, Peter J., " A Critical View of Theories of the Multinational Enterprise," edited by Peter J. Buckley and Mark Casson, The Economic Theory of The Multinational Enterprise, London: The Macmillan Press Limited, 1985, pp. 1-20.

Buzzell, R.D., Gale, B.T. and Sultan, R.G.M., "Market Share - A Key to Profitability," Harvard Business Review, January-February, 1975, p. 97.

Cantwell, John A. and Corley T.A.B., "The Theory of International Production: Some Historical Antecedents in Multinational: Theory and History edited by Peter Hertner and Geoffrey Jones, Brookfield, Vermont: Gower Publishing Company, 1986, pp. 19-42

Child, John, "Culture, Contingency and Capitalism in the Cross-National Study of Organizations," in Research in Organizational Behavior. vol. III, edited by L.L. Cummings and B.M. Shaw, Greenwich, Ct.: JAI Press, 1981.

and Monir Tayeb, "Theoretical Perspective in Cross-National Organizational Research," International Studies of Management and Organization, Winter 1982-3, pp. 23-70,

Currie, John, "The Role of Quantitative Models in Management Accounting Education," British Accounting Review, Vol. 24, No. 1, March 1992. pp. 3-16

Davidson, William H., "Administrative Orientation and International Performance," Journal of International Business Studies, Fall 1984, pp. 11-23.

Davies, Celia and Francis, Arthur, "There is More to Performance than Profits or Growth," Organizational Dynamics, Winter 1975, pp. 51-65. 
Demirag, Istemi S., "The Treatment of Exchange Rates in Internal Performance Evaluation," Accounting and Business Research, Spring 1986, pp. $157-63$.

,"How U.K. Companies Measure Overseas Performance," Accountancy, March and April 1987, pp. 101-3 and 87-90.

"Multinational Performance Measures and Their Association with Contextual Variables," Accounting and Business Research, vol. 20 No. 80, Autumn 1990, pp. 275-85.

"Assessing Foreign Subsidiary Performance: The Currency Choice of UK MNCs", Journal of International Business Studies, Spring 1988, pp. 257-75.

deVries, Henry P., "The Language Barriers," Columbia Journal of World Business, July-August, 1969, p.79.

Dowling, Peter J. and Nagel, Trevor W., "The Influence of Culture on Work Attitudes: A Study of Australian and American Threshold Managers," Working Paper No. 1. The Graduate School of Management, The University of Melbourne, May 1985, pp. 1-26.

Etemad, Hamid and Dulude, Louise Seguin, "Managing The Multinational Subsidiary", in Managing The Multinational Subsidiary: Response to Enviromental Change and to Host Nation R \& D Policies. edited by Etemad Hamid and Dulude, Louise Seguin, London: Croom Helm, 1986, pp. 1-21.

Farmer, R. and Richman, B.A., "A Model for Research in Comparative Management," California Management Review, vol. 4, No. 2, 1964, pp. $55-68$,

Feldman, J. M., Sam, I. A., McDonald, W.F., and Bechtel, G. G., "Work Outcome Preference and Evaluation: A Study of Three Ethnic Groups," Journal of Cross-Cultural Psychology, 1980, pp. 444-68.

Frank, Allan Dodds, "We Have Had Our Recession, " Eorbes, 3rd January 1983.

Franko, Lawrance, G., "Who Manages Multinational Enterprises?," Columbia Journal of World Business, Summer 1973, pp. 30-42.

Fry, Louis W. and Smith, Deborah A. , "Congruence, Contingency, and Theory Building," Academy of Management Review, January, 1987, pp. 117132.

Garratt, Bob, "Contrasts in Chinese and Western Management Thinking," LODJ. 2, 1 1981, pp. 17-22.

Geertz,C.,"Ritual and Social Change, A Javanese Example", American Anthropology, No. 59, 1957, p. 992. 
, "The Growth of Culture and the Evolution of Mind," in Theories of Mind, ed. by J. Scher, Glencoe, Illinois: Free Press, 1962, pp. 713-40.

"Ideology as a Cultural System", in Ideology and Discontent, ed. by

D. Apter, Glencoe, Illinois: Free Press, 1964, pp. 47-56.

"The Impact of the Concept of Culture on the Concept of Man," in New Views on the Nature of Man, ed. by J. R. Platt, Chicago, Illinois: University of Chicago Press, 1965, pp. 93-118.

," Person, Time and Conduct in Bali: An Essay in Cultural Analysis," Yale Southeast Program, Cultural Rep. Series No. 14, 1966.

Geneen, Harold S., "The Case for Managing by the Numbers", Eortune, October, 1,1984.

Ghoshal, Sumantra and Bartlett, Cristopher A., "Creation, Adoption, and Diffusion of Innovation by Subsidiaries of Multinational Corporations," Journal of International Business Studies, Fall 1988, pp.365-87.

Goodenough, W. H., "Comment on Cultural Evolution", Daedalus, 1961, pp. 522.

, "Culture, Language and Society," McCalb Module in Anthropology, Reading, Massachusetts: Addison-Wesley, 1971.

, "Cultural Anthropology and Linguistics", in Report of the Seventh Annual Round Table Meeting on Linguistics and Language Study, ed. P Garvin, Monogr. Series No. 9, Washington D. C.: Georgetown University, 1957.

Gordon, R., "Issues in Multiple Regression," Journal of Sociology, LXXIII, 1968, pp. 592-616.

Graham, John L., "The Influence of Culture on the Process of Business Negotiations: An Exploratory Study," Journal of International Business Studies, Spring 1985, pp. 81-96.

Gullahorn, J. T. and Gullahorn, J. E., "An Extension of the U-Curve Hypothesis," Journal of Social Sciences, January 1963, pp. 34-47.

Hall, David J. and Amado-Fischgrund, Gilles, "Chief Executive in Britain," European Business, January, 1969.

Harari, E. and Zeira, Y., "Attitudes of Japanese and Non-Japanese Employees: A Cross-National Comparison in Uninational and Multinational Corpo-rations," International Journal of Comparative Sociology, September-October 1977, pp. 3-5.

Harris, Marvin, "The Sleep-Crawling Question," Psychology Today, May 1983, pp.26-7. 
Hayes, J. and Allinson C.W., "Cultural Differences in the Learning Styles of Managers," (Research Note) Management International Review vol. 28, No. 3,1988 , pp. $75-80$.

Hays, R., "Expatriate Selection Insuring Success and Avoiding Failure," Journal of International Business Studies, No. 1,1974, pp. 25-37.

Hendry, Chris, "HRM in Internationalisation and Domestic Business Management: Is There Any Difference," Research Paper No. 63, Warwick Business Research Bureau, 1992, pp. 1-23.

Hertner, Peter and Jones, Geoffrey, "Multinational:Theory and History", in Multinational:Theory and History edited by Hertner, Peter and Jones, Geoffrey, Brookfield, Vermont: Gower Publishing Company, 1986, pp. 1-18.

Hickson, David J. , Hinings, C. R. , McMillan, C. J. and Schwitter, J. P., "The Culture-Free Context of Organization Structure: A Tri-National Comparison," Sociology, Vol. 8, 1974, pp. 59-80.

Hofstede, Geert, "The Cultural Context of Accounting", in Accounting and Culture edited by Barry E. Cushing, American Accounting Association, 1987, pp. 1-4

, "The Cultural Relativity in Organizational Practices and Theories", Journal of International Business Studies, Fall 1983, pp. 75-89.

Motivation, Leadership and Organisation: Do American Theories Apply Abroad," Organisational Dynamics, Summer 1980, pp. 42-63.

"The Ritual Nature of Accounting Systems," Paper presented at EISAM Workshop Accounting and Culture, Amsterdam, June 5-7, 1985.

Hofstedt, T.R. and J.C. Kinard, "A Strategy for Behavioral Accounting Research," Accounting Review. January 1970, pp. 38-54.

Holloway, R.J. Jr., "Culture a Human Domain", Curr. Anthropology,_10: pp. 395-407.

Hosseni, A. and Aggarwal, R., "Evaluating Foreign Affiliates: The Impact of Alternative Foreign Currency Translation Methods," International Journal of Accounting: Education and Research, Fall 1983, pp. 65-87,

Jacobson, Lyle, "Multinational Accounting: Research Priorities for the Eighties-Latin America," in Multinational Accounting A Research Framework for the Eighties edited by Frederick D.S. Choi, Ann Arbor: Michigan, UMI Research Press, 1981, pp. 221-39;

Jaeger, Alfred M., "The Transfer of Organizational Culture Overseas: An Approach to Control in the Multinational Corporation," Journal of International Business Studies, Fall 1983, pp. 91-114. 
Jaunch, Lawrance R., Osborn, Richard N., and Martin, Thomas N., "Structured Content Analysis of Cases: A Complementary Method for Organizational Research," Academy of Management Review, vol. 5, No.4, 1980, pp. 517-25.

Kanungo, Rabindra N. and Wright, Richard W., "A Cross-Cultural Comparative Study of Managerial Job Attitudes, "Journal of International Business Studies, " vol. 14, No. 2, (Fall 1983), pp. 115-129.

Keesing, Roger M. ,"Theories of Culture", Annual Review of Anthropology, 1974, pp. 73-97.

Kelley, Lane and Worthley, Reginald, "The Role of Culture in Comparative Management: A Cross-Cultural Perspective," Academy of Management Journal, vol. 24, No.1, 1981, pp. 164-173,

Kelley, Lane, Whatley, Arthur, and Worthley, Reginald, "Assessing The Effects of Culture on Managerial Attitudes: A Three-Culture Test," Journal of International Business Studies, vol. 18, No. 2 (Summer 1987), pp. 1731.

Kluckhuhn, Clyde ," Values and Value Orientations in the Theory of Action," in Toward a General Theory of Action, ed., Talcott Parson, Edward A. Shils et. al., Cambridge, Massachusetts: Harvard University Press, 1951, pp. 409-10.

, "Universal Category of Culture," in Anthropology Today, ed. Alfred C. Kroeber, Chicago, Illinois: University of Chicago Press, 1953, pp. 507-24.

, and Kelby, William, "The Concept of Culture," in The Science of Man in World Crises, edited by Ralph Linton, New York, NY.: Columbia University Press, 1945, pp. 95-101.

Knotts, Rose, "Cross-Cultural Management: Transformations and Adaptations," Business Horizons, vol. 32, No. 1, Jan.-Feb. 1989, pp. 29-33.

Koontz, Harold, "The Management Theory Jungle," Academy of Management Journal, IV, No. 3, December 1961, pp. 174-5

Kroeber, A. L. and Kluckhohn, Clyde, "Culture: A Critical Review of Concepts and Definitions," Papers of the Peabody Museum of Archeology and Ethnology, vol. XLVII, Cambridge: Massachusetts: Harvard University Press, 1952, pp.18-33. Also available in book now.

Lane, H.W., "Systems, Values and Action: An Analytic Framework For Intercultural Management Research," Management International Review, vol. 20, No. 3, 1980, pp. 61-70.

Laurent, Andre, "The Cross-Cultural Puzzle of International Human Resource Management," Human Resource Management, vol. 25, No. 1, (Spring 1986), pp. 91-102. 
"The Cultural Diversity of Western Management Conceptions," International Studies of Management and Organization, vol. XIII, No. 12, Spring/Summer 1983, pp. 75-96.

, "Cultural Dimensions of Managerial Ideologies: National Versus Multinational Cultures," Presented at the Fifth Annual Meeting of the European International Business Association, London Business School, December 12-14, 1979, pp.1-17;

Lee, James A., "Cultural Analysis in Overseas Operations, "Harvard Business Review, March-April, 1966, pp. 106-14.

Maddox, Robert C. and Short, Douglas, "The Cultural Integrator, "Business Horizons, vol. 31, No. 6, November-December 1988, pp. 57-9.

Man, Jeremy, "The Argentinian Web Trapping U.S. Lenders," Fortune, 20th August 1984, pp. 122-32.

Martyn-Johns, T.A., "Cultural Conditioning of Views of Authority and Its Effect on the BusinessDecision-Making Process with Special Reference to Java," in Basic Problems in Cross-Cultural Psychology, ed. Y.H. Poortinga, Amsterdam: Swets and Zeitlinger, 1977, pp. $344-52$.

Mauriel, John J., "Evaluation and Control of Overseas Operations," Management Accounting, March 1969, pp. 35-52.

McDonald, John G., "New Organizational Concept of the World Enterprise," Management International, No. 5-6, 1961, pp. 7-25.

Mclnnes, J.M., "Financial Control Systems for Multinational Operations: An Empirical Investigation," Journal of International Business Studies, Fall 1971, p. 12.

McKinnon, Jill, "Cultural Constraints on Audit Independence in Japan," The International Journal of Accounting: Education and Research, Fall 1984, pp.17-43.

Mead, George H., "From Gesture to Symbol," in Theories of Society: Foundations of Modern Sociological Theory, Vol. II, en. cit., pp. 9991005.

Meillet, Antoine, "How Words Change Their Meanings," in Theories of Society: Foundations of Modern Sociological Theory, Vol. II, ㅇp. cit., pp. 101318.

Mendenhall, Mark and Oddou Gary, "Acculturation Profiles of Expatriate Managers: Implications for Cross-Cultural Training Programs," The Columbia Journal of World Business, vol. 21, No. 4, winter 1986), pp. 73-79. 
Miller, Edwin L., "Managerial Qualification of Personnel Occupying Overseas Management Positions as Perceived by American Expatriate Managers," Journal of International Business Studies , SpringSummer, 1977, p. 57.

Morsicato, Helen G. and Diamond, Michael, A., "An Approach to Environmentalizing Multinational Enterprise Performance Evaluation Systems," The International Journal Accounting: Education and Research, vol. 16, No.1, Fall 1980, pp. 248-66.

Mouton, J. and Black, R., "Issues in Transnational Organization Development," in Managing for Accomplishments, edited by B.M. Bass, et al., Massachusetts.: Lexington Books, 1970.

Mueller, Gerhard G., "Accounting Principles Generally Accepted in the United States versus Those Generally Accepted Elsewhere," International Journal of Accounting, Spring 1968, pp. 83-94.

Murdock, George P., "The Common Denominator of Cultures," in The Science of Man in the World Crises, edited by Ralph Linton, New York, NY.: Columbia University Press, 1945, pp. 123-42.

Narain, Dhirendra, "Indian National Character in the Twentieth Century," Annals, March, 1967, pp. 124-132.

Nath R., "A Methodological Review of Cross-Cultural Management Research," in Comparative Management and Marketing, edited by J. Boddewyn, Glenview, II.: Scott, Foresman, 1969, pp. 195-223.

NeGandhi, Anant R., "Three Decades of Cross-Cultural Management Research: Alice in Wonderland," in The Enterprise and Management in East Asia, eds Stewart R. Clegg, Dexter C. Dunphy and S. Gordon Redding, Hong Kong: Centre of Asian Studies, University of Hong Kong, 1986, pp 35-66.

,Cross-Cultural Management Research: Trend and Future Directions," Journal of International Business Studies, vol. 14, No. 2 , (Fall 1983), pp. 17-28.

"Comparative Management and Organization Theory: A Marriage Needed," Academy of Managemnt Journal, June 1975, pp. 334-43.

, and Estafen, B.D., "A Research Model to Determine the Applicability of American Know-how in Different Cultures and/or Environments," Academy of Management Journal, December 1965, pp. 309-18.

Newman, William H., "Is Management Exportable?" Columbia Journal of World Business, January-February, 1970, pp. 7-8.

Odiorne, George S., "Measuring the Unmeasurable: Setting Standards for Management Performance," Business Horizons, vol. 30, No. 4, (JulyAugust 1987), pp. 69-75. 
Opler, Morris E., "Some Recently Developed Concepts Relating to Culture," Southwestern Journal of Anthropology, vol. 4, 1948, pp. 105-125.

, "Themes as Dynamic Forces in Culture," American Journal of Sociology, November 1945, pp. 190-207.

Parsons, Talcott, "Suggestions for a Sociological Approach to the Theory of Organizations," Administrative Science Quarterly, vol. 1, No. 1, 1956, pp. 63-85.

Pass, Chris and Neale Bill, "The Multinational Corporation in the UK Economy," Management Accounting, January 1990, pp. 30-32.

Redding, S.G., "Cognition As An Aspect of Culture and Its Relation to Management Processes: An Exploratory View of the Chinese Case," Journal of Management Studies, vol. 17, May 1980, pp. 127-48.

Reeder, John A.," When West Meets East: Cultural Aspects of doing Business in Asia," Business Horizons, January-February, 1987, pp. 69-74.

Renwick, G.W., "If Australian are Arrogant, Are Americans Boring?" The Bridge, Summer 1980.

Robbins, Sidney M. and Stobaugh, Robert B., "The Bent Measuring Stick for Foreign Subsidiaries," Harvard Business Review, Sept.-Oct. 1973, pp. 80-88.

Roethlisberger, Fritz J., "Contributions of the Behavioral Sciences to a General Theory of Management," in Toward a Unified Theory of Management, ed. Harold Koontz, New York, NY.: McGraw-Hill Book Co., Inc., 1964.

Ruff, Henry J. and Jackson, Graham I., "Methodological Problems in International Comparisons of the Cost of Living," Journal of International Business Studies, Fall 1974, pp. 57-67.

Runglertkrengkrai, Somkao and Engkaninan, Suda, "The Pattern of Managerial Behaviour in Thai Culture," Asia Pacific Journal of Management. Vol. 5, No. 1, September, 1987, pp.8-15.

Sadler, P.J. and Hofstede, G.H., "Leadership Styles: Preferences and Perceptions of Employees of an International Company in Different Countries," Mens en Onderiming 26 , 1972, pp. 43-62.

Sapienza, Alice M., "Believing is Seeing: How Culture Influences the Decisions Top Managers Make," in Ralph H. Kilman et. al (eds) Gaining Control of the Corporate Culture, San Francisco, CA.: JosseyBass, 1985.

Sapir, Edward ," Symbolism," in Encyclopaedia of the Social Sciences, New York, NY.: MacMillan Company, 1930, pp. 492-95. 
Stephens, D.B., "Cultural Variation in Leadership Style: A Methodological Experiment in Comparing Managers in the U.S. and Peruvian Textile Industries," Management International Review, vol. 21, No. 3, 1981, pp. 47-55.

Thurstone, L. L., "Attitudes Can be Measured," The American Journal of Sociology January 1928, pp. 529-54.

Tse, David K., Lee, Kam-hon, Vertinsky, llan, and Wehrung, Donald A., "Does Culture Matter? A Cross-Cultural Study of Executives' Choice, Decisiveness, and Risk Adjustment in International Marketing," Journal of Marketing, vol. 52, October 1988, pp. 81-95

Tse, Paul, "Evaluating Performance in Multinational," Management Accounting, June 1979, pp. 21-5.

Tung, Rosalie L., "Selection and Training of Personnel for Overseas Assignments," Columbia Journal of World Business, Spring 1981, pp. 68-78

, "Cross-Cultural Managerial Research: The Ostrich and the Trend," Academy of Management Review, April 1983, 226-32.

Vancil, Richard F., "What Kind of Management Control Do You Need?" Harvard Business Review, March-April, 1973.

Vermeulen, C. J. J. and Ruijter, A. de, "Dominant Epistemological Presuppositions in the Use of the Cross-Cultural Survey Method," Current Anthropology Vol. 16, No. 1, March 1975, pp. 29-52.

Wadia, Maneck S., "The Concept of Culture in the Analysis of Consumers," American Marketing Association Proceedings, 1967, pp. 186-190.

, "The Concept of Culture," Journal of Retailing, vol. 41, No.1, Spring 1965, pp. 21-30.

Walker, Patricia C., "U.S. Direct Investment Abroad in 1987," Survey of Current Business.U.S. Department of Commerce, vol. 68, No.8, August 1988, pp. 40-60.

Wilkins, Mira, "Defining a Firm: History and Theory," in Multinational:Theory and History edited by Hertner, Peter and Jones, Geoffrey, Brookfield, Vermont:: Gower Publishing Company, 1986, pp. 80-96.

Zeira, Yorman, "Rotation of Expatriates in MNEs," Management International Beview, 16, Fall 1976, pp. 37-46.

Zlatkovich, Charles T., A Statement of Basic Accounting Theory, Evanston, Illinois: American Accounting Association 1966. 


\section{MISCELLANEOUS}

Abu-Jbarah, Hani Mahmond, "A Subentity for Financial Reporting by Multinational Firms: A Cluster Analysis Approach" (Ph.D. Dissertation, University of Wisconsin, 1972).

Boyacigiller, Nakiye Avdan ," Why Multinational Corporations Use Expatriates: An Organizational and Environmental Study," (Ph. D. Dissertation, University of California, Berkeley, 1986).

Can,Sigma," Non-Financial Indicators in Performance Evaluation of Multinational Enterprises: Exploring the Use of Fuzzy Outranking Relations," (Ph.D. Dissertation, Unniversity of Illinois at Urbana Champaign, 1988).

Davar, V., "An Empirical Study of the Underlying Determinants of CultureShock Manifestation in American Expatriates" (Ph.D. Dissertation, The University of Nebraska, 1978).

Dugan, John A., "The Relationship Between Culture and Managers' Behavioral Decisions: A Two Country Study of the Preference Formation and Choice Processes, "(Ph. D. Dissertation, Temple University, 1984).

Fleming, R.J., "Cultural Determinants of the Effectiveness of American Executives Abroad" (Ph.D. Dissertation, Louisiana State University, 1966).

Gonzales, Richard F. and Negandhi, Anant R., The United States Overseas Executive: His Orientations and Career Patterns (Institute for international Business and Economic Development Studies, Division of Research, Graduate School of Business Administration, Michigan State University, East Lansing, Michigan, 1966).

Gaston, J., Frank, Director, International Studies - Conference Board, letter dated February 17, 1982.

Harandi, Farhad Fassihi ," A Comparative Study of Cultural Attitudes Underlying Management Practices of Iranian and American Managers,"( Ph.D. Dissertation, United States Intenational University, 1984), pp. 161.

Irish, Robert Reon, "The Measurement of Divisional Performance in Terms of Accounting Data" (Ph.D. Dissertation, University of Texas at Austin, 1977).

Ivancevich, J. M., The American Manager Overseas Representing Large U.S. Industrial Corporations: A Study of Selected Staffing Steps and Job Attitudes, Ann Arbor, Michigan: University of Microfilm, Inc., 1969. 
Jangho, Lee, "Strategic Choice, Foreign Involvement, and Firm Performance," (Ph.D. Dissertation, University of Washington, 1986).

Kurashi, Mohammed Farid Yasin, "The Social Responsibility of the Multinational Corporations Operating in Saudi Arabia," (Ph.D. Dissertation, Claremont Graduate School, 1984).

Lee, Francis A., "Reporting Transnational Business Operations", Research Report No. 780, The Conference Board, 1980.

Lee, Yosup ,"A Comparative Study of Manager's Perceptions in Korea and the United States on Selected Socio-Cultural Dimensions," (Ph.D. Dissertation, Claremont Graduate School, 1982), pp. 157.

Likert, R., "Trends Towards a World-wide Theory of Management", Proceedings of the CIOS XIII International Management Congress 2 , 1963.

Maher, Abu-Hilal, "Foreign Students' Interaction, Satisfaction and Attitudes Toward Certain Aspects of the American Culture: A Case Study of Arab Students in Southern California" (Ph.D. Dissertation, University of California, Riverdale, 1986).

Moon, Seong Rae, " Economic Impact of Multinational Investment on the Korean Economy," (Ph. D Dissertation, The American University, 1987).

Morsicato, Helen Gernon, "In Investigation of the Interaction of Financial Statement Translation and Multinational Performance Evaluation" (Ph.D. Dissertation, The Pennsylvania State University, 1978).

Nunes, Stephen Ayres ," Toward a Theoretical Framework for Cross-Cultural Training Programs," (Ed.D. Thesis, The Florida State University, 1987), pp. 210.

Paff, Bart Alister, "A Conceptual Study of Multinational Firms and the Major Dimensions of their Environments," (Ph.D. Dissertation, The American University, 1968).

Pribyle, Francis J., " The Image of the New Car Dealer as Perceived by the New Car Buyer: A Comparative Study of Differential Attitudes," (Doctoral Dissertation, North Texas State University, 1975).

Pritchard, Roger M., "Incremental Cost Associated with the Use of United States or Foreign Personnel in Overseas Operations", (S.M. thesis, Massachusetts Institute of Technology, Massachusetts, 1969).

Russell, Robert David," The Effect of Environmental Context and Formal and Informal Organizational Influence Mechanisms on the Process of Innovation: Toward An Integrated Theory of Innovation," (Ph.D. Dissertation, University of Pittsburg, 1986). 
Schwarz, Frederick H., "An Alternative Method of Evaluating the Financial Performance of Foreign Subsidiaries," (Ph.D. Dissertation, St. Louis University, 1986).

Vachani, Sushil ," Strategic Product Market Choices by Multinationals and Local Firms in a Newly Industrializing Country," (D.B.A, Thesis, Harvard University, 1985).

Wachtel, Jeffrey Marc, "A Cross-Cultural Comparative Management Study Measuring the Differences in Managerial Motivation and the Effects of Cultural and Other Explanatory Variables of Potential Managers from Mexico and the United States," (Ph.D. Dissertation, Georgia State University, 1986).

Wallace, Sally, "The Culture of an Organisation: A Case Study," (Ph.D. Dissertation, Marquette University, 1986).

Weinreb, Batya Bertha, "Cultural Reflections in Multinational Corporations: A Comparison Between Israeli and U.S. Subsidiaries," (Ph.D. Dissertation, Stanford University, 1987).

"Report of the Committee on International Accounting", George M. Scott, Chairman, in Supplement to Accounting Review (1973).

"Report of the Committee on International Accounting" (1974).

Center on TNC of the U.N., Survey of Research on TNC (New York, NY.: United Nations, 1978), pp.1- 40.

Forbes, April 30, 1984, pp.150-326.

Forbes, June 25, 1985, pp. 56-63.

Forbes, April 28, 1986, pp.231-260. 